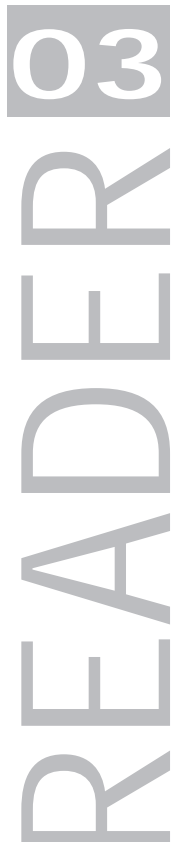

\title{
SHAPING TECHNOLOGIES
}

The Sarai Programme

CSDS, Delhi

The Waag Society/for Old and New Media

Amsterdam

February 2003
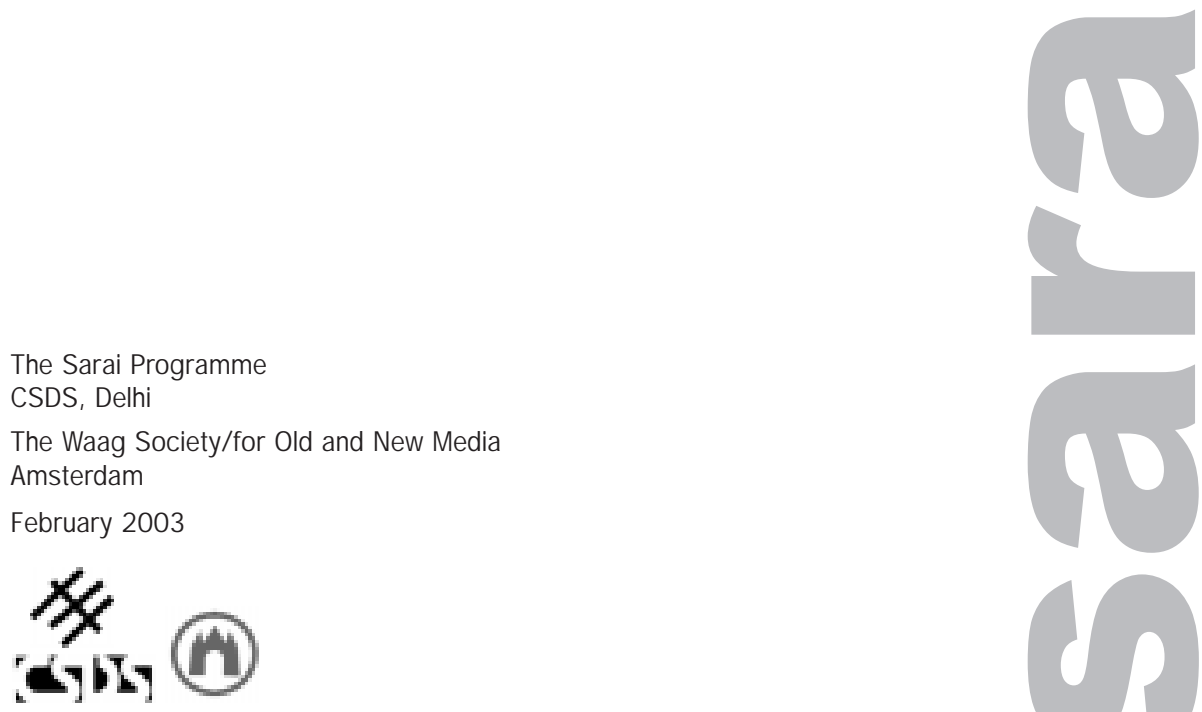


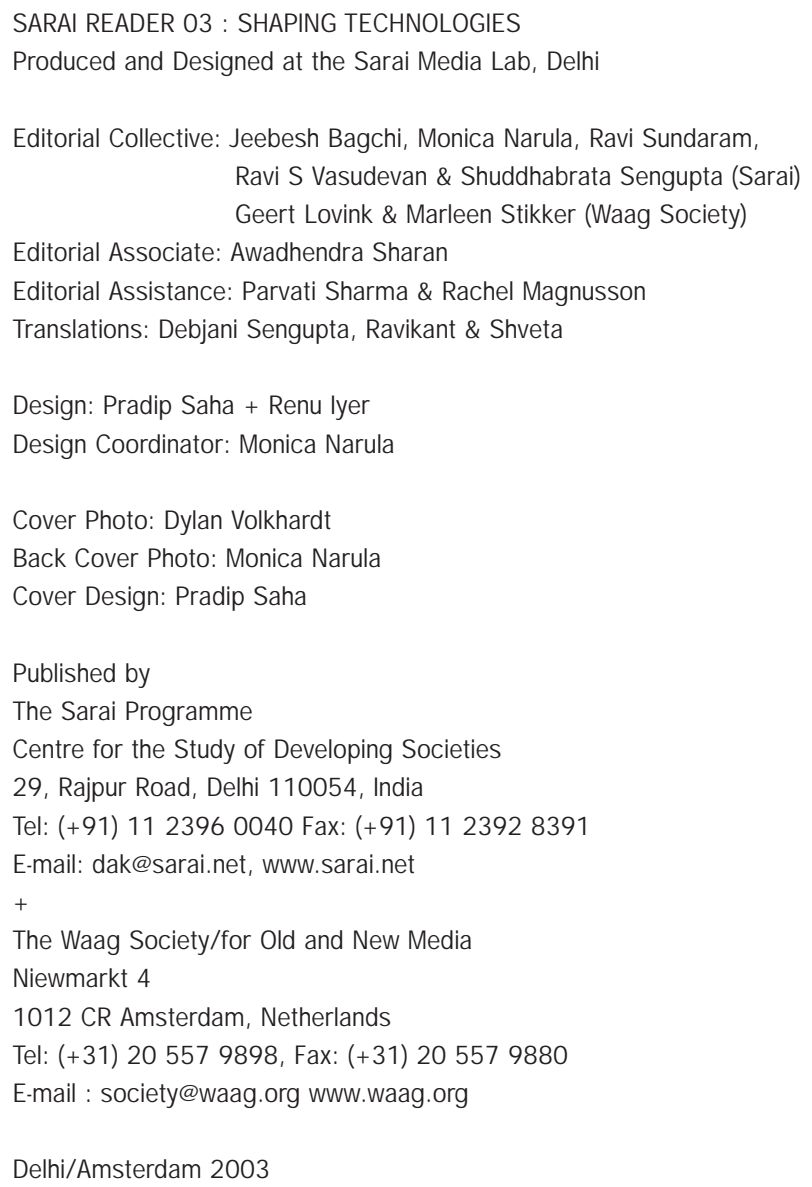

Any part of this book may be reproduced in any form without the written permission of the publishers for educational and non-commercial use. The contributors and publishers, however, would like to be informed.

ISBN 81-901429-3-3

Published by the Director, Centre for the Study of Developing Societies and printed at Thomson Press, Faridabad.

Price : Rs. 295, US\$ 15, Euro 15 (Paperback) 
Remembering, with affection and gratitude,

STEEF HEUS (1953 - 2002)

SIDDHARTHA GHOSH (1948 - 2002)

They would have been happy to hold this book in their hands. 


\section{O}

\section{INTRODUCTION - vii}

\section{LEVERAGES - 1}

The Possible Futures of Technology in China - Andrew Feenberg - $\mathbf{2}$

Lowtech: Escape from the Tyranny of the Leading Edge - Simon Griffiths - 7

E-Waste: Computers and Toxicity in India - Gopal Krishna - $\mathbf{1 2}$

Governing Technology: The City in the Age of Environmental Crisis - Awadhendra Sharan - 16

The Engineer in the Information Age - Arun Mehta - 22

Resisting Technology: Regaining a Personal Ecology - Ravi Agarwal - 30

Subterranean Labour - Srinivas Kuruganti - 35

\section{EXCAVATIONS - 43}

New Visual Technologies in the Bazaar: Reterritorialisation of the Sacred in Popular

Print Culture - Kajri J ain - $4 \mathbf{4}$

Taking Pictures: The Early Days of Photography in Bengal - Siddharth Ghosh

(Translation by Debjani Sengupta) - $\mathbf{5 8}$

The Home and Beyond: Domestic and Amateur Photography by Women in India

(1930-1960) - Sabeena Gadihoke - 61

Panchlight - Phanishwarnath Renu (Translation by Ravikant) - $\mathbf{7 0}$

Airborne: (from "In Persia") - Rabindranath Tagore (Translation by Debjani Sengupta) - 74

Sadhanbabu's Friends: Science Fiction in Bengal from 1882-1961 - Debjani Sengupta - 76

Acoustic Excavations: Soundings in the Ranigumpha Caves - Uma Shankar - $\mathbf{8 3}$

Old Scar - (photographs) Shahid Datawala, (text) Parvati Sharma - 90

\section{SCANS - 94}

Technologies of Self: Poverty and Health in an Urban Setting - Veena Das - 95

Intensive Care - Sumit Ray - $\mathbf{1 0 3}$

Stolen Rhetoric: The Appropriation of Choice by ART Industries - subRosa - 110

Reproductive Technologies in India: Confronting Differences - Rupsa Mallik - 120

Uncanny Bodies - 124

Shaping Technology / Building Body(Nets) - Ana Viseu - 128

Black Magic, Biotech \& Dark Markets - Eugene Thacker - 134

\section{REGISTRATIONS - 143}

McLuhan's Pendulum: Reading Dialectics of Technological Distance - Mike Hunter - 144

Becoming Mobile: SMS and Portable Text - Suzy Small - 157

Gadgetry and Subjectivity: The Making of the Tamil Brahmin Self - Uma Maheshwari Kalpagam - 160

Excelsior 3000: Bowel Technology Project - lan Haig - 168

Disruptive IT in South India - Nimmi Rangaswamy - $\mathbf{1 7 0}$

Call Centre Calling: Technology, Network and Location - Raqs Media Collective - 176 
DEVICES: CYBERMOHALLA DIARIES - 183

Transformer, Clock, Telephone, Cable, Generator, Tubelight

Naseem Bano, Babli Rai, Mehrunnissa, Dhirender P. Singh, Yashoda Singh (Translations by Shveta)

Metro Nights - Monica Narula - 197

IMAGINATIONS + AESTHETICS - 200

Dreams of an (Un)Certain Future - Steve Dietz - 201

Reading Technology: Curling up with a Good Information Appliance - Linda Carroli - 205

On Software as Art - Andreas Broekmann - 215

Waste Net, Want Not: Art and New Media in 90s Britain - Pauline van Mourik Broekman - 219

Creative Encounters: The Art/Science of Collaboration - Amanda McDonald Crowley - 227

Beyond the Apocalypse: An Unfinished Meditation on Ethics - Rana Dasgupta - 236

The Typewriter of the Illiterate: Interview with János Sugár - Geert Lovink - 243

The Way Home: Kattas as Navigation Aids - Bharti Kher - 247

Pet Architecture: And how to Use it - Yoshiharu Tsukamoto - $\mathbf{2 4 9}$

Colliding Soundscapes: Conversation with Hildegard Westerkamp - Lex Bhagat - 255

\section{ENCODE + DECODE - 263}

Beyond the Computer - Gabriel Pickard - 264

App.lying Software: A Reader-List Discussion - edit + design Are Flågan - $\mathbf{2 7 3}$

"No Other Hand will Scratch My Back": Interview with Arash Zeini - Ravikant - 282

Indic, Especially Hindi, Computing: An Index of Choices - Ravikant - 290

Jal Chitra: Water Map - Software for Rural Water Management - Vikram Vyas - 292

The (copylefted) Source Code for the Ethical Production of Information Freedom

- Biella Coleman - 297

The Ghost in the Machine: The Legal Capture of Technology - Lawrence Liang - $\mathbf{3 0 3}$

\section{PRACTICES + POLITICS - $\mathbf{3 1 2}$}

Technology, Trust and Terror - Langdon Winner - $\mathbf{3 1 3}$

Social Sorting in the Early $21^{\text {st }}$ Century: Video Surveillance and Governance - Volker Eick - 321

Resistance is Futile: Peer-to-Peer File Sharing and Big Media - Robert X. Cringely - 332

The 'Darknet' \& 'Trusted Computing' - Rana Dasgupta - 335

Free as in Air: An Interview with Vortex - Saul Albert - 337

The Language of Tactical Media - J oanne Richardson - $\mathbf{3 4 6}$

Alternative Radio: A Personal Testimony - David Barsamian - 352

\section{ALT + OPTION - 356}

The Concise Lexicon: Of / For the Digital Commons - Raqs Media Collective - $\mathbf{3 5 7}$

The Wireless Commons Manifesto - $\mathbf{3 6 6}$

A Hacker Manifesto: Version 5.7 - McKenzie Wark - $\mathbf{3 6 8}$

Notes on Contributors - $\mathbf{3 7 3}$

Acknowledgements - $\mathbf{3 7 9}$ 


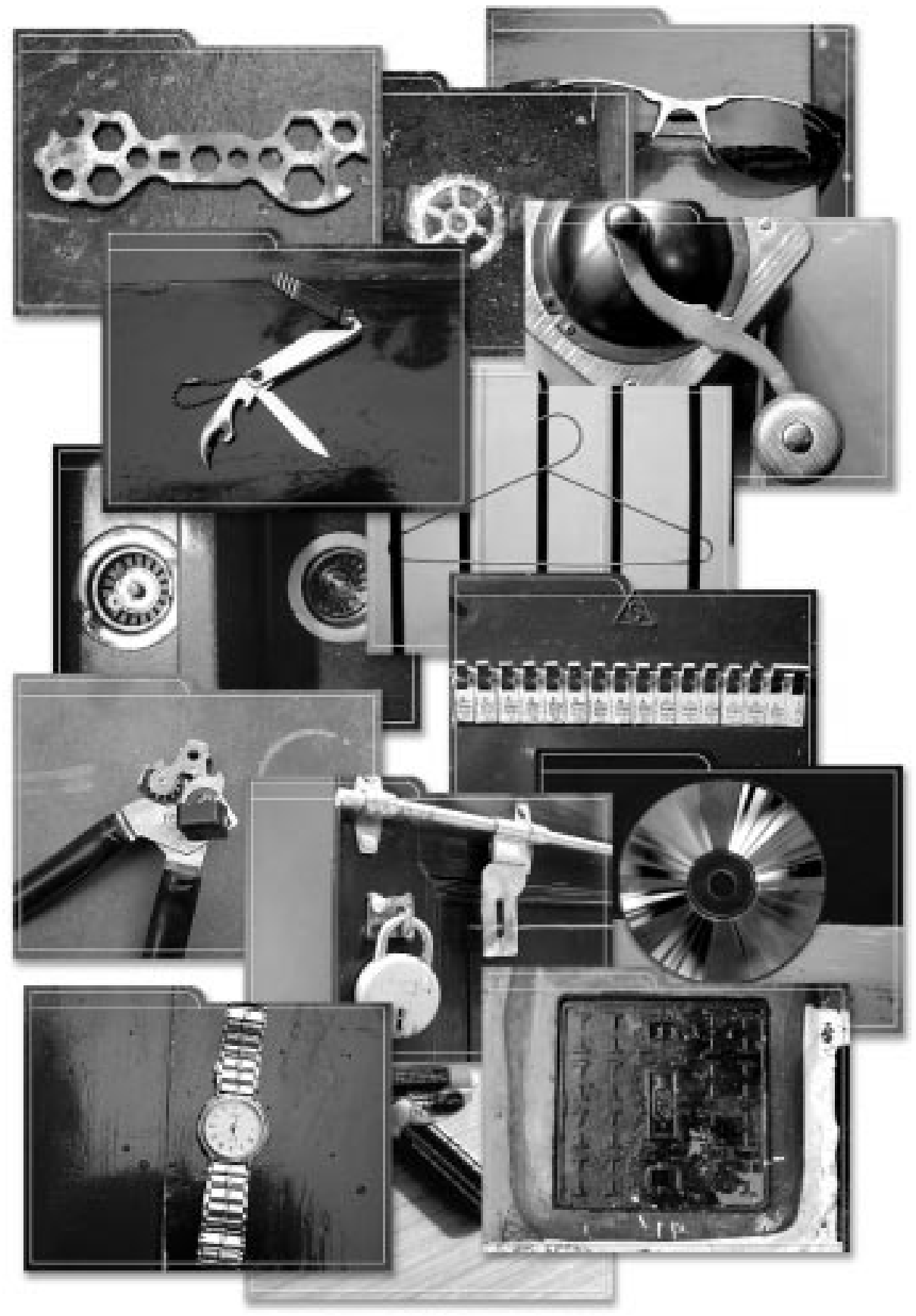


Sarai Reader 03: Shaping Technologies sets out to ratchet our engagement with the contemporary moment a notch higher, in directions that are sober, exhilarating and discomfiting, all at once.

Technology, which figures as an important strand in both previous Readers - Sarai Reader 01: The Public Domain and Sarai Reader 02: The Cities of Everyday Life - has here taken centre-stage as a multifaceted constellation of ideas, images, reflections, debates, histories and provocations. The first Reader held an encounter with the discourse around free software with which we viewed the possibility of the formation of a new public domain, and the second raised issues such as biotechnology, surveillance, and the politics of information technology. This third volume in the series presents a drawing together of many threads that echo and carry forward earlier themes and discussions to offer an array of considerations that locate themselves squarely within the present, while facing the future, and with an eye towards history. This collection seeks to bring to the fore a series of situations and predicaments that mark the encounter between people and machines, between nature and culture, and between knowledge and power.

These encounters, to our thinking, embody the taking on of a particular stance towards the contemporary moment, which, notwithstanding contradictions and beset by metastasizing, proliferating, accelerating energies that pull in different directions, even while marked in equal measure by confidence and scepticism, nevertheless represents a qualified assertion of commitment to living and working in the world today, as active, transforming agents, creating new truths and meanings through praxis.

This results in a wealth of questions and issues, that span a wide range - from the 
cognitive and ethical dilemmas that beset the engineer, to the legal and cultural implications of copying in a digital realm; from software as art to the history of science fiction; from wireless manifestoes to the domestication of photography; from kitchen utensils to airplanes; from mobile phones to kerosene lamps; from body nets to biotech; from reproductive technologies to technologies of reproduction; from computers to radios; from coal mines to call centres. Shaping Technologies brings together a host of original writing and images on these and other themes by a collection of writers, theorists, critics, photographers, philosophers, engineers, activists, artists, media practitioners and programmers from all over the world. It also excavates and connects little known histories with our present reality, finding, for instance, in Rabindranath Tagore's account of being airborne in 1934, an oblique way of reflecting on the consequences of aerial bombardment, the dehumanising mindset that implodes when the pious do battle, and the prospects of a war that threatens to break over Iraq, even as this book goes to press.

Today, technology is second nature to us. If the landscape of earlier times could be ideally represented by images of naturally occurring objects, then the landscape of the contemporary is one that can only be imagined as being peopled by machines. The 'nature' of our times is technological. We are embodied, articulated, located and governed by the machines we make to extend our lives, bodies and faculties. We shape the technologies that surround us and the technologies that surround us shape the contours of our lives. This is what we mean by the term 'shaping technologies', which suggests both a subjective, social appropriation of technological creativity, as well as the impact of technologies on society and life in general.

One may even say that technological ubiquity has gone so far as to make it nearly impossible for us to reflect upon technologies as phenomena separate from the general conditions of global urban life. We are what we work, play and think with, and today, we work, play and think with our machines. We are users, inventors, practitioners, artists, hackers and artisans who work with technologies. We are technology's consumers and users; we are hobbyists, enthusiasts and addicts just as we are critics, prophets, and analysts. We are masters, slaves, victims and rebels of technology. No one remains untouched by the machine.

And yet, we do not have an adequate language with which to understand and articulate the presence of technology in culture, society and politics. We are accustomed to construct utopian and dystopic technological imaginaries, even as we neglect the task of a sober and considered reflection of the ethical and cognitive dilemmas that the presence of technologies in everyday life confronts us with. And even as technology becomes increasingly ubiquitous, even as it touches wider populations, even as an immersion in technoculture becomes the condition of the contemporary moment, it becomes simultaneously the discursive monopoly of experts and specialists or of geeks and hobbyists, far removed from the concerns that animate scholars, public intellectuals, and the common curious person. Technology is the underpinning, yet the shadow of the public domain. Technology is ubiquitous, yet discursively obscure.

It is not as if a discourse of technology does not exist. Its arguments and narratives are well known, and in some cases over-rehearsed. It can be recognised by the rhetorical cycle that moves from myth and invention to hype and glorification, flipping occa- 
sionally in the direction of moral outrage, and silenced in the end by expert witness and ethics committees.

Sarai Reader 03 seeks to extend the terms of discussion by asking what other imaginary space there may be, besides the imperative to consume, the irrepressible desire to shop for the next gadget that comes our way, and the whine of the perennial victim of the machine, with which we can envision technology's presence in our lives.

The titanic proportions of 'technology' provoke the question of subjectivity. Are the machines too large, too fast, too invasive, too small for us to get a cognitive, and existential grip on them? But an unvarying narrative of scale, of 'how much' technology is or can be, how much 'out of control'/ 'in control', how mega, how nano, how liberating and how oppressive, makes it impossible for us to escape the trap of reiterated banalities. We need another language, another way of thinking, doing, criticising and celebrating technologies, technologists and technicians.

Is it possible for those of us who refuse to take on the mantle of techno-expertise to shape the field, to ask the questions that need to be asked about where we are taking the machines, and where the machines are taking us? Or are we condemned to be Homo Consumens forever? Is the supra-technical position only there for the chief scientists that oversee the field, steering their multi-million dollar research programmes? How can technology be shaped by those of us who are outside the laboratories?

Michel Foucault's use of the term "technologies of the Self" assisted a generation in the critical understanding that technology was about a lot more then dams and railways. Yet, a few decades later, the proliferation of his ideas is confronting us with another dilemma. What if everything is technology and there is nothing left untouched? Can we then begin asking questions about the possible technologies of resistance, even as we battle with our knowledge of the actual technologies of power?

In Shaping Technologies we undertake re-readings of past debates, and anticipations of future ones, weigh utopian visions against dystopic nightmares, perhaps to arrive at assessments that suggest sobriety and a 'cool' consideration of the cold touch of the machine, as well as of the heat of the fuel that animates it. We report the latest on surveillance, excavate histories of tech novelty, envision possibilities and examine blueprints and read the road maps to the futures that lie before us.

By doing all this we intend to ask: what kind of 'technological culture' exists, or may exist, outside of the cybernetic feedback loops of global products and services of capital? What space can we claim for freedom and function, safely out of reach of the apparatus of the state and the machine of the corporation? What leverage (to use a machine metaphor), if any, do we have to act - in haste, with urgency and intelligence - in these times?

Our work at Sarai is both with and about technology. Not only this Reader (which could never have been edited without editors discussing contents online, and contributors sending in articles and images by e-mail), but everything that we do is enabled by the choices that we make about which machines, techniques and software to use, and how. Our practices are inflected by the technological choices that we make on an everyday basis. This is because we give primacy to the realities of urban South Asia, and to the different histories and practices of communications that exist within this world. 
These are histories of improvisation and creativity with machines. These are contentious and fraught legacies of the interaction of the daily lives of people and the agendas of power. All of this brings in its wake specific and everyday political questions. Our intent is to always ask - "Who controls and governs the flow of knowledge that accretes to a particular technology or a practice?" This insistence on qualified questions and particularity of contexts is distinct from general, ideological statements for or against technology in the abstract. We are conscious that in articulating this insistence, we are registering a refusal to enter the binary of technofetishism and technophobia that marks the frugal discourse on technology that exists in contemporary South Asia, especially in India. To do this is to refuse to celebrate big dams or nuclear power (as the governing technocracies of South Asia have done), and at the same time to refuse to buy into the largely anti-technological rhetoric of what has passed for an 'alternative' political and cultural imagination. For us, the contents of this Reader suggest that the search for a third way that neither fetishises nor condemns is possible, and timely. In its own way, the Reader is itself a gesture of affirmation towards this possibility.

Editorial Collective

Delhi/Sydney/Amsterdam

February 2003 
LEVERAGESLEVERAGESLEVERAGESLEVERAGES LEVERAGES LEVERAGESLEVERAGESLEVERAGES LEVERAGESLEVERAGESLEVERAGESLEVERAGES LEVERAGESLEVERAGESLEVERAGESLEVERAGES LEVERAGESLEVERAGESLEVERAGESLEVERAGES LEVERAGES LEVERAGESLEVERAGES LEVERAGES LEVERAGESLEVERAGESLEVERAGESLEVERAGES LEVERAGES LEVERAGES LEVERAGESLEVERAGES LEVERAGES LEVERAGESLEVERAGESLEVERAGES LEVERAGES LEVERAGESLEVERAGESLEVERAGES LEVERAGES LEVERAGES LEVERAGESLEVERAGES

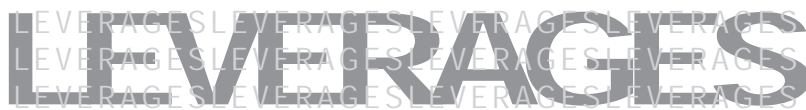

LEVERAGES LEVERAGES LEVERAGESLEVERAGES LEVERAGES LEVERAGESLEVERAGESLEVERAGES LEVERAGES LEVERAGESLEVERAGESLEVERAGES LEVERAGES LEVERAGES LEVERAGESLEVERAGES LEVERAGESLEVERAGES LEVERAGESLEVERAGES LEVERAGESLEVERAGES LEVERAGESLEVERAGES LEVERAGES LEVERAGES LEVERAGESLEVERAGES LEVERAGESLEVERAGESLEVERAGESLEVERAGES LEVERAGESLEVERAGES LEVERAGESLEVERAGES LEVERAGESLEVERAGESLEVERAGESLEVERAGES LEVERAGESLEVERAGESLEVERAGESLEVERAGES LEVERAGES LEVERAGESLEVERAGESLEVERAGES LEVERAGES LEVERAGESLEVERAGESLEVERAGES LEVERAGESLEVERAGESLEVERAGESLEVERAGES 


\section{The Possible Futures of Technology in China}

ANDREW FEENBERG

Is there a way out of the exaggerated technological optimism of the new technological elites and the pessimism of the older intellectual elites vis-à-vis technology? In this introduction to the Chinese edition of his book, Alternative Modernity, Andrew Feenberg argues that social constructionism rather than technological optimism or pessimism offers a more useful way to deal with the complexities of the contemporary. Here the Chinese are well placed, they have the experience of both the techno-disasters of the $20^{\text {th }}$ century and the new critical practices that have emerged in the last decade.

$\mathrm{M}$ odernity is a paradoxical concept. On the one hand, it refers to apparently universal accomplishments such as modern science and technology, democratic forms of government, urbanisation and so on. On this account, modernity is opposed to tradition and replaces it everywhere with a rational 'technoculture', rooted in the spread of a unique technological system. If this is true, there is only one modernity and it is gradually erasing the cultural memory of humankind and homogenising the globe. Modernity is a global phenomenon that first struck down the traditional cultures of Europe before spreading its universalistic rationalism to the rest of the world. I will call this the technological understanding of modernity. It assumes a determinist philosophy of technology according to which society is shaped by technical advances which themselves depend on the advancement of knowledge of nature.

But this is not the whole story. There is another cultural sense of modernity in which it is the expression of a particular tradition, the Western tradition, and more specifically American culture. Einstein is modern, but so is Mickey Mouse. How do these two sides of the concept of modernity relate? Is modernisation truly universal or is it mere Westernisation, Americanisation, a kind of cultural imperialism against which national cultural resistance is appropriate and necessary?

After World War II, as the United States became the dominant world power, the technological sense of modernity prevailed. With the collapse of colonialism, it seemed that what the world needed was the rapid replacement of traditional cultures by a modern culture based on technological rationality imitated from the US. The communist world resisted this analysis only to substitute a putative communist modernity for the one advocated by the US. At bottom, the position was similar: rationalistic universalism supported by technological determinism.

In the last decade or two things have begun to change. While the technical and policy apparatus of global financial institutions and most national governments continues to pursue technological modernity as a universal project, intellectuals have increasingly come to see modernity in terms of the second definition, as a particular culture masquerading as 
universal rationality; or in a more sophisticated version, they have charged that rationality as we define it in the West is culturally biased and lacks universal import. On these terms, technological modernity is denounced as a totalitarian imposition, a refusal of all that cannot be integrated to a smoothly functioning social machinery. This has led to various challenges to universalism, from the new fundamentalist ideologies of Islam to the postmodern philosophies of difference.

But these challenges have proven unproductive because they remain on such an abstract level that they do not have any implications for technological development, the actual foundation of modernity. One can hardly opt out of the modern world, so Islamic fundamentalists no less than postmodern critics end up bowing before the old gods - fundamentalists on the arms markets and postmoderns every time they turn the key in the ignition. Our way of life is rooted in modern technologies at such a basic level that radical ideologies seem unable to touch it. What we need instead is what I have called a 'critical theory of technology', a critique that enters into the life of the technical systems that underlie and shape our world. Where a purely negative critique of modernity leaves everything as it was, a critical theory of technology can reveal unexplored possibilities. Only with such a theory can we begin to unravel the paradox of modernity, which is both universal and particular, reason and culture at one and the same time.

Alternative Modernity is the second of three books I have written developing this approach. The first of these books, Critical Theory of Technology, appeared in 1991 and the most recent, Questioning Technology, in 1999. In the ten years it took to write these books much has changed. Two particularly dramatic changes have marked the end of the century: the fall of the Soviet Union and the rise of the Internet.

In the late 1980s, as I was preparing the first book in this series, the Soviet Union was gradually coming apart. But it seemed that Glasnost might lead to profound and positive developments, a reformed and more democratic socialism in Russia. I took this as evidence that the Western capitalist model might not be the only coherent organisation of modern technological society. It was at least possible to hope that a new form of socialism might represent an alternative modernity. This prospect inspired a refutation of technological determinism and reflection on the limits of the established model of modernity. But we now know that these hopes were not to be fulfilled, at least not as far as Russia was concerned. Gangster capitalism and social disintegration have prevailed instead, as income and even life expectancy decline. Whether China can accomplish what Russia failed to remains to be seen.

In the decade leading to the writing of Alternative Modernity, I also helped create the first online educational program, which was launched in 1982 at the Western Behavioural Sciences Institute in La Jolla, California. After years of study with Herbert Marcuse in the tradition of the Frankfurt School, I was suddenly plunged into the world of computer networks at an early stage, even before the Internet went public. Soon I was directing a project on interface design for computer communication for the Digital Equipment corporation, a major computer manufacturer.

From this intimate association with a developing modern technology, I learned another and more durable lesson in alternative modernities: the direction of computer development was not determined by the nature of the device but was chosen by users. They did not sim- 
ply take the computer as a given, but reoriented computer makers and system administrators towards communication functions, the importance of which had been greatly underestimated. Indeed, the explosion of activity on the Internet has completely changed our conception of the computer and is altering the social world in unexpected ways.

Alternative Modernity drew on these lessons of recent history to depict a world in which the future was still undecided, in which social movements, a variety of ethical and aesthetic values and differences in national culture could all play a part in influencing the definition of modernity. In support of this non-deterministic position, I relied on social constructivist theory, building a first bridge between philosophical reflection on modernity and the burgeoning field of science and technology studies. Social constructivism provides empirical evidence that technological development is not deterministically fixed by a universal rationality but instead depends on a variety of social factors. Actors are as important as reasons in this conception. I applied this approach to the critique of various philosophies of modernity and in the concrete studies that comprise the book.

Alternative Modernity argues that since technological development is contingent not just on reason but also on society, it ought to be democratised like other domains of social activity. My most recent book, Questioning Technology, carries the same argument forward with a detailed consideration of the nature of a democratic politics of technology. This question is of course relevant to China, where technological decisions of great moment are being made today by a small government and business elite without much public input.

Modern technology is transforming China, as it earlier transformed Japan and Russia and still earlier the Western countries in which it originated. But surely there is a difference between these episodes. China is no ordinary country but represents such a large percentage of the world's population that it cannot simply imitate the West without disrupting the world economy and ecology. This is most obvious in the case of transportation technologies. China will continue to develop, but it must innovate a path that does not depend on automobiles. One shudders at the thought of 500 million Chinese Fords and Fiats, the approximate number that would equate China with American levels of automobilisation.

Does this mean that China is forever doomed to poverty? Not at all. What we take for wealth today is relative to changing standards and values. These standards and values have tended over time to adjust to real constraints: to continue the example, the most desirable cars have varied greatly in size depending on the price of oil. We Americans did not merely resign ourselves to smaller cars after the first OPEC oil shock, but actually came to see them as superior to the behemoths we used to drive. When oil prices dropped, Americans gradually rediscovered the beauty of bigness and now they race around in cars twice as massive as before. Meanwhile, many residents of Amsterdam, Paris and New York are prosperous and content without owning a car at all. Such variations in taste testify to the lability of economic culture. China too will define its own model of wealth in a way that conforms with its real possibilities of development.

What kind of world will China create in the next century as it becomes rich? This is not a question that can be answered today. More important is understanding what kind of developmental process is best for the country. On that question there is much disagreement. As an outsider looking in I no doubt miss most of the nuances, and I apologise in advance for 
the limitations of my point of view. But so important is China that outsiders can hardly be expected to abstain from judgment. To me it appears as though the mainstream of development theory and practice in China is still wedded to many features of Western models long since either harshly criticised and discredited or abandoned altogether in the West. The pursuit of an original path of development has not yet begun. On the contrary, imitation of Western models is the order of the day and, for example, gigantic projects that disrupt society and damage the environment still have a certain charm in China, if not in the US and Europe.

In this context, Western reflection on technology and society can perhaps contribute to a more selective and critical attitude in China. It would certainly be helpful if Chinese intellectual and political elites took into account not only the official propaganda of Western governments and corporations but also the critical voices that will contribute to shaping the Western future. Otherwise, China risks ending up with 'white elephants', awkward monuments to past orthodoxies.

The ambition of Alternative Modernity is to provoke the liberating thought that the social future is not merely a quantitative extrapolation from the present. Of course we know this in a general way, but it is not so easy to apply that general knowledge to specific instances. In technical matters we tend to think in terms of less and more - more computing power, more electricity, more cars and planes, and so on. The tipping point where quantity turns into quality is overlooked; where, for example, adding more computing power transforms the computer from an instrument of professional work into a consumer technology. The resulting shift from one continuum of development to another is rarely anticipated in advance. But insofar as modernity is defined by the penetration of technology into every sphere of social life, these understandable limits on our technical imagination become unacceptable limits on social theory.

The idea of an 'alternative' modernity suggests a widening of the range of possibilities. Most importantly, it argues for including more actors in the process of technological decision-making. By actors we mean not only experts and corporate and government officials, but all those enrolled in technical networks, workers, users, victims or beneficiaries of the side effects of technical advance. Each of these unofficial actors has a unique perspective on development. Their experiences and opinions constitute what Foucault called a "subjugated knowledge", a knowledge from below revealing aspects of reality that are only dimly focussed on by those in positions of authority.

Let me offer an example from medicine of such an evolution under the influence of subjugated knowledge. This is a case of technology transfer, not in the familiar direction - from West to East - but in the reverse, from East to West. The point of the example is not to laud the merits of Chinese medicine, which are widely recognised by practitioners and their patients, nor am I concerned with whether science explains the effectiveness of this practice. Rather, this example is meant to show that a lay public can influence a scientific-technical profession, in this case the American medical establishment, with constructive results.

Western medicine has long treated Chinese medicine as an ineffective survival of a prescientific tradition. In the United States, this attitude effectively excluded Chinese medicine from a legitimate status as a healing art. No doctor would recommend and no insurance 
company would pay for such services as herbal treatments and acupuncture. However, American patients discovered the efficacy of some Chinese treatments for conditions with which Western medicine has limited success, such as soft tissue injuries and symptomatic treatment of chronic disease. More and more non-physician medical practitioners offered these treatments. By the early 1990s the demand for 'alternative medicine' became difficult to ignore. This demand resulted in the creation of an Office of Alternative Medicine at the National Institute of Health in 1992, and eventually insurance companies began to reimburse some Chinese treatments. In 1998, in a truly startling reversal of its earlier position, the Journal of the American Medical Association published an entire issue on alternative medicine. The articles applied modern scientific methods, such as blind clinical trials, to verifying the effectiveness of treatments that would have been dismissed out of hand only a few years before. The moral of this story is simple: scientific experts have their prejudices and ingrained traditions too, and can learn from interacting with the large store of experience available to the general public and the bearers of traditional knowledges.

The essence of a democratic politics of technology is to improve the communication between subjugated knowledges and the official technical knowledge of planners and executives. There are compelling reasons to favour such a democratic evolution of the Chinese technological system. In the first place, the costs and problems of development cannot be calculated where citizens find it difficult to protest and express their opinions. For this a relatively free and lively civil society is necessary. The Soviet Union now pays the enormous price of the ecological disasters caused by industrialisation uninformed by public opinion. But just as important, without opening the lines of communication between the underlying population and those responsible for development it will be impossible to find an original path native to Chinese conditions. No matter what their intentions, an isolated technocratic elite in a developing country can only imitate foreign models since the West is ultimately the source of its legitimacy. Only the rich and complex interaction of a whole people can innovate an alternative modernity suited to China. And surely this is what China deserves.

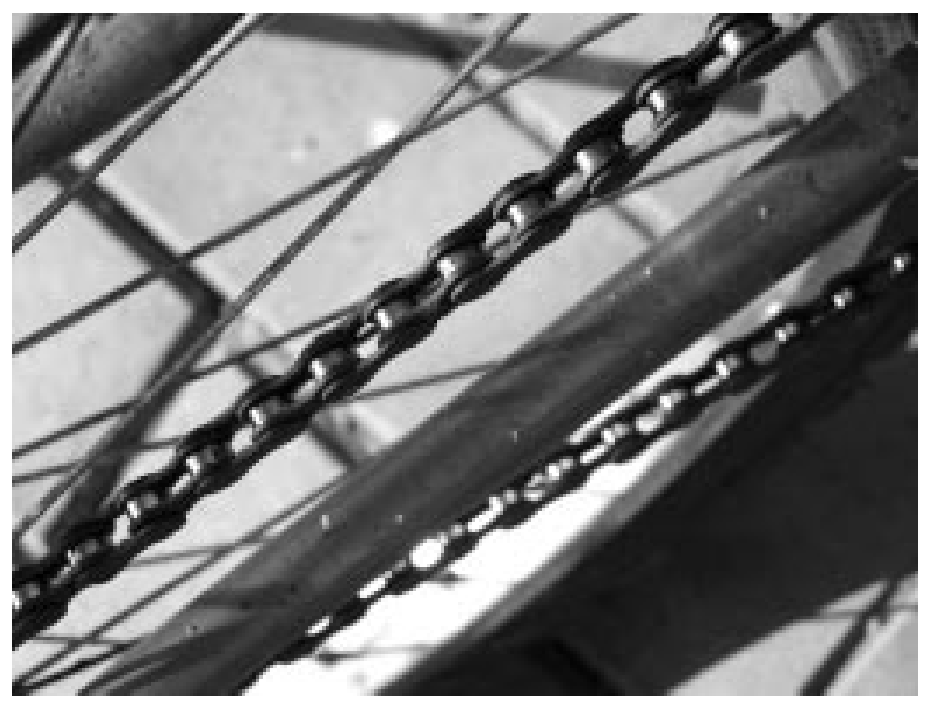




\section{Lowtech Escape from the Tyranny of the Leading Edge \\ SIMON GRIFFITHS}

$\mathrm{T}$ here are elements of fascism concealed within the marketing strategies used to sell the Information and Communications Technologies (ICT) revolution. Under the logic of such strategies the ideals of progress and perfection inevitably lead to those of freedom and creativity. It is a teleological and technological destiny that is unavoidable for all good consumers. Although many of us find ourselves with no particular desire to be good consumers, and while we share doubts concerning the various prices that such actions will extract, for those of us with the means there will, under the present system, always be the lure of the next hi-tech fix. The hi-tech fix that will eventually and ultimately cure all of our ills if only we keep purchasing the latest, smartest, fastest high-tech consumables entombed in the smallest, sleekest, 'sexiest' casing. Throughout his life's work William S. Burroughs never tired of explorations and exhortations warning of the dangers of such fixes. According to Burroughs the equation is always the same - control is what a dealer wants from and over a user.

It is in this sense, in terms of control, power and manufactured need that we can locate the fascism concealed within the marketing strategies of the leading edge. In short the kind of fascism that we are considering is, as Foucault once wrote "the fascism in us all, in our heads and in our everyday behaviour, the fascism that causes us to love power, to desire the very thing that dominates and exploits us". It is the kind of fascism that the ego feeds

"the fascism in us all, in our heads and in our everyday behajiour, the fascism that causes us to love power to desire the very thing that dominates and exploits us". 
upon, the myopic, the self-centred, the fearful, that which distrusts the world and that which wants everyone else to distrust the world; infecting everyone that it can lay hold of with its own brands of jealousy, greed, hate and fear. Such emotions may appear to belong to a different world from the pristine future conjured up by advertising campaigns, but listen to the childlike mantra of the ego, the voice within that such strategies depend upon: "I need a Nokia 7250, if I don't get one, if everyone else has got one and I haven't then they'll all be texting photos and I won't be able to etc, etc".

Ask yourself what form this voice takes within your own mind, ask yourself whether such manufactured need can ever exist without the emotions of jealousy and greed, both of which are ultimately fed by fear.

As we have already touched upon in our reference to Foucault, the fascisms interrogated by Gilles Deleuze and Felix Guattari in Anti-Oedipus: Capitalism and Schizophrenia are the fascisms of our everyday lives, the micro-fascisms that are implicit in everyday relations of power and domination. Whilst this essay does not have the scope to satisfactorily explore this conception of fascism in relation to the marketing strategies of the ICT revolution, it is important to at least sketch out the connections. For Deleuze and Guattari, fascism is a reactionary form of desire, desire that desires its own repression. Following Wilhelm Reich, they seek an explanation for the fact that the masses in Nazi Germany actually desired fascism. According to them modern society oscillates between two poles, the fascist-paranoid pole and the revolutionary-schizophrenic pole. From this conception of society the emotions of jealousy, greed and fear can be seen as reactionary desires drawn towards the paranoid pole of the continuum. The logic for this being that jealousy, greed and fear all rely upon a negative concept of desire as lack; in other words they all rely upon the formulation that you can only desire that which you don't possess. In contrast Deleuze and Guattari's conception of desire does not depend upon such negative Freudian notions. For them desire is a creative and productive affair. At society's revolutionary-schizophrenic pole desire produces and creates for the sake of production and creation; it does not desire what it lacks, it does not want what it does not possess, it merely produces and creates.

However as modern society tends towards the fascist-paranoid pole, social repression entraps desire within the reactionary position of desiring that which it lacks. This is the reactionary position upon which the marketing strategies of the ICT revolution feed. In order to maintain and stimulate artificial levels of consumption, and in turn economic growth, such marketing campaigns use the illusions of progress and perfection to sell consumers what they will always, sooner or later, lack - the latest upgrade, the most recent model of whatever line of high-tech consumable they choose to buy into. The nature of such essentially disposable products also means that once we have bought into them we tend to become trapped in an upgrade cycle from which we cannot escape. J ust think for a moment about giving up or downgrading your mobile phone or your personal computer. While some may deny that such a cycle is disempowering, there are other more visible, real world effects caused by the ICT revolution and its marketing strategies. And by such effects we should refer not to their effect on the lived daily realities of those of us fortunate enough to be able to afford the entrance fee to this exclusive club, but rather to the waste products that they generate and the ensuing environmental costs. 
The relentless drive of the two-year upgrade cycle and the two-month leading edge are not only responsible for the endless march of progress, they also bear responsibility for some rather more unsavoury and usually unmentioned side effects. It does not make pleasant reading and it is hardly surprising that such facts do not feature in the sanitised digital utopia that we are currently being sold. Few manufacturing processes come close to the high-tech electronics industry in terms of the extent of their environmental impact. Weight for weight the production of computer chips causes more damage to the environment than the production of cars. A large proportion of this damage is caused by the amount of natural resources that are required by the plants in which computer chips and components are manufactured. On top of this there is also the variety and quantity of toxic chemicals that are used during the production process. "It is widely known that the production of computer components - such as semiconductors, printed circuit boards, disk drives and monitors - use significant amounts of toxic gases, acids and industrial solvents". Such chemicals include lead, mercury, cadmium, chromium VI and brominated flame retardants, all of which are toxic to human bodies. Lead can damage the central nervous system; methylated mercury causes damage to the brain; cadmium chloride may cause cancer following prolonged exposure, while such exposure is made more likely by cadmium's 30-year half-life and the fact that it accumulates in the kidneys; chromium VI is considered genotoxic and has the potential to damage the DNA; polybrominated diphenylethers may act as endocrine disrupters and Polybrominated Biphenyls may increase the risk of stomach and lymph cancers. The most striking thing about such a cursory examination is not the list of possible damage to human bodies but rather the repetition of the modal auxiliary 'may', which perhaps goes to highlight the extent to which innovation in the manufacturing process is currently outstripping concern for or research into the safety of such innovation.

What is not in doubt however is that there is a contradiction inherent to the 'clean rooms' where computer chips are manufactured. While the 'clean room' ensures that computer chips are kept free from foreign bodies, the toxic chemicals that are used during the manufacturing process cause workers at semi-conductor plants to suffer from cancer clusters, miscarriages and birth defects at a higher rate than normal manufacturing workers. As a result of this "IBM and National Semiconductor have been involved in lawsuits filed by several hundreds of their employees related to illnesses - primarily cancer and birth defects - that claimants assert are due to working with chemicals in the semiconductor industry". The reasons behind such extensive and prolonged exposure to highly toxic chemicals can be laid upon what is often referred to as corporate greed or negligence, but what can more accurately be referred to as the profit motive. More specifically workers and the environment suffer from such exposure because of the high-tech industry's success in preventing safety regulation and unionisation from encroaching upon their profits; often using their position as the largest growth sector in the global economy to intimidate governments and communities into giving them concessions that include a lack of safety regulations; regulations which would only serve to hinder the manufacturing process. For the communities that surround semi-conductor plants such concessions often result in the pollution of the local environment with toxic, bioaccumulative substances, with the most recognised impact being the extensive contamination of groundwater. The environment also suffers because 
of the high-tech industry's intensive consumption of natural resources. As the Western nations have become more aware of the damage that these production plants cause to their local environment, high-tech industries have tended to relocate their operations to the developing world. However, relocation has not lead to a re-evaluation of past mistakes and as a result "many of the environmental and health problems that have been documented in Silicon Valley are beginning to emerge in these other areas".

Finally there is the issue of the huge amounts of electronic waste (e-waste) that are created as by-products of the two-year upgrade cycle. E-waste is the fastest growing and the most toxic waste stream in the industrial world. The manner in which it is dealt with is therefore of consequence to both the environment and communities living near disposal sites. Considering the amount of hazardous substances contained within e-waste it is hardly surprising that the disposal of e-waste through incinerators and landfills comes with its own set of problems. These include the emission of dioxins and furans when e-waste is incinerated, and the leaching and evaporation of various hazardous substances contained within e-waste when it is placed in landfills. In addition, the recycling of e-waste is often impractical due to the high cost of handling toxic substances. The net result of this seems to be that major re-evaluations need to be made in terms of the sustainability of high-tech industries. It should not however come as a surprise to learn that in light of the European Commission's directives concerning Waste Electronics and Electrical Equipment (WEEE) and Restrictions on Hazardous Substances (ROHS), the US Trade Representative, prompted by US electronics companies, has lobbied extensively against the adoption of the European WEEE and ROHS initiatives as a threat to trade and so illegal according to the World Trade Organisation. When trade and economic growth are the only factors considered to be of importance, over and above environmental sustainability and human health, then we have to ask ours elves whether the high-tech industry can ever become sustainable within the current economic model.

In contrast to the speed, efficiency and power maxims of the Leading Edge, the model of Lowtech operates according to a somewhat different logic. Lowtech involves acquiring old computers that have either been donated or put out in the trash by their previous owners following their latest upgrade. At the level of software it also involves migrating from proprietary software to open source or free software. Old machines do not work in the same manner as new ones and as a result the process of Lowtech is one that works in fits and starts; to put it another way, Lowtech works only through and by breaking down. Although this process of breaking down can be extremely frustrating, it is a frustration that ultimately leads to selfempowerment. Consider the example of leading edge technology when it breaks down: Frustrations begin on the Technical Support helpline, with the twentyminute wait to get through to a 'technician'. They continue with the indignity and disempowerment inherent in the process of following orders and instructions. You are offered no explanations and you gain little understanding, your role is merely to click the mouse where you are told and then report the computer's reactions to the technician. You are no more than a relay and you can sense the technician's growing frustration as you are unable to carry out commands at the speed that the technician prefers to work at. It is an experience that generally culminates in the distasteful feeling that the more technical aspects of com- 
puters are best left to 'the experts'. Such hierarchisation of knowledge, where certain sections of the population are excluded from certain types of knowledge, is another factor contributing to the relations of power, control and domination that surround the technologies of the Leading Edge.

It is also a hierarchisation of knowledge that Lowtech actively eschews with its hands on, or rather hands inside, approach to computer hardware. Diverging from such hierarchical methods, the process of Lowtech aims to be egalitarian. While there are, within the open source and free software communities, people with differing levels of programming experience and knowledge, Lowtech does not encourage or engage in the kind of guru worship that places those with more knowledge upon pedestals. Specifically, the ethos of Lowtech treats those who know something but are unwilling to share it with suspicion. The use of open source software should, on a practical face-to-face level, equate to openness in regard to the sharing of knowledge and skills. In practice this means that people share their knowledge, helping when they know and learning when they don't. Although Lowtech cannot solve the environmental problems caused by the ICT revolution it can, through the creative and dynamic use of what is supposedly trash technology, highlight such issues as e-waste and inbuilt redundancy. It can also serve as a tool with which to work upon your own subjectivity. Lowtech alters the relationship between person and machine, when something breaks down it is up to you to either solve the problem yourself or find someone else who knows the solution, whether that be on the Internet or the other side of the room. You cannot take it back to the shop and expect them to solve your problems for you. Within an age such as ours there is much to be said for such an antidote.

\section{REFERENCES}

1. BBC News (http:// news.bbc.co.uk/1/hi/technology/2444675.stm, November 2002).

2. Deleuze, G. and F. Guattari Anti-Oedipus: Capitalism and Schizophrenia (The Althone Press, 1984, London) p. 257.

3. Foucault, M (Preface) in Deleuze, G. and F. Guattari Anti-Oedipus: Capitalism and Schizophrenia (The Althone Press, 1984, London) p. xiii.

4. Girshick S., R. Shah and S. Waag Information Technology And Sustainability: Enabling The Future (in The Natural Step Working Paper Series, http:// www.svtc.org/cleancc/pubs/it_sustain_natstep.pdf).

5. The Future (The Natural Step Working Paper Series, http://www.svtc.org/cleancc/pubs/ it_sustain_nastep.pdf) p. 20.

6. Silicon Valley Toxics Coalition (http:// www.svtc.org/cleancc/pubs/2001report.htm, November 2002). 


\section{E-Waste Computers and Toxicity in India}

W aste is now electronic. It is ironic that the very speed of innovation that lies at the heart of computer manufacturing also leads to parallel product obsolescence. By current reckoning, the average computer platform has a lifespan of less than two years. Particularly in more advanced economies, it is cheaper and more convenient to buy a new machine than to upgrade an old one.

According to a recent US study, over 315 million computers will become obsolete by the year 2004. And by 2005, one computer will become obsolete for every new one put on the market. Preliminary research by the Basel Action Network (BAN) reveals that besides China, most e-waste exports are to Indonesia, India and Pakistan where they are processed in operations that are extremely harmful to human health and the environment. Even as the domestic electronic waste issue remains unattended, the export of hazardous waste such as outdated printed circuit boards, floppies and tonnes of copper sludge is going on in connivance with the authorities. According to a report in the Japanese newspaper Nikkei Weekly, in the aftermath of new laws, companies from the US and Europe are either disposing of their products or selling used components in the garb of recycled products to brokers for export to developing nations like India. The recycling industry thrives on electronic garbage. "We found a cyber-age nightmare" said Jim Puckett, coordinator of BAN. "They call this recycling, but it's really dumping by another name". Rather than banning it, the United States government is actually encouraging this ugly trade by failing to ratify the Basel Convention and exempting toxic e-waste from its laws governing exports, simply because the material is claimed to be destined for recycling.

\section{India}

Exporting Harm: The High-Tech Trashing of Asia, a groundbreaking investigation by an international coalition of environmental organisations, reveals that in Delhi, in Mandoli, Sadar Bazaar, Kantinagar Extension, Old Seelampur and Turkman Gate, e-waste trade is a thriving business. Indian e-waste dealers make bids on sea-going containers at the inland depot situated at Okhla. The material is taken, sorted and distributed between various recyclers according to specialisation. They obtain scraps from a process that involves using nitric acid on the circuit boards to remove gold and platinum. Both methods, open burning and acid baths, are fraught with occupational health risks as well as risks to the people living in the surrounding areas. Employees separate the parts from the circuit boards using wire-cutters and pliers. After some pin straightening, some of the IC chips and components are sold for reuse. Items not worth reusing are reduced to metals in outdoor fires. Following chip extraction and burning, the boards themselves are burned in an open pit to retrieve the rest of the solder and copper. After burning, the ashes are floated in water to remove lighter ash.

\section{Wrste is mow glectronis}




\section{China}

The Guiyu, in the Guangdong Province of China, is another major area for working with e-waste, with about 100,000 poor migrant workers employed in breaking apart and processing obsolete computers imported primarily from North America, using nineteenthcentury technologies to clean up the waste of the $21^{\text {st }}$ century. These include computer monitors, keyboards, photocopy machines and television sets. Small Chinese companies, many of them in the southeast near Hong Kong, tear apart derelict computers and other electronic items to recover gold and other materials, with most workers having no protection from the toxic fumes released when melting down parts.

The operations involve men, women and children toiling under primitive conditions, often unaware of the health and environmental hazards involved in operations which include open burning of plastics and wires, riverbank acid works to extract gold, melting and burning of toxic soldered circuit boards and the cracking and dumping of toxic lead laden cathode ray tubes.

Tons of e-waste is dumped along rivers, in open fields and irrigation canals in the ricegrowing area. The pollution in Guiyu is already so devastating that well water is no longer drinkable and water has to be trucked in from 30 kilometres away for the entire population.

\section{Future Prospects}

Experts have opened talks in Geneva to develop policies and technical guidelines for a major treaty on transporting and discarding toxic pollutants, which includes electronic wastes. The Basel Convention's Technical Working Group is expected to hammer out guidelines for environmentally sound management of waste, lead-acid batteries, metal and metal compounds, plastic wastes including electronic wastes, persistent organic pollutants (POPs) and the dismantling of ships.

What is required is a proper definition of electronic waste (which includes cathode raytubes, televisions and TV monitors, LCD screens and all circuit boards and equipment containing these items) as hazardous waste, as is mandated by the Basel Convention. Immediate steps are also required to forbid the import of e-waste into India. The growing problem of electronic waste is something computer companies too ought to take responsibilty for.

Environmental organisations are also calling on the United States to follow Europe's example and immediately implement the global ban on the export of hazardous wastes to developing countries, and to solve the e-waste problem 'upstream' by mandating that the electronics industry institute 'take-back' recycling programs, toxic input phase-outs and green design for long life, upgradeability and ease of recycling.

Even the best hazardous waste recycling operations are known to leave polluting residues and emissions in the environment. The export of hazardous wastes to developing countries to take advantage of cheap labour markets or weaker environmental standards and enforcement ability disproportionately burdens such countries with pollution simply because they are poor. ICT is a doubleedged sword - a life cycle assessment and clean production of ICT products is the only answer to deal with its negative features. 

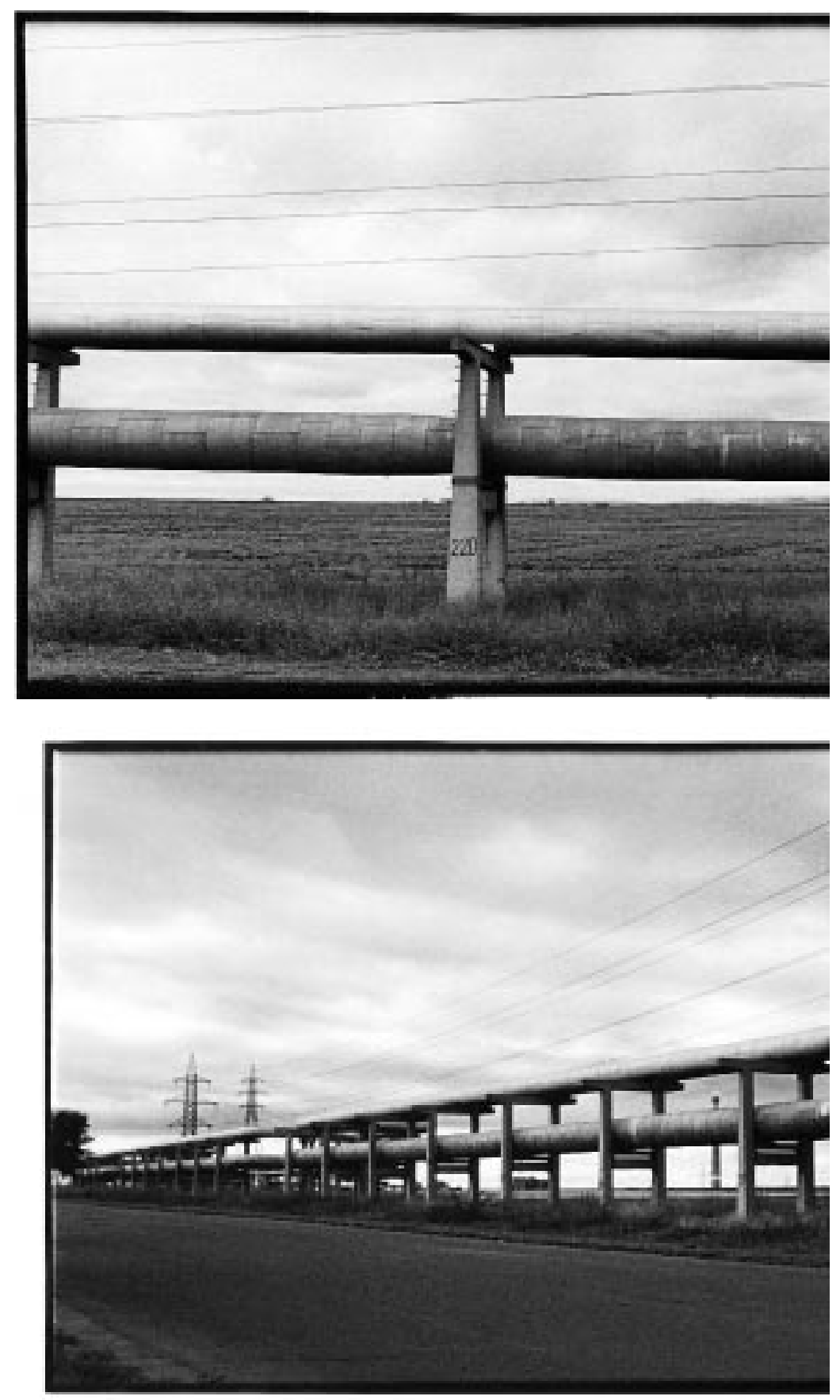

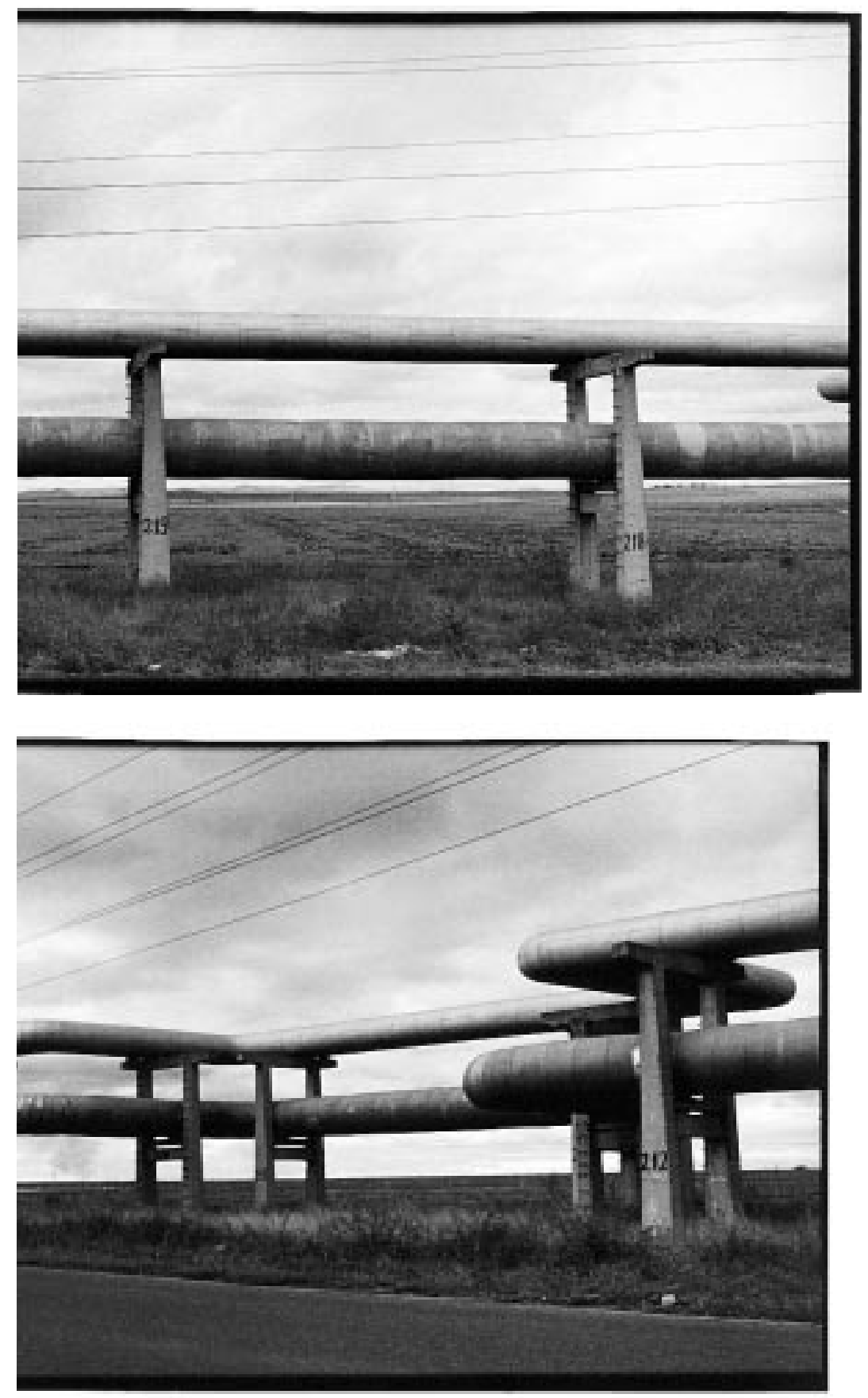


\title{
Governing Technology The City in the Age of Environmental Crisis \\ A WA DHENDRA SHARAN
}

\begin{abstract}
A different spectre haunts the contemporary city. This is not the fear of multitudes protesting against the bourgeois order. Rather, the uncertain effects of materials that sustain the modern world have come to haunt it today, in the form of particles and emissions. "Earlier concerns with pollution that was visible and degradable", the Ministry of Environment and Forests in India observed in 1992, "are giving way to new types of pollution with very small quantities of synthetic chemicals that are not so visible and are injurious to health and damage the environment because of widespread use, persistence and toxicity. Reducing the hazards from toxic chemicals is now a primary public concern... Despite uncertainties and insufficient knowledge, political and scientific decisions concerning environmental change will be necessary".

The distribution of environmental ills has a complex genealogy. The city has always been concerned about the 'environment' but perhaps it is only in the last decade or so that it has come to face an environmental crisis of sorts. This is the political and economic crisis of material flows and resource allocation, but also critically the crisis of managing technological transformations. If in the first half of this century the physical relocation of polluting materials provided an adequate frame for governance, such relocations can only provide partial solutions today. Urban futures must now be built on our capacities to deal with uncertainties, technical and otherwise, and evolving frames for governance that have, at best, unstable truths to guide them.

This essay concerns itself with one such narrative of technical uncertainties and contemporary urban governance, drawing upon the Compressed Natural Gas (CNG) crisis in Delhi. Very briefly, the facts of the case are this: The Supreme Court of India over the last few years has passed a number of orders to combat air pollution, one of which is that entire fleets of public transport in Delhi - autos, taxis and buses - be converted to CNG, which is argued to be a "clean fuel", or if not that a "more environmentally acceptable" fuel than petrol and diesel. This decision has been extremely controversial, and this essay seeks to open up questions that emerge from the process of effecting this transformation.
\end{abstract}

\section{Law/ Constitution/ Technology and the Environment}

Scientific/technological environmentalism in Delhi has many originary moments, depending on who is making the argument and to what purpose. For this essay an important originary moment can be located in the Supreme Court Judgment of 1986, relating to the leak of oleum gas from a unit of the Sriram Foods and Fertiliser Industry in Delhi. In his judgment (M.C. Mehta v. Union of India and Sriram Foods and Fertilisers Case, 1986 (2) SCC 175) Justice Bhagwati observed: "We would also suggest to the Government of India that since 
cases involving issues of environmental pollution, ecological destruction and conflicts over national resources are increasingly coming up for adjudication and these cases involve assessment and evolution of scientific and technical data, it might be desirable to set up Environmental Courts on the regional basis with one professional judge and two experts drawn from the Ecological Sciences Research Group keeping in view the nature of the case and the expertise required for its adjudication" (emphasis mine).

Two important developments followed from this line of reasoning. The first that strikes even a casual observer of the contemporary city is that notwithstanding periodic legislations and resolutions of the executive branch of the government, there has been a shift in responsibility for environmental improvement from the executive to the judiciary, a move that has been increasingly consolidated over time. Second, and this is something that deserves special merit, is that questions of environmental justice and equity have been brought within the ambit of constitutionally granted rights. This is based on a significant rereading of the Constitution and judgments of courts that have argued that the right to a clean environment is a fundamental right. This Constitutional basis of the Court's intervention is also laid out in judgments related to the CNG case, as for instance in the opening remarks of the order of April 5, 2002 that states that "Articles 39 (e), 47 and 48A by themselves and collectively cast a duty on the State to secure the health of the people, improve public health and protect and improve the environment. It was by reason of the lack of effort on the part of the enforcement agencies, notwithstanding adequate laws being in place, that this court has been concerned with the state of air pollution in the capital of this country".

The second important implication of the newly acquired centrality of the courts is the reliance on independent experts to serve as guides in matters of scientific understanding and technological options. It is not surprising then that the assertion of expertise has been an important component of the rhetorical strategy of each of the major players in the CNG controversy. The Mashlekar committee, set up by the Government of India in August 2001 to suggest a fuel policy for the country, comprised, in its own words, "eminent" experts in the fields of environment, energy, vehicular technology, public finance, management, and representatives of key Ministries/Organisations including Environment and Forests, central Pollution Control Board, Non-conventional Energy Sources, etc., though even this seems to be have been inadequate. As the Supreme Court, in the order just cited, observed: "The composition of the Mashlekar Committee was such that none of its members was either a doctor, or an expert, in public health. The said committee submitted its report which does not show any serious concern with the health of the people". The Centre for Science and Environment (CSE), a public interest organisation based in Delhi, not finding the necessary technical expertise in India, set up an international committee of technical experts to undertake an evaluative study of CNG and diesel in order to arrive at an "independent evaluation", while the Tata Energy Research Institute (TERI) asserts, on the basis of its long experience in monitoring pollution and other related activities, it possesses the necessary expertise to develop a methodological framework for assessing the extent of pollution and coordinate data compilation on the subject.

The task of these experts is clearly laid down too - to provide scientifically accurate data that can serve to shape policy. The Mashlekar Committee thus observes that "evi- 
dence based analysis backed up by scientifically validated data, especially under Indian conditions, should be the cornerstone of any sound policy". In a signed editorial in Down to Earth (30 April 2001), Anil Agarwal writes that "As the management of the process of conversion [of public transport to $\mathrm{CNG}$ ] required technical competence on auto emissions, technology and health effects and as generalist bureaucrats have no understanding of these matters, a technical team should have been put in place to advise the government. In the absence of this advice, the Delhi government has remained consistently confused and has allowed every vested interest to take it for a ride". TERI, one of the organisations that is implied in Agarwal's list of "vested interests", makes a similar claim while opposing the conversion of the entire public transport to CNG: "The prevailing public perception needs to be corrected. Much of the public perception is based only on 'visible forms' of pollution. The relationship between visibility and pollution is a very complex phenomenon requiring further scientific investigation. The relationship between air quality and vehicular pollution is far too complex to be influenced by simple measures; what we require are more informed probing of the issue (Press Note, 13 August 2001). And in yet another report it informs us that "in the absence of a scientific approach to the establishment of a reliable database [on vehicular pollution] it would be difficult to evaluate the impact of different measures in combatting pollution or priortise them for purposes of implementation".

But what if the experts fail to develop a consensus on their findings, as indeed they do in the case of CNG? The fault then lies not with science, but with partial, selective, deliberately misleading or genuinely ill-informed knowledge of it. Accusations on this count have flown fast and furious between the different experts, and studies from around the globe have been presented to the public and the courts, explicating this 'misleading' presentation of data. Thus, for instance, CSE contests TERI's use of data from the Expert Reference Group Study in Australia conducted in 1998 with a more recent study undertaken by the Australian Government's Council for Scientific and Industrial Research Organisation. Similarly TERI cites the approach taken by the European Programme on Emission, Fuels and Engine Technologies as providing a more comprehensive framework than that on offer by the Bhure Lal Committee and the Courts; or in another context, World Bank studies on Mexico city and Santiago on the inadequacy of what it calls this "technical fix" to reduce air pollution.

In brief, despite their many differences, a 'scientific' understanding of clean technologies is the only available framework within which the question of environmental improvement gets articulated in this instance. And this has interesting social implications. One of the important things that Frank Fischer, following Foucault, argues in his book Citizens, Experts and the Environment, is that "the focus on the political position of the technocrat in the decision structure misses the more fundamental power of professional discourses... the most significant power of the professional is lodged in basic conceptual categories of thought and language... Professional disciplines (in conjunction with the state) predefine the very worlds that they have made the object of their study" $(2000$, p. 24). This is something that, I suggest, very much describes the world of the CNG environmentalists, who act as advisors rather than decision-makers but whose vocabulary saturates almost every sort of opinion on the subject. If there are uncertainties, these are of science itself and can/must be solved scientifically. 


\section{Technological Choices/ Scientific Uncertainty}

The expert may well live with the uncertainty, but it is an entirely different kind of experience for those who bear the responsibility to govern, unaided as they are by unambigous truth. At one particular moment in the issue, after the Courts had passed strong strictures against her government, the Delhi Chief Minister took her predicament to the public:

I do not want chaos on the streets. We are all for reducing pollution but it is this war between CNG and anti-CNG lobbies which has landed us in a kind of spot. We do not know which way to go... Retrofitting and conversion are still not known technology... People cannot be expected to spend money on a technology which is not known... There is still a debate going on about CNG and we as a responsible government want pollution to be eliminated. But we also have to answer to the people and the money that they are made to spend... I do not know what is the truth (Down to Earth April 30, 2001).

But this argument no longer cuts ice, and we are brought back once again to innovations in the legal mechanism to address issues of environmental good. As explained by the Supreme Court, the precautionary principle is a necessary component of ecologically sustainable development. And what it involves, among various other things, is the following: $>$ The State Government and the statutory authorities must anticipate, prevent and attack the causes of environmental degradation.

$>$ Where there are threats of serious and irreversible damage, lack of scientific certainty should not be used as a reason for postponing measures to prevent environmental degradation.

It followed that the auto policy must, therefore:

Focus upon measures to "anticipate, prevent and attack" the cause of environmental degradation in this field.

In the absence of adequate information, lean in favour of environmental protection by refusing rather than permitting activities likely to be detrimental.

Make informed recommendations which balance the need to protect the environment and reverse the large-scale degradation that has resulted over the years, priority being given to the environment over economic issues. ${ }^{1}$

In each of these matters contemporary environmental initiatives, as largely undertaken by the courts and scientific bodies, are in marked contrast to the situation that obtained for the $50 \mathrm{~s}$ and $60 \mathrm{~s}$. In fact, they are in contrast even to more recent concerns about the adverse impact of environmental decisions on the economy. But what needs to be appreciated is that this concern with the economy comes from very different vantage points when the government speaks it is in the language of national progress: "In seeking a higher quality of life while developed countries need to focus on changing the composition of their processes and products, developing countries will need to obtain the benefits of economic growth". Others talk of "social responsibility": "There are costs involved to everyone that includes the Government, the fuel producer, the auto producer, and the user. One can have infinite desires but there are only finite resources. Therefore minimisation of social 
cost was considered to be one of the key guiding principles" (Mashlekar Committee). In yet another vein when the PUDR opposes the court's decisions on the closing and shifting of factories, the concern is from the prospect of job loss and adverse economic and health impacts on the workers.

What the precautionary principle does is set a new stage for when and what kind of action can be undertaken in anticipation of future harms rather than merely as a reaction to a situation gone out of hand. But its social implications are far from clear - what we find particularly interesting about the CNG issue is that its proponents have sought to bury the nationalist myth that higher standards are the luxury of the developed world. In fact, CSE argues, it is precisely in a city like Delhi, where particulate pollutants kill on an average one person per hour, that there is an urgency that we leapfrog to the cleanest technology if we are serious about addressing issues of public health. The judgment is backed by the Supreme Court which used a 1992 World Bank study to suggest that the annual health cost of air pollution in the city could well be to the tune of Rs. 1,000 crores, out of the country's share of Rs. 5,550 crores. And this data itself is about a decade old! Issues of costs become secondary in this reasoning for, as the Bhure Lal Committee submitted before the Court, countervailing health costs of air pollution have to be linked to investment and price issues, and no estimation of these had been made by the Ministry of Environment, leaving the World Bank data as the only available set of figures of just how high these costs could be (Report on Clean Fuels J uly 2001). Given that Delhi is an air pollution hot spot (due to high levels of Respirable Particulate Matter of less than 10 micron size), this report argues, even more needs to be done than what has been put in place till date.

\section{Citizens and their City}

But the question remains - where does that leave us as citizens and residents of this city? Clearly all strategies for environmental improvement will be accompanied by the notion of public good. There are efforts to 'educate' the public too - the CSE's campaign on the right to clean air aims to not only lobby with the government but also to "raise public awareness about poor urban air quality and risks to public health". This is the empowering of civil society against "vested interests" ("The Smokescreen of Lies: Myths and Facts about CNG" 2001). Similarly, TERI has produced a number of info-sheets on the premise that "an informed citizenry is an effective citizenry".

There are two issues at stake here. First, the deployment of the category of the 'public' is simultaneous with the recognition of 'interest groups'. Thus when the Environment Pollution (Prevention and Control) Authority was asked by the Supreme Court in March 2001 to report as to which fuel could be regarded as a clean fuel (which does not cause pollution or is otherwise not injurious to health) the Court observed that "it shall be open to the interested parties to make their representation directly before Bhure Lal Committee in support of their pleas as to what can be regarded as a clean fuel...". Accordingly, the EPCA received representations from the following parties: Ministry of Petroleum and Natural Gas; Oil Companies; Society of Indian Automobile Manufacturers; Tata Engineering and Ashok Leyland companies; Delhi Transport Corporation; All India Motor Transport Congress; Indian Tourists Transporters Association; Delhi Contract Bus Association; Delhi Transport Cor- 
poration; Private Bus Operators Welfare Association; Indian Association of Tour Operators; SHV Energy Pvt. Ltd.; and Delhi Petrol Dealers Association.

No public health interest group here! That apart, it remains an open question of democratic governance and environmental improvement as to what relationships are established between these recognised interests (or stakeholders, as they are often referred to) and the general public, in the interest of whose health the entire exercise is being undertaken.

Equally important, as has been clearly demonstrated in case after case, there isn't just one public out there. The closure of industrial units on account of pollution has severe effects on livelihoods and the health of many workers, just as slum relocation drives hardly benefit those who dwell in them. Is the CNG case another of those instances when the use of the term 'public' has been selective and biased against the poor? And this is where I have my reservations about adopting categories such as bourgeois environmentalism to understand all that is happening around us. The issue here might be slightly at tangent. This is how Dinesh Mohan puts it: "The questions [about CNG] are posed as if we are choosing between different flavours of ice-cream. There seems to be little concern over the decision-making process itself. The complexity of the technological, economic and social issues are completely ignored". It is dealing with this complexity, I suggest, that remains one of the more significant challenges of contemporary environmentalism, one that gives an added dimension to the concern with economic and social equity.

\section{NOTES}

1. It is in this context that the Court also made its famous observation that "if there is a short supply of an essential commodity, then the priority must be of public health, as opposed to the health of the balance sheet of a private company. To enable industries to cut their losses, or to make more profit at the cost of public health, is not a sign of good governance, and this is contrary to the constitutional mandate".

\section{REFERENCES}

1. Fischer, Frank Citizens, Experts, and the Environment: The Politics of Local Knowledge (Duke University Press, 2000, Durham, North Carolina). 


\section{The Engineer in the Information Age}

\section{Introduction}

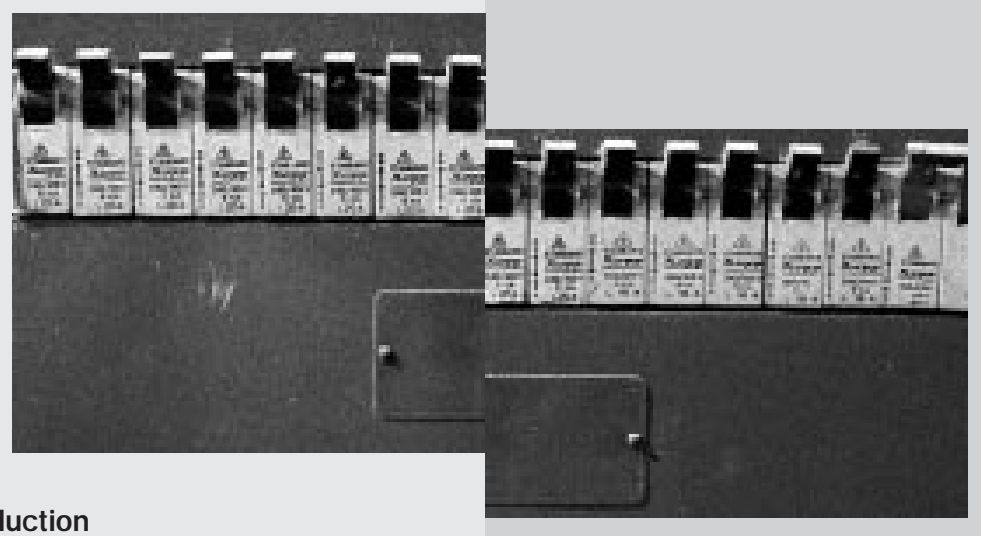

When looking at technology, we seem to see only machinery, not the people behind it. That filter determines our attitude towards technology and explains our neglect of the process of its creation. We seek to understand the tree without examining its roots.

Technology is "the application of scientific knowledge to the practical aims of human life or, as it is sometimes phrased, to the change and manipulation of the human environment". As such, it has played a crucial role in human survival, allowing a physically weak species to marshal natural laws and resources in its defence. Since the harnessing of plant growth in agriculture, the taming of fire and the invention of writing, the fruits of technology have surrounded and transformed us. The cumulative effect of technological development has brought us to a point where technology is intertwined with every aspect of our lives yet we are still not entirely comfortable with it.

There is passivity in modern society towards technology. While new products are continually brought to our attention through advertising, the degree of control most of us exercise is only in buying this or that product and, at most, in telling our friends about it. This is perhaps comparable with the degree of control a couch potato exercises through his remote over the content that networks beam at him.

However, there is a segment of society that actually makes technology, which trolls the journals of science for new ideas and looks at the reactions of consumers to old products in order to design new ones. These people also have the responsibility of keeping the old technology running and are the ones you call when products don't work as they should. These are, of course, the engineers who belong to a "profession in which a knowledge of the mathematical and natural sciences, gained by study, experience and practice, is applied with judgment to develop ways to utilise, economically, the materials and forces of nature 
for the benefit of mankind". ${ }^{1}$ Going by this definition, the term engineer must equally apply to practitioners of 'old' technologies - the farmers, carpenters, architects and plumbers as it does to geneticists and computer programmers.

\section{The Gap between Importance and Perception}

Oblique evidence of the supreme importance of engineers in recent times is available from the Soviet Union. Almost the entire generation of Soviet leaders that followed Stalin were engineers - including Kruschev, Kosygin, Brezhnev and Yeltsin. The probable reason for this was that while Stalin had little hesitation in wiping out everyone else, he must have appreciated that there was no way he could beat the Nazis, or compete with the West, without engineers. When he died these were the only people left in any sort of leadership positions.

A Martian reading of this might imagine that engineers are the stars of a civilisation that is totally dependent on technology. Yet nothing would be further from the truth! Like the craftsmen who created medieval architectural and other masterpieces, most engineers remain anonymous, even the brilliantly successful ones.

How many people could identify the inventors of the digital computer (John Mauchly and J. Presper Eckert), a device whose importance in modern life is second to none? Alfred Nobel was himself an engineer par excellence. His invention, dynamite, is still widely in use in mining and construction. ${ }^{2}$ That even he did not see fit to institute a Nobel Prize for engineering is typical of the modesty of the profession. Perhaps the best example of society's lack of attention to engineers, however, is the case of Claude Shannon whom few outside the profession have even heard of. This genius discovered that Boolean algebra, an area of mathematics thought to have no practical use, was perfectly suited to the design of digital circuits. H. H. Goldstine, in his book The Computer from Pascal to Von Neumann, called this work "a landmark in that it helped to change digital circuit design from an art to a science". In 1981 Professor Irving Reed, speaking at the International Symposium on Information Theory in Brighton, England, said: "It was thirty-four years ago, in 1948, that Professor Claude E. Shannon first published his uniquely original paper, "A Mathematical Theory of Communication", in the Bell System Technical J ournal. Few other works of this century have had greater impact on science and engineering. By this landmark paper and his several subsequent papers on information theory he has altered most profoundly all aspects of communication theory and practice". This paper has justifiably been called "the Magna Carta of the information age".

Shannon's work on information theory has also had significant impact on fields outside of communications - including linguistics, psychology, economics, biology, even the arts. Robert W. Lucky, executive director of research at AT\&T Bell Laboratories, called his work the greatest "in the annals of technological thought", while IBM Fellow Rolf W. Landauer equated his "pioneering insight" with Einstein's. Claude Shannon died as recently as February 24,2001 , but the Internet, inconceivable in the absence of his insights, barely noticed. ${ }^{3}$

If people pay no regard to those who make technology, nor make any effort to understand them, they will find it hard to appreciate the logic of the direction it takes - for the inventor and the invention resemble each other. If the products of technology often seem lacklustre and unimaginative, maybe this is a reflection of a similar lacunae in most engi- 
neers. We can also take the analysis one level upstream. To understand why engineers turn out the way they do, one must look closer at how they, in turn, are made through life in an engineering college.

\section{The Deficient Education of Engineers}

The manner in which engineering is taught is incredibly authoritarian and dull. The reason for this is not hard to find. As pointed out by Peter Senge and others, our modern education system was born during the Industrial Revolution, which faced a severe shortage of trained personnel. At the time, industrialists made a fortune by taking manufacturing out of the community and locating it in a new kind of space called a factory. Faced with a shortage of people skilled in manning these factories, the owners applied their tried and tested formula once again: they took education out of the community and made it the responsibility of a new kind of factory called a school. Indeed, our schools are organised along the same principles as assembly lines: students are like parts moving in lockstep from one class to the next, while teachers are like machines that impart education, within a highly authoritarian system. If a student cannot successfully pass the requisite tests, he is thrown out, not unlike a part that has failed quality control.

According to Senge, "while the assembly line school system dramatically increased educational output, it also created many of the most intractable problems with which students, teachers and parents struggle to this day. It operationally defined smart kids and dumb kids. Those who did not learn at the speed of the assembly line either fell off or were forced to struggle continually to keep pace; they were labelled 'slow' or, in today's more fashionable jargon, 'learning disabled'. It established uniformity of product and process as norms and thereby naïvely assumed that all children learn in the same way. It made educators into controllers and inspectors, thereby transforming the traditional mentor-mentee relationship and establishing teacher-centred rather than learner-centred learning... The assembly line education system is now under stress. Its products are no longer judged adequate by society. Its productivity is questioned. And it is responding in the only way it knows how: by doing what it has always done but harder".4

Is it any wonder that a system which discards human beings as scrap produces so many terrorists and criminals? Those who survive it are almost brainwashed into believing that having an opinion about anything outside of their narrow areas of technical competence is inadvisable. The syllabus pounded into them is needlessly voluminous and difficult, of which a practicing engineer only actually ever uses a tiny fraction. Teachers typically have almost no industrial experience, nor do students have any regular interaction with industry. Could anyone imagine a medical school without an attached hospital, where the teachers have almost never seen a patient?

It hardly comes as a surprise, therefore, that this profession attracts few women. Even among the men there is a very high proportion of, to say the least, poor communicators. Yet, these poorly equipped and trained people are the ones entrusted with running critical industrial establishments, and can be held partially responsible for such disasters as the Union Carbide plant in Bhopal and the nuclear reactors in Chernobyl and Three Mile Island. 


\section{The Gap Between the Humanities and Engineering}

There is much that can be done to improve this situation. For a start, what is clearly needed for a better understanding of technology and its dynamics, is greater interaction between the engineering and the humanities departments in universities. Such interaction is rare: often, the technical university is on the other end of town, and even where it isn't, the mental gap is large: students from these disciplines don't take each others' courses, unless they are forced to.

A laudable attempt to bridge this communication gap is Robert Pirsig's Zen and the Art of Motorcycle Maintenance. He shows how tackling repair problems that seem mundane, can be a highly creative, perhaps even spiritual activity. As he puts it, "Flight from and hatred of technology is self-defeating. The Buddha, the Godhead, resides quite as comfortably in the circuits of a digital computer or the gears of a cycle transmission as he does at the top of a mountain or in the petals of a flower. To think otherwise is to demean the Buddha... which is to demean oneself".

Bridging this gap has become far more important now that the world is changing very rapidly through advances in the field of information technology. Many new professions and industries have been created, including programming, web designing and systems administration. Others, such as mail and publishing, have been dominated, while other, like typesetting, even destroyed. Many big industries, such as music and telecom, are reeling under its impact. TV and cinema may be next.

Now that technology is receiving unprecedented media attention, so are its creators. Related, perhaps, to the relative newness of the Internet, there is now more glamour to be found here than in conventional branches of engineering. A student contemplating a choice between a career in marketing and computing can ask herself the same infamous question that Steve J obs used to convince J ohn Sculley to leave the giant Pepsi corporation for the then tiny Apple: "Do you want to spend the rest of your life selling sugared water, or do you want to change the world?". ${ }^{5}$ Indeed, there are many on the Internet who can lay claim to having significant part in changing the world: the members of the Internet Engineering Task Force, those in the open source movement, those who devised the software for mailing lists, chat, peer-to-peer file sharing, Internet Telephony...

\section{Gilmore's Hypothesis}

For a new technology to replace an older one is nothing new. Such innovation generates plenty of money for the industrialist, if the buyer can be persuaded to replace old products. However, on the Internet, in addition to an economic component, the role of the engineer has taken on an entirely new dimension - one which makes it vital for engineers to pay closer attention to what they can learn from the humanities departments. John Gilmore said, "The Internet treats censorship as a defect, and routes around it". This is a characteristic with political import. It was Arthur Koestler who said (I believe) that all it needs for the demise of authoritarianism is the free flow of information. Combine the two statements, and it would seem that the Internet and authoritarian regimes are incompatible. How does technology assume such political overtones?

Partly, what Gilmore said is a statement about the basic design of the Internet, which 
had as one of its objectives, robustness. If a part of the network became defective, the rest could automatically reconfigure itself, essentially routing around the defective part. The technology underwent a veritable test by fire during the Gulf War. Iraqi defense communications, built on the same technology that powers the Internet, could not be taken out entirely, no matter how hard the powerful opposition tried. ${ }^{6}$

This characteristic of the Internet is also a consequence of the relative lack of sophistication in decision-making that electronics is capable of. The Internet is a highly automated communications medium and any process which cannot run autonomously by electronic machinery is expensive and doesn't work very well on it. Censorship is a sophisticated decision-making activity. It requires extensive human intervention. However, as computers become increasingly sophisticated their capabilities will grow and this could change.

What started out as sound engineering design has, with the growing importance of the Internet, become something far more: a serious threat to the functioning of authoritarian countries such as China. No less serious is the damage that the music industry perceives peer-to-peer networks are causing. The movie business worries that, as Internet bandwidth improves, it will be next. Yet, try as they will, such political and economic powers seem powerless in influencing the direction of technology development on the Internet.

\section{Directing Technology Development on the Internet}

What is indeed unique about the Internet as a technology is the manner in which it develops. Arguably the only significant governance the Internet enjoys is that of the Internet Engineering Task Force. These people manage a process that ensures that the Internet keeps acquiring new abilities at a furious pace that leaves policy-makers and the legal system far behind. The bureaucrats at international decision-making bodies, such as the UN, must wonder how it maintains this speed in a process that is remarkably inclusive, consensual and transparent.

The IETF doesn't take decisions in favour of one approach or the other: if even after thorough discussion, there is a difference of opinion on how a certain objective is to be achieved, all the variants can be tried out, without fear of doing any serious damage. With the characteristic modesty of an engineering body, the standards that the IETF encourages the Internet to follow are published as "Requests for Comment". If, after some experience with the variants, one stands out, a new RFC that points this out supersedes the earlier one, and the discussion moves on to other objectives.

Handed earth shaking power, engineers have come up with a process to channel it effectively. This is hardly unfamiliar territory for them: learning how to harness power is what they have practiced since the beginning. The difference this time is that decisionmaking relating to the development of technology is not taking place behind the closed doors of conference rooms. The reason why the Internet turned out differently is that engineers and others interested in the development of technology could communicate.

Imagine, for instance, how the pharmaceutical industry might be different if it were to use the Internet model for development. To start with, molecules would be open source: companies would not have to pussyfoot around the patents of their competitors and reinvent the wheel. They could instead focus on improving medication that was proven, and 
therefore testing costs would go down. With raw materials available locally almost everywhere, production could be local too. There would be no marketing costs (ask Google). And finally, without IP costs, the price of medication would be only marginally higher than raw material costs, i.e. almost nothing, so many more lives would be saved.

However, the problem that pharmaceutical, and not Internet, companies faced was that their products could maim and kill people. Therefore a huge bureaucracy became involved in deciding what was researched, tested and approved for sale. Costs went up and the answer that the industry found was to bring in the concept of intellectual property. This made its products vastly more expensive and the process of designing and marketing them terribly inefficient.

Is the Internet model applicable in the rest of industry? It would be worthwhile to find out. The benefits to society of applying the Internet model for decision-making in technological development would be immense. In effect, this would be a much needed extension of democracy into a vital aspect of human existence.

\section{The Education of Engineers}

In light of the added responsibility that the Internet thrusts on the profession, a reexamination of the education imparted to engineers becomes vital. People with such power need to be taught ethics, and have a clear understanding of the legal aspects of their work. For instance, if the engineers who worked for Napster had a better appreciation of copyright law the company might well have survived its legal battles with the music industry. Engineers often have to make business plans these days, so financial skills are essential. Most important, however, are communication and teamwork skills - including how to participate in and chair meetings both on and off-line.

It is also a mistake to think that the education of an engineer is a one-time affair. According to Papert and Caperton, "Digital technology in the workplace requires a new definition of 'basic skills'. The transformation of work requires much more than a mastery of a fixed curriculum inherited from past centuries. Success in the slowly changing worlds of past centuries came from being able to do well what you were taught to do. Success in the rapidly changing world of the future depends on being able to do well what you were not taught to do". ${ }^{7}$ Engineers must, therefore, have ready access to their teachers and colleagues in the event that they need to learn something new.

A far more holistic approach to engineering education has become necessary. Engineering colleges focus almost exclusively on science and technology subjects, ignoring the other needs of their students. However, given the limited background and skill sets of faculty members at these colleges, one really cannot expect much more of them. It is time to bring the community of engineers back into the process of engineering education as both lifelong students and teachers.

Distance learning technologies running on the Internet offer an excellent platform for engineers to participate in courses as teachers or students, either from home or the workplace. Chat rooms that offer quality audio-conferencing, text chat and shared whiteboards are now commonplace. Facilities such as this would also make it simpler for non-technical people to participate in the education of engineers. No longer can it be acceptable that 
engineering education takes place in an environment divorced from industry. The PC is a potential software factory, so it is far easier to train people 'on the job'. Indeed, if students are required to participate in open source development projects at portals such as sourceforge. net, they will not only learn highly useful technological skills in the company of their seniors in the profession, but also imbibe better attitudes towards the ownership of ideas. The rapid pace of change in the IT environment also gives the young a relative advantage, making it harder for their teachers to behave in an authoritarian fashion.

The Internet has brought many changes for engineers. It has diminished their anonymity and isolation, increased their importance, taught them communication skills and forced another look at the manner in which they are educated. A necessary change in the role of the engineer in the information age is that she now also needs to become a teacher.

\section{NOTES}

1. http:// www.ee. bilkent.edu.tr/ eeweb/ eee101/ definition.html

2. http://www.nobel.no/eng_com_will1.html

3. http:// www.research.att.com/ njas/doc/shannonbio.html

4. Senge, Peter, Nelda Cambron-McCabe, Timothy Lucas, Bryan Smith, Janis Dutton and Art Kleiner Schools that learn: A Fifth Discipline Fieldbook for Educators, Parents and Everyone Who Cares About Education (Nicholas Brealey Publishing, 2000).

5. Sculley, John and John Byrne Odyssey: Pepsi to Apple: A Journey of Adventure, Ideas, and the Future (HarperCollins, 1989).

6. Levine, John and Carol Baroudi The Internet for Dummies (IDG Books, 1994).

7. Papert, Seymour and Gaston Caperton "Vision for Education: The Caperton-Papert Platform" (http:// www. papert.org/articles/Vision_for_education.html).

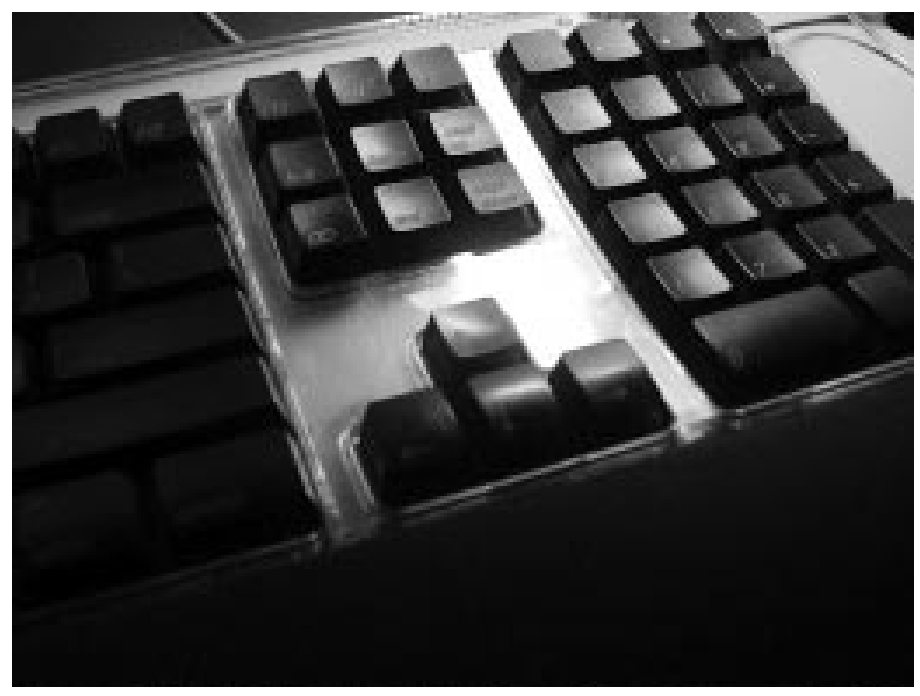



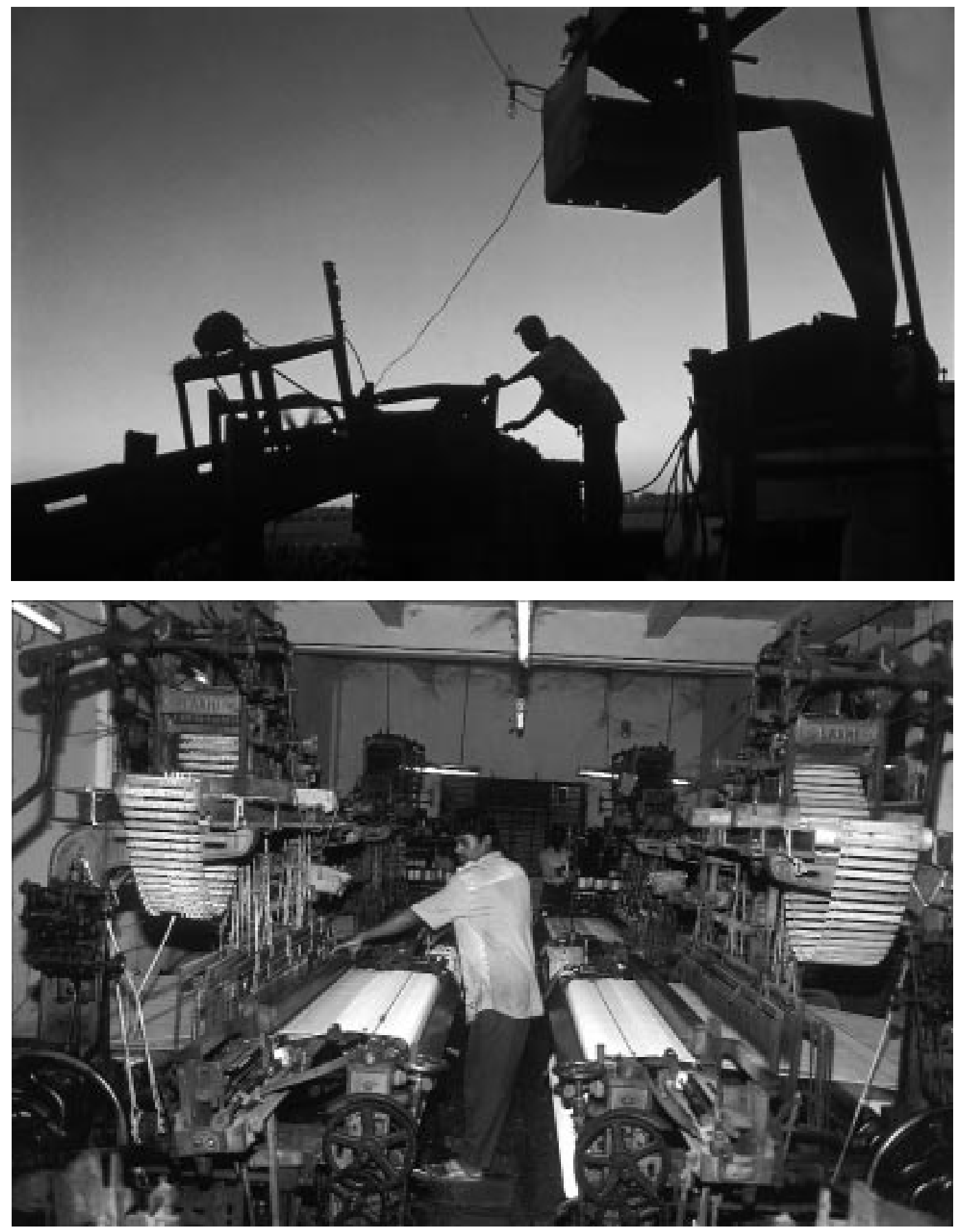


\section{Resisting Technology Regaining a Personal Ecology}

RAVI AGARWAL

W hile photographing migrant labour in the interiors of South Gujarat, my time was spent with those who toiled at the grassroots of the economy, labouring ceaselessly, unheard, unseen. "How has the lives of these citizens of modern India changed over the past half century?" I asked myself. My training as an engineer, obviously, had not provided me with an answer, or more importantly, confronted me with the question enough. As I shot a portrait of a tribal khaki-clad worker who had been retrenched from a large and highly mechanized textile mill, outside his thatched roof hut, I could not but help wonder how his relationship with the 'machine' had changed his life. He had worked for thirty years on an automated assembly line which was capable of churning out miles of yarn in a matter of minutes. It seemed that the technological revolution, or the information age, had discarded him back to his sparse existence, uncaringly passed him by. Meanwhile my tool for our encounter - a sophisticated microprocessor controlled camera, product of a highly 'advanced' system - and his contrasting 'basic' existence made me very uncomfortable. It was obvious that the person I was facing had not improved his possibility in the modern world. Clearly his encounter with technology and its promise had not changed his condition.

A short while later, I had to participate in a discussion about the details of a high-tech 'waste machine' with a former teacher and professor of technology. The discussion revolved around its potential to ensure waste sustainability and delved into the intricacies of its workings and the high technical standards it conformed to. "But how does this solve the problem of waste minimisation or of aiding community based initiatives for waste?" I asked. The discussion broke down. My professor immediately drew a wall around himself; he was "just an engineer", not a sociologist. Also I had seen the best of such machines regularly break down in human settings. I asked if it was the right solution at all, maybe it was inoperable in the context? Had the machine not presupposed the problem in an arrogant manner? Like wearing a suit on a playfield: wrong problem, wrong solution! I was shrugged off. This was somebody else's job. In a moment the experience of a highly trained technical mind and mine, that of a decade of addressing the question from a community perspective, seemed to have no common ground. For him, the 'machine' stood alone. To me it was a mere component of a larger human problem. We were on different terrains.

The discovery of my own self beyond my identity as an engineer has been a rediscovery of a personal ecology. The subversion has not been merely of a particular technology, but of a way of examining my own relationship with the world. My 'emergence' has returned me back to photography and turned me into an environmentalist. I have been left 
resisting technology. Though not unaware of its potential to serve humankind, and to create new social possibilities of new democratic structures in the digital age, I am skeptical of its intentions.

A student of engineering leads a very nerdy life. Everything is very precise and definite. From the killing 8:00 am to 5:00 pm schedule that does not end with sundown but continues to midnight assignments and tutorial presentations, it is a difficult path except for those who are really interested. Technology did fascinate me. The clear reasoning, the logic of circuits and equations, the flow of experiments and the infallible outputs, all challenged the mind to think clearly and in steady tracks. I suppose these tracks grew deep in the five years of such thinking, became etched in my mind, and became a challenge to overwrite in the years to come. Everything was quantified in numbers, formulas, and in the exceptional case that one encountered an enlightened teacher, one could put all this in a framework of understanding and actually relate it to real life. How the Schodinger wave equation or the Uncertainly Principle brings forth a way of looking at the world would be an interesting change from just mechanically solving triple integrals and complex Fourier transforms.

In some senses there was a constant discomfort throughout this intensive academic period. The divide was between 'real' life and the challenge of having to do something well as an end in itself. Of course there were very real linkages, but these were always somewhere below the surface. I suppose the attempt was to making analyses of real world problems second nature to the trained mind, and then to proceed to engineer solutions. However more often than not, it did not succeed. Real life was out there; even if the problem posed in the laboratory could be applied. For example, how do water-flows in a channel connect with what happens when rivers are dammed? Not that laboratory experiments did not offer clues to real life problems, just that there was very little encouragement or effort to do so. Maybe this divide emerged from the teachers themselves, many of whom had pursued academic careers without actually related their learning to on-the-ground situations. Whatever the reasons, it was learning in a box.

The social sciences were introduced into engineering schools a few years before I went to one. The purpose was to make engineers less narrowly focussed, and to make them 'integrate' with human society. The fact that this was felt necessary already demonstrated the divergence that had crept in. Unlike pure science research, technology needed to be applied. Had it now stopped asking the right questions? Did it ever question itself?

My relationship with technology in enginnering college was non-social, non-political. Technology exisited, and its processes and possibilities needed to be understood in a logical framework. Nowhere were the questions "what is technology, who does it belong to, how does it decide to do what it does, who benefits, who loses out?", queries critical to my current existence and engagements. From the now archaic 8085 microprocessor, on which I carried out my first college project, to the awesome Pentium IV, there has been an incredible journey of the human mind. Technology was taught as 'neutral'. It took me many years to discover that it is not. Technology was not set up to be democratic. And it was not designed for the greater common good, but for a greater common market.

Engineers think technology. It is their world and they hang on to it fiercely to the point of excluding everyone else. The language of technology needs translation for it to make 
sense to anyone outside. Though meant to provide answers to human problems, they create dominances and acquire the arrogance of being able to guide human destiny. Is information technology an outcome of a need to be more sociable, or do we have to change to accommodate the existence of a technology? It is akin to the advertising world: do products satisfy needs or create them?

Over the past decade, as an environmentalist and an engineer, I have found it possible to be part of what are technical discussions revolving around environmental 'management'. There is a firmly held view amongst many that environmental change is about the sciences alone and less about human behaviour and human inequities. Hence an inordinate amount of time is spent on making emission standards, quality indices and modelling. Almost no time is devoted to dealing with questions of governance, decision-making processes and how people behave. Environmental committees are stuffed with 'experts' from technology institutions. Like everything else this has roots in how other countries have dealt with the problem, and are in fact still dealing with it. Everything has a technofix; it is just a matter of making the right machine. But technology can be powerful and the forces around it fearsome. Keeping the focus on human needs can be difficult, and in that sense technology is dangerous.

Technology isolates. I have encountered displaced people who do not understand it and cannot participate in it. New industries and big dams located in 'backward' areas have destroyed local livelihoods. The technology drive production process needs 'training' and 'education', but has no use for the knowledge that people have. Skilled farmers, potters, blacksmiths, mud workers are turned into head loaders, trench diggers and 'coolies', while engineers and technicians become masters and 'experts'. The products of technology too do not filter down to those who are no longer valued by it. Knowledge is no longer local, it is centrally controlled and distributed to the more fortunate who can access it. Those who have it are at a premium and can command a better market price, higher salaries and partake in the promise of technology; our institutions ensure this.

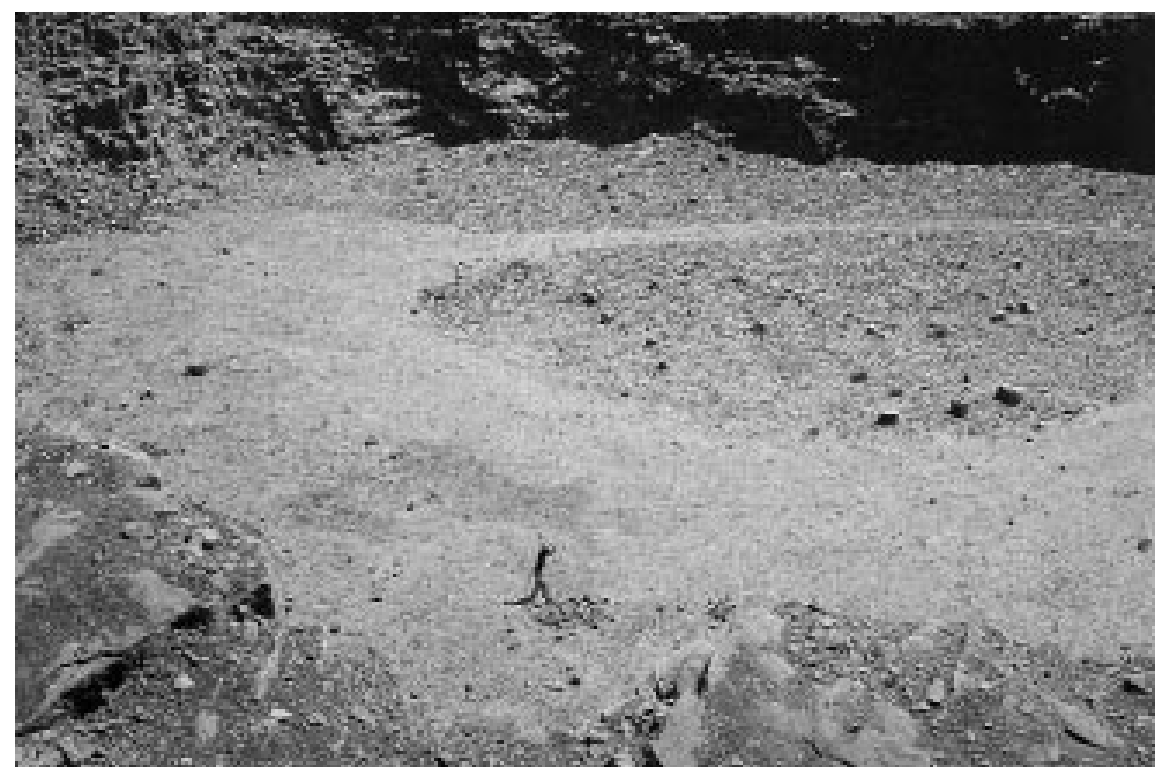


The isolation is not of 'backward' tribal people alone. Urban centres are probably the greatest technological creations of modern times. A city dweller has no connection with the world that supports him or her. Food, water, energy, building materials are all available off the shelf. No matter how many people are displaced from dams, or how land is tilled, or vegetables grown, or the lives which create bricks, stone and marble affected, city folk do not question their sustenance. The technology of water pipes, transmission lines, sewage conduits, food packaging, cold storage and super malls is the interface. It is an unreal world, where telecommunications and television complete the breakdown of social and ecological connectivity.

The isolation of the mind itself is probably more dangerous. My engagement with photography came from relating to and interpreting the world through the eye. Photography was a means to understand and express what I 'saw', and I felt alive with a camera in my hand. In my late teens it became a preoccupation with the technology of cameras. Each new button became a voyeuristic journey. Coincidentally or otherwise, this was the same time that I was in engineering school. I was becoming the tool. The camera dictated what I saw rather then being incidental to it. The subsequent years saw me work down my equipment to its basics, almost in an anti-technology model, to protect my 'seeing'.

Machines do not stand alone. They are the tip of the iceberg of a massive infrastructure of production, finance, corporations and markets. Together they pre-empt the possibilities of a sustainable ecology. Once physically created, a 'machine' makes it difficult for other approaches or possibilities to exist. What translates into a physical product is not a matter of addressing a human problem alone, but the 'choice' through which a product becomes 'real'. Why is it, for example, more difficult to promote a compost pit for a community than to sell an expensive incinerator to a municipality? An earthen dam is doubted while an engineered concrete structure is not. What chance does small-scale water harvesting have, faced with the gigantic structure of a big dam? The monoliths of technologies, be they incinerators or big dams, are morphed from amorphous entities of power, capital and their control.

It is not by chance that developing countries still use DDT for controlling malaria, which kills thousands each day in Africa, Asia and Latin America. Third World diseases do not provide lucrative markets for First World research investments by corporations and the universities they fund. Ten corporations worldwide control over $75 \%$ of pesticide sales. The reversal of climate exchange is more dependant on the entrenched interests of the energy lobby than on possibilities of alternative sources of cleaner energy. Biotechnology is marketed to provide food to the poor of the world, but is controlled by a handful of corporate giants controlling over $30 \%$ of global markets. The biggest hindrance to changing the manner in which chemical safety is ensured in the world is the chemical industry, and not alternate technological possibilities. Powerful nuclear boards set up by nations in search of global dominance have legitimised nuclear energy. AIDS drugs are prohibitively expensive for those who need them most, the world's poor. The largest resistance to making the globe a cleaner place is from existing investments in technology and related infrastructures.

The production and use of technology resides in the control of it, and possibly in its very nature. Gandhi, very importantly, argued that the logic of modern technology, like that of modern science, does not integrate the moral question. Are the values on which they are 
based fundamentally flawed and inherently destructive and polluting? The medicalisation of childbirth leads to machines like the Ultrasound 'serving' to abort female foetuses. Gandhi's charkha (spinning wheel) was a means to bring control back to the individual, of realising life's interconnectivities and of being self-sufficient. Technology without a moral dimension is rudderless, a monster let loose, cloning itself and now life as well.

Technology needs to be redefined, democratised and integrated. Corporations which control technology and its development need to be made accountable. People need to know and endorse the manner in which their lives will change. Technology has to be proven safe before it enters the public domain. The control must reverse itself. Engineering schools do not teach this. They are increasingly funded by corporations who see their future in them. The control over technology seems to be complete, from training minds to using them for social control.

Resistance must come from inside. Nothing that I was taught in my engineering school told me about resisting technology. It was a given good, the way ahead, an entry into modernity and the future. The precision of engineering should be used to question and to confront, and redefine 'knowledge' itself. Not only the environment but also all our ecologies are at stake. It is for this reason I do not help produce technology anymore. Why I am not an engineer.

The digital age has promised a new chimera. E-mail, cheaper production of information and its dissemination make high-tech commonplace, democratic and hence extremely powerful. Its potential power can be gauged by the attempts of the State to control it through new laws and rules. Yet, what is good can also be used for greater social control. What can democratise can also terrorise. Questions abound. Located in a technocentric world it is difficult to argue against its paradigm. Maybe going ahead is a means of exiting its seemingly seamless topography. However, for me the answers to even this hope lie in regaining personal ecologies. It could be a mistake to look towards technology to help in evolving these, which have to be determined by us, outside technology and not through it or centred around it.

Technology can be fascinating. Maybe it can still deliver its promise of changing the possibilities of the world, in this digital age. Why then do I resist it? To me its seduction is dangerous. It has the potential to take my mind over, and make me lose my basic interface with my surroundings. It threatens to overtake my person and the interface between the private and the public. A mediator is useful, but not if it can become my master. I do not want to become a commodity. I wish to stay free. 


\section{Wh \\ Subterranean Labour}

\section{photographs + text SRINIVAS KURUGANTI}
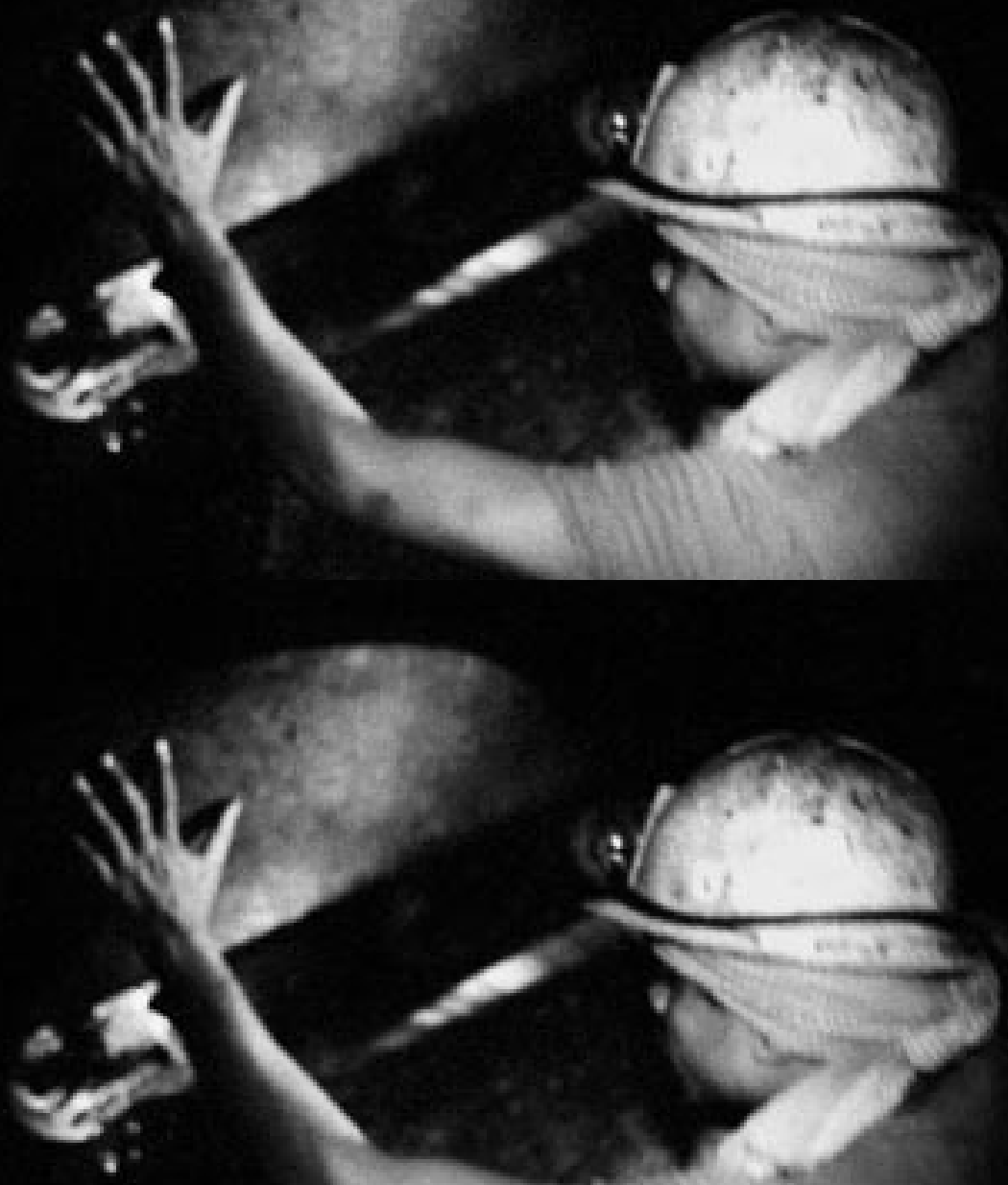
dhanbad, 9 aug 2002, 8:25 pm

i have finally gotten access to the mines.

i had spent ten days in delhi and now 4 days here.

i went to this small colliery called bussuria.

all around dhanbad there are collieries.

the streets are covered in coal dust. you see women carrying burlap bags full of coal on their heads which they have taken illegally from the coal mines or from wagons that are already loaded with coal. on stretches of roads you see them one behind the other carrying coal. even at the train station you see men and women carrying huge bags of coal. their life revolves around it.

i went to this village where the whole community lives right next to the train track. they all gathered around me as i got there.

they want me to come and stay in the village. i probably will, maybe for a night or two.

i also went to these open cast mines where huge shoveling trucks just dig up the ground creating massive craters.

most of them are left as is after all the coal is extracted. 

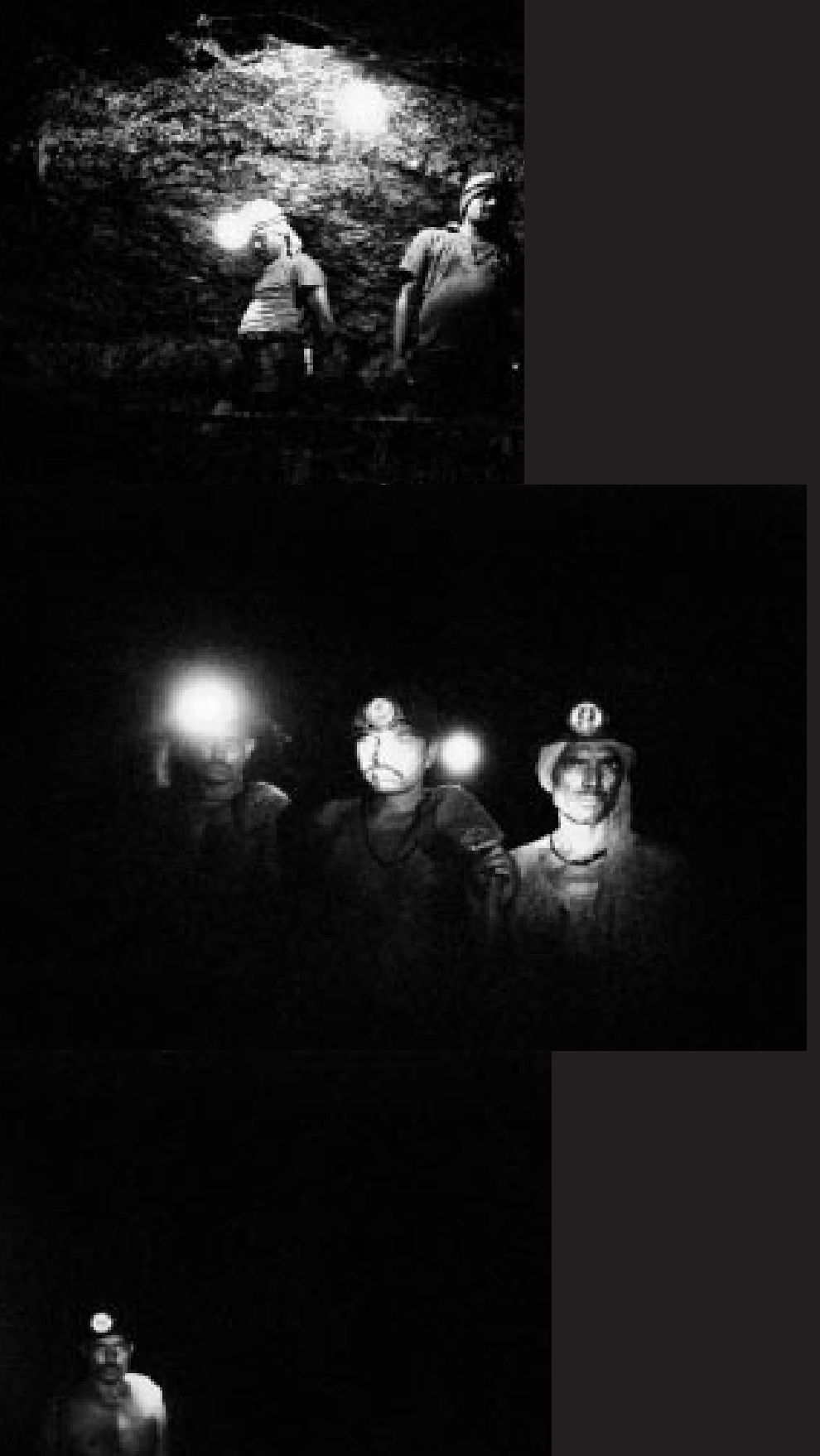
you also see many men on bicycles carrying massive bags of coal through the streets. the streets always seem kind of hazy partly because of the coal dust that is in the air. really hot today.

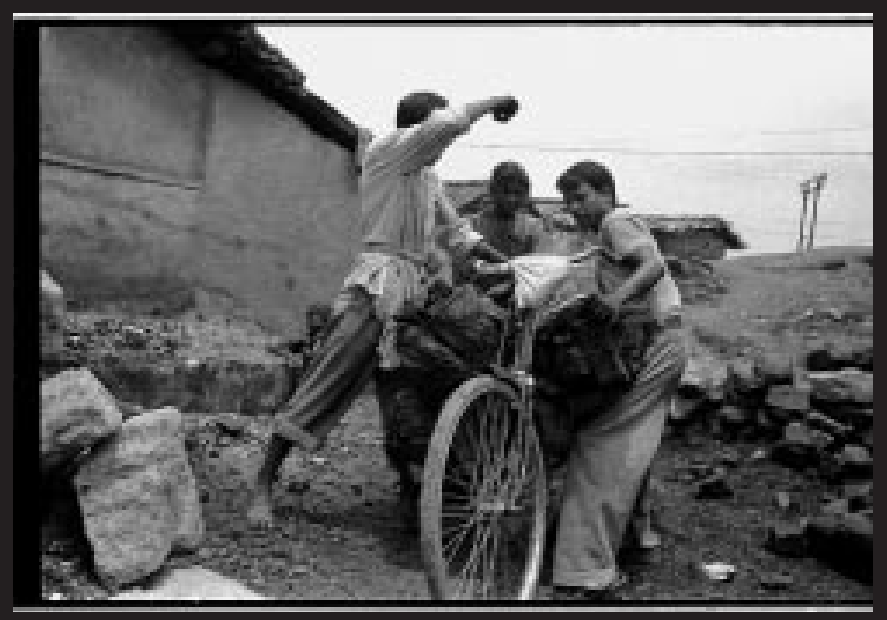

this private taxi driver walked up to me today, the same person who drove me around on my last trip here. he's going to be taking me around.

dhanbad is known to be a very lawless place. there used to be - at one point - daylight shootings, many of them, rapes... things are better but not great. i was told by many people to be careful photographing people because they can do things to you... there is a big coal mafia here and one apparently has to be very careful of them.

the police are very ineffective here.

lot of illiteracy too. one of the most corrupt states in india.

tomorrow i have to get to the coal mines at around 7:00 am.

a sikh family runs the cyber café that i use, they also have a restaurant besides other businesses.

i've become very friendly with the two sons. they were talking to me about how this palmist had come to stay at their hotel on a month-to-month basis and left without paying the month's rent. they then sent two guys with guns to his house in a different town and threatened him. it seems that the guy is going to be paying them very, very shortly. 

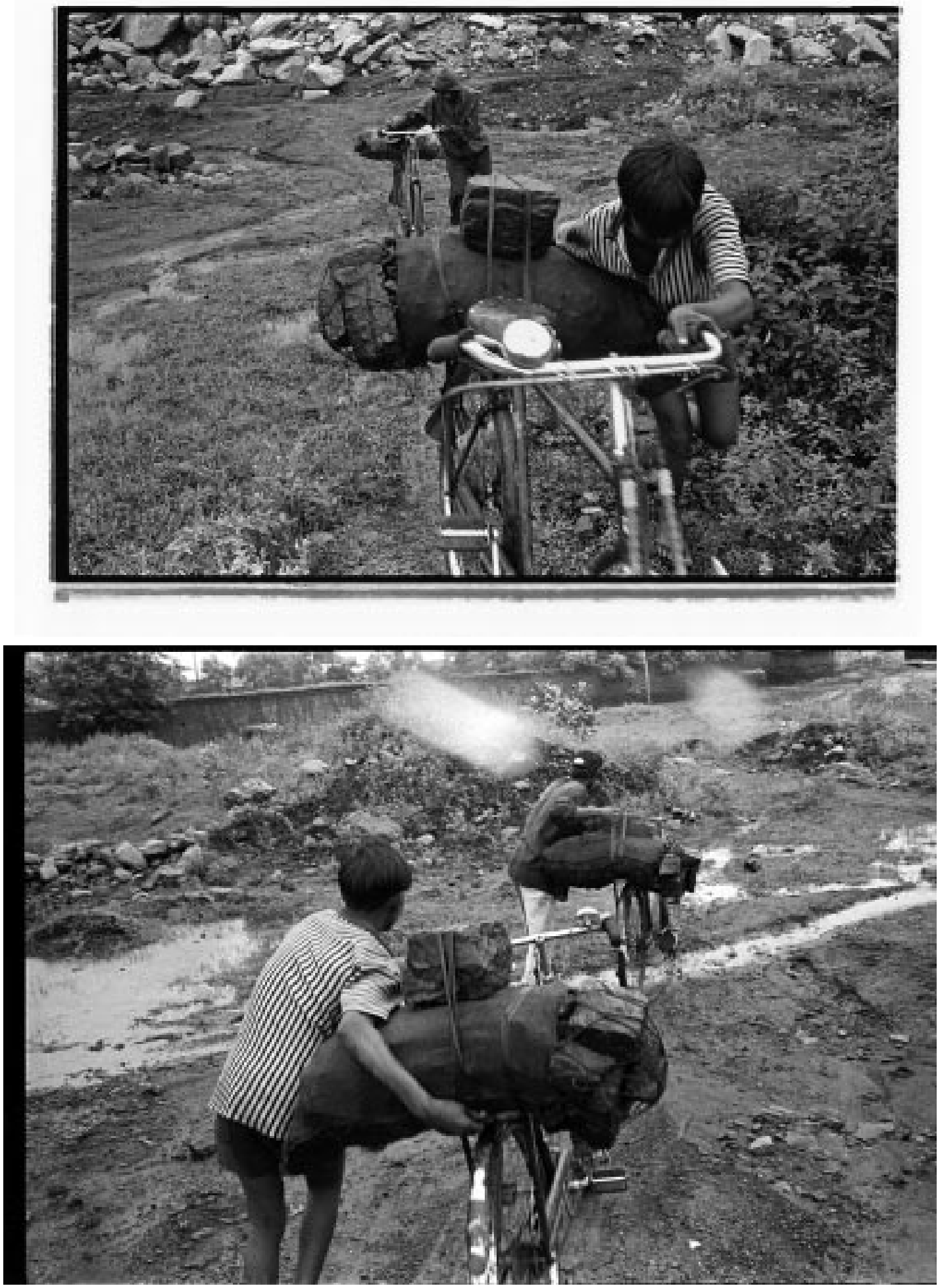
40 / Sarai Reader 2003: Shaping Technologies

dhanbad 12 august

every step you take, some one asks you

1. who are you?

2. where did you come from?

3. what is this for?

4. what is your "benifeet"?

5. is the sarkar/govt paying you to do this?

6. do you have permission?

7. take my photo!

8. hold the basket/ shovel. take his photoll

9. look! he's taking your photos. stand straight!

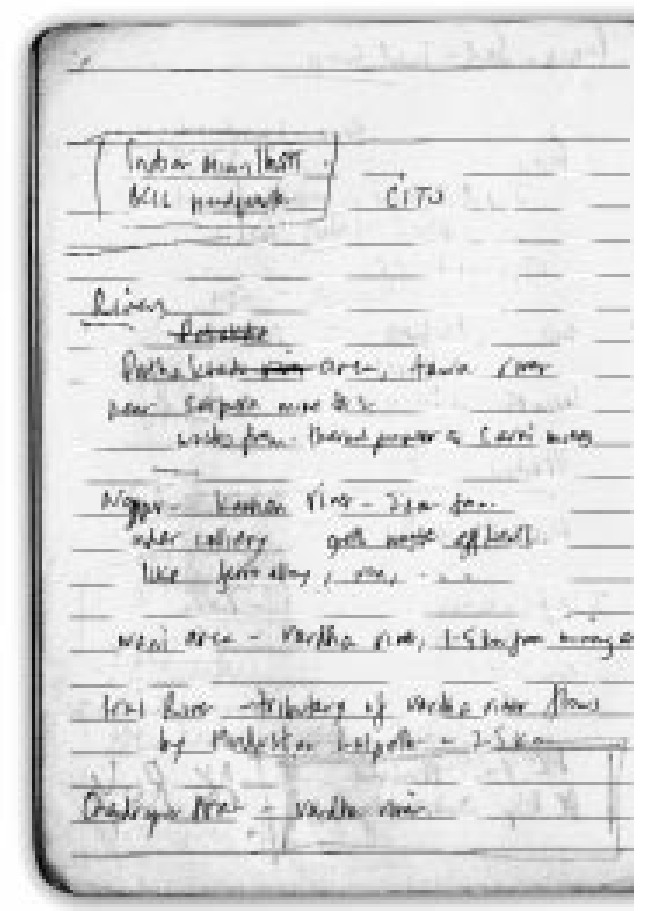




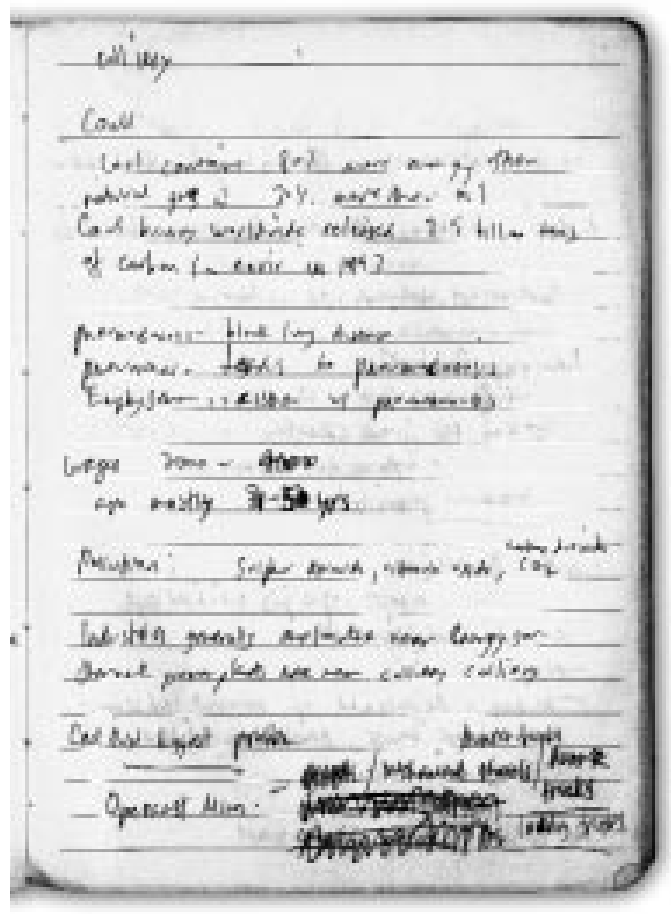

\section{4 august}

even the officials who try to be helpful don't realise that there is so much work involved in taking photos. they think one just goes there and takes a 'snap' and the story is done. they like to give you a guided tour and expect that the photos will be done in a few minutes. i have in the past three weeks met at least 30 officials who have the power to give me permission but no one wants to take the responsibility. they're all afraid.

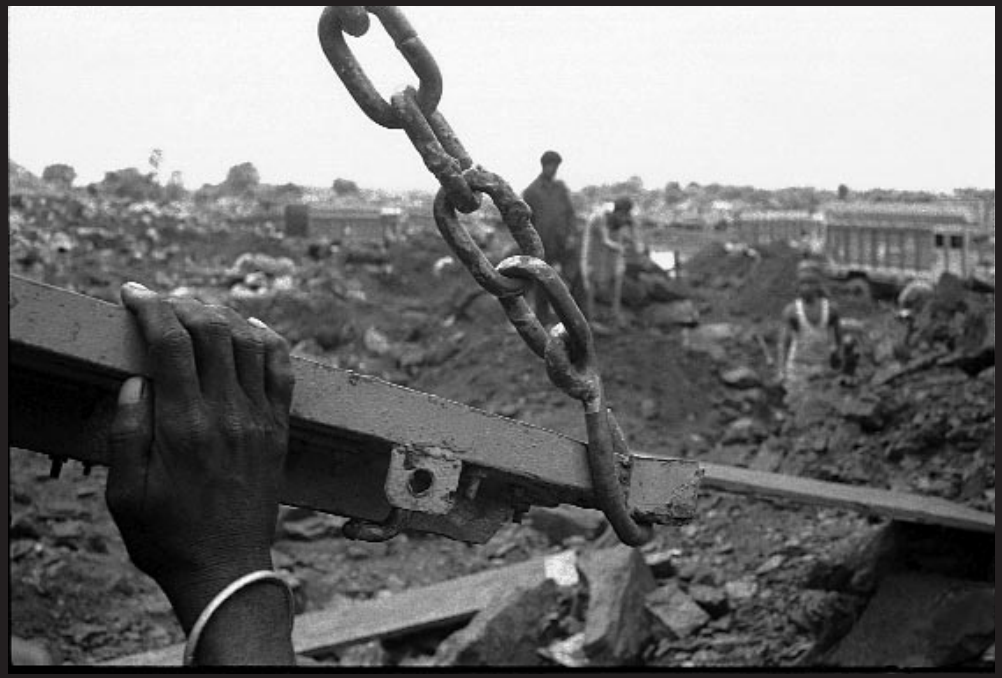


42 / Sarai Reader 2003: Shaping Technologies

\section{4 august}

yesterday, i had gone back to the place where they wash the coal. i got there early because i thought i would get an early start. the project officer there had given me permission to come back whenever i wanted to. i started to walk around with a safety inspector and suddenly a CISF (central industrial security officer) stopped me. he said that i couldn't take photos there without the permission of his supervisor. he then walked me over to his supervisor to get permission. his supervisor said that i need written permission from the P.O. i then went to the P.O. he said that i need written permission from coal india limited, only then he could write me a letter. i called the personnel director's office and none of those guys were around.

the security guys showed up again and said that they wouldn't let me leave till i got written permission. there was another administrative guy who was really helpful. the CISF guys just stood there while we were trying to make calls. and of course the phones weren't working right. we were in this office for almost about $4 \mathrm{hrs}$. we then told them that i would have to go to the coal india office to get permission. they said that then i would have to deposit my camera and all my film with them. i basically knew that no one would give me written permission. everyone is scared to have their name on paper.

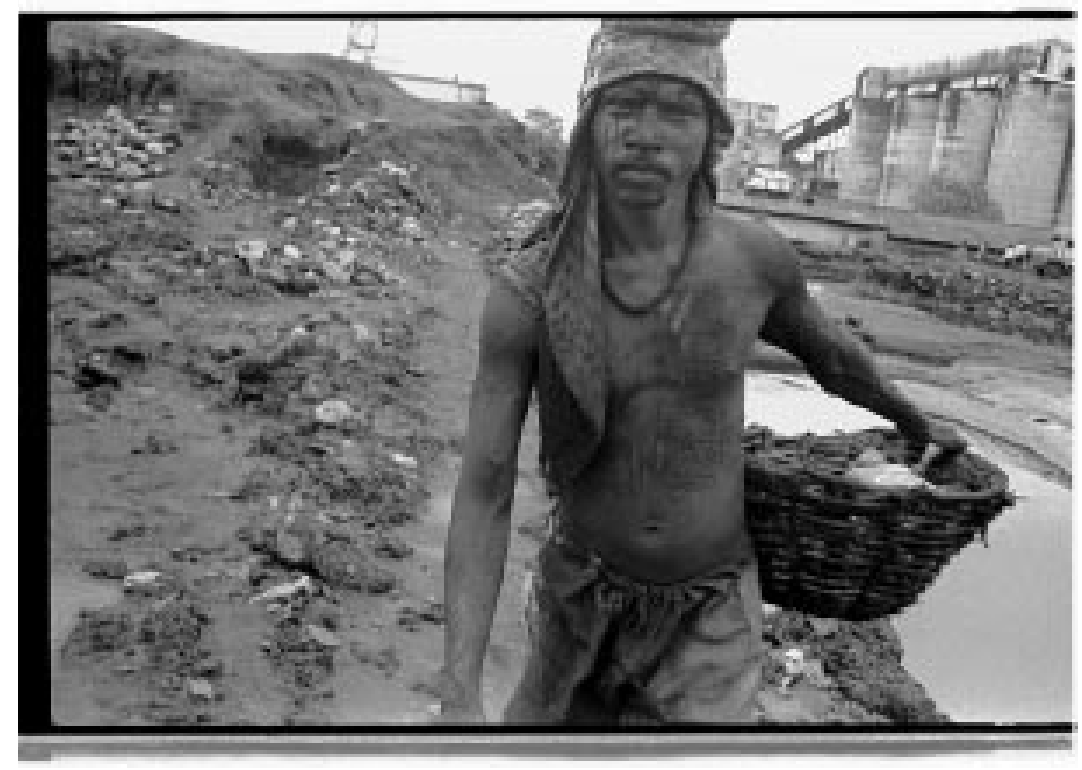


EXCAVATIONSEXCAVATIONSEXCAVATIONSEXCAVATIONS EXCAVATIONSEXCAVATIONSEXCAVATIONSEXCAVATIONS EXCAVATIONSEXCAVATIONSEXCAVATIONSEXCAVATIONS EXCAVATIONSEXCAVATIONSEXCAVATIONSEXCAVATIONS EXCAVATIONSEXCAVATIONSEXCAVATIONSEXCAVATIONS EXCAVATIONSEXCAVATIONSEXCAVATIONSEXCAVATIONS EXCAVATIONSEXCAVATIONSEXCAVATIONSEXCAVATIONS EXCAVATIONSEXCAVATIONSEXCAVATIONSEXCAVATIONS EXCAVATIONSEXCAVATIONSEXCAVATIONSEXCAVATIONS EXCAVATIONSEXCAVATIONSEXCAVATIONSEXCAVATIONS EXCAVATIONSEXCAVATIONSEXCAVATIONSEXCAVATIONS

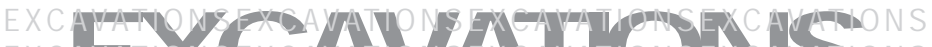
EXCAVA DONSEXCAVAT OW EXCAVATIGNSE CA WATIONS EXCAVATIONSEXCAVATIONSEXCAVATIONSEXCAVATIONS EXCAVATIONSEXCAVATIONSEXCAVATIONSEXCAVATIONS EXCAVATIONSEXCAVATIONSEXCAVATIONSEXCAVATIONS EXCAVATIONSEXCAVATIONSEXCAVATIONSEXCAVATIONS EXCAVATIONSEXCAVATIONSEXCAVATIONSEXCAVATIONS EXCAVATIONSEXCAVATIONSEXCAVATIONSEXCAVATIONS EXCAVATIONSEXCAVATIONSEXCAVATIONSEXCAVATIONS EXCAVATIONSEXCAVATIONSEXCAVATION SEXCAVATIONS EXCAVATIONSEXCAVATIONSEXCAVATIONSEXCAVATIONS EXCAVATIONSEXCAVATIONSEXCAVATIONSEXCAVATIONS EXCAVATIONSEXCAVATIONSEXCAVATIONSEXCAVATIONS EXCAVATIONSEXCAVATIONSEXCAVATIONSEXCAVATIONS EXCAVATIONSEXCAVATIONSEXCAVATIONSEXCAVATIONS EXCAVATIONSEXCAVATIONSEXCAVATIONSEXCAVATIONS EXCAVATIONSEXCAVATIONSEXCAVATIONSEXCAVATIONS EXCAVATIONSEXCAVATIONSEXCAVATIONSEXCAVATIONS 


\section{New Visual Technologies in the Bazaar Reterritorialisation of the Sacred in Popular Print Culture}

...If one wants to create something which gives the eyes heavenly pleasure, then students must understand that for them there is no better teacher than nature... Nature is the supreme God...

(S.M. Pandit, mythological artist, inaugural speech for the $22^{\text {nd }}$ Maharashtra State Arts Exhibition, 7 November 1981)1

\section{Naturalism, the 'Popular' and the Bazaar}

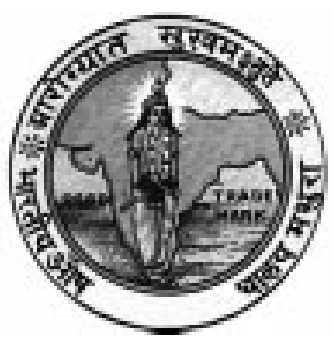

In 1912, Bhavanishankar Atmaram Oza moved to Bombay from a village in Saurashtra and opened a chemist's shop on Princess Street. In 1922 he was joined in this venture by Vamanbhai Kapadia, who opened a branch of their dispensing chemists' firm in Calcutta; they later extended their operations to Dacca and Rangoon. Oza was one of the many Gujarati businessmen in Bombay who responded to Gandhi's call for Swadeshi, and was imprisoned several times. On one such occasion, in 1928, the Gandhian activist and doctor Jivraj Mehta (who went on to become Gujarat's first Chief Minister) suggested to Oza that he start manufacturing a product that would compete with a foreign brand. Oza rose to the challenge, pitting his own Babuline (pronounced Babu-leen) Gripe Water against Woodward's, the popular British brand of infant digestive.

This tale of entrepreneurship, nationalism and modern medicine is recounted at the beginning of the 'History' section of the Babuline Pharma web site (http:// babuline.com). Its home page currently provides a choice of three links: one to B.A. \& Bros. (Bombay) Pvt. Ltd., distributors of pharmaceutical and diagnostic products; the second to Indo-German Laboratories, producers of coloured tablet coatings (now a wholly owned subsidiary of Colorcon USA); and the third to Shri Nathalia Uneval Sevak Mandal, an educational trust located in Una, J unagadh, a philanthropic project funded by families from the region including the Ozas. The profile of the Oza family business that emerges from these links is consistent with that of others from the Lohana community to which Oza belonged: migrating from Saurashtra to Bombay, starting out in trade and then venturing into manufacture and 
even multinational partnerships after the First World War, but without relinquishing their bazaar-style trading base, all the while actively participating in a community ethos and maintaining links with an ancestral place of 'origin'. These features, of keeping one foot in bazaar-style trade or speculation while venturing into modern manufacturing and of maintaining close ties with the community and 'giving back' to one's place of origin while also expanding geographically and forging new associations, also characterise family businesses emerging from other bazaar communities; a particularly well documented instance is that of the Marwaris.

The Swadeshi gesture of B.A. Oza and others like him constituted the nation as both market and locus of production, adding the mediating category of the nation-space to the bazaar's networks of commerce and community. If Raja Ravi Varma's prints actualised the spiritual-civilisational imaginary of late nineteenth-century nationalist thought, early twentieth-century Swadeshi deployed domestically produced commodities in general to posit economic autonomy as a basis for the claim to nationhood. Taking issue with Benedict Anderson's emphasis on the literary manifestations of 'print capitalism' in forging a sense of national identity, Satish Deshpande points out that in the Indian instance commodities as much as written texts came to be imbued with a nationalist charge, serving as 'mnemonics' of nationalist philosophy and the nation-space, and delineating the nation as an 'imagined economy' (Deshpande 1993). In positioning calendar art within the context of commercial culture in twentieth-century India, I build on the characterisation of mass produced commodities as vehicles for imagining and performing community and identity - not only national but also regional, linguistic, sectarian and caste or class based. In part I examine printed images themselves as commodities in the culture industry, but I also look at them in their capacity as part of the shiny skin, the schein (Adorno 1991, p. 53), of other commodities: as labels, packaging and advertisements, including calendars.

My attempt here is to work at the switching point between the 'textual' or representational register of the visual idioms deployed by commodity culture and the performative efficacy of mass-produced images in their animated and animating capacities as sacred and economic objects produced, circulated and used in the marketplace. I reexamine the role of naturalism in the discourse about Indian popular images, in the light of the bazaar as a context for image production and circulation positioned at the interface between a largely vernacular arena of trade, finance and entrepreneurship and colonial or Euro-American-style corporate cultures. I show how visual print capitalism worked through heterogeneous modes of signification, variously ranged (contra Anderson, as well as some of his critics) between the religious and the secular, to shore up a range of identity formations both supplementary to nationalism and forged in its image.

Scholars seeking to distinguish between 'Indian' and colonial or 'Western' image traditions have had an ongoing investment in the issue of naturalism. If Havell and Coomaraswamy condemned Ravi Varma's adoption of naturalism as inauthentic, more recent analyses have read the obdurate iconic frontality, temporal recursivity and indexicality of Indian images in terms of a 'popular' negotiation with colonial ideologies of space, time and signification. Particularly emblematic of the colonial episteme is perspectivalism's stilled or frozen frame, with its implied linear temporal continuum and unitary viewing position. As the 
sign of a limit to colonial power the 'popular' resistance to naturalism shores up a subalternist postcolonial politics or, as a repository of 'tradition', is appropriated by the marketplace, but also holds out the hope of providing the aesthetic resources for a national cultural avant-garde. While these accounts differ significantly, particularly over the question of subaltern subversion, they are also marked by some shared terms, notably the category of the popular - though, again, with varying use. And they all - I think rightly - link the forms taken by the negotiation with naturalism to the ritual and devotional components of image traditions in India. ${ }^{2}$

How does this framework of the popular square with the characterisation of the bazaar as a vernacular network of production, consumption and circulation of images, mediating between elite and popular, colonial and native, urban and rural, formal and informal, bourgeois and feudal - a network whose presence and valency persist well after Independence? The bazaar can be seen as a realm of both subordination and semi-autonomy vis-à-vis the colonial state and then the post-Independence, English educated technocracy. But we also need to recognise that with the growth of the domestic market for locally produced consumer goods, including the products of the culture industries, it also developed as a realm of relative cultural hegemony vis-à-vis other vernacular constituencies. In this intermediate role, vernacular and non-bourgeois yet dominant, the bazaar problematises bipolar accounts which counterpose the Indian 'popular' to the 'colonial'/ 'Western' or 'capitalist', thereby causing these domains to coagulate into singular, fixed entities. The European postEnlightenment ideologies informing colonialism, capitalism, nationalism - and indeed naturalism - are not necessarily consistent with the high degrees of fluidity that these phenomena have demonstrated in practice, both 'internally' and at their interface with heterogeneous moral, political and aesthetic systems.

Calendar art and other forms of commercial imagery circulating in the bazaar outline a dialectic between the expansive, deterritorialising aspect of capitalist mass production, with its implications of social linkage and mobility, and that aspect which feeds - and is fed by - the reterritorialising, stratifying logic of social power. The deployment of new imagemaking techniques, including technological mass reproduction and elements of 'Western' naturalism, was in fact integral to the success of mass manufactured images in bringing expanded sets of social constituencies into arenas of common address - that is, in 'naturalising' an expanded, heterogenous category of the popular. These 'cultural' linkages had a certain strategic efficacy in providing shared or hegemonic ideological resources, notably for anticolonial nationalism and then for the resurgent Hindu nationalism of the late twentieth century. Here I want to delineate two sites where this performative work of reconfiguration has been particularly in evidence: the iconic body in and of the image, and the figure of territory in and around images.

\section{Trading in Images (or, Consumption and its Consequences)}

The Swadeshi culture of domestic manufactures emanating from the bazaar, such as Babuline Gripe Water, did not do away with the concurrent formulation of consumer identity by Euro-American companies such as Woodward's. In 1932, around the time B.A. Oza started producing Babuline, Woodward's published a calendar advertising its gripe water, prin- 


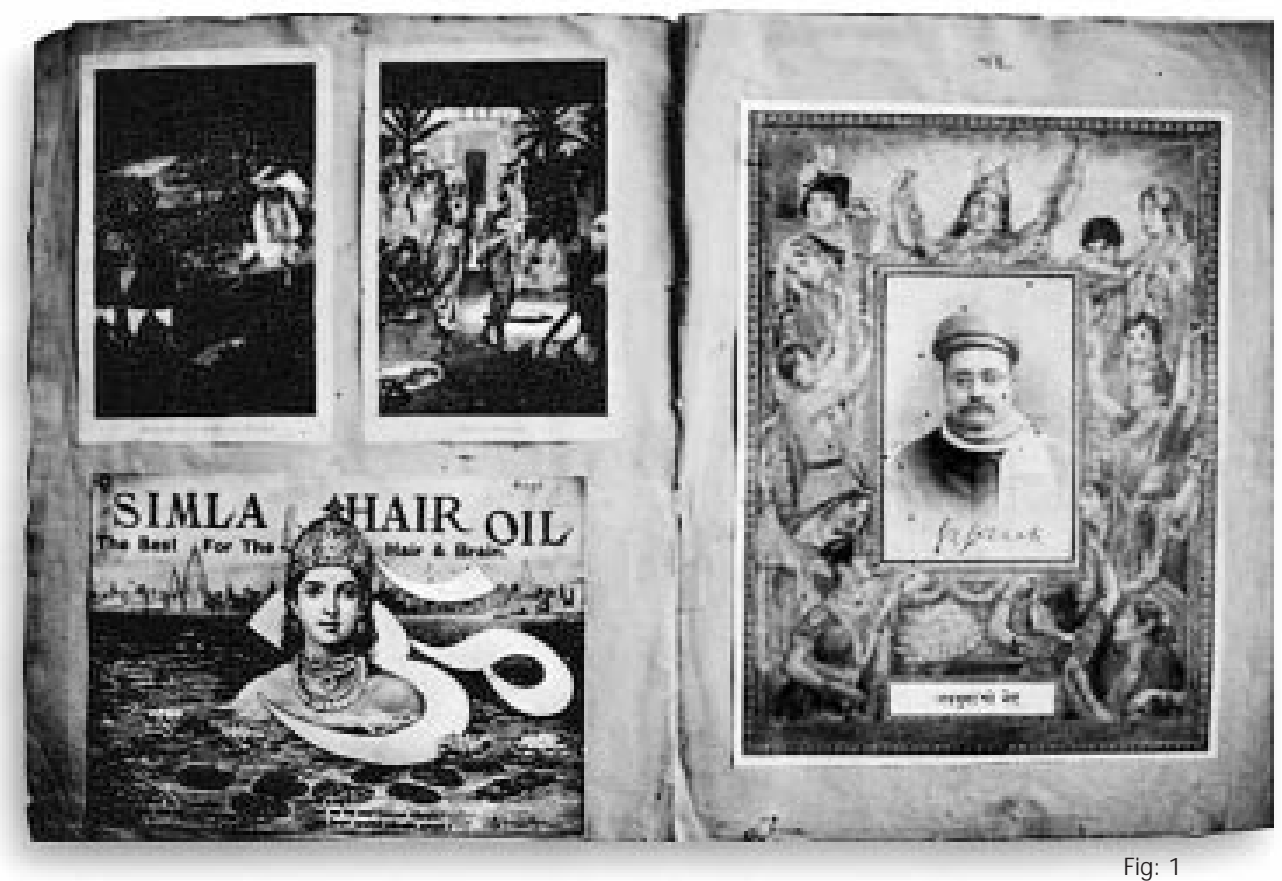

ted in England but illustrated by an Indian artist, Mahadev Vishwanath Dhurandhar (18671944). Dhurandhar, like Raja Ravi Varma, used illusionist techniques in oil and watercolour to illustrate Indian mythological, historical and literary themes, similarly negotiating the 'representational dilemmas' inherent in depicting timeless divinities and moments from epic narratives within a historicising, naturalist still frame. Located squarely within the mainstream of 'fine art' activity, Dhurandhar was trained at Bombay's J.J. School of Art and went on to enjoy the highest level of success that a 'native' artist at the time might hope to achieve, regularly winning awards at exhibitions and eventually becoming J.J.'s first Indian Headmaster. His work testifies to the fact that the criticisms of the neo-traditionalists in Bengal did not arrest Indian fine art's involvement with European-style naturalism. As Calcutta celebrated its 'Bengal Renaissance', the J.J. School remained a bastion of naturalism, with W.E. Gladstone Solomon, its Principal from 1919 onwards, centring his own "Bombay Revival" of Indian art on the idea that "Indian Art is permeated with Realism" (Solomon 1946, p. 117; emphasis in the original).

Dhurandhar's illustration for the Woodward's calendar (Fig. 2) depicts a smiling infant Krishna, standing in the centre of the frame resplendent in his peacock feather crown and ornaments, one hand full of butter and the other on his stomach, subtly signalling the threat of indigestion. Immediately behind Krishna, unusually, are two naked male babies (the conventional depiction is only of Krishna and his brother Balaram), notably fairer and 


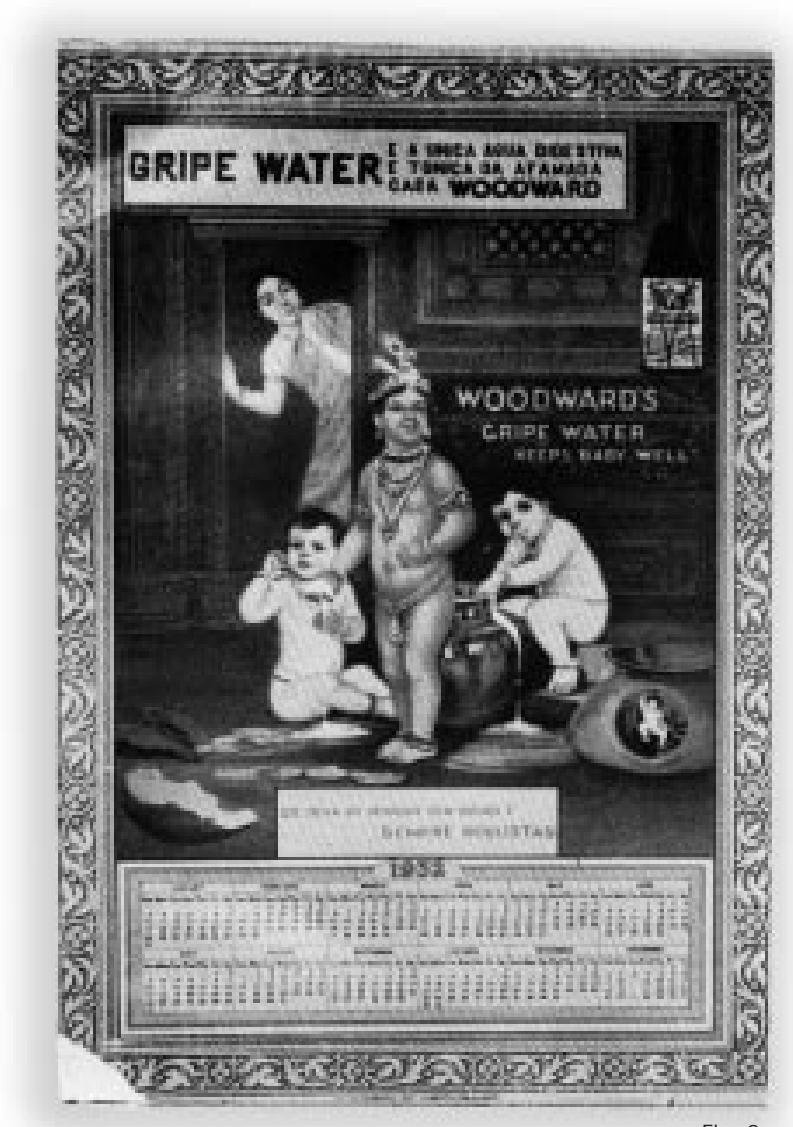

Fig: 2

relatively unadorned, also tucking into the butter pot. Their faces, like Krishna's, are directed at the viewer, although only the baby on the right engages the viewer's gaze. Central to textual descriptions of the famous makhan-chori or butter-stealing episode is the discovery of this mischief by Krishna's doting foster-mother Yashoda. Yashoda is a rural cattle-herder's wife; here, however, a modern, middle-class, sari-clad mother is peeking out pensively at this scene from an elaborately carved doorway, her eyes lowered towards the children, combining a 'frozen moment' narrativity with the frontal tableau of the oblivious buttereaters. It is almost as though the Krishna figure has a doubled presence: once in realist, narrative mode as an ordinary, everyday (albeit fair and middle-class) infant about to suffer indigestion, with an ordinary sibling and concerned mother, and then again in an iconic, frontal, explicitly godly (and explicitly racialised) form, as a materialisation from another dimension, or from a happy future, free - thanks to Woodward's - from gripes. 
This calendar is unusual in its simultaneous deployment of two distinct registers of signification: a representational mode which uses perspectival naturalism to narrative and allegorical ends, and an indexical mode whose frontal address acknowledges the viewer and institutes an iconic (that is, divine) presence. Also, while its theme evidently derives from Hindu traditions, its copy, extolling the virtues of Woodward's Gripe Water for keeping babies healthy, is in English and Portuguese. The calendar's peculiarly doubled address could be

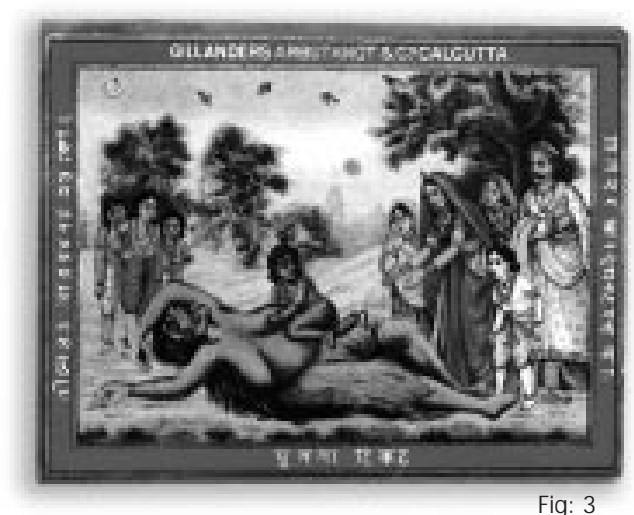
read as soliciting a domestic market comprised of both European residents and a modernising Indian elite. ${ }^{3}$ But mass reproduction and commodity culture also created sites of social mobility and new social articulations within and between 'native' constituencies: the feudal gentry and caste-based elites, the emergent entrepreneurial and professional technocratic middle classes, the trading communities of the bazaar, the rural and urban working classes and castes. The market's address to domestic consumers of varying degrees of vernacularity both created commonalities and reinforced distinctions between them, constituting an expanded arena of the 'popular' while reformulating sectarian, linguistic and territorial identities. (An instance of the latter is the Sivakasi print industry's post-Independence production of broad-based regional iconographies.)

The First World War was critical to the history of the bazaar. There was a growth of domestic manufacturing due to a reduction in imports and to the lucrative futures trading (futka) in the bazaar during that period, particularly by the Marwaris, which simultaneously disrupted internal supply lines to the expatriate managing agencies and provided bazaar firms with large windfalls of capital to invest in industry. While the Birlas pushed into the existing export industry of jute and the Tatas mounted an ambitious and successful foray into steel, other firms emerging from the bazaar after World War I focussed on products for the domestic market requiring relatively simple technology like cotton textiles, sugar and paper. This market already carried a variety of commodities for mass consumption such as matches, soap, bidis, ink, oils, tonics, non-allopathic remedies, incense and candles: the kinds of products advertised in the first decades of the twentieth century in the woodblock printed Bengali almanacs produced at Battala, and to a limited extent in the vernacular press. ${ }^{4}$ One instance of the latter was Amrutanjan pain balm, produced from 1893 onwards by the freedom fighter, reformer and journalist Nageswara Rao Pantulu and advertised on the front page of his Telugu newspaper, the Andhrapatrika, which he established in Bombay in 1908 and moved, along with the Amrutanjan factory, to Madras in 1914.

The inter-War period, starting around the mid-1920s but increasingly through the $30 \mathrm{~s}$, also saw the entry of multinational corporations into the domestic market for middle-class consumer goods and technology intensive products. Companies such as Lever (Sunlight soap), Wimco (matches), Associated Biscuit Manufacturers (Britannia biscuits), Dunlop 
(tyres and rubber goods), Bata (shoes), General Electric and Philips (light bulbs) set up manufacturing operations in India during this period. At the same time, commodity manufacturers based overseas also sought to 'Indianise' their products through advertising or, as British textile mills and managing agencies had done, through labelling. In what is by now a familiar operation, a set of signifiers developed in the context of resistance, in this case anticolonial nationalism, were seized by what we might think of as the re-personalising logic of commodity marketing. If Puranic imagery was used to forge an Indian cultural identity that formed a basis for the Independence movement, it was also quickly adopted as an instant cipher of Indianness, particularly by foreign firms seeking to tap into the 'native' market.

Indeed, it was most often Puranic images from the Ravi Varma press that were directly reproduced as labels and advertisements, primarily (if not exclusively) by foreign owned firms. While small coloured labels featuring popular imagery were directly affixed to commodities intended solely for the 'native' market, such as mill cloth and matches (the latter produced by J apanese as well as European firms), products with a more global corporate identity used advertising posters and calendars to target Indian consumers. Surviving examples include a 1914 calendar advertising hair dye and tonics from the London drug and chemical firm of Burgoyne, Burbidges and Co., with a Gangavatarana image featuring a Shiva with thick and lustrous locks, captioned 'After the picture painted by the late Raja Ravi Varma'; a 1930 advertisement for Sunlight Soap whose baleful Krishna was probably derived from a Nathdwara or Calcutta print; and a poster for Mellin's Food for Infants and Invalids (produced in Boston, Massachusetts) featuring a version of Ravi Varma's Birth of Shakuntala. Another poster for Woodward's Gripe Water similarly has their product and logo tacked on to the corners of the picture, which features a gentrified, sari-clad mother and naked infant son with a cow (or bull?) and calf, again reminiscent of Krishna and Yashoda, like their 1932 calendar discussed above.

It is hard to tell whether this Woodward's poster used a specially commissioned painting or adapted an existing print, as in the Mellin's Food and Burgoyne Burbidges posters. Like Dhurandhar's 1932 calendar, however, it uses the mother-child relationship as the common contour in mapping the everyday concerns of a modernising Indian middle class (including European residents) on to mythic narratives. To this extent the Mellin's, Woodward's and Burgoyne Burbidges posters all trade on naturalism to establish a thematic relationship between the product and the image used to promote it, creating an allegorical, if not playfully ironic, correspondence between gods and mortals. The schema of signification here, as in neoclassical painting, is one in which gods and heroes from a 'classical' past are deployed as figures with lessons for present human conduct. This is consistent, for instance, with Woodward's adoption of The Infant Hercules Strangling the Serpents (17861788) by Joshua Reynolds as the trademark for their gripe water (this appears on one of the butter pots in Dhurandhar's calendar, and in the top left corner of the poster). But this schema of allegorical correspondences with a mythic past belongs to an Enlightenment working hard to achieve and maintain a secular, 'post-sacred' universe, as opposed to a system that seeks to maintain the sacred as ever-present, integrally inhabiting everyday life. If Dhurandhar's butter-stealing calendar - which was expressly commissioned as an adver- 
tisement - is particularly strange and compelling, it is because of the doubled Krishna figure's simultaneous submission and resistance to this kind of allegorisation, its struggle against consignment to a mythic past. It oscillates uncannily between an allegorical mode aligned to a bourgeois historical consciousness, which seeks through representation to ennoble a mortal act of consumption, and an indexical mode which seeks to imbue the body of the image itself with the eternal, timeless cosmic presence depicted therein. To cite an instance of how this indexical register pertains to the image as an object (but with the important caveat that this is a retrospective formulation): according to the current Babuline management, they decided from the outset to use an image of the infant Krishna only in their calendars and other publicity, but not on their packaging because a package is meant to be thrown away - a disrespectful and inauspicious act. ${ }^{5}$

The use of 'motivated' thematic or representational links establishing an allegorical correspondence between the actions of mythic and human figures was readily adapted to political ends during the colonial period by vernacular cartoons, chromolithographs, theatre and film. However, my sense is that this mode of signification was relatively unusual in the context of commodity aesthetics in the bazaar where the use of mythic imagery has tended to invoke ethically and sacrally invested objecthood rather than allegorical resemblance. Images of deities (or indeed secular images) featured on woodblock labels for early twentiethcentury domestic manufactures, as well as subsequent lithographic labels and advertisements, did not necessarily draw attention to the specific qualities of the product or the benefits of its use. In such instances of labels, trademarks and calendars with apparently arbitrary connections to their products, the association with a divinity would have worked in an indexical register to seek the deity's blessings and impart auspiciousness not only to the

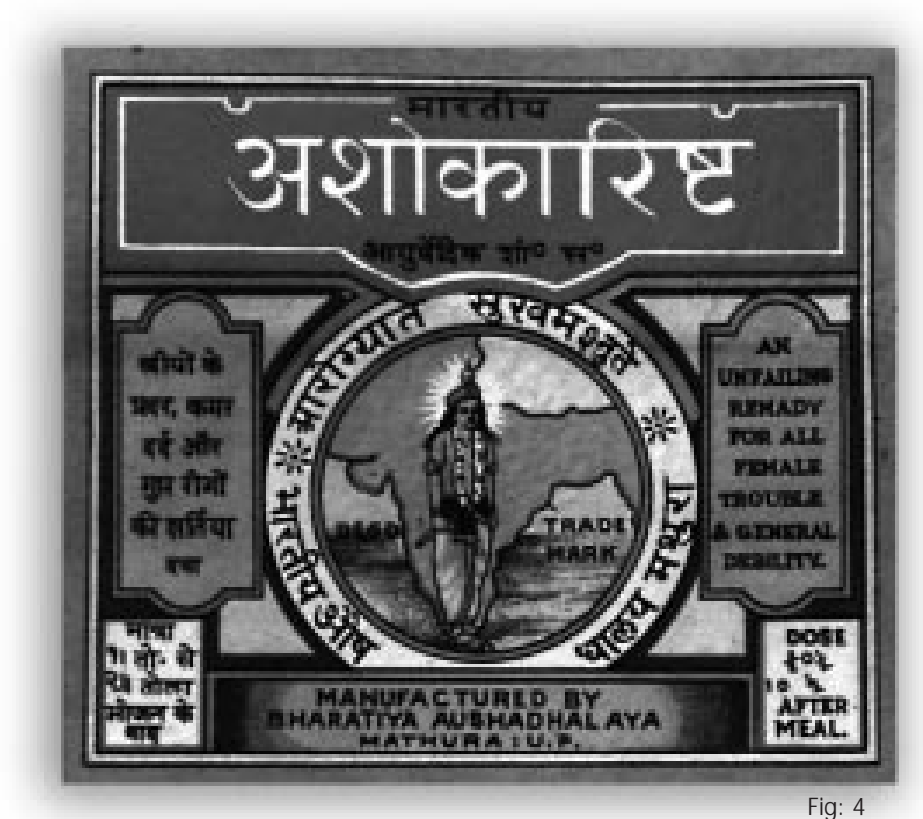




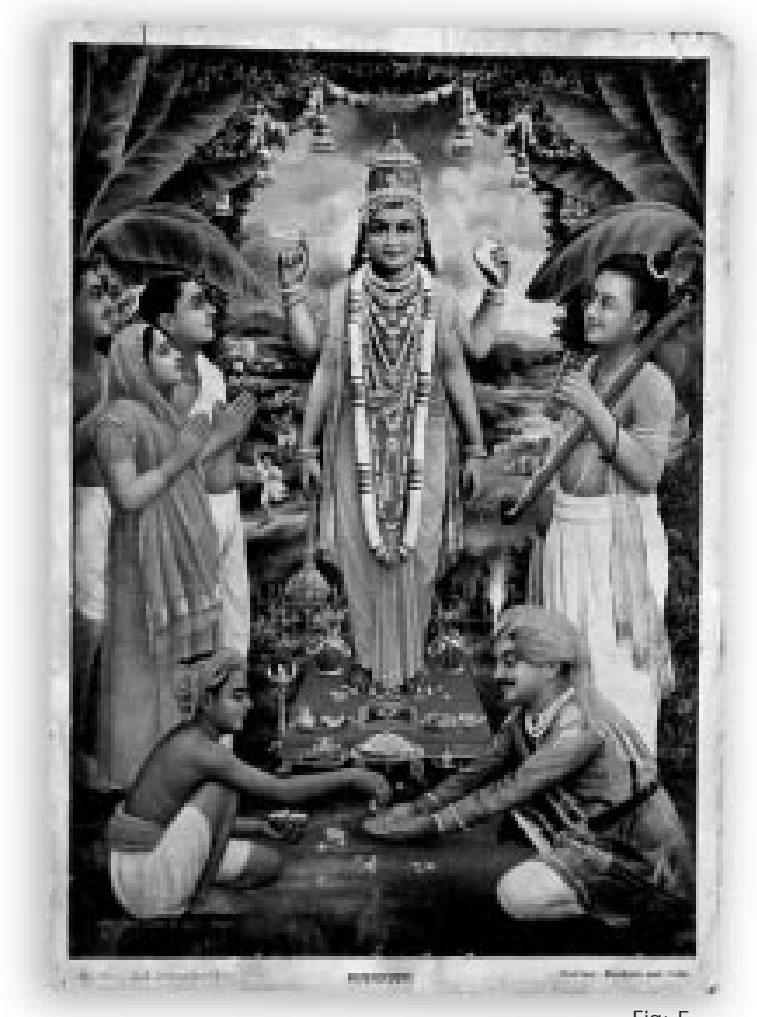

Fig: 5

calendar or image itself, but also to the product, its use, manufacture, and the transactions in which it is involved. Similarly, associating products with maps of India, as in the Amrutanjan and Ashokarishta advertisements (Fig. 4) served to imbue products, their manufacture and use with an ethical aura via the nationalist ideology of Swadeshi, which in turn took on ibidinal-sacral registers through the divine and/or feminine bodies inhabiting these maps.

Crucially, however, the distinctions I am making here between modes of signification do not necessarily correspond to images produced by overseas/colonial as opposed to Indian firms. While it is possible to think of Woodward's and Mellin's as expressing a postsacred, 'Western' sensibility in their posters (Woodward's is a British firm, and Mellin's American), the same does not go for the British managing agencies who were among the first to use iconic Hindu imagery on brand labels. ${ }^{6}$ Early textile labels occasionally featured depictions of cloth merchants' shops, but by and large the imagery on textile and matchbox labels seldom had a representational association with the product or its use. The choice of mythic themes for many of these labels, particularly by European firms, may have derived from an orientalist characterisation of Indians as 'superstitious', or simply from the ready availability of printed images with proven commercial success, or both. Either way, 
far from enforcing a post-sacred or secular ideology, or maintaining the material/spiritual divide organising the 'Protestant ethic' (Weber 1976), at this particular interface with Indian consumers colonial expansionism served to inscribe a space where the workings of commerce and the sacred were indissociable. If Ravi Varmaesque Puranic imagery had a history of mimicking Western naturalism, in replaying this imagery back to Indian consumers as part of the schein of the commodity it was now the colonisers who mimicked, and replayed back, their version of the colonised. The bazaar was a phenomenon of the colonial economy and the colonial state: a buffer zone whose mediation, and indeed maintenance, of arenas of difference from the avowedly liberal, post-Enlightenment ideology of the colonial state was crucial to the exercise of colonial power. ${ }^{7}$ The managing agencies' use of Puranic images to penetrate the domestic market demonstrates the extent to which they, too, were creatures of the bazaar, co-opting 'cultural' difference to their own ends and thereby furthering its institutionalisation.

By the same token, though, if the bazaar adopted naturalism to 'humanise' the gods and locate them within a quotidian mise-en-scène (A. Kapur 1993), this did not necessarily entail the triumph of the historicising allegorical universe implied by images like Mellin's and Woodward's posters, which were relatively short-lived. As Geeta Kapur has observed, the term 'realism' was construed in nineteenth-century Indian discourse "to mean an enabling technique rather than a philosophically accredited style of representation within a specific historical context" (G. Kapur 1989, p. 60; emphasis in the original). Right from the outset, there was a distinction to be made between naturalist techniques - perspective, anatomy, modelling, the rendering of light and shadow - and the institutionally sanctioned post-sacred schemata of signification through which they entered the colonial context: romanticism and the picturesque, neoclassicism, bourgeois realism, ethnographic documentation. The divergence between the two has been a source of tension, particularly for artists who have had to negotiate between the pragmatically 'enabling' and 'philosophically accredited' versions. But here I want to explore what it was that the selective adoption of naturalist techniques enabled, through their relative (but not complete) disentanglement from the specific ideological baggage that accompanied them into the colonial realm. One of these things, I would suggest, at least in the context of commercial image-making in the bazaar, has been the management of the relations hip between community and territory with the growth of domestic markets and the formation of the nation-state.

\section{Naturalism, Nationalism, Territoriality: The Case of Nathdwara}

The chromolithographs produced by the picture publishers S.S. Brijbasi from 1927 onwards represented a new phase of Nathdwara art, initially associated with Ghasiram Hardev Sharma (1868-1930: Dhurandhar's contemporary) and his illustrious apprentice Narottam Narayan and his associate Hiralal Udayaram. Ghasiram was both chief painter and head of photography for the Shrinathji temple under Tilkayat Govardhanlalji, doing his own developing and printing. ${ }^{8} \mathrm{It}$ is clear that by this time photography was not only setting the standard for naturalism in portraiture, but had also become an acceptable part of the image-making process: Narottam Narayan is known to have adopted the process of combining painting and photography. The work of Ghasiram, Udayaram, Narottam Narayan and later Nath- 
dwara painters such as Kamladevi is characterised by a photographic treatment of figures, and in particular of faces: photographic not in the sense of hyperrealism, but a literal replication of the monochrome tonalities of black and white photography, as in the greyish tinge that Narottam Narayan gives his Murli Manohar, Umapati Shankar or Satyanarayan (Fig. 5), or that Ghasiram imparts to the Shrinathii figure. There is, of course, an iconographic appropriateness in such a rendering of the dark (shyam) Krishna (though later copies of Murli Manohar revert to the more familiar blue), but the technique must also owe a great deal to Nathdwara's (quite literal) brush with photography. So this was an appropriation of naturalism, not in its techno-rationalist aspect, but in its personalising, affective, libidinal aspect, making the divine accessible to devotees as an empathetic presence: as the contemporary Nathdwara calendar artist Indra Sharma put it, the aim of images is to make the viewer mohit or mugdh (enchanted, seduced).

Even those techno-rationalist devices intimately associated with a 'realist chronotope' have been subject to similar selective reappropriations in calendar art. If the Nathdwara icons, addressed predominantly to a Hindu devotional context, rejected the perspectival grid and the time of clock and calendar, the later Sivakasi calendars do not reject perspective but deploy it to mesmerising decorative effect in their depictions of floor and wall tiles at Muslim shrines. Here clocks also figure prominently, but to 'messianic' ends, recalling the five daily prayer times. What is more, the signs of bureaucratic modernity and Westernisation themselves take on a utopian aura, as in the occasional framing pictures and calendars featuring painted city views. In an early instance from Nathdwara, a soaring perspectival view over a modern city (possibly modelled on Bombay's Marine Drive) swoops in a baffling curve past two Gujarati women buying cloth at "The India Fine Cloth House", such that stacked bales of cloth echo the proportions of high-rise buildings; a telephone features prominently in the shop, while one of the women holds a book. Here naturalist technique and an iconography of modernity speak to the Nehruvian interpretation of Swadeshi as a home-grown version of modern development, while the figures of sari-clad women serve to anchor that vision in a national culture. Signifiers of Western-style modernity are also incorporated in later prints as part of the regalia of modern forms of transcendental power, as with the watches that are de rigueur even in sacralised depictions of 'leaders' in the Independence struggle.

The social context of the bazaar communities is particularly pertinent to the embrace of landscapes, and to the specific form of objecthood of framing pictures and posters (as opposed, say, to books, magazines or films). It is no coincidence that the intense elaboration of landscapes as portable figures of territory in iconic prints should emanate from the image-culture of Pushtimarg, with its increasingly mobile, largely mercantile followers. Indeed, this artistic source was tapped by S.S. Brijbasi through their own combination of mercantile mobility and religious affiliations with Pushtimarg. ${ }^{8}$ Brijbasi's prints, like the Nathdwara pilgrim souvenirs, were geared towards the personalised worship made possible by portable images, providing a self-sufficient embodiment or housing for a divine presence. This worship was personalised both in the sense of catering to the individual devotee (as opposed to a large congregation in a temple) and in the sense of imagining a humanised divinity. If individualised worship was enabled by the mass reproducibility of 
icons, the humanisation of the divine was aided by the naturalist depiction of benevolent affect, echoed in the fecundity of the landscape. Abstracted from the spatial specificity of particular temples, the control of priests, or pictorial association with particular patron devotees, these mobile, mass reproduced icons begged the question of their location. Ravi Varma provided his frontal, iconic Lakshmi and Saraswati, and Narottam Narayan his bucolic Krishna, with their own auratic loci to accompany them on their travels, situating them within imaginative landscapes that were limitless, replicable and portable even as they evoked specific quasi-mythic territories: Braj and Vrindavan from the Krishnalila narratives, Mount Kailash and the Himalayas in the Shaivite images, the forests of Panchvati, Ayodhya, Lanka and other sites from the Ramayana, Vishnu's cosmic ocean and so on.

The miniature traditions of Nathdwara, Bundi, Kota and Mewar were already characterised by their use of lush, overwelling landscapes to intensify devotional desire and affect in narrative contexts, for instance when illustrating devotional poetry. However these narratively bound landscapes did not accompany liturgical figures: the gaze they engendered was too mobile to evoke the frontal convergence said to characterise the engagement with the devotional icon. I would suggest that what the Nathdwara artists took from the naturalist landscapes of indifferently painted European picture postcards was precisely their perspectivalist spatio-temporal stilling of the viewer and the viewed, which worked to counteract both the mobile gaze of the miniature tradition and the mobility of the image itself as an object. Perhaps the migration of naturalistic backgrounds into iconic imagery was also facilitated by the replaceable and portable painted backdrops (pichhwai) of Pushtimarg rituals, which instituted a certain flexibility in 'locating' the liturgical icon. In a sense, then, the Brijbasi prints reterritorialised 'landscape' itself, appropriating it from the narrative contexts of both miniature painting and Western academicism to instate it as the backdrop for mobile icons to be worshipped in domestic shrines. In a reversal of Walter Benjamin's account of the artistic aura (Benjamin 1969, p. 211-244), this appropriative move worked to harness exhibition value (landscapes from contexts of aesthetic contemplation) back to the service of cult value (devotional ritual).

If the Nathdwara landscapes demonstrate the persistence of the 'messianic' in the face of secular-modernist nationalism, they also register the ways in which the sacred or messianic took on its own forms of modernity, deploying colonial modes of signification to manage the new conditions of viewing and use accompanying the mobility or deterritorialisation of people and images. In their capacity as mass-produced, mobile objects in a commodity economy - as commodities in themselves, as visual heralds for commodities, or as emblems of locality that accompanied dealers in commodities on their travels - printed icons in the first decades of the twentieth century came to be twinned with highly charged figures of territoriality. Traversing the intra- and inter-national circuits of the bazaar in the form of printed images, and thereby establishing a material presence unassimilable to the boundaries of the state, the naturalistic yet mythic landscapes of the Nathdwara style icons made it possible to delink communal belonging from both 'feudal' and national territory or locality. While this delinking was particularly pertinent to the mobile communities of the bazaar, the personalised worship these icons fostered came to have an appeal well beyond the bazaar communities. At the same time, other kinds of printed images were also work- 
56 / Sarai Reader 2003: Shaping Technologies

ing to (literally) map nationally, or linguistically defined community identities on to a cartographic imaginary. Although here too, as Sumathi Ramaswamy has described (2001), "'disenchanted" techno-rational maps of India were supplemented by and enmeshed with somaticised, sacralised and libidinalised 'bodyscapes' such as those of Bharat Mata (Mother India) and Tamilttay (Mother Tamil). In these double movements of de- and re-territorialisation, vernacular commodity aesthetics worked both to inscribe a new space of mobility and to re-anchor its meaning and efficacy in reconfigured, re-sacralised notions of community.

This is an edited extract from Jain's forthcoming book, Gods in the Bazaar: the Economies of Indian Calendar Art.

\section{FIGURES}

1. Press advertisement for Shimla Hair Oil, M. V. Dhurandhar (circa 1920-1944, courtesy Ambika Dhurandhar).

2. Calendar for Woodward's Gripe Water, M.V. Dhurandhar (1932).

3. "Putana ticket", textile label for Gilanders Arbuthnot and Co., a Calcutta based managing agency (first-half of the 20th century, courtesy Priya Paul).

4. Label for Ashokarishta tonic for women, manufactured by the Bharatiya Aushadhalaya, Mathura (circa 1940 s or 50 s, courtesy S. Courtallam).

5. "Satyanarayan" by Narottam Narayan, Nathdwara, published post-Independence by S.S. Brijbasi and Sons (courtesy Shafi Hakim).

\section{NOTES}

1. I thank Baburao Sadwelkar for providing me with a copy of this speech, and Namrata Sahdeve for her assistance in translating it from Marathi.

2. Inadequately historicised formulations of the popular, however, tend to foster an essentialised account of religiosity. My own argument (in the chapter from which this extract is taken) is that the formation implied by the 'popular' is often retrospective; in the context of bazaar prints it primarily emanates from a specifically postIndependence configuration of the pan-national market, centred on Sivakasi.

3. Given the use of Portuguese it is conceivable that the calendar was aimed at European residents in other colonial contexts as well as that of India.

4. Describing the press in Punjab after the First World War, Prakash Ananda notes that "... in none of the Indianowned papers did advertisements occupy an important place. The major advertisers were British commercial firms which, understandably, patronised their own Press. It was rarely that a foreign advertisement appeared in the Tribune" (Ananda 1986, p. 77). Ananda then goes on to describe an advertisement in the Tribune for "Mr Bose's Kuntaline and Deklhosh" comprising a written testimonial from Lala Lajpat Rai that "They are in no way inferior to similar articles prepared by European manufacturers" (p. 78-9).

5. Bharat Oza (grandson of Babubhai and currently part of Babuline's management), personal communication; I thank Shri Oza for his assistance. As I said, however, it must be remembered that this is a retroactive explanation, and I would suggest that it belongs to a later discourse on the efficacy of images, associated in part with the resurgence of Hindu nationalism.

6. Nor is it necessarily the case that the use of mythic figures for advertising and branding in the EuroAmerican context, in the few instances where this does occur (as in the case of the St. George Bank, or 
Woolworth's brand name of St. Michael's), adopts this kind of allegorical mode. Indeed I would suggest that this kind of allegorical deployment was a particular feature of the 'intercultural' articulation of consumers attempted by the Woodward's and Mellin's firms, deploying allegory's openness to multiple interpretations to make several different kinds of representational sense to different constituencies of consumers.

7. Partha Chatterjee puts it succinctly: colonial power in its "true form" was "a modern regime of power destined never to fulfil its normalising mission because the premise of its power was the preservation of the alienness of the ruling group" (Chatterjee 1997, p. 18).

8. In keeping with the primacy accorded to visuality and the image in Pushtimarg, and particularly the emphasis on portraits of the gosains or high priests, Vallabha priests enthusiastically embraced photography, patronising it in the manner of rulers and merchants. Thus among the photographic portraits taken around 1863 by the early Bombay photographer Narain Dajee is a group of "Vallabhacharya Maharajas" (Falconer1995, p. 47, plate 4.4). By the turn of the century the gosains of Nathdwara and Kankroli (another Pushtimarg centre nearby) had employed their own photographers to document functions, fairs and festivities, and make portraits of the priests, their patrons and associates. One of these was Parasram Paliwal (1889?-1977), who was sent by Balkrishnalalji of Kankroli to be trained in Madras; after many years of working for the temple he eventually set up the Geeta Studio in Nathdwara around 1960. Interview with Ramchandra Paliwal (Parasram's grandson) and his father Kanhaiyalalji, Geeta Studio, Nathdwara (13 November 1995).

\section{REFERENCES:}

1. Adorno, Theodor (in Bernstein J.M. (ed) Schema of Mass Cultureí, in The Culture Industry: Selected Essays on Mass Culture Routledge, 1991, London) p. 53-84.

2. Benjamin, Walter "Central Park" (in New German Critique No. 34, Winter, 1985) p. 32-58; and Arendt, Hannah (ed.), trans. Harry Zohn Illuminations (Schoken Books, 1969, New York).

3. Chatterjee, Partha "Beyond the Nation? Or Within?" (in Economic and Political Weekly January 4-11 1997) p. 30-34.

4. Coomaraswamy, Ananda K. Introduction to Indian Art (Teosophical Publishing House, 1923, Madras); and "The Present State of Indian Art" (in The Modern Review August 1907; reprinted in Sharma, R.C. and Rupika Chawla (eds) Raja Ravi Varma: New Perspectives National Museum, 1993, New Delhi); and "The Transformation of Nature in Art" (Dover Publications, 1956, New York).

5. Deshpande, Satish "Imagined Economies: Styles of Nation-Building in Twentieth Century India" (in J ournal of Arts and Ideas No. 25-26 December 1993) p. 5-35.

6. Falconer, John "A Shifting Focus: Photography in India 1850-1900" (exhibition catalogue for A Shifting Focus: Photography in India 1850-1900 The British Council, 1995) p. 9-22.

7. Havell, E.B. Indian Sculpture and Painting (J ohn Murray, 1908, London).

8. Kapur, Geeta "Ravi Varma: Representational Dilemmas of a Nineteenth Century Indian Painterí" (in J ournal of Arts and Ideas No. 17-18, 1989) p. 59-80; and "Ravi Varma's Unframed Allegory" (in Sharma, R.C. and Rupika Chawla (eds) Raja Ravi Varma: New Perspectives National Museum, 1993, New Delhi) p. 96-103; and "Revelation and Doubt: Sant Tukaram and Devii" (in Niranjana, Tejaswini, P Sudhir and Vivek Dhareshwar (eds) Interrogating Modernity: Culture and Colonialism in India Seagull Books, 1993, Calcutta).

9. Weber, Max, trans. Talcott Parsons The Protestant Ethic and the Spirit of Capitalism (George Allen and Unwin, 1976, London). 


\section{Taking Pictures The Early Days of Photography in Bengal}

SIDDHARTHA GHOSH

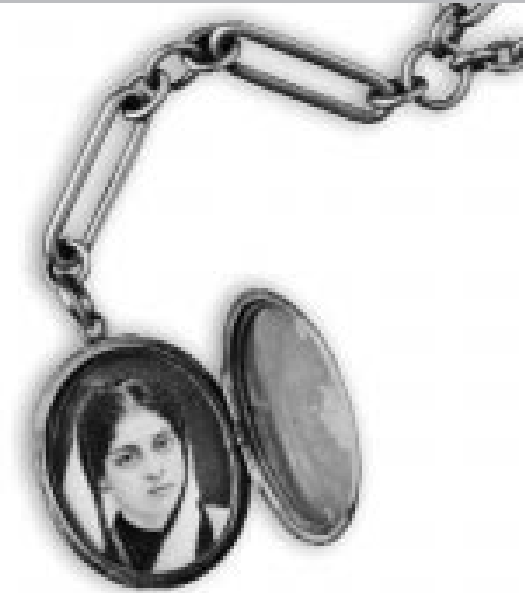

$\mathrm{T}$

he areas around Radhabazaar, Chinabazaar were once full of photographers' agents roaming the streets, a small photograph in hand, luring prospective customers from the country. "Sir, want a mug-shot? Four annas for a wonderful likeness". This is a description from the second edition of Adishwar Ghatak's book Learning Photography (1903). Well known, upper-class studios were by then advertising their photos as "an absolute match in every detail" for as little as "a hundred rupees", much less than an oil painting that would have cost a thousand. Ordinary photographers sold their glass photos for eight annas or less. Educated professionals like Adishwar Ghatak looked down on them, and Adishwar has not left any explanations of how these garden-variety photographers made a living by selling photos at such low prices.

After 1852, the advent of 'Ambrotype', Tintype', 'Ferrotype', or 'Glass Positive' made photography affordable. Instead of paper, the print was made on glass. Till 1880, these glass positives were very popular among the working classes in America. If some examples from the oeuvre of these street photographers had survived, we could have added a few less illustrious names in the gallery of portraits of the babus of $19^{\text {th }}$-century Bengal.

We learn from Adishwar Ghatak's book that by 1910, street photographers had become a rarity. "When still in school, we had once been to Chinabazaar to buy books and had also bought a glass positive. The photographer was a young man. We had noticed the sheen of his fashionable clothes. Nearly twenty-five years later I suddenly noticed, by a corner of a staircase in Radhabazaar, a grey-haired lean old man, clutching a glass positive and hoarsely crying 'Photograph! Photograph!'... Earlier it cost four to eight annas, now it was two. We climbed on to the terrace where he worked and I took a couple of glass positives 
myself. I never let on to the old man that I knew something of photography or I earned my livelihood from it."

Buendia was the leader of the men who cleared the dense South American jungles to found a village named Macondo. This is Marquez's Noble Prize winning novel. When Buendia saw a photograph on daguerreotype - a silver-covered metal plate used for printing - he was alarmed. It was the first time he had seen a photograph. He thought people whose portraits came into metal plates left some of their life force behind. Photographs hastened their deaths. Buendia became an expert in daguerreotype himself and began an innovative experiment. To prove the existence of God, he took a series of complex 'superimposed exposures' in various corners of his house to capture His presence.

Buendia was unable to take a photograph of God. That was in South America. In India, the Gods came to earth to be photographed. Durgacharan Roy's Debganer Martey Agamon ("The Gods Come to Earth"), published in 1886 but written much earlier, describes how Brahma, Vishnu, Indra and other gods decide to go on a Bharat darshan. While roaming the streets of Kolkata, they come upon a "Photographical Establishment". Indra is tempted by the studio's claim to produce a remarkable likeness for only two rupees. "It would be wonderful if we can take back a few pictures to Heaven to show off our disguises", he states. Brahma agrees. After their snaps are taken, the gods are ready to depart when a couple enter the shop. Brahma says, sotto voce, to Narayana, "If the woman wants her photo, that's alright, but the man must not... if his likeness turns out to be more ugly than he actually is, the woman may abandon him in the English fashion".

Brahma must have been ignorant of photography to voice such apprehensions. By the end of the $19^{\text {th }}$ century, Bengali photographers were veritable experts in the art of taking a good likeness. Adishwar Ghatak, who can claim to be the first Bengali writing on photography, has a detailed chapter titled "Likeness in Photographs" that supports this view. He states that a photograph can be called a likeness only when it is artistically executed. One must be acquainted with the works of famous photographers to realise the difference. In any appearance, the face is the most important feature to focus on. Next comes light. In those days photographs were taken in sunlight. Good studios boasted of a glass room. Light from the North was favoured. The face was lit from one side and a "play of light and shade" created. In the age of slow-speed films, the 'victim' had to sit still without even batting an eyelid. To stop the head moving, a 'head-rest' machine was in vogue. When photographed standing, its use was inevitable. Then came the decorations in the background and foreground. Like a theatre scene, a single hued pictorial backdrop was used. Sometimes it was folded up and the scene changed when required. The foreground "was a shrub, or a stone, or a wooden fence, sometimes picturesque weapons, even books. These made the photograph look good. There were numerous ways it was done".

Adishwar Ghatak's best advice concerns seating. Instead of an ordinary chair an upholstered dark-coloured chair looked better, but "a photograph must be taken in accordance with the seating habits of a race. If a white man were seated on the floor and a lower caste on a chair it would look absurd. Similarly if a Bengali woman, living under purdah, was made to sit on a chair, it would look unnatural".

Probably no lower caste had ever paid to have his photo taken and caused anxiety to 
Adishwar Ghatak. But looking at several old family albums, one is struck by the fact that leaving aside the Brahmo Samaj, many conservative Hindu women agreed to be photographed seated while their husbands remained standing. But the opposite is also true. The old and infirm husband in a chair while near his feet sits his shy young bride. It is futile to judge the status of women from these photographs of conjugal togetherness. Instead the patterns on the saris, their intricate folds, the jewellery, and the eloquent eyes tell a more complex story.

Europeans had shot portraits of famous Indians on commission. Individually, however, they had thought infamous, dangerous, superstitious natives and Oriental Maharajas to be fitter commercial subjects. Let me give an example. Vincent Brown, the Kolkata manager of the photographic studio John Blitz's (2, Hare Street), once gave an advertisement in 1899. In only one rupee, Tantia Bhil's photographs - the famous dacoit, Indian Robin Hood - were available in three different poses. In the first, he was dressed as a fisherman, with handcuffs and accompanied by two policemen. The second photo was the actual moment of capture with an accomplice; and the last one alone. The advertisement gave details of Tantia's career, his humanitarian impulses and why customers ought to buy the frames. A postscript to this advertisement stated that, as a suitable Christmas or New Year card for friends back 'home', the studio boasted of seventy rare photographs of "INDIAN CHARACTERS" in their collection.

Two old catalogues of Bourne and Shepherd, India's much discussed and oldest studio, also testify to this attitude. There are no publishing dates on the catalogues. One of them simply mentions a hundred years of experience, starting 1840. The claim to be founded in 1840 is, however, untrue. The Kolkata branch of Bourne and Shepherd was opened in 1864. If the studio in Simla, with another name, is taken as the original, it came twenty-two years after 1840. These two catalogues, one of 1840 and the other even earlier, have 167 pages with a list of thousands of photographs. Among the portraits are a negligible number of Viceroys, Mughal Emperors, Lieutenant-Governors, Governors of Bengal, Commanders-in-Chief and their supporters. In the section "Native Characters" we can see an Acrobat, a Salt-maker, a Goldlace Maker, a Hackney Driver, a Cultivator, a Snake Charmer, an Embroiderer, a Goldsmith, etc. In the section "Prominent Personality" we see portraits of only five Maharajas - Gobindalal Roy, R.B. Krishna, Padma Bahadur, Sir Narendrakrishna and Syed Asan Riza.

Yet Rabindranath Tagore had come to Bourne and Shepherd a number of times. So had many other members of the Tagore family, alone or accompanied. The studio had photographed Ramkrishnadev, Upendrakishore, and later Saratchandra. These are well known facts. It is unspecified how many famous Bengali men and women had come within their portals. If Bourne and Shepherd had sold the pictures of Rabindranath and Ramkrishna alone, they could have made a killing. This is also true for other European studios. They did not take Bengali portraits for Bengalis. While their cameras captured a remarkable likeness, they lost touch with the pulse of the people. Copies of photographs they had once taken, of Rabindranath, Bankim and Madhusudan, nicely framed, continue to sustain many Bengalis in business to this day.

Translated by Debjani Sengupta.

Image courtesy Ananda Publishers. 


\section{The Home and Beyond Domestic and Amateur Photography by Women in India (1930-1960)}

SABEENA GADIHOKE
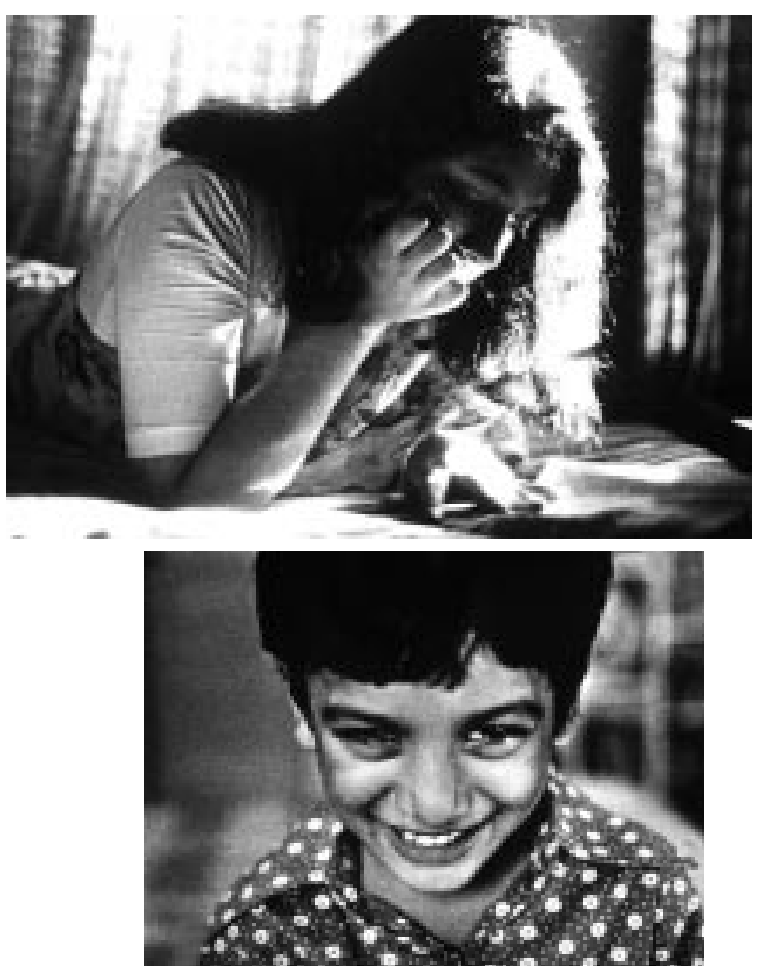

Photos courtesy: Debalina Mazumdar
"I used to dream that I am going to London or somewhere, and then after going to the airport, on the plane, I discover I haven't got my camera. I begin to cry. What will I do without my camera? I had that sort of an attachment with it. Somebody once told me that the eye is better than the camera. I said, that is all fine, but I would like to go over memories. Things as I saw them then."

(Debalina Mazumdar, July 2000)

7 his essay discusses the curious vision of women who photographed within the family from the thirties. Many of them had acquired the camera as an object of leisure. Confined at home and with restricted mobility, what would they have photographed? Would the camera have allowed them to view the world outside? How would they have used photography to think and imagine? More importantly what would have been the effect of their being able to look through the lens on their own lives? This is a segment of a larger project mapping a history of the woman photographer and photographic practices associated with women in India. Within a historiography of early Indian photography, women have hardly figured except as subjects of photography. Perhaps one reason for this invisibility is the way in which notions of the professional have been defined, which made it impossible 
for them to be part of this history. Most women in the past would have photographed in spaces that were not as visible as those in which male photographers might work. They also probably catered to needs within photography that were different. It is for these reasons that dichotomies between professional, amateur and domestic photography need to be challenged in order to reconstruct a history of the woman photographer.

It is important to revisit some of these practices for other reasons too. Most scholarship on photography in India has been restricted to the colonial period. ${ }^{1}$ These often canonised images focussed on 'grand narratives' of great personalities, important events or landscape, and therefore determined a particular visual discourse of the public. ${ }^{2}$ Other more subaltern practices of photography such as amateur and domestic photography or certain traditions of studio portraiture have not received the same attention. ${ }^{3}$ These practices need to be recuperated in order to construct a history of the 'ordinary' and the 'everyday'.

While there are some references to professional women photographers in Calcutta and Hyderabad at the turn of the $19^{\text {th }}$ century, photography became more popular among women in the home with the introduction of the Brownie camera. Encouraged by the proliferation of amateur photography all over the world, Kodak largely targeted women in its marketing strategy for the camera in 1888: "You push the button, We'll do the rest". Photography with the Brownie was so simple, that 'even women' could do it! This essay describes the experiences of five women who photographed from within the home from the nineteen-thirties onward. ${ }^{4}$ For some of them, the humble Brownie may have been a stepping stone to other more 'sophisticated' cameras or to amateur photography. For all of them however it was the means for a passion that extended far beyond a hobby.

Referring to the family album, Patricia Holland notes that while men often took domestic pictures, it was women who were largely the historians and guardians of memory, selecting and preserving the family archive. ${ }^{5}$ In doing so, they were performing an important function as chroniclers of everyday histories. One example of this is the personal photo archive created by Mira Chaudhuri (1905-1994). Both she and her sister Indira Dey (1912-1992) learnt photography with a Brownie camera from their father D.N. Maitro, a surgeon at Mayo Hospital in 1915. Coming from a well-known Brahmo family, Mira married relatively young and travelled extensively. She was socially very active. Among other activities she had edited Sreemoti, a women's journal, written articles, been a member of various clubs and charities and run an embroidery centre for women. She also photographed extensively throughout her life.

In a unique photo-autobiography, Mira created five volumes of family albums with selftaken as well as older photographs tracing genealogies of two generations before her. In 1978 she sustained a fracture of the femur bone from which she never recovered. Bedridden, she started to rearrange her albums. Detailed narratives were written around her photographs, reconstructing her entire life and of those before her. These handwritten accounts were pasted along with accompanying photographs. Their arrangement in albums was much like her memory, fragmented and non-chronological. Rather than being a structured autobiography, these jottings were like diary or journal entries. For instance, an entry (always with photographs) would describe a trip to Amarnath with a friend. The same page would carry another entry to mark his current status: "Telegram, Tejnath no more". The fol- 


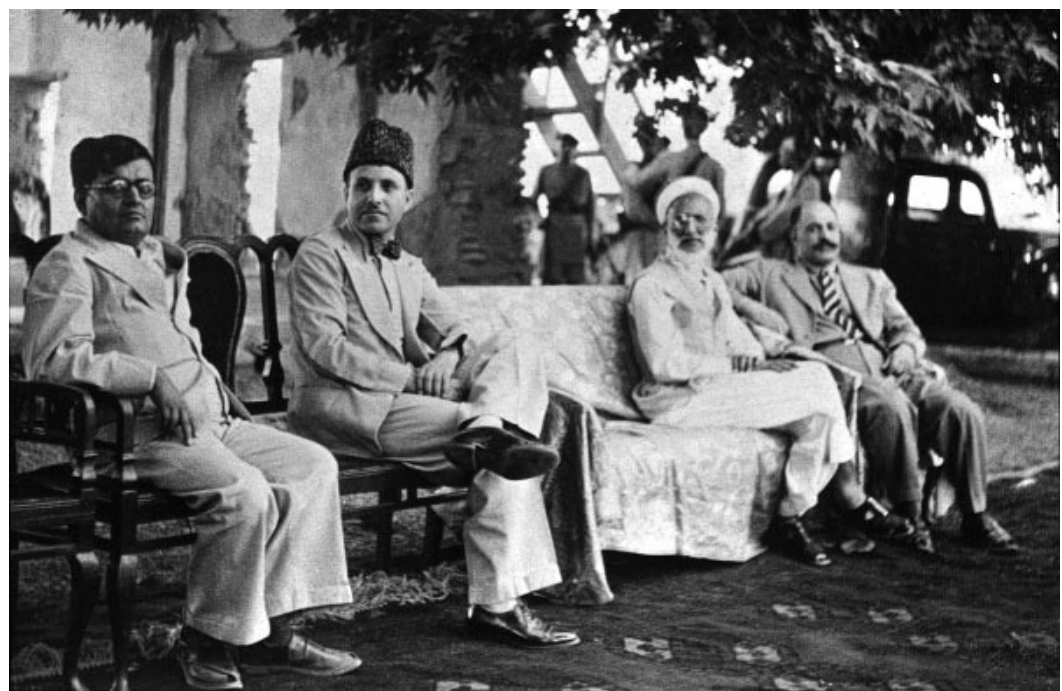

lowing page would describe the marriage of her sister Indira (with Mira's photographs of the couple) and jump in time to portraits of their children describing their current status and respective families. This bricolage was expanded to twelve volumes, copies of which were then bound and sent to every family member.

Mira Chaudhuri's photo archive describes not just events but feelings and emotions as well. One of the album pages has a photograph of her father and sister Indira looking at a portrait of her mother. Both images taken by her, the caption on this page reads "Ma's last days" and documents in detail the life of her mother and her subsequent death a month after the photograph was taken. This image, like others, stands out among the other fami-

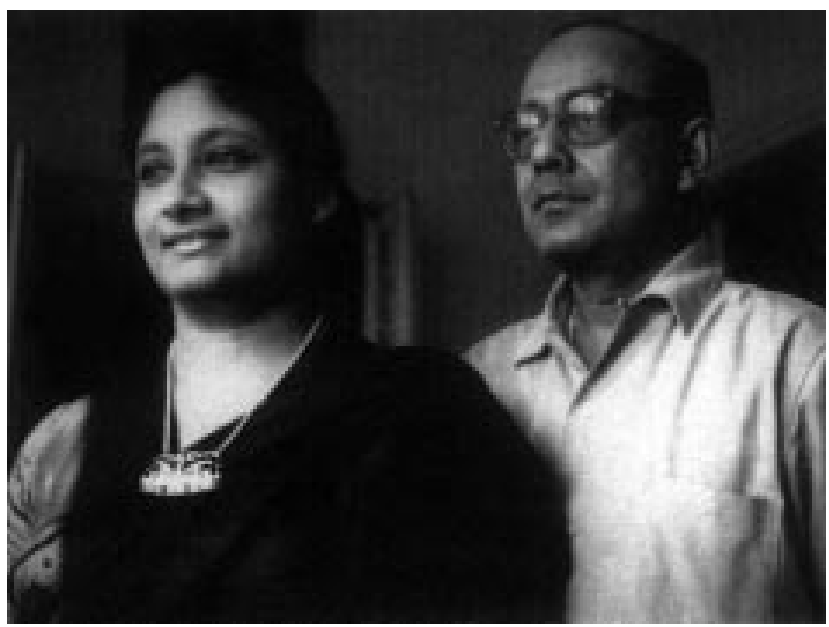

Photos courtesy: Mira Chaudhuri 
ly pictures for its deliberate attention to the function of photography. Mira's archive was however different from the standard family album in one major respect: it gave space to those outside the fold of the immediate and extended family. In documenting her own journey, Mira was not only speaking about herself, but about a larger world outside. There are innumerable people here, both known and unknown, and their histories too. ${ }^{6}$ In some senses the notion of the family seemed to be extended to a larger universe that she was acquainted with. In doing so, her images though based on private memories, negotiated a wider terrain of public history. Looking through her albums, one gets a sense not just of her personal history but also of a wider historical context and her own tensions within this context. There were significant changes occurring in the world outside. Gandhi was encouraging women like Mira to come out of the home and be part of a larger struggle. These changes and her conflicts with them are evident in her descriptions around the photographs. Her first meeting with Mira Behn, her first photograph of Nehru and Rabindranath Tagore, her encounter with Gandhi or with Wali Mohammed Khan where she was the only woman at a dawat (feast) of two hundred chieftains of the North West Frontier Province are some of the events documented in the albums. ${ }^{7}$

Photography allowed women to do things that they normally did not do. It allowed them to wander, to look and to stare. While the camera gave them some legitimacy to be in the public domain, it also made them far more visible on the streets. The urban street scene therefore remained largely the preserve of men. ${ }^{8}$ This situation however changed when they

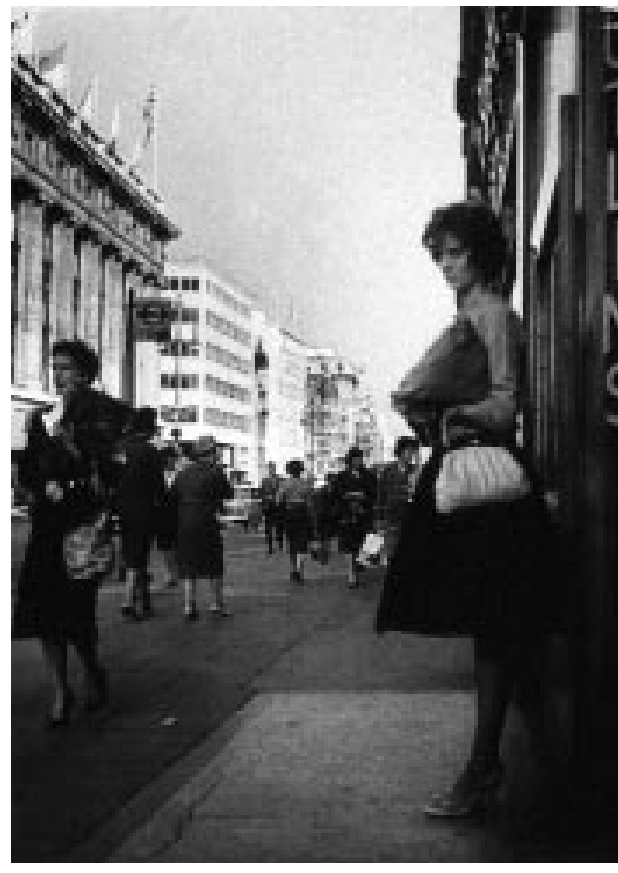

Photos courtesy: Manobina Roy

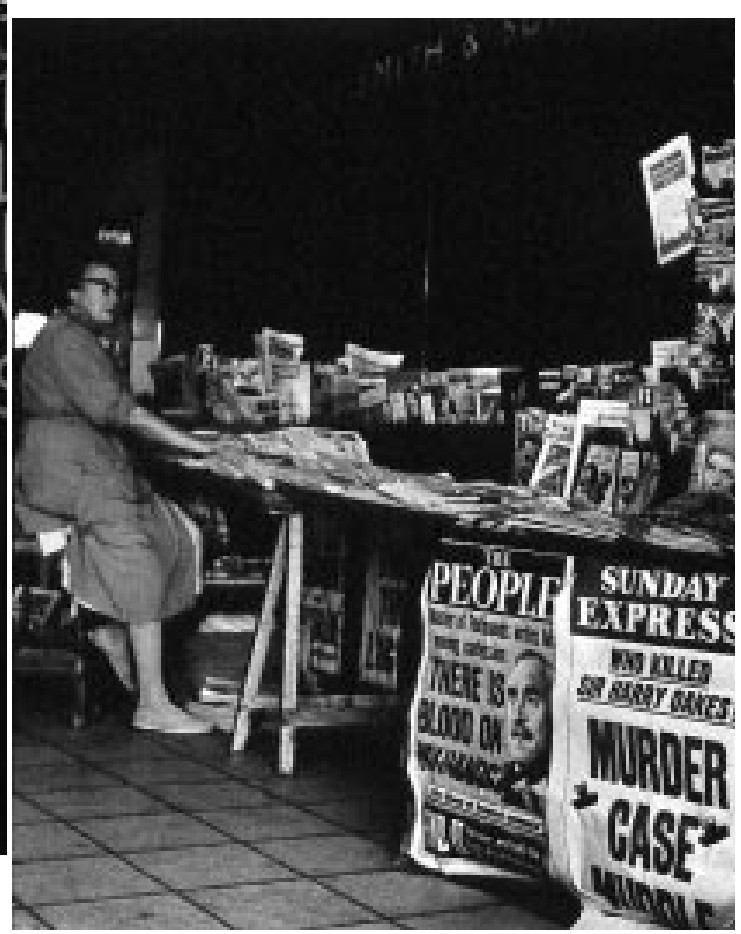


travelled, especially for holidays. In early 1932, Mira travelled to Europe by ship accompanied only by her mother and children, and took numerous photographs on this trip. While vacations and holidays legitimised the presence of women like her outside the home, the camera may also have contributed to this legitimacy. This was true for another set of sisters, Manobina Roy (1919-2001) and Debalina Mazumadar (b. 1919). They were twins and grew up in Ramnagar, Benaras where they learnt photography from their father with a Brownie in 1935. He was the principal of the local High School patronised by the ruler of Benaras and their mother had to observe purdah in Ramnagar. The camera, however, allowed the twins to travel around the city, in the thirties, where they would photograph nature or practice their photography by taking pictures of each other.

Manobina married early to Bimal Roy, then a young cameraperson employed by New Theatres in Calcutta. Being married to Roy was both an advantage as well as a disadvantage for her. Her husband was a still photographer and was associated with a studio in Calcutta. However after his move to Bombay in 1951, Bimal Roy was also becoming famous in the film industry. ${ }^{9}$ His home had a constant stream of guests and there was a lot of entertaining to be done. The actress Devika Rani once asked her how she passed her time. When Manobina described her day that consisted of looking after her children, running a house which always had Bimal da's guests staying over and helping him with his work, besides her photography, Devika became thoughtful and said, "Now I can see why Bimal is so successful". Her sister Debalina married into a family in Calcutta where her husband did not really care about photography. However, among those delighted with this skill were her in-laws, and soon she found herself shooting all the old people at home, the "jethus, kakimas and mashimas". Some of them would probably never have been photographed had it not been for the fact that a family member was a photographer. Debalina enjoyed taking portraits but there were some unpleasant tasks too. Each time there was a death in the family, she was called to take pictures for the shraddho. In spite of this both sisters were known as 'auspicious' photographers. It probably began as a joke, but the cousin whose portrait they took actually did get married and many young women wanted the same. Debalina's own portrait for marriage was taken by her sister. What was interesting in their narratives is that they were prompted to take these portraits because of their own subjective experiences as women and the humiliating terms upon which traditional marriages were arranged. Debalina, who married relatively late, talked about her early and disastrous experience of being shot in a studio. She also recalled an anecdote where she refused to go with her husband to the studio after their marriage because she didn't want to be photographed like a "jatra rani with her legs swinging from the chair". In recalling this image, Debalina was critiquing a certain kind of representation of women in older studio traditions. These were images that she rebelled against and it reflected in her portraits of women.

Photography's greatest advantage was that it could be adjusted to one's individual schedule. It also served as a temporary escape from a situation that left women with no time for themselves or for a fantasy world. ${ }^{10}$ Among the standard family album pictures of their children growing up were also some striking portraits of their daughters. These highly stylised photographs are taken with deliberate emphasis on light and composition. ${ }^{11}$ In 1959, Debalina and Manobina were in London where they also photographed British women 
and documented the isolation of the elderly in Hyde Park. Manobina described how older women would dress up just to buy a loaf of bread or to exchange a few words with strangers. Some of these insights were captured in her images of women window shopping, sitting in the park and on the streets. Both shot street corners and hospitals, the tabloid press and the suffragettes in Britain. Debalina also photographed rallies against the Soviet presence in Hungary. In doing so they were able to engage with the street and with experiences not limited to their own lives. Both sisters expressed a strong desire to document their experiences outside the home. While some of these were written and published, it was photography more than anything else that allowed them this space for self-expression. They both said that perhaps in another time they would have chosen to be photojournalists.

For most of these women, photography coexisted with the domestic responsibilities that compelled them to work late into the night, when they found the time and space to develop, print and enlarge. It is important to remember that, being women, their links and access to even the most rudimentary supports that amateur men had were limited. Indira would sometimes discuss her photographs with the maid. ${ }^{12}$ She also spent long hours at Santiniketan discussing photography with her young nephew Mukul Dey, who later made a profession as an industrial photographer. ${ }^{13}$ While they did not receive much encouragement either, Manobina and Debalina created their own links with photographic salons and societies. Despite being restricted to the home, both sisters made efforts to keep in touch with other amateur photographers. In Benaras they were members of the U.P. Photographic association and won prizes when their photographs travelled to competitions. Problems of mobility were solved by the "postal portfolio", which was like a travelling exhibition. ${ }^{14}$ This 'community' helped to sustain their photography and is evident in the technical quality of their photographs. The importance of their home-based photography however cannot be underestimated as it provided them with practical experience. After all, they would not have been good amateur photographers unless they had shot hundreds of photographs at home. Of course, many of these activities had to stop once they got married. When she came to Calcutta, Debalina had to turn down an offer to join the Photographic Association of Bengal $(\mathrm{PAB})$. She returned to the organisation only at the age of sixty, when her children were grown up. This time she became their President for three years. Meanwhile some of her contemporaries, like Oonawalla, Stanley J epson, T. Kashinath, Dr. Thomas, Sunil J anaah and Shambhu Saha went on to become significant names in the field of early Indian photography.

Most media technologies in India have been linked with issues of privilege and class and the still camera was no exception to this. These are stories of women from mostly middle-class and upper-middle-class backgrounds. However, for all of them, the camera provided a significant space for selfexpression. Of all the narratives presented in this essay, a sense of isolation was most marked in the case of Rajendra Kunverba (1920-2000), the late Rajmata of Kutch who was totally limited to the home for a major part of her life. However it is in her life that the camera played a vital role in the act of visibility. Born in 1920, Kunverba, the princess of Kishengarh, was married at the age of thirteen to the prince of Kutch. Her family could not afford to pay any dowry but the royal family of Kutch wanted a young and obedient daughter-in-law. Going to Kutch in those days was considered kala paani (a punishment), because the state was cut off for a major part of the year due to the 
monsoon. The isolation that Kunverba had to undergo was doubly reinforced because she had to suddenly be in purdah. This was a new experience for her as, like many Rajput princesses, she had been brought up like a boy till she was eleven, learning how to ride and shoot. Her husband would stay away for long periods of time, during which she would have to live in the old palace in Bhuj constantly guarded by Mian saheb, a eunuch who appears on the fringes of many of her photographs. It is from within this isolation that Kunverba began her photography. Her only contact with the outside world was through acquaintances who crossed over into the zenana. Two of them were significant for their relationship to her photography: the family physician, Dr. Tasker, who would give her tips on taking pictures with her Brownie camera, and a Parsi tutor/companion, Ms. Aloo Driver, who once secretly took a photograph of Rajendra Kunverba's grandmother-in-law. This was a particularly subversive act, because photographs of women in the zenana were strictly forbidden.

Against this background of confinement, photography became an escape for Kunverba. She would take photographs of mostly her children, but also the family pets, the beach at Kutch, her attendants and the women of the zenana. Her photographs are private. She never made enlargements and her films had to be sent outside Kutch for processing for fear that others would see them. These photographs intersect interestingly with a larger public history of a princely state and a world that was closed, at least for her and other women of the royal family, in terms of representation. Women in purdah were not photographed, unless by their husbands or by the state photographer. In Kutch even a court photographer was not allowed into the zenana. By photographing within, therefore, Kunverba was facilitating a visibility that was taken for granted by less elite women outside the royal family. She spoke in her interviews of how she would be begged by other women in the zenana to take their pictures and their excitement at seeing their own images. These photographs are also important because, being casual family snapshots, they would have been different from the scores of orientalist images of women in the zenana that had been taken in colonial India. Sadly none of these images remained with her in Bombay when I met her shortly before her death. Bhuj of course has since witnessed the earthquake and perhaps these images are lost forever.

The camera gave Kunverba access to a world that she was otherwise not able to be part of. She would often shoot her husband's hunting expeditions, but always accompanied by Mian saheb and through a car with blackened windows creating an interesting dichotomy: Kunverba could see through the camera, but without being looked at. Ironically, she stopped photographing in the fifties once she came out of purdah. Perhaps her need for photography was over by then. She was now free to step out into the world and look at things unfettered by the veil. As she said, "there was no need for me now to carry my camera". The camera had been her window to the world while she was in purdah.

Domestic photographs cannot be separate from their context. In looking at the images taken by these women, this essay attempts to understand the space that the camera gave them and the role of photography in their lives. The above stories cannot be used to generalise a larger narrative of domestic and amateur women photographers. However they can provide some insights about recovering photographic practices that have been marginalised because they have flourished within the private realms of the home. To recuper- 
68 / Sarai Reader 2003: Shaping Technologies
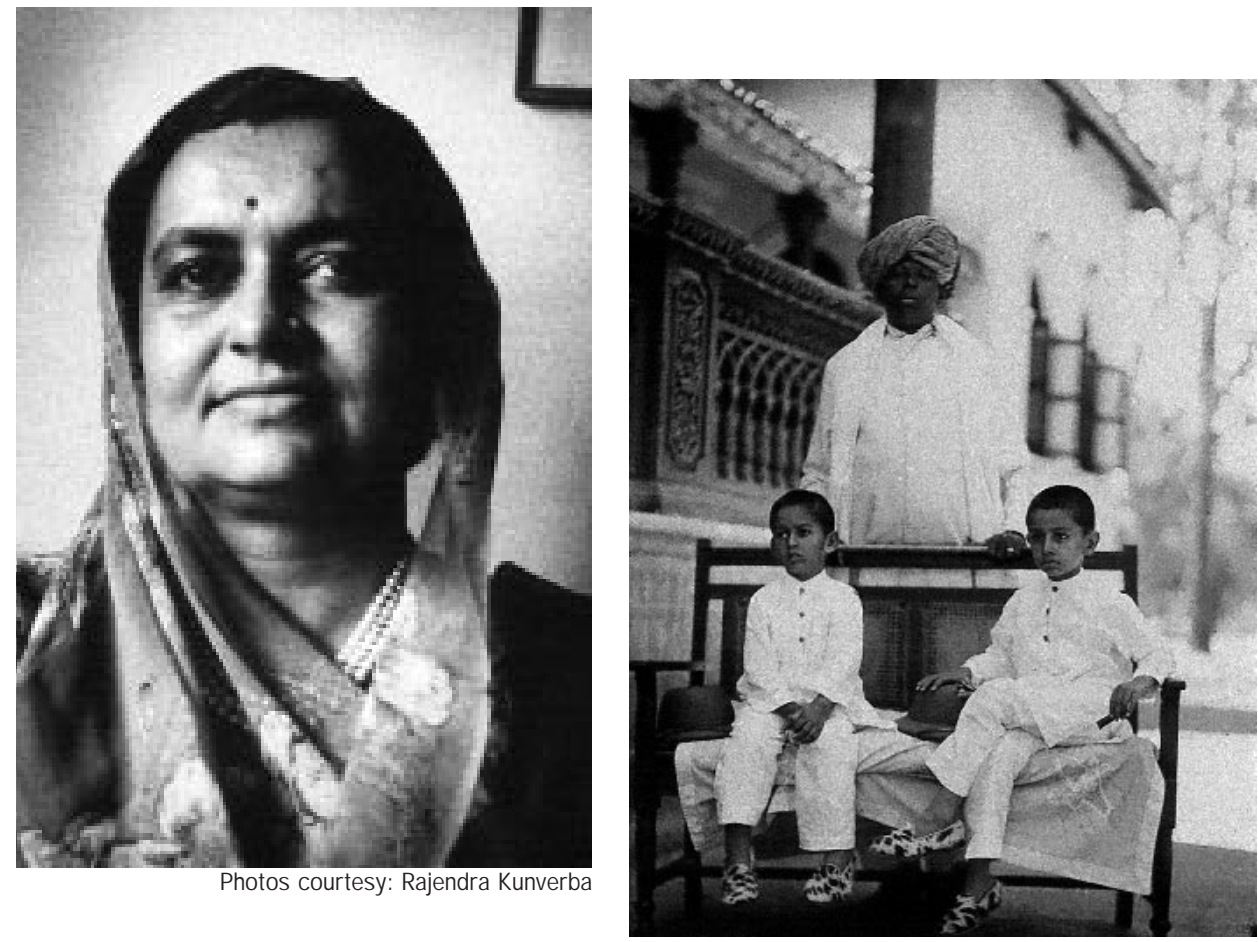

ate a women's history of photography, the historian has to move into realms of domestic and amateur photography, spaces that have hitherto been overlooked, even rejected. The still camera was a significant tool of representation because of its potential to be used in both the public domain as well as at home, as a profession as well as for leisure and as a hobby. In trying to recover a history of women's participation with this technology, perhaps we need to look more closely at some of these spaces and functions. These may have been personal histories but amateur and domestic photographic practices are significant precisely because of their ability to represent the experience of the 'everyday' and the 'unspectacular'. As pointed out earlier, these practices have the potential to stand in opposition to the generalities of other more canonised narratives of photography. Perhaps it is time to look at all these practices anew and to examine the work not just of women but also of other amateur photographers whose work has been invisibilised so far.

\section{NOTES}

1. Among these books are Dayal, Raja Deen Princely India: Photographs 1884-1910 (Hamish Hamilton, 1980); Worswick, C. and A. Embree The Last Empire: Photography in British India: 1855-1911 (Gorden Fraser Aperture Inc., 1976, London); and Gutman, J udith Mara Through Indian Eyes (Oxford University Press, 1982, New York).

This scholarship is either too general or deals with specific (and often elite) male photographers. Publications of the India Office Library such as Desmond, Ray Victorian India in Focus (Her Majesty's Stationary 
Office, 1982, London) and Faulkner, J ohn A Shifting Focus: Photography in India 1850-1900 (The British Council Visual Arts Publication, 1995, London) are restricted to particular collections and time periods, as is the more recent Dehejia, Vidya (ed.) India: Through the Lens: 1840-1911 (Mapin, 2001) where photography by women is described as "no more than a pleasant diversion".

All these books focus on colonial photography. The only exceptions are Ghosh, Siddharth Chhobi Tola: Bangalir Photographic Charcha ("Taking Pictures") (Ananda Publishers, 1988) and Pinney, Chistopher Camera Indica (University of Chicago Press, 1997) that provide much needed insights into local photographic practices and the social history of photography in India.

2. With the birth of the new nation state, photojournalism became the preferred form of archiving public history.

3. See Christopher Pinney's work on Bazaar photography in the small studio (1997).

4. I am grateful to the late Siddharth Ghosh for drawing my attention to some of these women who were first written about in his chapter on Women Photographers in Ghosh, Siddharth Chhobi Tola: Bangalir Photographic Charcha ("Taking Pictures") (Ananda Publishers, 1988). All subsequent research is based on interviews conducted with them by me during 1999-2001.

5. See "History, Memory and the Family Album" (in Spence, Jo and Patricia Holland (eds.) Family Snapshots: The Meanings of Domestic Photography Virago Press, 1991). Men also took family pictures and the camera was often their domain if they photographed at home. However domestic photography as a practice always remained feminised because it dealt with the family and children, considered a woman's arena.

6. While there are entire sections devoted to Aruna Asaf Ali, Pupul J ayakar, Satyajit Ray, Anna Pavlova and many others, there are also paragraphs about unknown acquaintances such as "the man in Jakimov who looked like a fair jethamoshai" or other friends all over the world.

7. Mira also took $16 \mathrm{~mm}$ footage of Rabindranath Tagore that was subsequently used by Satyajit Ray in his documentary on Tagore.

8. Shambhu Shaha and Sunil J anaah photographed extensively on the streets of Calcutta. There are very few instances of street photography in the work of these women except in some pictures taken by Manobina Roy and Debalina Mazumdar.

9. Bimal Roy started his career as a cinematographer and shot P.C. Barua's Devdas in 1935 among others. His first film was Udayer Pathey (Bengali, 1944) and he continued to make films till 1963 (Madhumati, Hindi), making 18 films in 19 years. He is famous for films like Do Bigha Zamin (1953), Sujata (1959) and Bandhini (1963). His films were known for their strong social concerns. Roy was deeply influenced by the Left and was a member of IPTA.

10. Spence, Jo and Patricia Holland (eds.) Family Snapshots: The Meanings of Domestic Photography (Virago Press, 1991).

11. Debalina has many such photographs of her daughter Komolini, and Indira Dey has an entire set of images of her daughter Anuradha in Italy.

12. G.Thomas in his History of Photography (1981) notes how the urge to extend the benefits of club membership to people who were scattered throughout the country took the form of an "out reach" in the shape of the postal portfolio movement. This was first started by the U.P. Amateur Photographic Association under S.H.H. Rizvi in 1940. It was soon taken up by other amateur photographic societies and clubs who went on to hold All India Salons. 


\section{Panchlight}

PHANISHWARNATH RENU

$\mathrm{F}$

rom collections made from fines over the last fifteen months, all the Panch of the Mahto toli purchased a panchlight at this year's Ramanavami fair. The village has eight Panchayats in all, each caste has its own assembly and each Panchayat owns a common rug, a sheet, a carpet and a Petromax, which is also known as panchlait in the rural idiom. Immediately after buying the panchlight, the headmen decided, while still at the fair, that the surplus ten rupees should be invested in articles for devotional offerings, as it was inauspicious to inaugurate a mechanical object without religious rituals. Even in the times of the Angrez Bahadur (the mighty British) they always made sacrificial offerings before initiating the construction of a bridge.

The headmen returned to the village while it was still broad daylight; the Panchayat Chhadidar walking upfront with the panchlight box on his head, followed by the chief, the deewan, and the other headmen. While they were still at the outskirts of the village, Futangi J ha of the Brahmin toli made an undesired enquiry - "How much did you pay for this lantern, Mahto?"

“...Can't you see, it is panchlight! The people of Brahmin toli have an exaggerated sense of self-importance. They would call a wick an electric bulb, if it happens to be their own, and will call others' panchlait a lantern!"

The whole toli - young and old, women and men, quit work and came rushing, "Come on, let us go, our panchlait has come, it has!"

Aganu Mahato, the Chhadidar, would caution people every now and then, "All right, stay away, don't try touching it! Watch out, you may just kick it!"

The Sardar told his wife, "We will have puja this evening - hurry up, take a bath and arrange the seat".

The lead singer of the musical group in the toli gave clear instructions to his fellow singers, "Listen, we will sing in the light of the panchlait today. Let me warn the discordant elements right away. If you mess up today with tunes or words then tomorrow you are boycotted".

In the women's group Gulari aunt began humming gosain geet. Small children began making a lot of useless noise out of sheer excitement. 
The people thronged to the Sardar's gate an hour before sunset - panchlait, panchlait!

All talk was panchlait - there was no other talk, no other topic. The Sardar took a puff on the hookah and said, "The shopkeeper first loftily announced, 'no less than five (times) twenty and five rupees'. I told him, 'Look shopkeeper sahib, don't you take us for complete rustics. We have seen many a panchlait, ok!' The shopkeeper gave me a careful look. He said, 'It seems you are the sardar of the caste! Alright, if you have taken the trouble of coming here to buy panchlait yourself, I will offer it to you for five kaudis only"'.

The Deewanji said, "What a perceptive salesman he was. His servant wasn't prepared to part with the panchlait's pack box. I said, 'Sahib, how can we carry the panchlait without the box!' The shopkeeper immediately shouted at the servant, 'Are you trying to trick the Deewanji, shame on you! Give him the box!".

The people of the toli looked at their Sardar and Deewan with renewed respect. Chhadidar informed the women's group, "It made a constant swishing sound all the way from the market this, panchlait?'. Then, at the very last moment, a big 'how' cropped up. Three bottles of kerosene had been acquired from Rudal Sah baniya's shop, and a tricky question now stared everyone in the face: who will light the panchlait?

Nobody had visualised this problem - neither before buying the panchlait, nor after. Now that the materials for puja were neatly kept on the chowk, the singers with their drums and cymbals raring to go, the damn panchlait was sitting dead. The villagers had never bought a thing that involved such complicated procedures of lighting and extinguishing. Should I buy a cow, but who will milk her, isn't this how the adage goes?... Now, have fun! Where does one get a person to light this contraption?!

It's not as if there was no skillful hand in the entire village. Every Panchayat had a panchlait and people who lit them regularly. But the inaugural is a moment of religion and ritual, a ceremonious occasion. So how could this toli borrow a man from outside to light it for the first time? Better to let the panchlait lie useless! For this involved inviting a lifetime of jibe from others. They would make it a point to remind us of this dishonour at every possible occasion... that we got somebody else to do it for the first time...! No, never! The honour of the Panchayat is at stake here. Don't ask an outsider!

A thick layer of melancholia hung over the toli as darkness started spreading its wings. Nobody had even cared to light a wick in their houses today... Why should they think of doing that when there was the panchlait!

The show, put up after so much hard work, was turning into a flop. The Sardar, Deewan and Chhadidar lost their voice. The shoulders of all the Panch drooped. Somebody tried to make a point in whispers, "These mechanical contraptions throw huge tantrums, really".

A young man came to break this piece of news, "The people in Rajput toli are going wild with laughter. They say, if you hold your ears and do five sit-ups in front of the panchlait, it will light up immediately".

All the Panch thought, "Why won't they laugh? God has given them reason and occasion to". An old man came to announce, "This Rudal Sah baniya has suddenly got loquacious. He is saying, be careful while pumping [air into] the panchlait". 
Gulari, Munari aunt's daughter, has a secret brewing up inside her. But how does she let it out? She knows that Godhan does know how to light a panchlait. But, he faces expulsion from the caste Panchayat. Munri's mother had appealed to the Panchayat, accusing him of singing the lewd Hindi film song "O my love, when I fell for you" to her daughter. And Godhan was already an entity resented by the Panch. He had come from outside to settle down in the village and he had not made the customary offerings to them. He simply did not care. So the Panch got their chance when Munari's mother appealed. They slapped a fine of ten rupees, failing which he was to be expelled from the Panchayat. Godhan is still facing boycott. How does one tell him! And the caste is facing utter humiliation.

Munari made a smart move. She told her friend Kaneli in their shared code, "Kaneli! chigo, chidha, chin...!" Kaneli smiled and kept quiet. Then, "But the Panchayat doors are shut on him!" Munari replied, "Take a chance, just tell the Sardar!" "Godhan knows how to light panchlait!" Kaneli blurted out. "Who, Godhan? Does he really? But..."

The Sardar looked at the Deewan and the Deewan turned to the Panch. All the Panch had expelled him unanimously. The whole village was angry with Godhan for his act of winking as he sang the film song. The Sardar said, "Why bother about the caste injunctions when the honour of caste itself is being washed away? What do you say, Deewan?"

Deewan, "I agree".

All the Panch also agreed, "Let Godhan be freed!"

The Sardar sent the Chhadidar to fetch Godhan. Chhadidar came back to report, "Godhan does not want to come. He says how does one trust the Panch? If I break a part or a tool I will have to cough up a fine, and get punishment".

Chhadidar seemed as if he were on the verge of crying. "Please do something, anything, to persuade Godhan, otherwise it will be difficult to walk around in this village".

Gulari aunt said, "OK, let me try!"

Gulri aunt went towards Godhan's hut and persuaded him to come along. The faces of all the assembled lit up with new hope. Godhan quietly got down to filling kerosene in the panchlait. The wife of the Sardar shooed away the cat taking rounds around the holy material for puja. The lead singer in the group began twirling his moustache. Godhan asked, "Where is the spirit? How can one ignite it without the spirit?"

Have more fun! Here comes another trouble! Everybody started cursing the wisdom of the Sardar, Deewan and the Panch - these people do things in bouts of absent-mindedness. The assembly went into a collective depression yet again. But Godhan is a truly clever fellow. He will light it without the spirit. "Get me a little coconut oil". Munari ran out and came back with a small bowl of coconut oil. Godhan started pumping the panchlait.

The light slowly started filling into the silken filament of the lamp. Godhan would alternate between blowing into the top and turning the knob. Very soon the panchlait began whizzing and then it turned brighter; the ill will they had in their hearts suddenly vanished. Godhan is quite a worthy boy!

And in the end when the whole toli dazzled in the light from the panchlait, the song party broke into singing with the collective shout of "Jai Mahaveer". Every face smiled as their faces lit up, making contours obvious. Godhan had conquered all hearts. Munari looked at him wistfully (with desire?). Their eyes met and exchanged notes, "Let's forgive 
and forget. It wasn't really my fault!"

Sardar called Godhan next to himself and spoke affectionately, "You have saved the honour of the caste. All your sins are written off. Didn't you always want to sing film songs? Go, sing now to your heart's content".

Gulari aunt said, "Godhan, why don't you come home for dinner tonight?"

Godhan looked at Munri one more time. Munri lowered her eyes.

The song party broke into another slogan at the end of a prayer, "J ai ho, J ai ho!" Every leaf in the surrounding trees thrilled under the illumination of the panchlait.

Translated by Ravikant.

\section{GLOSSARY}

1. Panchayat: The self-governing body of a village.

2. Panch: The five elected members of the Panchayat, with some judicial and executive powers.

3. Toli: Sub, caste-based group in a village.

4. Chhadidar: The Panchayat messenger.

5. Sardar: The chief.

6. Puja: Prayers.

7. Gosain geet: Religious songs sung in certain regions.

8. Sahib: Sir.

9. Kaudis: A count of twenty

10. Deewan: The treasurer.

11. Ji: An honorific.

12. Baniya: A trading caste.

13. Chowk: Here, a votive platform.

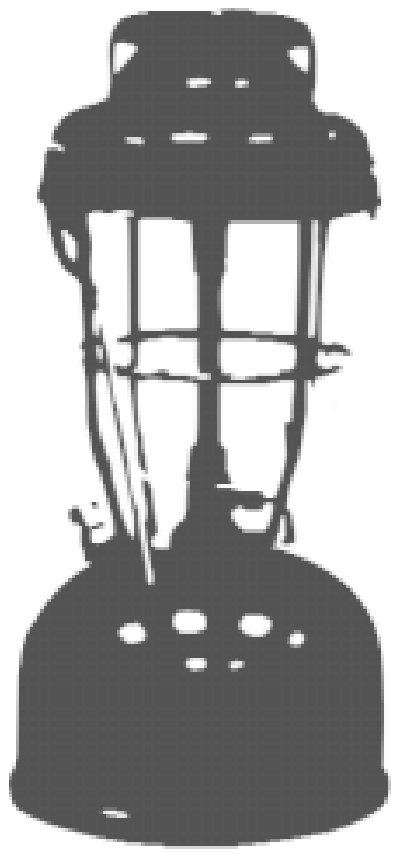




\section{Airborne From "In Persia"}

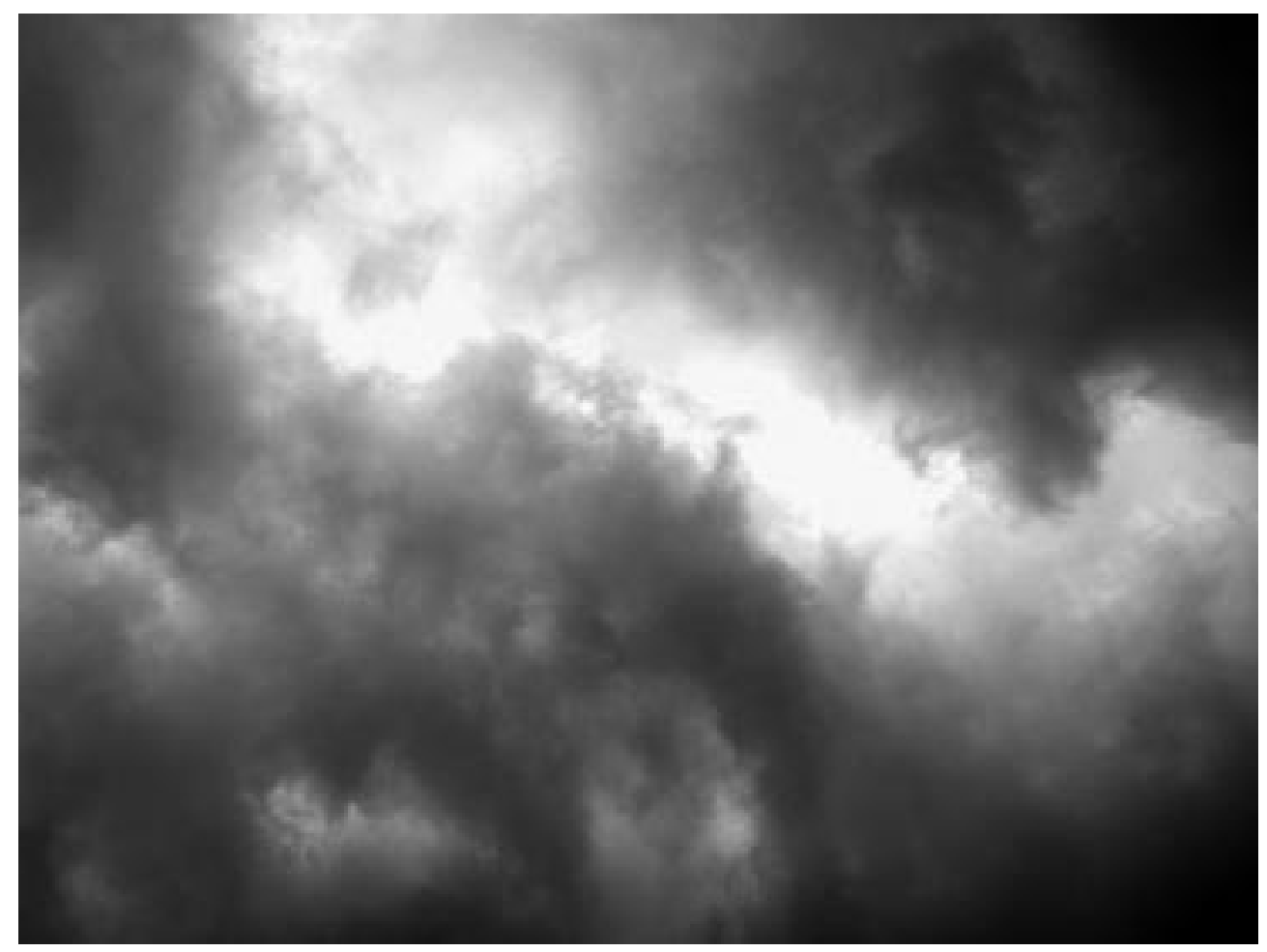

s the aircraft began to climb, the intimacy between the world and our five senses grew
faint, till it narrowed to only one - our sight - but it was too hazy for comfort. All
evidence of this certain yet diverse earth we absorb daily, now faded; a three-dimen-
sional reality became a two-dimensional picture. Creativity is manifest in varied structures
seen in the totality of space and time. As these distinctions become obscure, creation turns
out to be annihilation. J ust then, our earth appeared to me in that light of extinction. Her
identity vanished, her constant demands on the imagination ceased. In a similar state, when
a man sets out to drop fiery weapons from an aeroplane, he becomes unspeakably ruth-
less. His cruel arm does not hesitate in doubt. He is absolutely certain of his enemy's guilt 
- for they are so remote from him. Men have an innate tenderness for the natural world. When the reality of this world becomes unreal, his affection withers. The advice given in the Gita is comparable to this airplane - it removed Arjuna's compassionate mind to a distant world; from its pinnacle it became impossible to perceive who lived and who died. Men have many such theoretical aeroplanes to conceal reality in their armoury - in Imperialism, in theories of sociology, in religions. The blows that fall from those heights come pleasantly wrapped with one consolation: Na hanyatey, hanyamanye sharirey (The body can be slain but the the soul is indestructible). ${ }^{1}$

The British maintain an airbase in Baghdad. The resident Christian priest told me they were currently bombing a village of a Sheikh. The dead, old and young alike, were receiving these blows from the misty heights of the British Empire. It was easy to kill them Imperialism made their humanity indistinct. Christ had acknowledged these men too as children of his Father, but to the padre, Christ, his children were unreal. It was impossible to recognise them from the soaring aircraft of Imperialism, so all over the Empire today Christ received fatal wounds. Moreover, from an aeroplane it was easy to bomb the desert dwellers. There was no fear of retaliation; and the dead and injured appeared as mere statistics. People who can be killed thoughtlessly have never been alive in the minds of their killers. This is the reason why men and women ignorant of Western ways of destruction are slowly becoming a blur to these masters of war. ${ }^{2}$

Translated by Debjani Sengupta.

\section{NOTES}

1. A quote from The Bhagvadgita (Chapter 2, verse 20) when Krishna advises Arjuna to participate in war, fighting against kin and family.

2. Tagore visited Iran in April 1932, when he was seventy, at the invitation of the Shah. It was his second aeroplane journey and the longest. This essay, "Parosshey", records his thoughts on that long flight as well as his myriad impressions of the stopovers, and his final destination. (Rabindra Rachanabali, Vol. X, The Birth Centenary edition). 


\title{
Sadhanbabu's Friends Science Fiction in Bengal from 1882-1961 \\ DEBJAN I SENG UPTA
}

Lazy servants cause Sadhanbabu's ire. Babu says, "Servants out, robots the answer".

Robot inmate, Babu's in a state, Robot says, "Hey", Babu replies, "Master".

(Limerick by Satyajit Ray)

\begin{abstract}
S cience fiction in Bengal had always been fiction written for children, but not necessarily with childish concerns. The pulp category of SF in the 1920s and 30s in the West, with the vulgarity of titles, covers and blurbs is remarkably absent in the variety in Bangla, probably because of the colonised Bengali's awe and respect for western science and technology. For many of the early practitioners of the genre, science fiction was "the literature of the Technological era". ${ }^{1}$ The first science fiction to be written in Bengal was in the last decades of the $19^{\text {th }}$ century when the effects of the Industrial Revolution were beginning to be felt with the rapid rate of technological change, something noticed in one lifetime. For the urban elite of Calcutta, science stories were a kind of myth formation of the industrial age. Science was perceived as essentially 'Western', an attribute of European civilisation. Here I propose to see how a literary genre, based entirely on premises of science and technology, gained popularity and thereby accommodated Western science into a local worldview. This is very much a part of the intellectual discourse of the late $19^{\text {th }}$ and $20^{\text {th }}$ centuries.

The advent of Western science began in the $19^{\text {th }}$ century in Calcutta with the establishment of the Hindu College in 1817 and the teaching of mathematics, including trigonometry. The earlier contribution of the Asiatic Society (estd. 1784), cannot be denied in developing a scientific spirit as well, although most of its members were Europeans. ${ }^{2}$ One of the students of Hindu College, later called Presidency College, was Akshaykumar Dutta (18201886) who distinguished himself as a rationalist and one of the first writers in Bangla on scientific subjects. Presidency College produced several mathematicians like Gurudas Bannerjee and Ashutosh Mukherjee who earned their livelihoods from law rather than science. Two men who were responsible for an advancement of the scientific temperament in the city were Mahendralal Sircar (1833-1904) and Ashutosh Mukherjee (1864-1924). Sircar
\end{abstract}


was responsible for the establishment of the Indian Association for the Cultivation of Science in 1876. One of the most notable of the scientists of the age was J agadishchandra Bose (1858-1937), Professor of Physics at the Presidency College and a pioneer in the research on electromagnetic waves. The scientific and rational temperament was also aided by the growth of two schools of thought that had taken root in Calcutta - the Derozians had inspired rationality and scientific temperament much beyond their numbers, and the Brahmo movement, though a reformist one, had also inspired a similar creed. In spite of the deficiencies in the teaching and research of science in schools and colleges, science was increasingly gaining popularity among the educated elite. This was because of a rapid mechanisation of English businesses by the 1880s that led to a growing desire amongst the colonised Bengali to master these alien technologies and sciences, perceived as a remedy against superstitions and ignorance, and a way in which modernity could be mastered and understood. Economic factors and technological progresses interacted and interpenetrated in a variety of ways. This in turn affected the way people began to perceive the world around them. The interface between science, technology and culture could be duly seen reflected in literature. ${ }^{3}$

Asimov's statement that "true science fiction could not really exist until people understood the rationalism of science and began to use it with respect in their stories" is actually true for the first science fiction written in Bangla. This was Hemlal Dutta's Rahashya ("The Mystery") that was published in two installments in 1882 in the pictorial magazine Bigyan Darpan, brought out by Jogendra Sadhu. The story revolved around the protagonist Nagendra's visit to a friend's house, a mansion completely automated and where technology is deified. Automatic doorbell, burglar alarms, brushes that clean suits mechanically are some of the innovations described in the story, and the tone is of wonder at the rapid automation of human lives. Jagadishchandra Bose's story Palatak Tufan ("The Runaway Storm") in 1886 used the rationality of scientific theory to weave a tale of a storm at sea that is controlled by dropping a bottle of hair oil on the waves.

In 1879, Jagadananda Roy, an eminent science writer published Shukra Bhraman ("Travels to J upiter"), though it had been written twenty-two years earlier. This story is of particular interest to literary historians. Jagadananda describes an interstellar journey and visit to another planet. His description of the alien creatures that are seen in Uranus uses evolutionary theory about the origins of man: "They resembled our apes to a large extent. Their bodies were covered with dense black fur. Their heads were larger in comparison with their bodies, limbs sported long nails and they were completely naked". This story was published a decade before H.G. Wells' War of the Worlds (1889) in which Wells describes the aliens from Mars.

Sukumar Roy (1887-1923) was probably inspired by Arthur Conan Doyle's The Lost World when he wrote Heshoram Hushiyarer Diary ("The Diary Of Heshoram Hushiar"). Like Jagadananda, Sukumar was also a prolific writer on scientific and technological subjects explaining natural phenomena or new advances in technology to young readers. Heshoram is quite unlike any science fiction written in the West. It is a spoof on the genre because Sukumar is poking fun at the propensity of the scientist to name things, and that too in longwinded Latin words. He seems to be playing around the fact that names are arbitrarily con- 
ferred upon things by humans for their own convenience, and suggests that the name of a thing may somehow be intrinsically connected to its nature. So the first creature that Heshoram meets in the course of his journey through the Bandakush Mountains is a "gomratharium" (gomra in Bangla means someone of irritable temperament), a creature that sported a long woebegone face and an extremely cross expression. Soon the company comes upon another peculiar animal, not to be found in any textbook of natural sciences. They hear a terrible yowl, a sound between the cries of a "number of kites and owls" and find an animal "that was neither an alligator, nor a snake, nor a fish but resembled to a certain extent all three". His howls make Heshoram name him "Chillanosaurus" (chillano means to shout). Although just an extract, Heshoram Hushiyarer Diary is quite unlike anything written even in Bangla.

Premendra Mitra (1904-1988) was one of Bengal's most famous practitioners of SF. Poet, novelist, short-story writer, he also wrote brilliant and innovative science fiction. He had himself stated that SF not only talked of utopias, but that the best of them were based on firm scientific temperaments and facts. Two of his most well known stories are Piprey Puran ("The Story of the Ants") and Mangalbairi ("The Martian Enemies"). Piprey Puran begins with a dislocation of time from present reality: "This happened many years ago. Everything was strange then... The Earth was beautiful to look at! The ground was covered with soft green grass. Countless varieties of plants sported many hued flowers, and at night the sky was covered with thousands of stars - it was a wonderful sight". This displacement, when our present has become a thing of the past, introduces a comic note in an otherwise sombre story. This future world, now real, is overrun with Ants, huge in size, intelligent and organised. They have defeated the humans in battle, having taken them completely unawares. When humans were busy fighting each other, the Ants had begun their preparations to take over the planet. Six feet tall, they had emerged from their hideouts in the Andes Mountain and had begun their assault in the year 7757. One by one the cities of Peru, Venezuela and Ecuador came down like blocks of cards. A cavalcade of monstrous Ants had completely surrounded the few remaining humans and had annihilated them. The only man who escaped unscathed was Don Perito who escaped to Mexico. He was the first human to describe the destruction wrought by the Ants. Within a few years the Ants had taken over Guyana, Brazil, Bolivia and Argentina. The weapon of mass destruction that they used was a powerful bomb attached to the body of an Ant. They also used advanced technological weapons. In the battle that they waged with the humans, the Ants used a kind of searching, powerful light, somewhat green in colour. This light took away human sight in an instant. Under this onslaught all the nations forgot their enmity and came together to fight the common enemy.

This story of the battle of the Ants and Humans is broken into small sub-sections with first-person narrations. The first narrator is the storyteller who begins the story. Soon it is broken by the diary of Asesh Roy, an explorer who had first seen the Ants in 6757. The third narration is by Señor Sabatini, a famous writer of Rio de Janeiro who describes the third deadly attack by the Ants. The fourth and final narration is by Sukhomoy Sarkar, who was imprisoned by the Ants for five years and who gives the most comprehensive details of the social and economic organisation of the Ants. These breaks in the narrative structure 
create very interesting fissures in an otherwise continuous story. They not only make the impossible appear possible (because of 'eye-witness' accounts), but give a certain detachment to the narrator so as to emphasize the moral of his tale. This moral is to be found in comparing the Ants with humans, in which the humans are perhaps found wanting. The description by Sukhomoy Sarkar of the society of Ants makes this clear. The Ants live in an advanced democracy where there are no differences in wealth. What they do have are Ants of differing abilities. The intelligent Ants provide the scientific and technological know-how and are strategists who look after the state. They are highly advanced compared to humans in knowledge and social structures, and have a strict sense of justice.

The moral that we see in Piprey Puran can also be seen in Mangalbairi. When the Earth is attacked by Martians who poison its entire ecosystem by planting a new kind of seed that grows into a deadly flora that spreads like wildfire, all nations are united to fight this common enemy. "In this hour of danger... the one cause of happiness is that... humans have forgotten enmity as if by some magic. The whole world is united today". In both these stories Mitra hints at a time when the very existence of humans will be endangered, when common flowers and trees will be a thing of the past.

Another of Mitra's theme is the way we use science. Science is often misused out of greed or fear, and the character of Ghanashyam Das (Ghanada) who foils all such attempts is indeed memorable. He first appeared in a story called Mosha ("Mosquito" 1945) in which a mad scientist creates a new strain of mosquito, deadly and invincible. Ghanada's timely appearance saves mankind from this virulent breed. By one slap of his powerful hands Ghanada kills this enemy of man. Ghanada is famous for his tall stories, but this lanky, prankster also appears full of his own brand of courage and curiosity. Ghanada is a personification of Premendra Mitra's humanistic ideology and moral universe. Without greed and scrupulously honest, Ghanada is continually striving to rescue mankind from the apocalyptic failure of science. He is forever getting into escapades that make special demands on his human heart and virtues. He is sometimes outrageous in his tall stories but never unbelievable. This perhaps accounts for the way in which he has occupied a special place in the minds of SF readers in Bengal.

In collections of stories like Ghanadar Galpa ("Stories of Ghanada") and Abar Ghanada ("Ghanada Again") we see this quintessential Bengali travelling to space in search of a Black Hole, or diving under seas to discover the mysterious origin of the universe. Mangal Grahey Ghanada ("Ghanada in Mars") is an unusual novel featuring this uncharacteristic hero because it is one of the few Bengali SF stories that is concerned with gender. Ghanada is forced to travel to Mars with the mad scientist Ludvic where he discovers an even more advanced civilisation than ours. But their sophisticated technology has not stopped the Martians from fighting each other, and the only inhabitants of Mars now are a few Martian females. Ghanada comes to their rescue. In order to save their race he leaves behind Batukeshwar, the servant of a friend, exiling him to Mars for a good cause. The motif of the faithful retainer, seen in this story as well as in others, are pointers to the class relations in the real world. The working of power within these relations creates a subtext in which these stories can be read.

Two other contemporaries of Mitra who became popular SF writers in the 1940s and 
50s were Hemendrakumar Roy and Khitindranarayan Bhattacharya. Roy's Kacher Coffin ("The Glass Coffin") and Amanushik Manush ("The Super Human") have racy narratives and utopian visions. Chandrasen - the protagonist in Amanushik Manush - after years of experiments creates a breed of super humans who describe themselves in these terms: We are not incomplete or disabled like you. Our minds are not serving our bodies, they rule over them. We do not possess a single bone, because they are unnecessary. We can do what we like with this body of ours. Khitindranarayan's Akasher Galpa ("The Story of the Sky"), Luptodhan ("The Hidden Treasure") and Dhumketu ("The Meteor") are remarkable in their imaginative use of scientific facts. He states categorically that a science fiction writer does not simply evoke the curiosity of his readers, he "is also responsible to make them scientific minded, attract them to the magical powers of science so that they begin to respect it". ${ }^{4}$ This view is consistent with the ways in which science fiction was often used by some of these writers as a didactic means of mediating modern science and disseminating knowledge, similar to certain conceptions of science fiction prevalent in the West.

Satyajit Ray created Professor Shanku in 1961. The first SF featuring this eccentric hero was written for the magazine Sandesh and was called Byomjatrir Diary ("The Diary of the Space Traveller"). All thirtyeight complete and two incomplete diaries (the last one came out in 1992) narrate the fantastic world of Shanku's adventures, inventions and travels. Most of these stories are more than science fiction. They are also travelogues, fantasy tales, tales of adventure and romance. As a fictional character Professor Shanku is tremendously real. He is courageous yet forgetful, inquisitive yet self-controlled. His sense of humour makes him peculiarly human and his list of inventions is impressive. Anhihiline, Miracural, Omniscope, Snuffgun, Mangorange, Camerapid, Linguagraph - the list is long and impressive. Some are drugs, some gadgets, some machines, but they all have human purposes and use. None are allowed to reign over or be more powerful than the human mind and heart that invented them. Some of Shanku's machines take on human characteristics and are transformed from mere machines to the companions that humans have always craved for. This is amply illustrated in the very first diary. It starts by describing his efforts to build a rocket. The first one that he had built was unsuccessful and had come down on his neighbour Abinashbabu's radish patch. Abinashbabu had no sympathy for Shanku; science and scientists made him yawn. He would come up to Shanku and urge him to set off the rocket for Diwali so that the neighbourhood children could be suitably entertained. Shanku wants to punish this levity and drops his latest invention in his guest's tea. This is a small pill, made after the fashion of the Jimbhranastra described in the Mahabharata. This pill does not only make one yawn, it makes one see nightmares. Before giving a dose to his neighbour, Shanku had tried a quarter bit on himself. In the morning, half of his beard had turned grey from the effect of his dreams. Shanku's world is a real world, a human world. In his preparations for the space journey he has decided to take his cat Newton with him. For that he has invented a fish-pill. "Today I tested the fish-pill by leaving it next to a piece of fish. Newton ate the pill. No more problems! Now all I have to do is make his suit and helmet". Two more of Shanku's companions in his space travel will be

We are not incomplete or disabled like you. Our minds are not serving our bodies, they rule over them. We do not possess a single bone, because they are unnecessary. We can do what we like with this body of ours. 
Prahlad and Bidhusekhar. Prahlad has been his servant for twenty-seven years. Unintelligent but loyal, unimaginative but brave, Prahlad will make a good companion because Shanku believes those qualities will be useful in an emergency. Bidhusekhar is Shanku's robot. The first entry on him is worth a longer look.

"For the last few days I can hear Bidhusekhar making a 'ga-ga' sound. This is strange in itself because he is not supposed to utter a sound. He is a machine, he must do whatever he is told, the only sound that he is supposed to make is the clang of metals when he moves... I know he has no ability to think nor does he possess any intelligence. But now I can see a difference in him". Shanku then goes on to describe how he had tried to invent a new compound as a material for his rocket. He had mixed mushroom, snakeskin and the egg-shell of a tortoise and just when he was about to mix Tantrum Boropacsinate, he had heard a great din behind him. He saw Bidhusekhar shaking his head vigorously as if he was saying "No". Every time Shanku picked up Tantrum the same clatter ensued. When he decided to try another chemical called Velosilica, Bidhusekhar started nodding his head in agreement. That his robot had unimaginable human characteristics became evident to Shanku another time when he made Prahlad wear his spacesuit. "Today I called Prahlad to the laboratory to try out his suit and his helmet. He was in splits. To say the truth even I felt like laughing at this sight as well as his mannerisms. J ust at this moment I heard a metallic guffaw and turned to see Bidhusekhar sitting in his chair swaying and making a new sound. There can be only one meaning to that sound. Bidhusekhar was also laughing at Prahlad".

Most of Ray's intended audience was undoubtedly young readers. This was not a limitation as some SF practitioners have thought. The poet and SF writer Thomas M. Disch has propounded that most of what was "radically wrong with science fiction, as well as a good part of what was right" was that SF was a branch of children's literature. It operated under certain limitations, "intellectually, emotionally, and morally" because children remained outside certain "crucial aspects of adult experience... such as sex and love... the nature of the class system and the real exercise of power within that system". ${ }^{5}$ Disch goes on to state that genre fiction is shaped more by the demands of the audience than by the creative will of its writers.

Mitra's tales of extraterrestrial Martians as well as Ray's fictional narrative of Shanku's exploits are actually the exact reverse of these theorisations. Although hugely popular and often bestsellers, both these writers express a certain world-view through their fiction that is an integral part of how science is decimated and often looked at in the public domain in Bengal. Science is both a 'narrative of progress', a sign of modernity during the period of colonisation, and also a creator of a space in which a critique of modernity can be accommodated. This adjustment of science and scientific temperament can be seen in the profusion of articles and essays on science that were written during colonial times. But in the genre of SF at least we see a critique of Western science and 'progress'. The eccentric Professor Shanku's adventures point at one truth again and again. Machines must serve humans, and not the other way round. Talent is all very well, but that talent must be nurtured by society or it imposes a terrible burden on the bearer.

In the story Professor Shanku O Khoka ("Professor Shanku and The Boy") we see an appraisal of science and society that is extremely satirical. The Boy, a four-year-old child of 
a post-office clerk, is a prodigy. He became one after he fell and hurt his head. Professor Shanku is amazed at his extraordinary knowledge of mathematics, geography, anatomy and physics. He is able to speak of Einstein's equation, Shanku's polar rebellion theory, name the highest mountain in the world and recite Hamlet's famous monologue. This ability however makes him a sensation overnight much to Shanku's disgust. People flock to see the child prodigy and things become uncontrollable when the child himself decides to put an end to it. He creeps down to Shanku's laboratory one night and drinks a portion of Anhihilin, a deadly acid discovered by Shanku. He does not die but falls into a deep sleep. When the boy wakes he is a normal four-year-old asking for his mother.

A comparison between the science fiction of Maharashtra and of Bengal might be interesting here. Like many of the stories written in Marathi, the SF tales in Bangla have a male scientist as narrator. Both literatures use the stereotype of a lonesome individual in the service of science. But unlike the Marathi counterpart, the heroes in Bangla do not exist in social isolation: they have no wife or family but they have pets, friends, neighbours and colleagues with whom they interact. There is also another point of difference between Marathi and Bangla science fiction writing. The world of the scientist, unlike the one in Marathi, is not "sterilised and remystified". ${ }^{6}$ It is a world where a robot is called lovingly by name and accorded the status of a friend. It is a world accessible to its young readers, a utopian world full of possibilities, and real in its human concerns.

\section{NOTES}

1. Campbell, J ohn W.'s Introduction to his The Astounding Science Fiction Anthology (1952). The lone exception was Radhanath Sikdar (1813-1870) a Derozian and a mathematician.

2. I am indebted to some of the essays in Chattopadhyaya, D.P. Science, Technology, Philosophy and Culture (Project of History of Indian Science Vol. 6, 1996).

3. Quoted in Bal, Robin Banglay Bigyan Charcha (Shomila Press, 1999, Kolkata) p. 52; translation mine.

4. Quoted in Broderick, Damien Reading by Starlight: Postmodern Science Fiction (Routledge, 1995, London) p. 8.

5. Harder, Hans "Indian and International: Some Examples Of Marathi Science Fiction Writing" (in South Asia Research Vol. 21, No. 1 Sage, 2001, New Delhi).

6. All translations of Bangla texts are mine.

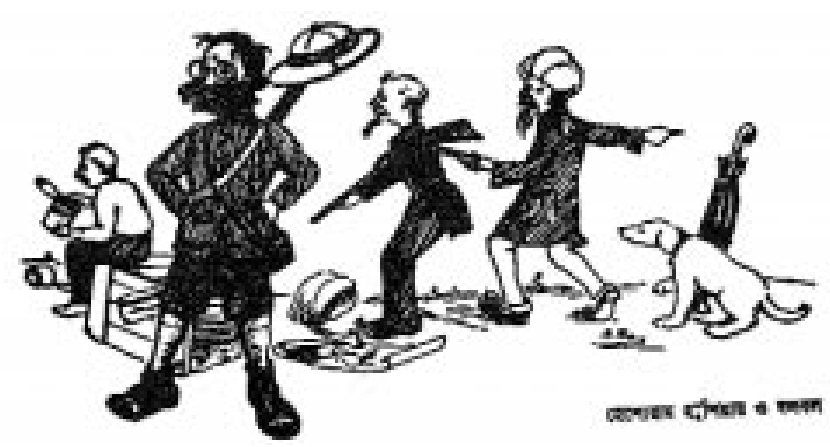




\section{Acoustic Excavations Soundings in the Ranigumpha Caves}

UMA SHANKAR

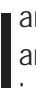

am a sound recordist. Have been one for about 30 years now. A sound recordist with an interest in technology, who had been building equipment and microphones for use in his work and fiddling with computers (with an Apple II and then with the inevitable PCs). I was asked six years ago to measure the acoustics of an ancient archaeological site. ${ }^{1}$

<Problem one: what does one actually measure?>

I knew it had to include Reverberation Time (RT measured in Sabines), but what else? I was quite sure reverberation time would not tell me very much, and this was an outdoor space where there should be no such thing as reverberation time. I was not even very sure that the site would amount to very much. From childhood, I had been taken and shown pillars that were tuned to musical pitches, whispering halls, echo spaces and had learnt not to be impressed. But one had to try.

$<$ What equipment would I be using?>

I knew acoustic measuring equipment was very expensive and I did not know where I could find any. In any event, even cheap sound cards had more dynamic range than expensive oscilloscopes and I had some faith in the power of well-written programmes using the resources of a personal computer. I had an unregistered shareware version of Cool Edit (version 1.3xx) so I created some files I hoped would be useful: a white noise burst, sine sweeps, and short bursts of pure sine waves at various frequencies.

A home-made mixer, an omni microphone, cables and $66 \mathrm{MHz} 486 \mathrm{PC}$ with a hard disk of about $540 \mathrm{Mb}$. Computer monitor, amplifier and speaker we would rent locally in Bhubaneswar. We hired a local electrician who jumpered the overhead electrical wires to power up the computer, and borrowed a bench from a nearby tea stall. We made quite a few measurements, with the mike in all the possible places I could think of, but ran out of hard disk space in one night. But one had heard the acoustics of this space, and one knew this was not enough. The place was immensely noisy with crowds, monkeys, tea stalls, temples and a heavily travelled highway, but after midnight the quiet was uncanny. 
$<$ The real odyssey began when I got home. What do you do with the measurements?> I knew my measurements were crude, but good enough to support my saying the acoustics of this space were very good, and generally a genuine surprise. But what else? I remembered an old article in the Wireless World which spoke of computer modelling of yet-to-be-built theatres to simulate their sound, and I thought that might be a good way of studying such spaces. I knew Bose Corporation was an early pioneer of this modelling, but not much else.

It was also the beginning of Internet in India, so I started looking for acoustics, for acoustic modelling and any search phrase that looked possible. I learnt that acoustic modelling was coming of age, its predictions were becoming useful and also that at least one major programme could be downloaded as a demo. ${ }^{2}$

In J une last year, five years after our first trips, I went back to Ranigumpha with a laptop with new software that would generate measurements instantaneously, and with a vague sense of disquiet. I wondered, "Did I imagine the sound of Ranighumpha - reconstructed and reinforced in memory - or did it really sound that good?"

One handclap standing on the stage, and it was all quite real. ${ }^{3}$

So now to what we are saying.

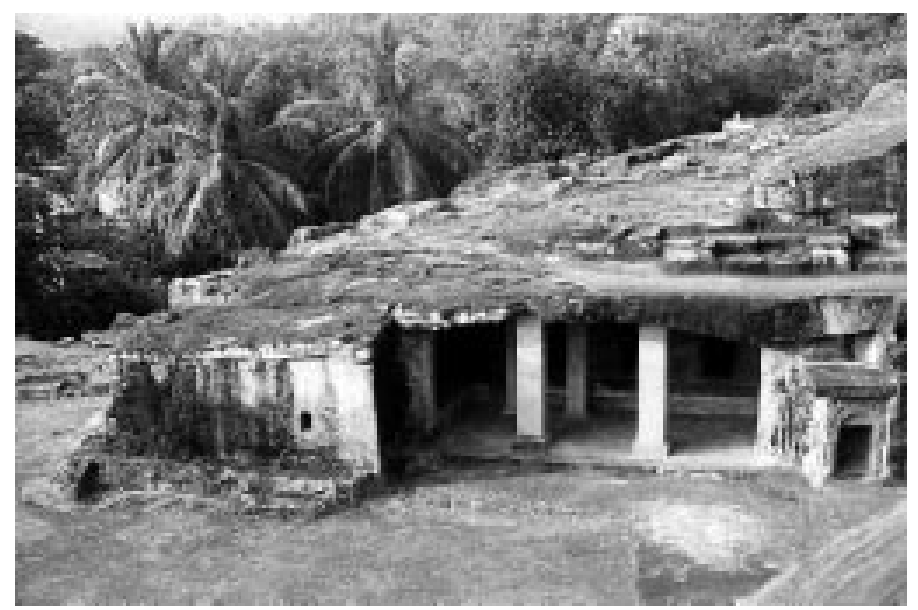

$<$ A third-century BC theatre in India $>$

Rani Gumpha is the current local name given to the largest structure in a group of excavated caves called Khandagiri, very close to Orissa's state capital Bhubaneswar. The structure dates to about the $2^{\text {nd }}$ or $3^{\text {rd }}$ century BC, the period just after Ashoka.

In Indian archaeological terms, it is a very early site and represents an important transitional period in the country's history. A long period of Greek influence on the western side 
of India had begun to ebb after Alexander's conquest and in the rise and decline of the Mauryas India had seen its first nation-wide empire.

It is an interesting site because it has no apparent religious function. It is very richly carved: an elaborate two-storey structure with evidence of a considerable amount of woodwork which decayed long ago.

In particular, there seems to have been a large wooden deck or platform extending in front of the first floor. And the flat space in front of the structure can accommodate $a$ large audience.

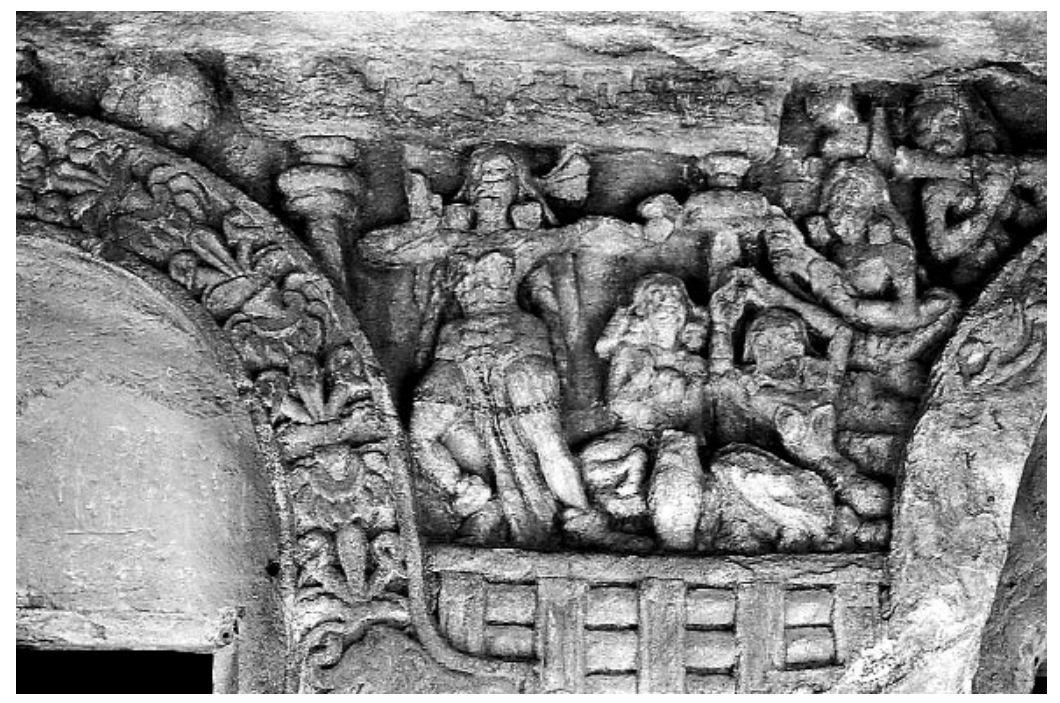

$<$ Could this have been a theatre? Or at least, some kind of a performance space?> The suggestion has been put forward before, notably by Percy Brown, art historian, and Dhiren Dash, theatre activist from the region. But the general explanation, offered by the Archaeological Survey of India and others, has been that these were just another set of caves set apart for meditation. ${ }^{4}$

The elaborate carving in a series of friezes suggests a narrative of some sorts, but no one has yet tried to link the images to any of the known epics or ancient stories. There are images of dancers performing in front of a seated personage, who could be a king. The treatment of the space on which the dancer stands - and this decoration is repeated all along the frieze - suggests the kind of wooden platform that extended in front and was dense and heavy, built up from many thick-hewn logs.

The structure is also very complex, with many small spaces connected with narrow openings, which seem to have no real function; as well as curved floors and rear walls.

Most remarkable of all are the acoustics of this space. It does not have the kind of unusual acoustics frequently associated with archaeological sites, no odd echos, no whis- 
pering spaces. But if you stand and speak anywhere in the performance area, you can be heard all along the audience space. A much louder sound than you would expect, very clear and detailed, with just enough hint of reverberation to provide body to the sound. Certainly not the kind of sound you would expect in an outdoor space. Remarkably, this effect disappears just a foot or two away from the performance space. ${ }^{5}$

It is now over six years since we started on this project, to measure the acoustics of Ranigumpha, and build a computer model to evaluate its properties. We now have a nearly complete model of the structure, built under CATT acoustic software. ${ }^{6}$ There are two ver-

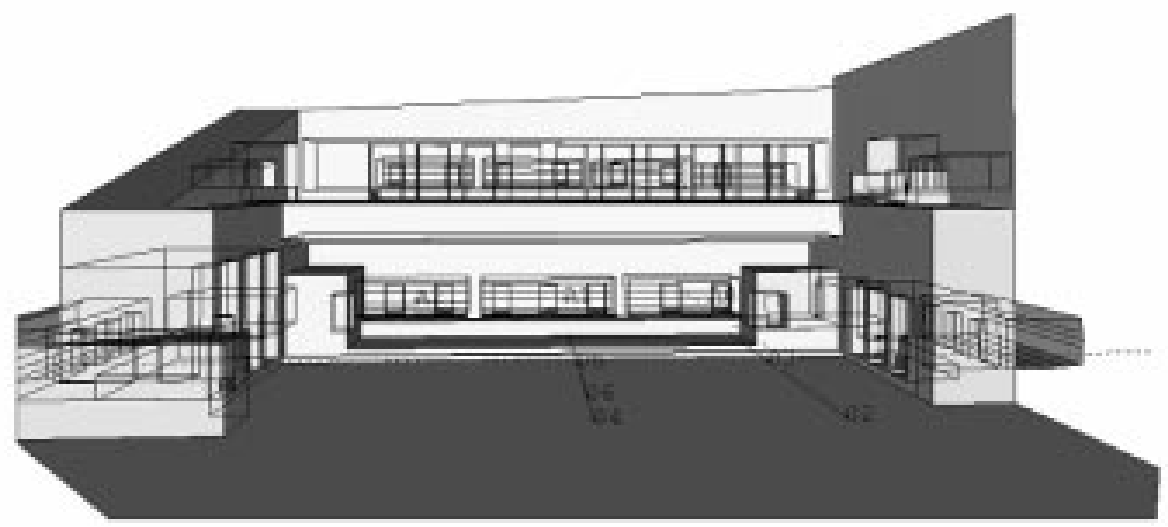

sions of this model, one with a wooden stage extension that no longer exists and the second without. Other models, removing and modifying various elements of this very complex structure, will also be built. A new set of acoustic measurements were carried out in J une last year, using a combination of new software and a portable kit that can be useful in many remote and inaccessible locations. Primarily, the measurements go to confirm the aural quality of this space: putting numbers on the extraordinary quality of the sound that anyone can hear.

We have simultaneously been building an acoustic model of the structure using CATT acoustic software and comparing the results generated by the model with those obtained at the site.

There are several reasons for building this model. First, one can separate the complex of interactions in the structure to try to define which parts of the building provide which elements of the sound. A second, more fascinating, proposal is the modification of the struc- 


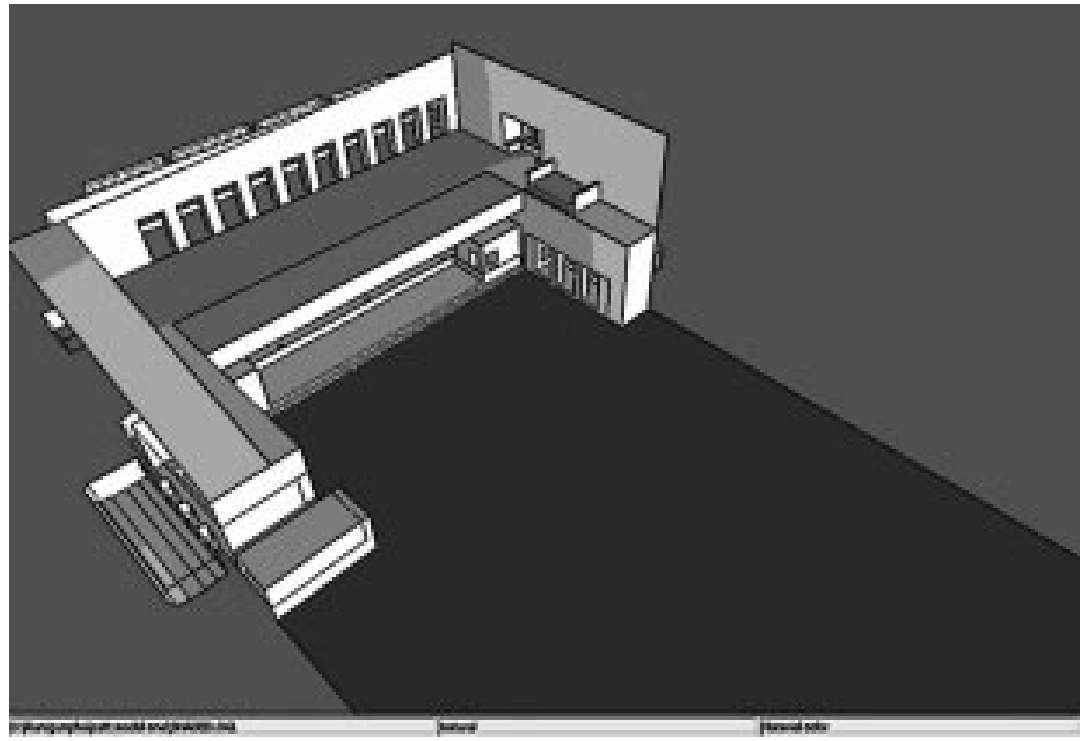

ture. Ranigumpha was carved out of rock. By simulating this process in the model, carving the structure again, step by step, we should be able evaluate the acoustic properties of the structure in the intermediate stages, all the way to completion.

We think the builders of Ranigumpha proceeded the way a maker of musical instruments does. The shape of the structure was predetermined, but the fine details were determined by the sound they heard from the structure. The builders stopped excavating further when the sound came out right. By building this structure again, and listening to its sound, one might learn something of the aural acuity of its builders.

We are not proposing that the builders of Ranigumpha (or other ancient sites in India and elsewhere in the world) possessed better hearing than us, or that they had early and better version of acoustics. What they did have to their advantage was an acoustic environment that was just very much quieter. No machinery noise, no traffic, not even too many humans!

Reverberation tails that now disappear into the general background noise, small changes in colouration, would have been very much more obvious then.

There are a few uncertainties regarding this model; in particular, we are not certain of the acoustic properties of the material used, a kind of sandstone that has, over two millennia of exposure, turned porous and crumbly.

Nevertheless, the model does reflect fairly well the acoustic properties of the site; in particular, the change in acoustic from on-stage to off-stage. 
In terms of the CATT model of Ranigumpha, we hope to elicit responses from musicians, musicologists and other scholars. We are also planning to improve the measurement kit a little more to produce more reliable and repeatable acoustic measurements of ancient sites, and use this to measure several more possible sites in India. In the long run, we hope to address some major puzzles in India's cultural history.

Beginning from the $5^{\text {th }}$ century $B C$, there are numerous references in Indian literature to theatre, actors, and performances. Panini's fifth-century BC grammer uses the speech of actors to illustrate grammatical structures. The Kamasutra (second century BC) sets out in detail the responsibilities of a citizen (nagarika) towards actors and their maintenance. Bharata's Natyasastra, compiled between the third century BC and the third century AD, is the world's oldest manual on theatre. It is also very comprehensive, beginning with the construction of theatres and going on to forms of theatre, dance, music, poetry and figures of speech.

$<$ But where are the theatres? $>$

In all the countless monuments excavated and preserved in India, only two have been tentatively identified as 'theatres', and these definitions have not been universally accepted. We have been measuring and modelling one of the two sites, and we plan to extend this to the other possible theatre sites at Sitabenga in Ramgarh hills. ${ }^{7}$

Our aim is to measure and model the acoustic properties of as many early sites as possible (by early we mean the period between $3^{\text {rd }}$ century $B C$ to $3^{\text {rd }}$ century $A D$ ). We do not wish to suggest that acoustics will completely answer one of the puzzles of archaeology, but we do hope it will provide clues.

Research in the last fifteen years are so has begun to unveil a fascinating chapter. The period is around the fifth century $B C$, when religion transformed itself from Vedic Hinduism to a system of more universal appeal, from esoteric rituals of sacrifice to public and popular worship and prayer. At least one author writing of this period suggests that theater played a mediating role in this transition, and the first representations of gods in fact occur not as stone images but as masked and painted actors. She also suggests that the reason no theatres have been found so far is because we have looked for the wrong kind of structures. ${ }^{8}$

Perhaps a deeper appreciation of the role acoustics might have played in the structures built in this period would help in this search.

Photos and drawings by Uma Shankar.

\section{NOTES}

1. Dr. C. Thomas Ault, a theatre historian now teaching at the Indiana University of Pennsylvania.

2. By this time, I was sitting in in Dr Ault's house in the US, more for undisturbed peace than for technological assistance. I met Dr. Leo Beranek in Boston, as well as students and professors of anthropology, archaeology, and ancient mathematics at Brown University. I also made contact with the Acoustical Society of America, where David Lubman was trying to organise the first special session on ancient acoustics. Meanwhile, Dr. Angelo Farina of the University of Parma offered free software and to check my measurements. He also offered to publish a joint paper on the subject. Dr. Bengt Ing Dalenbeck, author of the modelling software, got 
in touch and asked to look at my model so he could evaluate it. ( I wonder if anything at all would have happened without the Internet? These, and other people I have never met, have genuinely been my collaborators in this project.)

3. With new measurements, with the completed acoustic model, Dr. Ault and I went to Mexico for a new session of ancient acoustics. This is a brand new science, but we now have a large group of 25-50 people interested in it. We also have at least some tools, and the first book in this discipline (Devereux, Paul Stone Age Soundtracks: The Acoustic Archaeology of Ancient) has been published; and we even had the press interviewing some of us!

4. A major inscription in one of the caves at this site, Hathi Gumpha, links it to King Kharavela of Kalinga. Many of the words in the Hathi Gumpha inscription are effaced and there is considerable disagreement about their meaning. The following does come through:

From line 5 we learn:

"Expert in the Gandharva Veda, or in all histrionic arts himself, Kharavela arranged the entertainment of his citizens, items such as Dapa (combats), Nata (dance), Gita (vocal music), Vadita (orchestral music), Usaba (festivals) and Samaja (plays)."

Line 13 informs us that:

"Kharavela built in his kingdom Vithi (roads), Jatara (theatre), Paligkhani (canals), Gopurani (gates), Siharani (temples), etc."

In line 16 we are told:

"(His majesty) revived the Tauryatrika (performance of song, dance and concert) included in the sixty-four branches of art, which had been suspended during the time of the Mauryas."

5. Ranigumpha is one of a number of ancient performance spaces in India. Theodore Bloch was the first to comment on these spaces in his report to the Archaeological Survey of India. In 1884, he identified the performance spaces at the Sita Benga and Yogi Mara caves just outside Ramgarh and noted Greek influence in the configuration of the seating arrangement. Commenting on Khandagiri, Bloch said: "As a matter of fact, we find traces of dramatic representation in the cave inscriptions of Nasik during the time of Siri Pulamai ( $2^{\text {nd }}$ century A.D) and in the Hathi Gumpha inscriptions of Kharavela of Kalinga" (Bloch, 1917).

6. www.catt.se

7. As I write this paper, I have just heard there is a book out on the theatre at Ramgarh.

8. Lidova, Natalia Drama and Ritual in Early Hinduism (Motilal Banarasidas, 1994, Delhi). 

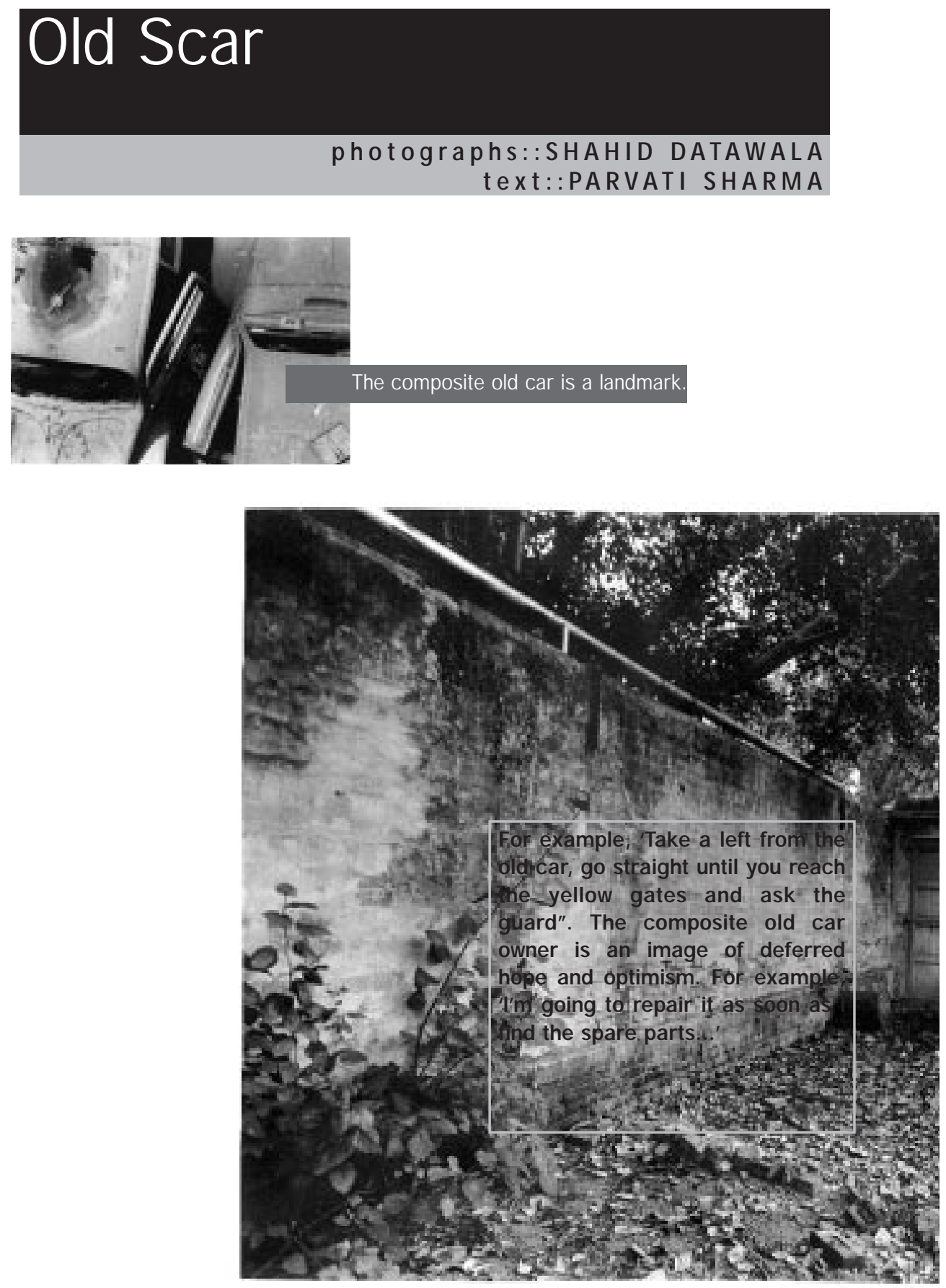
Old cars live in the imagination of their owners,

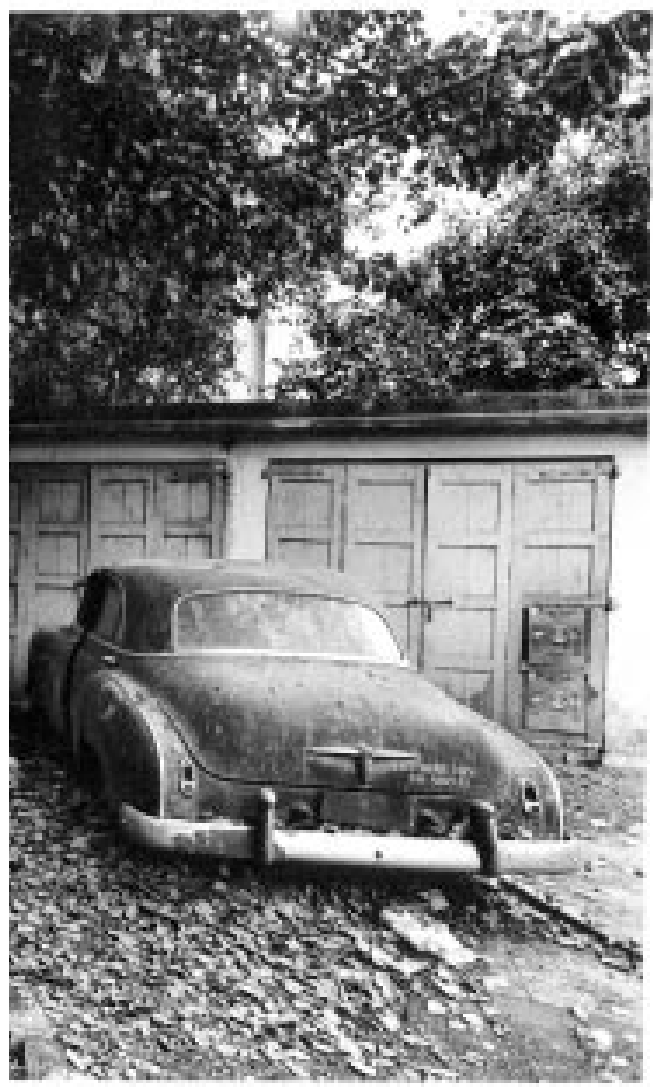

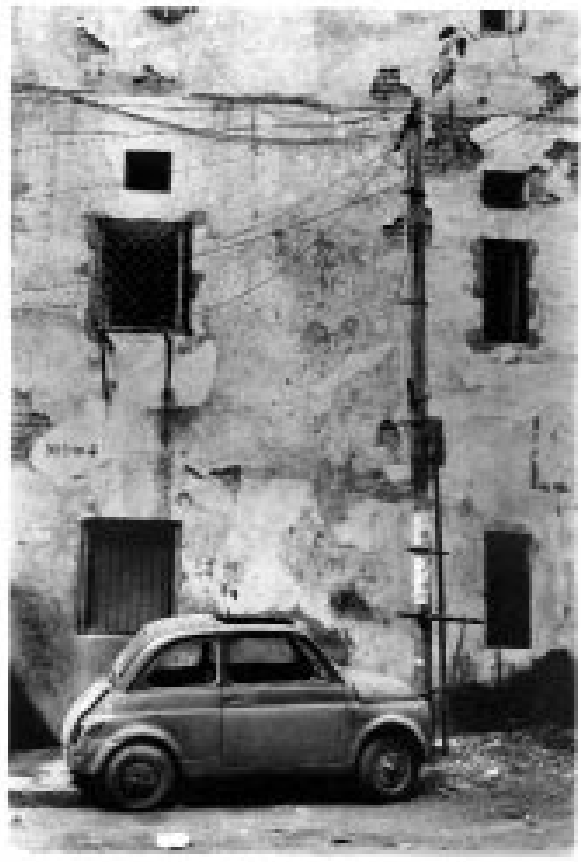

and the owners can live in an imagination like this:
Sometimes they are institutions, and their collective memory amounts to scrap; the old car abandoned to its fate in a forgotten corner, its best hope a whimsical bureaucrat or manager who may set an entire department in its service to restore its original circumstance. This does not happen too often. 


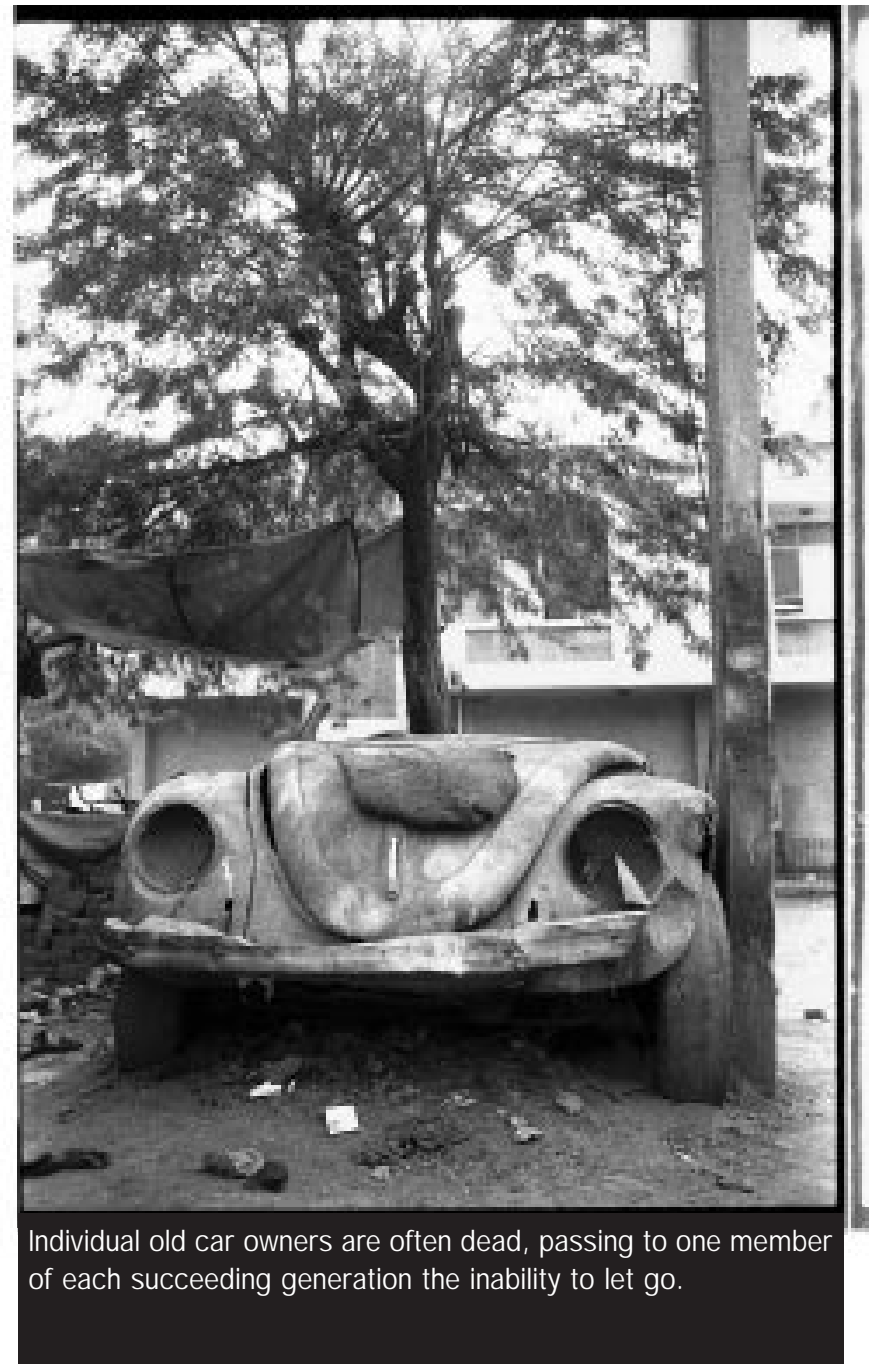

This can translate into the belief that the old car is immortal, and that peeling paint, rusty engine, torn bonnet and a family of rats living under the back seat are merely illusory indications of decay the essential grandeur of its conception and design having survived so many years, it no longer requires a full set of wheels to prop it up. 
For the old car owner, the car is a legend; and the person who has not junked it is participating in an epic debate between things that are useless and things that are useful, between preserving memory and letting memories grow old, between accusations and a stubborn refusal to defend oneself outside the realm of the absurd, between "Fix the car!" and "As soon as I can find the spare parts..."

In this way, for the old car owner, the old car is a legend: the everyday familiarity of its rust disguises treasure. The more it decays and crumples, the greater its value in a future that becomes, irresolvably, equidistant from its past. The end is a transcendence of obsolescence so much so that the very presence of the old car in a doorless garage is an argument for it to remain in there.

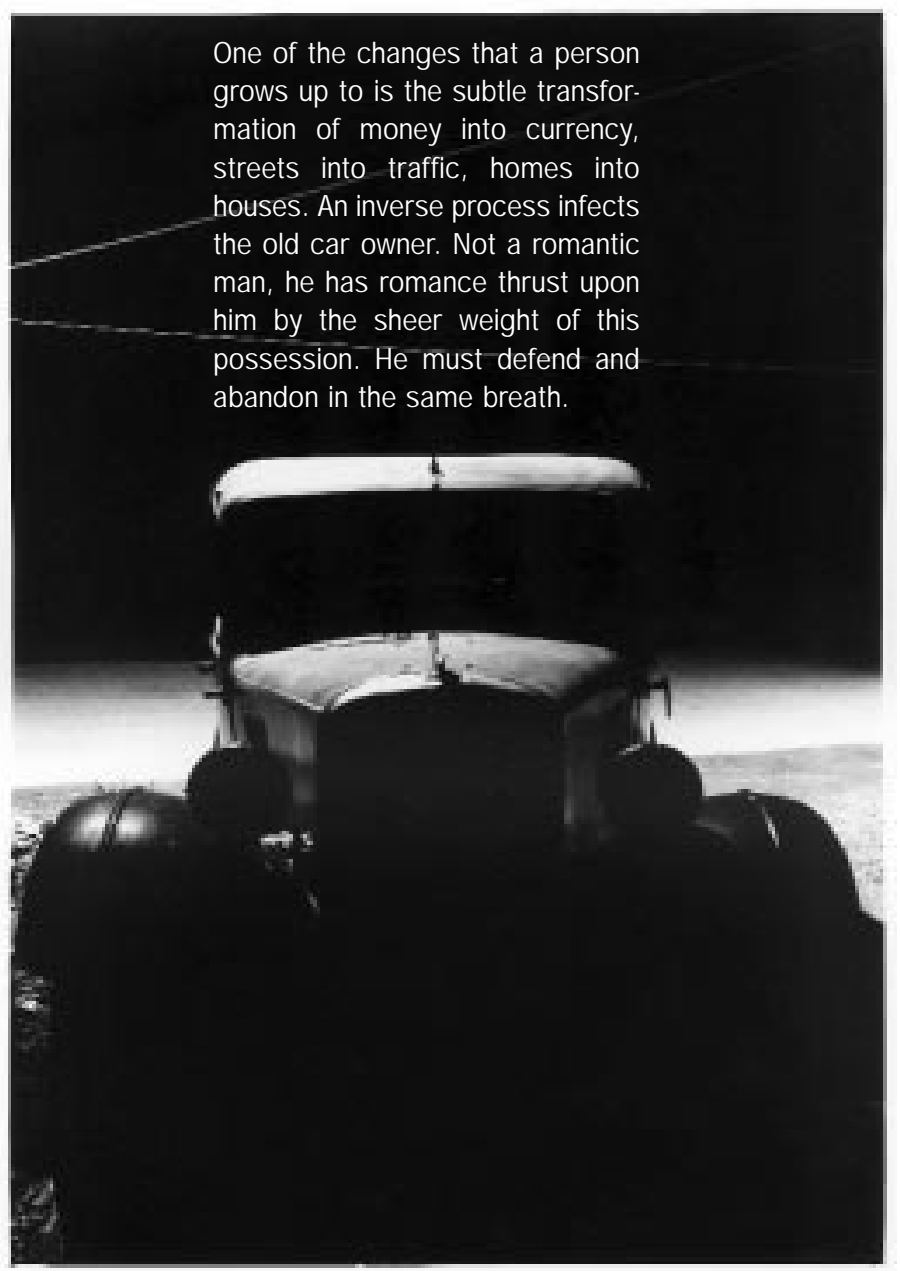




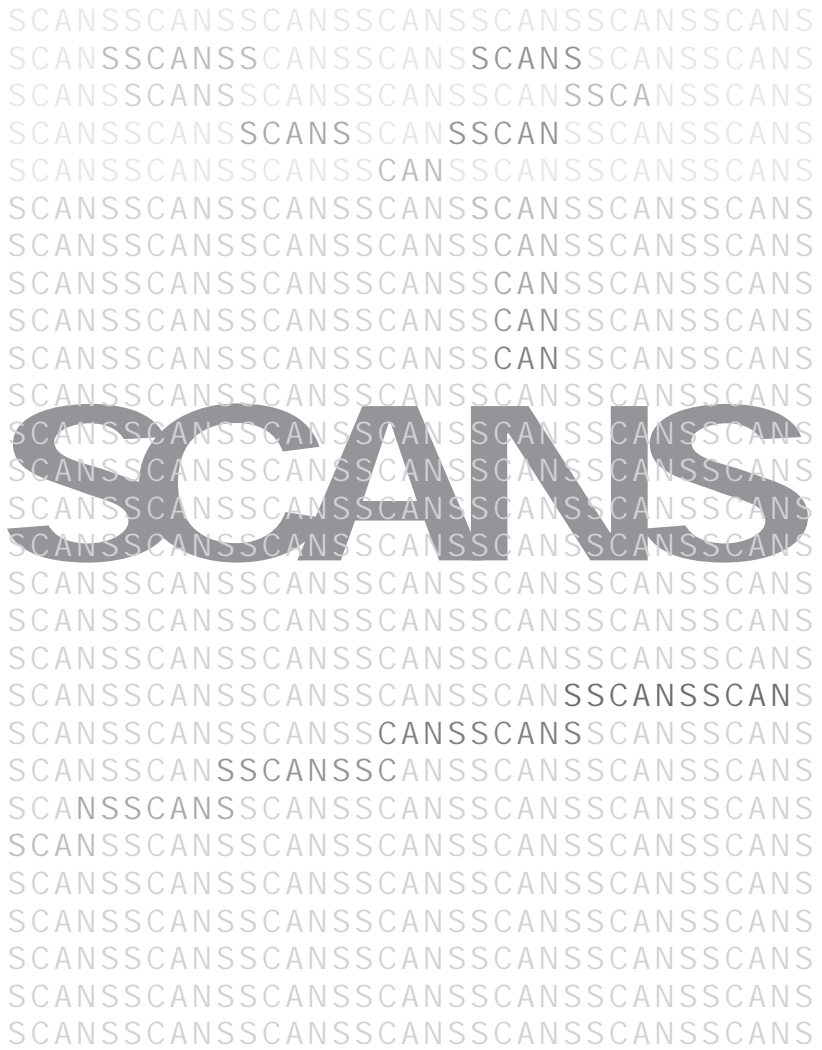




\section{Technologies of Self Poverty and Health in an Urban Setting}

VEENA DAS

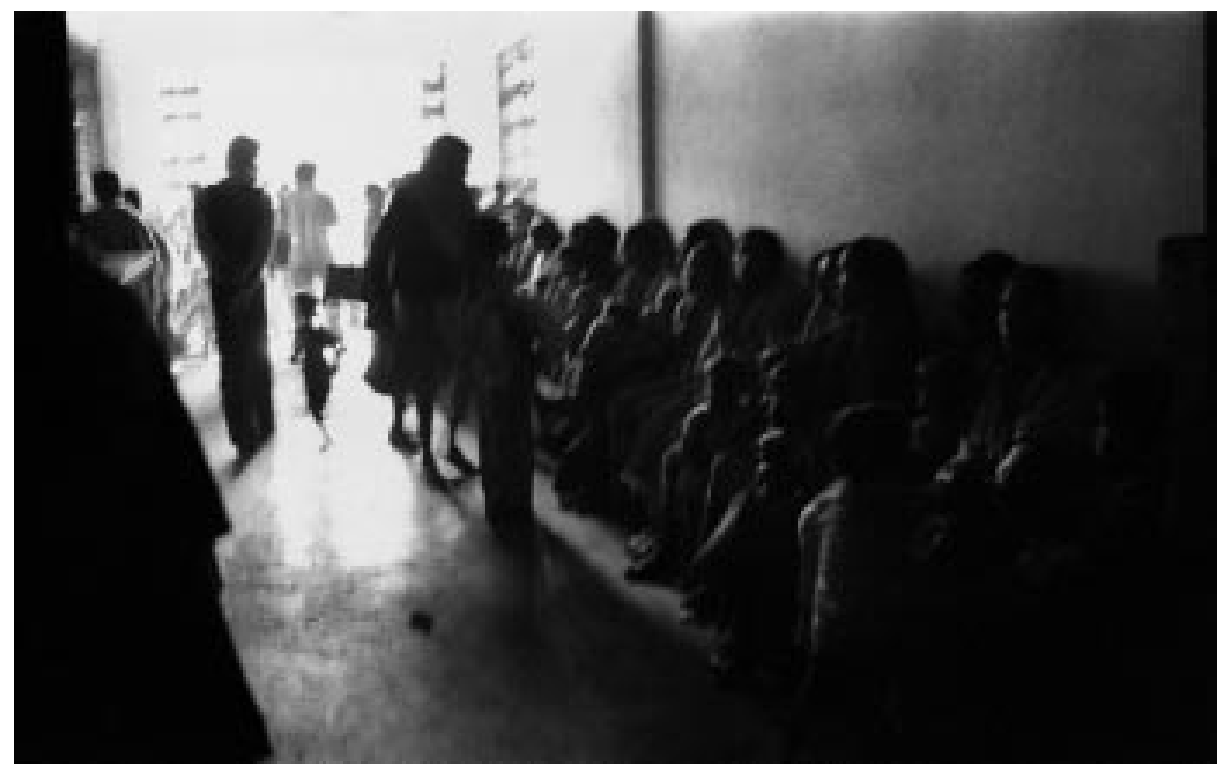

$\mathrm{M}$ ichel Foucault's subtle differentiations between the different forms of writing as examples of the government of oneself offers important insights on the philosophical cultivation of the self. ${ }^{1}$ But can those insights be put into conversation with the search for care in neighbourhoods inhabited by low-income families in the urban milieu of Delhi? In this essay I describe some experiences with illness trajectories and the modes of subjectivity through which questions of belonging and cultivation of the self are addressed in households in one low-income neighbourhood. My ethnography is drawn from an ongoing study of the pathways between urban poverty and health in seven neighbourhoods in Delhi. ${ }^{2}$ While the act of writing is not central to the lives of the people I describe, the specificities in their modes of narration stand out in sharp relief against the kind of questions raised by Foucault on the relation between truth and subjectivity. 
The essay on "self writing" opens with the declaration that "These pages are part of a series of studies on the 'art of oneself', that is on the aesthetics of existence and of the government of oneself and others in Greco-Roman culture during the first two centuries of the Empire" (p. 207). The form that is of interest to me is that of the "correspondence" letters in which information is exchanged on one's activities, successes and failures, good luck or misfortune, but also through which the writer makes himself present to the receiver. An important part of the correspondence was in the form of health reports that included detailed descriptions of body sensations, impressions of malaise and various disorders one might have experienced. The letter was also a way of opening oneself to one's correspondent in the unfolding of everyday life. "To recall one's day, not because of the importance of events that may have marked it, but precisely even though there was nothing about it apart from its being like all others, testifying in this way not to the importance of an activity but to the quality of a mode of being - forms part of the espistolatory practice" (p. 218). Thus the coming into being of the subject happens not at the moment of crisis but in the reflections on how feelings of malaise or experiences of disorder are part of everyday life. And further, the reality of these experiences is testified by making oneself present to the gaze of the other. This conception of subjectivity forged in the workshop of everyday life is quite different from the analytical take in the anthropology of illness narratives that traces the emergence of subjectivity at the critical moment when the body ceases to work. While I do not deny the importance of crisis in generating a discourse that connects the self to the world, I am interested in seeing the working of the ordinary in terms that Foucault's essay opens for us.

\section{>Bhagwanpur Kheda}

One of the distinct features of low-income localities in Delhi in terms of their medical environment is that they are saturated with practitioners from different streams of medical training. ${ }^{3}$ While a genealogical analysis of the various kinds of medical degrees that proliferate in the areas (e.g. MBBS, BAMS, BUMS, BIMS, Ayurveda Ratna, Vaidya Visharad, in addition to RMP or PMP) provides an important insight into the processes of state formation, from the perspective of the households there are two dominant cross-cutting distinctions through which practitioners are classified. The first distinction is between practitioners with certification and those without. The second is between government facilities (sarkari) versus market operated ('private'). ${ }^{4}$ Thus although BAMS (Bachelor of Ayurvedic Medicine and Surgery) and MBBS (Bachelor of Medicine and Bachelor of Surgery) are from the streams of ayurve$d a$ and biomedicine respectively, they are placed in the same category as practitioners with degrees in the narratives of the households, and are distinguished from those without any degree. This may appear surprising to those who assume that the pluralism of medical systems runs across the lines of modern versus traditional medicine, but the households go more by the fact that both kinds of practitioners have degrees and both dispense the same kinds of medicines (analgesics and antibiotics) for sickness. The second distinction (between sarkari and 'private') is embedded in narratives that refer to crowding and the long queues at government dispensaries to receive free consultation and medications. This is contrasted with the convenience of being able to access the 'private' practitioners at any 
time without delays although this is an expensive option. ${ }^{5}$ I would like to tag the fact that state, market and community are present in everyday life - in fact, people's testimonies to their mode of being assume the gaze of the state and the community, although these, as we shall see, are not distinct forms of belonging. The markets around the neighbourhoods are absorbed within the community, for some purposes, and engender brokered forms of sociality, for others.

The literature on the interface between poverty and health had led me to assume that the basic issue in health care for the poor would be the lack of access to practitioners; so I was surprised to see that in fact there was a high incidence of use of practitioners even for minor illnesses such as colds, coughs or headaches. Further, serious illnesses could remain undiagnosed for long periods despite the fact that those who were reporting sick were routinely visiting the practitioners in the locality. To get an idea of the kinds of actions taken consequent upon illness in a particular week consider Table 1, which is based upon data collected in the locality over a sixteen-week period through a weekly morbidity survey, in which the trajectory of illness and of household decision-making was tracked in 40 households with 270 individuals.

Table 1:Patterns of action consequent upon illness reported that week in Bhagwanpur Kheda

\begin{tabular}{|l|c|c|c|}
\hline Action & Frequency & Percent & Cumulative \\
\hline No Action Taken & 319 & 21.75 & 21.75 \\
Practitioner Visit & 508 & 34.63 & 56.30 \\
Consulted Pharmacist & 48 & 03.27 & 59.65 \\
Medicine bought & 389 & 26.52 & 86.16 \\
without Current & & & \\
Prescription & 203 & 13.84 & 86.16 \\
Two or More Actions & & & 100.00 \\
\hline Total & 1467 & 100.00 & \\
\hline
\end{tabular}

As this table shows, out of the 1467 instances of reported sick weeks over a 16-week period, there were only $21.75 \%$ instances when no action was taken that week. In all other cases there was either a visit to a practitioner, or medicines were bought from the pharmacist on the basis of an existing prescription. ${ }^{6}$ Let me now address the question: in the context of the frequent recourse to practitioners, as in Table 1 , how did the narration of illness on different sites become a testimony to modes of being? The coming into being of the urban subject is here suspended between complex negotiations of community, market and state within the life world of the urban poor. 


\section{> One Morning at the Government Dispensary in Bhagwanpur Kheda}

In the course of our work with the practitioners in the area, several members of our research team conducted participant observation with randomly selected practitioners from each locality. This is how I came to be in the government dispensary on a hot J uly morning. The attending physician was sitting on a chair next to which there was a stool for the patient. There was barely any place for me to sit, so I stood near the door watching the interactions between physician and patient. Even at nine in the morning there was a huge queue outside the room in the corridor. Scuffles were breaking out and the physician had to interrupt his consultation by admonishing the crowd from time to time or turning his back to the patient he was seeing and saying that unless some order was restored in the queue outside, he would not see any patient. At this display some self-styled leaders would shush everybody into a queue and ask people to be quiet. I noticed that there was no washbasin to wash hands, no gloves and no instruments such as a thermometer or an instrument to measure blood pressure or a weighing scale. The temperature was touching 40 degrees centigrade - the fan in the room did not work since there was no electricity. I should also note that in two hours that morning the physician attended 104 patients, spending less that one minute per patient, and also that even when clinics (including private ones) were not overcrowded, practitioners in the locality spent an average of two-and-a-half minutes per patient. I describe an encounter to show how the state gets embedded into the narration of illness.

The thirtieth patient to present herself was an old lady reporting symptoms of cough, cold and intermittent bouts of fever. As soon as she sat on the stool reserved for patients and handed over her OPD card, the physician said "Kya bimari hai? - What is the illness?" The woman said "Doctor Sahib, I have fever, cold, cough, I feel weak - I was going to Raju Doctor - the private one - he gave an injection but see Doctor Sahib - what to do, we are poor people - we..." The physician interrupted her in mid-sentence and said, "Have you come here to tell me stories or to get treatment?" Meanwhile he wrote a prescription on her card - as with every other case of cold, cough and fever, he wrote "Caps x TDS x 2". I had already learnt that "Capsule" referred to tetracycline, which was the only antibiotic available in the dispensary that month, and the physician had given the same prescription to every patient with similar symptoms. The woman now folded her hands and said, "Aapki daya hai, sarkar hi to ma-bap hai - it is your beneficence, the government is our mother and father". Again the physician interrupted rudely, "Don't waste my time - I am not here to hear your stories..." Anyway the next patient in line was pressing to enter and so the encounter ended.

A comparison of illness in the correspondence of Seneca (referred to in Foucault's essay with which we began) and the mode of telling here quickly reveals that the voice is thwarted in mid-sentence. The patient has no way to make her story known. She gets the medicine and that is proof for her that her visit has yielded some result. And this, for this patient as for the many others we interviewed, becomes the mode through which the state is present in the life of the subject. Vahan hamari sunvai nahin hai (We are not heard there) is the dominant expression used to refer to one's encounters with government hospitals and dispensaries; yet there is also a sense that one has claims over the state so that when all else fails, the sarkari facilities will be available. 


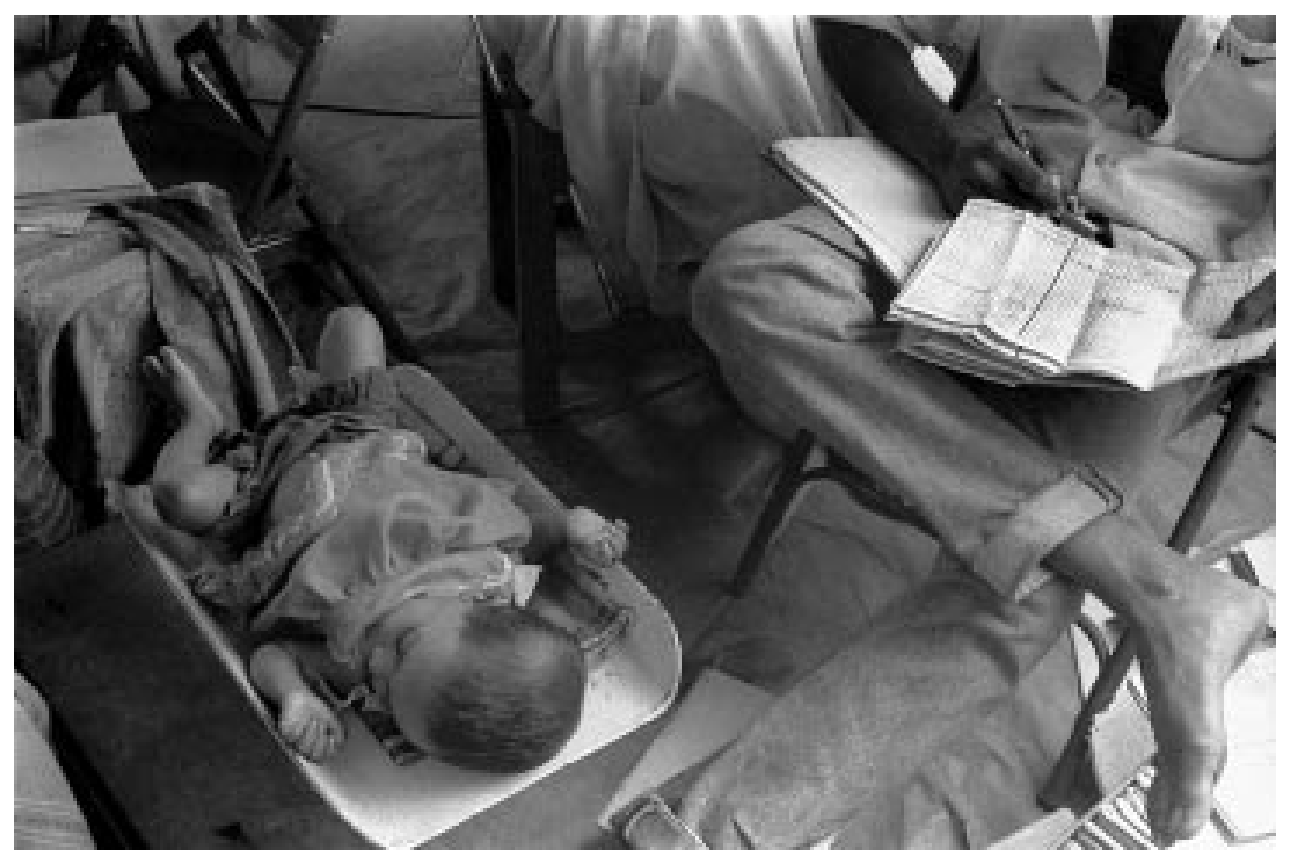

\section{$>$ The Brokered Subject and the Pressure of Voice}

Walking in the streets in Bhagwanpur Kheda one comes across practitioners who have a single room with one telephone and perhaps an oxygen cylinder lying on the side, but whose billboards announce "We also have facilities for MIR, CT SCAN, X RAY, PREGNANCY TESTS". I asked a practitioner who had a degree in integrated medicine (BIMS) where he conducted these tests. He replied that he knew many diagnostic laboratories in the area and, for a commission, he took patients to these facilities. This encounter was indicative of a major role that practitioners in low-income neighbourhoods play in the lives of households - that of brokers to the outside world.

Seventy percent of the illness episodes we recorded in the 16 weeks of the survey in this locality lasted less than one week. In these cases households would go to a local practitioner, or even send a child to pick up medicines. "Bukhar hua tha, dawa le aaye mote dactar se - There was fever, we got the medicine from the fat doctor" is how the explanation would rest.

More than $6 \%$ of the episodes recorded in the 16 weeks, however, lasted three weeks or more. In such cases, faced with life-threatening illnesses, families began to despair of therapy within the local context. The worsening of illness to the point that it became life- 
threatening always led to a search for therapy outside the local into the world of specialists and hospitals, when brokered forms of sociality began to be visible. One form of brokerage was with modern institutions, for which not only the practitioners but also members of kinship and neighbourhood networks acted as intermediaries. Relatives who worked in hospitals as janitors or ward boys figured prominently in stories for their crucial roles in getting admission to hospitals or appointments with an attending physician; the use of these 'contacts', in which the physician was cast in the role of patron, was widely acknowledged. ${ }^{7}$ But while on the one hand relatives were sources of support, their voices were also experienced as lethal - they inserted themselves in the space of the imaginary when the hold over the real was seen to slip. ${ }^{8}$ The following excerpts from an interview conducted by Rajan Singh of the ISERDD health research team with a recovered TB patient show the struggle in authoring the real.

\section{>Sangeeta's Story}

How did you discover you had TB?

I had many problems, a lot of weakness, so much so that it was difficult for me to sit. So you had weakness - did you have any other problem?

No brother, but it was that I did not feel like eating, nothing seemed to interest me, my heart did not engage.

And fever?

Yes there was constant fever, there was also coughing.

For how long did you have this?

Some days, some weeks. See, first I started to take medicines: private [in English] was started.

So, which practitioner did you go to first?

See first medicines from here and there. The local doctor gave medicines - I was not getting better. Then my daughter was born - because I was feeling quite sick, they took me to hospital for the birth (it was my time). ${ }^{9}$ I would feel great pareshani [trouble] in my throat - so they took me to hospital for my throat - initially they roamed here and there [idhar udhar le ke dole]. Then my daughter was born - still I could not eat anything - so then I had gone to my Mummy's place. I could not still eat anything. So Mummy took me to sarkari hospital - there they did an X-Ray - so in the hospital an $X$-Ray was done. Then it was known. So then in the Government Hospital they said I had TB. They told us to go to this TB hospital for medicines.

So you did not have to take any private medicines?

No, first Mummy thought that the private medicines will be better. See there were problems with my throat - there was swelling, difficulty in swallowing, no appetite - so we also had it seen from a private doctor in Mayur Vihar [an upper-middle-class neighbourhood] but there the doctor said, don't worry - it is just a cold, you will get okay - so he gave some medicine but it was very expensive and anyway there was no improvement.

In the next segment of the interview she described how some people said that it was magic or sorcery and they should have it blown away through a diviner or a healer, and how others recommended other private doctors. 
Then my Mummy said that I would just take her to the sarkari hospital - the TB hospital where they had told us to go. She said that she would not listen to anyone. You mean you decided to go to the TB hospital - the one where doctors from the hospital where your daughter was born asked you to go?

Yes, that is the one. People said go here, go there, but Mummy said whatever anyone says - I will take her to that government hospital.

What happened there? Did you get medicines? X-Ray?

Yes, they gave medicine - two tablets a day. The doctor there said that the medicines must be taken. He said you can forget to eat your food but you cannot forget to take your medicine. So my husband did not have time to take me there to get medicines - so I stayed with Mummy.

As the interview progressed Sangeeta described how she managed to overcome the obstacles in the treatment process and completed her therapeutic course.

Towards the end of the interview Rajan asked, almost as a matter of courtesy, "So your daughter who was born at the time that your TB was discovered - is she okay?" No, she died when she was two years old. Everyone said I should not feed her my milk - she became weak. She hardly spoke. See, you have to listen when people say things. I became pregnant again and had a son but he too could not survive.

Did the doctors in the TB hospital advise you not to feed your daughter breast milk - did they tell you anything about what to do when you became pregnant?

No, the doctors did not tell me anything but everyone said that my milk was not good because of the disease.

We can see that the outside space of therapy in this story was made up of a crisscrossing of possibilities. Suggestions and counter-suggestions came from all directions you did not know who to trust. And though Sangeeta managed to complete the anti-TB regime of medication, she could not ignore the advice to withhold milk from her newborn child. The deaths of her two children did not seem to belong to the narrative of TB; which is not to suggest that she did not mourn for her dead children. Yet the overall effect of the story was about the care she received from her mother and the success of the therapy. For Sangeeta, the positive effect came from the fact that she experienced her social relations to have endured through the course of the illness. Such is the face of success.

There were other cases in which though the illness was cured, social relations were not. This entanglement of illness and experiments with forms of sociality are testimony that the relations of an individual to her kinship network, her community or her neighbourhood is not one in which one can be said to belong as, let us say, water belongs to the bottle or clothes belong to the wardrobe. If Seneca's experience with the cultivation of the self, as Foucault records, was through forms of letter-writing that authorised one's relation to oneself in the gaze of the other, the biggest difference in the stories we encountered was in the nature of this gaze. Whether in the embodiment of the state in clinical encounters or in the community whose voices figure so prominently in Sangeeta's story, the gaze of the other is either inverted or punitive - surveying you but always failing to acknowledge you. The dominant metaphor is not of seeing but of hearing. Vahan hamari sunvai nahin thi (We 
102 / Sarai Reader 2003: Shaping Technologies

were not heard) appears to be the opposite of Mummy ne kaha main kisi ki nahin sunungi (Mummy said I will not listen to anyone). But both these forms of attesting to the mode of the everyday show that crises do not lie outside the horizon of the everyday - buried in the everyday they constitutes its eventedness. Such are the stories of hope and despair that line everyday life, within which the subject as a point of contact between the self and the world is forged.

\section{NOTES}

1. Foucault, Michel (Paul Rabinow ed.) Ethics: Subjectivity and Truth (The New Press, 1997, New York).

2. This study is being conducted by the Institute of Socio-Economic Research in Development and Democracy (ISERDD). I am grateful to the entire ISERDD team for the stupendous efforts they have put into this research, and to J ohns Hopkins University for financial support. Most of all, I would like to thank the members of the 300 households who have made us welcome in their homes every week for at least four months of the year, for the last three years.

3. The density of practitioners in these areas can be gauged from the fact that there were 263 practitioners in the four low-income localities in our sample, within 15-minute radii of the sample households, which are clustered in neighbouring streets in the locality.

4. The term 'private' was used in English - the sarkari-private dichotomy was used frequently to refer to various kinds of services ranging from health services, schools, transport to liquor shops.

5. The normal charge for both consultation and medication in the area, regardless of the qualifications of the practitioner, ranges from Rs. 15 to Rs. 30. The normal practice is to dispense medications for one or two days and ask the patient to report again. In those cases when symptoms have persisted or there appears to be a life-threatening condition, the practitioner may prescribe medicines to be bought from the pharmacist or he may advise the patient to go to a more qualified practitioner, or to a hospital.

6. For a detailed examination of this question see Das, Veena and Ranendra K. Das "Pharmaceuticals in urban ecologies: The register of the local" (ISERDD Occasional Paper Series J anuary 2003).

7. Anyone who has worked in institutions in India will recognise that the subordinate staff invariably create narratives in which one is cast in the role of a patron and, depending upon temperament, one ends up lending money to deal with an emergency, negotiating admissions in schools and being pushed towards using one's 'influence' to get jobs for relatives. The boundaries between the formal organisation and its environment run through the organisation like rivers running through a territory.

8. Important evidence of the lethal character of these relationships is to be found in the accusations of magic or sorcery, and in the work of the diviners and healers who deal with the occult. For reasons of space I am unable to take this point for discussion here.

9. Literally "mera time aa gaya tha" (My time had come). 


\section{Intensive Care}

SUMIT RAY

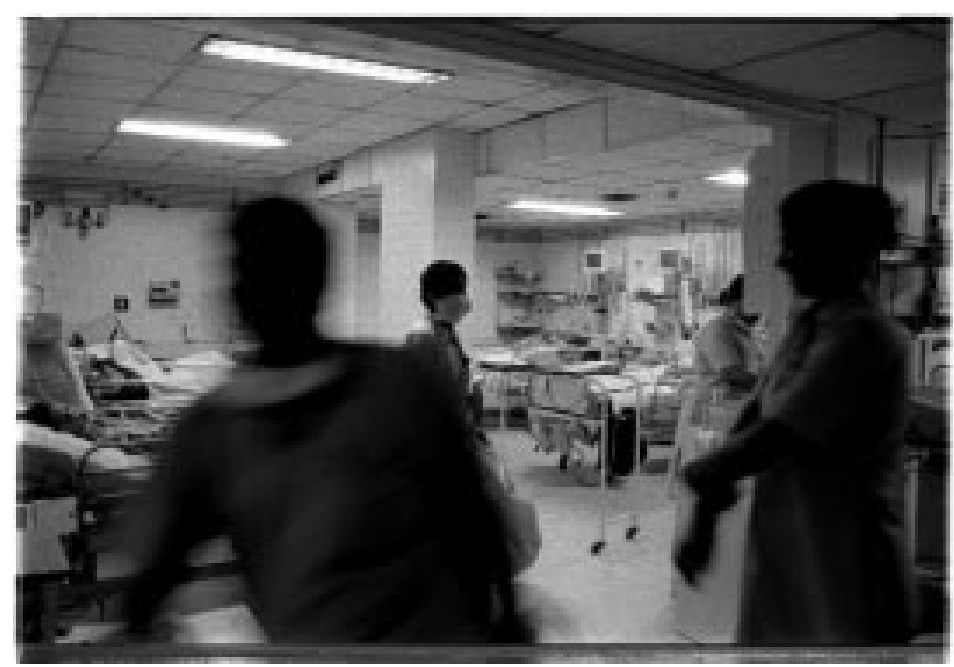

0 ne Friday evening in early December, after trying to recover from the exertions of a night spent in the Intensive Care Unit (ICU) of a big private hospital in Delhi (where I take care of critically ill patients six days a week, about 47 weeks in a year), I walked into a Barista outlet for a cup of coffee and picked up a leading news magazine. One of the main stories in that issue was about this 'new' technique of cardiac surgery which was being introduced in a major cardiac center of the city. The hero of the piece was obviously a very famous cardiac surgeon of the city and country who had trained and worked "extensively" in the US. The article was hard pressed to prove how 'new' the technology was - it had been introduced in the US "just six months back". What was even more interesting for me was that another weekly also carried a very similar article on the same procedure, with very similar points being stressed. Both the articles spoke about how precise the technology was, how the surgeon did not touch the patient at all but operated through very precise robotic arms "which took away the minutest tremors of the surgeon's hands". It spoke about how the incisions were very small compared to the "large incisions and spillage of blood and gore" during conventional open-heart surgery. I am no proponent of the 'old is gold' adage, and I do not doubt that this procedure when mastered actually causes much 
less post-operative pain and discomfort to the patient and possibly requires a somewhat shorter stay in hospital.

However, what is interesting for me as a doctor (who works in the ICU, with a high concentration of modern technology) is how easily a cardiac surgeon, renowned for his fantastic hand skills, was ready to give up that reputation. Instead, the robot had been acknowledged as far more capable of making surgery safe and sure, free from the slightest of tremors. I am very sure that before the introduction of this robotic technique journalists would have been hard pressed to make him accept that his fingers had even the faintest of tremors! But even he, the Indian avatar of the God of Cardiac Surgery, was ready to bow down to the God of Technology and accept his human frailties.

Surprisingly, the article did not raise any questions about this new procedure. Questions about the percentage of patients who have to be taken back for surgery due to complications during the first surgery, about re-blockage of the arteries that were used for the bypass as compared to conventional surgery, and many others. There was an attempt to juxtapose precise sanitised robotic surgery (where the surgeon is "gently humming under his breath") against the confusion and "blood and gore" of conventional surgery - the popular film and television image of the surgeon with an intense expression on his face and the sweat being wiped from his brow by a nurse. Those were the good old days of 'seat of the pants' kind of tough surgery. Does it make me nostalgic or what?

I finished my cup of coffee and walked out of Barista into the bright city lights. I crinkled my eyes against them, squared my shoulders and walked to my car - there I was, the last stand of the clinician against the onslaught of technology! I got into my car and was driving back home when I remembered an earlier incident in the ICU.

It was another night on call, in October. We had our hands full with twenty-two sick patients when I got a call from the Casualty Medical Officer (CMO): a patient who had reached Casualty following a car accident was having difficulty breathing and was sinking. I rushed to the casualty accompanied by my senior resident, Dr. Rakesh Gupta. The accident victim was a well-built man of 28-30 years who had been out driving with his friends when his car banged into a stationary van near India Gate. His friends had escaped with cuts and bruises but he was behind the wheel and had got crushed between the seat and the steering wheel.

When we examined him, his chest was moving in an odd way and his breathing was laboured - seemed like fractured ribs on both sides of the chest. His pulse was very feeble and his blood pressure was just $70 \mathrm{~mm} \mathrm{Hg}$ systolic (normal range is $110-140 \mathrm{~mm} \mathrm{Hg}$ ). ${ }^{1}$ His heart was beating very fast and he was moving in and out of consciousness. He didn't seem to have any major injuries on his face and head - but one couldn't be absolutely sure on cursory examination.

I asked for a spine board to be put under him so that his neck could be kept stable if his neck was broken, any movement could completely paralyse him by injuring his spinal cord. We were giving him oxygen through a mask. A nurse was trying to put in a catheter to infuse him with intravenous fluids as his blood pressure was low and sinking, but she was finding it difficult to find a vein as his blood flow was poor. His heart rate on the Electrocardiograph (ECG) was getting faster and the size of the ECG was getting smaller. There

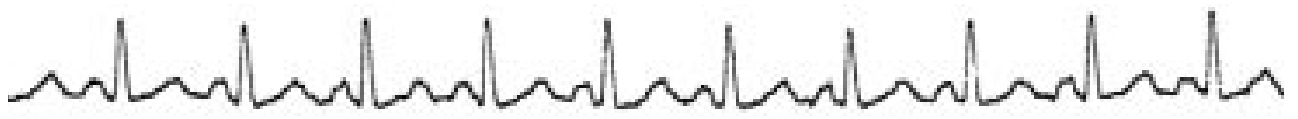


could be two reasons for this - either there was blood in the sac around the heart (i.e. the pericardium) or the fractured ribs had punctured the lungs causing air and blood to collect in the pleura (sac around the lungs), which was pressing on the lungs. This would make it difficult for him to get enough oxygen. The pressure transmitted from the lungs was probably also squeezing the heart, and making it difficult for it to pump.

The heart was further compromised by the lack of blood flowing back to it, and the patient seemed to be losing blood somewhere. All this took about a minute to assess. Rakesh managed to find a vein in the patient's forearm. I asked them to pump fluids into him. We had very little time and very few choices. Either we put a tube down his trachea (wind-pipe) to give him artificial respiration and improve the oxygen levels in his blood, or push two tubes into his chest (chest tubes) on both sides to release the pressure on his lungs and heart. The latter would help the heart pump more easily. Both the procedures had their problems. In the first case, the oxygen leaking out into the pleura due to the artificial respiration through the tracheal tube could increase the pressure on the heart and make it stop. On the other hand, the chest-tubes would take longer to insert and the lack of oxygen during this time could also stop the heart as well as cause brain damage.

The decision was taken out of my hands. Suddenly, the patient took a last desperate gasp and stopped breathing. The pulse-oximeter showed very low oxygen levels and the patient turned blue. ${ }^{2}$ I asked for the AMBU bag to give artificial respiration. I had no choice now but to put in the tracheal tube. As I put in the tracheal tube, I asked Rakesh to push two large-bore I.V. needles into both sides of the patient's chest. That would help release some of the pressure from the heart while I was giving him artificial respiration and buy us time to put in the chest-tubes. I gave him a few small breaths from the AMBU bag - the lungs inflated a little. Then suddenly the ECG became a flat line - Shit! His heart had stopped! The CMO jumped up and began pumping the chest with his hands to keep the heart pumping artificially. Rakesh shouted, "Sir, there is a tamponade, ${ }^{3}$ we need to put in the chest tubes!" "Yes, yes!" What we had feared had happened. Despite the large-bore needles in the chest, the pressure from the artificial respiration had increased the pressure on the heart, already compromised by the lack of blood flowing back to it, and had made it stop.

As Rakesh was preparing to put in the chest-tubes, I stopped giving the patient artificial respiration. The heart was at a standstill and the patient had no respiration. Something had to be done quickly. "Come on Rakesh, the chest-tube." Rakesh was calm and concentrated as he found the right space to shove the chest-tube in - there was a rush of air and blood as the chest-tube slotted into place. "Keep giving cardiac massage!" we shouted to the CMO. "Nurse, adrenaline and atropine intravenous immediately!" I started giving small artificial breaths to the patient. "OK Rakesh, chest-tube on the other side!" Rakesh was cool and unflappable - in one smooth strong movement, he pushed the other chest tube in, another gush of blood and air. Now I could ventilate the lungs much more easily.

Now to get the heart pumping again. "Nurse, another adrenaline and atropine! Pump him with fluids - he is losing blood somewhere!" The ECG monitor showed some activity of the heart, ventricular fibrillation - it had started making small contractions, not enough, but at least there was some electrical activity. "We need to shock him, sir", said Rakesh. I said "200 joules". He put the defibrillator's paddles on the patient's chest, adjusted the energy

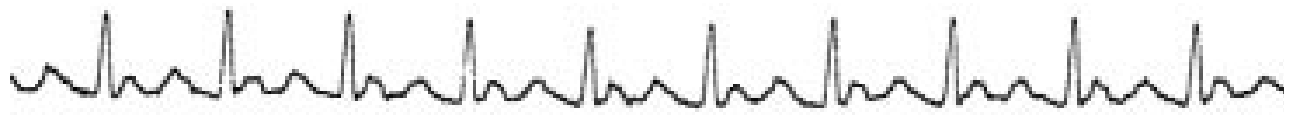



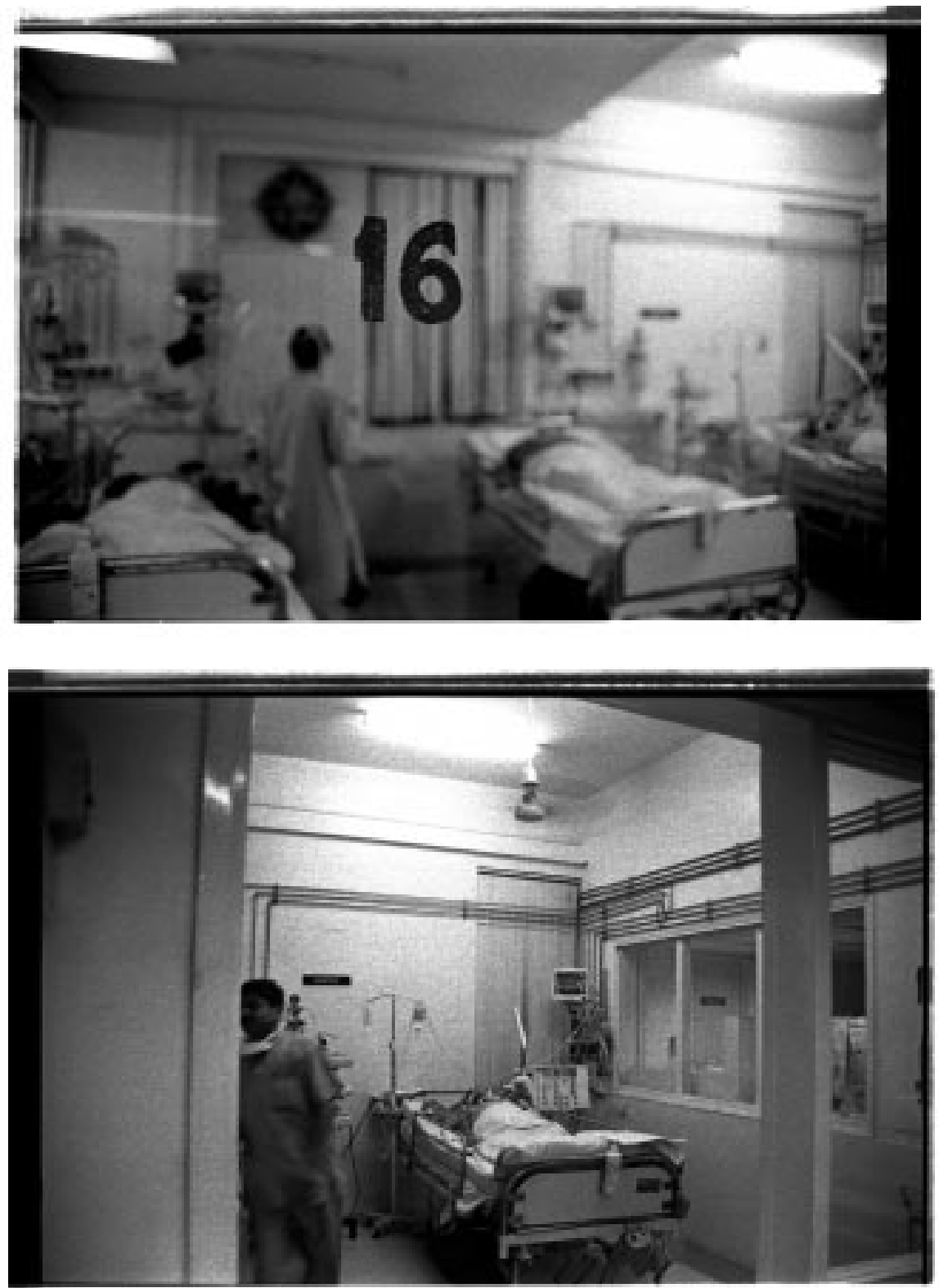
level and delivered the shock. "We got a rhythm back sir! We got a rhythm back!" "Keep pumping fluids in." "Sir, we got a pulse, we got a pulse!" screamed the nurse. "Start dopamine to keep the blood pressure up and pump him with fluids. Find another intravenous line." "Yes sir!" There was a smile in the voice. We had got him out - he had been dead for all practical purposes for one to one-and-a-half minutes. But he wasn't out of the woods yet.

We shifted him to the ICU. I asked the CMO to talk to the friends and relatives. I had no time. It was going to be a long night. The patient wasn't conscious yet. I tried to call out to him and assess if he had regained consciousness, but in all the tension we had forgotten his name! After shifting him to the ICU we had to stabilise him or else he might arrest again. We put in a central venous catheter (a tube, the thickness of a fine pencil) into a deep vein in his chest, close to the heart, to assess the pressures on his heart, so that we could pump in I.V. fluid and blood accordingly. We put an arterial catheter (a fine plastic tube) in his radial artery (an artery in the arm) to monitor his blood pressure (BP) more effectively. Emergency blood was arranged and given to him, but his BP remained low.

Surgeons and neurosurgeons were then called in. There seemed to be some bleeding in his abdomen and we needed an urgent CT scan of the abdomen and chest to look for any other injuries. A CT scan of the head and spine was required to assess injury to the brain and spine.

I called out to him, "Ajay, wake up, open your eyes!" His eyelids fluttered but didn't open fully. I pinched his hand - he grimaced and moved it away. He seemed to be waking up, but how much brain damage had been sustained due to the lack of blood when his heart had stopped was difficult to say. We called in his brother and parents to meet him and to tell them about his condition. As they came in, I explained to them that Ajay was much better, but not totally stable. That we needed to give him more blood, and needed to do CT scans of almost his whole body to assess the extent of his injuries. I showed off all the gadgetry with which we were monitoring him. An arterial line in his artery for his blood pressure, a central venous catheter for filing pressures in the heart, a pulse oximeter for the oxygen levels in his blood, an ECG monitor, a carbon dioxide monitor, a urinary catheter for his urine output and kidney function and a ventilator which was helping him breathe. I guess I showed them all this because I felt better able to reassure them through technology than through the clinical skills of our nurses and doctors. My hunch was that this monitoring made them feel secure that every aspect of their son/brother's body had been accessed and was being monitored.

The CT scan of the head and spine showed no injury, but the scan of the abdomen showed that he had sustained an injury to his liver, which was bleeding. We had to transfuse him with eight units of blood and four units of plasma. The CT scan of the chest showed multiple rib fractures and some contusion to the heart muscles. ${ }^{5}$ The injury to the heart muscles was causing his heart to pump less hard and required some medicines to pump normally. But the liver injury had to be operated.

At 4:00 am Ajay was taken for surgery. The surgery required all the skills of the surgeon to excise almost a quarter of the left side of his liver, and all the skills of the anaesthetist to keep him from having another cardiac arrest during the procedure. Ajay was brought back to the ICU at about 10:00 am. We hooked him up to all the lines, tubes and catheters 
which monitored and supported all the systems of his body. His bleeding from the liver and lung injuries had slowed down but still required blood transfusions, though less and less. I drove back home around one o'clock in the afternoon and fell asleep, dead to the world.

Ajay was making slow but sure progress. He required less medication to support his heart and kidney functions and almost no blood and plasma transfusions over the next week. Although he was fully conscious, the worrying part was that his lungs were badly affected due to the injury and the massive amount of blood we had transfused. He was still on the ventilator. Every day we decreased the amount of support and oxygen that the ventilator was giving him. The longer the breathing tube remained inside and he was on the ventilator, the greater the chances of lung infection. We had put in a fine plastic catheter close to his spinal cord (epidural catheter) and were giving him analgesics through it so that breathing did not cause him pain. We didn't want to use the intravenous route to give him analgesics because the high doses required to relieve the pain from the rib fractures would put him into deep sleep and depress his own efforts to breathe.

Every day we called his parents and brother in, and showed them all the parameters on the monitors, ventilator and blood tests, and assured them that he was getting better but was not totally out of danger. Over this period of a week or more they learnt what parameters to ask and look out for on the monitors to assess his recovery on their own. Everything boiled down to numbers on a monitor or chart. It didn't matter that the nurses had taken such good care of him that he had no bedsores and no lung infection. That they had kept each of the invasive monitoring lines and support systems absolutely free of any serious infection (more than a quarter of patients who die in ICUs all over the world die of severe infections acquired in the ICU, which further complicate their already compromised body physiology). That they had helped to keep him cheerful and in a positive frame of mind.

About ten days after this accident, I was on night call again. Over the last ten days we had tried to reduce the support from the ventilator - it was a difficult back and forth process. (Unlike what Bollywood would like us to believe, after a serious accident the hero doesn't sit up immediately following a 'successful' surgery - all cheerful and perky! It is a slow and difficult process.) Finally, the decision had to be taken to take him off the ventilator and take out his breathing tube. I watched all the monitoring systems as I put him on minimal support on the ventilator. He seemed to be doing fine. "OK. Let's extubate him." We took out his tracheal breathing tube and put him on oxygen by a mask. He heaved a sigh of relief. He was sick of not being able to speak. We watched him on the monitors for any signs of distress. He seemed to be fine. We heaved a sigh of relief! But we had to watch him carefully for a while. I chatted with him. The nurses and other doctors came and congratulated Rakesh and me - he had been our 'save'. It felt good, really good!

Suddenly from the corner of my eye I saw somebody trying to catch my attention from the next cubicle, separated from us by a glass pane. It was Nurse Jeesha: she was indicating that her patient had no BP and pointing to the ECG monitor - the patient's heart was slowing down! I mouthed the letters "D-N-R!" (Do Not Resuscitate). There was no point doing anything for that patient - Naseem Bano. She was a case of end-stage disseminated tuberculosis. She had been with us in the ICU for the last 50 days. Nurse Jeesha looked down and shook her head, and then looked up again, staring at me. I repeated the letters 
"D... N... R". Woman, don't spoil my evening - I have just saved this young man from near death! Don't try to make me feel bad for not doing anything for a patient for whom we have not been able to do anything in the last 50 days.

Naseem Bano was a 23-year-old girl from a village near Meerut. She was married four years ago but couldn't get pregnant and had been losing weight and weakening. Her husband took her to Meerut where she was diagnosed with disseminated TB, which had also affected her uterus. She began taking anti-TB medicines, but after about three weeks of treatment with multiple drugs she continued to worsen. She seemed to have a resistant type of TB. About two months back she became unconscious, started having seizures and went into a coma. The TB had affected her brain. She was taken to a hospital in Meerut, but her coma didn't improve. Meanwhile she had also acquired serious secondary infections of the lungs and the bloodstream, which further affected her kidneys. Fifty days ago she had been brought to our ICU. She had to be put on a ventilator and multiple support systems but her coma deepened, and her other body functions deteriorated. She was beyond hope.

Her father had sold his land to pay the bills in our ICU - it had crept up to almost Rs. 4.5 lakhs and he was nearly bankrupt from the loans. I looked at Ajay and smiled. He smiled back a tired smile. Then I walked over to the next cubicle. Nurse J eesha's eyes were filling up. She was young. She would learn and get tougher. Hadn't I become tougher in the last twelve years that I had worked in various ICUs? She would learn that some patients cannot be saved. But for now she felt terrible. The nurses had worked hard on Naseem. They had massaged her and exercised every part of her body. They had kept her clean and battled every source of secondary infection. Naseem had no bedsores in the 50 days she had been with us and looked nearly as well preserved as she had the day she came in. Her heart slowed down even further. J eesha tried desperately to find her BP - there was none. Her eyes pleaded with me to do something. I shook my head, "There is nothing we can do J eesha, she is in an advanced stage of resistant TB. Let her go!" Another one added to the list of 500,000 who die of TB every year in India. Another one added to the statistics, because we lacked research to find better drugs against resistant TB. Her heart stopped. Nobody moved to give her a cardiac massage or any medications to bring back her heart. I was in-charge and I had said "No". I had made my peace with Modern Medicine.

\section{NOTES}

1. Blood pressure is measured in millimeters of mercury $(\mathrm{Hg})$. The higher pressure is called systolic and normally ranges between 110-140. The lower pressure is called diastolic and normally ranges between 70-90.

2. Instrument that measures the oxygen in the blood.

3. A life-threatening condition in which pressure around the heart leads to its compression and decreases its ability to pump. It can be due to the collection of fluid or blood in the sac around it (pericardial sac) or due to transmitted pressure from large amounts of air or blood collected in the sacs around the lungs (pleural sac).

4. An abnormal irregular heart rhythm in which there are very rapid, uncoordinated fluttering contractions of the ventricles (lower chambers) of the heart that are ineffective in pumping blood out of the heart. It's a lifethreatening situation.

5. Another name for a bruise. It is caused when superficial blood vessels are damaged or broken as a result of a blow, and leak out into the tissue. 


\section{Stolen Rhetoric The Appropriation of Choice by ART Industries}

S U B R O SA

$\mathrm{B}$ iotech industries currently expanding globally, but especially in the US, have opened new frontiers for colonising bodies - and commodifying and patenting life - at the molecular and genetic level. Gamete harvesting and freezing, In Vitro Fertilisation (IVF), Intra Cytoplasmic Sperm Injection (ICSI), pre-implantation embryo screening and genetic manipulation of embryos are just some of the new techniques transcending previous limits of reproductive intervention that have profound repercussions for the human genetic heritage. Under the guise of optimising reproduction - and 'improving' human beings - ART (Assisted Reproductive Technologies) are rapidly being naturalised in everyday life. As feminist theorists have pointed out, the new biotech reproductive order has territorialised the female body as a pre-eminent laboratory and tissue mine for a lucrative medical/ pharmaceutical industry. ${ }^{1}$

The women's liberation movement of the early $70 \mathrm{~s}$ formulated a politics of women's autonomy and control over their sexuality and reproduction that included the right to safe contraception and abortion. By the late $80 \mathrm{~s}$, after almost two decades of abortion wars, the politics of autonomy and liberation had been transformed into a rhetoric of 'choice' typified by the slogan "A woman's right to choose", which became identified with the pro-choice movement. Since then, the rhetoric of 'choice' has become firmly associated with reproductive liberalism.

Using strategic marketing, a seductive consumer industry intent on normalising ART in everyday life has appropriated the rhetoric of 'choice' in order to appeal to a broad constituency of progressive consumers ready to produce "children of choice". Marketers of new reprogenetic technologies (ReproTech) were quick to capture this rhetorical territory, cashing in on the expectation that it would appeal to liberal, educated, middle-class consumers schooled by feminist activism to be proactive in personal health care. ART industries, principally driven by profit making motives and embodying eugenic ideologies, have recuperated the politicised rhetoric of 'choice' by concealing a deeply embedded conflict between the macro-politics of rationalised reproduction in late capital and a micro-politics that capitalises on individual desires.

Despite the highly invasive and risky body processes of ART, many feminists have explicitly welcomed the development of ReproTech for its promises of an expanded range of reproductive choices for women. Others have recognised that ReproTech represents not only an ultimate form of body colonisation, but that its practices and ideologies reinforce patriarchal systems of scientific and medical authority, control and rationalisation of reproduction - contradicting radical feminist philosophies of women's autonomy.

\section{"A woman's right to choose"}


Appropriation of radical feminist rhetoric and practices by liberals and conservatives alike became rampant in the abortion movement. In the 70s, the nationally mobilised Feminist Women's Health Movement (FWHM) developed clinics that offered a wide array of feminist health care services to women. Most controversial were their abortion services, especially the technique of menstrual extraction pioneered by the Los Angeles Feminist Women's Health Centre. This vacuum suction procedure could be done by lay practitioners and was often used as a form of early abortion. Abortion services made feminist health clinics the target of vicious attacks from anti-abortion and right-to-life fundamentalist groups like Operation Rescue. These groups appropriated many of their confrontational direct action occupation and blockage practices, as well as their spectacular visual tactics - such as their use of the foetus - from leftist activist movements including feminism. 'Pro-choice', 'anti-choice' and 'pro-life' are rhetorics that now signify a divisive, often anti-feminist partisanship. Diverse and bitterly contradictory feminist positions on abortion have been subsumed under the liberal rhetoric of 'choice'. Abortion became such a loaded political and cultural issue that the medical profession tried very hard to wash its hands of it as much as possible. Clearly, abortion could not be made to suit capitalist ends. No sexy consumer market of clinics and products could be developed around the 'choice' of abortion, but the rhetoric was perfect for the purposes of the new infertility industry that promises to be a lucrative new flesh frontier - some have estimated the potential IVF market alone at 40-50 million dollars a year. It is time to question the capitalist marketing strategies of ReproTech and the imbalance of macro and micro-politics masked by the stolen rhetoric of 'choice'.

\section{Models of Choice}

Many feminists and bioethicists have argued that despite their risks the new reproductive technologies represent greater reproductive choices for women (and men) - most notorious among the latter is J ohn A. Robertson whose passionate advocacy of "procreative liberty" concludes: "There is no stopping the desire for greater control of the reproductive process. There is no better alternative than leaving procreative decisions to the individuals whose procreative desires are most directly involved". ${ }^{2}$ Such arguments appeal to the deepest democratic beliefs of Americans, but they overlook the way entrepreneurial marketers and fertility services providers are exploiting the rhetoric of choice to naturalise ART. Their clinic brochures, fertility advertisements and web pages pitch the many reproductive choices and techniques available to satisfy the desires of different sectors of the population - including people who are not biologically infertile. Rather than selling ART principally as a set of biomedical procedures designed to cure or circumvent severe cases of infertility, ReproTech marketers highlight its many benefits for those who want the control made possible by scientifically managed reproduction. ART is represented as a means to realise lifestyle choices and support career goals - key factors in reifying its use in everyday life.

For example, an advertisement from the Genetics and IVF Institute offers a "large choice of fully evaluated and screened donors who are immediately accessible", and a "revolutionary technique enabling men with long-term vasectomies to father children". ${ }^{3}$ Though never mentioning any of the risks involved, such ads imply that almost anyone (who can afford it) can 'make' a baby with purchased donor eggs and/or sperm, and the use of

\section{'Pro-choice', 'anti-choice', 'pro-life'}


a hired gestational womb. ART would therefore seem to be the ideal choice for people living in 'non-traditional family' configurations, which group includes single women or men, older couples, affinity groups, lesbians and gays. Thanks to entrepreneurship - although most fertility books are aimed squarely at married couples - there is a thriving niche market of reproductive choices. There seems to be a specialised clinic for almost every group; for example, there are feminist and gay sperm banks and insemination clinics, as well as those that specialise in male infertility problems, or treating older women. ART is also sold as the reproductive solution for couples or singles who have pursued career goals and postponed childbearing. Healthy people considered at risk for certain diseases, or exposed to environmental hazards at work, can choose to use ART procedures such as gamete banking before they are ready to reproduce as insurance against future infertility.

ART procedures promote new eugenic consciousness. ${ }^{4}$ Marketers sell IVF as a family building technology; infertile couples are encouraged to bypass adoption and instead 'make' a child of their 'own'. IVF is a eugenic procedure because it involves screening and selection for 'fit' gametes and embryos. Currently between $60-70 \%$ of US pregnancies are already being screened using methods such as amniocentesis and ultrasound. The discovery of individual gene functions through the sequencing of the human Genome will facilitate the routine use of embryonic genetic screening and manipulation. Parental 'choice' now encompasses so much more than whether to have children, or not. Consumers can purchase a wide selection of pre-screened and tested human gametes that come with detailed profiles of donor characteristics promising improved success and health for offspring. IVF produces excess embryos, and multiple embryos are usually inserted to ensure implantation of at least one. By using the technologies of pre-implantation embryo screening and selective reduction, parents can select precisely which embryo is to be gestated. Selective reduction - a euphemism for abortion - is justified by the (eugenic) argument that it is the necessary means by which only 'fit' embryos are selected to be carried to full term. Here the rhetoric of choice is firmly bound to an individualistic micro-politics of manipulating consumer desire. (Note: we are not making an argument for or against abortion here, but wish to note how the rhetoric of choice is used to make controversial issues acceptable.)

The liberal rhetoric of 'choice' has long been used in the mass media to imply that women can 'have it all' no matter what the personal or social costs. Infertility discourse similarly promotes as a given the idea that everyone has a right to choose to have a child using whatever methods s/ he can afford (procreative liberty). ART can be used to tame recalcitrant bodies. The titles of infertility books clearly tell the story of the enterprise of conquering (in)fertility, for example: Overcoming Infertility; How to Get Pregnant with the New Technology; RESOLVE Infertility; Taking Charge of Infertility. The imperatives to "take charge" and "overcome" urge the individual woman to take control of her body - with the help of her doctors and technology, of course. What she learns by reading further is that ART requires her to surrender her body to disciplinary medical manipulation, surveillance and invasion. While clients are urged to shop around for clinics with the best specialists and success rates for particular procedures, they are given virtually no tools to assess the risks associated with ART. Instead, ART brochures and books highlight the hundreds of healthy babies that have been born using IVF. The models of 'choice' offered by ART promote nei- 
ther anti-authoritarian social and political values, nor do they liberate women from their biology. Rather, they reify cultural values of compulsory motherhood and represent an intensified control of women's bodies. In this context, the notion of choice is appropriated to promote corporate economic interests rather than personal autonomy.

\section{Reproduction and Feminist Utopian Thought}

Understandably, feminist analyses or critiques of ReproTech are rarely mentioned in mainstream ART literature. Feminist responses to assisted reproduction are too complex to be summarised here. However, contradictory strands of utopian feminist thinking regarding reproduction and maternity are well illustrated by two very different texts; the first, the extraordinary feminist utopian novel Herland (1915) written by the prominent socialist feminist Charlotte Perkins Gilman during the height of the first wave of feminist suffrage struggle; the second, The Dialectic of Sex (1969) by Shulamith Firestone, a fiery socialist feminist tract that inspired women during second-wave feminism.

Gilman's Herland presents a country populated solely by women. Over the course of several thousand years they have created a rational, stable, peaceful, prosperous economy and social order - including voluntary eugenic reproductive practices - based on exalting the social principle of Motherhood. The grand task of Herlanders is "Making People" in every sense of the word. There is no individual ownership of children. All the women act as nurturing and social mothers to all the children, who are all girls. There is no sexual intercourse and no "sex feeling". To solve problems of population control each adult woman is allowed to bear only one child. When born, this child - who is engendered by the intense inner desire and preparation of the mother-to-be, becomes part of the community, not part of a nuclear family. In Herland women can only get pregnant because of their great desire for a child. For the good of the community, some women voluntarily defer or forgo motherhood, satisfying their desire for it by tending the communities' babies. In Herland hundreds of years of rational, diligent attention to the problems of weeding out undesirable characteristics and choosing good characteristics by voluntary eugenics have paid off in a population that is strong, healthy, beautiful and multi-talented.

Gilman was simultaneously a radical socialist feminist and a believer in "positive eugenics". Her writings call for women to be liberated from the biological burdens of compulsory reproduction, motherhood and domestic work. Gilman believed in 'female values' of cooperation rather than competition, sharing skills and property and the labour of raising children. Though she welcomes technology to liberate women from backbreaking labour, in Herland Gilman solves the problems of fertility and reproduction with social engineering and the development of a strangely mythic reproductive biology - a kind of parthenogenesis, like that practiced by creation Goddesses. In her utopia, reproductive self-repression for the good of the community takes the place of autonomy, as the solution to overcoming the constraints of biology and sexual reproduction.

In The Dialectic of Sex, on the other hand, Shulamith Firestone is adamant that technology - and technology alone - will provide human mastery of matter and free women from the tyranny of biology: "The biological family unit has always oppressed women and children, but now, for the first time in history, technology has created real preconditions for 
overthrowing these oppressive 'natural' conditions, along with their cultural reinforcements. ${ }^{5}$ Only women's technological control of their biology will change the patriarchal balance of power. Firestone was writing in the late $60 \mathrm{~s}$, a time when research on reproductive technologies was developing rapidly. Astoundingly, by the mid-80s many of the reproductive techniques she anticipated were already in place. Firestone speculates that the invention of an artificial womb will solve the vexing problem that women are still the sole bearers of children; pending this, she suggests that women pay other women as surrogate mothers. Concluding her feminist socialist analysis of the biological and material causes of women's oppression, Firestone calls for a feminist revolution based on the creation of a humanly controlled ecological balance using cybernetic feedback systems and artificial reproductive technologies. Today, though the technologically based systems she advocated are highly developed, the feminist 'revolution' is bogged down in conflicted debates about the impact and consequences (for women) of the purportedly liberating new technologies. In different ways, both Gilman and Firestone pin their utopian dreams on women freeing themselves from traditional (heterosexual) and 'natural' biological reproductive processes. However, neither Gilman's eugenicism nor Firestone's techno-utopianism (which is also racist) is defensible, since both depend on repressive or rationalised bodily and social processes, anathema to the goals of feminist autonomy.

\section{Individual Desire and Reproduction in Late Capital}

From the mid-60s onwards, women's liberation, widening use of the birth control pill and the availability of abortion began to give large numbers of women the experience of separating sex from reproduction. Feminist health and abortion services supported a politics of female autonomy and helped change women's attitudes toward childbearing and motherhood. Books like Adrienne Rich's Of Woman Born, and Nancy Chodorow's The Reproduction of Mothering, provided generative theoretical studies of female ambivalence toward societies' constructions of reproductive functions and the institution of compulsory maternity. Crucially, they questioned and challenged the assumption that the desire to bear children is a 'natural' and innate one common to all women.

The following three decades saw significant changes in women's reproductive patterns and choices. Many women began to defer childbearing to pursue higher education and careers. Many opted for single lifestyles, childfree marriages, lesbian relationships (with or without children), or experimented with collective household and child sharing arrangements. The entrepreneurs of new ReproTech took advantage of these new cultural and social patterns. Deferring childbearing lowered women's fertility rates, and ART was ready to step into the breach with techniques of ovarian hormone stimulation, IVF procedures and egg donation. During this time new definitions of infertility were established by medical authorities, and 'infertiles' - supporting a growing culture of infertility - demanded that it be recognised as a disease or disability whose treatment should be covered by insurance. (At present infertility treatments and ART are financed almost entirely by the private monies of mostly middle-class and affluent users, who often mortgage houses, sell stocks or raise bank loans to pay for treatments.) Fertility doctors have supported this move; for example, the American Society of Reproductive Medicine (ASRM) and RESOLVE (an infertility support 
group) have joined in endorsing the FAITH (Fair Access to Infertility Treatment and Hope) Senate Act that calls for insurance to pay for up to four IVF treatment cycles and promises "minimal impact on the cost of health insurance". ${ }^{6}$ While such legislation may seem like a progressive move to make ART widely accessible to all economic classes, it does not acknowledge that it still won't benefit the majority of Americans who have no health insurance at all.

American commodity desire is immediate, and is fed by the belief that science can provide technological solutions for every biological problem. The still highly experimental technologies of assisted ReproTech have a low success rate and their long-term safety and biological and genetic risks have not begun to be adequately assessed or studied. But ART is being driven by the twin engines of (manufactured) consumer desire for new technologies and the enormous profits to be made off the infertility business. At the macro level of politics the function of reproduction in late capital is to produce compliant workers and successful consumers to serve and feed a global commodity economy. Corporate biotech entrepreneurs must find ways to divert reproductive desire and autonomy to serve market imperatives to colonise and patent genes, germ lines and life processes. Rationalised and optimised methods of new eugenic reproduction are represented as far more efficient than the random chance method of sexual intercourse, because they can be technologically controlled and promise improved human characteristics and successful offspring. Even though the success rate of ART (between 15-22.5\% of IVF cycles result in take-home babies) is still very low, its spectacle is one of scientific authority and control. The ideology and practice of new eugenic principles that is part of the macro discourse of ART has been masked by the (micro) discourse of individual choice. Many sperm banks, for example, accept only certain categories of donors - Nobel Prize winners, successful professionals, heterosexuals, non-artists, athletes - and all require extensive genetic, medical and racial background profiling. Preferred and highly-paid egg donors must generally be young, intelligent, college educated, from selected ethnic and racial backgrounds, healthy, good-looking and able to pass a battery of psychological tests.

\section{Radical Ideas and Normalised/ Naturalised Process}

In order to be territorialised by capital, radical ideas and processes must be normalised/ naturalised in everyday life, and their dangers rewritten as benefits. This is done through literature, art and mass media representations. Religious indoctrination works this way, as does political propaganda. Science too relies on these instruments to make it appear rational, humanistic and necessary, rather than outlandish and threatening. In the consumer culture of late capital, public acceptance of formerly frightening or taboo scientific ideas is managed through carefully orchestrated propaganda campaigns that domesticate the previously unthinkable with promissory rhetorics of 'improvement' and 'choice', and with seductively aestheticised images of scientific processes, products and services.

The often extreme biotechnological procedures of ART have been naturalised in this way within a few short years. Starting with the birth of Louise Brown, the first IVF baby, in 1978 in Britain, the new reproductive technologies were at first both sensationalised and glorified in the media, often by the use of apocalyptic language, or dire warnings about the 
monstrous experiments scientists were conducting in their labs. These media reports played to the fears and fantasies of people worried about becoming guinea pigs in an authoritarian scheme to remake humankind. The media revisited all the classic archetypes and eugenic myths from Frankenstein to Brave New World. The icon of the baby in the bottle literally in vitro, in the glass - was updated with pictures of doctors mixing gametes in petri dishes, and hundreds of frozen embryos crammed into cryotanks. ${ }^{7}$

To counter much negative publicity and push their business, ART doctors and entrepreneurs entered the battle of representation, writing their own books and launching web sites that present reassuring images, human interest stories, and descriptions of ART in matter-of-fact and easily assimilated ways. For example, detailed diagrammes of the interior of the female pelvis and reproductive organs are often shown with a vision machine or surgical instrument in place. These cyborgian images help to normalise the idea of technological intervention into the reproductive body. The literature is usually directed at the (white) educated, middle-class, professional couple, or career single; it is reassuringly scientific (i.e. it gives assurances that ART is cutting edge medicine, not stitching together corpses), affirmative and upbeat. It represents ART as an exciting creative venture any couple could undertake with their doctor.

ART literature also paints a picture of how clients can integrate these processes into their everyday lives (i.e. "our clinics open early and close late so you can come in for your tests every day"), and helps them work out payment plans. Crucially, this literature pitches its utopian and promissory rhetoric in the non-sensationalised, calmly authoritative voice of the expert: "I helped to create the United States' first pregnancy produced from a frozen embryo". ${ }^{8}$ Disguised as consumer advice, this approach benefits capital and reinforces scientific authority.

Consumer persuasion also works by aestheticising scientific processes. An iconic representation of ART that has recently been circulated widely is a colourised microphotograph of ICSI (Intra Cytoplasmic Sperm Injection), a delicately precise micro manipulation process in which a single carefully screened, washed and capacitated sperm is inserted through the zona pellucida of a selected egg by means of a hollow glass needle. This is an image of wilful creation every bit as compelling as Michelangelo's iconic Sistine Chapel image of God creating Adam. It is simultaneously the ultimate image of scientific control and triumph, and a secular visualisation of miraculous creation. Most viewers have no scientific understanding of the precise biotechnological process this image demonstrates, but the ideological reading is clear: technological control over life processes. Further, it is an image of (eugenic) 'choice' that brings one superior egg and one fit sperm together in a technologically mediated act of fertilisation. Without needing to spell it out directly, the ICSI picture has become an unparalleled poster child for the new eugenic processes of genetic screening and manipulation. Such consumer friendly representations have been effective in helping to naturalise the often frightening and extreme processes of ART in everyday life.

The abstract beauty of the aestheticised scientific ICSI image is made possible by sophisticated new visualisation instruments including sonography, hysteroscopy, laparoscopy, microphotography, tunnelling microscopy, PET and MRI. After all, the breakthrough step of being able to 'see' the foetus in the womb opened the way for it to become a trag- 
ic icon in the abortion battles. Both ART and abortion foreground the foetus or take-home baby, not the mother or the woman. Since the foetus icon was contested territory already claimed by anti-abortion crusaders, ART adopted the image of the radiant biotech baby the child of choice. After all, what ART was promising was a live baby, not just an unformed foetus. (Hard statistics of ART success are measured in 'take-home-babies' not pregnancies). These iconic baby pictures have helped to domesticate strange and threatening technologies that were previously unthinkable.

\section{Conclusion: New Practices, New Rhetorics}

The micro and macro-politics of the public discourses of ART are unbalanced; currently the forces of market capitalism have won the field with the consumer friendly appropriated rhetoric of 'choice'. Research in assisted ReproTech is still advancing rapidly, and increasingly there are contestatory interests at stake. Meanwhile, growing bodies of feminist cultural theory and literature, as well as new media practices and art works, play with concepts of the post-human cyborg body and recombinations of women and machines. The $80 \mathrm{~s}$ saw strong feminist activism, both in the US and internationally by groups such as FINRRAGE (Feminist International Network of Resistance to Reproductive and Genetic Engineering, founded in 1984), that critiqued and opposed new ReproTech using many classic feminist arguments and tactics. But currently there is a wide gap between liberal and radical feminist theory, activism and practice in the domains of biotech and ART. An important goal for new (cyber)feminist artists working with these issues must be to expose the ways in which the marketing of biomedical technologies promotes the colonising interests of late capital, rather than the critical goal of women's autonomy. The rhetoric of 'choice' is too compromised to be useful for feminism any more. Instead, a new critical rhetoric must be introduced to describe changed conditions and new practices.

The challenge for feminist activists/artists now is to create strategies that counter corporate biotech's increasing pressure to control the female body and reproductive processes. Recent techniques such as harvesting live foetal stem cells for medical research, suggest the urgent need for new ways to assess the threats to women's health and autonomy posed by the rapid naturalisation and deployment of such technologies. Since most women do not understand many of the complex implications and consequences of new ReproTech, it is necessary that feminists begin to generate autonomous (free from state, corporate or entrepreneurial control) cross-cultural, decentralised, biomedical sex and reproduction education projects transnationally. In Women as Wombs, radical feminist J anice Raymond suggests that science has become overly dependent on developing new technologies; she calls for a new feminist reproductive science that doesn't hinge on often risky, high-tech approaches that are financially unavailable to most women anyway. ${ }^{9}$ (Feminists should not be afraid of critiquing the ways in which intensified biotechnological intervention is increasingly offered as the solution to every problem from infertility to world hunger). Such a science could recombine diverse sources of knowledge to create new sexual and reproductive options that take into account women's differing economic, social and political conditions and desires. New feminist reproductive science would have to devise flexible information and distribution mechanisms, perhaps based on a combination of electronic networking and 
performative practices. As the autonomous method of menstrual extraction practiced by lay people (bypassing the medical authority system) proved, new approaches to reproductive science can enlist feminist activists from diverse backgrounds to act as trained, nonspecialist practitioners teaching methods that foster principles of autonomy and physical and social well-being.

subRosa has begun to activate a resistant cultural practice based on the goals discussed above. Initially, we have focussed on aspects of ART that have largely been silenced in public discourse. We hope to disrupt the current 'choice' discourse of ART; to initiate an interventionist debate and practice among diverse non-specialist audiences; and to further probe and expose biotechnology's far-reaching repercussions for women's health and bodily autonomy worldwide. subRosa projects to date are: 1. Does She or Doesn't She, SmartMom and Vulva De/Reconstructa which expose gender differences in ART practices, and highlight the effects of high-tech body invasion on women's health and bodily autonomy; 2. Expo EmmaGenics and The Economies of ART which question and challenge the ways in which market forces drive the research, development and deployment of ReproTech's products and 'services' through an analysis of the economies of ART; and 3. Sex and Gender Education in the Biotech Century which interrogates the intersecting ideologies and practices that serve to normalise and naturalise ART, exposing their historical connections to eugenics and colonial ideologies.

This essay has been previously published in: Richard, Birgit and Sven Thuen (eds) Kunstforum "Klonen und Mutante" (2001) and subRosa Domain Errors. Cyberfeminist Practices (2002).

\section{NOTES}

1. For a bibliography on women and biotech see www.cyberfeminism. net

2. Robertson, John A. Children of Choice: Freedom and the New Reproductive Technologies (Princeton University Press, 1994, New Jersey) p. 235.

3. New York Times Magazine (21 July 2000) p. 42.

4. For a discussion of "new eugenic consciousness" see Critical Art Ensemble Flesh Machine: Cyborgs, Designer Babies and New Eugenic Consciousness (Autonomedia, 1998, New York).

5. Firestone, Shulamith The Dialectic of Sex: The Case for Feminist Revolution (William Morrow, 1970, New York) p. 193.

6. See http:// www.resolve.org/RELEASE_FaithBill.htm

7. Squier, Susan M. Babies in Bottles: Twentieth-Century Visions of Reproductive Technology (Rutgers University Press, 1994, New Brunswick).

8. Marrs, Bloch, and Silverman Dr. Richard Marrs' Fertility Book (Dell Publishers, 1997, New York) p. xiii.

9. Raymond, J anice G. Women as Wombs: Reproductive Technologies and the Battle over Women's Freedom (HarperCollins, 1993, New York). 
Scans / 119

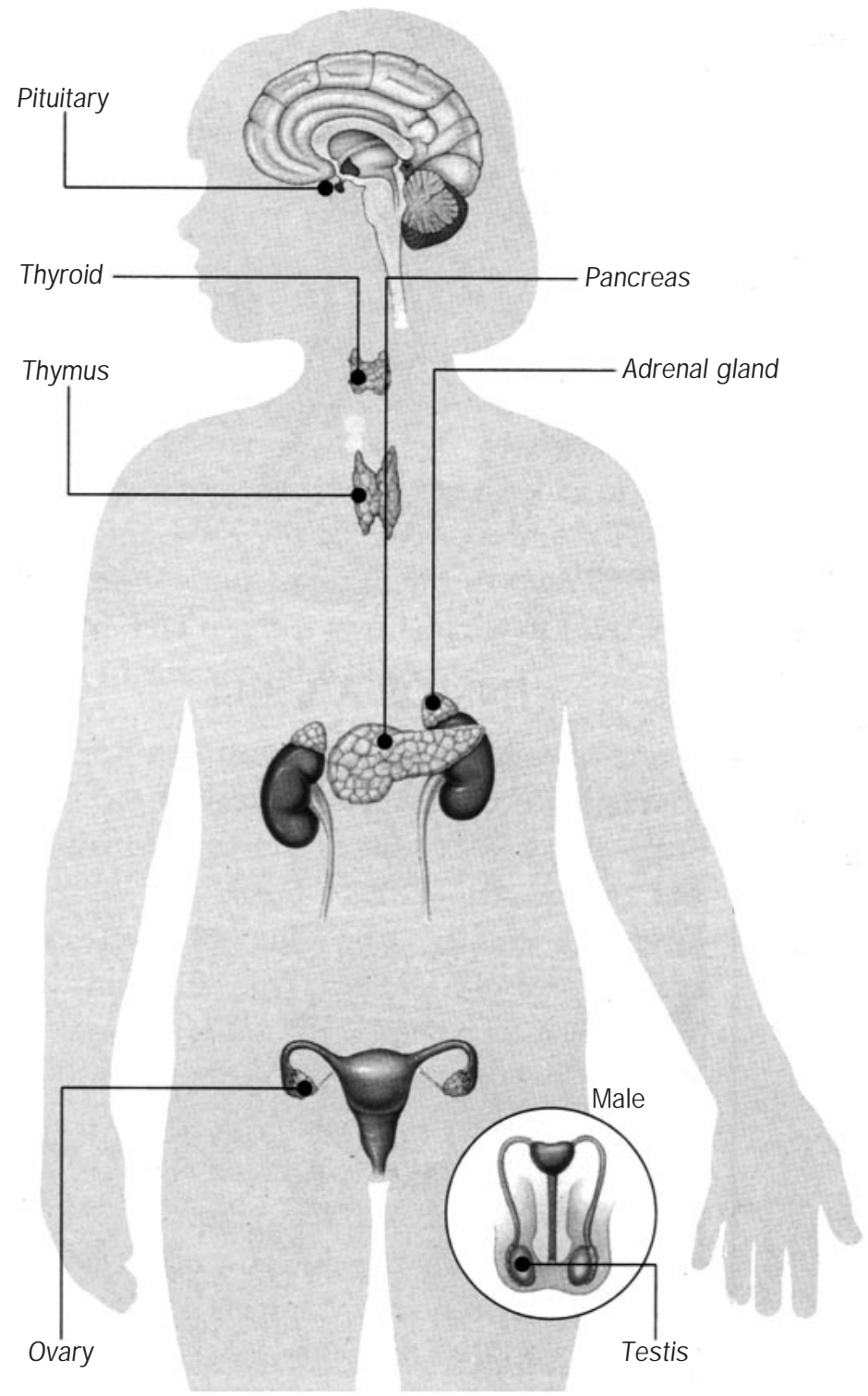

Image from The Visual Encyclopaedia 


\section{Reproductive Technologies in India Confronting Differences} inevitable and often indispensable part of women's lives. ${ }^{1}$ On the one hand, the increased knowledge and availability of a wide range of RT options has redefined 'traditional' notions of conception and procreation. On the other, the introduction of each new device or technique has served to renew a growing flux in the way reproductive choice is understood. The right to bodily integrity - defined as the inalienable right of women to have control and autonomy over their bodies - has been central in the feminist understanding of choice. Women's expanded access to reproductive technologies (RTs), including abortion, is an essential corollary to this argument. Access to certain types of RTs have indeed saved women's lives and often provided them with expanded choice with regard to reproductive decision-making. However, there is a continued need to evaluate the role of RTs in gendered terms and examine their role in providing women with real choice. This need becomes particularly acute in the face of the growth of the non-medical use of RTs to satisfy individual and sociocultural needs.

Women's bodies, in particular her reproductive functions, are increasingly being subjected to technomedical interventions to satisfy non-medical aspirations with regard to conception and procreation. The case of sex selection and sex selective abortion in India is a classic example of both the non-medical use of RTs and of the misappropriation of the definitions of reproductive choice. In light of this, and numerous other RT-related 'events' in India, there is need for an urgent reassessment of the way bodily integrity is defined in the Indian context. This is imperative in order to be able to frame adequate norms and standards for RT use in ways that do not limit women's access to RTs and at the same time find ways to limit the gendered context within which they often find use. In this article some of these issues will be examined in an India specific context in an attempt to illustrate a conceptual path that might serve to build bridges between different constituencies that are increasingly positioned on opposite sides of a growing chasm.

\section{Contextualising the Reproductive Rights Discourse}

The feminist discourse on reproductive rights rests on the notion of procreative liberty defined as the right to reproduce (positive right) and the right to avoid reproduction (negative right). Both these rights carry with them an implicit assumption of first, bodily integrity 
- the right to control and autonomy over one's body - and second, an implicit assumption of the use of varied RTs. For example, the negative right to avoid procreation can be attained through access to abortion. However, this right based claim cannot be universalised and needs to be examined in a relational context (Menon 1995; Steinbock 1998).

In India, women's health and rights activists have often emphasized the need to define reproductive rights and choice in gendered terms so that its fulfilment is not only dependent on the availability of technical choice and information. It is indeed important to argue that RTs cannot be viewed as a magic bullet that will help alleviate women's reproductive 'burdens'. When this is done with little or no effort to change the often oppressive arrangements for reproduction, the result can be a reinforcement of gender based inequality. The misappropriation of prenatal obstetric diagnosis and abortion, by families and medical community alike, to systematically eliminate female foetuses is one example. The introduction of hormonal and other provider-controlled contraceptives has also been the site of controversy. Besides questions concerning the safety of these methods, the government's efforts to achieve its demographic goals by using women as the vehicles for population control, while disregarding their safety and well-being, has been harshly criticised.

Unfortunately, controversies surrouding the use of RTs have resulted in the consolidation of opinion, in line with moral and legal absolutes, rather than producing a constructive dialogue between the different constituencies. As Birke pointed out, the "problem with moral absolutes is that they do not take [us] far, they tend to result in an insensitive politics, which says little about the needs that gave rise to the discussion in the first place" (Birke et al 1990, p. 282). Hidden within these absolutes is the female person whose specific context and needs often find no place in current discussions. Little or no account of the social position of women, and the socially determined needs that position generates, is taken into account when pronouncing judgments (Petchesky 1980). J ust as pushing technologies without addressing arrangements for reproduction often proves to be detrimental, 'banning' a technology without advancing non-exploitative definitions and methodologies for use of RTs serves little purpose. There is an urgent need to undertake this task as increasingly "these technologies and the 'choice' they offer are gaining considerable validity for women who are its direct users" (Mallik 2002, p. 189). In the absence of choice in real terms, these RTs often represent the only power base for women from which to negotiate the terms of their existence (Rowland 1985). The legitimacy of the non-medical use of RTs is a powerful example where women are as much the agents seeking sex selection as they are victims of the social pressure to have sons.

There is a need to examine the introduction of certain types of RTs in India within a framework that responds to the process of technological advance as a whole rather than as isolated procedures. It is, for example, important to be able to illustrate the way the RT industry has built its profits on the basis of reconstituting reproduction into varied 'pathologies', more often than not through reinforcing gender based stereotypes and inequalities. Previously, reproduction was regulated largely through sociocultural principles. Today this reality remains unchanged and further overlaps with technomedical control. Together these serve to create a complex terrain on which decisions about reproduction (by women) are made. At the same time it is important to deconstruct, for example, how non-medical use 
of RTs for sex selection has gained legitimacy as a result of their potential to alter the balance of power between individual men and women, as well as between women and institutional control - something that is not fully understood (Gimenez 1991). It is evident that the advent of RTs and their use, particularly non-medical use, has precipitated the need to redefine our understanding of procreative liberty and, more specifically, issues of reproductive choice and autonomy.

\section{Needs Interpretation - Who Defines the Female Lifeworld?}

In India the varied interpretation of what women need has resulted in polarised debates on the need and importance of talking about reproductive rights and choice; and within that the need to expand women's access to RTs. Interpreting needs has been reduced solely to a political idiom in which conflict is played out through inequalities, which are differentially positioned and then symbolically challenged (Fraser 1989). The interpretation of needs with reference to reproductive rights, choice and the role of RTs, for example, is often talked about within a dichotomous and hierarchical framework that characterises socioeconomic and cultural-symbolic injustice as two separate injustices. Socioeconomic injustice and the need for a politics of redistribution is often favoured over a politics of recognition that talks about cultural-symbolic injustice. The first step towards being able to frame a meaningful discourse around reproductive rights and choice means bridging the gap between these two struggles and illustrating the interconnectedness that exists between the two.

This understanding can be a first step towards building bridges between the two constituencies that are currently aligned as being those that fight inequality, and those that stress difference and fight for recognition. In pooling resources it is possible to participate more equally in what is currently an unequal discursive struggle to influence the agenda for the development and use of RTs. Making a dent on the existing scenario, currently dominated by big pharmaceuticals, the medical community and the Indian state through its undue emphasis on anti-natalist population policies, is a complex and difficult goal in both theory and practice. The fragmented and varied nature of claims made by and on behalf of women often acts as an impediment in countering the more homogenised discourse of these powerful actors.

The deterministic role that RTs play in women's lives, and the fact that a woman's body is often the site for this technological advance, is an irreversible fact today. Furthermore, it is important to note that the wide range of RTs have the power to directly impact social relations that govern procreation and conception. For example, sex selection and sex selective abortion in India has dramatically redefined both conventional notions of biological reproduction and kinship building, as well as altered the way women experience pregnancy and motherhood. It is also an undeniable fact that in a culture which can only be described as being extremely antagonistic to women there is a misuse of RTs. However, none of the above should deter or undermine efforts to evaluate the potential of technologies in making real improvements in women's lives. Feminist activism should come together to undertake the collective task of developing a holistic vision of RTs that combines transformatory goals to advance women's reproductive well-being within the need based context of women's lives. 


\section{NOTES}

1. For the purpose of this article the term 'RT' is used in its broadest sense to indicate the wide spectrum of devices and techniques that facilitate fertility control, infertility treatment and prevent sexually transmitted infections and disease.

\section{REFERENCES}

1. Birke, L., S. Himmelweit and G. Vines Tomorrow's Child:Reproductive Technologies in the 90s (Virago Press, 1990, London).

2. Fraser, N. "Struggle Over Needs: Outline of a Socialist-Feminist Critical Theory of Late Capitalist Political Culture" (in Unruly Practices: Power, Discourse and Gender in Contemporary Social Theory Polity Press, 1989, Cambridge) p. 161-87.

3. Gimenez, M.E. "The Mode of Reproduction in Transition - A Marxist-Feminist Analysis of the Effects of Reproductive Technologies" (in Gender and Society Vol. 5, No. 3, 1990) p. 334-50.

4. Mallik, R. "Sex Selection: A Gender-Based Preference for a Pregnancy" (in Reproductive Health Matters Elsevier Science, Vol. 10, No. 19, 2002) p. 189-90.

5. Menon, N. "The Impossibility of 'J ustice': Female Foeticide and Feminist Discourse on Abortion" (in Contributions to Indian Sociology Vol. 29, No. 1 and 2, Sage Publications, 1995, New Delhi) p. 369-92.

6. Petchesky, R.P. "Reproductive Freedom: Beyond 'A Woman's Right to Choose'” (in Signs: J ournal of Women in Culture and Society Summer, Vol. 5, No. 66, 1980) p. 1-85.

7. Rowland, R. "A Child at Any Price? An Overview of Issues in the Use of the New Reproductive Technologies, and the Threat to Women" (in Women's Studies International Forum Vol. 8, No. 6, 1985) p. 539-46.

8. Steinbock, B. Rethinking the Right to Reproduce (Harvard Working Paper Series, Harvard School of Public Health, http:// www.hsph.harvard/HW papers/reproright.html, 1998, Cambridge).

9. Young, I.M. "Unruly Categories: A Critique of Nancy Fraser's Dual Systems Theory" (in New Left Review May-April, Vol. 222, 1997, London) p. 147-160. 


\section{Uncanny Bodies}



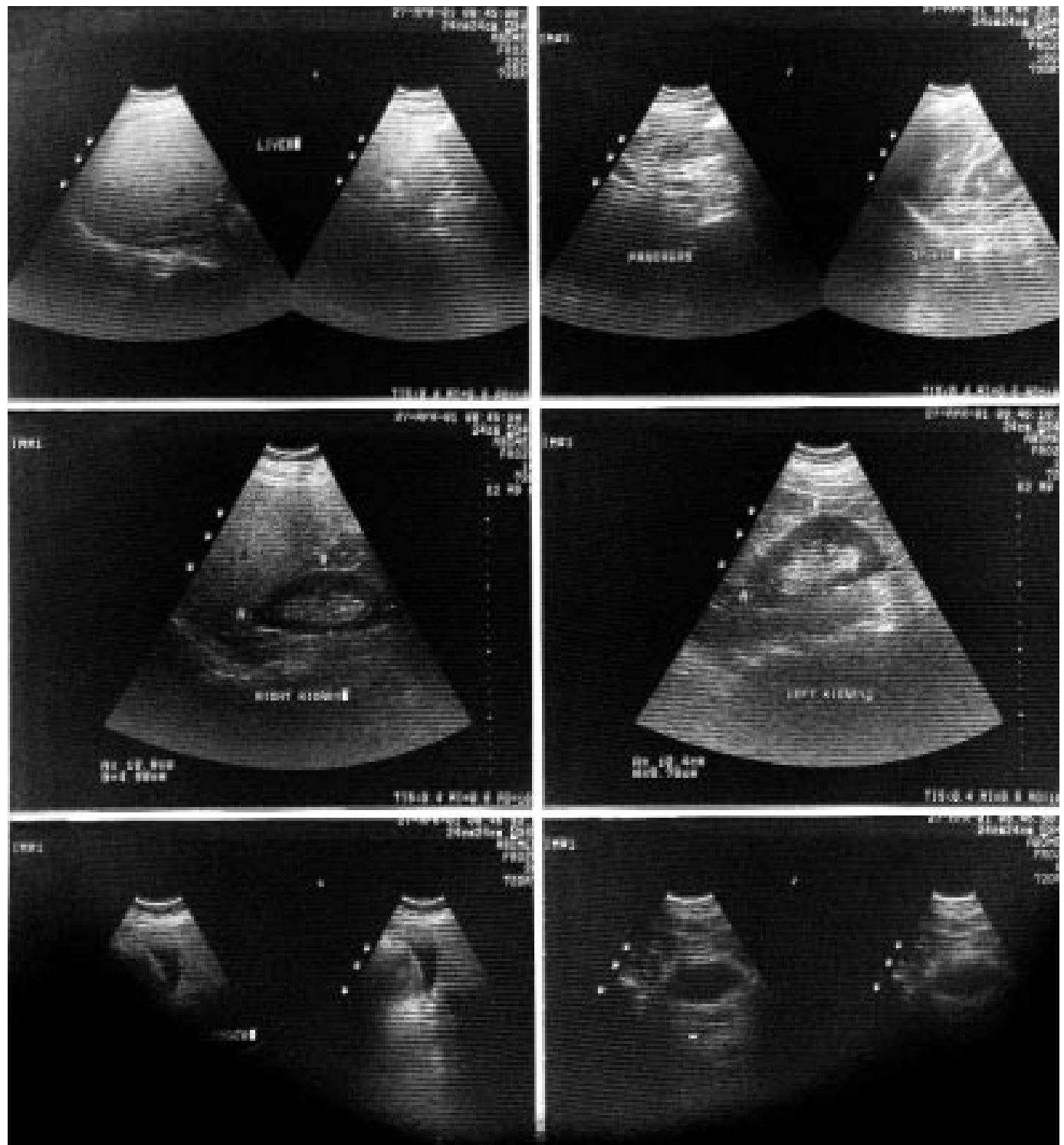

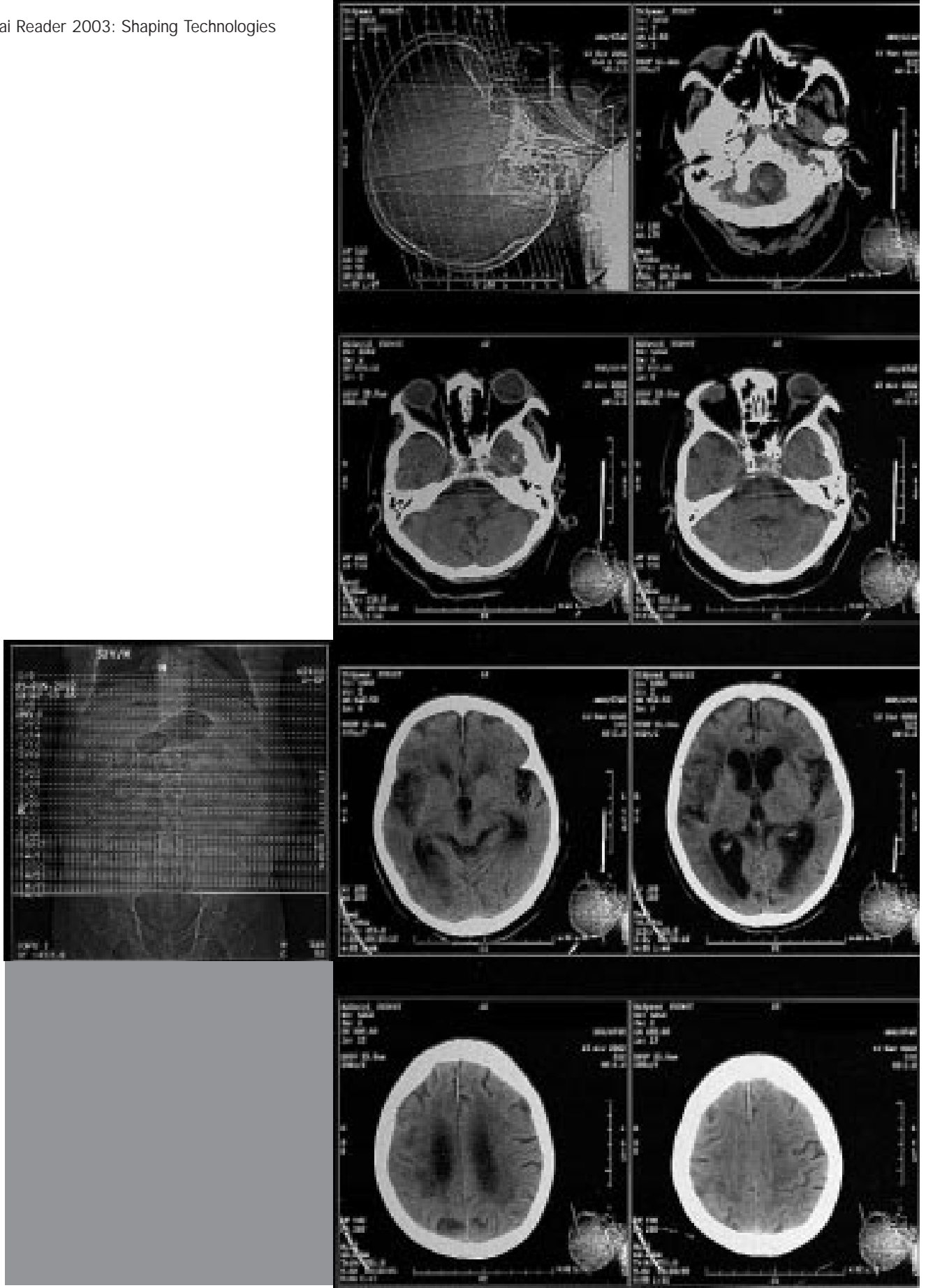

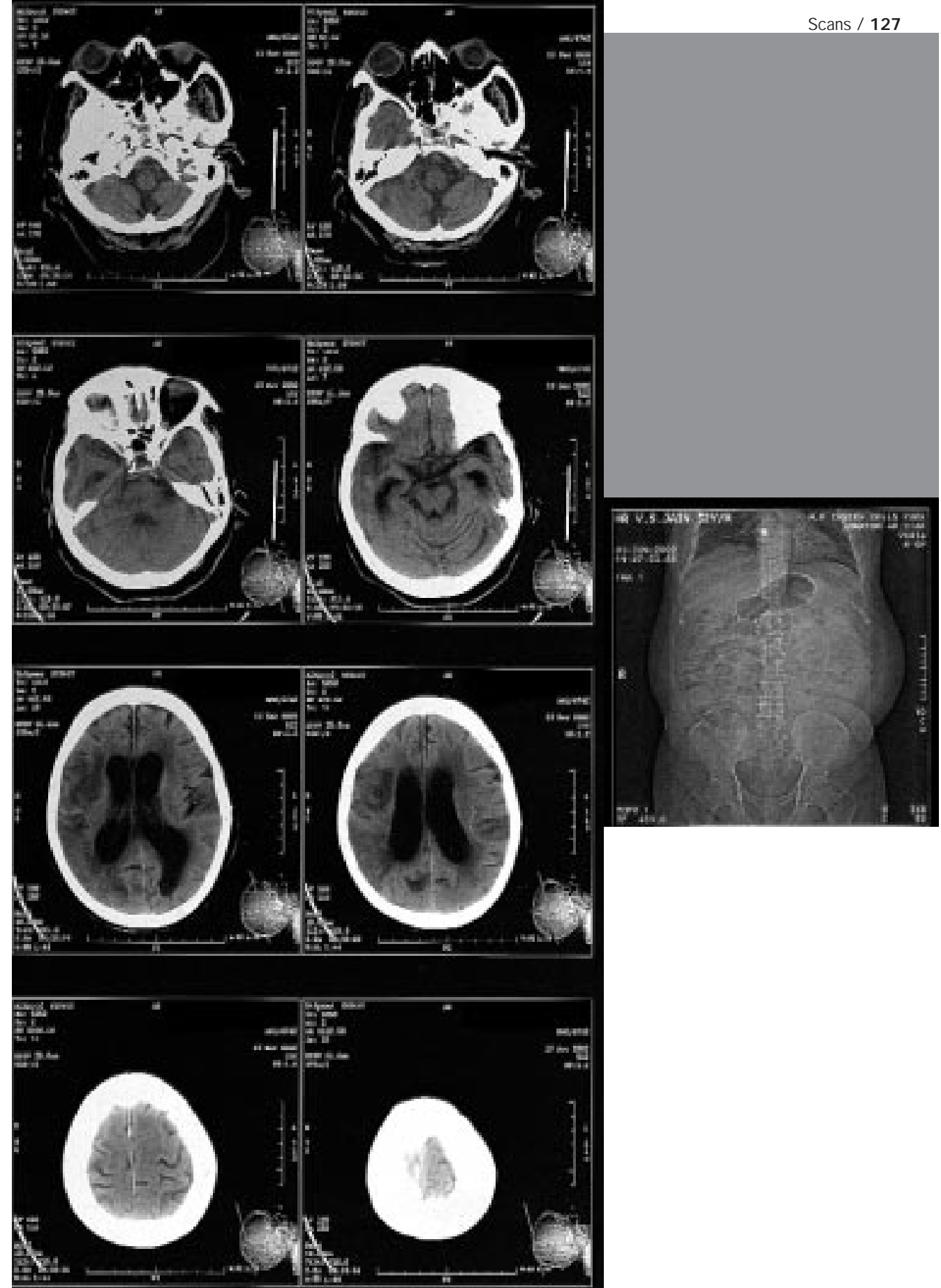


\section{Shaping Technology / Building Body(Nets)}

ANA VISEU

\section{Technologies as Environments}

Imagine two cities separated by a river and connected only by boat. Now think of the changes that are brought about by the construction of a bridge; transformations will be felt throughout, affecting all the elements involved in this interaction. These transformations will, to a great extent, be caused simply by the presence of the new artefact (bridge). However, the properties of the artefact will also influence the character of the changes. There is, for example, a great difference between a small wooden bridge that can only carry pedestrians and bicycles and a steel bridge that is equipped for cars, buses and trucks, but not for pedestrians. The characteristics of the bridge affect the two cities it connects. The contrary is also true; that is, the characteristics of the cities affect the shape and use of the bridge. Before the actual building of the bridge, studies were done (hopefully) and assumptions were made (certainly) regarding the characteristics and needs of the cities on both sides of the river. Hence, much in the same way that the social (the two cities) is shaped by the technical (the bridge), the bridge is shaped by the cities it connects. This is true of the processes of development, implementation and use of any technical artefact.

Other actors, besides these immediate ones, also affect, and are affected by, the introduction of the new bridge. For instance, the river actively shaped this process, as its characteristics had to be taken into consideration while the bridge was being designed and developed. However, the river does not remain unchanged when the bridge comes into existence. While earlier its crossing may have presented itself as a recalcitrant, often rebellious, obstacle, or perhaps as a moment of joyful leisure, it is now silenced, almost invisible. It loses the physicality of an "obligatory passage point", ${ }^{1}$ awarding it to the bridge instead, and in the process acquiring a new identity. The river shores, freed from the requirement of anchoring boats, may become the perfect place for a Sunday morning promenade.

In the network of river, bridge, cities and surrounding environment nothing remains unchanged. Social and technical actively interact, exchange properties and negotiate identities, thus shaping one another. Technologies, then, are not neutral tools, or passive containers, but environments that shape and hold together a set of social dynamics that are simultaneous ly a consequence of their existence and necessary for their survival. ${ }^{2}$ The intro- 
duction of the new bridge does not result in two cities plus a bridge, but in a qualitatively different urban landscape composed by distinct social relationships. ${ }^{3}$

The metaphor of technological environments highlights the networked, distributed character of a socio-technical project and emphasizes the multi-directional influence of the actors' (people and artefacts) actions, thus leading to the rejection of cause and effect, deterministic theories. The connections between social and technical can be studied simultaneously, as they actively shape one another.

However, it is also true that the identity of the actors involved in this interaction is not infinitely fluid or malleable. ${ }^{4}$ Technological artefacts have characteristics that need to be taken into account in this mutual shaping relationship. For instance, if our bridge is built for pedestrians it may be used by bicycles, perhaps even cars, but certainly not by trains.

In this framework, the separation of social and technical vanishes and is substituted by hybrids that defy categorical divisions. Technologies become socio-technologies, i.e. materialisations of a given view of society and behaviour that enhance or constrain certain social dynamics. For instance, if our bridge is one-way only during rush hour, those who find themselves excluded from using it must find alternative ways to cross to the other side. If, at a later stage, city planners arrive at the conclusion that traffic is becoming unbearable, they may decide to add a public transportation lane that works both ways, thus making it more attractive to take the bus. We can say, therefore, that the way a certain technology is, that is its present shape, reflects the result of the struggle between different actors. ${ }^{5}$

\section{Creating Networked Bodies}

Although there is no formal definition of body(nets), ${ }^{6}$ I propose that we think of them as bodies networked for (potentially) continuous communication with the environment (humans or computers) through at least one wearable device, that is, a body-worn computer that is always on, always ready and always accessible.

Body(nets) constitute new bridges between individuals and the environment - composed of humans and nonhumans, things and non-things. As such, we must ask what new socio-technical environments are being created. How are body and technology interacting and actively shaping one another to create a new hybrid entity or environment with its own specificities and dynamics?

As a concept, body(nets) are largely a product of the Information Age. They apply the Internet phenomenon, with all the hype that surrounds it, to the human body. Body(nets) are interesting entities in that they condense and make visible many of the tenets that rule contemporary Western societies: a desire for mobility, continuous access to information, personalisation, networking and control. Their imperativeness stems, at least partially, from the urge to bring the body up to speed with the new production demands of a society where digital information is the most valuable asset. ${ }^{7}$

As they (re)connect and mediate between body and environment, body(nets) transform, and are transformed by, all the elements involved in this interaction. Hence, body(nets) are not merely tools to be used, but active shapers of experience. A body(net) can be used, for instance, as a "reality mediator", 8 that is, it can alter, by enhancing or diminishing it, one's perception of the world. Steve Mann's Eyetap is perhaps the best example 
of this. ${ }^{9}$ The Eyetap transforms the eye into a camera and a screen where reality is projected. Reality is recorded through the movements of the eye and then it is projected on to the eye itself. This allows all sorts of manipulations, for instance its wearer can spend his/ her nights reliving his/her mornings!

Body(nets), these new bridges, contain assumptions about that which they connect, and these assumptions affect their shape, the nature of their mediation and the behaviours they enhance or constrain. For instance, a body(net) that is equipped only with a transmitter allows its user to transmit data, but not receive it. If this transmitter is controlled by a third party, then the user has no control over the data flow. If the body(net) is equipped with a transceiver and is controlled by the user, then the user is able to control every piece of information that enters and leaves his/her personal space.

Due to the high degree of intimacy with the user, the body(net) becomes an extension of the self, a second brain. In fact, it has been argued that the 'always ready' capability of body(nets) leads to a new form of synergy between human and computer, with each hanging on to the other in a feedback loop. ${ }^{10}$

When extending the body, and creating new connections to the environment, body(nets) blur the boundaries between internal and external, between self and others. The individuals' body and cognitive abilities are extended, their boundaries no longer determined by skin, or even by the body's proxemics, ${ }^{11}$ but by the artefacts that are part of his/her network, and respond to his/her presence.

Hence, a recurring futuristic vision of this tech/body/environment network is one in which the environment recognises and adapts to the individual. In this brave new world, individuals always feels at home, safe in any environment, with the environment actively enhancing this well-being. The environment begins to "morph into the figure of a software agent" that acts on the individual's behalf, ${ }^{12}$ anticipating his/her wishes, desires and needs.

Imagine, if you will, an individual equipped with a shirt outfitted with biological sensors that measures the heart rate, body temperature, neural activity and respiration rate, among others, thus denoting, in principle, its wearer's mood, mental and physical state. ${ }^{13}$ In this version of the future, if the individual's mood becomes gloomy the shirt can activate a room's soothing music player, alert a third party, or perhaps even inject a drug. It is conceivable that other uses will be found for this data. For example, it could be utilised by a health insurance company to determine that individual's premium. Or, the individual could start refraining from performing any kind of activities that would affect him/her in ways that might be understood by the shirt's sensors as 'depression' (for instance, watching a sad movie). What is measured, and how it is measured affects not only the individual's behaviour and the response of others to it, but also the very definition and experience of the emotion itself. ${ }^{14}$

Companies like VivoMetrics are developing products that do something of this sort. VivoMetrics markets its LifeShirt System (TM) as a tool for electronic care management. Its web site announces that rather than collecting a "snapshot" of a patient's health, the "LifeShirt System's embedded sensors and patient diary capture continuous data - a 'movie' of health". This continuous feature affords "an unprecedented, real-world view of the patient, providing researchers and clinicians with a more comprehensive understanding of how respiratory, car- 
diovascular and other physiologic functions interrelate - even how they are affected by [that] patient's frame of mind - as well as the effect of specific therapeutic interventions". ${ }^{15}$

Others, currently in the workings, are oriented towards everyday lifestyle applications. Lifestyle applications are believed to be the 'killer app' that will turn wearable computers into everyday apparel. Paradoxically, there is also a consensus that until these applications look and behave like actual clothing they will not be accepted by the general public and become mainstream items. ${ }^{16}$ MIThril, a prototype being developed by the Massachusetts Institute of Technology, offers an example:

A full-fledged personal computer network woven into an individual's clothing, MIThril will learn the preferences of its owner by watching behaviour and taking note of habits. It will manage a personal datebook and know where its owner should be even before departure. And by pre-emptively scouring web sites, it will constantly be updating the best way to tackle the next task. Suppose a beach party is on the schedule, MThril will know this because the event is in the calendar and there's a note on a to-do list that says, for example:

Pick up beer.

When the system observes its owner getting on a bike, it immediately seeks the best directions to the party by way of a packaged goods store - taking into account that its owner hates heavy traffic. After calculating all of this information, MIThril displays a map to the beach on the owner's glasses without even being asked. ${ }^{17}$

The emphasis is on anticipation, pre-emptive action. The body(net) knows the individual as well (or better) than he/she knows him/herself. It acts on the individual's behalf without the need for conscious input. The possibilities for control and loss of privacy, although not explicitly mentioned, are certainly a possibility. Among the more subtle effects we could imagine, for instance, the creation of invisible entities - spaces or activities - that are not modelled into the body(net) and thus become intangible.

Other areas that are currently explored are those of work, to increasing the ease and efficiency of hands-free task performance and security, to enhance (in the case of soldiers) or diminish (in the case of criminals) physical abilities. After the events of September 11, 2001, investment and interest in the area of security has increased exponentially.

In their article, "Basic Concepts in Wearable Computers and Augmented Reality", Barfield and Caudell project that in the future "[the networked] computers [on our body] will monitor our physiological state, perform the duties of a secretary and butler in managing our everyday life, and protect us from physical harm". ${ }^{18}$

Others, however, are not so enthusiastic and warn of the dangers of this merger. For instance, in 1999 Critical Art Ensemble criticised the invasion of the body by biotechnologies, arguing that it creates a "flesh machine" ruled by the same values as all other machines: efficiency and productivity. ${ }^{19}$ Peter Weibel made a similar point in his essay, "Virtual Worlds: The Emperor's New Bodies", when arguing that the successful implementation of virtual reality models is accompanied by a mechanization of the human. ${ }^{20}$ Elsewhere I have also discussed the issue of the losses that accompany the merging of the human body with technology. ${ }^{21}$

However, in this paper I propose that we think of body(nets) as environments, thus shifting our attention from the effects of the merger of body and technology to the 
process of mutual shaping, or "translation", in Callon's words, ${ }^{22}$ of the different actors involved in it.

In this way, body(nets) are understood not as the sum of body and technology but as a qualitatively new entity. As body and technology actively shape one another, new practices are created that sustain the body(net) and give it existence. The roles and characters of the actors involved change, and with them the ways in which we relate to the world and to ourselves.

When analysing the processes of mutual shaping that occur within a socio-technical environment, we become aware of the process of its construction, of the strategies used to convince (or force) different actors into their places and identities. The relational character of the project is exposed and so are the visions and goals of the participating actors.

This facilitates the recognition of the sociological theories that are inscribed into each technology, ${ }^{23}$ the social relationships that it materialises, the identities that it makes vital and those that it replaces and relegates to invisibility.

The desire for accountability and visibility in socio-technical projects runs counter to the common assumption that the greatest sign of the adoption of a technology is its disappearance into the background: a technology is considered adopted when we no longer think about it. ${ }^{24}$

I propose that we open up and question these black boxes, make them visible again, not as isolated artefacts but as socio-technical environments, constituted of relationships among different entities that rely on them for their identity and, sometimes, even existence.

Title inspired by the book Shaping technology/Building society studies in socio-technical change, edited by Wiebe Bijker and J ohn Law (MIT Press, 1992, Cambridge, MA).

\section{NOTES}

1. Callon, Michel "Some elements of a sociology of translation: Domestication of the scallops and the fishermen of St. Brieuc Bay" (in Power, Action and Belief: A New Sociology of Knowledge? Routledge \& Kegan Paul, 1986, London, UK).

2. For more on 'technology as environments' see McLuhan, Marshall Understanding Media: The Extensions of Man (MIT Press, 1964, Cambridge, Massachusetts) and, McLuhan, Marshall and Eric McLuhan Laws of media: The New Science (University of Toronto Press, 1988, Toronto).

3. See Marvin, Carolyn When Old Technologies were New (Oxford University Press, 1988, New York) for an interesting, descriptive analysis of the introduction of the telephone and the shaping of the socio-cultural environment. 4. Callon, Michel and John Law "After the individual in society: Lessons on collectivity from science, technology and society" (in Canadian Journal of Sociology Vol. 22, No. 2, 1997) p. 172.

5. Latour, Bruno "Technology is society made durable" (in A Sociology of Monsters: Essays on Power, Technology and Domination Routledge, 1991, London/ New York).

6. In the scientific and popular literature body(nets) are often referred to as 'wearable computers'. I prefer the term body(nets) because it shifts the attention from the anatomy of the technical artefact to the shape of its network.

7. Critical Art Ensemble "Links and Synchronisms on the Flesh Frontier" (in Readme! Autonomedia, 1999, Brooklyn, NY). 
8. Mann, Steve Cyberman (movie) (The Nature of Things series, directed by Peter Lynch, CBC Television, 2001).

9. See Mann, Steve Eyetap (http:// eyetap.org/ defs/intro.html).

10. Mann, Steve "Wearable Computing: A First Step Toward Personal Imaging" (in IEEE Computer Vol. 30, No. 2, 1997) and Frishberg, Manny "What to Wear: Why Not a Computer?" (in Wired News http://www.wired.com/ news/gizmos/0,1452,55669,00.html, 10 October 2002).

11. The body perceives the close space around it, its 'aura', as being part of the body. To this space Hall, E.T. The Hidden Dimension (Anchor Books, 1982) gives the name "proxemics".

12. Suchman, Lucy "Refiguring interactivity at the interface" (Paper presented at the workshop on Absent Presence: Localities, Globalities and Method 10-12 April 2002).

13. Barfield, Woodrow, and Thomas Caudell "Basic Concepts in Wearable Computers and Augmented Reality" (in Fundamentals of Wearable Computers and Augmented Reality Lawrence Erlbaum Associates, 2001, Mahwan, NJ).

14. For more on this topic see Suchman, Lucy "Replicants and Irreductions: Affective encounters at the interface" (Paper presented to the European Association for the Study of Science and Technology, August 2002, York, UK) and Dror, Otniel, "The Scientific Image of Emotion: Experience and technologies of inscription" (in Configurations Vol. 7, No. 3, 1999) p. 355-401.

15. VivoMetrics' web site: http:// www. vivometrics.com/site/system.html

16. See Post, R., and M. Orth "Smart fabric, or washable computing" (in proceedings of the First International Symposium on Wearable Computers 1997) and Woodrow Barfield et al "Computational Clothing and Accessories" (in Fundamentals of Wearable Computers and Augmented Reality Lawrence Erlbaum Associates, 2001, Mahwan, NJ).

17. Wood, Christina "I, PC" (in Popular Science http://www.popsci.com/popsci/computers/article/ 0,12543,198188,00.html, 14 March 2002).

18. Op. cit. 13, p. 24.

19. Op. cit. 7.

20. Weibel, Peter "Virtual Worlds: The Emperor's New Bodies" (in Ars Electronica: Facing the Future MIT Press, 1999, Cambridge, MA).

21. Viseu, Ana "Simulation and Augmentation: Issues of Wearable Computers" (in Ethics and Information Technology in press).

22. Op. cit. 1.

23. Madeleine Akrich "The De-Scription of Technical Objects" (in Shaping Technology/ Building Society Studies in Socio-technical Change MIT Press, 1992, Cambridge, MA).

24. Hence the efforts of ubiquitous computing and embedded computing, efforts to hide the 'computational' character of artefacts while maintaining their physical shapes. For more on this see Viseu, Ana (op. cit. 21). 


\section{Black Magic, Biotech \& Dark Markets}

EUGENE THACKER

"On some islands mana [magic] is the word for money"

Marcel Mauss

"... death is only a state of black magic which did not exist so long ago"

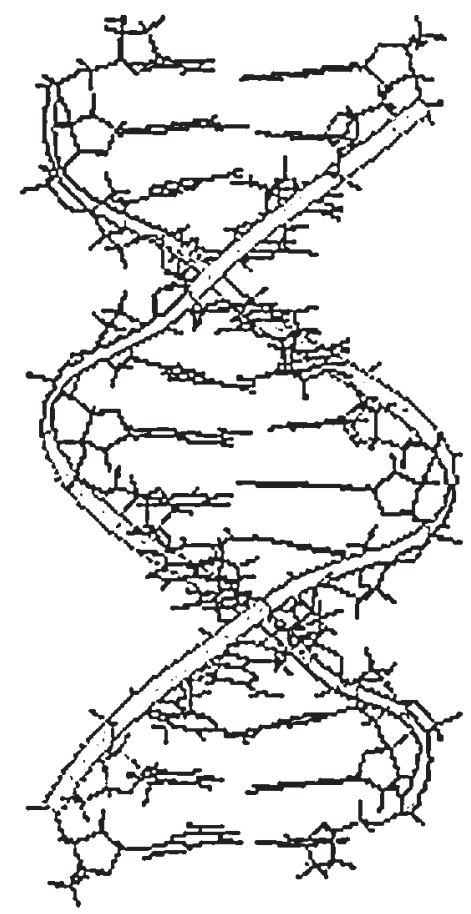

Antonin Artaud

T

he proposition here is that biotechnology is a unique mode of generating value. This value is simultaneously economic, ethical and medical. Biotech is in this sense a creative endeavor; it creates a context in which biological 'life' can be assessed, and it creates the terms through which negotiations on biological life can take place.

A number of well known examples are worth mentioning in this context: US Patent \#4237224: the patent for the techniques for working with recombinant DNA, filed by Stanley Cohen and Herbert Boyer, the researchers who conducted the first genetic engineering experiments in the early 1970s. This patent showed that techniques for manipu- 
lating biological life at the molecular level could be open to the criteria of property and patent law. ${ }^{1}$

Diamond vs. Chakravarty: the first case in which the question of "patenting life" was raised. In 1980, researchers sought a patent for a genetically modified microbe which would clean up oil spills in the ocean. The ruling declared that the microorganism was patentable since it had been modified, and was therefore a human-made technology rather than naturally occurring. When anxieties concerning genetically mutated bacteria arose, Congress and the US Environmental Protection Agency intervened, temporarily limiting such organisms to the lab. ${ }^{2}$

Human Genome Diversity: in 1995, a US patent was granted to the National Institute of Health $(\mathrm{NIH})$ for the unmodified cell line extracted from a New Guinea tribesman, the first patent on human biological materials. NIH-funded researchers collected genetic samples from indigenous populations as part of an effort to establish a genetics database (Human Diversity Genome Project). The individuals whose cell lines were patented were not aware of the economic consequences of the patent, nor of the patent itself. The case attracted much criticism by the Rural Advancement Foundation International (RAFI), and led, in part, to stricter protocols of informed consent for scientists. ${ }^{3}$

IHD (Icelandic Health Database): in the late 1990s the biotech start-up DeCode Genetics announced its intention to create a comprehensive health database of the Icelandic population, including genomic data, genealogical records and selected medical records. The IHD would be enabled by new computer-based genome sequencing technologies, and would in part be licensed to pharmaceutical corporations for in-house drug development. Similar projects have been initiated for genetically-isolated populations around the world (including Tonga, Newfoundland, Mormon and even African-American population genome projects). ${ }^{4}$

On the one hand the issues which such examples raise are quite evident. But the economic component of the biotech industry is also highly diversified: the financial markets of biotech start-ups, product pipelines of drug development in the pharmaceutical industry, technology development geared specifically towards niche markets in biotech research, and the expansion of patent laws and notions of property in relation to biological materials. In addition, biotechnology companies and pharmaceutical corporations spend a great deal of money and resources on advertising campaigns, public outreach programmes, TV commercials and even web site design, in order to convey a set of complex messages concerning biotech research and its potential medical applications. Whether the message conveyed is one of technological progress ("delivering on the promise of biotechnology") or of humanitarian missions ("science for life"), there are various features of the biotech industry that one cannot ignore.

First, biotech is as much an economic endeavour as it is a medical one. This is, to be sure, undeniable, although too often the economic face of biotech becomes the mythologised, anonymous corporation invading natural resources and violating human rights. The problem is not that this is exaggeration; the problem is that this is accurate. The examples above all illustrate the economic bottom line of the biotech industry. Recent debates often centre around the nexus between biotechnology and information technologies (genetic privacy, population-specific genomes, privatised databases, knowledge economies). ${ }^{5}$ 
Second, biotech is as much a technoscientific endeavor as it as medical one. The human genome is an exemplary case of 'big science' precisely because its main focus was not biology or medicine but technological development (in particular, the advancement of information technologies via biotech research). The most recent example of this mobilisation of biopolitics was in the post-9/11 Anthrax scare, in which the notion of "terror networks" took on a decisively viral meaning. Months after the events, there was news of research into the Anthrax genome and of biotech-IT companies working on advanced biochips for biological detection. ${ }^{6}$

Third, biotech has never been a medical endeavor. Or, to put it differently, biotech can be defined by the manner in which it constantly holds medical application at bay. For the biotech industry, application is always potential, and this potentiality is both economic and ideological surplus-value. Constantly postponing application is akin to what Critical Art Ensemble call the "promissory rhetoric" of biotechnology. ${ }^{7}$ The biotech industry's social contract is made like a physician's drug prescription, a prescription which is always temporary.

To be sure, the current debates concerning the nexus of biotech and business are crucial to the possibility of any collective voice, be it through activism, awareness-building, education or lobbying for policy change. But, along with this, there are a number of changes affecting biotechnologies which may shift the terms of the debate in the future. One of these is the increasingly important role that computer and information technologies play in biotech research and medical genetic diagnostics. ${ }^{8}$ Virtually every field in the biotech industry has been radically enabled by developments in infotech, the human genome project being the most noteworthy example. However, it is one thing to use the metaphor of 'information' to describe DNA (as post-war molecular biology had done), but it is quite another to take that metaphor literally and construct genome databases, gene-finding software and protein structure simulations. The situation becomes more complicated when these instances of computational biology are then decoded, potentially affecting 'real' bodies through gene therapies, genetically-designed drugs, or even GM foods. It appears that the aim of technology development in biotech research is to facilitate a fluid passage between DNA in the living organism (in vivo), in the lab (in vitro) and in the computer (in silico).

The question which this confluence of computers and biology - or bioinformatics raises is this: how is the correlation of biological life and economic value transformed by new computer and information technologies?

\section{II}

We can begin addressing this question with the following statement: an economic critique of biotech would need to consider not only the economic activities of biotech, but biotech as an economic activity. In other words, we need to understand not only the multiple economic activities which constitute the biotech 'industry', but also the generative value network which 'informs' biotechnologies. From one perspective, we can consider biotech first as a science, which then separately negotiates potential application, clinical trials, patents and investment capital. The problem with this position is that it not only assumes the division between science and economics, but it configures economics as coming after science.

From another perspective, science does not precede economics, nor is it completely 
separate from it either. To borrow from sociology, we can say that the technology of biotech is 'socially shaped' by a range of factors which are only indirectly economic, but which pertain directly to the structuring of generative value networks. ${ }^{9}$ The question is not how the biotech industry commodifies the knowledge and artefacts produced by scientific research; the question is how an economy of valuation is immanent to all biotech practices. In this sense, valuation is simply modes of thinking and acting in asserting values and meanings it is the efficiency of what 'matters'. In conjunction with the biotech industry, valuation operates via an economic logic (we could say axiomatically) that must be linked constantly to notions of biological life (even if this life is conceived of as information). The wager of the biotech industry lies in the ability to establish a transparent link between biological life and economic value.

A given artefact - a biochip, or stem cells, or a database - materially expresses sets of values concerning specialist and non-specialist notions of biological health, disease and technological development. In a sense biotechnology manufactures novel artefacts which act as "corporealisations" of value, nodes which condense often ambivalent attitudes regarding biological 'life' and high technology. ${ }^{10}$ Again, the space which biotech's economy of valuation must traverse is that between biological life and economic value.

How do we characterise such valuations and linkages between biology and economics? A number of researchers studying complex networks have suggested that economic relationships display characteristics of decentralised or 'scale-free' networks, in which control is spread throughout the network in distributed, though uneven ways. For instance, Walter Powell has suggested that the traditional models of economic systems - the vertical hierarchy of the firm and the horizontal ephemerality of the market - gloss over a more fundamental structure, that of the network. ${ }^{11}$ In a series of papers which looked at the pharmaceutical industry as a case study, Powell has suggested that economic networks are common in certain conditions (unstable resources, rapid technological change, need for long-term sustainability). Powell shifts his analysis from the units of economic transaction to the dynamic relationships which those transactions enable. In doing so, he suggests that factors of co-dependence, mutual benefit and strategic cooperation characterise economic networks in a way that is significantly different from either firms (which operate by governance) or markets (which function according to fluctuations). Networks work towards establishing both indebtedness and reliance over the long term, and in this sense networks affect even vertical structures such as corporations (e.g. strategic partnerships in the biotech industry with academia or government). In other words, Powell suggests that between the centralised topology of firms/corporations and the distributed topology of markets, there is a more universal topology of decentralised interaction.

Similarly, Albert-László Barabási's group, studying networks as diverse as protein networks in the yeast cell, web site traffic and the networks between corporations, has suggested that there are general, universal laws that complex networks exhibit. ${ }^{12}$ These include a 'scale-free' or decentralised topology, composed of a certain number of hubs that are significantly more connected than others (the "power law"), which produce a "small world" effect, in which the path between any two nodes on the network is relatively short (the six degrees of an enzyme...). For Barabási, the significance of this model of scale-free net- 
works is that it produces an image of control-without-control, a "web without a spider" as he terms it. Like the work of Powell and other network scientists, this view of complex networks reiterates one of the central ideas of complexity: multiple agents + local interactions $=$ self-organising global effects. ${ }^{13}$

But there is something amiss with this picture. If network science portrays economic networks as "neither a market nor hierarchy", as a "web without a spider", then how do we account for the blatant inequalities in economic networks such as the biotech industry? If the research of network science is correct then, presumably, the controversies surrounding the patenting of biological materials, bio-IPRs and genetically-modified organisms would be regulated by the factors of dependency, reciprocity and flexibility. Clearly this is not the case, as the recent examples of GM foods and population genomics indicate.

\section{III}

The answer we can give to the question of control-without-control is both ironic and serious. How can a network such as the biotech industry display control-without-control? Through a particular type of magical practice - a black magic indissociable from technology.

The characterisation of biotech as black magic is primarily meant to indicate the ambivalence of instrumentality in biotech, an ambivalence which actually enables the connection between biological life and economic value. Traditionally, black magic refers to the use of magical actions for maleficent purposes (spells, witchcraft, demonology). The idea of black magic took a particularly strong hold in Renaissance Europe, where it coincided with trends in J ewish and Christian mysticism. The infamous black magicians of the period and after - from Cornelius Agrippa to Eliphas Levi - were often seen as instrumentalists, manipulating the forces of the natural world (in the Hermetic tradition) or of the traditions of 'white magic' (occultism, cabala, alchemy). ${ }^{14}$ At the root of black magic was the fear induced by an instrumentalisation of the natural world, in order to gain 'unnatural' control.

Curiously enough, the tropes of black magic specifically, and magic generally, are not uncommon in popular accounts of the biotech industry. For instance, Cynthia Robbins-Roth's book From Alchemy to IPO provides a hero-narrative of the biotech industry, recounting the development of recombinant DNA techniques and the formation of Genentech, the first biotech start-up. ${ }^{15}$ For Robbins-Roth, the biotech industry realises the dream of alchemy, not only through its ability to control matter, but in its ability to generate value through this transformation of matter. Robbins-Roth does not mention black magic, because this alchemical biotech activity is seen as the ultimate in humanistic endeavor. But neither does she explore in depth the controversies genetic engineering experiments prompted in the 1970s.

In contrast is Jeremy Rifkin's Algeny, a precursor to his more popular The Biotech Century. ${ }^{16}$ Rifkin is known as a sometimes conservative activist who heads the Foundation for Economic Trends. Rifkin's approach to biotech is highly cautious, if not technophobic. His picture is the exact opposite of Robbins-Roth's: the problem is precisely the over-emphasis on economics in the biotech industry, resulting in privatised knowledge and the commodification of life. While the problems Rifkin raises are incontestable, his alarmism often amounts to a wholesale rejection of biotechnology. In contrast to the economically-driven 
alchemy of the biotech industry, Rifkin proposes a more environment friendly "algeny", in which scientific research can take place without the intrusion of economic imperatives.

Certainly both Robbins-Roth and Rifkin use the term 'alchemy' quite broadly, but both are concerned with the issue of control vis-à-vis biological life. For Robbins-Roth the promise of the biotech industry is in its ability to control the mysteries of natural life for humanistic purposes; for Rifkin the very life which biotech controls is the living body of people and the environment. Both agree, however, that biological life is essentially a mystery, and that the task which bioscience sets itself is the understanding and control of this mystery. Out of convenience both make reference to magic in relation to the biotech industry.

But what if we take this trope of biotech as magic seriously? We would, first of all, have to point to a definition of 'magic' that would warrant the connection to biotech. A number of historians of religion, including James Frasier, have positioned magic as incommensurate with technology (for Frasier magic is situated between religion and technology, for it has a logic, but that logic is not rational or 'scientific'). Indeed the division persists to this day, along the lines of the rational/ irrational.

In this context, Marcel Mauss' famous study, A General Theory of Magic, is useful, for it attempts to conceive of magic as deeply connected to both the social and the technological. ${ }^{17}$ Mauss provides three phenomena which explain the efficacy of magic in any given social formation: first, the laws of similarity (like produces like) and contiguity (acting at a distance); second, the transfer of magic properties (manifestation of magical force in phenomena); and third, the practice of demonology and possession (association with the taboos of death and necromancy). Mauss' examples are wide-ranging, from Aboriginal agricultural rites, to Melanesian healing practices, to numerous examples of 'private magic' in the everyday. In any magical practice, efficacy will be judged by a combination of tradition, belief, and 'common sense' reasoning according to these three manifestations.

However, for Mauss these do not fully explain the specific 'magical' element of magic, but only provide external sociological criteria for verifying that a magical phenomenon has taken place. Mauss contends that in any magical phenomenon there is always a "residue" or an excess portion which cannot be incorporated into logical thought, and which forms the core of magical practice. In particular, the combination of a world-view of interacting "forces" and the particular "milieu" or context of the magical phenomenon combine to give the sense of a something other that is happening. That is, the notion of magical force and the milieu of magic combine in a concept Mauss calls mana. Taken from magical practices in indigenous Melanesian cultures, the term mana designates a number of things simultaneously - magician, magical act, magical rite, magical force, magical objects, even more common notions such as luck and fortune. Indeed Mauss suggests that mana just as easily refers to a more intense spiritual character as it does to one who is wealthy - both individuals are said to 'have' mana. ${ }^{18}$

Mauss' study suggests that a number of cultures have a term like mana to designate the intractable in magical phenomenon. Mauss even makes the point that the notion of mana operates in a manner akin to the notion of the sacred (though magical acts can be composed of everyday activities and can include secretive or personal actions). For Mauss magic is a social phenomenon, even when magic is understood as illicit, or as 
black magic. Mana is the expression of magic in the social (even when in a forest). The social is therefore a collective expression via mana through belief, valuation and instrumental efficaciousness.

Mauss' study, though not without its problematics (including an exclusive focus on 'primitive' cultures), is noteworthy in that it redefines magic according to social and technological criteria. It suggests that magic is not transcendental (above and beyond social reality), but immanent to collective and individual practices in daily life. Mauss' theory of magic also points to the implicitly pragmatic and instrumental character of magic in society; magic rites associated with healing and medicine are among his most common examples. To this we can add several more qualifiers, for we want to suggest that biotech is a form of black magic, and not just magic generally speaking. If magic is both immanent (social) and instrumental (technological), then black magic is an instrumental use of the immanent qualities of magic. That is, black magic folds the instrumental back upon the immanent, it folds technology back upon the social. When this happens, the object of the magical action becomes the social body itself. Instead of magical practice constituting or contributing to the social (as in Mauss' theory), in black magic it practices on the social. (This is biopolitics with smoke and mirrors.) In this folding back of the instrumental upon the immanent, the social body is 'shaped' according to the hermetic dictates of the technological (the technological becomes synonymous with its efficaciousness). This can be said to constitute the maleficent character of black magic. It results less from a desire for world domination and more from a confusion specific to black magic, a confusion of the interrelation of the immanent (social) and the instrumental (technological).

What does this have to do with biotechnology? On one level all of this is perhaps too abstract. But, if we keep in mind our notion of black magic (aided by Mauss' theory), then it is hard to deny certain analogies in the biotech industry. For instance, consider the pharmaceutical industry. The manufacture of drugs has long been the single most lucrative output for bioscience research. Even when discussions of 'post-genomic complexity' abound, the output for such research is first and foremost in drug discovery. Drugs operate not only by sympathy (vaccines), antipathy (anti-virals) and contiguity (GM foods), but the integration of the pharmaceutical industry with health care systems means that a network for regulating "biovalue" operates in the long term (health insurance, drug prescriptions and subscriptions). ${ }^{19}$ Likewise, any computer based laboratory technology achieves a magical transfer of properties, simply by encoding and decoding DNA into a computer. Finally, the biological database can be seen as a means of 'capturing' or possessing biological life via the various property and patenting structures and health care systems.

Recall our initial question: how does biotech create a link between biological life and economic value? And how does it do this as a network which displays control-without-control? In short, biotech as a form of black magic mediates between 'life' and 'property' via the use of information technologies. Information is the 'medium' - in both senses of the term. The space in which black magic biotech operates is the space which separates and connects biological life and economic value, matter and property. 'Information' has become the equivalent of mana in the biotech industry. The notion of information - genetic codes, computer data, stock quotes - covers a wide range of meanings, and in doing so it func- 
tions as the means by which biotech establishes and regulates the interactions and transactions between life and property. For contemporary biotech, 'information' is mana.

\section{IV}

The challenge with any consideration of biotechnologies - cultural, political, sociological, philosophical - is to assert the problematic of economics in the biotech industry, while also asserting the moral irreducibility of biotechnologies. Yes, there are deep, fundamental problems with the biotech industry, especially in terms of economic issues. But these issues and these problems should not automatically reduce biotech into a debate between pro and contra-biotech positions. Clearly there are positions between these, or indeed outside of them altogether. As Geert Lovink has commented, dark markets are problematic precisely because they configure technology as use rather than critique (don't think, click...). ${ }^{20}$ The challenge is therefore not that biotech is too 'big' an evil - a position of political apathy which ends up reinforcing the characterisation of biotech as a "dark market". Rather, the challenge is how to create new positions which refuse the moral binarisms into which public debates often descend.

\section{NOTES}

1. For more on the scientific and social issues in genetic engineering see Aldridge, Susan The Thread of Life: The Story of Genes and Genetic Engineering (Cambridge University Press, 1998, Cambridge) and Ho, Mae-Wan Genetic Engineering Dream or Nightmare?: The Brave New World of Science and Business (Continuum, 2000, New York).

2. For more on biological patents see Belcher, Brian and Geoffrey Hawtin A Patent on Life: Ownership of Plant and Animal Research (IDRC, 1991, Canada) and Kimbrell, Andrew The Human Body Shop: The Cloning, Engineering, and Marketing of Life (Gateway, 1997, Washington, D.C.).

3. For more on biodiversity see Shiva, Vandana Biopiracy: The Plunder of Nature and Knowledge (Between the Lines, 1997, Toronto) and Harry, Debra "Biocolonialism: A New Threat to Indigenous Peoples" (Indigenous Peoples Council on Biocolonialism web site, http:// www.foel.org/ LINK/ LINK93/ biocolonialism.html, 1998).

4. See Brower, Vicki "Mining the genetic riches of human populations" (Nature Biotechnology Vol. 16, April 1998) p. 337-340.

5. See the Scientific American special issue on "The Human Genome Business" () uly 2000).

6. See Hollon, Tom "The Biodefenders" (Signals Magazine http:// www.signalsmag.com, J une 2001).

7. See Critical Art Ensemble "The Promissory Rhetoric of Biotechnology in the Public Sphere" (Digital Resistance Autonomedia, 2000, Brooklyn).

8. See Howard, Ken "The Bioinformatics Gold Rush" (Scientific American July 2000) p. 58-63 and Persidis, Aris "Bioinformatics" (Nature Biotechnology August 1999) p. 828-830.

9. On social shaping approaches see MacKenzie, D. and J. Wajcman The Social Shaping of Technology (Open University Press, 1999, Buckingham, UK). While not generally included under SST, the work of Bruno Latour (on germ theory) and Donna Haraway (on technoscience) can be said to have similar interests, if not general theoretical commitments.

10. On "corporealisation" see Haraway, Donna Modest_Witness... (Routledge, 1997, New York) p. 141-48.

11. See Powell, Walter, "Inter-Organisational Collaboration in the Biotechnology Industry" Vournal of Institutional and Theoretical Economics Vol. 512, 1996) p. 197-215 and "Neither Market Nor Hierarchy: Network 
Forms of Organisation" (Research in Organisational Behaviour Vol. 12, 1990) p. 295-336. Powell's work has recently been extended by quantitative analysis in network science.

12. See Jeong, Hawoong, and Albert-László, Barabási "The Global Organisation of Cellular Networks" (Department of Physics homepage, University of Notre Dame, http://www. nd.edu/ networks/cell, 2001) and J eong, Hawoong et al "The Large-Scale Organisation of Metabolic Networks" (Nature Vol. 407, 5 October 2000) p. 651-54. For a popular treatment see Barabási's Linked: The New Science of Networks (Perseus, 2002, Cambridge). In a related vein, see the work of Alan Kirman, such as his article "The Economy as an Evolving Network" (Journal of Evolutionary Economics Vol. 7, 1997) p. 339-53.

13. The research on economic networks is wide and varied, with a great deal of it growing out of complexity research at the Santa Fe Institute. For information on other research related to network science, see Arthur, W. Brian et al (eds) The Economy as a Complex Evolving System (Santa Fe Institute Studies in the Science of Complexity, Perseus, 1997, New York) and Rauch, Jonathan "Seeing Around Corners" (The Atlantic Monthly http:// www.theatlantic.com, April 2002). For a broad sociological analysis, see Castells, Manuel The Rise of the Network Society (Blackwell, 1996, New York).

14. For a classic historical treatment of the occult see Yates, Frances The Occult Philosophy in the Elizabethan Age (Routledge, 2001, London). For a popular treatment of black magic see Cavendish, Richard The Black Arts (Capricorn, 1968, New York).

15. See Robbins-Roth, Cynthia From Alchemy to IPO: The Business of Biotechnology (Perseus, 2000, New York). 16. See Rifkin, Jeremy Algeny (Viking, 1984, New York) and The Biotech Century: Harnessing the Gene and Remaking the World (Tarcher/Putnam, 1998, New York).

17. See Mauss, Marcel A General Theory of Magic (trans. Robert Brain, Routledge, 2001, orig. 1902, London). Though more recent books have explicitly addressed the relationship between technology and magic, Mauss' study was key in asserting the coexistence of magic, the social and technique. For recent examples see Davis, Erik Techgnosis: Myth, Magic and Mysticism in the Age of Information (Three Rivers, 1999, New York) and Stivers, Richard Technology as Magic (Continuum, 2001, New York).

18. As Mauss states, "Mana is not simply a force, a being, it is also an action, a quality, a state... One the whole, the word covers a host of ideas which we would designate by phrases such as sorcerer's power, the magical quality of an object, a magical object, to be magical, to possess magical powers, to be under a spell, to act magically... It reveals to us what has seemed to be a fundamental feature of magic - the confusion between actor, rite and object" (p. 133-34).

19. On the concept of "biovalue" see Waldby, Cathy The Visible Human Project: Informatic Bodies and Posthuman Medicine (Routledge, 2000, New York) p. 33-34.

20. See the web site for the Dark Markets conference (http:// darkmarkets.t0.or.at). As suggested by Lovink, the notion of dark markets (and a new media dark age) is more impressionistic than historical. It is meant to describe the current condition in which total technological enablement (net rhetoric) is accompanied by total political inactivity (apathy, agonism, confusion). Dark markets denote the black boxing of technopolitics, while technology itself becomes increasingly diversified and even open source (inasmuch as open source and development are seen as new niche markets). From this perspective, the strategy is to get people to use the technology, and divert attention from political inquiry and pragmatics. 
REGISTRATIONSREGISTRATIONSREGISTRATIONSREGISTRATIONS REGISTRATIONSREGISTRATIONSREGISTRATIONSREGISTRATIONS REGISTRATIONSREGISTRATIONSREGISTRATIONS

REGISTRATIONSREGISTRATIONSREGISTRATIONSREGISTRATIONS REGISTRATIONSREGISTRATIONSREGISTRATIONSREGISTRATIONS REGISTRATIONSREGISTRATIONSREGISTRATIONSREGISTRATIONS REGISTRATIONSREGISTRATIONSREGISTRATIONSREGISTRATIONS REGISTRATIONSREGISTRATIONSREGISTRATIONSREGISTRATIONS REGISTRATIONSREGISTRATIONSREGISTRATIONSREGISTRATIONS REGISTRATIONSREGISTRATIONSREGISTRATIONSREGISTRATIONS REGISTRATIONSREGISTRATIONSREGISTRATIONSREGISTRATIONS

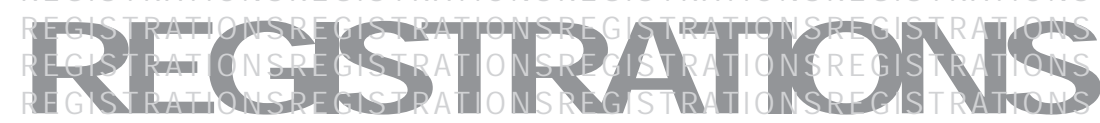

REGISTRATIONSREGISTRATIONSREGISTRATIONSREGISTRATIONS REGISTRATIONSREGISTRATIONSREGISTRATIONSREGISTRATIONS REGISTRATIONSREGISTRATIONSREGISTRATIONSREGISTRATIONS REGISTRATIONSREGISTRATIONSREGISTRATIONSREGISTRATIONS REGISTRATIONSREGISTRATIONSREGISTRATIONSREGISTRATIONS REGISTRATIONSREGISTRATIONSREGISTRATIONSREGISTRATIONS REGISTRATIONSREGISTRATIONSREGISTRATIONSREGISTRATIONS REGISTRATIONSREGISTRATIONSREGISTRATIONSREGISTRATIONS REGISTRATIONSREGISTRATIONSREGISTRATIONSREGISTRATIONS REGISTRATIONSREGISTRATIONSREGISTRATIONSREGISTRATIONS REGISTRATIONSREGISTRATIONSREGISTRATIONSREGISTRATIONS REGISTRATIONSREGISTRATIONSREGISTRATIONSREGISTRATIONS REGISTRATIONSREGISTRATIONSREGISTRATIONSREGISTRATIONS REGISTRATIONSREGISTRATIONSREGISTRATIONSREGISTRATIONS REGISTRATIONSREGISTRATIONSREGISTRATIONSREGISTRATIONS REGISTRATIONSREGISTRATIONSREGISTRATIONSREGISTRATIONS REGISTRATIONSREGISTRATIONSREGISTRATIONSREGISTRATIONS REGISTRATIONSREGISTRATIONSREGISTRATIONSREGISTRATIONS REGISTRATIONSREGISTRATIONSREGISTRATIONSREGISTRATIONS 


\section{McLuhan's Pendulum Reading Dialectics of Technological Distance

t seems a perpetual human characteristic that we continually exert our collective selves ever outward in space. While outer space, cyberspace, web space, personal space, quiet space are examples of metaphors through which we endeavour to explore 'space', I wish to address a relationship between geographic and social spaces manifest in discourses of distance - separation in space and time ${ }^{1}$ - using primarily Marshall McLuhan's (1964) controversial probing of media. Distance (Latin: distantia, distare: stand apart, be different) ${ }^{2}$ may be expressed as an interval, separating any two instances in time or place (place, I take to be the intersection of time and space). It is expressed as a point far away, aloofness, measurement, ${ }^{3}$ the property, terrain (or attitude) of the space between two objects (or ideas), remoteness or the impression of remoteness, the condition of being apart.

In the network of river, bridge, cities and surrounding environment nothing remains unchanged. Social and technical actively interact, exchange properties and negotiate identities, thus shaping one another. Technologies, then, are not neutral tools, or passive containers, but environments that shape and hold together a set of social dynamics that are simultaneously a consequence of their existence and necessary for their survival. The introduction of the new bridge does not result in two cities plus a bridge, but in a qualitatively different urban landscape composed by distinct social relationships.

Reflexively, we may also declare, humans have forever been obsessed with moving outward to control both geographic (physical) and cognitive distance. From our earliest forms of communication to the most current - from gestures and grunts to speech to currency, art, the alphabet, writing, mechanical printing, electric, electronic to digital wireless and deep space - we continue to express ourselves through a desire to understand and command distance. As communication is the chief operative here, we may say that distance is space which diminishes communication. At the same time, communication diminishes various frictions of distance (i.e. terrestrial, geographical distance), which may be measured in time or in the cost of overcoming it (Harvey 1990). The achievements of social communication to affect social organisation are what we must name technologies - tools intelligently created in response to visceral needs and intellectual curiosity.

I would suggest, in fact, that all technological developments are related to our obsession with distance. Language brought once-isolated families and tribes together and organised them into cultures. Culture accumulated knowledge and technique and created territory; horticulture allowed people to be more stationary. Likewise currency, which also per- 
mitted property and profit from afar. The wheel, ships, print - the list of distance controlling innovations is endless. Language expresses distance. Aristotle defined 'verbs' as significant sounds marking time, present or past, and 'nouns' as sounds not marking time - something named and static in a space. ${ }^{4}$ We frequently misspeak expressions of occurrences happening 'over' a period of time, as through a physical space (distance).

Marshall McLuhan (1964) called communication technologies extensions of our human selves. Each medium of communication represents an acceleration over the last (I'll refrain from calling it a 'forward' movement or the 'progress' of communication) and, as such, each has increased the sense of human power over distance (and sometimes over whatever lies in the interval). Expressions of this empowerment have been caught up in the acceleration as well, so that in our contemporary communication environment we practically beat our breasts ape-like while proclaiming that we are indeed lords of the jungle - finally. Cheerleaders and prophets tout new systems of communication as the effective annihilation of distance, an implosion of space and time, of topography, and they foresee a new era of neutral, barrier-free access to information, ideas and material things.

Communication enables us to keep our distances too. We humans have an ironically inverse relationship with distance, of which urbanisation serves as a straightforward example. As people move closer together physically they do not necessarily move closer together communicatively. Kern, in Harvey (1990), says proximity generates anxiety and apprehension. We know people across town better than our next-door neighbours, while people who live within walking distance of one another, or work in the next cubicle, will communicate by telephone and e-mail - concomitantly bridging and preserving their distance, their physical space.

As such, electronic communications technologies do not remove boundaries, as is imagined by many proponents of the Internet and its World Wide Web of services. At best, I suggest, technology simply rearticulates communicative distance. I will try to avoid the rocky road of technological determinism, ${ }^{5}$ by focussing instead on the discursive terrain of the so-called borderless society and propose that, in practice, information and communication technologies (ICTs) cannot change such boundaries, other than to rearticulate them

Space, time and distance are integral to our everyday existence. We know instinctively what they are and our relationship with them, as evidenced by their metaphoric ubiquity in language, and nowhere is that more evident than in communication technology which permeates the contemporary lexicon. Wireless telephones keep us in constant touch with each other; automated tellers mean we don't have to visit the bank, while Internet shopping, video movies on demand and many more examples promise us that distance doesn't matter anymore.

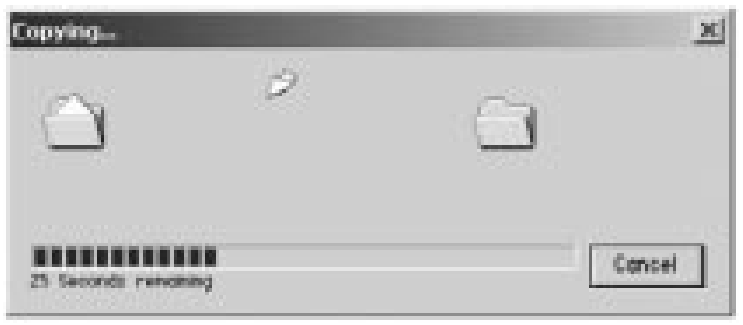


Remote and rural communities are told they are no longer disadvantaged by geography, by the friction of distance. Some are told by proponents of ICT that they live on nodes, not islands (assuming sufficient bandwidth) - that they can take advantage of the global economy because communication makes participation possible irrespective of locale. Personal experiences, however, tell us that this is not always so - that, despite getting the jump on geography, communication technologies sometimes hamper efforts/ needs to communicate. Later in this essay I will offer several anecdotes that illustrate the point. Suffice it to say here that there is an acknowledged ambivalence towards technology regardless of distance. We at once embrace its promise of bigger, better, faster but remain suspicious of its effects. While communications media connect us over distance, many people, as I shall outline, believe technology disconnects us from our 'natural selves' - what I like to call a kind of anomiedia.

McLuhan taught us that these polemics of technological discourse are predictable contestations, and that by examining the discourse of the discontinuities between established and intervening modes of communication we learn how changes are bound to affect us socially. McLuhan's probing of the discontinuities between the Age of Print and the Age of Television serve as an example of such a discussion, and I explore some of them as a means of working out competing discourses of communication technology and distance. One demographic, frequently addressed by both sides of this discourse, is youth; and McLuhan's observations about the behaviour and social communication of young people of the TV generation are a good place to begin.

\section{Understanding Media}

On the cusp between the established and the future, youth may be seen as a bellwether of attitudes, problems and change. From the writings of the so-called Beat Generation in the 1950s, through the Baby Boomers who were adolescent in the 1960-80s, to Generation X and now the Net-Generation (Tapscott 1998), youth has always embodied the spirit of innovation, of acceleration - which helps to overcome barriers (Harvey 1990) - of communication and social change, especially since the Second World War. They have also been the focus of consternation for adults; in the West the youth has the affectations of a society liberalised by mass media. Radically different tastes in music, attitudes toward sexuality and political activism are concomitant with the aforementioned acceleration.

McLuhan attributed these shifts to television. He theorised that in TV was a completely new form of technology, that involved communicants in ways the telephone, radio and books could not, because TV required greater sensorial participation than its predecessors (although he did not regard TV as an extension of them). Television involved visual as well as audile senses, and he said it had a tactile quality as well. TV reception is effectively the sequential electronic beaming of thousands of points of light on a screen in a luminous mosaic from which the brain must make sense. It is with no small degree of cognitive ability that the brain, with the help of culture, deduces what the audio-visual mosaic conveys, assembles it and processes it as an image fully formed. McLuhan called this sensorial experience audile-tactile, and believed that it more closely reflected the social communication experience than any form of mass communication had since the advent of the mechanized word. 
This he called "re-tribalisation" (1964), a return to the "allatonceness" (Horrocks 2001) of pre-literate society, when humans relied on all their senses for communication. It was from the idea of the re-tribalisation of the mass audience that McLuhan coined his famous term, "global village". He attributed the social disruptions of the 1960s to the TV generation - a generation spurred to more visceral participation and experimentation in part by audile-tactile participation in a society whose dominant medium was so. The "radio and gramophone and tape recorder gave us back the poet's voice... TV caused young poets suddenly to present their poems in cafés, in public parks, anywhere. After TV, they suddenly felt the need for personal contact with the public" (McLuhan 1964, p. 53).

McLuhan saw in television a simultaneity which figuratively brought people together because they shared the same information - like the gathering of parishioners around the town crier - broadcast at the same time through the same medium. Therefore, at least insofar as communicating information was concerned, distance would be gradually less inhibiting, he predicted. This is in contrast, he suggested, with earlier forms of mass communication, specifically the mass-produced book which effectively isolates each communicant by 'cutting off' the use of all but visual senses as they concentrate on what is before them.

As the dominant medium of its day, McLuhan suggested, the book cut people off from the tactile world, distancing them from the communicative environment which makes them human. McLuhan allows that through the Age of Print, partly as a result of the predominance of print structure, reproducibility and linearity, Western society in particular became both intellectually and kinaesthetically distant from their natural allatonceness, transformed into a narrow-minded, mechanistic, scientistic and individualistic society. Printing from moveable type was a major discontinuity in the history of literacy, "just as the phonetic alphabet had been... between tribal and individualist..." (Ibid. p. 39). The re-tribalisation of social communication in TV disrupted those tendencies, brought us closer to our human selves, as I have said, and thus closer together as a community of humans. In McLuhan's probing we see evidence of ideas of the technological mediation of both cognitive distance (e.g. creation of, by mechanised print) and physical distance (e.g. annihilation of, by TV).

In contrast, he also spent no small amount of time expressing ideas of media from which we might gather almost the opposite. He suggests there is a numbness that comes with the successive extensions of our human selves. "Thus the age of [discontinuity] and of electric media is also the age of the unconscious and of apathy" (Ibid. p. 47).

J oshua Meyrowitz (1985) agrees with McLuhan's synopsis of the Age of Print, but sees the visceral behaviour of the TV generation in a less positive light, suggesting (having twenty more years of TV maturation to consider than had McLuhan) that the behaviour of young people from the 1960 s to the 1980 s was symptomatic of a cognitive dissonance, a

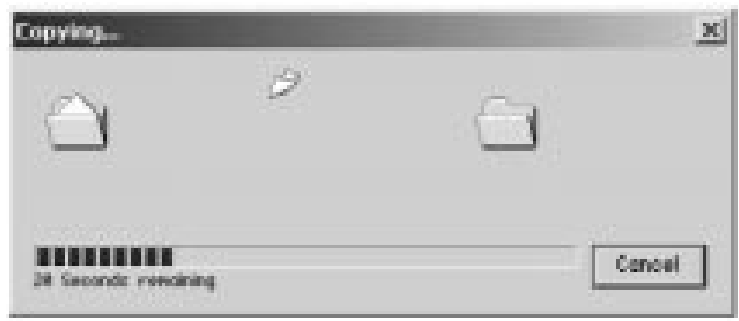


distancing of their "sense of place" (Meyrowitz 1985). Whereas McLuhan theorised television as something entirely new, Meyrowitz recognises it as an extension and subversion of the linearity of social thought and behaviour shaped by print literacy. McLuhan stuck to the sensorial, audile-tactile aspects of the new medium, whereas Meyrowitz concentrated on the interpersonal and intergenerational aspects, suggesting that electronic media have removed barriers of significance, loosening ties with old spaces.

"Electronic media affect social behaviour - not through the power of their messages but by reorganising the social settings in which people interact and by weakening the once strong relationship between physical space and social 'place'"' (Meyrowitz 1985, p. ix). As we gain new exposure to (if not appreciation for or appropriation of) other behaviours, we lose our "sense of place". Media "are not simply channels for conveying information between two or more environments, but rather shapers of new social environments themselves". For Meyrowitz, media reshapes situational geography - distances (Meyrowitz 1994, p. 51).

Orality requires physical presence. As such, change is slow because survival depends on memory and tradition - creativity and newness are discouraged as potentially destructive. The fixity of writing began the breakdown of social cohesion by allowing people to distance themselves from tradition - symbolic communities competing with practical communities. Critical to Meyrowitz's sense of this social change is that unlike hearing and speech, reading and writing are less natural means of communication and acquiring them will have full effect only when they are learned at a young age. There is a discontinuity when succeeding generations are alienated from their forbears because of new forms of communication.

Print divides people into separate communication systems, distancing them from sound, touch and face-to-face response, allowing them to become more introspective and individualistically rational. In turn, individualistic, linear thinking distances people from natural cycles and substitutes new logics. Following McLuhan, Meyrowitz says electronic media recall simultaneity, a key aspect of oral societies - action, perception and reaction again become prime forms of communication. Only this electronic aurality is far different from that of olde; it is not limited physically to time and space. The impression of experiencing distant events fosters a decline in power-instigated, print-supported, implicit hierarchies, thus imploding social structures.

The TV generation rejected traditional roles and discourses for young and old, breaking long-standing connections between where one is and what one experiences. It blurred the distance between public and private and lifted many of the old veils of secrecy between children and adults. "As we move forward [sic] our society spirals backwards" with middle and upper-class people acting out behaviours of the lower classes (e.g. less restrained sexuality, drug use, civil disobedience), supporting a view that we are moving from literate to oral forms of behaviour (Meyrowitz 1994, p. 68).

McLuhan's vision of the global village is predicated upon people's access to and sharing of the same information, thanks to electronic media. Meyrowitz suggests that the mere sharing of opinion and life options is too weak a bond to hold some people together - that one cannot realistically consider the whole world as one village. If our contemporary world at times seems senseless and erratic, it may be because electronic media have untethered 
us from place, from roots and time, from distinctions between here and there, live and mediated, personal and public. We are distanced from our place.

Neil Postman (1993) highlights the discontinuity between print and TV generations by suggesting that children are required to circulate in multiple perspectives. On the one hand is their world of television - in which, from a young age, we are all so thoroughly immersed - and its "emphasis on imagery, narrative, presentness, simultaneity, intimacy", immediacy and emotion, not to mention commercialism. On the other hand, we send them off to school and the pedagogical world of print, "with its emphasis on logic, sequence, history, exposition, objectivity, detachment and discipline" (Postman 1993, p. 16). The classroom exemplifies what he calls a centuries-old "truce" between orality and print - into which we send our children, long weaned on TV, and expect them to sit still for it.

Like McLuhan, Meyrowitz finds importance in social relations on the cusp of change and allows that relations are often hostile to change during an initial period of disruption, only later settling into separate but equal roles and status - succeeding generations having bypassed the distance of previous generations' constraints of mediated knowledges. He suggests, and many agree, that electronic media facilitate greater awareness than they do understanding. "Being smart", he says, is a command of knowledge that "plays well" in everyday discourse (Meyrowitz 1999, p. 115).

Don Tapscott's Growing Up Digital (1998) "plays well" in contemporary discourses surrounding youth and new media culture. McLuhan, Meyrowitz and Postman focussed on generational discontinuities between the Ages of print and TV while only speculating on what it will all mean in an age of digital communication. Although they recognised aspects of print and television in new media, they didn't seriously articulate what, if any, disruptions were likely from its adoption. McLuhan, we remember, treated TV as something new, as a break from print. Meyrowitz treated it as an extension of print and radio, but noted the kinds of social change it facilitated. Postman doesn't like what he sees in our technological society, dominated as it is by television, but is nostalgic for the logic and tradition of print. Tapscott sees computers and the Internet not as extensions of either print or television, but as a break from both. The "Net-Generation" (N-Gen) distances itself by its command over a new manner of communication that barely resembles the earlier, he says. Tapscott is an unabashed cheerleader for new media and the manner in which young people interact with and use it. In doing so, he doesn't mince words about TV and print social histories. He suggests that N-Geners are more "alert, aware, focussed, and certainly in control" (Tapscott 1998, p. 85) of their information media than were previous generations, and argues this is a result of leaving behind the broadcast world which distanced producer and viewer. Their interactive media elicit "intensely heightened curiosity" (Ibid. p. 87) - they are more com-

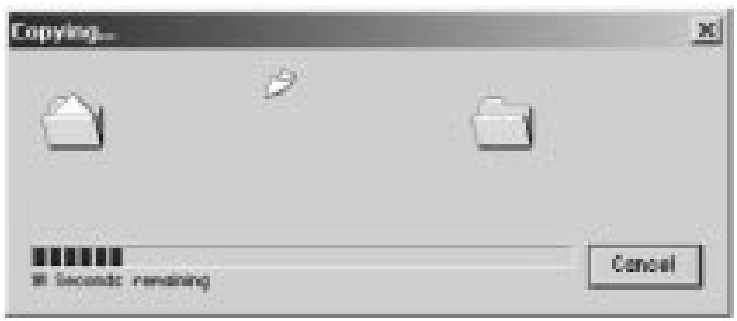


fortable, knowledgeable and literate than their parents and "through... digital media... will develop and superimpose [their] culture on the rest of society" (Ibid. p. 1-2).

Tapscott says digital media are different from previous media paradigms because they offer many-to-many communication as opposed to the one-to-many communication of broadcast, and he sees TV's only future in being incorporated into the Internet. N-Geners want to be users, "not just viewers or listeners" (Ibid. p. 3). They are using digital media for entertainment, for communication, for shopping and for learning. "Kids use computers for activities that seem to go hand in hand with our understanding of what constitutes childhood... they use the technology to play, learn, communicate and form relationships as children have always done" (Ibid. p. 7). It involves the development of logic, thinking, personality and autonomy, all of which are enhanced in an interactive world. "When children control their media, rather than passively observe, they develop faster" (Ibid. p. 7).

He admits, however, that issues of imbalance in childhood development, such as too much computer time, TV time, and lack of fitness needed for healthy development, require parental intervention, but that most children "correct such imbalances themselves". Importantly, Tapscott states: "What we know for certain is that children without access to the new media will be developmentally disadvantaged" (Ibid. p. 7), distanced from their peers and an education system that is bent on computers.

Unlike television, which "robbed children of hours of play each day", digital media is restoring precious play time - it is not the end of childhood but a brave new world of play, he proclaims. Time on the Net "is not passive time, it's active time. It's reading time. It's investigative time. It's skill development and problem-solving time. It's time analysing, evaluating. It's composing your thoughts time. It's writing time" (Ibid. p. 8). But whose time is it and what does it cost?

McLuhan would, I think, have reminded Tapscott that a computer is the medium, while the Internet, WWW, chat rooms and games are content and therefore play a lesser role in the uses of time. The modestly tactile interactivity of the computer (i.e. keystroking) is different from the sedentary activity of television watching and far and away greater than the isolating activity of silent reading, with which McLuhan and Meyrowitz had so many problems for its "enclosure" of thought (McLuhan and Zingrone 1995, p. 138). Although I don't think McLuhan saw it, computer and TV screens are enclosures too, confined to their screens and conventions, distorting what they strive to represent (Harvey 1990). Time in front of the computer is surely as disorienting and distancing from the real as TV - story and image are biased against space/ place and against time/memory despite being in motion (Ibid.).

In a momentary and characteristic leap from known electric media (he was writing in the 1960s remember) McLuhan makes reference to the data-isation of human endeavour through the overwhelming expansion of communication technology. Our every action, he reports, is "noted by some computer that translates our least gesture... Our private and corporate lives have become information processes..." (McLuhan 1964, p. 52). Our physical selves, like physical distance, can disappear in information. Digital graphics, for instance, communicate in visual perspective, but ultimately are an applied perspective of algebra and geometry. Computer generated and mediated images are mathematically perfect but do not satisfy our desire for reality (Bolter and Grusin 1999). 
Even the latest in virtual reality, or immersive media, while they may nominally disorient the body's multi-sensorial mechanisms for balance, require varying degrees of cybernetic peripherals which mediate the experience. It is important, therefore, as McLuhan and Meyrowitz have shown, that we continue to ask questions, to probe the varied affectations and effects of digital media, particularly in this contemporary period of discontinuity. We will need to know where new media will affect social organisation. Perhaps some of the following anecdotes will resonate.

\section{Experiencing Technological Distance}

It is too soon to state categorically the long-lasting effects of new media in the $21^{\text {st }}$ century on social organisation in wider (Western) society. A future generation of critics face making that judgement of us, but many observers would suggest that we are seeing a few, at least, today. I suggest that many of our day-to-day interactions with communication media and other digital devices provide some hints, and in this section I will share some anecdotal observations and explain how I believe they relate to technological distance. Later, I will return to McLuhan, Meyrowitz and Tapscott to contextualise relations of distance in their key points, thus condensing the discourse so that we may observe its dialectics. ${ }^{6}$

The consumer-level world of electronic appliances has many products which articulate what I have already called 'anomiedia'. TEAC, a Japanese maker of consumer electronics now carries a line of nostalgia-inducing stereo systems - their radios, for instance, have knobs for analogue-like tuning and come complete with the sounds of static between station frequencies, a tacit signification of the 'distance' between stations represented by their numerical spectrum frequency. This is not to be mistaken for static, mind you, it's the sound of static provided electronically just for effect. Apparently the throwback products are selling well, perhaps as people become increasingly anxious with the array of sophisticated devices that permeate their lives (Hafner 2002). Communication technologies may fool us, are sometimes startling and confusing and therefore make us feel, but experientially we remain distanced.

Not only are stores well stocked with digital devices for sale, they are well equipped with them. My favourite example is the customer-accessible scanning device strategically located in popular department stores. The device works the same way as scanners at the check-out counter: an infrared laser 'reads' the UPC (bar code) label on the product and displays the price as it has been programmed into the store's database. At a store near my home, the installation of these devices seems to have coincided with fewer and fewer items on the shelf displaying a price. Whereas they were intended to assist customers in anomalous situations when a tag has fallen off, or the prices are confusing, they seem to have

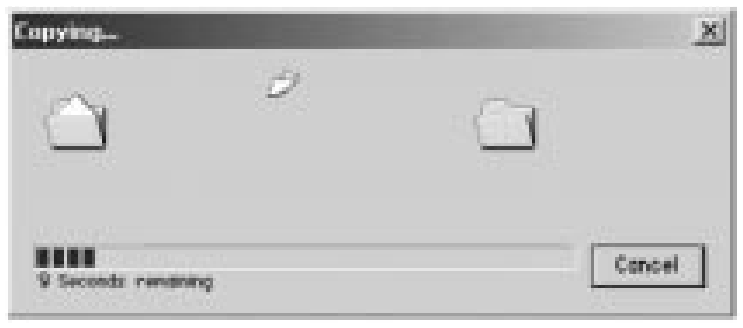


been adopted as a labour-saving device and shifted the onus on to the consumer to do the work of store clerks. The installation of technology seems often not only to distance people from each other, but sometimes from their responsibilities as well.

In early 2000, a Canadian national bookstore chain severed their shared online (WWW) presence with a national newspaper, through which (after a long semi-Luddite period of reluctance) I periodically ordered books. It concerned me that they had not notified their customers of the change and confounded me when I tried to find out what they did with the personal financial information on my file. I attempted to contact them by telephone, but of course telephone systems are highly automated now as well, so one has to be aware and creative just to reach someone to speak with. When I did get through, no one could answer my question: What happened to the confidential client information in their database, including credit card numbers? For weeks I attempted to reach customer service representatives who did not return my calls or e-mails, so I telephoned the main switchboard and asked for the street address of customer service so I could make my inquiry in person - the receptionist didn't know.

Eventually, after three months and several visits to their physical offices to resolve an online problem, I was mailed a letter of apology and some coupons (neither of which I had sought) for my next online purchase. Ironically, they didn't work and I had to go into a store, physically, to take advantage of the coupons. Further, my question was never answered. The ability of technology to mediate customer interaction has distanced service from transaction, despite the rhetoric of being in the relationship business (whether terrestrial or electronic). It is true that this is an evolving use of technology, but one which has caused a devolution of common courtesy and reasonable business practices.

For about twenty-five years, Canada's national postal service, like the chartered banks, has been closing storefront services in small and rural communities in favour of group mailbox sites and the licensing of local retailers to sell postage stamps. As part of the effort, terrestrial mail delivery addresses changed, all but erasing the names of many roads and communities. In more recent years, centralised and computerised dispatch has caused the reappearance of community names to facilitate the delivery of emergency workers, such as ambulance and fire personnel, who may be unfamiliar with local place names and landmarks. Reductions in labour costs precipitated the disappearance of places. Their reappearance, while welcomed on both counts (sense of belonging and sense of security) has been to suit technology; databases are also used to manage taxation and demographics. Person-to-person communication facilitated the obliteration of place and distance; technological communication restored them.

Electronic mail has, for many people, lessened the degree to which they use conventional surface mail (which might explain the radical improvement in mail service and customer service at Canada Post) because they feel they are able to communicate more often. It's easier to keep in touch if you can type out a few words on a whim, rather than plan out a legible letter. I never communicated so much with my own family as when all got e-mail; it reduced the frictions of communication distance between us. For a long time, we would also share photos and the visual humour that so permeates the Internet. Not any more. The frequency and threat of e-mail borne computer viruses has not only stopped us from open- 
ing attachments, it has actually curbed the frequency of communication. For a time, technology improved our communication over distance, but it later instilled a paranoia that has supplanted that distance.

As part of the planning for a Saturday conference in the Spring of 2000, I had occasion to request equipment from a university's audio-visual department. Because the conference was outside the institution's network of connected buildings I would have to pick it up and return it. Further, it being a Saturday, and despite the fact that there would be employees about picking up other equipment in nearby buildings until 4:30 pm, I had to return mine before the counter closed at 12:30 pm - four hours before I would be finished with it. For a few minutes I had the clerk agreeing with me that perhaps we could find a way around this, until he went to fill out the requisition on his computer. No alternative arrangements could be made because the computer could not, as it were, think outside the box. On a person-to-person level, we were able to negotiate, to communicate, and the computer was supposed to facilitate this. Instead, it distanced us from our goal.

Computer mediated transactions merely cut out communication with salespeople, the goods still have to cover the distance. Automated bank teller machines let us communicate with our virtual money, but distance us from the institution. (In fact, as clients we now perform functions formerly required of bank employees - and pay for the privilege). Personal digital devices hold our attention on public transport and sidewalks while distancing us from the sounds and smells of the people around us. In sum, while these communications technologies mean we can buy what we want without stressed, rude, unhelpful or pushy salespeople, while they mean we can access our money without lining up in an understaffed bank listening to impatient children haranguing parents to go home, and while they allow us to be in touch with friends and lovers at all times, they exchange distance for distance.

\section{Conclusion}

Information and communication technologies are often held up as portending greater democracy - they are supposed to bring us all closer together in a neutral, egalitarian space - and in many instances and examples this has been true. There are some remarkable stories about the use of ICT to call attention to people's plights, to provide alternative information and news sources, and to coalesce groups of like-minded individuals. Proponents of the 'information highway' have always said that it would facilitate progress, democracy, solutions to environmental issues and greater awareness of the world (cf. Robins and Webster 1999). These, however, are examples of improved communication between like-minded individuals for whom intellectual distance is already somewhat diminished by what they have in common.

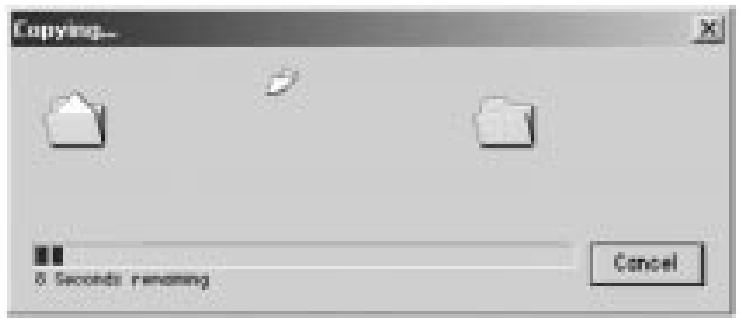


There have been countless ruminations on the decentralising possibilities of ICT, as I mentioned much earlier in this essay, sometimes borrowing from the urban longing for connections with simpler times often heightened by continual interaction with the plastic "ruralism", Robins and Webster call it - by suggesting that ICTs may "effect a return to a lost way of life" (Robins and Webster 1999, p. 70), a search for "more secure moorings... in a shifting world" (Harvey 1990). McLuhan and Meyrowitz both wrote about the implosion of centre and margin, as a result of the outward accelerating dynamics of electronic communications, both implying that distance was less relevant. Yet their academic predecessor Harold Innis (1952) showed that communication technologies centralise power, at the expense of the peripheries - information distance vs. distance from power.

In this essay I have discussed, however briefly, a number of ways we express and experience distance and highlighted the ways in which this important but abstract aspect of our communication ecology pushes us to command it. We are driven to fool ourselves (and allow ourselves to be fooled) that we can. McLuhan showed us how the technologies of alphabet and printing, as the dominant media, distanced us from our humanness by the virtual amputation of some senses (and some sense) through concentration by one sense. He attempted to suggest that TV, as the dominant medium, reactivated those senses and put us in touch with our humanness, breaking down those barriers. Yet he recognised the distances in expressions of discontinuity - distance between generations, for instance. Meyrowitz acknowledged the distancing tendencies of print, as well as a subsequent weakening by electronic media. At the same time, we have seen, media exacerbates the discontinuity of place - a cognitive distancing. Tapscott claims that new media are creating new spheres of communication among young people, yet they are being distanced from the previous generation by an even wider learning curve than that which separated their parents from their parents. Children have access to more communication devices, but these do not collapse distance.

It is clear, then, in these theories and anecdotes presented, that communicative distance is not easily overcome, and here lies the dialectical discourse of communication technology in relation to distance. While technologies may mediate the friction of terrestrial, physical distance, the mediation itself subverts it, masks it, re-presents it. Harvey says distance is "both a barrier to, and a defence against, human interaction" (Harvey 1990, p. 219). Communication, as Peters (1999) following Locke suggests, is not merely information, not the emanation or the transmission, or even the reception of information; it is the digestion and understanding (even misunderstanding) of what is communicated. Distance, while measurable between places and across space and time, must also be regarded as the space between understanding and not.

An example of this may be in the fact that, despite numerous previous lessons, the world has never been more torn up by terrestrial conflicts than it is today - a result of conflicts over economics and over place. One of the great ironies of communication is that world war became possible only after the world had become highly united (Kern, in Harvey 1990). While Western-centric economic and financial communications empires tell us that place is less important for communication, it is becoming more important to people the reduction of barriers, as illustrated above, requires productions of new, and often con- 
tested, spaces (Harvey, 1990). The collapsing of spatial barriers does not mean that social distance is decreasing.

Very early in this essay I highlighted that our obsession with distance emanates from our most basic communicative selves; we pursue the control and continuity of distance instinctively. In discontinuity we also have a natural tendency, it seems, to pull back - not just because we become anxious and resistant to change, but perhaps because we understand the consequences. So, what pushes us onward, we must ask. Who/what are the beneficiaries of the acceleration of information and the perpetuation of the myths of the annihilation of distance?

To answer that question we might more closely examine the dialectic to learn what language is being spoken and who is speaking it. Clearly all the above examples and theories demonstrate that what is being privileged in this discourse is commerce. I suggest that the discourse of technological distance is articulated in the language of Capital, new "light capitalism" (Harvey 1990, p. 193) now predominantly concerned with the production of signs, images and information. New media of communication have collapsed distance in order to allow the free flow of capital into the space evacuated. Communication technology and social organisation is about commodity, not social communication, connecting economic forces, not people. If there is an annihilation of distance, it's an economic distance. Our consuming selves and our asset selves are drawn closer to those forces which relieve the former of the latter.

\section{NOTES}

1. The American Heritage Concise Dictionary (Microsoft Encarta 97 Encyclopedia).

2. Whitaker, William Download Words (http://lysy2.archives.nd.edu/cgi-bin/ words.exe?distantia).

3. Op. cit. 1.

4. Aristotle, trans. Butler, S.H. Poetics C. 350 B.C.E. (Hill and Wang, 1961, New York).

5. Called by some a crude theory of social change, technological determinism asserts that most social changes are the result of changes in technology, in technique. A problem with this causal view is that it regards technology as neutral, or of having properties that are outside the social. Fontana Dictionary of Modern Thought (1988).

6. 'Dialectic': detection and interpretations of contradictions, even opposites, and collision of ideas through debate and disputation. Fontana Dictionary of Modern Thought (1988); Brooker, P. A Concise Glossary of Cultural Theory (Arnold, 1999 London).

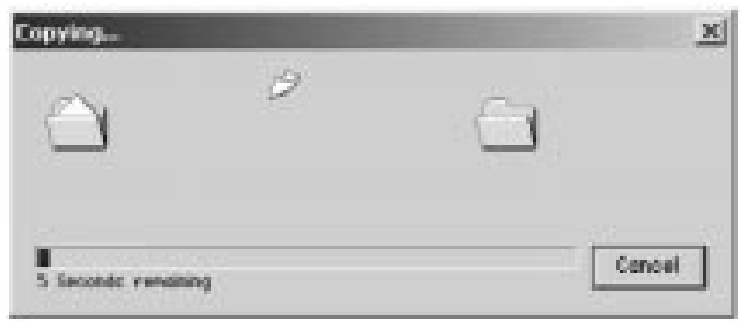


156 / Sarai Reader 2003: Shaping Technologies

\section{REFERENCES}

1. Bolter, J.D. and R. Grusin Remediation: Understanding New Media (MIT Press, 1999 Cambridge, MA).

2. Hafner, K. "Home not so sweet when living digitally" (in The Toronto Star 29 April 2002) A3.

3. Harvey, D. The Condition of Postmodernity (Blackwell, 1990, Cambridge, MA).

4. Horrocks, C. Marshall McLuhan and Virtuality (Icon Books, 2001, Cambridge).

5. Innis, H.A. The Bias of Communication (University of Toronto Press, 1995, orig. 1951, Toronto).

6. Ivins, W.M. Jr. Art \& Geometry: A study in Space Intuition (Dover Publications, 1946, New York).

7. McLuhan, H.M. The Gutenberg Galaxy (Signet, 1969, orig.1962, New York).

8. McLuhan, M. Understanding Media: The Extensions of Man (McGraw-Hill, 1964, New York).

9. Meyrowitz, J. No Sense of Place: The Impact of Electronic Media on Social Behaviour (Oxford University Press, 1985, New York).

10. Meyrowitz, J. "Medium Theory" (in Crowley, D. and D. Mitchell (eds) Communication Theory Today Stanford University Press, 1994, Stanford, CA) p. 50-77.

11. Meyrowitz, J. "No sense of place: The impact of electronic media on social behaviour" (in MacKay, $\mathrm{H}$. and T. O'Sullivan (eds) The Media Reader: Continuity and Transformation Sage Publications, 1999, London) p. $99-121$.

12. Peters, J.D. Speaking into the air: A history of the idea of communication (University of Chicago Press, 1999, Chicago).

13. Postman, N. Technopoly: The surrender of culture to technology (Vintage Books, 1993, New York).

14. Robins, K. and F. Webster Times of the technoculture: From the information society to the virtual life (Routledge, 1999, New York).

15. Tapscott, D. Growing up Digital: The rise of the Net generation (McGraw-Hill, 1998, New York). 


\section{Becoming Mobile SMS and Portable Text}

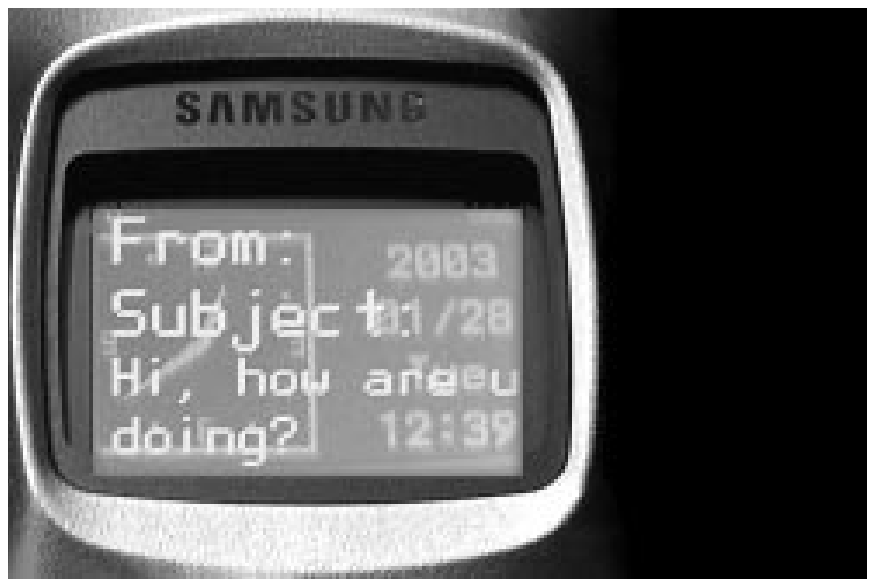

A multitude of uses for SMS have evolved during the short time that the process has been available. At the most basic level, this "short message service" allows the exchange of brief written texts which are sent from mobile phones or via the Internet and received on mobile handsets. As it makes use of existing hardware, text messaging can perhaps be best analysed if it is examined as a series of practices rather than a technology in its own right. As the process has only existed for a short time, the way that people use it is still in a state of flux. However, users are already developing conventions for the medium, many of which are based around the portability of SMS, its unintrusive quality, and its ability to fill 'dead time' and eliminate redundancy in language.

The success of SMS also owes much to the increase in text based communication that has occurred as a result of the popularity of the Internet and e-mail. Although the Internet contains inconceivable numbers of photographs, animations and sounds, the bulk of the information that people access via e-mail is written. This has been the first new form of mass communication for many years that has used a predominantly textual form, and it has affected the way people who use the medium relate to written language, and how they produce it.

Walter Ong hypothesised that the introduction of television and radio lead to a secondary orality, where people who had adjusted to written language became more familiar again with the spoken word. In a similar way, the use of e-mail and text messaging indicates the growth of a secondary literacy, with people who use these media becoming more comfortable expressing themselves in a textual form. Text messaging also affects the way 
that people express their thoughts because of its brevity - users are forced to express their thoughts concisely because of the 160-character limit the technology imposes. Perhaps because it affects the way that these users express their thoughts, it also affects the way that they think.

By primary orality, Ong refers to cultures that have not yet been affected by written language and the changes it brings to communication. Primary literacy had huge effects, especially after the advent of the printing press which allowed print media to become accessible to far more people than before. Secondary orality became widespread through broadcast media, such as television and radio, which once again foregrounded speech in popular consciousness.

The secondary literacy that has been called into being by media such as the Internet does not have the widespread repercussions of primary literacy, when the advent of radio and television had great impact on large sections of society. The texts being sent by SMS and e-mail that constitute this secondary literacy are primarily person-to-person transmissions, unlike the mass communication brought about by the printing press, radio and television. However, Ong also mentions the telephone as a significant element in the introduction of secondary orality. ${ }^{1}$ The telephone was revolutionary in the way that it allowed social functions previously confined to letters or telegrams to be discussed orally, in the privacy of the home. These telephone conversations bear a greater resemblance to the way that SMS, along with e-mail, is increasing the significance of literary texts in contemporary culture. Although these texts can be generated by anyone, and are usually only distributed to people known by the sender, they still hold power. The speed with which e-mail hoaxes and SMS pictures fly around the globe indicates the impact of this seemingly limited mode of transmission.

The convenience of text messaging cannot be underestimated. Its use of existing technology was a great advantage for the medium, especially as it made using that technology more affordable. However, another aspect of the medium's appeal can be found in its 'inconvenience': the effort taken to create messages. SMS provides evidence that in our society where communication is becoming increasingly effortless, there is a desire for media which require skill. So much of new media has focussed on ease of exchange, the almost effortless explanation of concepts and achievement of contact.

However, perhaps the ease with which a call can be made to anyone from anywhere, or a lengthy e-mail be sent in an instant across the globe, has revalued messages requiring more effort. The 'fun' that is associated with text messaging seems related to the time required to input messages, giving senders more opportunity to consider their message. An advantage of the character limit is that it makes this process bearable - repeatedly pressing keys to enter a longer text would doubtlessly prove unpopular. The combination of manual dexterity and verbal creativity required to compose a text message adds value to the process for both sender and recipient.

Text messaging allows private communication to occur in public places. This reterritorialises the spaces that users operate in, and affects their sense of self and home. Voice calls on mobile phones can be limited in some situations because of the need for privacy, but because text messaging is silent and discreet it can be used anywhere. The 'beep beep' 


\section{The 'beep beep' of an incoming message is a refrain that is capable of bringing home and community into an unfamiliar space.}

of an incoming message is a refrain that is capable of bringing home and community into an unfamiliar space.

Through sending messages the way users perceive themselves may change. Users practised in exchanging short texts may feel increased confidence in their social adroitness, even if they are uncomfortable when conversing in person. They are prepared to contact people who they would not dare call, as a rejection by message is far less crushing. The way that SMS users perceive time also changes. This is an effect of mobile telephony as a whole, where plans can be altered at short notice and arrangements deferred until the last moment. However, text messaging allows the user to change or cancel arrangements without the awkwardness of having to speak to the recipient.

Text messaging as a medium carries a dual function. The actual content signified by the message, the issues in the outside world that are referred to, is important. However, a large amount of the meaning in an SMS comes from within the world of the message, and without referral to the outside. The users create meaning in their composition of the message, their use of abbreviation and their manipulation of the character limit. This game-like aspect of the messages is extremely satisfying for both sender and recipient, and enhances the content value of each text.

In his discussion of McLuhan's work, Paul Levinson explores the concept of "remedial media", ${ }^{2}$ forms which function to counter the failings of an earlier process. The remedial aspect of text messaging is part of its appeal. Sending messages allows the user to conduct conversation in a new way, capitalising on the beneficial aspects of mobile telephony, but avoiding the inconvenience of long conversations or awkward voicemail messages.

The way that SMS has evolved supports the view that media are best thought of as 'boutique' practices, which are narrowly purposed. Although it has great value to those who use it, text messaging is restricted to specific groups. The digitised world is so disparate that it is no longer possible to make sweeping statements about the 'effects' or 'benefits' of any particular medium. While a medium may have distinct benefits or disadvantages for one group, it may make no impact at all on other sections of society. The days when the telephone or the telegraph affected entire countries are gone. Consumers now adopt new media in a far more specialised and selective way, choosing a medium which suits their lifestyle and then refashioning it according to their needs. The primary reason that SMS has been successful is that it offers the chance to reclaim text, releasing it from page and monitor, and allowing users to carry out familiar social processes in new surroundings.

\section{NOTES}

1. Ong, Walter Rhetoric, Romance and Technology (Cornell University Press, 1971, Ithaca/London) p. 295.

2. Levinson, Paul Digital McLuhan: A Guide to the Information Millennium (Routledge, 1999, London) p. 178-79. 


\section{Gadgetry and Subjectivity The Making of the Tamil Brahmin Self}

UMA MAHESHWARI KALPAGAM

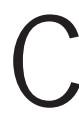

an we really deny that the food is not constitutive of the Self? I don't mean fat or slim and the varieties of slimming diets that are offered these days for a good price. That too does make our Self; the fact that America is so obsessed with obesity that they give tax-breaks for joining slimming programmes or buying exercise gadgets is enough of an indicator. Nor do I mean vegetarian, non-vegetarian, dairy free, sugar free, salt free and so on, the kind of menu indicators you most often forget to tell your travel agent about while booking international flights, only to find an overworked and unfriendly in-flight attendant serving a red-dotted pack of steak so you wake with your Brahmin sensibilities all shaken saying to yourself "Shiva! Shiva!" and hope the smiling stewardess in the other aisle will show some kindness and give you a green-dotted food pack. We never entered the flightcaterers' kitchens and don't really know whether the chef used the same knife to chop both the meat and the vegetables before you. Such mistakes of ritual pollution do not generally occur in the kitchens of our Brahmin households. For that matter they do not occur, or so we believe, in the numerous Udupi hotels that dot the cityscape of Chennai, or the numerous other vegetarian restaurant chains like Saravana Bhavan and Sangeetha Hotel that have left Udupi hotels trailing far behind. Here in J husi, Allahabad, which really does not offer much by way of cuisine other than the usual chai-samosa, I have often engaged in deep introspection on what makes those Chennai hotels tick. It didn't take long to figure that out. It's unarguable that idlis and dosas have more culture and commerce than chai-samosa.

We can argue whether culture precedes commerce or commerce precedes culture, but we do know for sure that whatever the commerce of idli-dosa in North India, its culture lies wholly in the heart of the South. Rather, the heart of the Tamil Brahmin, even if Chettinad Aatchis raise a few objections and the Kanchepuram lyengars staked claim to an independent identity long ago on the basis of their Kanjeevaram idlis. The fried idli of the North is an unwelcome intruder, which seeks to dislodge both idli and vada from their cultural heights through the power of vulgar commerce. But how did idli-dosa become the quintessential feature of Tamil Brahmin culture, at ease when juxtaposed with Carnatic music? For that matter, why did idli-dosa as an aspect of Brahmin culture spread and find acceptance among the Tamil subalterns, while Carnatic music suffered elite containment within the Mylapore Music Academy? These perennial questions can preoccupy the new breed of cultural theorists but one thing is for sure: when culture and technology meet, the filter coffee that distinguished Brahmin culture in South India loses out to idli-dosa.

Filter coffee, the Brahmin specialty, remained technologically stagnant, not giving way either to Starbucks culture or the commerce of coffee percolators. Not for us the Café

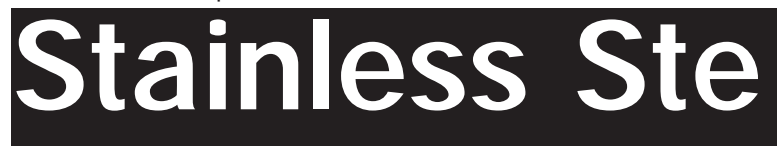


Latte, Café Mocha, Cappuccino, Turkish coffee, Brazilian or Colombian coffee. Not even Nescafé or Bru for that matter. Not for us the filter papers and electric coffee makers that compete with each other in American department stores; even liberalisation and duty-free imports have not brought those coffee makers to Chennai's recent fad, Spencer's Shopping Mall. Although coffee filters may not have much to offer as a story, the small black coffee grinder from Brahmin kitchens of some 30-40 years ago has now become a museum artefact. In those days when there were no television cartoons, the coffee grinder helped mothers discipline naughty children in the afternoons. They filled it up with roasted beans and made them grind it all. Coffee filters made little progress, only the brass ones were replaced by stainless steel. And therein lies the little known story of the stainless steel modernity of Brahmin kitchens.

\section{Stainless Steel Modernity}

Traditional Brahmin kitchens took pride in their collection of brass, bronze and copper utensils. Shining brass and bronze vessels like kuja (screw type flask), kudam (water pot) and shombu (small water pot) were cleaned meticulously with tamarind and ash every day by the non-Brahmin domestic servants of Brahmin households, while the Brahmin women themselves spent considerable time in acquiring them and comparing their collections with others'. A considerable part of the collection was part the dowry and part the heirloom of the family. But no 'utensil dowry', known in Tamil as paathra sheer, was considered complete without the Adhirsam container - thooku, sampadan or adhuku. The long traditional bronze lamp called kuthu vilaku still remains in all Brahmin homes, almost the sole relic of the era of brassware. The replacement of these brass and copper vessels by 'ever-silver' (stainless steel) was mainly on account of the 'ever-silver' quality. Brass and bronze vessels tended to get tarnished and their cleaning was a complex process done by domestic servants. As urban poverty made survival increasingly difficult for poor households, most domestic servants had to take up such work in more than one house. They were the first to resist brassware, as cleaning consumed a lot of time, which they could not afford. Also, as absenteeism among maids became routine, the task of cleaning was often left to the grown-up daughters or daughters-in-law of the house.

Brahmin mothers of the sixties and seventies collected 'ever-silver' vessels with a passion, but were still attached to the brass and bronze they brought along as dowry or heirlooms. Now the daughters took up the cudgel against brass and copper ware, and either through tactful persuasion or aggressive initiatives compelled their mothers to take them to the utensil stores that ran a profitable business in repurchasing old brassware. For days after, mothers were still to reconcile parting with them, and the few hundred rupees in their handbags concealed in the steel trunk were a poor substitute for the lost wares. They said to themselves and to other family members that they had not used those brass and copper vessels for ages, but they had a store of memories associated with each of them, such as how their mothers had got them, from where, about how her other sisters wanted them but that she was lucky, and so on.

The physics and chemistry of why a particular utensil was made of bronze and not of brass was common knowledge to women. It had to do with both heat regulation and chemi- 
cal reaction of the particular food that was to be cooked in it, and almost each food item had its own special utensil. To this day there is a consensus among Tamil Brahmins that rasam (a light souptike dish had with rice almost daily) tastes best when made in tin shombu, which has now disappeared from all Brahmin kitchens. As Brahmin women generally observed pollution taboos and were secluded during their menstruating period, young girls, often five-yearolds and above, were sent to the kitchen and forced to learn cooking. It is often remarked that no girl learns to make rasam without melting away at least one tin shombu in the process. The tin shombu was popular when charcoal fire was used in a small iron chula called kumuti. It started going out of use when kerosene stoves replaced the kumuti in the early sixties, and by the mid-seventies when gas stoves entered most Brahmin kitchens, the tin shombu vanished, as gas fires would melt the tin much faster than slow charcoal fires.

Among the vessel collection, the appam kuzhu and idli pathram stood out, the one for slowly deep-frying balls of jaggery and flour in ghee (clarified butter) and the other for steaming rice and lentil cakes. There was of course more than one idli pathram in every Brahmin kitchen. The smaller one was for family use, and made between 7-12 idlis at a time, and the bigger one, which could steam up to 36 idlis, was used for ceremonial occasions like marriages, when there were many guests. Every few months, the artisan who specialises in coating brass vessels with tin would be called in. That was perhaps the first lesson in metallurgy that children learnt, enthralled by the rubber billow being pumped to keep the fire going on a small tunnel-like chula dug in the ground. For days after, children went to that spot, where some ash still lay, and wondered how it was all done.

Those artisans are rarely seen these days in cities; like many others, they probably took to selling vegetable or something like that. However, while the tin-coating artisan has vanished, the knife-sharpener still comes around the streets of Chennai. Generally, he sharpens few regular knives, but more a special type of knife known in Tamil as aruvamanai. This is a broad metal knife with a base and a coconut grater at its head, which allowed women to cut vegetables squatting on the ground. Like a good typist who never looks at the keyboard, the expert in cutting vegetables worked very fast, without even looking at the aruvamanai. Their hands alone moved in rhythm while they engaged in serious gossip about the moolam nakshatram in a girl's horoscope or the maham nakshatram in a boy's, as their favorite pastime was often matchmaking. The aruvamanai remains in kitchens these days, if not for cutting vegetables at least for cutting sugarcane into small pieces on Pongal (Tamil harvest festival). But the coconut grater on top is rarely used, overtaken as it is by a modern contraption, which is faster, less strenuous and can be used while standing; and also fits on both the granite platforms in the kitchen or the sunmica-topped dining tables. In the 90s, as apartments became more common in Chennai and elsewhere, women preferred to do most kitchen chores standing, although it was the increasing use of dining tables in the $80 \mathrm{~s}$ that began dispensing with squatting on the floors.

Eating at dining tables became a status symbol just like the possession of refrigerators, although both severely compromised Brahmin notions of pathu (pollution taboo associated with cooked food). But in many ways the replacement of brass, bronze, copper and tin vessels by stainless steel was the more significant change in terms of constituting indigenous domestic/kitchen modernity. All other modern status symbols in the realm of 
cooking and dining came later. In the early phase, the 1950s, stainless steel modernity in Chennai distinguished Brahmin households in terms of those that possessed locally available stainless steel utensils and those that could procure the utensils available in Poona and Bombay through kin networks. The passion to collect stainless steel vessels found many Brahmin women spending their afternoons either in utensil stores or haggling with the vendors who brought utensils home in huge round baskets. Today there are few of those stainless steel vendors in Chennai and many have taken to selling plastic buckets and plastic containers. The reason has more to do with developments in the textile industry than a lack of buyers, for such utensil vendors now dot the roadsides much like vegetable or fruit sellers.

\section{Vendors, Chits and All}

Stainless steel utensil vendors who came home did not sell their wares for cash, but exchanged them for old clothes. They collected all kinds of clothes that were worn out but not soiled, be it cotton, silk, nylon or polyester. The most prized items were worn out Kanjeevaram silk saris with jari borders; the thicker the jari the greater the customer's bargaining power. Those days jari borders were made with gold plated silver threads, which had resale value for the precious metal content that was melted and recovered. Now such jari borders set the price of saris so prohibitively high that consumer preference has shifted to synthetic jari, or what is popularly called 'J apan jari', and gold color thread work. The clever vendor was one who could tempt buyers with a particular utensil and induce them to part with clothes they had not considered ready to give away. Many women gave away a sari or two in anticipation of the next Deepawali purchase because they just could not resist a particular utensil; more often women judged the utensils by the thickness of the sheet metal and the finish. With silver jari going out of vogue, such vending practices have been rendered unprofitable forcing vendors to start selling plastics to an altogether different clientele of slum and low income hous eholds. Analogous to the stainless steel modernity of Brahmin households in the $60 \mathrm{~s}$ and $70 \mathrm{~s}$, the $90 \mathrm{~s}$ saw plastic modernity enter the slum households. They too replaced their few brass water pots with plastic ones, as these could be left unattended near public water taps and hand pumps when acute water scarcity hit many urban centers. Also, as more water had to be carried home, plastic vessels were less heavy. Most people probably pawned their brass utensils and never redeemed them.

Apart from this kind of barter trade, many Brahmin women acquired more utensils by enrolling themselves in 'utensil chits', known in Tamil as paathra chits. Stainless steel utensil stores first acquired pre-eminence in the two Brahmin localities of Mylapore and T. Nagar in Chennai, and subsequently set themselves up in other localities, as upper-caste nonBrahmin kitchens too joined the stainless steel modernity. All the well known utensil stores in Mylapore and T. Nagar had schemes of monthly 'utensil chits'. These were like a recurring deposit account into which monthly payments of a fixed amount were made for a certain number of months at the end of which one could buy any utensil of one's choice. Invariably the shops also had a lucky draw every month, and if one were lucky enough to win, one could pick up the utensil without making any further payments. Most non-working Brahmin housewives generally do not have bank accounts, and most of the household finance is controlled by the male head. Women generally save a little every month out of the 
money they are given for household expenses, which they use to join the utensil chits. These women rarely buy utensils as outright cash purchases, except of course when they buy for marriages in their homes. Many begin collecting 'ever-silver' utensils for their daughter's marriage when she is just two or three years old. For women who could not make trips to the shops, most shops had a team of mostly Brahmin women of lower economic strata, who would go around enrolling women for the chits and collecting their monthly payments as well. In the $60 \mathrm{~s}$ and $70 \mathrm{~s}$, stainless steel modernity had caught on most particularly among Brahmins, and the Brahmin women who went around enrolling women in the utensil chits did more than just that. They often helped women exchange horoscopes of boys and girls and carried the neighbourhood Brahmin families' news and gossip from one house to another. They acted as marriage counsellors for young married women, advised them on pregnancy-related health care, could be counted on to come and receive betel leaf and betel nut during religious ceremonies like Mangli Pondugal, and shared with the women the secrets of the deities in various temples, like whom to propitiate on which occasion.

Today, utensil chits are not as popular as they were; nor do women attach themselves to any particular utensil store as regular customers. There are far more stores around and equally large numbers of roadside vendors of stainless steel vessels. With the Salem steel plant's production of sheet metal, utensil prices have become affordable, and cooking sets of saucepans and copper-bottom utensils of the Butterfly brand have become the heartthrob of many. Roadside vendors of stainless steel utensils do a good business these days, for Brahmin women used to giving two-by-two blouse pieces with betel leaf and betel nut on every auspicious occasion to other Brahmin women find that giving a small utensil is more affordable. Women of non-Brahmin households too have adopted this practice. Maybe one can call it "Sanskritisation under Modernity".

\section{Cooker, Gas Stove and Smartness}

The most remarkable consequence of utensil chits was that most middle-class Brahmin households acquired their first pressure cooker through them. The pressure cooker was probably the first contemporary gadget to enter the Brahmin kitchen, and almost simultaneously the gas stove followed. To have acquired both was then considered by women as worthy of news among one's kin and friends circle, and it was said over and over again how considerably cooking time was reduced and how fast the toor dhal got cooked. Before the pressure cooker one is inclined to believe that rice was cooked in pots, if not exactly over a wooden chula, at least with the help of the kerosene stove. That was not quite how. The 60 s saw the introduction of a variety of kerosene stoves, but the Primus stove introduced much earlier was preferred. The Primus stove inspired some awe among women for it was a contraption whose principle they did not quite understand. Before lighting, the stove had to be pumped to bring the kerosene up from the base, which was a delicate job as one might pump too much kerosene and let it spill over, causing fire. This was when nylon saris had just been introduced, and there was the perennial fear that it might catch fire. It is also possible that many deaths due to kitchen fires, today deemed dowry deaths, were then written off as caused by the Primus stove.

Although wick kerosene stoves were considered safer, changing the wicks in a ten-

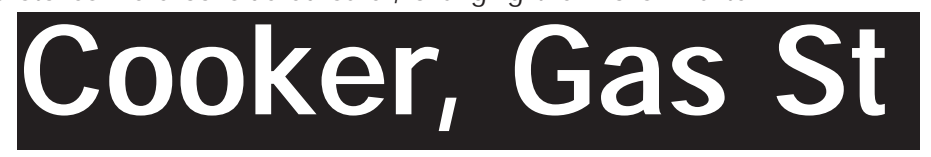


wick stove was tedious. The gas stove in comparison had far too many plus points. The only problem was the long wait to get a new connection. In many Brahmin homes, young girls were asked to register themselves after matriculation at the nearest authorised dealer for a new gas connection in their name. They got their gas connections just after post-graduation, a good five to six years later, when their marriages were being arranged. A gas connection thus became part of the girl's dowry. There was a time when a family was considered smart if it secured two gas cylinders so as to ensure uninterrupted supply. Some homes strictly enforced the rule that the cylinder suppliers should wash the cylinders in the bathroom or the nearest available tap before bringing it inside the kitchen, and the suppliers generally obliged for an additional rupee or two.

For a long time, the pressure cooker contest in Chennai was between the Prestige brand manufactured by the TTK House, a Chennai-based industrial concern, and Hawkins. For many Brahmin households, the choice was over-determined. The Prestige brand won over, though not on account of Brahmin loyalty to a Brahmin industrialist. Rather it was considered more convenient, because of its high-raised lid that allowed one to pile up the family's requirement of rice over toor dhal to be cooked simultaneously, than Hawkins with its flattened lid. If a woman had a line of lunch-carriers to be packed all at the same time, or if the family had lunch as early as 8:00 or 9:00 in the morning, these were serious considerations. Women soon learnt the basics of steam pressure cooking; they knew that if the Prestige cooker gasket was new, they should allow the steam to release three to four times for the rice and dhal to cook, and that as the gasket became old and slightly loosened, they should let the steam release a few more times. Often they kept tab of their neighbours' cooking schedules from the pressure cooker noise. The pressure cooker too underwent progress from aluminium to stainless steel, but unlike stainless steel utensils these were less popular. Nor has the recent Rice Cooker, an electrical appliance, caught on; it remains a showpiece for enthusiastic window shoppers, largely because it can cook rice alone, while the staple diet of the Brahmins requires toor dhal as well.

Despite its daily use, the pressure cooker never became the pride of the kitchen, nor for that matter did the refrigerator. The refrigerator became a marker of social and economic status along with the TV, both often standing in the same living or drawing-cum-dining room. And these days, if the apartment is small, sometimes you will find the washing machine there as well. In an era of competitive consumerism, families are eager to possess and display these items, to let the world know their worth. But the pride of the kitchen for every Brahmin woman is the Sumeet Mixie. What did the Mixie do to acquire this status? If we recall our earlier observation that idli and dosa have more culture and commerce than has hitherto been acknowledged, then the mystery of the Sumeet Mixie's status in the Brahmin kitchen is easier to decipher. Long before American and the French nutritionists came up with their theories of how the ratio of carbohydrates and proteins had to be maintained for a healthy diet, the Tamil Brahmin had already figured it out in his idli and dosa.

\section{Grinders, Mixie and Subjectivity}

Idli and dosa made of rice and black gram lentil, the one steamed and the other fried like a pancake, need the dough to be ground after soaking the ingredients in water for several 
hours. For centuries, women ground the rice and lentils in a stone grinder called the aatukal, used for wet grinding. It is by all accounts a back-breaking job and was usually an afternoon chore. The aatukal usually stood close to two other grinders, one a flat stone surface with a pestle known as ammi, and the other, yendram, a grinder with two round flat stones, the one on top to be rotated and used to grind dried cereals and lentils. Of the three, for some unknown reason, the ammi acquired a ritual status, and was obligatory near the homam fire in Brahmin weddings. Marriage ceremonies at the auspicious Muhurtham time required the bride to place her foot on the ammi, and the groom to wash her feet. For most women, it is symbolic of bondage to kitchen life and grinding stones.

Perceptions of the extent of bondage varied both between the different grinding technologies as well as the different Brahmin groups. The ammi was used almost every day to grind the masala needed for cooking. A quick glance at the English edition of Meenakshi Ammal's Samaithu Par ("Cook and See") the most popular cookery book of Tamil Brahmin food, indicates the extent of grinding, usually with grated coconut, required for the different kinds of food. Kootu, avial, sambhar and sometimes even rasam, the staple of a Brahmin meal, all required the use of ammi for grinding. Even though grinding on the ammi was never considered as tedious as grinding on the aatukal, many Brahmin households with office-goers whose lunch times varied from 7.30 to 10.30 in the morning found even the limited time for grinding on the ammi so bothersome that women often invented abbreviated versions of cooking. Grinding on the aatukal, however, was definitely a drudgery and considered unavoidable at least twice or thrice a week. It is said that Thanjavur Brahmins would not like to get their daughters married into Palghat Brahmin households, because in such households grinding on the aatukal was a daily compulsion. The Palghat Brahmin's fondness for a special variety of lentil pancakes called adhai required grinding every day, although in recent years their claim to it has been undermined by the Udupi hotels in Chennai that offer it on their menus as 'Malabar Adhai'.

After centuries of cultural adaptation, and many decades after electrical and mechanical inventions had caught on, aatukal grinding became mechanised, with large versions of the present wet grinders. In the late 60 s and early 70 s, wet-grinding shops came up all over Chennai, often managed by Brahmin-looking men who wore their threads prominently as markers of status. Despite the Brahmins' fussiness about matters of ritual purity and pollution, they took their rice and lentils to these shops to be ground into dough, while complaining endlessly of possible cheating. Scientifically minded Brahmins, and there are many like that, resorted to theories of physics and chemistry to suggest that electrically operated machines tended to heat up quickly leading to quicker fermentation of the dough. This process, they believed, reduced the dough. But entrepreneurial talents were soon to outwit everyone, and the grinding shops hardly knew that theirs was a very short life indeed.

If today Coimbatore remains on the industrial map despite the secular recessionary trend of its long-standing textile industry, it is largely due to the wet grinder industry. Much as computers shrank in size from IBM mainframes to desktop PCs, laptops and palm tops, wet grinders too kept shrinking. First to fit into kitchens, and replace the traditional aatukal. Then they became sleeker, and tilted, to fit on top of the narrow kitchen platforms of new apartments. With electrically operated wet grinders, the long-standing practice of having

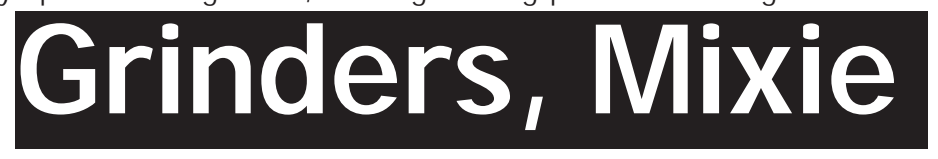


idlis and dosas thrice or so a week, what elderly Brahmins used to call pala aharam or 'variety food', continued. Wet grinders may have reduced the drudgery of the aatukal, but office-going women found that washing the grinder was still an unavoidable chore. Yet another instance of entrepreneurial acumen was the sale of ready-made dough in plastic pouches; appropriately, the most popular pouch is called Thayar, meaning 'ready' in Tamil. Dry mixes for instant idlis and dosas, even those of the famous MTR brand, lost their market share to the 'ready' mixes. And the sleek, bright blue and red wet grinders now stand unused, but remain an important marker of consumer status in most Brahmin kitchens.

In contrast, the Sumeet Mixie that replaced the traditional ammi remains the heartthrob of Brahmin women. No marriage paathra sheer or utensil dowry is complete these days without one. Its versatility for both wet and dry grinding makes it possible to retain the authenticity of Brahmin cooking. Working women especially find that it enables them to balance their dual roles - to prepare the preferred but complicated combination of kootu and thogaial in the morning and take the 8:45 bus from Perambur to reach their office in Adyar on time. Even in households where NRI children bring back an Osterizer bought from J ackson Heights in Queens, New York, the Sumeet Mixie stands next to it, unruffled by foreign competition.

Behind the story of the Sumeet Mixie lies the little known story of the "entrepreneur for the masses", V.G. Panneerdas or VGP, a Nadar Christian whose life moved from rags to riches. On Chennai's famous Mount Road is the VGP showroom, stacked with consumer durables. VGP can be credited for truly understanding the links between gadgets, desires and money much more than the firms producing the durables, who thought that advertising alone was enough to create a demand. Before the days of credit cards, VGP realised that desires alone were credit worthy. Many middle-class homes purchased their first ceiling fan in the 60 s under the instalment scheme begun by VGP, the VGP men coming home to collect monthly instalments.

Much the same happened to the Sumeet Mixie in the 70s. Once again the VGP instalment scheme got the Mixie into Brahmin homes until there was no looking back. It moved from there to refrigerators, two-in-ones and black and white TVs. By the time it came to colour TVs, most salaried Brahmin households had the advantage of a few pay scale revisions and outright purchases of colour TVs and washing machines became the norm. With more and more cash and credit card transactions, there are more festival discounts in the year. Not just for Deepawali or Pongal, which was the practice till recently, but newer discounts like Aadhi Thallupadi during the Tamil month of Aadhi - interesting instances of the merging of temporal modernity with temporal tradition. Even jewellery and silk sari shops, the two crazes of middle-class Tamils if one goes by the crowds, have followed the VGP approach.

An "entrepreneur for the masses" could make the masses dream and transform their dreams into reality. He has now put up a beach resort in Chennai, for people to dream in comfort on weekends, not just about gadgets but also their Singapore holidays and Dubai shopping. It is an altogether different story why his astute understanding of gadgetry and subjectivity failed to make people dream about 'homes' in the way he wanted them to.

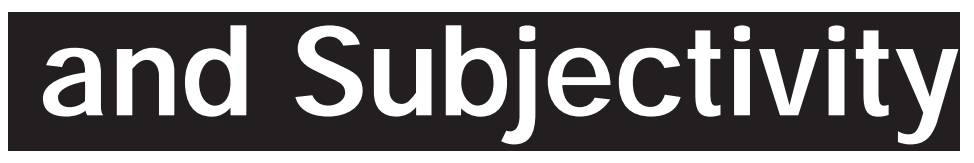




\section{Excelsior 3000} Bowel Technology Project

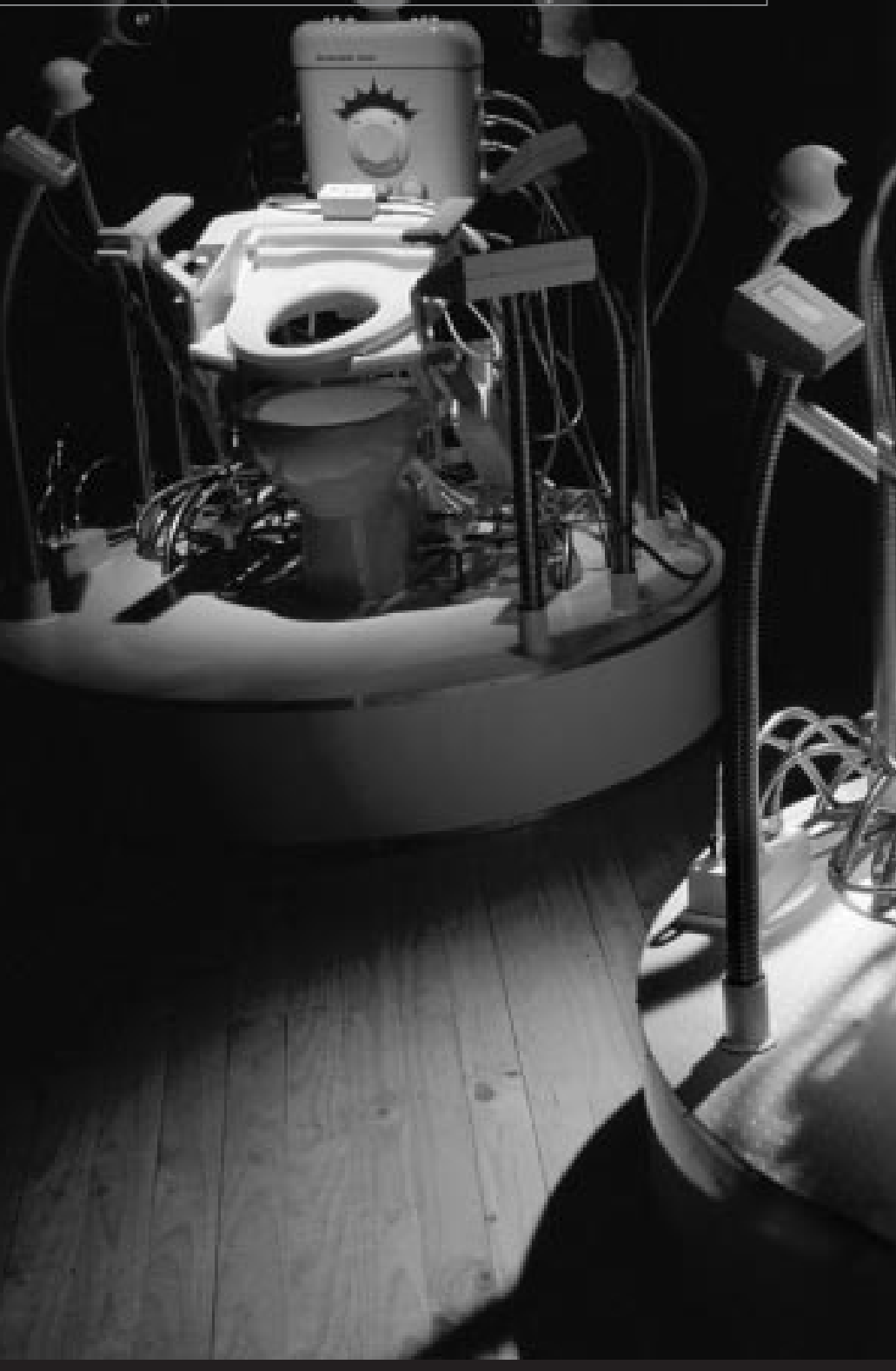




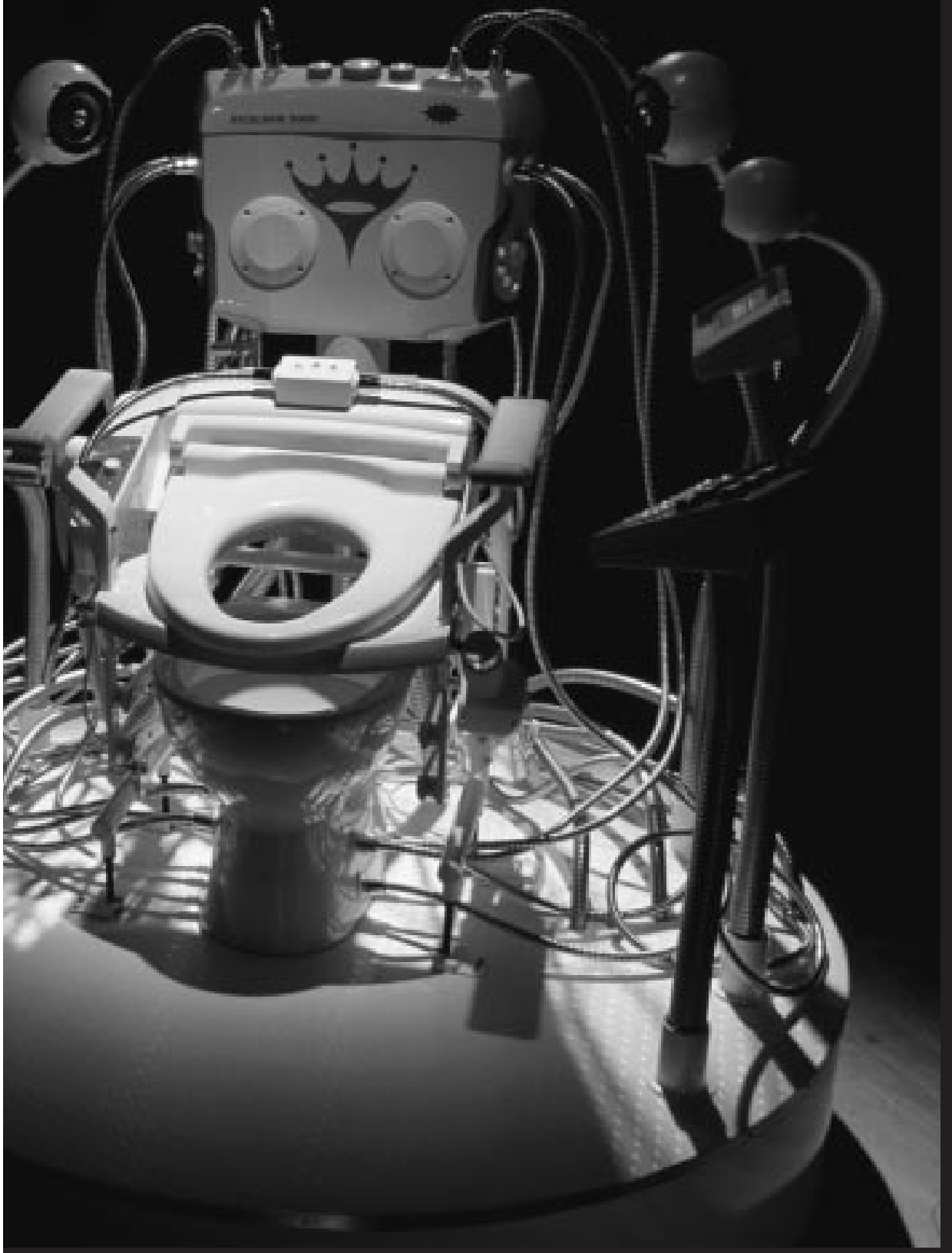




\section{Disruptive IT in South India}

N IMM I RANGASWAMY

$\mathrm{T}$ here is a visible shift in perspective in viewing the IT miracle and how it can merge profits with prosperity for the hitherto downtrodden. The new lens of "inclusive capitalism" promises to include the bottom of the economic pyramid in "sharing spoils", thereby making way for innumerable contributions to the forgotten and invisible masses. ${ }^{1}$ This obviously points to an emergent, equitable socioeconomic system that eludes the Third World for reasons well documented and analysed by concerned scholarship worldwide. Several studies have since appeared to render visible the millions who were not part of earlier traditional markets. This visibility warrants a revolutionary model for the growth and development of these countries and their peoples.

'Disruptive technology', seemingly, is the key word in shifting the debate on lowcost/ high-utility technology for the non-consumer. What this technology does is to master current knowledge, turning it around and innovating upon it to produce a revolutionary model suitable for the needy. Disruptive innovation suggests that existing mainstream markets are not starting places for waves of growth, and there is need to "incubate technologies from ground up rather than introduce top down".

Faculty members at IIT Madras of the Telecommunication and Computer Networking (TeNet) group took upon themselves to pursue such R\&D and found success and recognition. The group has developed the CorDet and the WLL telecom and Internet systems, ${ }^{2}$ which would cost about a third less than normal. These are decentralised access infrastructure technologies that would not only function in a harsh environment (high temperature and power fluctuation) but would also require significantly low initial investment. N-logue, a company in league with TeNet, has introduced 'disruptive IT', setting up Internet kiosks in Melur, a rural district near Madurai. Doing development in Tamil Nadu for TeNet and N-logue is not a government/NGO supported/subsidised process but linked to doing business with new groups, creating a business environment wherein the local unit can afford buying power and use technology profitably. For them, disruptive technologies will target the poor, drawing them within the market economy such that the transaction is enabling and empowering, and will create active agents in the circulation of capital, cash and material well-being.

My essay will look at a few case studies of what has been happening at the ground level in the Melur area, documenting the uses to which IT is put, and what people instrumental in initiating the process have to say. It is definitely premature to assess and map clearly the social outcome of such interventions and how this may affect emerging social structures and cultural landscapes. But we need to search for clues as to how new technology is received and used, the expectations it provokes and the ways in which social traditions grapple with 'disruption'. Closely linked to 'shaping technologies' is how much/far 
social responsibility/caution can be exercised to deploy new technology in societies unawares. In due course, consequences also overtake us unawares, despite careful mapping and surveying of the socioeconomic field. It is necessary to remember that technology is not power per se with its limited capacity for social engineering. It has to "tread softly for it treads on society".

\section{How to Network the Rural}

Given the fact that rural India contributes significantly to the national GDP, it makes immense business sense to enable rural connectivity, while at the same time the Internet can become an enabling technology. But then we need telecommunications that are cheap, operable and accountable; in short, a 'disruptive IT'. Disruptive technology is conventionally understood as a new product or service that 'disrupts' an industry and eventually wins most of the market share. According to Clayton Christensen, these are "simple, convenient-to-use innovations that initially are used only by the unsophisticated customers at the low end of markets". ${ }^{3}$ He suggests that fatal threats to markets may begin as low quality, low margin products that customers don't want and can't use - yet. Ignore these disruptive technologies and they just may grow in capability to meet mainstream needs and develop into a competitive threat, dramatically transforming the marketplace. The personal computer is a good example, changing the map of computer usage, freeing computers from the confines of labs, making it affordable to the common man - in the process killing its predecessor, the micro-computer. It definitely disrupted the path of computer usage, taking it to personal spaces and changing lifestyles at several levels. ${ }^{4}$ 'Disruptive', though at the outset not of society - scientists at TeNet endorse the view that societies have always been transformed in due course, for better or for worse, with technological interventions.

A more liberal and generous usage views disruptive technology as mastery over manufacturing processes, and innovation upon them. More often than not, disruptive technology can be reduced to simple economics. The instance of the proliferation of cable TV in India from nothing in 1992 to fifty million now was achieved by the indigenous use of simple technology and the provision of cheap and accountable services. More importantly, the nature of the organisation that provided services was by less trained people using a complex technology, rather than better trained technicians handling relatively simple technology, and incurring more costs; an example here is of telephone wiring. In the case of cable TV, the small-scale entrepreneur incurs manpower cost several times lower than in the organised sector and these costs are passed to subscribers, making cable TV affordable. ${ }^{5}$

Telecommunications conventionally require large initial investments (of the order of several tens of millions of rupees) to start providing connections. Development of research has lead to reduced equipment and reduced investment to provide telecom connectivity and operation costs, as well as the possibility of coming up with small access systems that can be connected to a backbone telecom network. A small entrepreneur can then serve a neighbourhood (either a few streets in an urban area or a few blocks in a rural area) and provide accountable, low-cost services.

In order to "think and act rural", the company n-logue was incubated with the sole aim of providing telephone and Internet connectivity in villages and "by charter... not operate in 
urban areas". This business model is based on two of the biggest entrepreneurship successes in India today - that of the PCO-STD booths and cable TV operators. n-logue uses a similar kind of business unit, called the local service provider, for services in Internet kiosks in a service area. ${ }^{6}$ Their project of connecting one thousand rural villages in Madurai aims to empower rather than place more connections in urban areas. The growth of users would help "support financial viability, aggregate demand and develop a community integrated by a common route of communication". This in turn would harness the demand for more such connectivity and the accompanying benefits to society at large. The SARI project, Sustainable Access in Rural India, ${ }^{7}$ is the sponsor working with similar objectives in the district of Melur, where each and every village would have Internet connectivity through kiosks. The project envisions sustainable development strategies, seeking viable markets for information and communication services aided by "innovative and enabling technologies and business models".

\section{Case Studies $^{8}$}

In Melur, a paddy growing district with $42 \%$ literacy and one-third of its population living abroad, the need for communication services is high. The area has huge dependency on the government for all the services, big and small, that it provides. With the setting up of 64 village Internet centres in Melur and Madurai North taluks, some in areas with no public telephone facilities, a new mode of communication has opened up. Apart from six connections in schools, 19 operated by a local NGO and three by taluk offices, the rest are operated by individual kiosk owners with technical and hardware support from n-logue. Villagers now use this facility with support from the district collectorate, and services available include income, community and nativity certificates, online application for encumbrance certificates and welfare schemes, tie-ups with an eye hos pital for online appointments, with agricultural and veterinary colleges for online consultancy and even a web-based travel agent booking bus and train tickets online. I will turn to data from case studies in three villages highlighting the social profiles and the entrepreneurial skills of operators, and how the sociocultural landscapes in these villages can slowly change with these tele-services.

Padinettankudi, 35 kilometres from Madurai, became home to the first Internet kiosk in rural Tamil Nadu. The owner built a room behind his tea shop and, with loans for the PC, connection and with basic computer training, started his e-business. Since the village is small and poor, with no public phone, "Yahoo Messenger seemed to be the only means of communication other than physical travel". The operator, Rosy, a feisty woman of twentyone with a diploma in computer applications from Melur, has a marketing success story to her credit. From speaking to people who frequented the tea shops to door-to-door campaigns in both low and upper-caste colonies, she sold the concept of telecommunication to Melur residents. The promise of tuitions for children in computers, astrology from the web, and film shows further aided the steady growth of user population in the village.

In contrast to Padinettankudi, Keelavalavu is a prosperous village, and Abdul Razzak, the kiosk owner, holds a diploma in engineering, has studied computers and has teaching experience in an Aptech centre. In order to sell his services, Razzak created free e-mail IDs for the villagers, tuning them into sending and receiving mail, and also conducted free eye- 
screening camps, besides launching e-government, travel and VOIP-chat services. The economic profile of the village has shaped a certain demand for such services. Quarrying is the main source of livelihood, and a small percentage is engaged in farming. The village is located on a main highway and equipped with basic health and banking services. Razzak has now bought a second computer for teaching and has about 1,500 students using computer education and games. The fee he charges is almost ten times less than his urban counterparts, and the students save on travel costs. Despite aggressive and continuous marketing, he feels that this prosperous village is still not giving enough dividends. But what motivates Razzak is the knowledge that rural India will soon be a component of the digital revolution; he likes playing a role in developing the next computer generation in his village and believes that children and the educated in the village can be influenced even if little mark has been made on the consciousness of the older generation.

Vellalur is a rich agricultural village with ground water, schools, PHC's, banks and other amenities. An engineer in the PWD, Madurai, started the kiosk in Vellalur, his native village. The Internet business has done very badly here, more so in comparison with its poorer cousin Padinettankudi. One may argue that good business is a combination of aggressive, purposeful marketing, public relations and personal attention, coupled with a good hold over new knowledge and how to sell it. A shy uncommunicative operator coupled with an absentee owner made for bad business in this kiosk.

Speaking to members of n-logue's team, one realised the challenges of the not-sosimple process of selling telecommunication to people, some of them unexposed even to telephones. Aimed to bridge the 'information gap', Melur became the 'incubator' for e-business with self-sustenance, progress and endurance. Doing business was intimately linked to impact the overall nurturance of a community in terms of computer literacy, starting up a computer culture in day-to-day dealings and replacing earlier (ineffectual) modes of communication. We ask traditional sociological questions like: which strata of society is being most affected by this intervention, how is it going to change social compositions/profiles, will new leadership/entrepreneurs emerge out of the process dislocating the entrenched, are social hierarchies clogging the spread of this communications culture? The team felt that these differences are not showing up, as yet, as business interests are overriding others. It was usually an influential person who set up the kiosk, but caste has not intervened in recruiting employees/operators in daily business operations. (The case of Rosy was interesting, and there was a view that her being Christian helped in taking kiosk culture across caste groups). The difference, as the team perceived it, is in the 'nature of technology', which could neither stall people from using it nor let it be usurped by a few. Hence the issue of affordable technology becomes crucial.

Sometimes reactions in a community are inevitable since one cannot ignore the arrival of a powerful means of communication. The online veterinary and agricultural consultancy tied to research institutes, eye/ health care tied to hospitals and e-government services are the beginning of a culture that promise much in terms of introducing a mode of communication accessed by all, leading to more public participation in the village economy.

Dr. Ashok J hunjhunwalla, who leads the TeNet group in IIT Madras, opines that it is a little early to start speculating about social impact and change. He confessed, in a lighter

\section{Yahoo Messenger seemed to be the only means of communication other than physical travel.}


vein, about portents from friends and foes that this 'revolution' may well result in a new set of landlords dotting the social landscape, and a new era of e-feudalism in an age of telecommunications. Self admittedly, the TeNet mantra was to indigenise a complex technology, to make it affordable to rural populations and, more importantly, usher in a democratic digital revolution. All this had to make business sense without creating economic cleavages. One instance of a business model that was cheap, reliable and absolutely essential was the "way milk packets reach the doorstep, for a wee bit of expense which the consumer bears" - telecommunication has to be the same for rural India. Dr. J hunjhunwala felt that cheaper technology coupled with accountable services would win the day in areas hitherto unavailable to reap benefits. Disruptive IT may ultimately take over and race ahead through the process of heeding rural consumers.

Bhaskar Ramamurthi, senior scientist at TeNet and one of the initiators promoting R\&D for wireless technology, had interesting insights to offer. Using the example of telecommunicating in Melur, he is very clear that technological options now available have rendered certain processes transparent and are making systems work. The erstwhile lethargy of e-governance is being challenged as information exchange becomes transparent and online applications and appointments go on record. Similarly, online consultancy for crop diseases, soil and health care has hastened information exchange, resulting in monetary saving and delivering timely advice. However, the interesting quip from Dr Bhaskar was that it is still unclear if computers have enabled anything "new which could not have been possible earlier". Consultancies, government certificates, health check-ups were all possible in earlier times with human intermediaries instead of computers. He adds that with human functionaries, social positions and status played a big role in shaping an imperfect, sometimes nonexistent, public governance. ${ }^{9}$ Delays, corruption or simple non-performance point to a system that did not work. Computers are not going to 'create' a complete performance-oriented culture but they can, by ensuring the transparency of information exchange, alter performances for the better. With predictability, time and money are saved. Intended or unintended consequences follow such interventions. For example, the shadow economy of touting and corruption was dented when computerised ticketing, reservations and phone bills came into use. Here, introducing technology for efficiency aided cleaning up petty crime. Computers can definitely not play God in any human endeavour, nor are they empowerment per se. While committed to people's participation and empowerment, scientists feel responsible for the extent to which technological interventions, keeping in mind the baggage of the past, are deployed. What may happen, the longue durée, remains unforeseen.

\section{In Conclusion}

It is the firm belief of the TeNet group that rural India is ready to reap the benefits of the Internet era. There is visible enthusiasm among users and entrepreneurs about changes poised to take over traditional communication culture. It has also become clear that technology has to be affordable to connect and sustain rural India, and to do so a "business model has to be envisaged in each region that will work locally". This particular experiment has stumbled upon the clear viability of Internet kiosks managed by local entrepreneurs and operators. There is no gainsaying the fact that the evolutionary path of this technology may 
lead to unforeseen changes in the socio-cultural fabric of society. It augurs well for researchers and scientists to be alert in such scenarios; to study, document and possibly predict outcomes.

\section{NOTES}

1. Hart, Stuart L. and C.K. Prahalad "The Fortune at the Bottom of the Pyramid" (in Strategy + Business January 2002) p. 54-67. The authors envisage a capitalism that would include the billions of aspiring poor who join the market economy for the first time.

2. A detailed appraisal of this technology can be found in, J hunjhunwala, Ashok "Making the Telecom and IT Revolution Work for us" (in Hypertext http:// www.tenet.res.in/Papers/techolo.html) and "Can Telecom and IT be for the Disadvantaged?" (in Hypertext http:// www.tenet.res.in/jhun/ papers/Tel-IT/TelecomAndIT.html).

3. Christensen, Clayton M. The Innovator's Dilemma: When New Technology Cause Great Firms to Fail (Harvard Business School Press, 2001, Boston).

4. For case studies of several disruptive technologies at work, Christensen, Clayton M. op. cit. and Hart, Stuart L. and C.K. Prahalad op. cit.

5. Developing disruptive technologies for developing countries is premised on catering to a large market that is otherwise deprived of the fruits of technological advancement. To provide infrastructure products, access products and backbone networks at very low cost, an efficient marketing of these is imperative. It was obvious that such tasks cannot be successfully undertaken without totally mastering the technologies, turning them upside down and innovating upon them, as well as acquiring an understanding of the directions in technology development and the costs associated with each element. While IIT faculty understood the concepts and theory and had some idea about implementation, the task at hand required significant industrial expertise. After toying with several ideas, the group decided to give a call to their alumni working in industry around the country. These alumni have come together and formed companies working jointly with IIT.

6. The CorDet can connect the fibre-ised taluka headquarters to villages around a radius of 25 kilometres and can provide simultaneous telephony and $35 \mathrm{kbps}$ dedicated Internet to each connection. It leverages the fact that fibre reaches over $85 \%$ of taluka headquarters in India. There is a fibre connected rural exchange for every $150 \mathrm{sq} \mathrm{km}$ of rural India. Thus a wireless system with a 10 -kilometre range, if installed at existing connected exchanges, would cover $80-85 \%$ of villages in India.

7. The Sustainable Access in Rural India project (SARI) seeks to show that viable markets exist for information and communication services in 'rural poor' areas by inventing and deploying innovative technologies, assessments and business models. Through the development and introduction of appropriate and enabling technologies and applications, SARI will foster economic development and improve health and learning. It will do so in a financially sustainable way, even as it reaches into the poorest and most disadvantaged communities. SARI's diverse partnerships with universities, non-profit organisations and the private sector have begun to implement a unique project that will begin by wiring approximately one thousand neighbouring villages in Madurai.

8. Material for this section is derived from my fieldwork and from Kumar, Richa and Ashok J hunjhunwala Taking Internet to Village: A Case Study of Project at Madurai Region (Report submitted to the United Nations Centre for Regional Development, 2002, Chennai).

9. If caste status was a major barrier in creating an open public culture, it is not as if the 'pariah' or the palla is about to visit the kiosk. What one hopes for is that sheer affordability and business sense may allow a dilution of social prejudices. 
176 / Sarai Reader 2003: Shaping Technologies

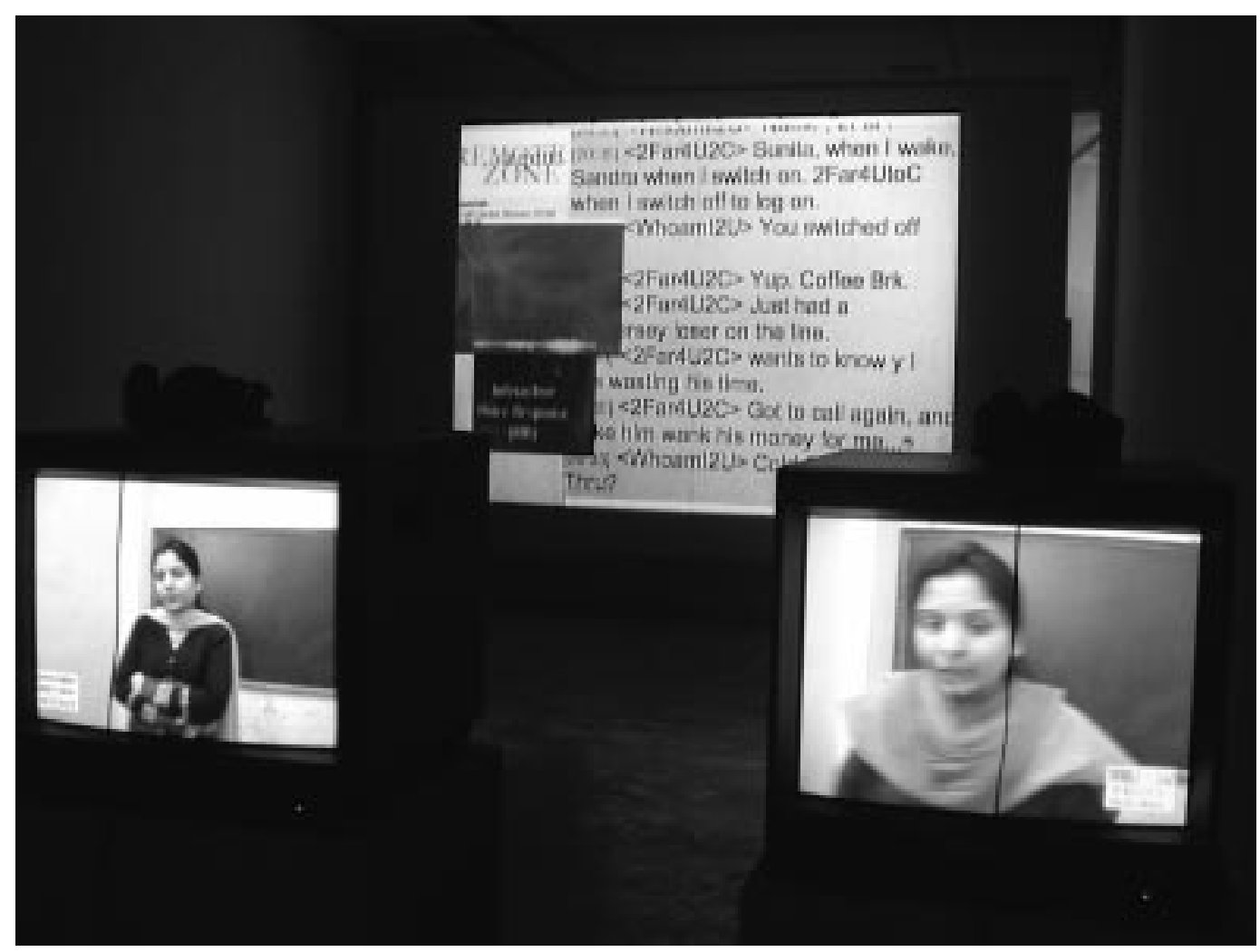




\section{Call Centre Calling \\ Technology, Network and Location \\ RAQS MEDIA COLLECTIVE}

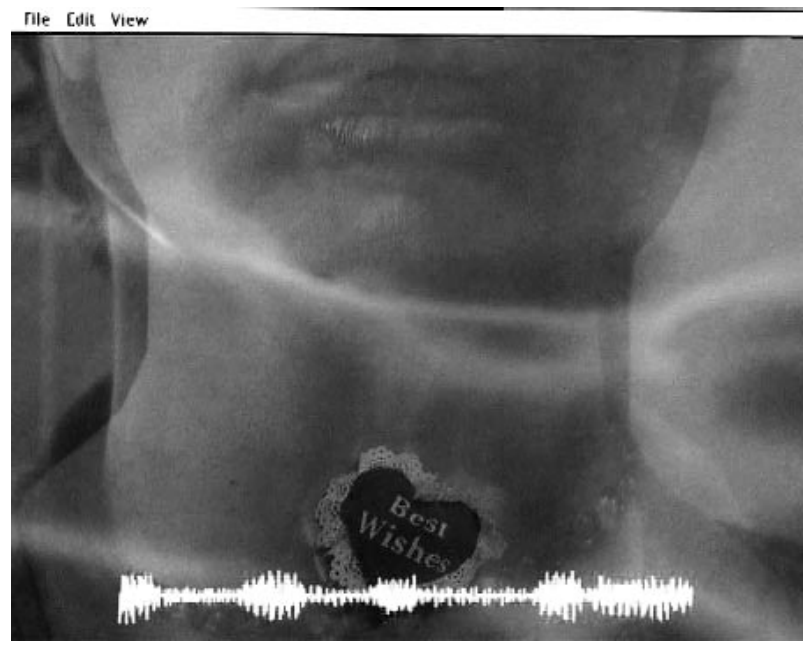

A call centre is a central place where customer and other telephone calls are handled by an organisation, usually with some amount of computer automation. Typically, a call center has the ability to handle a considerable volume of calls at the same time, to screen calls and forward them to someone qualified to handle them, and to log calls. Call centres are used by mail-order catalogue organisations, telemarketing companies, computer product help desks, and any large organisation that uses the telephone to sell or service products and services.

searchCRM.com Definitions - Call Centre http:// searchcrm.techtarget.com/sDefinition/0,,sid11_gci211736,00.html

< Call Centre Work: The Positives and Negatives > [2002-09-30 02:03:56]

On the other side, is it really thrilling job?... What about the long work hours? Are you not tired of speaking for others in 'customised and programmed language'? Are you living most of your time as another person? Do you like to be monitored throughout your work and get fired for a minor mistake?

From a posting on a bulletin board http:// www. callcentersindia.com/ showall. php?valuel $=40$ 
...It's $6.30 \mathrm{pm}$ as Ritu Sharma gets ready to leave her modest apartment at Paschim Vihar, West Delhi, in her smart casuals for another evening out. No, she's not going out partying with friends. A car will soon ferry her, along with other colleagues to her new place of work, GE Capital's sprawling communications complex in Gurgaon. The moment she enters the complex, she will turn, quite literally, into another person. Ritu will become Ruth, a customer-relations executive with an American accent. As the sun rises over the Atlantic coast of the United States of America and sets on North Delhi, Ritu, now Ruth, will start calling customers across the US, moving slowly towards the west coast, following up on credit card bills, mortgages, dues and doing the occasional tele-marketing.

"You wake up as Ritu, but answer to the name Ruth" 30 March 2001, Economic Times, New Delhi

The emergence of the global call centre industry, of which the city of Delhi is an important node, demands a new and incisive look at the intersection of networks, technology and culture. It signals a new kind of work, and a new kind of worker, whose invisibility (in the network) is mirrored by a rhetorical excess of 'national wealth generation', 'new global work culture' and 'cheap labour' that, in the end, renders the conditions that produce this work and the experience of the worker, equally invisible.
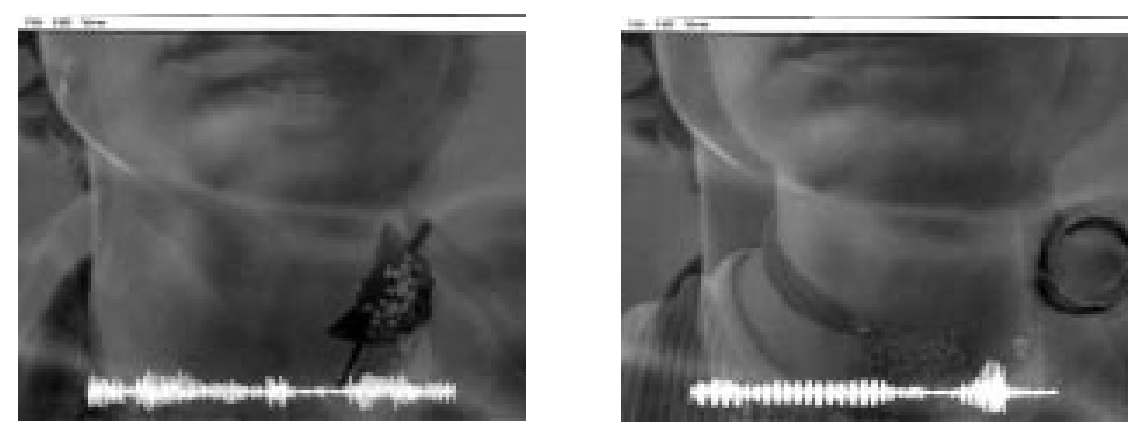

\section{The Historical Location: The Making of a Productive Larynx}

$>$ India has the second-largest English speaking population in the world.

$>$ English is the principal language for the business transactions in India.

$>$ India has the second largest and the fastest growing pool of technical manpower.

$>$ High availability of Computer literate, English speaking and educated customer care professionals.

$>$ India has the lowest manpower cost. Manpower cost is approximately one-tenth of what it is overseas. The annual cost per agent in USA is approximately $\$ 40,000$ while in India it is around $\$ 5000$. 
The new economy in our part of the world is cantilevered on a fortuitous accident of geography and culture, and a long history of reading and writing in the English language.

It is important to remember that India contains the second largest pool of proficient English speakers in the world. The intensity of the education system is able to produce millions of English speaking young people from lower middle-class and middle-class backgrounds from the metropolitan cities and small towns of India. This is the legacy of a troubled and violent, complex and contradictory history of the last 300 years in South Asia, which has to do with the histories of colonialism, and the nation-building project. These are histories of the movement of ideas, technologies, goods and people, enforced and voluntary.

From within this history has emerged a body, more specifically a larynx that is gifted at learning - very quickly - diverse accents, styles and manners of speech in the English language. This historically constructed larynx is today a precious lode of raw material ripe for mining in the global economy.

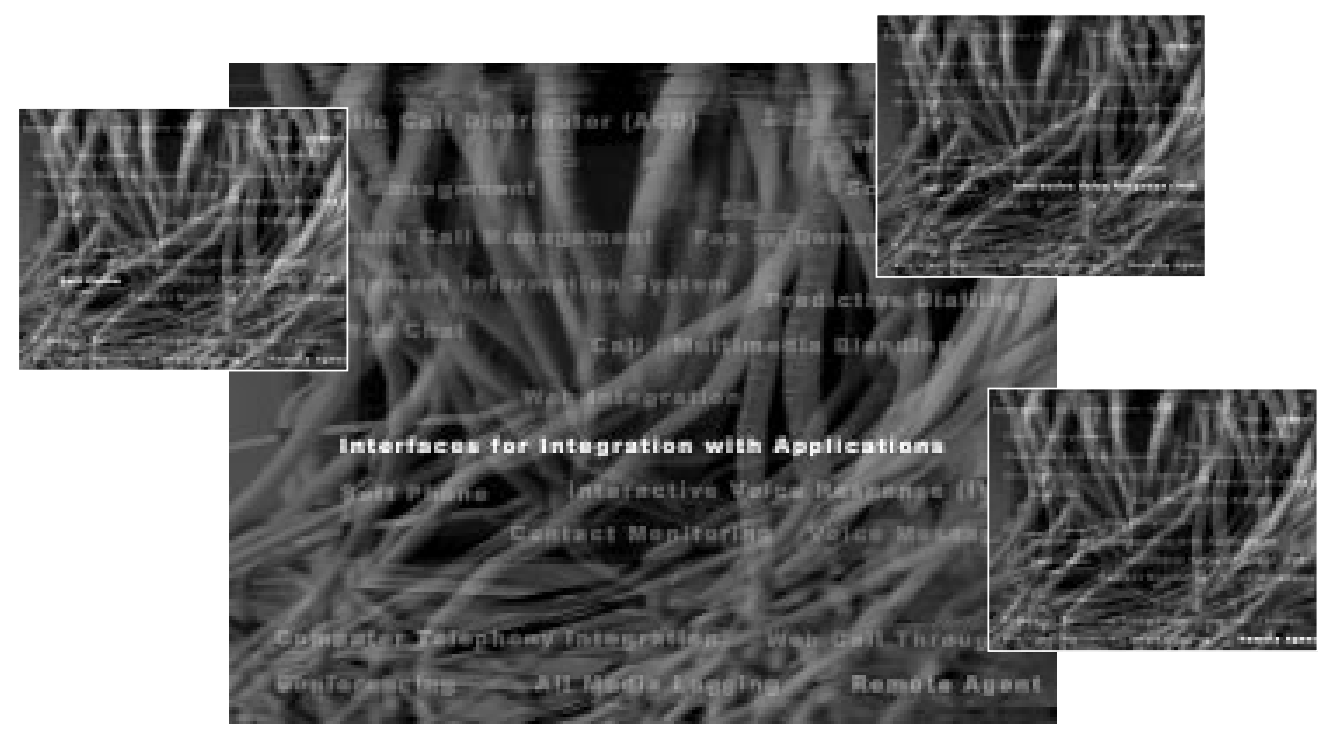

II. The Networked Location: The Anxiety of Location

...once, while working I got someone on the line who got really difficult to deal with. I was calling him to follow up on his credit card payment record. This guy knew that I was calling from a call centre, somewhere in India. So he said to me, "Do you even know how to spell CREDIT? I mean, C-R-E-D-I-T! Put me through to your supervisor, or some real American person..."

Anchal/ Anna, in conversation with Monica Narula 
Indian companies can provide call centre services to clients based in the US or the UK at one-sixth to one-fourth of what it costs in the US, UK or Australia.

Time Zone: A virtual 12-hour time zone difference with the USA and other markets for Call Centre services is in India's favour.

The India Advantage

http:// www. delhicall.com/ why-india.html

Paradoxically, the more 'world class' and globally produced the products are, the greater is the level of anxiety about their place of origin. The realities of contemporary trans-national capitalism require a global workplace, but the 'else-where-ness' of this workplace is always a problem. The fantasy that capitalism wants each of us to buy into is that of an endless circulation of materials and products across space, coupled with an unwillingness to accept anything but an adhesion or stickiness of people within space - something that functions as the sheet anchor of an increasingly unstable world.

If you are a person who has defaulted on their credit card payments somewhere in the United States, it is unlikely that you will take seriously a voice that originates far away, especially in India, when that voice threatens you to send the credit sharks after you if you don't pay. This claim to authority that call centre workers frequently have to deploy loses all credibility if it is seen as being made from a remote location. The same goes for an aggressive sales pitch. Proximity is the key to the blandishments as well as the rewards of capitalism. As a client I must get a sense that the offer, or the threat, is 'at my threshold' for it to have an acceptable reality quotient. The virtual masquerade that underpins the work of the remote agent is based on a sense of what is viably 'real' in today's world.

\section{III.The Economics of Location: Not just 'Cheap Labour'}

$>$ The work force is highly reliable and can deliver world-class quality and ensure rapid delivery of service. Indian companies are also increasingly adapting to international quality and security standards.

$>$ India is outfitted with well-connected telecommunication systems on a world-class scale. High availability of infrastructure resources.

$>$ India's satellite-based telecommunication network enables almost instantaneous highspeed transfer of voice and data across the globe.

$>$ Maintains High cost-competitiveness in service sectors

$>$ Proactive Govt - 10-year tax holiday. Duty-free import of capital machinery and software.

The India Advantage

http:// www. delhicall.com/ why-india.html

India, with its intrinsic strengths is being touted as "Outsourcing Destination of Choice" for call centres and global players are fast calling up Indian shores for outsourcing their requirements. With NASSCOM having projected a US\$142.0 billion industry by 2008, there is a gold rush happening today.

India Calling - A Report on the Call Centre Industry http:// www. researchandmarkets.com/ reports/2387/ 


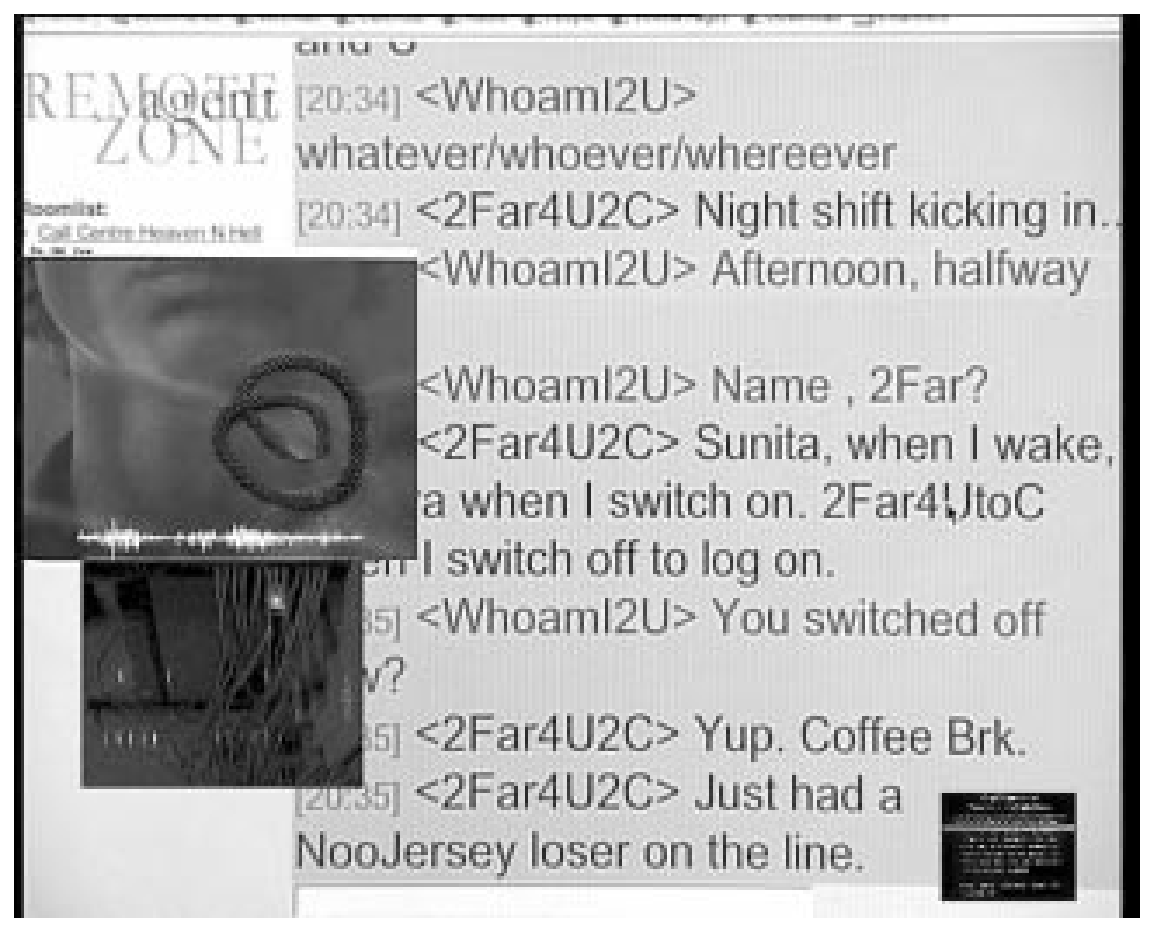

Generally, when call centres are referred to, they are bracketed within the rhetoric of 'cheapness of labour'. A critique based on this view expresses a 'moral turn' built into the larger rhetoric of 'the exploitation of poor countries by rich countries'. These theorisations are over simplifications. They are signs of a deep inability to think about the political economy of the trans-national present.

It needs to be understood that the benefits of the masquerade are not translatable simply in terms of the much touted possibility of employing 'cheap labour' in a third world location. Every investment decision rests on a careful calculation of 'the cost per unit' within a framework of legitimate industrial activity and the larger politicaleconomic stability of the 'space of production'. Infrastructural capacity, the cost per unit of energy, taxation policies, interest rates, and the relative flexibility of labour laws are all elements in such a calculation.

Further, when talking of labour, particularly in a global context, we often tend to forget that labour capacity is always calculated within pre-defined parameters of cognitive and operational skills. Hence, productivity, efficiency, bargaining norms and the normative concerns that mark the workplace (what management can do, enforce, get away with or even what it cannot do) are all crucial to the cost/ benefit calculation. 
It is critical to understand that socially necessary labour time is required to reproduce any specific kind of labour. This implies a level of material, educational and cultural attainments that a given society can make available to its workforce and the drive towards labouring that it induces by offering a series of quantifiable wages or value-laden rewards.

At present many spaces within the territory of the Indian state seem to be favourable to the corporations who are constantly in search of spaces of production with the lowest overall cost per unit. It would not be unrealistic to visualise a future in which Call Centre Industry corporations based in India invest in creating remote agents in Bangladesh, Myanmar or Cambodia.

To assume otherwise is to misread the faceless and placeless global nature of networked (C)apital.

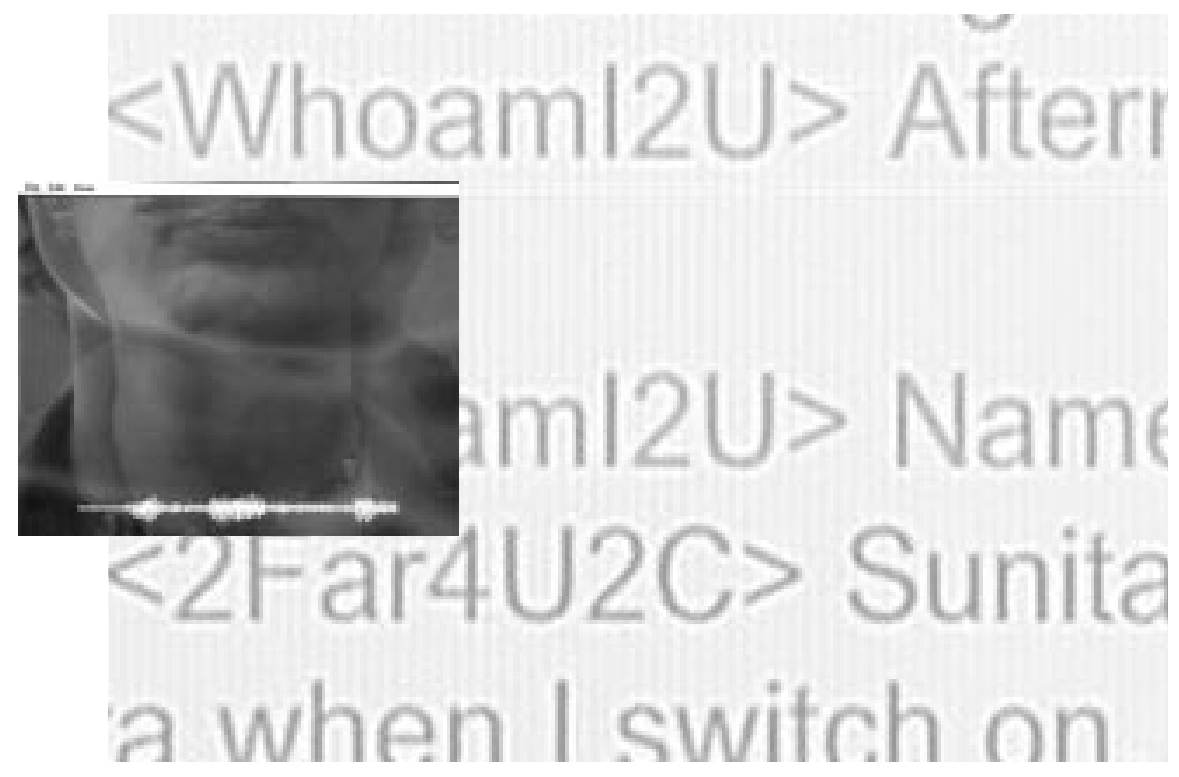

The images accompanying this text are taken from $A / S / L$, a video+text+sound installation by Raqs Media Collective (presented at the "Geography and the Politics of Mobility" exhibition curated by Ursula Biemann for the Generali Foundation, 16 January - 27 April 2003, Vienna).

A/S/L credits - Editing: Parvati Sharma; Sound Design: Vipin Bhati; Production Assistance: T.Meyarivan, Ashish Mahajan; Acknowledgements: Amanda McDonald Crowley, Shveta Sarda, Tripta Chandola, Rachel Magnusson. Produced at: Sarai Media Lab, Sarai, CSDS, Delhi. 
CYBERMOHALLADIARIESCYBERMOHALLADIARIESCYBERMOHALLA CYBERMOHALLADIARIESCYBERMOHALLADIARIESCYBERMOHALLA CYBERMOHALLADIARIESCYBERMOHALLADIARIESCYBERMOHALLA CYBERMOHALLADIARIES CYBERMOHALLADIARIESCYBERMOHALLA CYBERMOHALLADIARIESCYBERMOHALLADIARIESCYBERMOHALLA CYBERMOHALLADIARIES CYBERMOHALLADIARIESCYBERMOHALLA CYBERMOHALLADIARIES CYBERMOHALLADIARIESCYBERMOHALLA CYBERMOHALLADIARIES CYBERMOHALLADIARIESCYBERMOHALLA CYBERMOHALLADIARIES CYBERMOHALLADIARIESCYBERMOHALLA CYBERMOHALLADIARIES CYBERMOHALLADIARIESCYBERMOHALLA CYBERMOHALLADIARIES CYBERMOHALLADIARIESCYBERMOHALLA

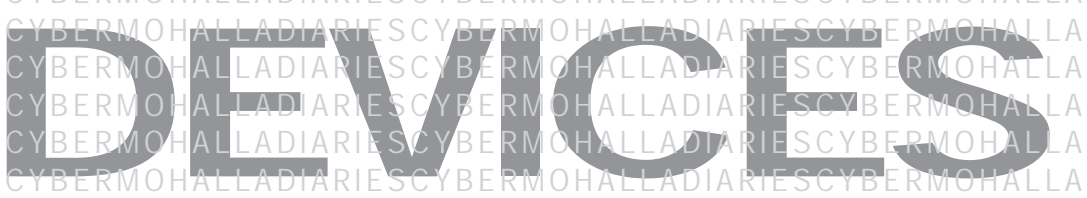

CYBERMOHALLADIARIES CYBERMOHALLADIARIESCYBERMOHALLA

\section{CYBERMOHALLA DIARIES}

CYBERMOHALLADIARIES CYBERMOHALLADIARIESCYBERMOHALLA CYBERMOHALLADIARIESCYBERMOHALLADIARIESCYBERMOHALLA CYBERMOHALLADIARIESCYBERMOHALLADIARIESCYBERMOHALLA CYBERMOHALLADIARIES CYBERMOHALLADIARIESCYBERMOHALLA CYBERMOHALLADIARIES CYBERMOHALLADIARIESCYBERMOHALLA CYBERMOHALLADIARIESCYBERMOHALLADIARIESCYBERMOHALLA CYBERMOHALLADIARIESCYBERMOHALLADIARIESCYBERMOHALLA CYBERMOHALLADIARIESCYBERMOHALLADIARIESCYBERMOHALLA CYBERMOHALLADIARIESCYBERMOHALLADIARIESCYBERMOHALLA CYBERMOHALLADIARIESCYBERMOHALLADIARIESCYBERMOHALLA CYBERMOHALLADIARIESCYBERMOHALLADIARIESCYBERMOHALLA CYBERMOHALLADIARIES CYBERMOHALLADIARIESCYBERMOHALLA CYBERMOHALLADIARIESCYBERMOHALLADIARIESCYBERMOHALLA CYBERMOHALLADIARIESCYBERMOHALLADIARIESCYBERMOHALLA CYBERMOHALLADIARIESCYBERMOHALLADIARIESCYBERMOHALLA CYBERMOHALLADIARIESCYBERMOHALLADIARIESCYBERMOHALLA CYBERMOHALLADIARIESCYBERMOHALLADIARIESCYBERMOHALLA 


\section{<The Transformer >}

I am sitting in my house with my back resting against a wall.

I run my eye over every object in the house, and in every direction.

I can't understand what to write on...

I look around again, when suddenly the light dims, the fan slows down and it starts to get dark in the house. Immediately Bhai, who was sitting against the wall near the transformer, stretches out his hand towards it and increases the voltage. The light increases and the fan moves faster.

Suddenly the transformer fascinated me, and I looked at it closely, carefully. Right then, I started to remember the day the transformer first came to our house.

It's been six years. It was green in colour. It cost Rs. 2,500. This transformer had been bought with Chacha's money. We had a house in Sambal. Chacha had come after selling that house for Rs. 25,000. From this, some money was spent on my elder sister's marriage, and the transformer was bought with the remaining 2,500. It's the only thing we have to remember Chacha by. When the house was kuccha, the transformer was kept in the same place as it is today. That is even after the house was made pukka, the transformer continued to be kept in the same place as before, so there isn't any chance it will ever be moved from there!

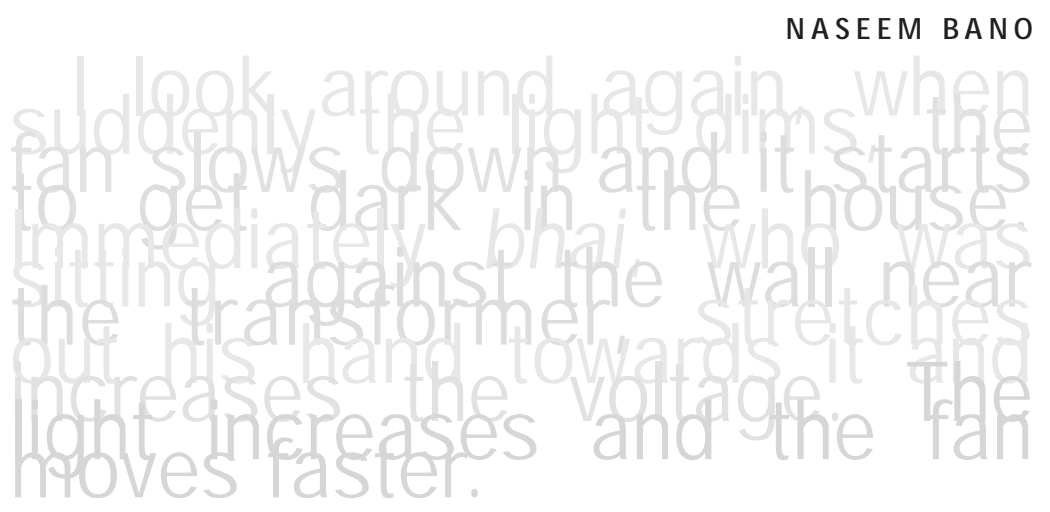




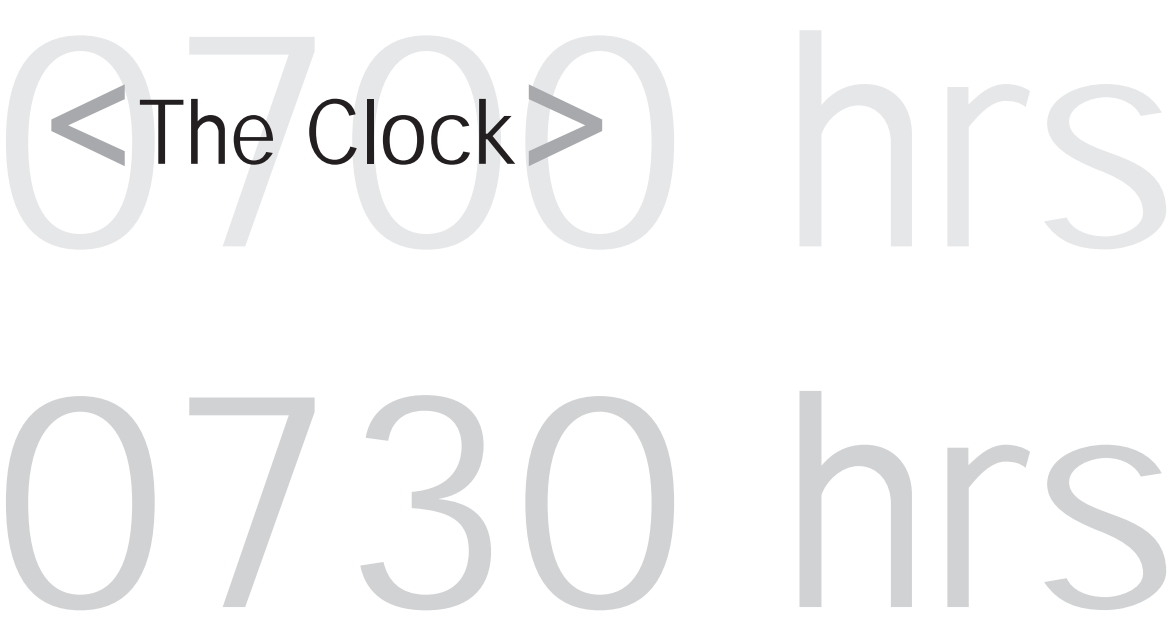

\footnotetext{
0
} $\mathrm{n}$ Tuesday night I was thinking about what I would like to write on. I was watching TV but also began thinking of objects that hadn't been moved for many days, and were unlikely to be moved in the near future. Many things came to my mind. For instance TV, photos, fan, wall, door. But I didn't think about them further because these didn't trigger my imagination. I let these questions be, and watched TV. A film - Prithvi - starring Sunil Shetty and Shilpa Shetty, was playing. But I didn't like the film, and turned my head away and tried to sleep. I don't know when I fell asleep. I got up the next morning.

My eyes first fell on the clock. It showed 7:00 o'clock. I got up and went to Swati. Swati is a five-month-old girl. She is dark-skinned, her eyes are big, nose flattened, forehead broad. She looks just like a boy. And whenever she sees someone talking, she starts laughing, all on her own. I'm her aunt, her mother's sister. After playing with her and making her laugh, by 7:30, I went to the public toilet to shit. This toilet is near our house. Whatever time you go there, there is almost always a crowd...

After reaching home, I opened the door and my eyes fell on the wall clock. I quickly washed my hands and came inside. The clock is clearly visible from the door. It's not very big. It has roman numbers written in it. It's colour is chocolate brown, but the exterior has a black net-like design. This clock has an interesting story.

Earlier, we had a wristwatch at home, but no clock. We used to keep asking Papa to get us one, but he wouldn't. Then, four years ago, he got this one and showed it to all of us. I asked Papa where he had got it from, and for how much. Papa said he had found it in the scrap he deals in. It wasn't working, and I pointed this to him. He said, "Silly girl! It doesn't have any cells! Would anyone throw a functional clock in the garbage?" 
Papa put cells in it, and it started working. It still is. I had said to him then, "Good that you found a clock, because you would never have bought one". But when I started thinking about the clock, I had many questions. Looking at it, I also remembered another watch, a wristwatch which would tell the time only when tied on the wrist. As soon as you would take it off, it would stop. Seeing its erratic behaviour, Papa had gone and sold it for ten rupees.

I asked Papa if he could think about the life of the clock before it got here, to us. Can you think about that time? Papa said, "This is not a human being which would have a life. It's lifeless". I said I was sure it had a life. Maybe it was made in a good shop by a skilled artisan. And maybe after getting made, when it started showing time, it was proud that people depended on it for accurate time. And then maybe someone who needed it bought it for Rs. 150 or 200, but when it stopped working threw it in the garbage. But by putting cells in it, we started its life again.

And the clock is functional even now.

BABLI RA I
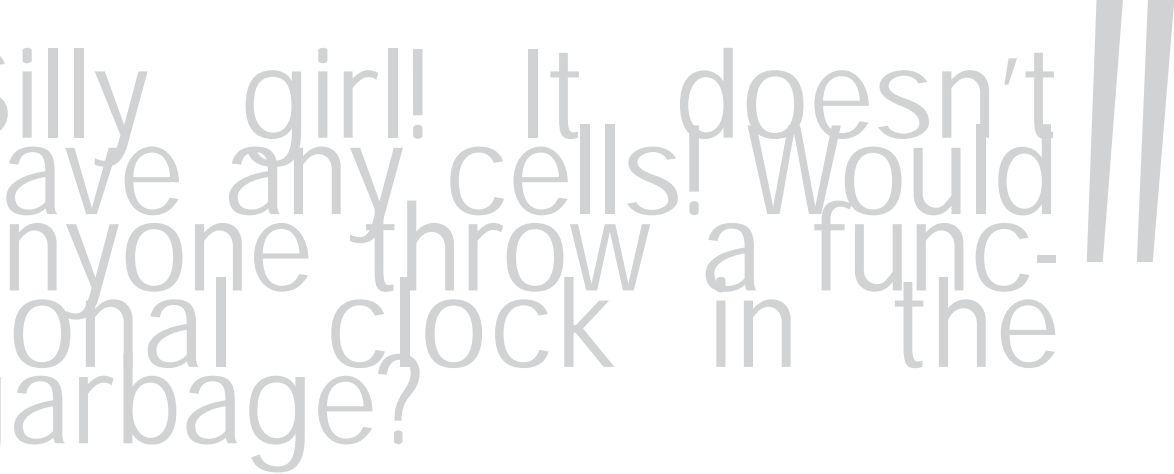


\section{"The Telephone>}

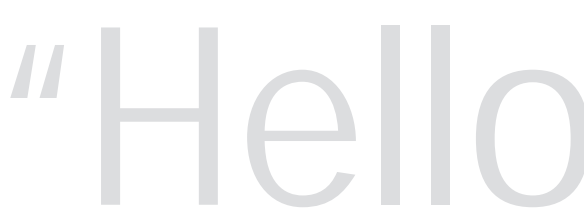

T

he telephone is common now. Almost everyone probably has a telephone at home. My aunt (mother's brother's wife) has a telephone at home, but sometimes it doesn't work. In her house, the telephone instrument keeps changing. Just a few days ago, there was a red instrument. What went wrong with that was that whenever someone would call, the voice from the other end would reach us, but ours wouldn't reach them. The man who fixes telephones came to her house and replaced the instrument with the oldest possible one. Its colour is quite obnoxious. Quite a sight, really.

One day, I had to go towards my school as usual. I wanted to call my friend. To ask her the time. I asked my aunt if I could make a call. She said, yes, go ahead. I made my call, and must have just said "Hello" when my uncle came in. I told my friend I would call later and quickly put the phone down. As soon as my uncle came, I went back home. That I was upset showed on my face. My elder sister saw my swollen face and asked me what had happened. I said if we had a phone at home, I'd be able to use it without hesitation. She asked me if Uncle had come. I told her, yes, that I had only said "Hello" when he came in. And I had to come away. I said to my sister, "Baji, get us a phone connection. Ask Ammi to get us one". But when she asked Ammi, she said, "What relatives do we have who'll call us?!"

Sometimes it happens that when I go to my aunt's house, and the phone rings when she is reading her namaaz, and I move towards it to pick up the receiver, her daughter comes in and says she'll get it. I move back. She picks up the receiver, and I wait for her to put it back down. Then I ask her, "Why, could I not have picked it up?" And she replies that it was her friend on the phone. Then I ask her how she could possibly have known that from before. There is nothing she can say to that.

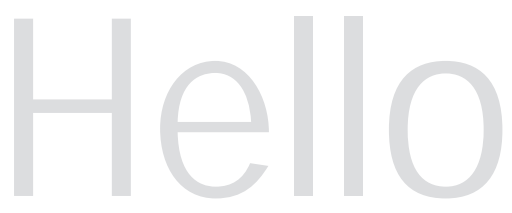

M EHRU N N ISSA 


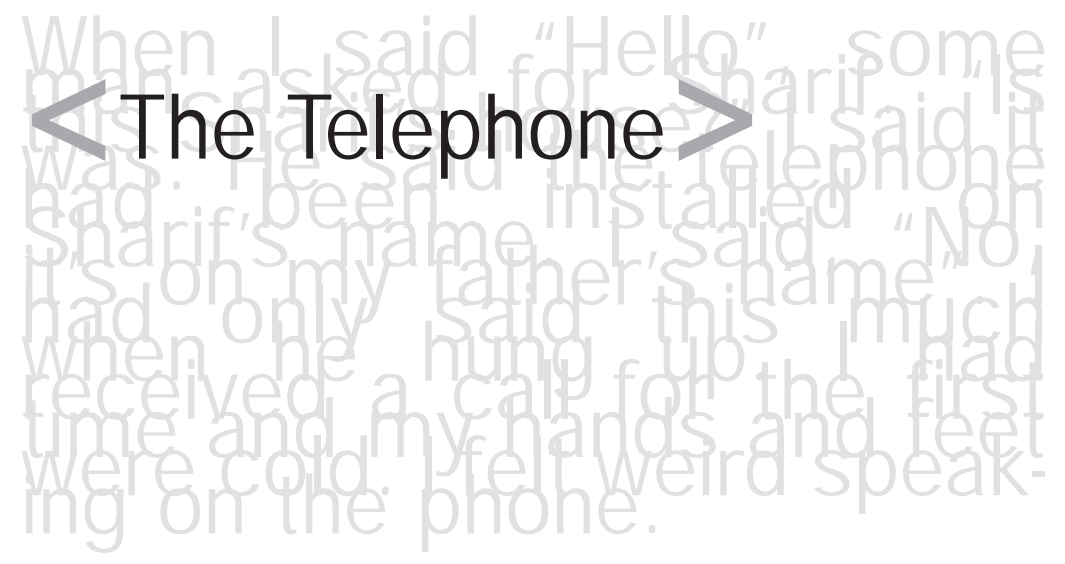

T here is a karkhana (workshop) next to our house. When our house was still kuccha (impermanent), the karkhana got a telephone connection. Two to three days after that, Bhai jaan (elder brother) got us a connection in our house as well. Our telephone was black in colour, and used to shine brightly. Two or three months later, the amma with the cat next door also got a connection. I liked the ring of our phone much more than either of theirs. Our ring was really loud, nice to hear. I didn't like the ring of the amma with the cat. Whenever I would hear her ring, I would feel like picking up the telephone off the table and throwing it on the ground. And when the phone used to ring in the karkhana next door, they would take very long to pick up the receiver. Only after six to seven rings. They had a telephone connection, so they would really show off.

And in our house, when the phone bell would ring, everyone in the house would rush towards it. Ammi and Rani Baji would be the first to run, but if they would take time to climb the takht, Sayra would pick up the phone. And if I would be sitting near the phone, I would pick up the receiver.

When we first got the telephone, we didn't know the phone number. Bhai said we should keep a diary and a pen near the phone. When we get the call from the telephone exchange to tell us the number, we could quickly note it down. On the fourth day when the call came, I was sitting on the takht doing my schoolwork. I picked up the receiver on the second ring. When I said "Hello", some man asked for Sharif. "Is this Sharif's house?" I said it was. He said the telephone had been installed on Sharif's name. I said, "No, it's on my father's name". I had only said this much when he hung up. I had received a 
call for the first time and my hands and feet were cold. I felt weird speaking on the phone.

When Bhai came he asked if there was any call. I said someone had called, but he didn't tell me the phone number. He didn't say anything and went out. Next day Bhai went to the exchange and found out the number and came home and told us.

The first person we gave the number to was our baji (elder sister), who has been married into a house in Seelampur. And I called up Chandrakanta Didi and told her as well. And the neighbours who had telephone connections as well. Then calls kept coming. Don't know how everyone else in the mohalla got to know our number. There would be calls from so many people. Baji also got herself a connection. When she would feel lonely, she would call us. We would also call her and speak with our nephew.

One day, Rani Baji dialled 161 and put the receiver down. When the phone rang, Ammi picked up the receiver and said "Hello". We had such a laugh over that. I told my friend Nazmeen. She also recounted a story from her house. They were all watching television, and Bhai was sitting on the chair smoking a bidi. J ust as we call our father Chacha, she calls hers Bhai. A phone rang in some serial on the television, and Bhai quickly threw his bidi, picked up the receiver and said "Hello". This had really tickled Nazmeen.

When relatives, guest and people from the mohalla started making calls from our phone, the bill really increased. So Bhai jaan got a telephone box made and put a small lock on it. It had two keys, one of which Bhai kept, and the other he gave to Ammi. He said to tell anyone who came to make a call that the keys were with him, or that we didn't know where they were, that Salman must have lost them, that we couldn't find them. We hid the key in the cup. But somehow everyone knew where they were and whoever wanted to make a call would take the keys out of the cup!

My mother's younger sister's hus band would come from Muradabad to work. And if had to make a call, and would find the telephone box locked, he would just ask us for a screwdriver to open the box and make his call.

When Chacha had a heart attack, it was late one night, around 1:00 or 2:30 am. We called Baji up at Seelampur so she would come immediately. When we had got the connection, Bhai, who is quite frugal, had complained that it was an unnecessary expenditure. "Why can't you just go to a phone booth and make a call?" Then we gave the phone number to his in-laws, and there would be a call from there every other day. We couldn't say anything to Bhai, but we'd say to Ammi, "So now it's ok to have a phone, isn't it!" Ammi wouldn't say anything, she'd keep quiet.

Bhai jaan would pay all the phone bills. He would take care of the household expenditure, and also pay the installments for his vehicle. Then things turned for the worse, and Bhai had to stop running his vehicle for months. Meeting daily household expenses was getting difficult. Telephone bills kept piling up. We couldn't pay, and the phone was disconnected.

We had the phone for around two-and-a-half years. After it got disconnected, 
we gave everyone our neighbour's phone number so they would still be able to contact us. This was my friend Nazmeen's house. They would tell us if our relatives, or anyone else called. And they'd say we could also make calls from there, but we used a public phone booth. After all, how long can you call from someone else's house without eventually irking them?

When there was the fire in the basti, our house also was gutted in it. The phone also got burnt in that fire. We didn't even have the money to call up Baji. From a burnt box, Ammi found 42 one-rupee notes. She gave me two rupees to call Baji. We called Zaibun Khala's house. It was six in the morning, everyone was sleeping and we got worried that we'd end up with two calls instead of one. Then Dulha Bhai came. We told him to come and take Chacha with him or, on seeing the condition of the house, he would have another heart attack, and replaced the receiver. I remember we were at Baji's house when Bhai had got divorced, and Dulha Bhai had informed us on the phone.

After the fire, we didn't get a connection. When Chacha had had a heart attack the last time, we had made calls from Khala's house to inform our relatives. And then when he died, it was through the phone again that we got in touch with them. After the fire, when our house was rebuilt, no one spoke even once of getting a phone connection.

NASEEM BANO

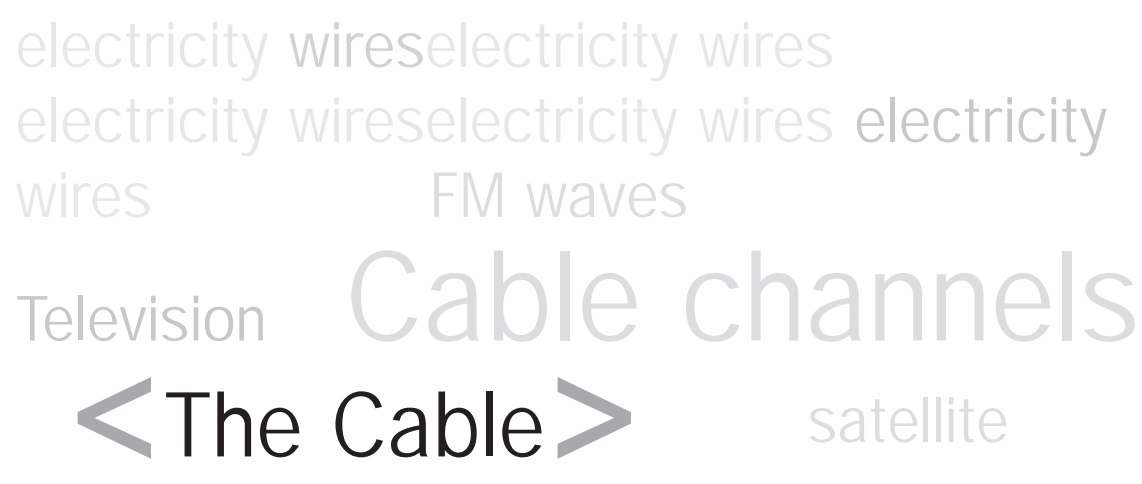

remember little about the time we had a black and white television. That was in 1994. Cable must have just about started when we bought the TV. Maybe at the time I didn't even have enough sense to think about getting a cable connection. The television used to be kept in a room on the first floor of the house.

Once, I was sitting alone watching it. At the time B\&W televisions didn't have remote controls, but perhaps now they do. Sitting all by myself, I thought why not twist the television's ears and change channels. Thought to myself that just like the transistor catches radio and FM waves, maybe the TV will catch some cable chan- 
nels. Twist by twist, I reached one such channel which was showing a film. I thought why not try and move the wire around a little to see if the image clears a little more. But the image didn't change. I thought something must be done so I can watch cable. The cable-guy's satellite was just five steps away. The wires were tied to an electricity pole in front of the house. All that separated me from them were the electricity wires to the pole, and the breadth of the lane. I cast a glance at the rooftops in the market. People had tied a speaker, the rim of a cycle and a magnet to the antennae on their roofs.

I thought, something has to be done. I went to the kabari (scrap dealer) shop in my lane and bought a cycle rim. Then, went up to my roof, removed the wire from the antenna and tied it to the cycle rim. Back downstairs to the TV, I saw that the cable (transmission) was clear. When Mummy came back from her vegetable shopping, she was surprised to see a new movie on television. She asked me, "There is a new film on TV?" I said I made it happen with my brain. She said, "What did you do?" I told her to go up and see for herself. I was sitting downstairs, watching the film. Mummy quietly went up and removed the rim from the antenna. I thought maybe there is some problem from the main transmission. Mummy came back down and said, "Go return this rim to wherever you got it from". I asked her why she had removed it. Mummy said, "When your father returns from duty today, we'll get a cable connection". I replied with an "Okay".

Papa came back in the evening. I asked him to get a cable connection. He said we'd get it done the next day. But I was restless for cable. I sneaked Raju into the house and started to think about a new plan.

And this is what I did - I took the TV antenna wire, removed the insulation, and pulled out the strands of wire one by one. I told Raju, "I'll keep peeling off the insulation, you keep winding it up". Two hours passed. We estimated the length of the wire would be enough to reach across now. I said to Raju, "You go stand on the roof opposite, and throw two small stones from the window".

I was on the second floor, and just below me was the electricity wire. Raju threw in the stones. I tied the wires I had peeled, the thickness of which was microscopic, to these stones. Then I threw them across. But they got entangled in my hand and landed straight on the electricity wires. The shock I got then! For a second I thought I was dead and gone to heaven. But I didn't relent, and threw the wire once again. Raju was quick. He caught them and quickly swung up his arms. I ran up to that roof, and simply tied the wires to the joint in the cable. I came back to find the transmission was smooth and clear.

Next day, Papa said, "Get a cable connection today". I thought, who wants to give a hundred and fifty rupees every month? I said, "Let it be. What's the need". 


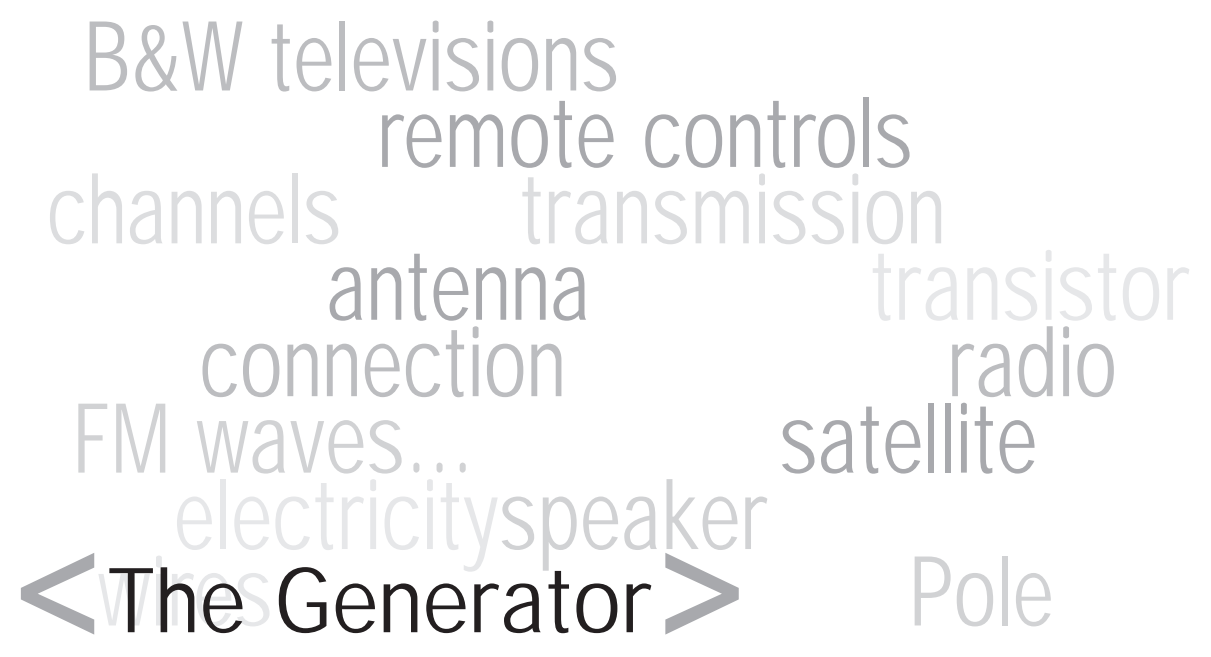

T

his is about the time when the World Cup was going on. I don't recall the day and the date, but do remember however that it was a league match between India and Pakistan. At that time, I was in charge of my shop. The match was to begin at 2:50 pm. All the people in the market were kind of excited. Eventually the match began. I stopped my work where it was and told my artisans to call me in case a customer came. Then I went upstairs into my house and started to watch the match. India won the toss, elected to bat first and set a target of 227 runs before Pakistan.

India had finished batting, the match was to resume in half an hour. I thought why not go and sit in the shop. I went down. As soon as I sat down, the electricity went. Everyone said electricity would surely be back soon. I was thinking, if it doesn't, I will start the generator and watch the match! Then Raju's father came and said, "Chintu, take the generator out of your shop into mine. We'll all sit together and watch the match". At that time Raju's father had kept his television in his shop. I said, "Uncle, my generator runs on petrol and its tank is completely dry". He said never mind, let's all pool in money and get petrol. There were three to four other people and everyone put some money together and gave it to me.

There were ten minutes to go for the match to begin, and the light was still out in the entire area. Raju's father said, "Now go and get the petrol". After taking the money I said, "Give me a bottle or a can, if there is one". They said everything is kept all over the place, we wouldn't be able to find one in the dark.

My eyes fell on a water bottle lying in the shop. I emptied it, kickstarted my motorcycle and, as I was leaving, told my blacksmith to move the generator out. I 
was getting quite excited. I rode with speed, quickly bought the petrol and returned. The blacksmith had shifted out the generator. Everyone was waiting for me. Like a marriage procession waiting for the bridegroom! I parked my bike and had the generator picked up and kept in a corner in Raju's shop. In it I put but one litre of oil, and the rest I saved and put away in the shop. Then Raju's father pulled the generator's rope and the generator started. Everyone rejoiced loudly. I connected the television wire to the generator. Electricity wasn't back yet. A crowd had gathered in Raju's shop. Now I also sat down and started watching the match. Pakistan was two wickets down in six overs, and had scored 30 runs. Everyone was jubilant, I think I also shouted with joy.

I was thirsty. I got up quickly, and went to my shop. I was so engrossed in the match that I was quite oblivious to the world! All the artisans were sitting in the shop. I went in hurriedly, and drank about half a litre petrol from the bottle lying there. I was so thirsty then that everything looked like water to me! I kept drinking. Suddenly it occurred to me that perhaps I was drinking petrol! I looked at the bottle, and it WAS petrol! I didn't quite feel the effect then.

It was past nine at night. I saw India had won the match against Pakistan. I shut the shop and came up. I was fine. Then, suddenly, I kind of smelt petrol on my breath. I drank water and started to tell everyone at home that I drank petrol thinking it was water!

Papa said, but you look fine, absolutely nothing has happened to you. Mummy said I should wash up, "I'll get you food". I thought food would subside the smell. Mummy brought the food, and I ate it. After eating, I went up to sleep. As I was climbing up the stairs, I was burping burps of petrol. My sister was boiling milk in the kitchen. I quickly moved away from the flame. What if my mouth were to catch fire!

I lay down on the cot. It was past ten at night. My sister finished boiling the milk and came to the room. She said, "Don't you smell petrol?" I told her what had happened. She told me to have water, and that that would make me all right. She went to watch TV. I started feeling suffocated. I rushed downstairs and asked to be taken to the doctor, that I was feeling ill.

Papa and Mummy quickly took me to Dr. Amit's shop, which is in the lane outside. Raju's father also followed us there. I said I didn't think I would survive. The doctor asked Papa what had happened to me. Papa said I drank petrol thinking it was water. The doctor said, "This is a police case! In all probability, this has to do with a matter of the heart. Maybe he drank petrol for the love of someone". Everyone said it was no such thing. My condition was deteriorating. After much argument, the doctor gave me medicine and said, "There is still time, tell me. Did you drink petrol because of some silly crush?" I persisted, "No, no!" Then we came away from there. After returning, I had my medicine and went to sleep.

Even today, when I see petrol, I remember that time. I do see it, but with love! 


\section{<rom Tubelight to Makadi

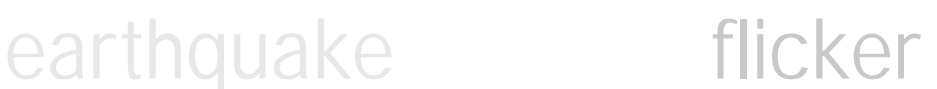

It was the $22^{\text {nd }}$ day of the month, eight at night. I was sitting on the wooden seat, my legs folded under me. I was jerking my hand from time to time. It had been hurting since morning. Chacha (my father) was sitting on a mattress on the floor, smoking a bidi. Chacha looks old. In any case, it is his age to look that old now. It seemed he was lost in some thought, puffing on his bidi. Mummy was just as lost in eating. We were having turnips that day, which she absolutely relishes. I don't quite enjoy turnips that much. The house was filled with the smoke of bidi and the smell of turnips. The curtains were keeping these smells in. It's getting quite cold, so we keep our curtains drawn. The sound of children from the street below was also much softer than usual.

Suddenly the tubelight began to flicker. I switched it off and put the bulb on. Chacha said, "Arre girl, why don't you switch the tubelight on?" There was an urgency in his voice, as if the switched off tubelight would result in an earthquake. Oh! Earthquake reminds me of the time when my younger brother Rahul had insisted on getting a tubelight in the house. His stubbornness had almost caused the tremors of an earthquake here! Chacha had responded with an "Of course, first a tubelight, then a refrigerator! Son, we are not in a position to be able to afford all of this! Stretch your legs according to the size of your quilt!"

"But Chacha, a tubelight is not that much expenditure."

"Son, how much ever the expense, little or much, it is beyond our means."

But maybe a tubelight in the house was the way things were to be, because as soon as Rahul began to get his Rs. 200 a month, he got a tubelight installed.

And today, with the tubelight having been barely switched off, Chacha has become so restless. I thought a while before I said to him, "Chacha, you never wanted a tubelight in the first place. You only liked the light from a bulb!" Chacha looked at me and said, smiling, "Yes beta, you're right. But I've become used to the tubelight now. Without it, things begin to look hazy. And when it is lit, it seems as if the moon has risen. It's because its light is white and cool". Chacha stood up as he was saying this. He switched the transformer on and started fidgeting with its starter. The tubelight started to flicker again. Mummy laughed and said, "Look at him! In his younger years, he never even fixed a nail. And now, in his old age, he wants to play around with electrical appliances!" Mummy's words seemed to me bitter as the neem leaves. I pressed my hand, got off on to the mattress and said to her, "You taunt Chacha at the slightest instance. Why can't you be quiet some times?" 
Mummy turned to me in anger and said, "Yes of course, aren't you Papa's darling! When have you ever sided with your mother?"

Without replying to her, I moved Chacha aside and moved the starter. As I was doing this, I could hear Makadi's sound from behind me. And seeing him, Chacha burst out in anger, "Abbe, I asked you to get us a packet of milk and you simply disappeared!"

"Arre Chacha, I didn't disappear. I had gone to Emergency."

Hearing that, I immediately put the switch off and turned towards Makadi and said, "Why did you go to Emergency?"

"Arre nannhie, you know Kallu, the ration guy, no? His granddaughter was hit by a two-wheeler. She lost so much blood, it's unaccountable. I thought if I take her inside she'll lose too much blood, so I took her to the Emergency myself. And the shopkeepers outside? They gave the news inside. Chacha, I took her, but got stuck there". I was looking at him, and asked, "How is that?" He moved his hand through his hair and said, “They asked me her name. I didn't know. So I told them, Gulbashan, and said her mother's name was Tahira. Then they asked me the father's name". Knitting his brows, he said, "Chacha, at this my head started to spin uncontrollably. Just then I thought of my brother's name, and said, Mohammad Yamin. After some time, all of the girl's family members reached there and I told them, 'Friends, whatever name came to my mind, I got those written down. Now you can read the form'. And finding the first opportunity, I slipped out of there".

I thought, if his shirt got drenched with blood, then why aren't there any stains to be seen? But then my eyes moved towards his hands, feet and forehead, which still shone with droplets of sweat. Then my eyes got fixed on his face. At that time, he seemed to me a dear. Don't know what those feelings were that arose in me for him at that time. Actually, Makadi is not particularly good-looking. It isn't so much his looks as his habits that are good. He is as short as Sachin Tendulkar, dark, short-limbed, has round eyes, a small nose and his body is tied up in a very limiting frame. He crops his hair short, just like soldiers.

He had come here some ten to twelve years ago. I think I was in Class 2 then, and used to play gitthas right in front of his workshop, where the spread of a big stone made picking up the small gittha stones easy. Actually, that stone is there even today. Children don't play with gitthas there any more, just jump around a lot on it. Boxes for visiting cards are made in his workshop. Actually, the name of the owner of the workshop is Mohammad Yamin, but everyone calls him Bhai. He had bought the small room (for the workshop) from my grandfather for eight thousand rupees.

When Makadi first came here, he would wake up at night, crying and saying, "Oh mange, oh mange". I used to feel very bad for him. At that time he must have been as old as I am now. Or maybe a little older. In the initial days, he used to shit and pee in the workshop itself. Bhai used to beat him up for that. Also, his only work was to serve tea and water, and he used to sit in a corner, sad. Seeing this, everyone in the locality used to feel sympathy for him. Everyone wondered what 
name to call him by. And because he used to cry "mange mange", he was named Makadi (Spider).

Actually his real name is Mohammad Kasim. He is from district Katihar in Bihar. His mother, Hasina Khatoon, and sister Shehnaz live in the village. He has his own land in the village, but because he wouldn't pay attention to farming, his mamu (mother's brother) brought him to Delhi. Once in Delhi, he stuck fast to the city, and remains stuck even today. Now he is the favourite not only of Bhai, but of the whole lane. Whenever I step out of home to go somewhere, he asks me with authority, "Nannhie, where are you going?" The question makes my blood boil and I invariably say sharp, cutting things to him. But when I need him to do something for me, I speak to him with lots of love. I say, "Bhai Mohammad Kasim, please will you come here?" Hearing this, he comes promptly, his teeth shining from behind his smiling lips, as if I have given him some precious gift.

But in Bhai's house, he is famous by the name of Chhuwara. That's because he is small and dark like a chhuwara (a dried, sweet date). He is cared for in Bhai's house just like a member of the family. A few years ago because of some problem in the house, Bhai was not able to look after his workshop as much as he would have liked to. So Makadi not only managed the workshop, but also took care of the sale and purchase of materials. He could easily have cheated and fooled around with the accounts. But he did no such thing. He treated his employer's trouble as his own. Since then, Bhai has grown particularly fond of him.

Whenever he goes somewhere to meet his friends, not only the workshop but the whole lane becomes quiet. And as long as he in the workshop, there is always hustle bustle because someone or the other sits with him, chatting away. Now it seems as if it's not Bhai who gives Makadi an identity, but Makadi who gives Bhai his.

YASHODA SINGH

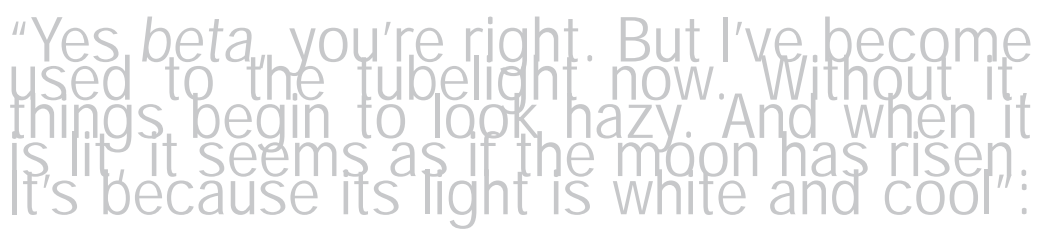

Translations by Shveta. 


\section{Metro Nights}

MONICA NARULA

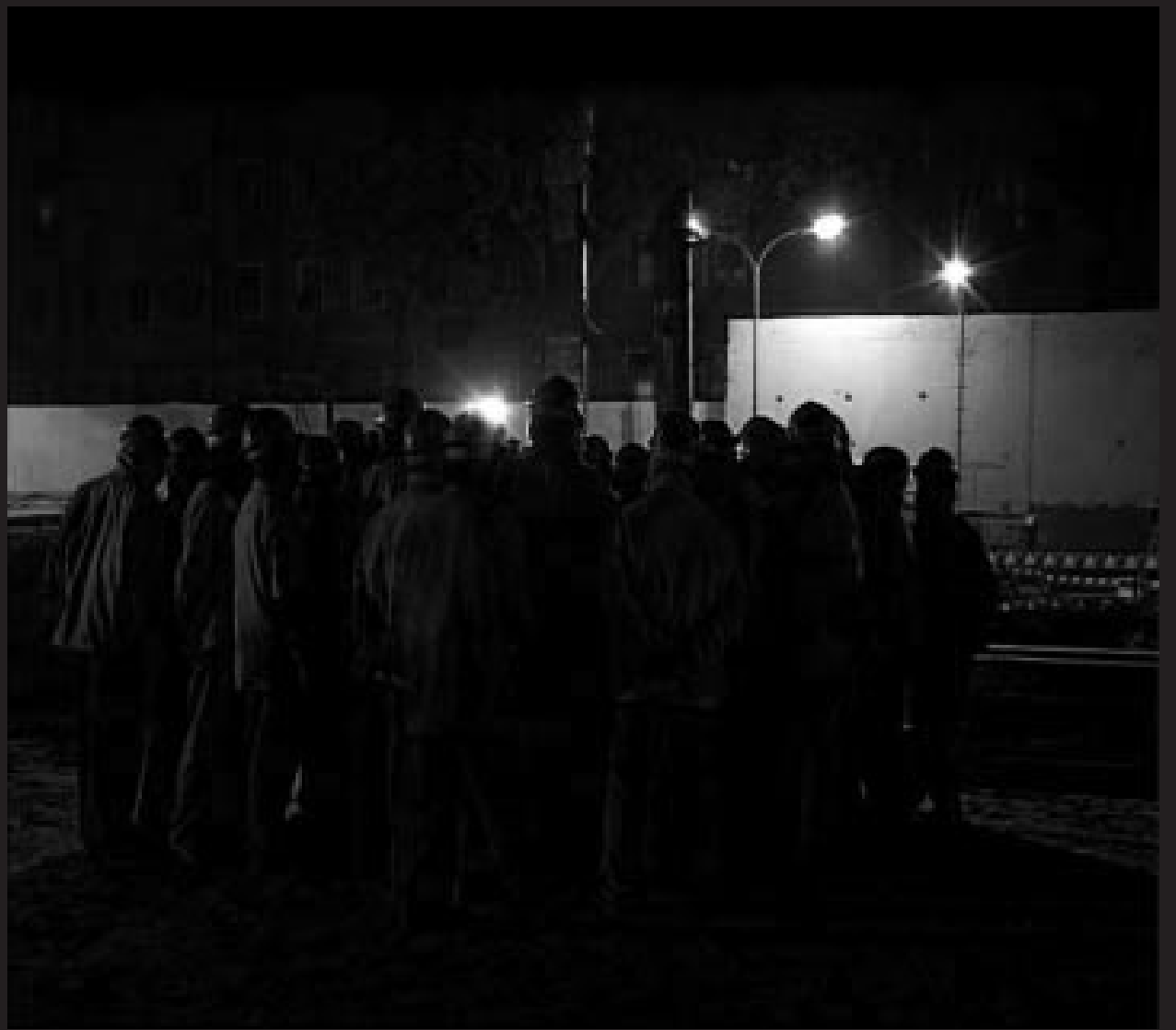



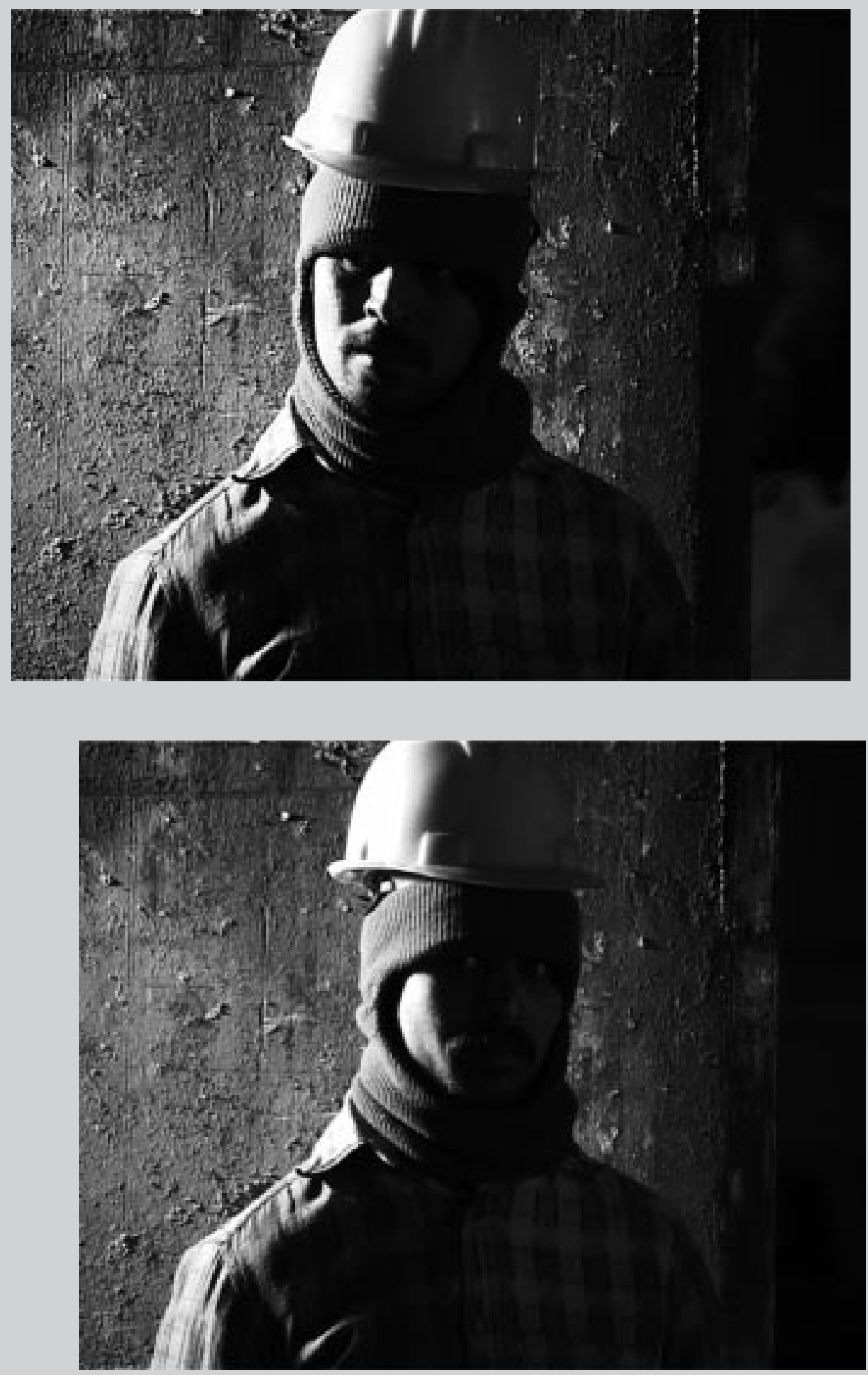
Metro Nights / 199
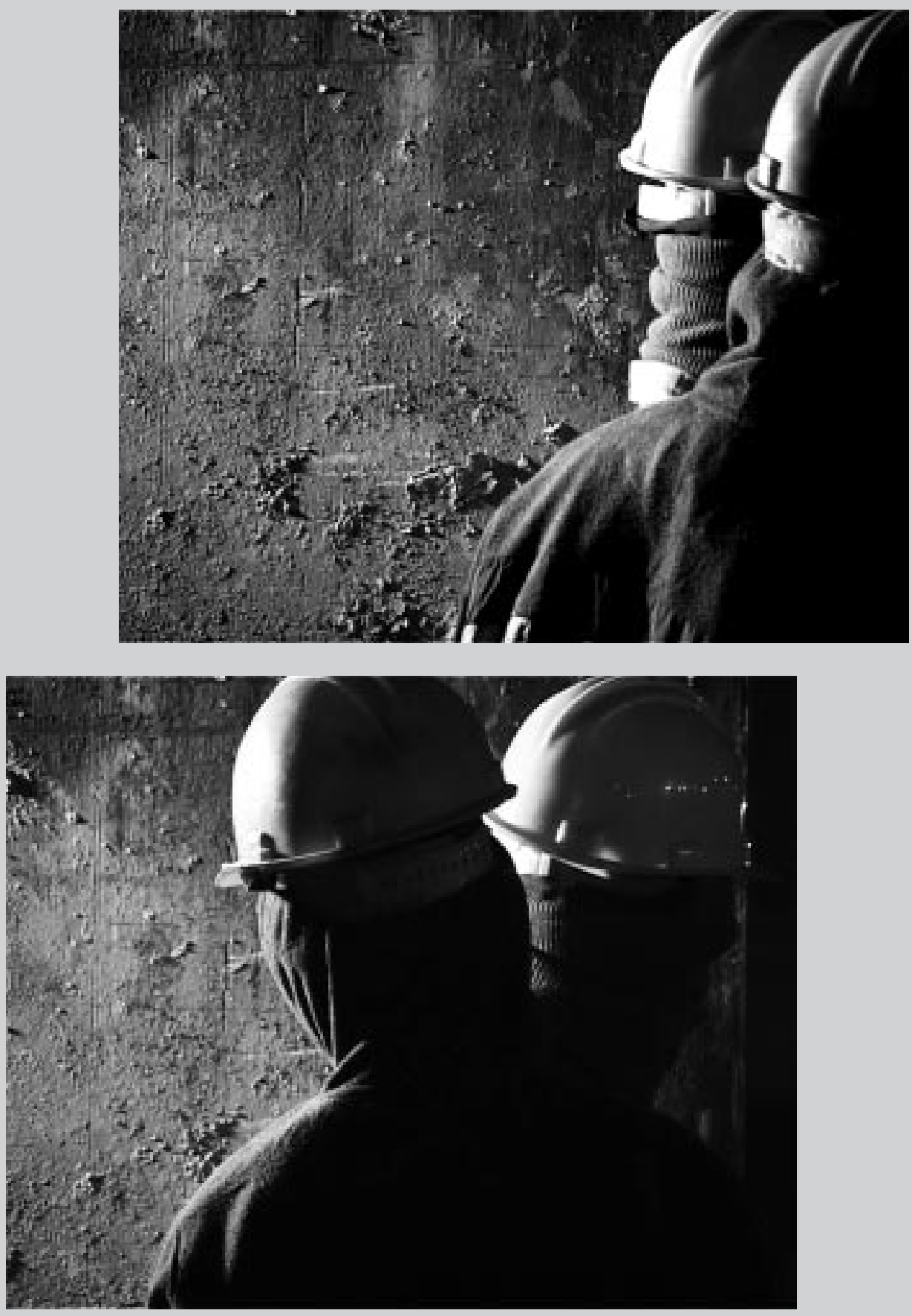
IMAGINATIONS + AESTHETICSIMAGINATIONS + AESTHETICSIMAGINA TIONS + AESTHETICSIMAGINATIONS +AESTHETICSIMAGINATIONS + A ESTHETICSIMAGINATIONS +AESTHETICSIMAGINATIONS + AESTHET CSIMAGINATIONS + AESTHETICSIMAGINATIONS + AESTHETICSIMAG IMAGINATIONS + AESTHETICSIMAGINATIONS +AESTHETICSIMAGIN A IMAGINATIONS + AESTHETICSIMAGINATIONS +AESTHETICSIMAGINA IMAGINATIONS + AESTHETICSIMAGINATIONS +AESTHETICSIMAGINA

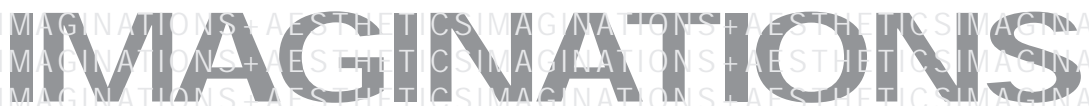

IMAGINATIONS + AESTHETICSIMAGINATIONS +AESTHETICSIMAGINA IMAGINATIONS + AESTHETICSIMAGINATIONS + AESTHETICSIMAGINA IMAGINATIONS + AESTHETICS IM MÁMG MivaTION S + AES THETICS IM A G IN A IMAGINATIONS +AESTHETICSIMAGINATIONS +AESTHETICSIMAGINA IMAGINATIONS + AESTHETICSIMAGINATIONS + AESTHETICSIMAGINA

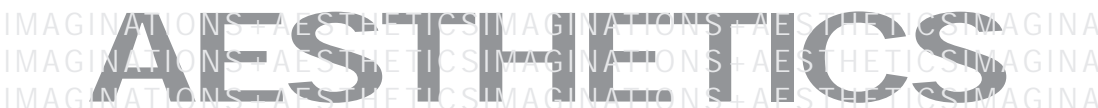

IMAGINATIONS + AESTHETICSIMAGINATIONS + AESTHETICSIMAGINA IMAGINATIONS+AESTHETICSIMAGINATIONS+AESTHETICSIMAGINA IMAGINATIONS+AESTHETICSIMAGINATIONS+AESTHETICSIMAGINA IMAGINATIONS + AESTHETICSIMAGINATIONS + AESTHETICSIMAGINA IMAGINATIONS + AESTHETICSIMAGINATIONS + AESTHETICSIMAGINA IMAGINATIONS + AESTHETICSIMAGINATIONS + AESTHETICSIMAGINA IMAGINATIONS + AESTHETICSIMAGINATIONS + AESTHETICSIMAGINA IMAGINATIONS + AESTHETICSIMAGINATIONS + AESTHETICSIMAGINA IMAGINATIONS + AESTHETICSIMAGINATIONS + AESTHETICSIMAGINA IMAGINATIONS + AESTHETICSIMAGINATIONS + AESTHETICSIMAGINA IMAGINATIONS + AESTHETICSIMAGINATIONS + AESTHETICSIMAGINA IMAGINATIONS + AESTHETICSIMAGINATIONS +AESTHETICSIMAGINA IMAGINATIONS+AESTHETICSIMAGINATIONS + AESTHETICSIMAGINA IMAGINATIONS+AESTHETICSIMAGINATIONS + AESTHETICSIMAGINA IMAGINATIONS + AESTHETICSIMAGINATIONS + AESTHETICSIMAGINA IMAGINATIONS + AESTHETICSIMAGINATIONS + AESTHETICSIMAGIN 


\section{Dreams of an (Un)Certain Future \\ STEVE DIETZ}

echnology is whatever is new since you were born.

Bruce Sterlinc

1 between the invention of a technology and its quotidian disappearance are the manifestos, declaimed and implicit. From Richard Wagner's gesamstkunstwerk to Marinetti's Futurist Manifesto to Nam J une Paik's "electronic highway" to J aron Lanier's VR universe and Roy Ascott's "vegetal reality", the history of the intersection of art and technology is one of prognostications of an irrefutable, inevitable, even immanent future that never comes to pass - at least not exactly as we thought it might.

The ultimate demo may have been Douglas Engelbart's mouse - a spellbinding vision of a future few others could even imagine at the time - but it is Perry Hoberman's Cathartic User Interface that is the most compelling, or at least cathartic, statement of where that future has dumped us. ${ }^{1}$

Janet Murray, author of Hamlet on the Holodeck has suggested the notion of "incunabular" media, for this stage in which we can imagine the outlines of a Shakespeare - of the very idea of a written literature - in the magical, mechanical reproductions of the early printing press; in which we can imagine something beyond the incunabular RPG and shooter video games that grab out imagination like videodromes.

These dreams of a certain future have such compelling vitality that we must admire them, even as we quibble about their navel gazing mediumness, complain about how simplistic - and complex - they are, acknowledge their inability to change humankind in the likeness of their vision and bemoan the obviousness of their shortcomings with perfect hindsight.

Here, in no particular order, are some dreams of technology that have a future, even if we do not yet know what it is, despite the certainty with which it is predicted. 


\section{The Dream of Symbiosis}

"The hope is that, in not too many years, human brains and computing machines will be coupled together very tightly, and that the resulting partnership will think as no human brain has ever thought and process data in a way not approached by the information-handling machines we know today" (J.C.R. Licklider 1960). ${ }^{2}$

Norbert Wiener is credited with coining the term cybernetics from the Greek kybernetes ("steersman"). His research into controlled feedback loops - interaction - between humans and machines postulated that by allowing each to learn from the interaction with the other, both could evolve to higher levels of functioning. Many artists have dreamed the dream that Wiener's younger contemporary, J.C.R. Licklider referred to as man-machine symbiosis, from Joseph Weizenbaum's Eliza (1966) to David Rokeby's Giver of Names (1990-present). ${ }^{3}$

At the same time, as Rokeby suggests: "interaction is banal... We talk to each other on the street. We breathe in air, modify it chemically, then breathe it back out to be breathed in by others. We drive cars. We make love. We walk through a forest and scare a squirrel. I am looking forward to a time when interaction in art becomes as banal and unremarkable... merely another tool in the artistic palette, to be used when appropriate". ${ }^{4}$

We are already coupled tightly, and it is not entirely clear we can distinguish appropriate use. We are symbiants who mould ourselves into carpel tunnels repetitively caressing Engelbart's dream of the future. We heed the siren cell phone and crash our four-wheel exoskeletens on the asphalt highway. Are we sheep who dream of becoming androids?

\section{The Dream of Mastery}

\section{DREAM}

Einstein's relativity and Heisenberg's uncertainty have become our own. Even if we do not understand the science, we experience the reality.

Artists have long tried to capture the dynamic nature of the universe, from Cubist fracturing to Rashomanic indeterminacy. Computational media can begin to model it, yet such faithfulness, like Borges' fable of a 1:1 map, ${ }^{5}$ runs the risk of becoming a cartography of uselessness. And Borges' ultimate knowledge map, The Library of Babel, only postulated one thing. Precisely the knowledge that all knowledge was at hand, neatly and precisely laid out, made it contingent, always open to review. Even, presumably, for a manmachine symbiont.

With a project like Knowbotic Research's 10_dencies (1996-98) however, there is no such dream of mastery. As Yukiko Shikata put it, "Regarding the 10_dencies project, it was very important that no one could have an overview of what was happening, as the totality of the information flow was happening only invisibly at info-level - on the server. Each participant had a different experience. No one could share the same reality". ${ }^{6}$

Modelling, mapping, mirroring can be appropriate tools for abstracting a level of information too broad or too deep or too dispersed or too dynamic for the human sensorium alone to comprehend; but the dream of mastery is masturbatory. 


\section{The Dream of World Peace}

\section{DREAM}

"An ocean cable is... a living fleshy bond between severed portions of the human family, along which pulses of love and tenderness will run backward and forward forever. By such strong ties does it tend to bind the human race in unity, peace and concord" (Henry Fielding). ${ }^{7}$

As Fielding rhapsodised about the transatlantic cable, there has been no communication technology that does not assure world peace. The ability to communicate quickly and easily, the rhetoric goes, leads to greater understanding, which leads to tolerance and the certainty of harmony. Demonstrably, this is not true; and arguably, whether it is the goal of prosecuting war without casualties by remote communication with munitions, or networks of terrorist 'sleeper cells' also remotely activated, the communication networks and technologies have not led to any calculable diminution of humanity's penchant for destruction.

Nevertheless, the dream remains powerful. Community activation pioneers Kit Galloway and Sherrie Rabinowitz write, "we must create at the same scale as we can destroy... [The] counterforce to the scale of destruction is the scale of communication, and... our legacy or epitaph will be determined in many ways by our ability to creatively employ informal, multimedia, multi-cultural, conversational, telecommunications and information technologies". ${ }^{8}$

Perhaps, however, it is not so much about scale as intimacy; not so much about the ability to broadcast anywhere as to connect somewhere, to converse. Is creating a system open to the network enough?

Warren Sack, creator of Conversation Map and, with Sawad Brooks, the forthcoming Translation Map, recently wrote in an e-mail that "From an analytic perspective one can assume that accountability is something that exists in a conversation. However, from a design/synthetic point of view (i.e. from the point of view of someone designing a new conversational system) I think it is an open question as to whether or not the new system is actually a facilitator of conversation or whether it is just a sort of two-way transmission system in which conversations might happen by accident or great effort, but cannot be assumed to take place". ${ }^{10}$

As the poet J ohn Berryman said so aptly, "in dreams begin responsibility".

\section{DREAM}

\section{Hacking the Dream}

Artists were among the earliest and most active participants to recognise the potential of the Internet - certainly long before most institutions and corporations. One result was to hack its capabilities for alternative purposes. From Rachel Baker's Sainsbury TM to Electronic Disturbance Theatre's Floodnet, there is a long history and active contingent hacking the dreams of e-commerce and universal surveillance.

For instance, Mongrel's Natural Selection was set up as an alternative search engine. Most of its queries, it simply passed to a commercial search engine such as Google or Alta Vista, and then presented the results as its own. For certain keywords however - generally to do with race - Natural Selection would create a result set that linked to artist web sites 
about that keyword. Often, a casual browser might not realise that a site presented a very different worldview than $s /$ he had been looking at for some time.

There is a disturbing trend, however, for such efforts to be shut down by "legal bugs", a termed coined by Knowbotic Research when its Minds of Concern project was shut down because a museum's upstream ISP had the equivalent of a shrink-wrap licence stating that port scanning, even if non-invasive and otherwise legal, was not allowed contractually. More recently, The Thing, a New York based host to various artists and organisations, was shut down because of the actions of a single site under its domain. It was easier for Dow Chemical Co. to bully The Thing's ISP Verio into shutting down The Thing than to pursue its true antagonist. ${ }^{11}$

In an earlier version of this article, I ended with the suggestion that the open protocols of the network were a kind of ultimate defence against such legal bugs, but now this does not seem so clear. The dream of the possible is only that: a dream; unless there is a concerted, ongoing, tough-minded effort on the part of a wide range of the translocally concerned to create and sustain a commons, a public domain, that is responsible and human.

\section{NOTES}

1. Regarding Douglas Engelbart and the first mouse with button and tracking wheels see http://www.artmuseum.net/w2vr/archives/Engelbart/02_Mouse.html and Hoberman, Perry Cathartic User Interface (http:// www. hoberman.com/perry, 1995).

2. Licklider, J.C.R. "Man-Computer Symbiosis" (originally published in IRE Transaction on Human Factors in Electronics Vol. HFE-1, http:// memex.org/licklider.pdf, March 1960) p. 4-11.

3. Weizenbaum, Joseph Eliza (http:// web.mit.edu/STS001/www/Team7/eliza.html and http://www-ai.ijs.si/ eliza/eliza.html, 1966) and Rokeby, David Giver of Names (http://www. interlog.com/ drokeby/gon.html, 1990-present).

4. Rokeby, David Lecture for 'Info Art' (Kwangju Biennale, http://www.interlog.com/ drokeby/ install.html 1996).

5. Borges, Jorge Luis "Of exactitude in Science" (in A Universal History of Infamy).

6. "Translocations: A Conversation with Steve Dietz, Guna Nadarajan, Raqs Media Collective and Yukiko Shikata" (in How Latitudes Become Forms: Art in a Global Age DAP/Walker Art Center, 2003, New York).

7. Quoted in Standage, Tom The Victorian Internet (Berkeley Books, 1998, New York) p. 104.

8. Galloway, Kit and Sherrie Rabinowitz Ecafé Manifesto (http:// www.ecafe.com).

9. Correspondence with the author, 4 January 2003 (see http://www.sims.berkeley.edu/ sack/CM/ for Conversation Map and http:// translocations.walkerart.org for Translation Map).

10. See http:// unitedwehack.ath.cx 


\section{Reading Technology Curling up with a Good Information Appliance \\ LINDA CARROLI}

M y copy of Scripts, Grooves and Writing Machines split while I was reading it for the first time. Broken in two, a chunk of the book fell out, leaving an empty paper and card shell. Then it continued to break. Each turn of the page caused a leaf to sever from the sad, glued spine. Landow takes the durability of paperbacks seriously, observing their flimsy construction as an indication that we are "beyond the book". ${ }^{1}$ Referencing the student experience, Landow claims that books "embody ill-designed, fragile, short-lived objects". Consequently, "students have lost much of the experience of the book, as we recall - and occasionally idealise - it". ${ }^{2}$ For Landow, the book, as a technology, is in the throes of decline and awaiting replacement by information technologies.

In this essay I address a tension between the technologies of ebooks and books as textual devices. ${ }^{3}$ I present the practice of these technologies in the context of the everyday and habit. In recent years, there has been concentrated speculation and hype surrounding ebooks and their reading devices. Commentaries have been presented in trade and industry publications as well as the media. The spokespeople of multinational publishing houses waxed lyrical about electronic futures for publishing as moves were made into the field. While Coover's commentary in The New York Times proclaiming "the end of books" seemed premature in 1992, ${ }^{4}$ it fuelled a decade of debate and research about books and their electronic counterparts. His declamation is echoed, for example, in Landow's claim that we are "beyond the book".

\section{Habit, Memory and Everyday Practice}

This discussion of reading and technology hinges on notions of 'everyday practice'. Implicated in everyday practice are concepts of habit and memory which I discuss in concert to develop a framework through which to consider tech- 
nology and textuality. I am referring to de Certeau's notion of everyday practice as "ways of operating or doing things". ${ }^{5}$ With a focus on consumers - those users who are "dominated" in society - de Certeau undertakes a study of 'everyday' practices, including reading, in order to illuminate "models of action". Consumers do not only consume, they also "use", "make" or "do" with that which has been purchased or imposed. This making or doing gives rise to "tactics" which the user deploys, and so "many everyday practices are tactical in character". ${ }^{6}$ Borrowing from Gitelman's account of late $19^{\text {th }}$ and early $20^{\text {th }}$-century technologies, and Hayles' ideas about virtuality, print and electronic reading, technologies are addressed as habit and disruption. Gitelman proposes the 'successes' and 'failures' of emergent writing technologies as sites of negotiation for meaning and subjectivity. She proffers that technology is both physically and discursively constructed and that technologies of inscription are materialised theories of language.

A regularly repeated refrain, 'no one will ever curl up with a good ebook', dismisses ebooks. For many, this is a compelling argument against ebooks. With this statement an exchange between the reader and the book is charted. The book is imbued with a corporeal significance that a computer (or other reading device) cannot possibly dis place. Clearly, 'curl up', as a comfortable or pleasurable embodiment for reading, is exclusively reserved for the book and it is unimaginable that the body would 'curl up' with a substitute book. A substitute book lacks authenticity. It is important to note that reading is a plural and variable practice which individuals do for diverse reasons: there are likely to be books for which this 'curled up' posture is not desirable or necessary but which are read regardless. For the purposes of this essay, I am interested in the 'curled up' posture because the presumed experience of reading from a different technology in this 'curled up' posture is allegedly not as desirable or pleasurable as reading a book in the same posture. It is not the same experience and therefore not as apparently rewarding.

In his exposition of memory and habit, Connerton addresses posture as an incorporating practice stating that: "where the characteristic postures of [for example] men and women are almost identical, there may be very little teaching of posture and there may be very little conscious learning of posture... Postural behaviour... may be so automatic that it is not recognised as isolatable pieces of behaviour". ${ }^{7}$

Learning the posture of 'curling up with a good book' emerges from sighted and practiced repetitions. This 'curling up' position as a reading posture results in contingent incorporating and inscriptive practices, or, as Connerton explains "no type of inscription is at all conceivable without... an irreducible incorporating act". ${ }^{8}$ In reading, it is the body that "curls up' and flips the pages and these actions are performed in concert with a knowledge of technology, language and writing. Further, "patterns of body use become ingrained through our interactions with objects... Postures and movements which are habit memories become sedimented into bodily conformation". ${ }^{9}$ De Certeau suggests reading is a "silent production" in which a reader "insinuates into another person's text the ruses of pleasure and appropriation: he [sic] poaches on it, is transported into it, pluralises himself [sic] in it like the internal rumblings of one's body.". ${ }^{10}$ Reading is an embodied and technologically contingent practice in a web of other practices and circulations including pleasure and consumption.

'Curling up with a good book' has become both 'naturalised' and 'authentic'. There is 
a perceived relationship, an exchange between body and book that another technology can neither account for nor accommodate. Building on Connerton's propositions, Hayles provides a framework through which to consider embodiment in an age of virtuality. This consists of two interacting polarities: body and embodiment, inscription and incorporation. She explains the interaction thus:

as the body is to embodiment, so inscription is to incorporation. Just as embodiment is in constant interplay with the body, so incorporating practices are in constant interplay with inscriptions that abstract the practices into signs. When the focus is on the body, the particularities of embodiment tend to fade from view; similarly, when the focus is on inscription, the particularities of incorporation tend to fade from view. ${ }^{11}$

Hayles contends that an "incorporating practice" is "an action that is encoded into bodily memory by repeated performances until it becomes habitual". ${ }^{12}$ Connerton explains these practices "cannot be reduced to a sign which exists on a separate 'level' outside the immediate sphere of the body's acts. Habit is a knowledge and a remembering in the hands and in the body; and in the cultivation of habit, it is our body that 'understands'". ${ }^{13}$ As a habit of reading, 'curling up' is a form of corporeal knowledge or embodied knowing. 'Curling up with a good book' is performed repeatedly and, ultimately, habitually. For Hayles, "habits do not occupy conscious thought; they are habitual precisely because they are done more or less automatically, as if the knowledge of how to perform the actions resided in one's fingers or physical mobility rather than in one's mind". ${ }^{14}$ As a habitual movement, "curling up with a good book' is accepted as an unconscious action and is rendered invisible when the technology and the text have disappeared into the task of reading. Subsequently, 'curling up with a good ebook' represents a threat or disruption to that habituated behaviour. This disruption is not straightforward due to reading's implication in other habitual practices and sensory experiences of literacy. In concert with reading and so much else that we do, these practices are also everyday practices. De Certeau states:

to read is to wander through an imposed system (that of the text, analogous to the constructed order of a city or of a supermarket)... [The reader] invents in texts something different from what [was] 'intended'. He [sic] detaches them from their (lost of accessory) origin. He combines their fragments and creates something unknown in the space organised by their capacity for allowing an indefinite plurality of meaning. ${ }^{15}$

'Curling up' becomes the posture which a reader adopts in order to undertake this "wandering through" and "reinvention" of the text. 'Curling up' is how we image or imagine ourselves reading in the realm of habit-memory and how we see others reading. As de Certeau posits, reading transports the reader "elsewhere", to a "secret scene" where the reader arrives and departs at will, and so, 'curling up' is the posture of this transportation. To proclaim that we are "beyond the book" dis-

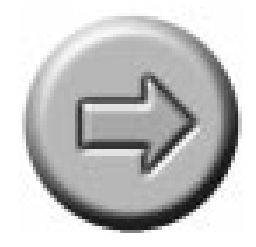


avows this everyday quality of reading, of curling up, of split spines and torn pages. It also disavows, as Connerton suggests, that habit and corporeality or inscription and embodiment are tied to memory. Connerton argues that "every group will entrust to bodily automatisms the values and categories which they are most anxious to conserve. They will know how well the past can be kept in mind by a habitual memory sedimented in the body". ${ }^{16}$ If reading books or 'curling up with a good book' is among those things that we seek to conserve and retain in habitual memory, then any attempt to replace the book meets with resistance. Hayles observes that when "changes in incorporating practices take place, they are often linked with new technologies that affect how people use their bodies and experience space and time". ${ }^{17}$ The ebook reading device and the book, as technologies, are not the same, do not produce the same relationships with the body or embodiment, inscription or incorporation, and are not readily interchangeable.

Virtuality has bearing on the spatial arrangements of objects and bodies. Hayles defines virtuality as "the cultural perception that material objects are interpenetrated by information forms". ${ }^{18}$ She refers to proprioception, "the sense that tells us where the boundaries of our bodies are", to describe human relations with books and computers, on screen and in print. ${ }^{19}$ Accordingly, "proprioceptive coherence... refers to how these boundaries are formed through a combination of physiological feedback loops and habitual usage". ${ }^{20}$ Hayles describes a difference in corporeal relations with various technologies and "although a reader can imaginatively project herself into a world represented within a print text, she is not likely to feel that she is becoming physically attached to the page itself". ${ }^{21}$ Hayles attributes this to the tactile and kinaesthetic experience of print, which provides less feedback and less interaction. While the reader might feel that "she is moving through the page into another world", she is unlikely to experience the same sense of immersion and interactivity as with electronic interactive texts. The 'curled up' position seems to reiterate this experience of reading as boundary between reader and technology. In curling up, one's body, while drawn into a relationship with the technology, is distinct from it. The reader is wrapped around the book, cradling it with their body.

A question raised by Hayles' discussion of proprioception is how readers negotiate print forms replicated on screens, and whether a search or dictionary function is sufficient to afford the material experience of the screen text. For Hayles, "the materiality of... [our] interactions is one way in which our assumptions about virtual writing is being constituted as distinctively different from print. Even when its output is printed and bound into codex books, we know from the inside that it operates according to spatial principles and a topographical logic of its own". ${ }^{22}$ In addressing technology as plural, decentred and indeterminate, Gitelman calls for technology to be "the reciprocal product of textual practices, rather than just a causal agent of change". ${ }^{23}$ In this respect, "changes to writing and reading matter in large measure because they equal changes to writers and readers". ${ }^{24}$ Likewise all new technologies and media, despite their uses, "inspire conflicted cultural moments of self-consciousness about the making of meaning". Hayles addresses technology in this way when she states that the integration of corporeal perceptions and movements with computer architectures and topologies has resulted in humans expressing cyborg subjectivity.

Readers, technologies (books, computers or reading devices) and texts are interde- 
pendent, and consequently our habits of reading, technologies and texts are also interdependent. In the technology of the book, a reader is habituated to that particular relation of text and technology. The introduction of ebook reading devices threatens to disrupt that relation, charting other reciprocal relations between technology and textuality, virtuality and subjectivity. In focussing on the phrase 'curling up with a good book' as the locus for this exploration, I am concerned with how this framework can be applied to new reading technologies (ebooks, personal organisers and ebook reading devices) in order to consider the ways in which these technologies might affect reading and the subjectivities of reading as performances of the everyday.

\section{Reading, Appliances and Devices}

At present, ebooks are produced for reading on a variety of platforms including personal computers, dedicated reading devices and multipurpose reading devices (such as personal organisers). Manufacturers are marketing, if not the 'best' then, the technology that they hope endures in the manner that Gitelman describes. In assessing the "successes" and "failures" of technologies, she asserts a problem of evaluation: "the notion that the 'best' technology succeeds only makes sense if 'best' can involve extrinsic as well as intrinsic advantages... Rather than try to settle which is the 'best' system, better to seek the variables of contemporary evaluation and the social and economic conditions that helps make those variables potent ones". ${ }^{25}$ The success as well as succession of technologies is bound in a network of relations, negotiations and possibilities that determine their use and, ultimately, endurance. In his critique of the computer industry, Norman's criteria for 'best' technologies are those which are "human-centred" rather than technology-centred. He argues for technologies which are task-specific, fitting a task for which they are built. Such specificity produces the "information appliance", defined as "an appliance specialising in information: knowledge, facts, graphics, images, video, or sound... A distinguishing feature of information appliances is the ability to share information among themselves". ${ }^{26}$ To be information appliances, reading devices must be specifically designed for the task of reading. Both the book and ebook reading devices are information appliances to different degrees. Using Norman's schema, the book is an effective information appliance because the technology has been absorbed into the task and become invisible: when we say we are reading a book, it is usually a text rather than a technology to which we refer.

For reading to shift beyond a naturalised and self-contained text and technology such as the book to digital technologies that require a reading device, software application and ebook, requires an effect on the social and material circumstances of reading. Importantly, in Western societies more authority is attributed to the printed word as textual representation, and much of what is presented in electronic formats is presented as untrustworthy. ${ }^{27}$ For Duguid, "the advent of multiple new technologies is probably changing not only particular works, but also the social system in relation to which the works were written and read". ${ }^{28}$ Ebooks and information appliances can generally be described as "disruptive technologies" in the sense that they disrupt established habits and tasks, bringing something new to those practices or tasks. ${ }^{29}$ While habit might be stubborn, it is neither wholly intractable nor unnegotiable. Fidler argues "as

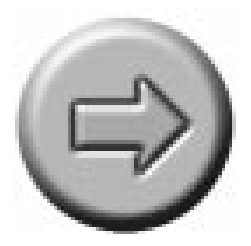


with traditional print media, digital forms must be comfortable and convenient to read while lying in bed, riding on a subway, dining in a restaurant, or sitting on a park bench". ${ }^{30}$ Inasmuch as reading is a habituated practice, so too are the reading postures which Fidler identifies. Cultural artefacts such as books and technology should be considered as agents within social networks and exchanges. The network in its entirety is what shapes the artefact and imbues it with significance.

A reader knows - by their embodiment - the difference between an electronic and printed text, or an electronic and print technology, despite efforts by hardware manufacturers to make the ebook reader more 'bookish'. For Norman, personal document assistants or personal organisers are evolving into information appliances. Having learned from the failures of earlier models, manufacturers are honing their devices for usability and simplicity. Handheld devices fail as information appliances when they replicate the complexity of the desktop or laptop computer. ${ }^{31} \mathrm{~A}$ question emerges about whether the differences between electronic and print information devices are acceptable to the reader or not. While several commentators have addressed this issue of 'sameness', current ebook readers are either single or multi-purpose devices, some of which resemble or simulate books while others resemble personal organisers or laptops. Many reading technologies seek to reproduce the linear reading experience with added functionality such as search and dictionary tools. While software that reproduces the sound of turning pages has been developed, some handheld devices allow the reader to 'dogear' pages, provide highlighting functions and postit notes. Ditlea observes that the publicity surrounding ebooks "has been drawn to single-purpose devices whose function is to display reading matter in a booklike fashion". ${ }^{32}$ Of the millions of personal computers now in use around the world, only a few hundred thousand users have downloaded ebooks. ${ }^{33}$ As users develop their computer and information skills, download culture and other aspects of cyberculture such as online shopping and browsing can develop as everyday practice. Gasson proposes that "e-books have to look and feel better than p-books, or they aren't worth inventing". ${ }^{34}$ Similarly, co-founder of ePress.com Kirvin admits that ebooks "don't have the curled-up-by-the-fireside aesthetic of a nice hardcover". ${ }^{35}$ Also, O'Brien, CEO of Forrester Research, suggests that handheld devices will "ultimately... look and feel more like a magazine... the kinetic experience that people are used to". ${ }^{36}$

A 1999 study of reader preference for electronic (personal organiser and web site) and print formats of newspapers found that readers preferred portable document viewer formats to print and web site formats of newspapers. This study also found that "the more respondents wanted to own a PDV, the more they like that format". ${ }^{37}$ Of course, reading a newspaper and reading a book are different readerly and reader experiences, but the role of desire in creating approval of new formats cannot be overlooked. Conversely, the more users desire printed formats, the more likely they are to disregard electronic formats. A reader takes more pleasure in a text which is read in a technology they desire. As Gitelman has pointed out, consumer expectation and behaviour plays a role in shaping the market and determining the use of particular technologies. Anderson Consulting predicts that by 2005, 28 million ebook reading devices will be in use worldwide. ${ }^{38}$ By mid-2000, the number of single-purpose dedicated readers reached 20,000 while Palm devices - only one type of handheld PC - reached 6 million. ${ }^{39}$ As 'information appliances', handheld PCs are 
surpassing single-purpose device sales and winning buyers despite the task specificity of a single-purpose device. According to Wilson, the trend towards convergence is yet to reveal the form of overlapping functions and technology. The issue here is whether converged or dedicated technologies will have greater appeal among users. Wilson proposes that "the future shape of portable electronic books is, at least in part, dependent on whether the trend towards convergence applies equally to ebooks as it does other technologies". ${ }^{40}$

From a reader's perspective, the cost of handheld PCs is prohibitive. When asked how much they were prepared to pay for a handheld device, $44 \%$ of respondents to a survey at BookBrowse.com wanted the devices to be free while $14 \%$ were prepared to pay over US\$ 100 . Of the respondents, $4 \%$ already owned a handheld computer and $22 \%$ would buy one if it cost less than US $\$ 100 .{ }^{41} \mathrm{~A}$ Wired report proposes that the "industry will soar when an ebook reading device with a high quality screen and full PDA functionality hits the market for under US\$100, which is expected to happen [by the end of 2003]".42 Palm recently confirmed its plans to release highend devices by the end of 2002.43 These emerging trends indicate that one way competition among handheld devices may be manifest is as 'portable entertainment'. Anderson Consulting predicts a need for broad-based content and a growth in digital music and video on demand. These types of content should be available on the same device. ${ }^{44}$ While Norman discusses task specificity as 'writing' or 'note taking', I prefer to think of tasks in a different way. Personal organisers are task oriented, and the task they are specific to is time management, mobility or personal organising. With their calendar, clock and diary functions, handheld organisers are used for marking and arranging time. One task is interconnected with other tasks, yet Norman tends to group tasks as disciplines such as music or photography rather than interconnections grouped as everyday practices. In their user's 'free time' or 'spare time', those devices are used to 'fill in time' in the sense that entertainment and leisure have a temporal or contextual quality which can be met by the device: read a book or play games while using public transport, or listen to music during lunch.

Ditlea proposes that content for electronic readers will be diversified, moving towards hypertextual, multimedia and interactive content. According to Stein, founder of Night Kitchen, the shift to electronic environments will happen because those environments are richer than print: "electronic media easily facilitates links to other information sources, it supports multimedia, and it affords richer interaction between authors, publishers and readers". ${ }^{45}$ It remains to be seen whether this richness will mean a wholesale shift and whether users will look to their PDAs for a particular kind of (media) richness. For Ditlea "lurking amidst e-publishing today is the notion of multimedia books that seamlessly incorporate hypertext, sound and animation. A hypertext branching narrative in a novel or a history book, for instance, would be impossible to reproduce in a book". ${ }^{46}$ Ditlea, like other commentators, is predicting that as content diversifies and as electronic texts do things not possible for print texts, electronic reading will become more desirable. It will provide something new and disruptive. A Fortune article suggests that consumers will ultimately demand ebooks that "do things" that print books cannot. ${ }^{47}$ The opportunities for hypertext and other forms of new media writing in this environment should be apparent. Given the emergence of the Internet, MP3s, culture jam-

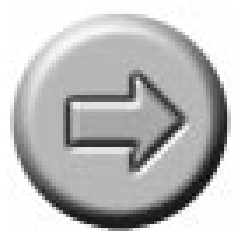


ming and sampling-type practices, there is the possibility that users will create their own content for their handheld devices. Users will continue to own other technologies such as computers, CD-players and burners, televisions and Playstations, using these technologies to develop or download content for their handheld device. The computer, in this context, occupies a different role: for storage, production, distribution, access and the like while handheld devices give users mobile information and content.

'Curling up with a good information appliance' may not have the same ring as other articulations of 'curling up', but this is not because the experience is a substitute for the real thing. This raises the question of whether books and ebooks should be regarded as different kinds of texts and technologies, perhaps necessitating a different kind of literacy. New reading tropes require definition against existing textual practices and need to be "contextualised". ${ }^{48}$ I have sought to demonstrate that the handheld reading experience is different and requires a different kind of engagement with texts and technology. It does not necessarily supplant existing ways of reading or technologies of reading, and exists among a plurality of reading practices and technologies. In electronic environments, certain devices are redefining the functionality and, indeed, textuality of what we have come to know as books. For Gitelman, "digital textuality... [is] about the identity of authors and the psychology of authoring, about the subjectivity of reading in its relation to the subjectivities of buying, eating, driving, and all the rest of the things people do". ${ }^{49}$ There is no apparent winner in the reading device race because it is not solely the prerogative of hardware manufacturers to determine which technology is 'best', which succeed or fail, or to be the only vested interest whose experiences of these devices as textual technologies matter. ${ }^{50}$ Rather, it is local and global networks of exchanges, geographies, users, subjectivities, technologies, histories and so on that will determine the fate of handheld technologies. This complex field of influences, resistance and interaction is in keeping with everyday practices of technology and textuality, virtuality and subjectivity.

\section{NOTES}

1. Landow, George "Twenty Minutes into the Future: Or How Are We Moving Beyond the Book?" (in Nunberg, Geoffrey (ed) The Future of the Book University of California Press, 1996, Berkley) p. $209 \mathrm{ff}$.

2. Ibid.

3. As a provisional definition, "ebook" is shorthand for a range of technologies and is not a static form. It has included, warranted and evoked a plurality of formats, software and hardware. There has been some fluidity in the use of the terminology of electronic books resulting in uses of 'e-book', 'eBook', 'ebook' and other formations of ' $e$ ' and 'book' to evoke both the ebook reading device and the ebook (the text). For the purposes of this essay, I refer to ebook reader or reading device as the technologies used to display, interact with and read ebooks, the texts which are loaded, stored and read via the ebook reading devices. While this also includes desktop and laptop computers, this study is concerned with handheld devices.

4. Coover, Robert "The End of Books" (in The New York Times Book Review Late Edition, 21 June 1992) p. $23 \mathrm{ff}$.

5. de Certeau. Michel, trans. Rendall, Steven F. The Practice of Everyday Life (University of California Press, 1984, Berkley) p. xi.

6. Ibid. p. xix 
7. Connerton, Paul How Societies Remember (Cambridge University Press, 1989, Cambridge) p. 73.

8. Ibid. p. 76.

9. Ibid. p. 94.

10. de Certeau op. cit. p. xxi.

11. Hayles, N. Katherine How We Became Posthuman: Virtual Bodies in Cyberspace, Literature, and Informatics (University of Chicago Press, 1999, Chicago) p. 199.

12. Ibid. p. 102.

13. Connerton op.cit. p. 90.

14. Hayles op.cit. (1999) p. 204.

15. de Certeau op.cit. p. 169.

16. Connerton op.cit. p. 204-205.

17. Hayles op.cit. p. 205.

18. Hayles op.cit. p. 13-14.

19. Hayles, N. Katherine "The Condition of Virtuality" (in Lunenfeld, Peter (ed) The Digital Dialectic: New Essays on New Media MIT Press, 1999, Cambridge) p. 88.

20. Ibid.

21. Ibid.

22. Ibid. p. 89.

23. Gitelman, Lisa Scripts, Grooves and Writing Machines: Representing Technology in the Edison Era (Stanford University Press, 1999, Stanford) p. 2.

24. Ibid. p. 11.

25. Ibid. p. 28-29.

26. Norman, Donald The Invisible Computer (MIT Press, 1999, Cambridge) p. 53.

27. I mean a range of practices which may include: mutable identities, the proliferation of pornography, concerns about the 'safety' of children, excess of content, lack of regulatory controls on content which means anyone with access to the web can publish and so on.

28. Duguid, Paul "Material Matters: The Past and Futurology of the Book" (in Nunberg, Geoffrey (ed) The Future of the Book University of California Press, 1996, Berkley) p. 83.

29. Norman op.cit. p. 232.

30. Fidler, Roger Mediamorphosis: Understanding New Media (Pine Forge Press, 1997, Thousand Oaks) p. 236.

31. Norman op.cit. p. 237.

32. Ditlea, Steve "The Real E-books" (in Technology Review Vol. 103, No. 4, 2000) p. 77.

33. Ibid. p. 72.

34. Gasson, Christopher "Towards a paperless future" (in New Statesman Vol. 129, No. 4515, 2000) p. 57.

35. J eff Kirvin cited by Broida, Rick "Not off the Presses - Paperless publishing is taking off with big-name authors and improved hardware. But are e-books require reading yet?" (in Computer Shopper March 2001) p. 149.

36. Dan O'Brien cited by Mayfield, Kendra "Getting a Read on New E-Books" (in Wired 11 December 2000, http:// www. wired.com/news/ print/ 0,1294,40470,00.html, accessed 20 April 2002).

37. Schierhorn, Carl, Stanley T. Wearden, Ann B. Schierhorn, Pamela S. Tabar and Scott C. Andrews "What digital formats do consumers prefer?" (in Newspaper Source Journal Vol. 20, No. 3, 1999) p. 16.

38. Anderson Consulting Reading in the New Millennium: A bright future for eBook Publishing:

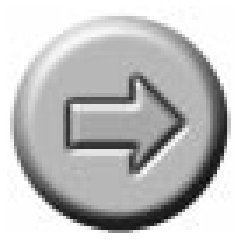


Facilitated Open Standards (http:// www.publishers.org/ ebookstudy.htm, 22 March 2000, accessed 22 April 2002).

39. Ditlea op.cit. p. 72.

40. Wilson, Ruth "Evolution of Portable Electronic Books" (in Ariadne Vol. 29, http://www.ariadne.ac.uk/ issue29/ wilson, accessed 23 April 2002).

41. BookBrowse.com "Audience Profile and Demographics" (http:// www.bookbrowse.com/ media/audience. cfm, March 2001, accessed 23 April 2002).

42. Rose, M.J. "E-Books Live on After Mighty Fall" (in Wired http://www.wired.com/news/print/ 0,1294,49184,00.html, 18 December 2001, accessed 20 April 2002).

43. Batista, Elisa "Palm Unveils Cheap PDA for Masses" (in Wired http://www.wired.com/news/business/ 0,1367,55555,00.html, 7 October 2002, accessed 8 October 2002).

44. Anderson Consulting op.cit.

45. Kahney, Leander "E-Books: The Next Killer App" (in Wired http://www.wired.com/news/print/ 0,1294,21550,00.html, 2 September 1999, accessed 20 April 2002).

46. Ditlea op.cit. p. 77.

47. “Now Showing: Books: Digital books are beginning to do things that paper-and-ink versions can't. Get Ready for multimedia 'read-ies'"' (in Fortune Vol. 142, No. 12, 2000) p. 281.

48. Gitelman op.cit. p. 99.

49. Ibid. p. 229

50. Ibid. 


\section{On Software as Art}

ANDREAS BROECKMANN

\section{Parameters}

For a long time, computer software has been understood as a purely functional element of digital technology. Only since the late 1990 s has it come under the scrutiny of media theoretical and cultural research. After the age of garage based computer bricoleurs, followed by the massive distribution of personal computers that came with standard proprietary software but without the necessary media competency, the last years have been characterised by a growing 'do it yourself' culture where programmers cooperate internationally on writing free software, and musicians, visual artists, literary critics and architects are increasingly acquiring programming know-how.

At the same time, we see the rise of a generation of media critics who are equally familiar with the Internet's technology, standards and politics; and with the marketing and technopolitics of computer hard-and software. The debates of these media critics show that software is a medium, and a cultural artefact that is being designed in a specific way that carries a particular socio-cultural meaning. Analogous to the cultural analysis of technology as it has emerged from social historiography over the past decades, we can observe the exploration of a technical medium being investigated with regard to the social and economic conditions of its development and application.

Since 2001, the Berlin-based international media art festival transmediale has been committed in its programme to the cultural and artistic dimensions of software. The transmediale was the first festival to award a special prize for software art, and it has hosted a whole series of discussions and lectures in order to foster the dialogue between programmers, artists, sociologists and media researchers. This initiative is not aimed at installing software art as yet another independent art category, but is meant as a heuristic intervention that seeks to stimulate the discourse in this important socio-cultural field.

In cooperation with transmediale, the art organisation hArtware in Dortmund, Germany organised the exhibition "Control Panels" (Kontrollfelder, April 2002) which focussed 


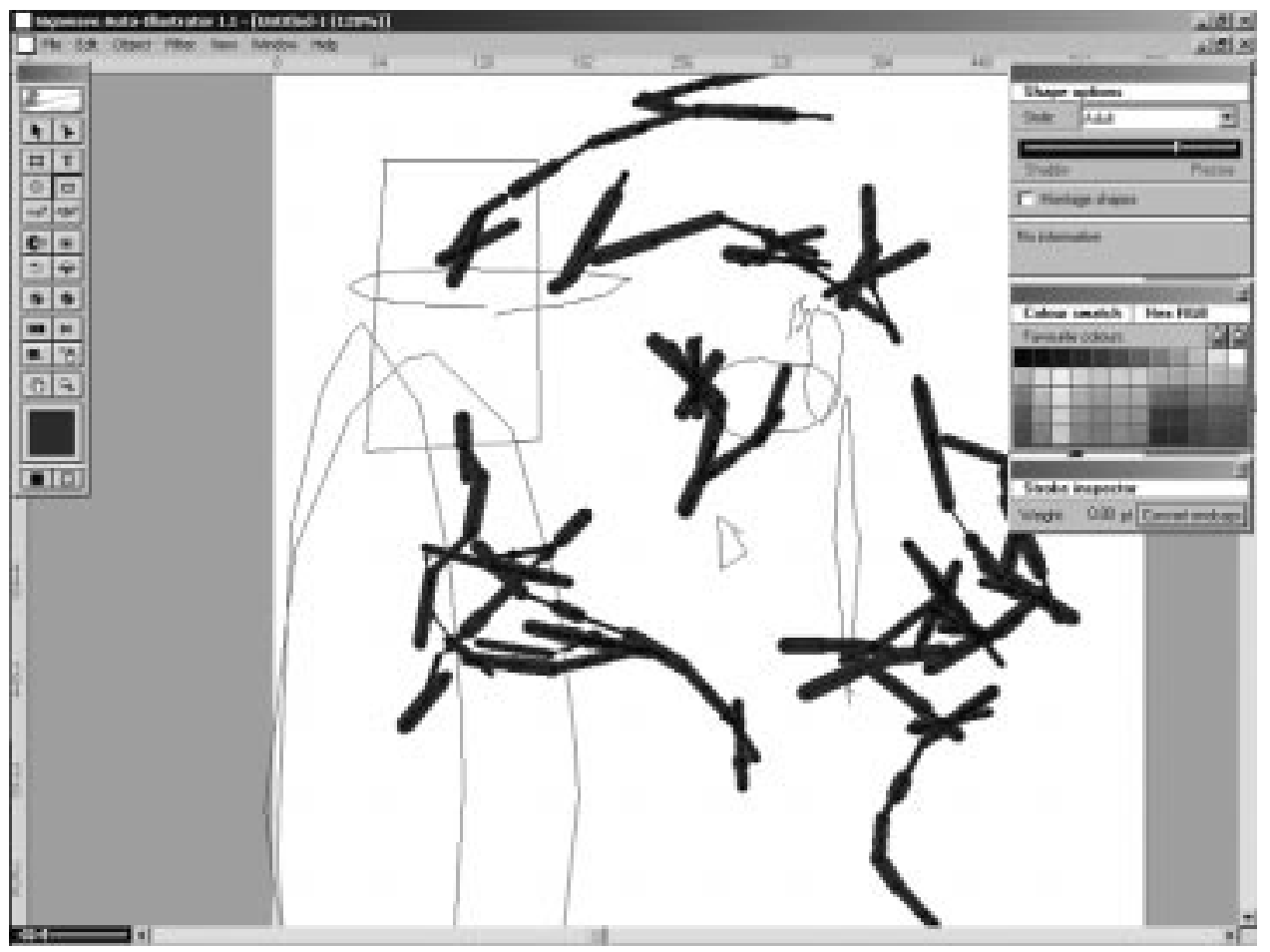

entirely on software art projects, and which pursued the question of how far software art can be described as a form of 'autonomous' artistic practice; autonomous, that is, of the normal functional and utilitarian requirements of software. (It was soon to be followed by the "Generator" show in Liverpool, UK; links to other, related events are listed below.) The exhibition tried to show the aesthetic potential of the creative practice of programming. In a text developed from their original jury statement, Florian Cramer and Ulrike Gabriel, who were members of the first Software-f ury of transmediale.01, put it like this: "Coding is a highly personal activity. Code can be diary, poetic, obscure, ironic or disruptive, defunct or impossible; it can simulate and disguise, it has rhetoric and style, it can be an attitude. Such attributes might seem to contradict the fact that artistic control over generative iterations of machine code is limited, whether or not the code was self-written. But unlike the Cagean artists of the 1960s, the software artists we reviewed seem to conceive of generative systems not as negation of intentionality, but as balancing of randomness and control. Programme code thus becomes a material with which artists work self-consciously. Far from being simply art for machines, software art is highly concerned with artistic subjectivity and its reflection and extension into generative systems".

Most of what constitutes software art today belongs in the field of media art - insofar 
as it is concerned with the formulation of aesthetic modes of expression, with the expansion of the artistic field, and with the articulation of the shifting relationships of human and medium, or human and machine. Software programming will, not unlike photography, video and the Internet, move from a status of novelty to being one more medium which artists can make use of according to their individual tastes, expressive needs and technical faculties. A software art exhibition will then make as much and as little sense as an exhibition dedicated to photographs, or to video art.

Another area of the artistic work with software concentrates not so much on the aesthetic but on the social and technocultural dimensions of computer software. It is closely related to a critical tradition of the avant-garde, rather than to an artistic modernism striving for autonomy. In this field of practice we find works that deal with the social processes enabled by software, as well as ironic or politically motivated analyses of the functionality and economy of proprietary software products. For this kind of creative work, Matthew Fuller has coined the term "speculative software", which I would suggest can be used to describe this particular type of software art: "Speculative software is software that explores the potentiality of all possible programming. It creates transversal connections between data, machines and networks. Software, part of whose work is to reflexively investigate itself as software. Software as science fiction, as mutant epistemology. Speculative software can be understood as opening up a space for the reinvention of software by its own means".

The reflection of the aesthetic and cultural aspects of software are crucial gestures of software art, and it remains to be discussed whether it would be necessary to differentiate between art, critique and speculation, or whether such differentiation is superfluous.

\section{Suggestions towards an Analysis of Software Art}

We are currently only beginning to develop a critical understanding of what software/art might be (a computer programme? An executable text? A generative process?), where its boundaries might be and what might be adequate aesthetic and critical criteria for its description and interpretation. The following is a first and incomplete attempt to develop something like a taxonomy according to which such an analysis might be pursued.

\section{Tools}

These are closest to the 'normal' function of software, i.e. to 'make', 'do' or 'show' something else. They can be:

- performative (as in Golan Levin's Audiovisual Environment Suite)

- reflexive (as in Adrian Ward's Signwave Auto-Illustrator or Frédéric Durieu's Puppet Tool)

- networked (as in Knowbotic Research's Minds of Concern or LAN's TraceNoizer)

- mapping and visualising (like IOD's Webstalker, Schoenerwissen's minitasking or RSG's Carnivore)

- browsers (as in NN's Nebula.M81 or Jodi's Wrong Browser)

2. Interactive Environments

These follow the idea of an interactive engagement with the machine and are, in a mutated form, modelled after:

- games (as in Joan Leandre's retroYou) 


\section{Code as Text}

These are closest to conceptual art and most strongly concerned with the textuality of (often experimental) computer code that is written and executed. It can be more:

- literary (as in J aromil's forkbomb.pl)

- political (as in Projekt Gnutenberg's textwarez)

- technological (as in Alex McLean's forkbomb.pl and animal.pl)

4. Machinic Autopoiesis

These are generative dispositions which, in my view, are closest to a generic form of software art. They can be:

- autonomous (as in Antoine Schmitt's Vexation1)

- semi-autonomous (as in David Rokeby's n-Chant or Knowbotic Research's Anonymous Muttering).

\section{Selected Projects and Exhibitions:}

transmediale (Berlin, http:// www.transmediale.de).

Kontrollfelder (Dortmund, http:// art.net.dortmund.de).

I Love You, Frankfurt/m. (http:// www.digitalcraft.org).

Digital is not Analogue (Bologna, http:// www.d-i-n-a.net).

Read_Me, Moskau (http:// www.macros-center.ru/read_me).

Generator (Liverpool, http:// www.generative.net/ generator).

Art Bit (Tokyo http:// www.art-bit.jp).

Electrohype, Malmö (http:// www.electrohype.org).

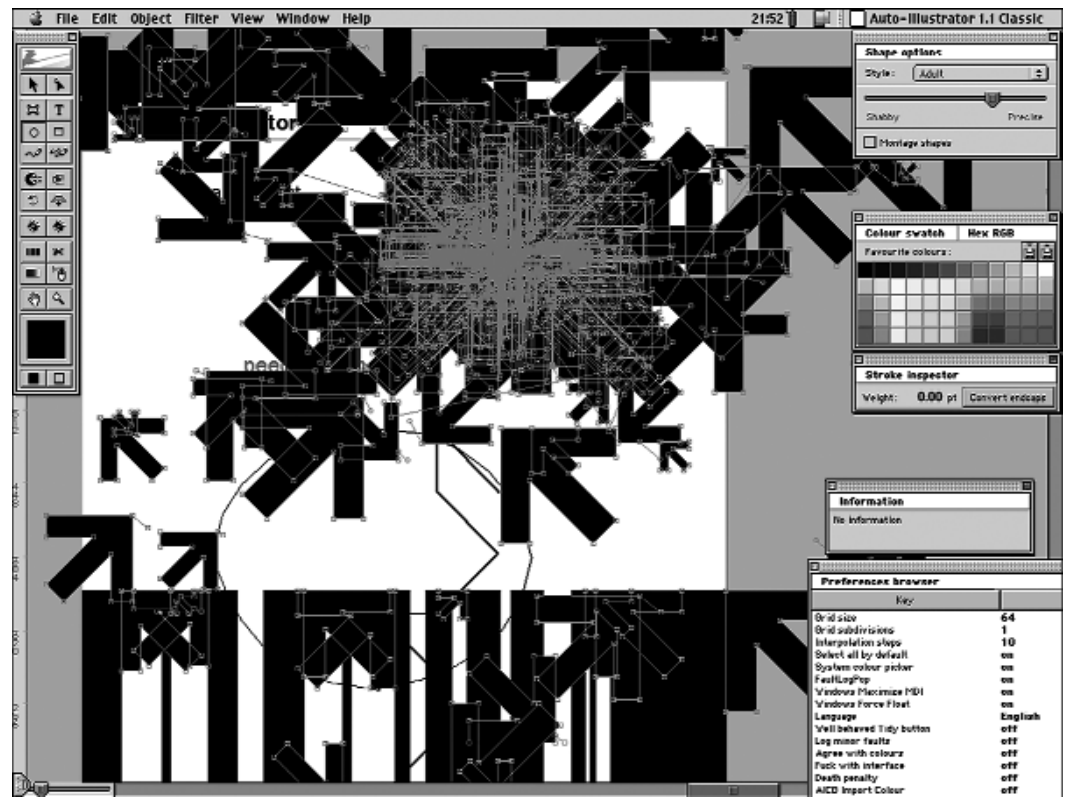




\section{Waste Net, Want Not Art and New Media in 90s Britain}

$\mathrm{T}$ 0 write an essay on recent new media art from the UK invariably means promoting a definition of that category itself. In doing this, you inevitably run into the problem that new media does not respond well to singular classification. Beyond glossing over the heterogeneity of contemporary practice, such popular products of unification deceive by homogenising the many histories and trace routes that feed into a genre. This unfailingly consolidates narratives that confound the more elliptical movement of cultural history.

New media art, whose 'post-historical' status is attributable to new media's general claim of being a meta-medium capable of replicating and synthesising other media, appears even more bedevilled by this problem than other art forms. ${ }^{1}$ This can be seen in its relationship to electronic art, arguably new media art's most natural antecedent. Electronic art's apogee occurred in the late 1970s and early 1980s and coherently announced many of what are now perceived as new media art's characteristics; namely a preoccupation with 'interactivity' between author, viewer and work; a time based production/ exhibition process; and a dispersal of agency across machine or network enabled systems. Yet the international group of artists who made their names with ludic feats of engineering, mythical constructions in outer space, collaborative global communication experiments, interactive installations, and basic video, TV and virtual reality projects seem strangely absent from contemporary critical discourse on new media art. ${ }^{2}$

Maybe the apparent disinterest of new media artists in the utopian interactive experi- 
ments of their direct precursors should come as no surprise, and we should see the more conspicuous dues being paid to the $20^{\text {th }}$ century's avant-gardes, traditions of performance, mail and conceptual art, or capitalist parody and institutional critique, as a negotiation of the vertigo of 'having never seen this before', and 'having seen it all before'; a critical but self-conscious eclecticism born of the net's notional post-historicity. After all, the radical new tools of self-historicisation, which the net and its ancillary networks granted artists (the mailing lists, community portals, individually owned web sites, and self-publishing projects) ${ }^{3}$ also knitted them into the "Total System" of globalisation and networked capitalism. ${ }^{4}$

As with classifications, one could of course argue that making any art-historical alignment based on such singular, strict and sequential periodisations is fallacious, and that trying to address that problem 'from within' is a game without end. All of history is encapsulated in the smallest object, act, and individual. Moreover, the insistent presentation of alternative histories for any contemporary cultural phenomenon itself tends to affirm a recursive logic of one-upmanship. This then merely aims for 'improved' hierarchies of valorisation that essentially work to reflect better the vested interests of the relevant artist, critic or historian, rather than the historical nuance or veracity to which the original contestation lays claim.

Any survey of recent practices, especially one artificially circumscribed by national boundaries and various practical contingencies (this selection, for example, focusses primarily on Internet based work), can easily misrepresent what is going on in a cultural field. Whether this occurs purposefully or through happenstance is immaterial as the understanding of it is tacit and cannot be properly disseminated beyond the originary group of artists and organisers.

The cultural histories produced by the institutions that now promote British New Media culture nationally and internationally illustrate this well, especially that of the stylistically disparate group of artists who came to be known as the "yBas" (Young British Artists).

It has been argued by Simon Ford and others that such institutions (business consortia, national public bodies) share responsibility for having exported an image of British art practice during the 1990s that was both politically motivated and misrepresentative of the art scenes it was held to mediate. As Ford states, "The yBa [was] called upon to justify increasing social division and disempowerment through a recourse to the values of self reliance and a rejuvenated entrepreneurialism". ${ }^{5}$ The confident, individualist art that was publicised internationally was certainly not one in which histories of overt collaboration, informatisation, social engagement, political, corporate and institutional critique found a place. In terms of the institutionally sanctioned framework of British art over this period, these themes were, in fact, conspicuous by their absence.

At this juncture, the first high profile acts of historiography are taking place for new media in the $1990 \mathrm{~s}^{6}{ }^{6}$ They should not allow new media art to harden into the politicised corrective to $\mathrm{yBa}$ : it seems appropriate therefore to reiterate the truism that personal surveys such as this should function to challenge narratives of art-in-general rather than merely illustrate the recent movement of one artistic offshoot or sub-genre whose only role in an institutional setting is to further illuminate the rich soil in which the master narrative took root.

The new media art of the 1990 s may be an unstable and historically contested category, however that is not to say that there are no coherent threads to be observed in its 
development, nor clear lines of identification in existence between groups of artists - at national and international levels. In the context of British new media art it should be stated that, though far from insignificant, those that are more geographically bound are latent in as much as they lack a tight fix to its electronic frame. The most obvious of these are the associated 'services' artists provide (especially for public or corporate bodies), or the sites in which work is produced, discussed and exhibited. The artists' affective milieu has been distinctly marked by the proximity of the cultural and commercial sectors; the fact that the UK dotcom 'boom' was not only the first but the most exuberant in Europe; New Labour's use - from 1997 on - of the potent symbology associated with new technologies to reanimate its export industry under the sign of culture and creativity; and the deep permeation of public culture by the ideology of the Third Way. ${ }^{7}$

In the wake of the strategic slash-and-burn performed on it in the Thatcher era, New Labour's social and economic policies and its absolute orientation towards the media bore a comparable weight of influence over the production and lionisation of market-oriented subjectivities. Some remarkable ironies reside in the fact that persistent institutional marginalisation during this period has consolidated new media art's perceived radicality while simultaneously robbing it of the kind of mainstream cultural analysis that would allow for an informed debate on it. Conversely, that new media artists' oft cited collaborative impulse and engagement with social and technical systems paradoxically falls in line with the state's professional ideal type of a socially integrative creative practitioner, rather than the revolutionaries as which they are so frequently cast.

So what are the coherent threads that momentarily hold together the fledgling cultural form of new media art? Going back to those that are less geographically determined: one can point the way with well known projects, such as I/ O/D's Webstalker, Graham Harwood's Rehearsal of Memory, and Rachel Baker's TM Club Card, which share a preoccupation with the denaturalisation of sovereign information systems. Each of these works is bent on disrupting that distended process whereby graphic user interfaces, software platforms, operating systems and even entire information networks are epistemologically normalised. Their functional inevitability is usually achieved by familiarity, practicality and a patronising accommodation of the user; the desired rupture is therefore often achieved by deconstruction or by making violent intrusions into the digital domain's illusion of seamless technological functionality. In Rehearsal of Memory, Harwood does this by inserting fragments of the flesh, trauma and language of sectioned subjects - culturally constructed as alien to the realm of CD-Rom technology. And in Webstalker, I/O/D does it by stripping away the retinal obfuscation of the Web's navigation icons - that strange maritime-administrative concoction of globes, windows, pages, houses, envelopes, and pencils - to reveal the underlying connective skeleton. Crudely put, this turns out to be an unstoppable structural birthing system in which informational wheels (web sites' internal links are displayed as spokes coming off a central core) beget wheels, beget more wheels (external links providing the various branches outwards). Stalked, the Web does not offer up the restrictive navigation of small slices of a domesticated terrain, but rather a view onto the infinite virtual territorial expansion that is its raison d'être.

If we accept the fact that these works are always already imbricated in the discursive 
environments that help constitute artists' habitat, then they express their provenance clearly. Over the years of their production, levels of anxiety regarding the so-called 'corporate takeover' of the Net rose steadily. If any one aggregate force was regarded as being able to produce a dominant episteme, it was the corporate producers of information systems, together with the powerful clients that put them to use. Now that globalisation was coming of age, this unholy alliance with its handmaidens in press and multilateral organisations was symbolic of the ideological closed circuit of neo-liberal rule. Where cultural geographer Saskia Sassen railed against corporate globalisation's "new normativities", and Le Monde Diplomatique editor Ignacio Ramonet castigated the New World Order for its "Pensee Unique" (The One Idea system), new media artists engaged with an all-enveloping information environment to propose that, as the incipient anti-capitalist movement had it, "Another world is possible".

Of course, it would be inaccurate to suggest that an unfettered unity of purpose exists or existed between artists and activists, practitioners and theorists, the new media arts and their radical politics. But information networks have created unforetold proximities, and have therefore instrumentalised cross-fertilisation - of tools, organisational practices, aesthetics and purpose. In this context, the political ferment of the anti-capitalist movement could only act as a magnet - drawing social formations closer together, and amplifying their intent. Out of this process, interesting commonalities are emerging. In her work on cybernetic politics, Tiziana Terranova has discussed online activism's obsession with 'off-line' effectivity. ${ }^{8}$ Her characterisation of the virtual protest movement's constituencies, as well as their differentiated use of place and placelessness (i.e. the expanded socio-technical field of mailing lists, meeting places, mobile phone conversations, Internet sites and so on, in which globalised and localised geographies fuse) problematises the popular, reductive image of virtual protest as passive and overmediated. Cohabiting as they do, I think it's fair to say a comparable interest in effectivity permeates artistic production, and it is one that acknowledges but seeks to go beyond the historical dichotomy between the fine and applied arts as much as that between form and function. Artists continually modulate these with issues of complicity and autonomy to test the medium's ontology and implication in larger spheres of interest (be they corporate, state or other). Over time, these efforts have accreted an elaborate nomenclature. Some terms, such as digital art, have taken on universalist ambitions whilst others, such as software art, follow quasi-modernist, 'formalist' explorations of processes and tools. Though it has never carried this descriptive tag, the latter has its forebears in the work of Dutch/Belgian artist duo J ODI (J oan Heemskerk and Dirk Paesmans), whose html détournements are notorious for undermining the prescribed use value of everyday web authoring systems, forcing them to surrender a world of strange, alterior meaning.

Webstalker, which co-producer Matthew Fuller described as wanting to be "not just art", moved stridently on in the direction of a qualified applicability. ${ }^{9}$ In a recent essay, Saul Albert takes this premise and runs with it to chart a path wherein artists gradually step away from the game of gestural deconstruction and the concomitant rejection of cultural proprietorship and position themselves as the autonomous producers of counter code for the open market. ${ }^{10}$ After Webstalker, Albert sees the value of these works in "[seeking] to 
be relevant in multiple contexts, [moving] between use value and conceptual value seamlessly... [rejecting] the dead end-dichotomy of culture vs. counter-culture, and [suggesting] hybridised, developmental, unstable cultural forms that can sustain themselves outside of art's frame of reference and financial backing". ${ }^{11}$

To point the way further (and look at some works included in this selection) I'll return to themes of informational denaturalisation. Tomoko Takahashi's piece Microsoft Herd, for example, offers a playful parallel to Webstalker, as well as a less well known installation by Matthew Fuller, A song for occupations. ${ }^{12}$ Others submit the tools of their trade to largescale professional projects, such as group curatorship (Nina Pope and Karen J. Guthrie's TV Swansong took nearly two years to produce, combined on and off-line projects, and involved the creation of a nation-wide network of access points in libraries, galleries and educational institutions, as well as workshops for children and local communities, and massive outdoor music events). ${ }^{13}$ The managerial aesthetic that TV Swansong embraces returns in more schizophrenic form in Adrian Ward's software work, Autolllustrator, which is a privately sold package whose 'Unique Selling Point' is its continual unhinging of the hierarchy of authorship. User, producer and platform are forced to constantly renegotiate the terms and conditions of production, as the first two are variously subjected to enhanced versions of the bugs and algorithms that commercial packages would rather hide from view. Having

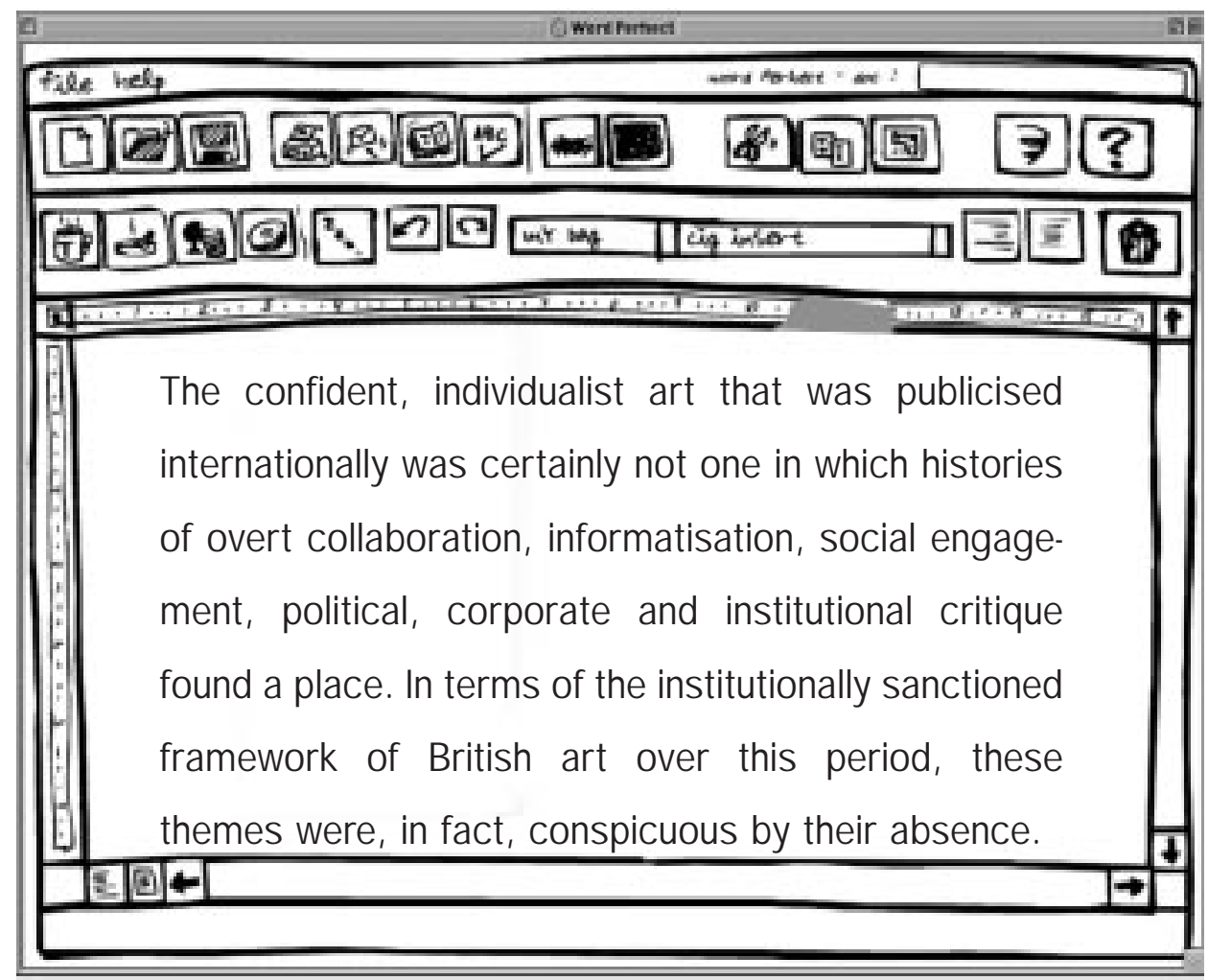


positioned him/ herself higher up in the productive tree than the media producer - who uses, rather than codes software, and has significantly less power to determine its application it is incumbent on the artist-software producer to provide back-up and technical support. ${ }^{14}$ In the case of Ward's business, Signwave (a company run by one man), this means presenting a multiplicity of computer-generated aliases, whose answers confuse, illuminate and entertain in equal measure. Perhaps this is the "death of the author" so mercilessly parodied in J on Thomson and Alison Craighead's piece, Trigger Happy, where icons of the early interactive age - lo-res space invaders - take pot shots at an earnest chunk of postmodern theory for long enough to make it sound like the incoherent mutterings of a pathetic authorial 'I' on the verge of dissolution.

Like Autolllustrator, Richard Wright's project Bank Of Time and Heath Bunting's BorderXing resource flirt seriously with the myths of utility. Bunting's BorderXing resource - in which a range of sure-fire, personally tested European border crossings are laid out (complete with pictures, practical tips on what to eat, etc.) - does this by working against the grain of progressive computer culture's idée fixe of openness for its own sake. He skirts public net artists' implied responsibility to make her work available for domestic consumption by refusing access to all users whose access context can't be described as socially constituted. The work excludes every home browser on the planet and includes cyber cafés, schools, public institutions and so on (their necessary details can be inputted after e-mailing the author). Richard Wright's Bank Of Time instead cocks a snook at the sacred cow of productivity and resource management. It mimics computer sharing networks like SETI@Home (Search for Extra Terrestrial Intelligence), which tap more energy out of a decentralised net of privately owned computers than could ever be squeezed out of a centralised one - only to ignore these wonders of the world's central diktat. ${ }^{15}$ The extended screensaver Bank Of Time wants its users to do nothing more, or perhaps nothing less, than rear a family of computer animated plants whose 'life' is negatively indexed to productivity (when computers are used, their screensaver home is inactive and cannot tend to its plants; when they are out of use, it - and they - come alive and can grow). Albeit on a fictional plane, the attention economy's maniacal drive to annex every human life hour here comes full circle. In a dark combination of Gardeners' World and Big Brother, users submit the necessary details for 'the network' to monitor their digital labour - all for the price of simulations of the natural world it is fast making obsolete.

\section{NOTES}

1. The phrase 'meta medium' is meant to stand in for, and allude to, widespread theoretical tussles over the essential nature of computer mediated communication technologies. Specifically, I am referring to the discussion concerning these technologies' status as tools, media or meta-tools/media. Core questions in this debate are whether the capacity of computer based tools to digitally encode and hybridise other tools constitutes a historical, perceptual - and hence aesthetic - paradigm shift, and whether networked technologies' exponentially growing connections and their linkage to 'intelligent' machines creates an operational field whose properties are 'emergent'.

2. For contextualising material on the history and discourse of electronic art, see Linz's Ars Electronic Centre web site (http://www.aec.at). And for a better sense of continuity in its critical discourse over the last few decades, see Leonardo Online (http:// mitpress2.mit.edu/ e-journals/ Leonardo). 
3. In the absence of a family tree which accurately illustrates the fractal development of this discursive culture, influential platforms such as thing.net and rhizome.org, as well as mailing lists such as Nettime and 7-11 should be mentioned. Electronic journals such as Switch (http://switch.sjsu.edu) and Telepolis (http://www. telepolis.de) have also been instrumental in shaping a sense of collectively authored history.

4. Josephine Berry uses this Marxian term in her PhD thesis The Thematics of Site Specific Art on the Net. The chapter "Global Art in a Total System" deploys Frederic Jameson's description of new technologies' (and, as Berry suggests, later the Internet's) capacity to "think the impossible totality of the contemporary world system", to unpick the relationship of net art, globalisation and late capitalism. Berry, Josephine The Thematics of Site Specific Art on the Net (PhD, unpublished, 2001, Manchester University) p. 65.

5. Ford, Simon "Myth Making" (in Art Monthly No. 194, March 1996). For a glimpse of other critical sentiments stirred by the discussion on yBa, see also Beech, David "Chill Out" (in Everything magazine, http:// www. backspace.org/ everything/ e/ hard/ text/ beech.html).

6. Across the commercial, independent, and cultural fields, curtains are coming down on the new media boom. Symptomatic of this are the slew of post-dotcom books (Ernst Malmsten's Boo hoo, Rory Cellan-fones's Dot.bomb and John Cassidy's Dot.con, to name a few examples), as well as more subjective accounts of the fledgling 'critical' new media scene, such as media theoretician Geert Lovink's Dark Fiber.

7. The New Labour government has come to be associated with the creative industries due to Tony Blair's creation of the Creative Industries Task Force in 1997 and their heavy-handed promotion of the term ever since. Importantly however, many of its policies express legacies of J ohn Major's Conservative government.

8. Terranova, Tiziana "The degree zero of politics: virtual cultures and virtual social movements" (in Network Culture: The Cultural Politics of Cybernetic Communications Pluto Press, London, forthcoming).

9. Webstalker can be found at http:// bak.spc.org/iod and Matthew Fuller's phrase "not just art" in the accompanying essay, "Means of Mutation" (http:// bak.spc.org/iod/ mutation.html).

10. Albert, Saul "Useless Utilities" (http:// twenteenthcentury.com/saul/useless.htm, 2001).

11. Ibid.

12. A song for occupations (2000) maps out the software package Microsoft Word. For the accompanying essay, "It looks like you're writing a letter: Microsoft Word" see http:// www.axia.demon.co.uk/ wordtext.html 13. TV Swansong, whose archive can be found at http://www.swansong.tv streamed the performance and video commissions of Jordan Baseman, Graham Fagen, Rory Hamilton and J on Rogers, Chris Helson, Nina Pope and Karen J. Guthrie, Giorgio Sadotti, J essa Voorsanger, Zoe Walker and Neil Browmich on one dedicated day (20 March 2002). The project intended to contemplate the past, present and future of television at a point where it might converge with other communication networks, and to demonstrate the potential of artists having control over a cultural space comparable to that of television. As it happened, technical problems meant there were numerous hiccups with the 'broadcast', though this seems to have only confirmed the febrile status of net and TV fusions. See also Nina Pope, Karen Guthrie, Rachel Whithers, Pauline van Mourik Broekman "TV Swansong - A partial view" (in Guthrie, Karen and Nina Pope (eds.) TV Swansong ARTicle Press, 2002).

14. This line of argument is taken from Saul Albert (Ibid.) who uses the software industry's terms market share and mind share to demonstrate its hierarchy of productive power (mind share being the Orwellian mental correlate of market share).

15. SETI@Home (http://setiathome.ssl.berkeley.edu) functions by having individual users download a programme that can analyse radio telescope data, and pooling theses rources in a massive parallel net. 
226 / Sarai Reader 2003: Shaping Technologies

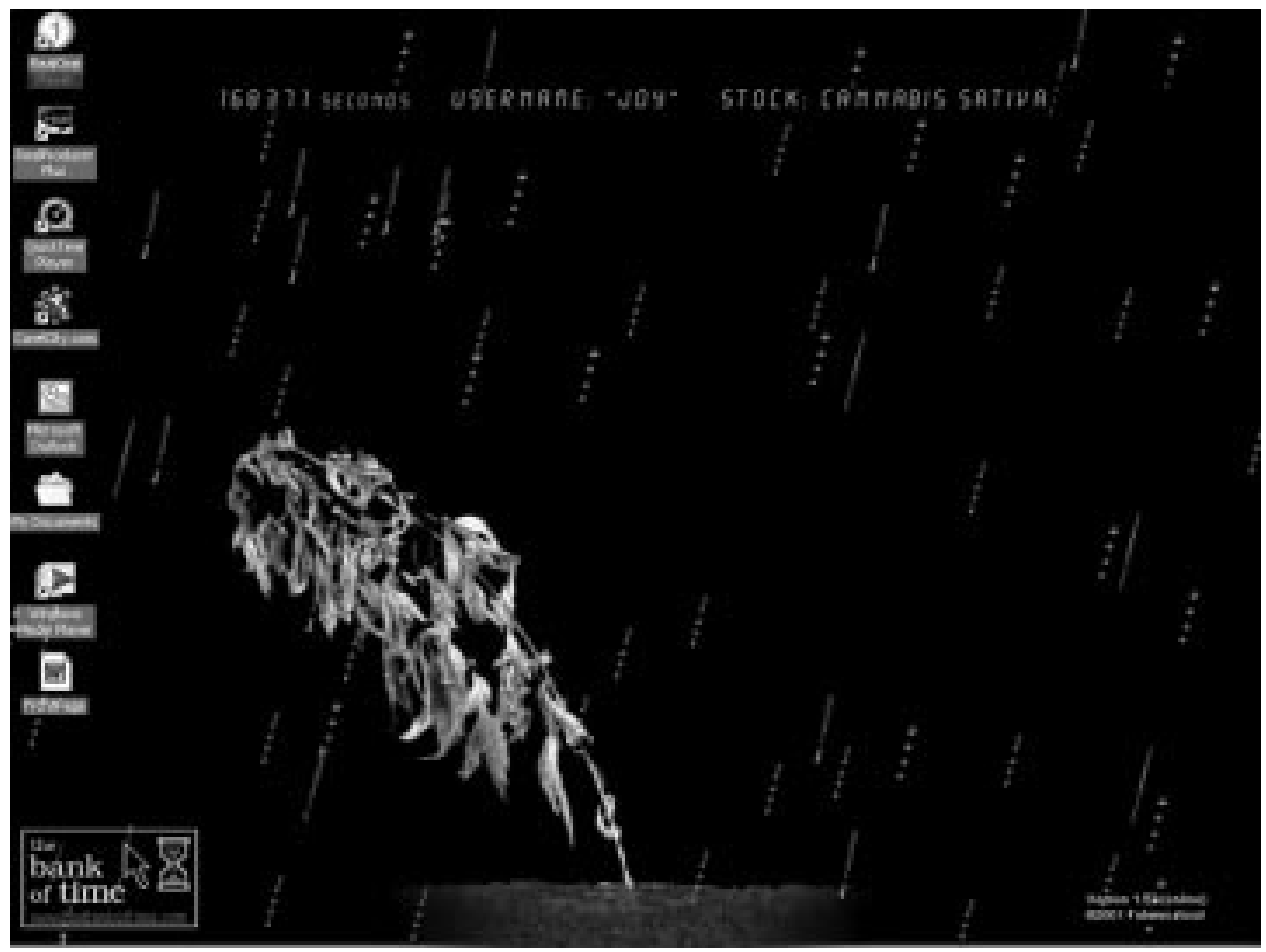




\section{Creative Encounters The Art/Science of Collaboration}

AMANDA MCDONALD CROWLEY

"An integration of art and science promises to be much more appealing and understandable to a larger public than either are alone."

"Research is the search for the future. Science and art are major forces in contemporary society. They must both contribute to the shaping of that future."

Stephen Wilson ${ }^{1}$

artis this article I look at three different approaches to creative and experimental projects that artists have developed addressing contemporary scientific knowledge. In the spirit of this Reader, this is an attempt to understand and articulate the (omni)presence of science and technology in culture and society. A number of contemporary artists are currently not just looking at digital technologies, but are also exploring and critiquing a range of scientific practices, including biotechnologies, in their work. These artists are attempting a sober but creative exploration of the ethical and cognitive dilemmas that we are confronted with by the presence of technologies in everyday life.

Jeremy Rivkin, writing about J. Craig Venter's recently announced plan to develop artificial life forms in laboratory environments, suggests that "other scientists worry that Ventner's creation could wreak havoc on natural ecosystems or be used to create new kinds of biological weapons". ${ }^{2}$ Such concerns are, however, not just the domain of scientists: whether they are opportunities or threats, discussion about such scientific 'discoveries' and research must be open for public debate.

The space that artists provide for an interrogation of a creative (public) imaginary provides real possibilities for informing technological innovation and scientific enquiry; indeed in this context, art has the potential to provide a forum in which to examine scientific and intellectual inquiry in very real social and cultural contexts; and to interrogate, intervene and sometimes co-opt the debate.

\section{The Art/ Science of Collaboration}

Australia's Back to Back Theatre Company has, over recent years, been driven increasingly by an ambition to create a new theatrical space that merges screen and live performance. They make extraordinary multi-disciplinary theatrical events which merge architectural design, live performance, animation and sound. In their most recent and probably most ambitious project to date, the research and development of the work revolved around the current debate of genetic screening and the social implications of the human genome

The space that artists provide for an interrogation of a creative (public) imaginary provides real possibilities for informing technological innovation and scientific enquiry 


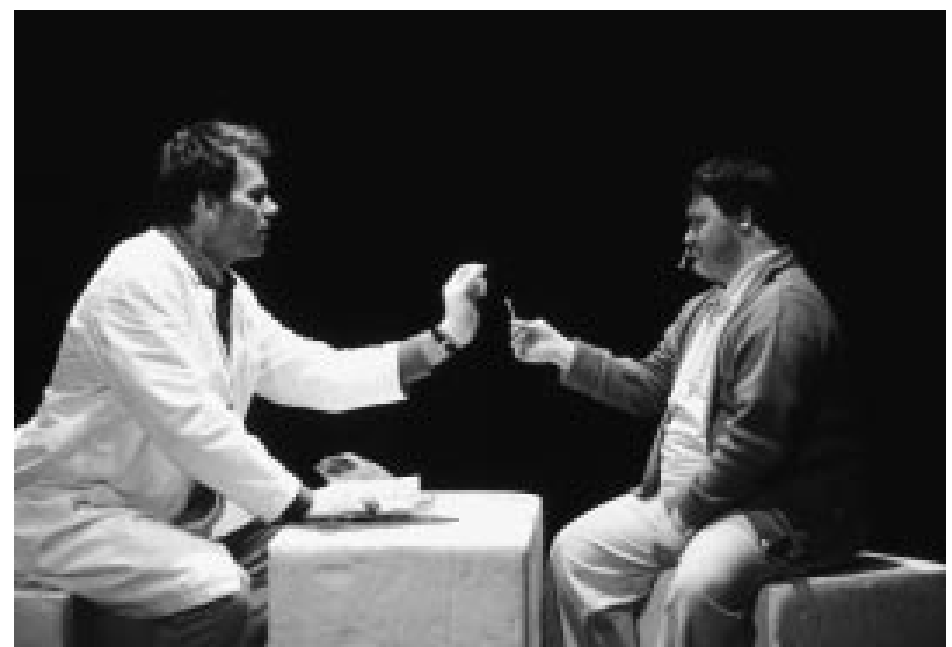

Image courtesy: Jeff Busby

project. At the Cytology Department at the Murdoch Children's Research Institute where prenatal screening for chromosomal disorders occurs, scientists were given the opportunity to engage in dialogue with the Back to Back ensemble - who physically and intellectually represent the disorders that the doctors seek to identify.

SOFT is a work that Back to Back describe as: "A soluble theatre product that won't affect your regularity. Taken once only, SOFT will give you greater understanding of what it means to be human. In a world where stem-cell research, cloning and pre-natal screening blur the line dividing humanity and technology, SOFT offers immediate insight and clarity". ${ }^{3}$

Bruce Gladwin, artistic director of Back to Back, said of the research, "The initial dialogue was a series of short field trips to the Murdoch Children's Research Institute in Melbourne. The aim was to bring the scientists who are involved in the development and application of the prenatal testing technology in contact with the actors who have the genetic condition which is detected in the test. As the scientist in charge of the department said - 'This is very confronting to the people who work here' I responded: 'Not half as confronting as it is for the actors'. The staff of the research institute explained what they do in the lab and the tools and methods they use do this. We spoke to the counsellors who consult couples who have entered the prenatal testing conveyor belt, also ethicists involved in the department. We also spoke to a scientist (J sev Gesz) in Adelaide from the Womens' and

"A soluble theatre product that won't affect your regularity, Taken once only, SOFT will give you greater understanding of what it means to be human. In a world where stem-cell research, cloning and pre-natal screening blurs the line dividing humanity and technology, SOFT offers immediate insight and clarity. 
Children's hospital who has discovered three genes which are linked to an inheritable form of intellectual disability in boys. The implication is a screening test which will soon be developed which will lead to further research and development of methods for increasing intelligence... Essentially SOFT focussed on current prenatal screening technology and the ethics surrounding it. It is often perceived that genetic technology is going to have implications for us in the future. However, for people with Down Syndrome, they are already being eliminated from our community. Ninety percent of pregnant couples terminate after a positive indication for Down Syndrome in an amniocentesis test. It seemed no one in the community was raising this as a concern and Back to Back seemed well placed to comment". ${ }^{4}$

Back to Back felt it was essential that the wider community hear this dialogue between scientist and artist. For them, three key questions from the research offered the narrative direction for the work:

$>$ What is the 'function' of disability? What repercussions would we encounter by eliminating 'genetic disorder' and consequently narrowing the diversity of the human genome?

$>$ What is the link between economics and human life?

$>$ Is there a gene responsible for 'obsession for perfection'? The concept reinterprets 'perfection' as a genetic disorder in it's own right, allowing it to be treated as an illness, or even via termination. This utopian quest for 'perfection' has repercussions beyond the thematic here, and makes links with all human endeavour.

Inherent in the work is the symbiotic relationship between content and form. SOFT advocates for the value of diversity of human form and explores the subject through "diversity of theatrical form". To this end, they collaborated with a range of artists from diverse art form areas, including professor of architecture Mark Burry, animator Rhian Hinkley, sound artist Hugh Covill, designer Efterpi Soropos and emerging artists Dave Morrison and Chris Price. Whilst the work is not the direct result of collaboration between the artists and scientists, it was inspired by conversations between them. The pertinence of exploring relationships between human and technical is amplified for a company like Back to Back with an ensemble of people who have traditionally been seen as less than human. The work was premiered at the Melbourne Festival in 2002 to high praise and full houses.

Many contemporary artists see opportunities for working collaboratively across a range of disciplines as essential to the development of broader debates about the future of our planet. As we live through an age of increasing uncertainties, a deeper understanding of our environment - social, spiritual, emotional as well as physical - are key to developing a more intricate and integrated relationship with the world around us. Internationally, the rapid growth in the number of artists interested in this field is partly due to the artists responding to the key drives of social change: our current technological and scientific knowledge. These linkages are essential if we are to meet the complexities and challenges our future is already presenting.

Critical Art Ensemble is a group of artists whose work over some fifteen years has been based on the principles of collaborative practice. ${ }^{5}$ Over the past five years CAE's work has focussed on biotechnology and new forms of representation that emerge from this vast field. As tactical media artists, the group has completed major projects examining various aspects of the biotech revolution in theatrical forms that invite public participation and pro- 


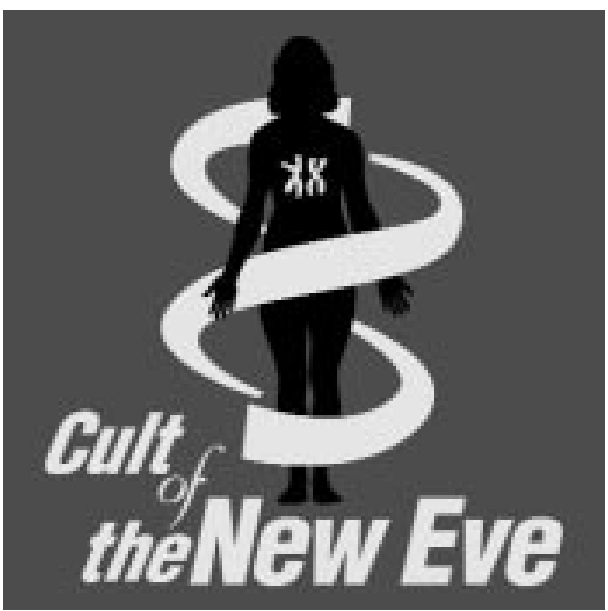

Cult of the New Eve logo

vide a context for lived experiences. For them, it is not so much about collaboration with specialists from divergent fields of expertise, but rather a gathering and sharing of knowledge and experience.

The recent body of 'biotech' work includes Flesh Machine (1997-98), which highlighted eugenics in the discourse and practice of current human reproduction technologies, and featured the actual genetic screening of audience members and the diary of a couple going through in-vitro fertilisation; and Cult of the New Eve (2000), developed in collaboration with Paul Vanouse and Faith Wilding, in which CAE used the apocalyptic language of an imaginary cult to explore the rhetoric surrounding recent genomic research. In Cult of the New Eve, CAE 'perform' dressed as a cross between the Heaven's Gate Suicide Cult and the Unabomber. Cult of the New Eve addressed the rhetoric that was being used (particularly by scientists) to calm public fears. They said, "It was listening to an entrepreneurial scientist called Lee Hood that got us thinking about this project". In one of his lectures he apparently announced, "I am going to make you all immortal". CAE became intrigued by recent biotechnological promises to create a New Eden: the fact that the Genome Project is described as the Holy Grail or (their favourite) the words echoed by President Bill Clinton, that the Genome Project is "God's Blueprint".

They see the key problem with such rhetoric in that it is believable when a scientist says it - dressed up wearing the authority of a white coat, it all sounds so possible. So CAE rethought the rhetoric deciding that best way to do that was to take the same messages from the most believable place and send it from the least believable place. In other words, take it from the mouth of the scientist and put it into the mouth of a cult figure. No one believes a word they say.

The term New Eve came from the first donor of DNA in the beginning of the Human Genome Project. This single DNA sample was taken from a woman in Buffalo, USA. CAE 
decided to take her genome, splice it into some yeast, and use the yeast to make beer and cookies. "So there it was - eugenically pure. This was our communion - instead of wine and a cracker with us, when we say you're getting Eve, you're getting Eve! As you would expect not many people were enthusiastic about this particular proposition". ${ }^{6}$

Their most recent work, Molecular Invasion, developed in collaboration with Beatriz da Costa - a work they describe as a "Direct Action Project" - deals with "roundup ready canola", which has become a super weed. CAE worked on identifying the enzyme that is in 'roundup ready' plants so as to develop an inhibiter that stops aromatic amino acid creation: in effect reverse engineering the genetically modified canola. "We believe we have found a good compound - at least it works in the lab. So we are trying to make that into a 'defence kit' for the farmers. Next step is field-testing". ${ }^{7}$ For all their projects, CAE enlists the aid of scientific specialists in the field under scrutiny, while at the same time encouraging amateur knowledge across various fields of expertise. Their intention is to demystify scientific processes and contribute to an informed, critical, but most importantly public, discourse on biotechnology.

While certainly in great part pedagogical, their work is often hilarious, always rigorous (even when one doesn't agree with their position), as well as entertaining. As they suggest in their most recent publication, "Amateur discourse clearly has a place in the transgenic debates since some levels of study can be reviewed by nonexperts. The stakes are too high for product safety testing to be left solely in the domain of corporate and scientific experts". ${ }^{8}$

CAE also suggest that "the goal for cultural resistance is to create temporary public space where education and inter-subcultural labour exchange can occur. Opening the knowledge bases and dissolving boundaries of specialisation is a primary goal... Under such conditions, dialogue can occur that is grounded in the present rather than in utopian or apocalyptic projections for the future". ${ }^{9}$

As technology further enables global multi-cultures and economies, the challenges of communication across disciplines becomes even more urgent. To borrow from the rhetoric of the Bridges Summit, Banff Centre, 2002: "Differences in work and communication styles, priorities, educational principles, institutional frameworks, temperaments, fundamental beliefs and values have the potential to become either obstacles or stimulants to effective collaboration. The BRIDGES consortium pinpoints collaboration itself as a skill... it identifies best practices, amplifies networks and provides a means of communication for those engaged in the reality of collaborative research across disciplines, borders and cultural contexts". ${ }^{10}$ It is important to acknowledge that collaboration is at the core of the development of new, innovative research. The arts must be at the heart of this endeavour.

Unlike the work of CAE and Back to Back, which begins with research undertaken with scientists, Patricia Piccinini's work is primarily studio based in its development. However, it is thoroughly researched, meticulously executed and luscious in its realisation. Piccinini has developed several bodies of work over the last few years which invoke near futurist scenarios, categorising them as atmosphere/autosphere/ biosphere. ${ }^{11}$ The latter began when she launched her Mutant Genome Project in 1996 where she marketed the computer generated LUMP (Life form with Unevolved Mutant Properties) where audience members could, via a computer terminal, customise features for their very own LUMP - gorgeous but mon- 


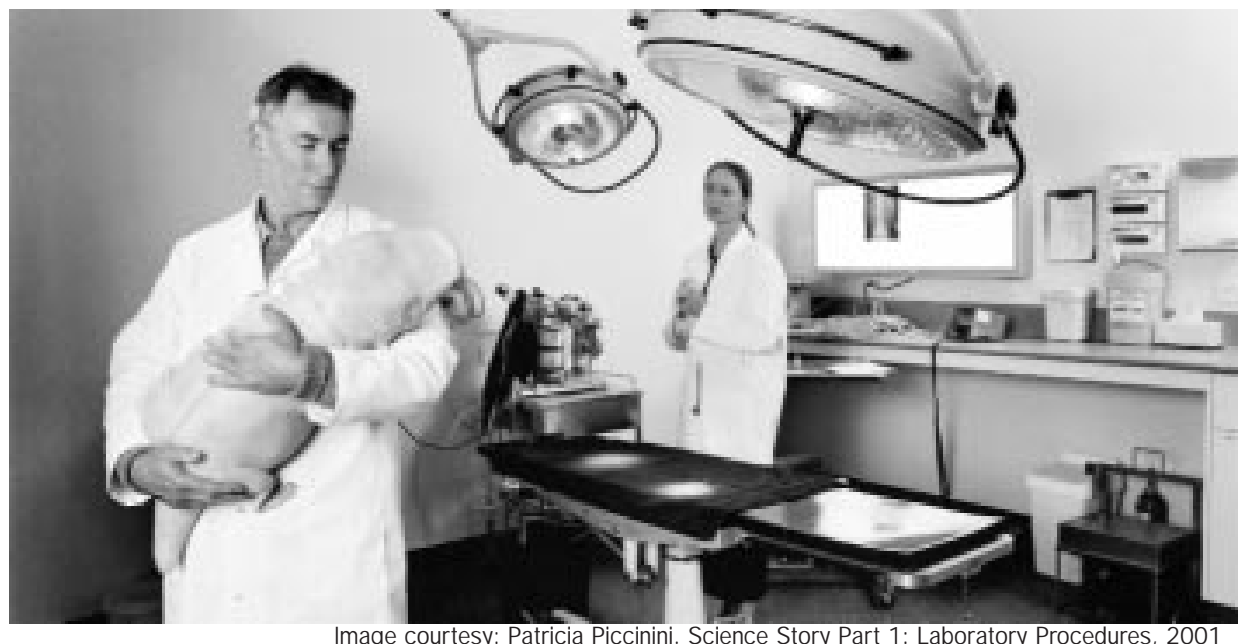

Image courtesy: Patricia Piccinini. Science Story Part 1: Laboratory Procedures, 2001

strous artificial life forms. But this, like all of her subsequent work, deals with personal responsibility as well as the potential impact of genetic research.

Piccinini finds it thrilling, as an artist, to make something new or to bring something from her imagination to life. She says, "I imagine that is also what drives a lot of scientists to do what they do and I find a lot of things that happen in the science world exciting but also really frightening". ${ }^{12}$ Piccinini believes that humans have always interfered with and altered nature and doesn't make value judgements about such research. In a recent work, SO2, she was inspired by the idea that we are about to produce the first synthetic organism. "I asked the question, why would you create a synthetic organism when we have so many organisms that are about to be extinct - why do we need a new one". ${ }^{13}$

The answer, of course, is because we can; and so she did. Piccinini made her own animal - Siren Mole - without consultation. It wasn't until later that all its defects were pointed out: it is naked so it gets sunburnt, it's got small legs so it can't run away and will never survive on its own. "Initially I was really upset about that because I felt I'd failed it - I'd made something that could not survive on its own. Then I thought, that's all right, it's very symbolic. This animal has to be looked after by people. It has to be nurtured and I think that was what inspired the next series of photographs with the scientists, the need to look after new life forms". ${ }^{14}$ For Piccinini it was critical that her animal, her new creation, was named. She consulted with a zoologist at the Taronga Z0o. "The siren that was washed up on the shores of Naples was a wondrous creature. No one knew where she came from but she was beautiful, but also dead. That was how I got the common name for my creation - the Siren Mole... at least my animal has a name, a context and a family, as the scientists are its parents and I guess that's one of the things that runs through my work, that there is a sense of care and nurturing for these life forms". ${ }^{15}$ 
"Piccinini's work does not suggest that human intervention in the essence of life is morally wrong; exuding as it does the sophistication of highend technology, her work partakes in a discourse of first-world progress founded on the commercialisation of scientific and electronic innovation. Piccinini rather forces us to confront [the fact] that this intervention is well and truly with us, that the implications are not clear-cut but ambiguous, even contradictory, and that it is therefore vital that we see the consequences of technological innovation with clear eyes". ${ }^{16}$

In her work, Piccinini urges us to take collective responsibility for advances in genetic research and biotechnology. She urges us to understand the science, to name it and own it.

As Stephen Wilson has also suggested, "It is a critical error to conceive of contemporary research as merely a technical enterprise; it has profound practical and philosophical implications for culture. The shaping of research and development agendas could benefit from the involvement of a wider range of participants including artists". ${ }^{17}$

A handful of initiatives have emerged over the last decade which provide residency style programmes to foster this kind of cross disciplinary 'art/science' engagement. A forerunner to these kinds of projects was the Xerox PARC Artists in Residence (PAIR) program, ${ }^{18}$ which was a unique experiment bringing together artists and scientists for deep, long-term engagements. In a recent publication of the Australian Network for Art and Technology (ANAT), scientific serendipity, which documents the four residencies undertaken by artists working with scientists and scientific organisations ANAT has developed over the last four years, Rich Gold writes: "Designers and engineers often think of what they do as solving problems, but that's not how artists and scientists think of what they do. They create objects and ideas that bend the very fabric of our lives, pushing out the envelope in which innovation can occur. Combining the aesthetic with the physical, the artist with the scientist produces not just more art and science (which it does); or better artists and scientists (which it does); but it might also transform the matrix of innovation here to create a spectacular and productive six billion-seat spaceship that we want to live on". ${ }^{19}$

As Linda Cooper and I suggested in a recent essay: we can no longer talk in art or science about the future of humanity and its biosphere without engaging with the very real and often frightening possibilities raised by biotechnology and genetic engineering. ${ }^{20}$ New techniques of molecular biology give us both the ability to read the code of life and the potential power to manipulate it. As social objects and consumers of new technologies, we must be alarmed by claims such as those of Michio Kaku: "The next century will witness an even more far-reaching scientific revolution, as we make the transition from unravelling the secrets of Nature to becoming masters of Nature". ${ }^{21}$

"It is a critical error to conceive of contemporary research as merely a technical enterprise; it has profound practical and philosophical implications for culture. The shaping of research and development agendas could benefit from the involvement of a wider range of participants including artists. 
The tendency for knowledge to be confined within disciplinary silos has led to serious problems in applying that knowledge to the complexity of the real world. In the past, many art/science collaborations were less partnerships than adjuncts: artists illustrating scientists' research outcomes through illustrative representation; the scientists facilitating art production through access to technologies and research. Increasingly there are a number of artists whose work is more involved in process - where perspectives are challenged and altered through cross-disciplinary contact. Art/science collaborations are now moving towards projects with conceptual contributions from a range of people and with corresponding opportunities for mutual benefit. The move towards such creative collaborations reflects a departure from specialisation, which in turn mirrors a growing trend in contemporary scientific research. Understanding the world as an infinitely complex system of interactions rather than a plethora of independent causes is a significant move away from reductionist approaches to understanding.

The role of science and the role of art are entwined: both disciplines are engaged with the principles of 'pure research'; of discovery and an exploration of paths to understanding. By allowing people from both realms to interact and cross-fertilise ideas and knowledge, very real opportunities for the development of new research and fresh critiques can be provided, which is essential for informed and public debate.

A range of programmes that have been recently established by arts and cultural funding agencies such as the Canada Council, the National Endowment for Science and Art and the Australia Council suggest that social innovations can be merged with technological development in the form of creative cultural expression, socially relevant actions, and economically promising products and services. ${ }^{22}$ As identified by Linda Cooper in her report to the Australia Council "creativity is a process, a way of thinking. We need to foster environments that are conducive to creative enquiry and innovation". ${ }^{23}$ Such bureaucratic interventions come with their own sets of problems, but the institutional recognition of the importance of cross-disciplinary dialogue is noteworthy.

Identifying science and technology as an artistic medium in itself, as opposed to an integral part of human existence up for critical artistic reflection like all other aspects of our existence, is probably a circuitous dead end. At the same time, discussion of these issues must be opened up for informed public debate, as implementation of current research should not solely be left in the hands of scientists (and the corporations and governments that employ them). Artists, cultural workers and scientists must engage with the nexus between art and science at the very point where these collaborations fuse the complex social and political issues that face us in the $21^{\text {st }}$ century.

This article is dedicated to the memory of Rich Gold (Richard Goldstein). Rich Gold was a digital artist, inventor, cartoonist, composer, lecturer and inter-disciplinary researcher. It was Rich Gold who founded the influential PARC Artist in Residence Programme in 1993 (mentioned in this article) which has been a model exemplar of successive programmes of this nature. Rich Gold died in his sleep on $9 \mathrm{~J}$ anuary 2003, aged 52. He will be profoundly missed and fondly remembered as a visionary thinker and tenacious supporter of inter-disciplinary research and practice. 


\section{NOTES}

1. Wilson, Stephen Information arts: Intersections of art, science and technology (MIT Press, 2002) p. 877.

2. Rivkin, Jeremy "Dazzled by the science: Biologists who dress up hi-tech eugenics as a new art form are dangerously deluded" (in The Guardian http:// www.guardian.co.uk/ comment/story/ 0,3604,874312,00.html, 14 J anuary 2003).

3. http:// www.backtobacktheatre.org.au

4. E-mail discussion with Bruce Gladwin (18 J anuary 2003).

5. http://www.critical-art.net

6. Critical Art Ensemble presentation at conVerge symposium, bioeconomics panel (Adelaide Festival 2002, http:// www.adelaidebiennial.com, 3-4 March 2002).

7. Ibid.

8. Critical Art Ensemble The Molecular Invastion (Autonomedia, 2002) p. 5.

9. Ibid. p. 65.

10. Banff Centre, New Media and Visual Arts programme, Bridges II Summit (http:// www.banffcentre.ca, 4-5 October 2002).

11. http://www. patriciapiccinini.com

12. Patricia Piccinini from an artists' talk at the symposium converge: where art and science meet (http:// www.adelaidebiennial.com, 3-4 March 2002).

13. Ibid.

14. Ibid.

15. Ibid.

16. Millner, Jacqueline "Patricia Piccinini: Ethical Aesthetics" (in Artlink 2001).

17. Wilson, Steven "Art as Research" (http:// userwww.sfsu.edu/ swilson/artist.researcher.html, 1996).

18. http:// www. pair.xerox.com; this programme is examined in detail in the publication Art and Innovation: the Xerox PARC Arist in Residence programme (MIT Press, 2000).

19. Gold, Rich "I've been thinking about collaborations" (in Scientific Serendipity Australian Network for Art and Technology, 2002) p. 52.

20. Cooper, Linda and Amanda McDonald Crowley "Catalogue Introduction" (2002 Adelaide Biennial of Australian Art, conVerge: where art and science meet Art Gallery of South Australia, 2002).

21. Kaku, Michio Visions, How Science will Revolutionise the Twenty-First Century (Oxford University Press, 1998, Oxford) p. 10.

22. For details of these kinds of programmes, refer to the web sites of these funding agencies:

Canada Council (http:// www.canadacouncil.ca);

National Endowment for Art Science and Technology (http:// www.nesta.org.uk/);

Australia Council (http://www.ozco.gov.au/newmediaarts/synapse.html).

23. Cooper, Linda Creative Encounters: art and science collaborations (Australia Council, April 2001). 


\section{Beyond the Apocalypse An Unfinished Meditation on Ethics}

RANA DASGUPTA

\section{Prelude: The Brick Wall of the Imagination}

Around the time of the Fall, Hollywood was in the process of making a \$70-million film version of The Time Machine, H.G. Wells' early novel (1895). It was directed, interestingly enough, by his great-grandson, Simon Wells.

H.G. Wells' original story is narrated by a member of the London bourgeoisie who assembles in the evenings with stock-figure bourgeois friends ("the Lawyer", "the Psychologist", "the Editor", "the Doctor"; he is referred to only as "the Time Traveller") to hear these incredible stories of the future. Having discovered that time is only another dimension within which movement is as possible as in the first three, the Time Traveller tells of his journey to the world of 800,000 years in the future where the human species has split into two: the bourgeoisie has become a race of effete aesthetes ("Eloi") who are preyed upon by the Morlocks, a hideously transformed working class, entirely dehumanised by underground toil. After his own narrow escape from the Morlocks, the hero embarks on a meditative exploration of the even more distant future - ending up thirty million years away - where the simultaneously enfeebling and brutalising forces of capitalism have finally destroyed humanity.

Two things should be noted.

First, the dispassionate context of the narration. The Time Traveller is a scientist motivated simply by the acquisition of knowledge and completely involved in the telling of it. There is no attempt to enliven the fireside chat amongst educated men from different intellectual backgrounds, for this ability of such men to comprehend all has its own drama: it is central to the heroism of nineteenth-century imperial bourgeoisie.

The second point is the extraordinary periodicity of a story which, after all, is about the very contemporary issues of Wells' class based society. So eternal is the class system of industrial capitalism that its effects are still dominating the progress of nature thirty million years into the future. While the story speaks of the threat to humanity that the class system represented, readers at the time cannot have felt that the dangers he was describing were exactly imminent; and indeed the triumph of bourgeois science and the magnitude of the capitalist project seem far more impressive in his story than their eventual decline.

A number of changes, apparently minor, in Simon Wells' scenario transform the vision of the novel utterly. In fact, Wells junior was adamant that the demands of film and of our more relaxed times necessitated a new vision: 
"The problem with adapting The Time Machine from the book is that it was written much more as an essay about the grand scheme of time and is less of a personal adventure story. To be honest, I'd feel rather cheated if the movie were a word-for-word version of the book". ${ }^{1}$

Despite his family ties, Wells chose to eliminate most of the class issues from the film because "A hundred years on from when the book was published, I'm not sure the class struggle is all that relevant". ${ }^{2}$

Alexander Hartdagen, his (no longer anonymous) hero, now based in New York, is neither disinterested nor dispassionate: he undertakes his experiments in time travel in order to try and undo the murder of his fiancée; when his successful arrival in the past does not avert her death a second time he decides to travel in the opposite direction to see if future humankind has discovered why the past cannot be changed. He lands in 2037 where a space exploration catastrophe has caused the moon to rain down on the earth, destroying capitalist society utterly. He only just manages to escape from the disaster zone, and collapses, stunned, over the controls of his machine as it careers 800,000 years hence. There is of course now no historical continuity between the world he discovers and our own since the technological disaster has created a tabula rasa; and yet the pastoral community of the future has made a little place of contemplation out of stone fragments from the past ('Brooklyn Bridge' and 'New York Public Library') from which, amazingly enough, some of them have been able to learn English. Hartdagen saves the people of the future, falls in love with the most buxom and beautiful of them and decides to stay, teach them all English and describe for them the wonders of American civilisation - 8,000 centuries after its destruction. His destiny is tragic: once he finds out that he is living at the end of capitalist time he does nothing but settle down with ignorant people and teach them to join him in mourning it.

The shift from a 19th century vision of capitalism, in which it sets the terms of the world for thirty million years to come, to this one in which it destroys itself through technological hubris a mere thirty-five years from now, is dramatic. Of course the $20^{\text {th }}$ century was full of voices, often dissenting ones, predicting technological calamity; but what is remarkable is that this has, increasingly over the last twenty years, become the orthodox vision of the future in that crucible of capitalist fantasy, Hollywood. From Bladerunner, Aliens and Brazil to Gattaca, Dark City, Twelve Monkeys, The Matrix and the recent Minority Report, the idea that technological and corporate excesses will destroy us over an ever shrinking timeframe has become the received wisdom of cinema.

But just as the nineteenth-century bourgeois' confident and epic relationship with time in Wells' novel must be understood not in terms of how events were actually to unfold, but in terms of how a specific set of circumstances contributed to a certain confident relationship with the course of history, so we must see Hollywood's "precipice of time" not simply as an objective narrative of impending apocalypse, but as a sign that the framework within which we recognise ourselves as 'our selves' is in crisis, and that we are thus unable to project these 'selves' confidently into the future. More precisely, I choose to see in this a lurking sense that the structures (political, social, legal, etc.) through which we have constructed ourselves as agents of history in control of our future, have become inadequate in the face of the seemingly more mighty, and historically more consequential, forces of techno- 
logy and capitalism. The cessation of 'our' time in these films is about the imagined expiry of these structures, and this expiry is seen as apocalyptic because whatever framework will supersede our current thinking and allow human time to continue is currently difficult to imagine. In short, the end of capitalist time in such movies is a brick wall at the end of our own imagination.

This 'brick wall' has not gone unnoticed. The last five years have seen the emergence of a now well established genre of apocalyptic writing by dissenting economists and scientists who see the twin juggernauts of freewheeling capitalism and new technologies sweeping away everything that we know and value. In most cases such books and articles are unable to point towards convincing solutions, and end on a grave and somewhat mystical note: if we are to avoid the foregoing terrible scenarios we had better sit up and think very hard about ourselves. The debate leaves behind, in other words, the specific areas of IMF policy or the declining power of national governments or the threat of genetically modified foods, and gestures despairingly towards a different territory: the realm of ethics.

I am entirely in agreement with the idea that we are all currently faced with profound ethical questions. I think that our inability to imagine our own future is, fundamentally, a breakdown of an ethical imagination. I also think, however, that the way in which these problems are often discussed is too quaint to really address the scale of our imagination block. The rest of this essay will seek to find points of departure for the imagination of a new ethics.

\section{The Failure of Ethics: A Biotechnological Scenario}

Where does the sense come from that our current ethical framework is not working? Let us look at a simple scenario drawn from the world of biotechnology - one of the most popular subjects for dystopian fantasies. This is the kind of scenario that would inform a popular sci-fi nightmare like Gattaca (1999).

It seems difficult to imagine that genetic 'improvements' will not be offered in the marketplace to new parents at some point soon in order to give their future children the best life possible. After all, this would only be an extension of the same logic of technological improvement that governs discourses of inoculation, fitness, dietary supplements, etc. It would only be one more service being offered in our crowded marketplace; only another set of companies bringing the benefit of their research to consumers and making legitimate revenues from their investment. In this context, would it not be nearly impossible for any parent who could afford such a technology to shun advantages for their children that would probably be decisive in a biotechnological future; would there not be a massive boom in the industry as every family acted in its own private way out of a fear of relegating their child to a future exclusion or obsolescence; would all this not happen in spite of the fact that many of these parents would feel great moral concern or even repugnance at what they were doing; would it not be facilitated, rather than hindered, by the ruminations of in-house corporate bioethics experts whose impressive jargon and moral seriousness would help people to suspend their uncertainty; would it not, independently of the desires of any of the individual actors, necessarily generate a society obsessed with genetic hierarchy in which

\section{Where doess the sense come from that oyr
current ethical ramework Is not working?}


the children of the poor were doubly cursed - through poverty and through genetic inferiority; and would not this make a mockery of the discourses of rights and equality, dependent as they are on that essential liberal category - the species - that has defined the terms of moral and political philosophy for the last two hundred years?

All the tiny steps on the path to such a scenario are in themselves both plausible and humdrum - it would seem strange even to raise moral questions about many of them. Yet the world that would come about through this process is, at this point in time, alien and, to many of us, horrific. In contemplating such a sequence of events it is easy to feel that the ethical opinions that human beings might hold have become rather irrelevant to the course of history and that 'human time', in this sense, is in its last days. Easy to see why the subjectivity of the age is put forward in culture, not as rational and epic, but as private, painful, and constrained. Ours is not the relaxed armchair contemplation of a future that our curiosity and energy can only improve, but the fear that we will be able to do nothing while technology takes us over and destroys us - even as we continue to put our faith in new cures, new security systems and new forms of communication.

Such "sci-fi" scenarios as that sketched above encapsulate effectively and melodramatically a more everyday sense: (1) that the interlocking systems of technological development, state power and commerce are leading us into social situations where the moral discourse of capitalist societies (liberalism, democracy, peace, progress, etc) will finally become completely unsustainable; and (2) that the direction in which these systems are headed will not in any way be set by the ethical beliefs and practices of individuals and informal communities. I would suggest that the fundamental problem that we face lies in this second point: in the complete disjunction of ethical experience between informal, interpersonal networks, and formalised, impersonal systems.

\section{The Narrowing Ethical Code}

If we are pessimistic about our ethical future, it is not because people don't know how to be ethical anymore. In such informal networks as families, friends, many small communities and trading circuits, some online communities, ethical codes are an important part of the functioning of social life. Most of us live our lives with a set of ethical values which are important components of who we consider ourselves to be and how we are known by those around us. The problem we face is not about people's inability to think or behave ethically. It is rather that the operation of this "ethics" has become increasingly restricted as more and more of life becomes formalised and dominated by a larger logic that is not available to individuals for negotiation or manipulation.

Why we feel this narrowing of our ethical possibilities is not particularly obscure; I give here only those observations that are relevant to what follows:

$>$ Everyday experiences of work provide an increasingly stark sense of the difference between the ethical climates of informal and formal settings. While an individual may place a high value, for instance, on compassion when thinking about her interpersonal behaviour, she may be taught that harshness will be a much more successful strategy for her dealings in the workplace. This placing aside of personal 'values' in favour of institutional 'techniques' 
while one is at work has become much more significant over the past twenty years. When Hollywood wishes to demonstrate that someone is a good person they must show us how much they love their spouse and children: the domestic has become the only place where ethics is easy to represent.

$>$ The sense of the global. The national stage, especially in 'welfare states', allowed citizens to subcontract their ethical responsibilities towards their fellow citizens to governments through taxation, and thus to find an ethical framework that bound their domestic, professional and civic lives. It now becomes impossible to avoid the sense of being part of a global system, which simultaneously extends the potential ethical responsibilities of the individual while denying him even a theoretical framework for fulfilling them. This creates political personae fraught with ethical uncertainty.

$>$ The vocabulary of ethics has retreated significantly from debates on the economic system which gives shape to so many of the formal structures of our lives. The assorted assaults on, and failures of, organised alternatives to free market capitalism over the last two decades have allowed the market to occupy significantly more of our imaginative space: it is no longer an ideology, simply a fact. The market need make no reference to outside moral principles: it has a set of procedures and regulations which, if they are upheld, are supposed to guarantee that all outcomes from the system are just. If such a situation seems risky for ethics - since the system becomes an end in itself, immune to moral critique - it is remarkable how deeply it has taken hold in many places of the world.

$>$ The sense that the 'large debates' of society, as opposed to our own personal dilemmas, require a very different set of skills from the ones we have available to us. It is crucial to note the critical importance of 'experts' within the systems that generate and manage the incredible dynamism of our world, discrediting not only all 'amateur' thought, but also most intercourse between different areas of thought (such as moral philosophy and science). The intellectual and expressive passivity that is prescribed in this way as the proper attitude of the individual is one of the primary issues that must be addressed by any ethics of social systems.

Even this cursory picture gives a sense of why it is that individuals might feel that, in contrast to an intimate or informal sphere of human plenitude, the world at large might seem alienating and out of control, and why we might be faced with a "brick wall of the imagination" when we try to construct a credible ethics for it.

\section{Two Common Strategies}

Unfortunately, the most common strategies for thinking about how to solve the problems of our future keep this separation between formal systems and the informal life of individuals firmly in place.

The most obvious place to turn if we wish to address the problems of a world without ethics and 'out of control' is to regulation - i.e. to the tools of management. It is of course entirely right that powerful institutions should be regulated. But it should be clear, too, that our problem of an ethical imagination is not solved by simple regulatory 'containment': 
First of all, a regulatory framework is not something that enters laboratories and corporations from the outside. We are living in the most regulated world that has ever existed, and the power of those forces that seem to evade ethical control is dependent on this regulation. Regulations may prevent certain forms of undesirable behaviour but they also reinforce the non-negotiability of impersonal processes. This is precisely what has contributed to the obsolescence of ethics in favour of institutional authority.

Secondly, and this follows on from the above, all regulation is about defining legitimate and illegitimate behaviour, and it is not only powerful institutions that are controlled by this. Every category of our being (space, leisure time, the body, everything we say or write, etc.) is over-determined by a stranglehold of regulation that makes it increasingly impervious to new thought. Much of the cautiousness, passivity and hopelessness we feel when we try to imagine new realities for ourselves is due to the fact that our reality is not ours to imagine differently.

Finally, it should be clear that even if regulation will have to be a part of any ethical thinking that is trying to address problems on such a large scale, it must logically be preceded by an ethical vision of which this regulation will be an expression. After all, and this is crucial, we already have a complex regulatory system, which has not prevented us getting into the dire straits we are in today.

But a second position is also often put forward, by conservative critics and radicals alike, that people themselves need to become more sensitive to the problems of the world. A recent essay by Zygmunt Bauman outlines the great moral challenges of the "global" society, and concludes thus:

"The awesome task of raising morality to the level of new, global challenges may well start from heeding the simple advice [Richard] Rorty offers: 'We should raise our children to find it intolerable that we who sit behind desks and punch keyboards are paid ten times as much as the people who get their hands dirty cleaning our toilets, and hundred times as much as those who fabricate our keyboards in the Third World."'3

Again, we can have no argument with moral sensitivity. But this idea too is a greatly inadequate response to the problems we are discussing:

Firstly, it is a problem posing as a solution. Bauman says nothing about how we might go about making people 'better', although his comments about the family confirm one's suspicion that the modus operandi of this "turn to psychology" is social conservatism: a nostalgic valorisation of a lost order of familial stability, religious instruction, etc. Once again, this is to solve nothing. The technological drive of capitalism is a rapid and exhilarating one, to which nostalgia is always going to be an ineffectual response.

It is also highly questionable whether we are living at a time when people are particularly insensitive. There is nothing that anyone could present as evidence that contemporary human beings are more or less 'moral' than those of another time. In the last section we discussed precisely how even if moral concerns are the most important thing in your life, the problem of how you behave morally in a world of large, impersonal forces is one that poses an almost impossible challenge to the imagination.

Finally, to pin our ethical hopes on the myth of the 'better' human being is a gesture of desperation. Because there is no way that an ethics that can merge with the forces of mar- 
ket society and take them over can be based simply on individual feelings of compassion or honesty or community. It must engage with systems and social forms, and it must, at some level, be indifferent to individuals' moral thinking, just as capitalism is itself - for we have long since left behind the age of the moral consensus and we are not going to find it again soon.

From the 'remoralisation' of society to ethical consumption to better corporate governance to global regulatory bodies: the responses to these issues, even by brilliant and radical critics, are conspicuous by their conservatism. We need to find a new vision, in which the fundamental divide between the logics of informal and formal systems are overturned, and in which the ethical creativity of individuals and communities can be allowed to interact in more significant ways with the knowledge of institutions.

\section{A Half-glimpse of a New Ethics}

This new vision, I would argue, will not consist of a set of ideas. It will consist of a set of procedures by which we can build a new kind of ethical agency for ourselves. The profound sense of disenfranchisement, and the accompanying fears of a desperate, amoral future, is what we need to tackle first - and this can only happen by imagining new kinds of community and communication through which informal ethical practices can be given greater salience.

Our ethics must concentrate less on the plodding development of great ideas and more on the modes by which a variety of ideas, perhaps sketchy and unfinished, can become dynamic energies in the public domain. We cannot assume that the mere existence of ethical, critical argument is enough in itself to transform the terms of a particular debate; we will look at how ideas can take on a life in a community. And we will seek to overturn the fantasy of the perfect regulatory system, and the crippling inferiority complex that sets the horizon of possibility for the 'non-expert' in market society, by encouraging new forms of public knowledge and expression.

The last decade has given us some striking examples of how networks of people can create and organise themselves into new community forms, often with compelling ethical visions. Such projects, I would argue, are essential if we are to avoid pinning all our hopes on mere unfelt regulation or on a more sensitive generation to come. We need to look into unknown territory. Perhaps there we will find new forms of human relationship and ethical thought that will allow us to believe in a long future.

\section{NOTES}

1. "Director Wells keeps Time in the family" (Chicago Sun-Times 29 March 2002).

2. "Time Machine emphasis shifts to love interest" (The Milwaukee J ournal Sentinel 3 March 2002).

3. Bauman, Zygmunt "Whatever happened to compassion?" (in Bentley, Tom and Daniel Stedman J ones (eds) The Moral Universe Demos, 2001, London) p. 56. 


\section{The Typewriter of the Illiterate Interview with J ános Sugár}

GEERT LOVINK

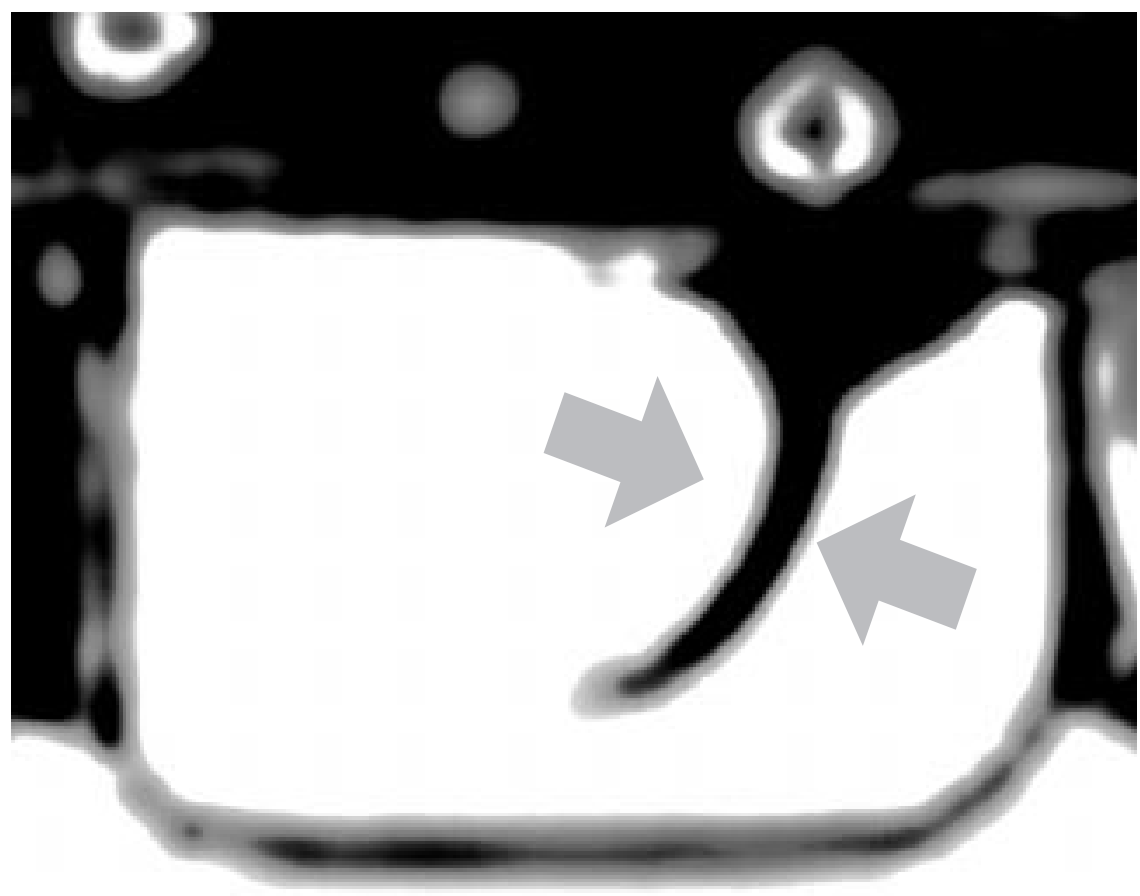

The Hungarian artist János Sugár ${ }^{1}$ produced a stunning short video piece about the popular technology of the Kalashnikov machine gun. He used still photos from mainstream news magazines that are displaying the world's conflicts and morphed them into one, with the Kalashnikov gun as its continuous centrepiece. I heard about the video from the Dutch sociologist J ohan Sjerpstra who explained to me why such a minimalist, almost non-video might be interesting among such an overproduction of images. Sjerpstra saw the piece for the first time in Mexico City at the Without Emergency Exit exhibition of Centro Multimedia. Sjerpstra was fascinated by the press photos that show the Kalashnikov turning into each other. The centre of the morph is always the gun. He also noted how special the sound is - the work of a famous jazz drummer, Bobby Previte from NYC, who once played a jazz drummer in Robert Altman's movie Short Cuts. According to Sjerpstra the 
music track of The Typewriter of the Illiterate is a perfect mixture: a real sound morphing of the sounds of a machine gun and a typewriter.

$>$ GL: How did you come up with the idea to make a video piece about the Kalashnikov?

>S : I always collected particular images. I call it "collecting analogies". For instance, I take a picture whenever I see a broken shop window, or religious graffiti, or a piece of furniture on the street, etc. I like those series of images, connected only by a similar detail; it represents a special kind of a narrative. For me it is all about the foreground/background issue: what we consider important, the foreground, is only a pretext, and with the passing time the background becomes more interesting. Besides taking pictures with my camera I collect press images for the same reason. Among many other topics since the beginning of the $90 \mathrm{~s}$ I started gathering images of people wearing or using the AK 47 gun. I was amazed by the fact that sophisticated weapons systems were never used, they were built, and they were carefully dismantled later on. They boosted national economies and the Americans won the Cold War with them.

The development of sophisticated high-tech weapons systems has had an enormous impact on the economies and politics of the world but, thank God, they have never been really used. What has actually been in constant use since the late $40 \mathrm{~s}$ is the Kalashnikov machine gun. In fifty-five years, approximately 100 million Kalashnikov have been built and have killed more people than the atomic bomb. Its silhouette became the symbol of revolt and the favourite logo of freedom fighters and terrorists. In Burkina Faso, the Kalashnikov for some years was on the national coat of arms. Mozambique has the Kalashnikov beside an open book and a spade on the national flag.

In 1995 I had already a large enough collection, but I had no access to the proper hardware. I started morphing the images, but it looked too clumsy and complicated. Only six years later technology, accessible to me, had developed to such an extent that such a simple work could be realised.

$>$ GL: Could you tell us something about the history of this world-famous machine gun?

$>$ S : The general history of the machine gun is also interesting. When engineering helpfully solved the technical problem of a fast killing machine, it was considered so immorally savage that for a while it was used only in the colonies; just at the end of WW1 was the machine gun used in European battlefields. Analogies of the machine gun to the film camera are also obvious. Paul Virilio writes about this in his famous War and Cinema book. Nowdays the infamous AK 47 (later AKM) is a fetish, a cult object, and a successful design piece. Right besides the Jaguar E type, the Kalashnikov should be on display in the New York MoMa's design show; and in an instant with these two objects we depicted the $20^{\text {th }}$ century.

The technical specialty of the AKM is its simplicity and efficiency. It has only a few parts; even a village blacksmith could repair it. But its other specialty is maybe more important: as a part of the Soviet power politics, it was licensed to clone, like the IBM PC; it was produced in twenty countries (including Denmark, Sweden, Finland, Italy, Israel, Egypt) and 
the Kalashnikov made a bloody carrier as the poorest peoples' master key to history. The Soviets discovered the distribution of unrest. Need a gun? Here you are. Like selling drugs in front of a school. With one loading one can kill twenty people, and in societies where ambitions cannot have other safety valves, it is an option for expressing oneself. In Uganda you can have it for a chicken, in Angola for a sack of rice. It is the Esperanto of aggression. Aggression is a status symbol, even in the poorest countries.

Somalians have a familiar proverb: "I and Somalia against the world, I and my clan against Somalia, I and my family against the clan, I and my brother against the family, I against my brother". Around 50 Million AKMs are in use around the globe.

$>$ GL: What do you know about Mr. Kalashnikov himself? Do you see it as a symbol of Soviet power?

>S I I have seen him a couple of years ago in a German documentary. My impression was that he is a rather nice person. He said it is the Germans' fault that he became a weapon designer, the Germans had such a machine gun and the Soviets didn't. He comes from a peasant family of 18 children, he went to the war (to the Great Patriotic War, as they called it) and in 1941, as a 22-year-old wounded tank commander, made the first sketches of a new weapon in a military hospital. Later, his first prototype was refused by the experts but he was sent to Moscow to study. He did not mentioned there that his parents were exiled by Stalin, and one of his brothers was in a forced labour camp for nine years. And he spent most of his life as a weapon designer living in anonymity in a closed-off military area. In some of the early interviews he gave after 1990 he speaks about his concerns about being a weapon maker, feeling somehow guilty; but as he became later a celebrity he consciously avoids those issues. With his son he produces mainly hunting weapons, and useful goodies, like lawnmowers, fire extinguishers, sprinkles. And the newest, NATO compatible, $5.56 \mathrm{~mm}$ AKM.

$>$ GL: The title of the piece, Typewriter of the Illiterate, is amazingly precise and tells half the story. Where did you find the title?

$>$ S : I found it in a German newsmagazine. Der Spiegel used it as a motto in an ad for a book of Barry Sanders, professor of English at Pitzer College, author of A Is for Ox. The Collapse of Literacy, Rise of Violence in an Electronic Age and The Private Death of Public Discourse. He says "The gun is the typewriter of the illiterate", or something like this, because I had to translate back from German to English, since I couldn't find the original source. I like the poetical absurdity of this extremely simple and precise definition. Sanders claims that the contemporary erosion of our interior space - where the reflective life occurs - accounts for the decline of private ideas and decent public discourse. Why has our culture become increasingly violent? The falling apart of evidences of identities creates aggression, and literacy supplies not just criticism, but empathy too.

$>$ GL: Would you relate the widespread use of the Kalishnikov with the rise of a global civil 
war, a conflict of all-against-all? Do you see any use for the machine gun type of art? I'd relate the Kalashnikov somehow with remote conflicts. But then it was used extensively during the nineties' Yugoslav wars. How near is the Kalashnikov?

$>$ S : Maybe the gun itself not, but the concept of the Kalashnikov is very near. In the western hemisphere we have a broad choice of handguns, Kalashnikov is only the solution for historically unbalanced places, as one has to use a Landrover in Africa, not a Ferrari. The interesting thing is that the Kalashnikov fits into the process of a once special and expensive product getting cheaper and cheaper through mass usage. The watch was a rarity and now you can have it in every corner. In this sense the Kalashnikov, as the ultimate attention generator, is a similar consumer product, an element of a certain lifestyle. We live much more in an all-against-all situation, because the final frontier of all the consumer products is the single individual. Everyone has to have one photo/video camera, telephone, etc. on his/her body. We are individually fragmented communication centres, and a gun is a possible direct communication accessory.

Geert Lovink conducted this interview with J ános Sugár after a private screening of his work in Sydney.

\section{NOTES}

1. János Sugár studied in the Department of Sculpture at the Hungarian Academy of Fine Arts in Budapest from 1979 to 1984. Between 1980 and 1986, he was actively involved in the exhibitions and performances of Indigo, an interdisciplinary art group led by Miklós Erdély. His work includes installations, performances, as well as film/video. He has exhibited widely throughout Europe including at the Documenta IX, Kassel (1992) and Manifesta I, Rotterdam (1996). Since 1990, Sugár has been teaching art and media theory in the Intermedia Department, Hungarian Academy of Fine Arts, Budapest. He completed an Artslink residency at the Cleveland Institute of Art in 1994, and fellowships at Experimental Intermedia, New York (1988 and 1999). His films were screened at the Anthology Film Archives in New York in 1998. He can be contacted at: sj@c3.hu.

\section{REFERENCES}

1. http:// www.artic.edu/ webspaces/systematica/J anos\%20Sugar.html

2. http://www.icols.org/pages/J Sugar/J Sugar.html

3. http://subsol.c3.hu/subsol_2/contributors/sugartext.html

4. Sugár, János The Typewriter of the Illiterate (Digital Video, 8 min, 2001).

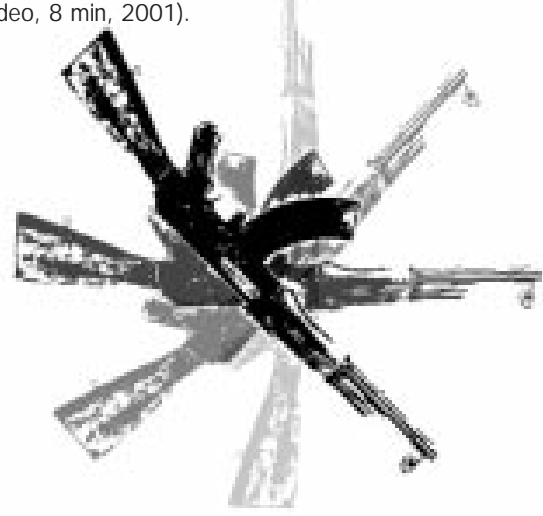




\section{The Way Home Kattas as Navigation Aids}

BHARTI KHER

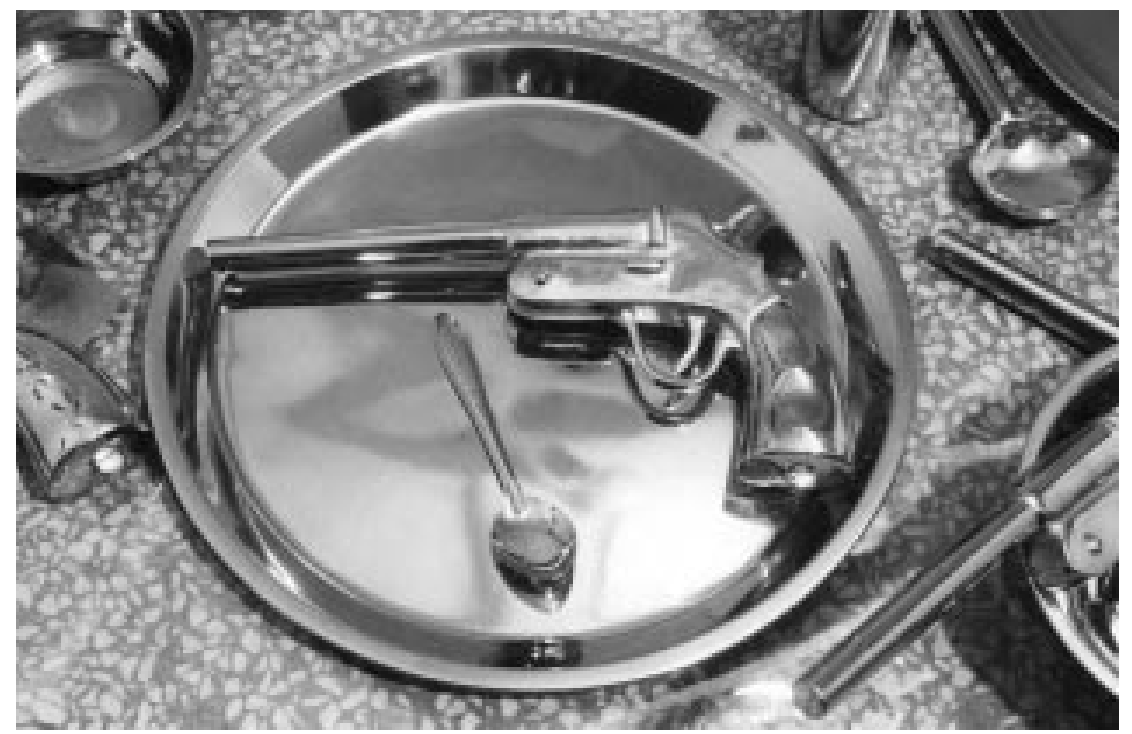

Image courtesy: Subodh Gupta

7

his title refers to an installation made by Subodh Gupta in 2000. As part of the work he placed almost 200 steel utensils on the floor and interspersed them with chrome polished kattas. ${ }^{1}$

These aren't strictly your typical type of gun... they are colloquially known as kattas in Bihar and U.P. (to those unfamiliar: handmade revolvers). Guns have an image of being sophisticated and sexy and dangerous. Heroes fire guns, round after round, killing the bad guys. We accept them as part of contemporary life now. The professionals or city elite do not keep kattas since their gun culture takes on a different socio/political agenda.

Kattas are the cheapest firearm you can buy. They are the stainless steel plates of crockery. Underworld operatives approach the arms dealer directly while neophytes have to go through a dalal (broker). They come in from Uttar Pradesh, Bihar and Madhya Pradesh, but are made increasingly in and around Mumbai, such as Thane, Andheri MIDC, Virar and Panvel. More sophisticated arms are smuggled from Karachi, Kabul, Colombo and Kathmandu.

"Ek kaua 15 blue mein mileaga (One country-made revolver will be available for Rs 1,500)", said Mumbai's biggest illegal arms supplier, known by the alias of Bullet Bhai. ${ }^{2}$ Bullet Bhai's mobile number isn't very difficult to get and both con and cop allegedly avail 
of his services. Gangsters use him to purchase and dispose arms, while the police allegedly buy weapons off him that they plant on gangsters after encounters.

The katta is commonly found in homes across Eastern India. They are kept for protection, aggression and, ironically, to maintain a state of neutrality. What happens instead is that this trend has fuelled the widespread violence and intolerance that had become synonymous earlier with small towns in Bihar and now, also, with towns in Western India. Handmade, kattas are often crudely crafted from steel pipes that sometimes even explode or backfire, causing injury to the possessor. If you've seen the bullets they look large enough to kill an elephant.

Subodh's guns are both seductive and repellent. So obviously fake - the barrel is solid, all the way through. It is weighty though, like a real one, and has the customary top heaviness that results from crude assembly. Its beautifully contradictory... you want to hold it and stroke it. He has made the katta sexy and shiny and new, like the steel utensils that are commonplace but increasingly becoming the fashionable material for a new discerning class (another example of the cheap ready-made being reinvented to become exclusive by the upper middle class).

In effect these are guns that do not exist: there is no record of how many are made or how many kill or injure others. If we were to compare research and statistics in America (which - to an extent at least - was built with firearms), guns kill nearly 40,000 Americans a year, injure over twice as many and are involved in nearly a million crimes. But, like many people here, Americans have mixed feelings about their guns. Two-thirds believe guns contribute to violence. The same number believe they need them for protection as well, and the opinion that it is certainly a person's civil right to own a firearm to defend the family has led to the widespread distribution of illegal weapons pretty much all over the world.

How do you keep a gun away from its owner? An oft-quoted statistic: "a gun kept in the home for self-protection is twenty-two times more likely to kill or injure someone you know than to be used for self-defense". ${ }^{3}$

How does a gun that was never made kill an innocent person? The answer leads to a world of corporate neglect and criminal greed, to a black market in guns and an illicit business of trafficking in firearms which is capitalism at its best. Capitalism is all about return, the selling of goods for the highest return. It is a thriving, big business and these are times when there is no turning back. The way home is fraught with obstacles and dangers.

\section{NOTES}

1. Gupta, Subodh The Way Home (2000). Subodh Gupta can be contacted at: khergupta@sampark. online.com

2. Khan, Jake Bombay becoming biggest illegal arms bazaar in India (in Bombay Rediff News, 12 J uly 1998).

3. Kellerman, A.L et al "Inquiries and Death Due to Firearms in the Home" (in Journal of Trauma, Injury, Infection and Critical Care Vol. 45, No.2, 1998). 


\section{Pet Architecture And how to Use it}

YOSHIHARU TSUKAMOTO

W hen we walk on the streets of Tokyo we find amazingly small buildings between streets, along widened roads and in the spaces between tracks and streets. Most of these buildings are cheaply built, and therefore not spectacular in design, and they do not use the forefront of technology.

However, they attract us. It may be because their presence produces a relaxed atmosphere, and makes us feel relieved. Their shapes and forms that do not conform to styles and pretensions are refreshing to our eyes. They illustrate unique ideas with elements of fun without yielding to unfavourable conditions such as small area, size and width.

Their laudable presence reminds me of something I thought when one day I realised that they are like pets. Our society does not consist only of human beings. Various animals come into our lives as 'pets', and they are given spaces to live. It may be for our own convenience, but playing with pets is a lot of fun. It is said that connecting with pets relieves many people psychologically. It is because they live a totally different existence from us who stand on two feet, wear clothes and speak words. This play is quite good for our mental health since pets are not subjects of direct comparison to us, human beings. In other words, if decent buildings standing in decent spaces are to be considered 'human beings', small buildings standing with all their might in odd spaces would seem to be like pets in urban spaces, due to the sense of distance from human beings and the sense of presence in scenery. If we think this way, we are able to enjoy many different kinds of buildings. As a result, we have decided to call small buildings "Pet Architecture"; those that are smaller than 'rabbit houses' (a term used to make fun of small houses in Tokyo) and bigger than doghouses. We allow the existence of pets in the jungle of buildings, as there are pets in the worlds of human beings.

By giving this title, we aimed to establish one new category in urban structure by giving them a certain name and not by negatively considering them as openings and fragments. I have tentatively talked about this concept to different people and, surprisingly, found that many of them tell me about their "My Pet Architecture" existing in their daily lives, 

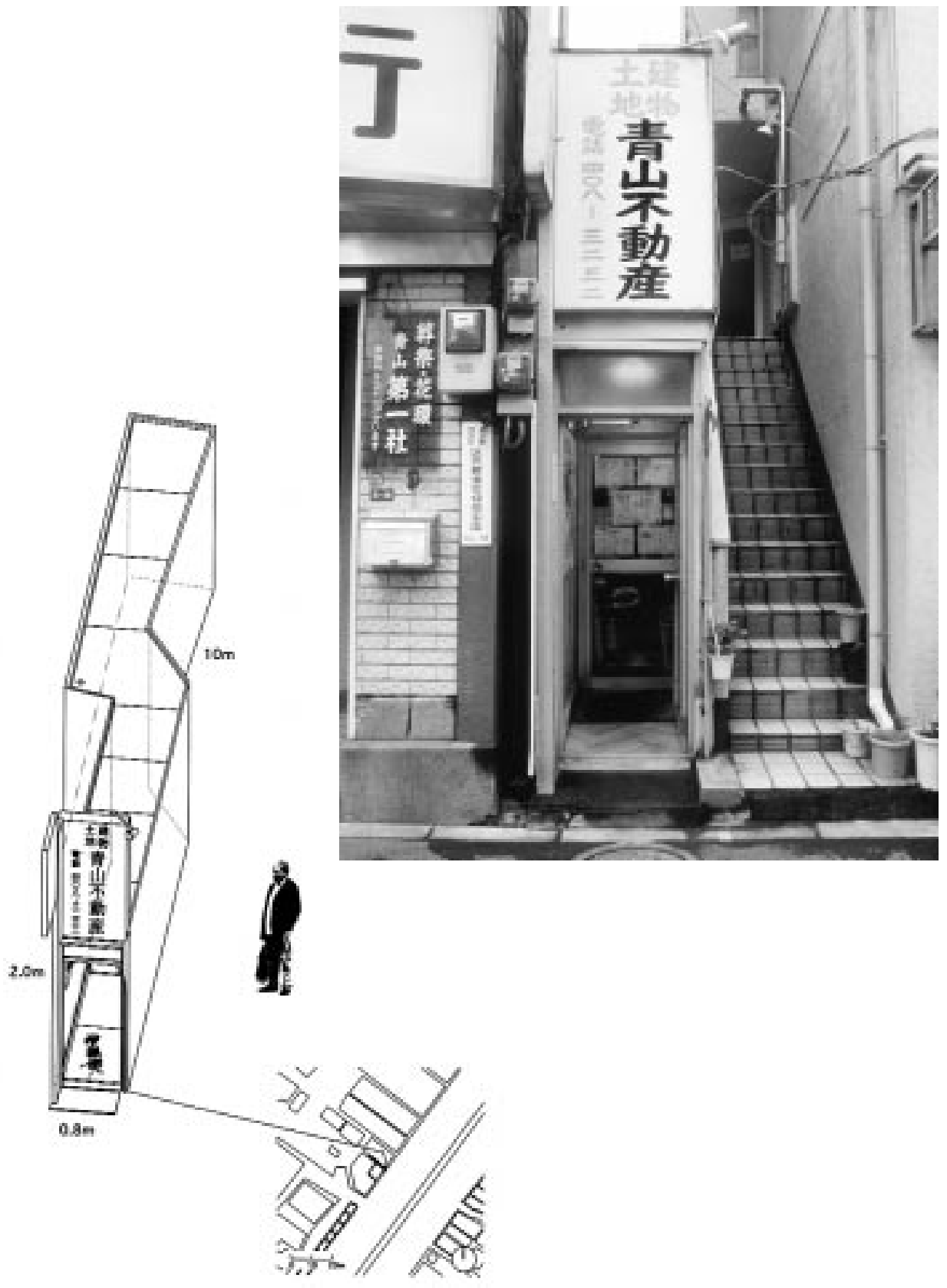
such as "I found it there" or "That could be a Pet Architecture". Everyone seems to have seen unique buildings, and those buildings that are extremely small or narrow attract people. There is communication between human beings and buildings.

In order to enrich this communication, we need to 'read' buildings. If we were able to 'read' buildings, it would make our lives happier, just as when we take a walk, or even just go to work or school.

How would Pet Architecture, then, function specifically in our society? Because they are small in size, their functions are limited to a certain extent. There are many small retailers selling seals, cigarettes and lunch boxes. Recent newcomers are shops selling small objects and items dealing with information such as cellular phones. There are also small restaurants and houses that agitate our imagination towards our lifestyles and even our living conditions.

How is Pet Architecture constructed? Even store signs, vending machines and exterior attachments for air-conditioners that are of not worth being concerned about when we construct normal sized buildings become relatively important aspects for constructing Pet Architecture. It is easier to explain them with the theory of 'using' rather than the theory of 'constructing' buildings. In other words, Pet Architecture is a tool for users to customise buildings. Every building has secondary aspects of customisation, and due to the small size, customised areas can be seen in Pet Architecture. In that sense, it can be said that Pet Architecture is construction of customisation. Since Pet Architecture has less consideration of its appearance, it shows a sense of willfulness, unexpectedness and handmade feeling in its structure. It cannot be done objectively, but naturally.

Where is Pet Architecture? Through careful examination of places with Pet Architecture, it can be observed in areas with a one-metre opening between buildings, subdivided small lands, narrow ground yielded from gaps between geometric designs of roads, railroad tracks and rivers, street corners clipped out by road widening construction, spaces between new roads and old towns, and other areas that are spin-offs from urban developments. Pet Architecture accurately shows in its size and shapes the conditions of unique locations. We become eyewitnesses of urban changes.

Conversely, we are able to imagine how those areas and towns have been developed through observing Pet Architecture. Therefore, we are able to recognise in photographs of towns that the passage of time has been layered in the scenery.

The popularity of Pet Architecture with its unique sense of scale as the smallest structure in Tokyo allows differences in the concept of building lots, constructing techniques and ways of customising to resurface. It also makes Tokyo a unique urban space that allows Pet Architecture in the city.

There have been many Pet Architectures constructed, and they have been spread in peculiar places in the cities. They can also be built with low costs. By using these aspects, we may be able to utilise Pet Architectures as a tool to direct the use of urban spaces and to recycle unused urban openings in the coming future. This is my ongoing project. 
252 / Sarai Reader 2003: Shaping Technologies
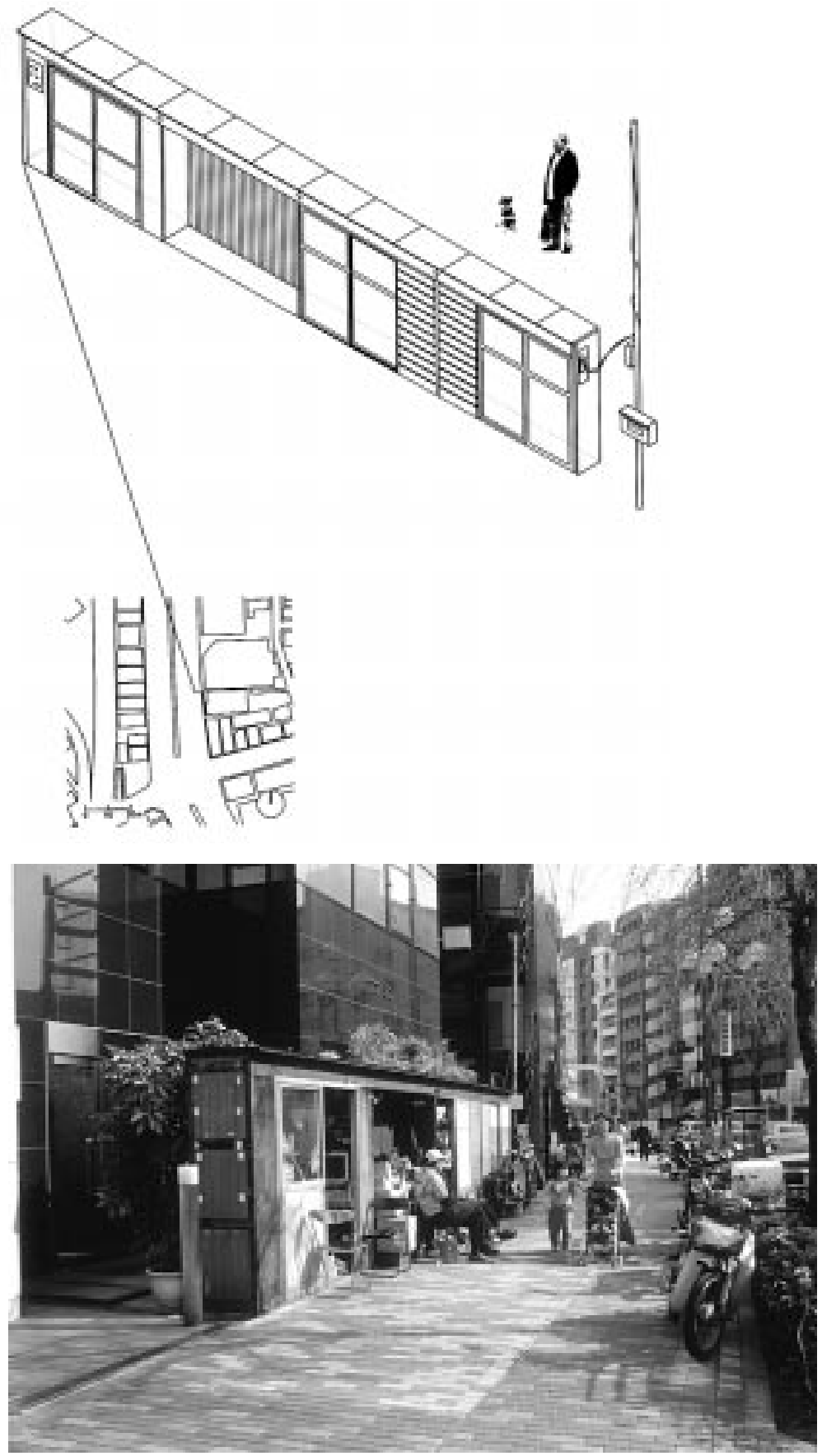
Imaginations + Aesthetics / 253
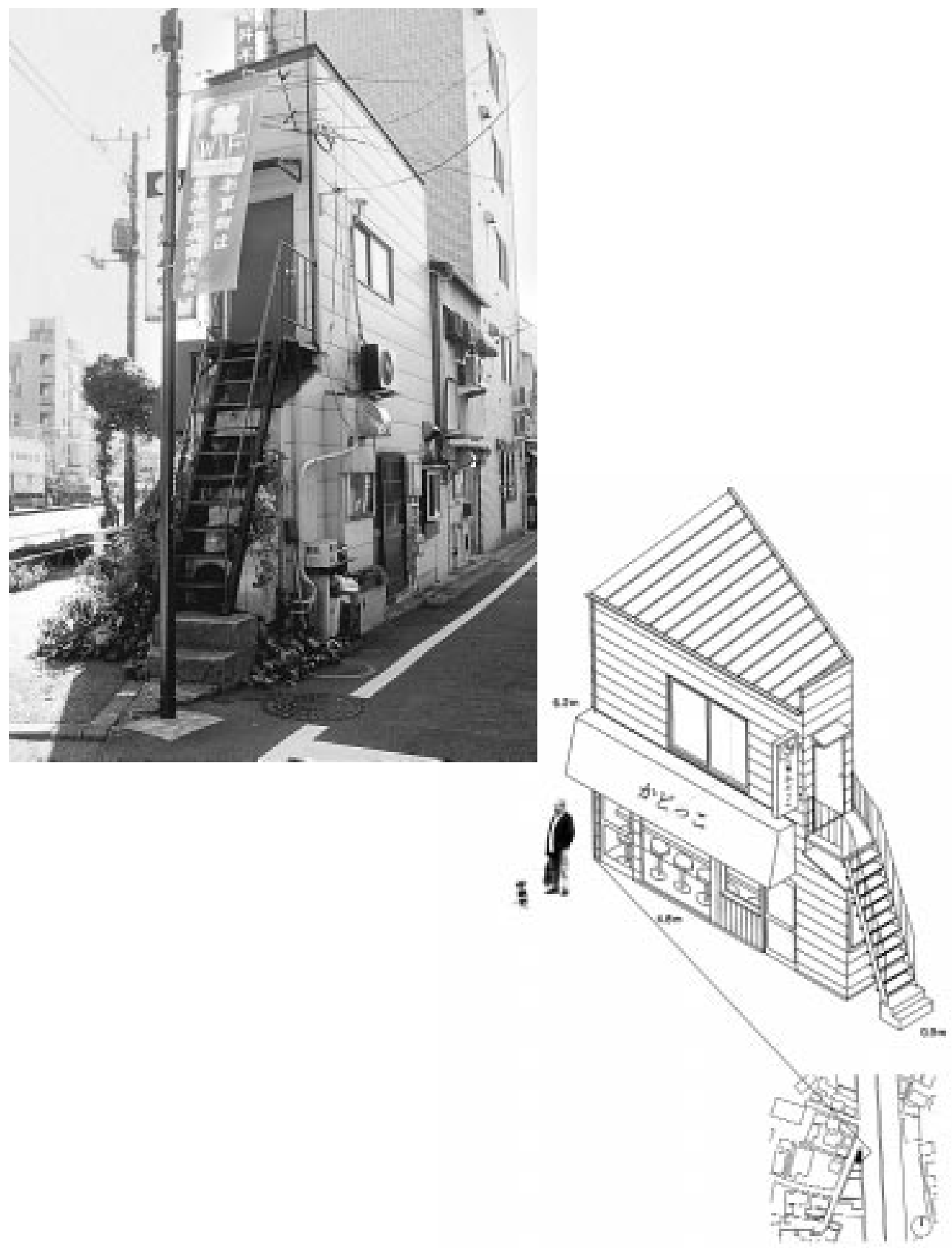
254 / Sarai Reader 2003: Shaping Technologies

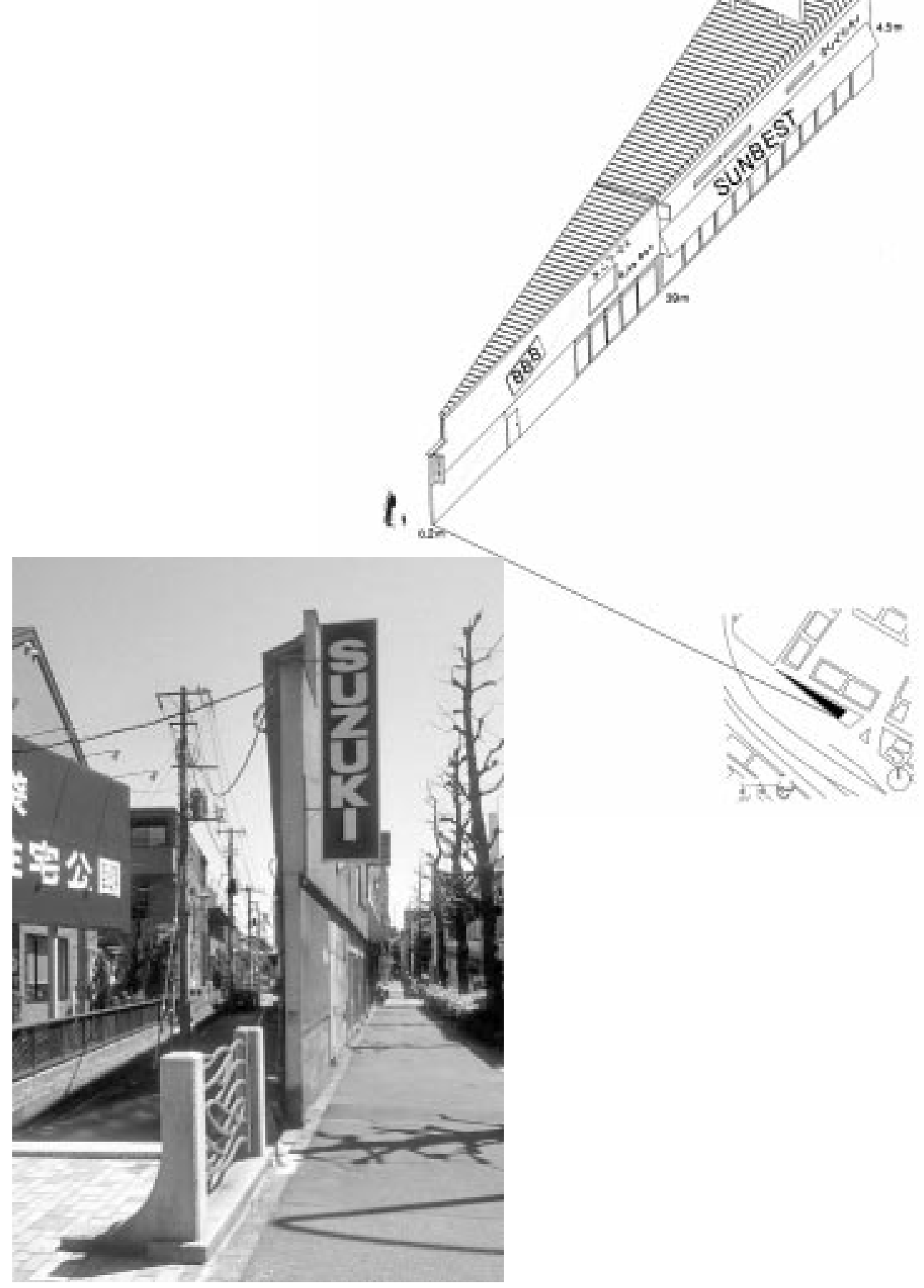

Photos and drawings courtesy Yoshiharu Tsukamoto. 


\section{Colliding Soundscapes Conversation with Hildegard Westerkamp}

LEX BHAGAT

Hildegard Westerkamp is a composer, radio artist and sound ecologist. ${ }^{1}$

Lex: Can you tell me on what you're currently working?

$>$ Hildegard: Right now, I'm working on a piece which is slightly unusual in that it has a live instrumental component. I don't actually work so much with live instruments. I really have no training in it, and I get slightly anxious because I don't know much about it.

The piece is called Like a Memory. It has a bit of a story because it comes out of another project I did previously - a sound installation with photographer Florence Debeugny about ghostowns in one of the old mining areas of British Columbia. That area is called the Kootenays and was an active mining area around the turn of the $19-20^{\text {th }}$ centuries. I've known about this place since I emigrated in 1968. My ex-husband grew up there and showed it to me. I was always very enchanted by these abandoned sites. You find lots of scrap metal, and collapsed houses, and traces of past activity. But, it's also a huge mess, an environmental mess.

So, there is that edge between the incredible mess that industry left behind once it was finished and of nature moving back into the abandoned sites. It was exciting to find traces of former activity in places that nature had begun to reclaim. I proposed to Florence that we should do an installation about this.

We went to the area. It's a quiet area, so you have wilderness sounds, and water sounds, but it's generally very quiet. What I love doing, often when it's quiet, is to touch the materials. Banging on the wood and the metal. You find these incredible resonances in the old metals: steam engines and what not.

$>$ Lex: Were you just using condenser mikes or did you use pick-ups?

$>$ Hildegard: Actually, for this project I rented a Sony MS-5, which is a very good stereo microphone. It's wonderful, although it's not actually so good for close-up sounds because it's too sensitive. So, it was a bit difficult because I would have the microphone in one hand and be playing on these objects with the other and had to be very careful not to distort. Or, I had the microphone placed further away, so I could bang on the objects and record from a distance. But this microphone gives you an incredible depth spatially. So, you don't just

So, there is that edge between the incredible mess that industry left behind once it was finished and of nature moving back into the abandoned sites. It was exciting to find traces of former activity in places that nature had begun to reclaim. 
pick up the foreground sound of the instrument, you also get a strong sense of space. It's a mountainous area, so you get reverberation, echoing. In that time, I also went to an abandoned children's camp, a place I had discovered years before. The main house had a piano in it. An old piano was all that was left. It was totally broken. Strings were broken. There were rats' nests in it. One day, I went there with my tape recorder with the intent to play the piano. This was years ago, in the early $80 \mathrm{~s}$. I still have these recordings on cassette. Then I met the pianist J amie Syer last year. He told me that he was interested in working with me. It turns out that he has a lot of connection to that area: there's a music camp there now, where he teaches every summer and which didn't exist in the early days. He knew all about the ghostowns. So, I said, "Look, I have all these recordings of this old piano. Why don't we do something with that?" So, what I'm doing right now is exactly that. I'm working with the piano sounds I've recorded in the abandoned house; I recorded Jamie on his piano at home, and I am using a few excerpts from the installation piece as well. The reason I'm telling you all this in detail is that it's actually quite important to me to have a connection to the environment, to the place, I record in; to have a story, some content that the recordings already give me. The reason I felt enabled to do a piano piece is because of my connection to this old piano.

I used to play the piano. I used to study classical music, but l've never really seen much sense, as a composer, to compose abstract instrumental pieces. I don't feel the inclination. It doesn't inspire me. What would I say with such music?

>Lex: Were you trained as a concert music composer?

$\gg$ Hildegard: Well, I wouldn't say that. Yes, I studied music - piano and flute - in Germany. When I went into music studies, it was because I really loved music. I barely got in, because I wasn't such a great pianist. I had a horrific experience studying music: I wasn't 'up' for that level of playing at all. And, I wasn't interested in it - in practicing so much.

When I emigrated, I had had it up to here with music studies, and wasn't going to continue. Then I came [to Vancouver] and there were no entrance exams at the University of B.C. music department at the time, in 68. I thought, maybe I'll try again. The atmosphere here on the West Coast was so much softer, so less judgmental, in terms of music-making that I just really loved studying here.

$>$ Lex: The open definition of music here kept you working here?

$>$ Hildegard: Absolutely.

$>$ Lex: Did you ever make a clear break out of the tradition of music, or has your definition of music expanded to include all that you do?

> Hildegard: Yeah, well, what happened was that when I was a student, Murray Schafer came to give a lecture here. And that lecture 'did it' for me. His lecture was, first of all, very interestingly structured. He had three or four music stands on the stage. One stand was 
connected to him talking about his trip to Persia. Another was connected to general soundscape matters here in Vancouver. Another was connected to music composition and his own work. Some of it was connected to contemporary composition.

The World Soundscape Project (WSP), ${ }^{2}$ at that time, already existed - the research group. He had placed members of this group into the audience. Every so often, one of them would get up and ask something like, "How many birds have you heard today"... How many airplanes have you heard today?" All these questions totally blew my mind. I came out of this lecture, suddenly hearing absolutely everything. I think at that point, I became aware that I was always connected through the ears to the world. I hadn't been aware of it.

Years later, when I was teaching music, I remembered that lecture. Someone told me that they were working on The Vancouver Soundscape, and Murray Schafer had written the Book of Noise. As a teacher, I ordered this book for my students. Then, I thought, I really want to know more about this. I found [Murray Schafer]. At that time, he was working on The Tuning of the World, at Simon Fraser University. ${ }^{3}$

The book offers an overview, like an anthology almost, of the soundscape in general. He finished it in 1975. The book covers the natural soundscape, rural soundscapes, city soundscapes, post-industrial soundscapes. Then, it speaks on music and soundscape, followed by the analytical part. In other parts he talks about listening, the acoustic community, the soniferous garden, silence. He was trying to cover the whole spectrum.

I eventually gave up teaching and became a member of the World Soundscape Project. I was hired to do research for the book, and never turned back. It was so fascinating for me to get to know the world through the ear. As an emigrant from Germany, this was particularly interesting. I think I had been here for four years by the time I met him. It opened up this Vancouver world and the Canadian, North American world in a different way. I just loved it: to listen with a musician's ear to the world.

Murray suggested at the time to listen to the world as if it were a composition, and to analyse it with a musician's ear - analyse the instruments with which this world makes its sounds. He took it very much from that aesthetic point of view, and that's sometimes where he gets criticised these days.

$>$ Lex: Do you find that aesthetic approach limiting ever?

$>$ Hildegard: I definitely found at a certain point that I had to expand my language. That was when I went into communications. I was also involved with a local group here organised to fight noise, so I was a bit of an activist. There, it was interesting, because the listening sensitivity didn't seem to fit into the activist mode at all. It was difficult. The environmental activist is not necessarily a listener. There is a political agenda to get rid of noise. To ask noise activists to stop and listen and to include the information that comes from listening into their activist mode - that often is too much of a jump to make for them. To me, it's not a jump. There's continuity there. We had this noise workshop here in town. We invited the City Council. The Mayor and quite a few council members came. We had them all blindfolded, took them on a soundwalk, and also had them listen to a recording we had made, with basic messages about noise. 
When you get everyone to listen to the actuality of what's happening, it adds a whole dimension to the political work. We were fighting the expansion of the airport, and were moving to improve the city noise by-law. To ask people to go on a soundwalk, and listen to the environment while they're frantically trying to put out petitions and do all this activist stuff: it's difficult, because it asks people to stop. Just for an hour, put your mind out of this and just listen. J ust take in what is.

Also at that time, we had the experience of starting a community radio station, Vancouver Co-Operative Radio. At the time when we started it, VCR gave us an outlet for the recordings we were producing. We could broadcast our soundwalks and environmental recordings.

The combination of all those things at that time really created the energy of a cultural activism that was very fascinating for me, for us. Interestingly, it got me into composing. What happened was that, my colleague Barry Truax - a composer and musician, coming like me from the University of British Columbia - was very connected with the European scene, the studios and the classical techniques of the 'traditional' electronic music studio. I didn't know much about those things.

$>$ Lex: They were already considered classical techniques by then?

$>$ Hildegard: Yes, in a way. Stockhausen in Cologne and Pierre Schaeffer in Paris, at GRM, which is now producing GRM Tools. These are very good by the way, because they're so subtle in terms of processing possibilities. They are based on the studio techniques that were developed at GRM around the sound object. Except that in the old sound object approach, the French were not interested at all in keeping the sound source recognisable.

Lex: What is the sound object approach?

> Hildegard: Pierre Schaeffer developed a whole treatise on what he called l'objet sonore, which had to do with processing recorded sounds, as opposed to Stockhausen who was generating electronic sounds. The sound object is a small unit of recorded sound. Schaeffer developed a theoretical framework of how to categorise sound - a complex task, literally a type of objectification of sounds, given that he was dealing with very much alive, recorded sounds. What was so interesting, from the soundscape perspective, was that Schaeffer did NOT want the listener to recognise the original sound source. It was meant to be musical material for their abstract compositional purposes. When we began to record here, and create, for example, a portrait of Vancouver called The Vancouver Soundscape, ${ }^{4}$ we made probably the first attempts to process sounds slightly, not in order to obscure but to bring out certain aspects of the sounds which were attractive.

That really interested me, because on the one hand you have the real sound, and on the other you have the processed sound, which is exactly what happens in listening. Your interpretation, your imagination changes and processes sound. Like where you are sitting near a creek, and the sound is so busy that you start hearing voices in it, you imagine sounds. There's an acoustic imagination. Processing sounds has always taken me into that abstract arena of the imagination. That's the edge with which I like working. 
$>$ Lex: What kind of equipment were you using in the 70 s?

$>$ Hildegard: My very first piece, called Whisper Study - we did not even have a mixer then! I don't know if mixers existed, but we didn't have one. We edited by cutting tape. We had three very good, very big, Ampex reel-to-reel stereo tape recorders. They were 1/4", but halftrack, not quarter-track, so that the two tracks covered the whole tape. We had one machine that had four tracks, which used 1/2" tape. There we could do some multi-tracking, with four tracks! That's probably how I ended up doing the piece, with various stages of multitracking on to the four-track. The tricky part was that you built up noise, tape-hiss, with every dub. And because the piece was based on silence and whispering, it was a tricky situation.

Which was good, because it was my first experience in the studio, and I was forced to pay attention to how to make it as clean as possible. So, I learned all about best possible dubbing and recording - to record as loudly as possible without distortion, which then allowed me to reduce the overall level of the piece and in doing so reduce the noise. In that way I learned all about clean, analogue studio work. But sometimes it was hard to avoid building up noise.

Editing and mixing, filtering, looping and delayed feedback were the basic studio techniques. And, we had this lovely machine that one of the technicians had made, to do what is now called pitch shifting. It was a speed changer, connected to one of the tape machines; so you didn't just have 15 ips (inches per second) and 7.5 ips and 3.75 ips as the tape machine speeds. With this you could fine-tune the speed, and over four or five octaves, from very slow to very fast. And, one knob did the whole thing! I have never seen a machine like that, ever again. It finally broke, in the $80 \mathrm{~s}$, I think. But, now you have all the pitch shifting you want in the digital software.

I didn't get into computers until the mid-90s. Because, for my ways of working there was never enough memory. The technology was just not ready for fairly large sound files. I always use long recordings, with small sound objects at the same time. Finally, when there was enough memory and enough power/speed, I went straight into the PowerMac about seven years ago. Up to that point, I either worked in other studios that had the equipment, or I worked analogue.

$>$ Lex: How was it when you first made the shift into digital?

> Hildegard: It was weird. The choices are different. Conceptually, when you edited analogue tape, you had a recording, and you took out what you didn't want. You dealt with a whole thing and you took out. With the digital, you have your recording, and you put into the digital domain that which you want. To me, that was a big switch, because I like to work with a whole recording and then come into the detail of it from the large perspective.

Also, with digital, you have to select at an earlier stage. That's not so much a problem now, as it was earlier, when the computer couldn't take big files, and you really had to make choices, early on. I found that confusing, quite difficult actually. But, now it's not so much of an issue. 
$\gg$ Lex: And what about the nature of time? That you have so much control over time in the digital environment, whereas with tape it's flowing?

$>$ Hildegard: Actually, there's a different problem. Time moves aurally in the analogue domain. You don't see the sound waves; you work through your ears. All the editing that happens isn't visual: you make an edit because it sounds right, not because you see a smooth connection on the screen between soundwaves.

That is a huge problem, I think; people working in ProTools, ${ }^{5}$ for example, are often not aware to what extent they are working visually. I tend to encourage people to make a dub of what they've just done and play it back in a different environment. In fact, play it back some weeks later when the inner visual image of the mix on the screen is gone. Listen to it: hear whether the work makes any sense from the purely aural perspective. Because in my own experience I find myself so busy with these visual details on the screen that I think I've done a lot. I think that's the biggest danger, and I think the danger is that we end up with a lot of very flat work that isn't all that complex, or interesting aurally. Because the composer is in a mind space of visual busy-ness.

So, time passes visually when you compose in the digital domain. You can't help it. Visual time passing and aural time passing are very different, quite antithetical. That's the one big shift from the analogue to the digital sound-processing domain.

$>$ Lex: For a very different historical question, how has the soundscape changed since you were doing your early soundscape work? Here in Vancouver, or in the world?

$>$ Hildegard: Certainly, one thing that has increased enormously is the sound of media, the sound of music in the environment. The "schizophonic soundscape" - this is a term that Schafer coined - has changed. A schizophonic sound is any sound that comes out of a loudspeaker, where the source of the sound does not occur in the same place as the reproduced sound. If you hear an orchestra playing through a loudspeaker, the source was somewhere totally different in time and place. That's where the 'schizo', the split, comes from.

Whatever we hear through a loudspeaker is not of this place, ever. To us, now, and to young people in general, it is quite natural to perceive the loudspeaker as the place of the sound source. But, when you think about it, of course it isn't. A loudspeaker introduces something quite foreign into an environment, something that does not naturally belong there.

At that time, in the seventies when the word was first used, the split between soundsource and reproduced-sound was still pretty obvious. When you think about the Muzak Corporation, and how they were trying to manipulate customers into staying in stores for longer or shorter time spans, for buying more, or have staff work harder, or whatever there you have a strongly manipulative example of that medium. Designing it explicitly so that it is not listened to, a musically designed soundscape is used to somehow manipulate people into changing the pace of their activity, whether it is consuming or working, preferably without them noticing it. 
The Muzak Corporation is, in my opinion, one of the most sinister representatives of this type of manipulation of consumers or a work force, where the sound itself is used to increase corporate profit.

At the same time in the seventies, as I mentioned earlier, I was working at Co-op Radio, a radio station that was trying to connect with its listening community - also a schizophonic medium, but totally at the opposite pole from the Muzak Corporation. Co-op Radio is a medium of connection and conversation with community, to animate conversation, to disperse knowledge, to analyse and understand social processes.

Lex: To articulate a place through art.

> Hildegard: Exactly. The Muzak Corporation has defined itself as saying that they are creating music NOT to be listened to. They don't want to connect on a conscious level with their listeners. They in fact want to reach you subconsciously in order to get something from you. It's a very underhanded capitalist way of getting you to do something that you're not conscious of, spend more money, work harder. For me, those are the two poles of the spectrum of the schizophonic environment. And, as you've noticed yourself, you're also engaged with a schizophonic activity right now. You are in the same place as I am, but you are hearing it through the headphones as you record the interview. That can be very positive, in that it switches your perception: it makes you aware of the environment in a different way because you are hearing it differently. The microphone is your new ear. So, it presents the environment to you quite differently. There again, that is a very positive aspect of sound technology and the recording medium, connecting you to the environment in an awareness-raising way.

If the media sound - radio, TV, whatever - does not do that, that's when it becomes manipulative, exploitative, when it speaks AT you, and doesn't want you to speak back.

The presence of such media really has increased. And I think the normality of such sound in our environment is very dangerous, because people grow up with it as if it's a necessity of daily life, almost like an addiction. People tend to feel that they have to surround themselves with sound and music all the time.

When the Walkman appeared it became apparent that people enjoyed making a personal choice in their listening. Now, the technology is so small that it can be carried around everywhere. With the cell phone we can speak to anyone at any point, or be spoken to at any point. Suddenly, we hear sounds in environments that we never heard before - the phone ringing in the middle of the street downtown was not heard in the $70 \mathrm{~s}$ or $80 \mathrm{~s}$. Now, if someone behind me is saying a loud "Hello?" it's usually not for me, it's for someone else somewhere else, right?

Those kinds of voices are emerging in many places, and that loud telephone voice can be very disruptive, very obtrusive. There's a normalisation going on there: people are accepting it. On trains in Europe for example everyone is talking on their cell phones. You are forced to listen to something that you really aren't interested in. You get drawn into quite intimate personal emotions because you hear the voice. Not necessarily because you hear the story, but because you hear the voice, the voice quality. That's usually more than you 
262 / Sarai Reader 2003: Shaping Technologies

want to experience on a train ride. In fact, it means that it is harder to be in touch with your own inner voices because you're constantly disrupted by other voices. You can't block them out. Muzak, we've learned to block out. Foreground music even, we learn to block out. But, voices! We don't want to block them out. We're social beings. But the cell phone forces us to block out the next person.

This conversation was recorded at Vancouver, British Columbia, June 2002, and prepared for "Sound Generation: Recording - Tradition - Politics" (Chronoplastics, 2003).

\section{Notes}

1. Hildegard Westerkamp was born in Osnabrück, Germany in 1946 and emigrated to Canada in 1968. She is a founding member and is currently active on the board of the World Forum for Acoustic Ecology (WFAE), as well as the Canadian Association for Sound Ecology (CASE). Between 1991 and 1995 she was the editor of The Soundscape Newsletter and is now on the editorial committee of Soundscape - The Journal of Acoustic Ecology, publication of the WFAE. Her writings can be accessed at http://www.sfu.ca/ westerka/writings/ writings.html

2. The World Soundscape Project (http:// www.sfu.ca/ truax/wsp.html).

3. Schafer, Murray R. The Tuning of the World: A Pioneering Exploration into the Past History and Present State of the Most Neglected Aspect of our Environment: The Soundscape (http://www.philmultic.com/ composers/ schafer.html).

4. The Vancouver Soundscape (http:// www.sfu.ca/ truax/ vanscape.html).

5. ProTools is an audio production environment for recording, editing and processing in the digital domain (www.digidesign.com). 
ENCODE+DECODEENCODE+DECODEENCODE+DECODEENCODE
ENCODE+DECODEENCODE+DECODEENCODE+DECODEENCODE
ENCODE+DECODEENCODE+DECODEENCODE+DECODEENCODE
ENCODE+DECODEENCODE+DECODEENCODE+DECODEENCODE ENCODE+DECODEENCODE+DECODEENCODE+DECODEENCODE ENCODE+DECODEENCODE+DECODEEN CODE+DECODEEN CODE ENCODE + DECODEENCODE+DECODEENCODE+DECODEENCODE ENCODE + DECODEENCODE+DECODEENCODE+DECODEENCODE EN CODE + DEC ODEENCODEFDE CODEENCODE + DEC ODEEN C ODE ENCODE + DEC ODE E CO DE +DE CODEE CODE + DEC ODEENCODE EN CODE + DECODEEN CODE +DE CODEE NCOE LDEC ODEENCODE ENCODE + DECODEENCODE+DECODEENCODE + DECODEENCODE ENCODE+DECODEENCODE+DEGODEENCODE+DECODEENCODE EN CODE+DECODEEN CODE + DEC OEENCODE+DECODEEN CODE ENCODE+DECODEENCODE+DECODEENCODE+DECODEENCODE ENCODE+DECODEENCODE+DECODEENCODE+DECODEENCODE

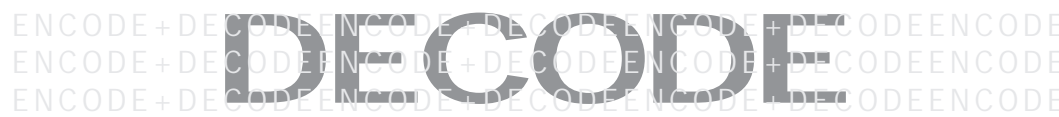
ENCODE+DECODEENCODE+DECODEENCODE+DECODEENCODE ENCODE+DECODEENCODE+DECODEENCODE+DECODEENCODE ENCODE+DECODEENCODE+DECODEENCODE+DECODEENCODE ENCODE+DECODEENCODE+DECODEENCODE+DECODEENCODE ENCODE+DECODEENCODE+DECODEENCODE+DECODEENCODE ENCODE+DECODEENCODE+DECODEENCODE+DECODEENCODE ENCODE+DECODEENCODE+DECODEENCODE+DECODEENCODE ENCODE+DECODEENCODE+DECODEENCODE+DECODEENCODE ENCODE+DECODEENCODE+DECODEENCODE+DECODEENCODE ENCODE+DECODEENCODE+DECODEENCODE+DECODEENCODE ENCODE+DECODEENCODE+DECODEENCODE+DECODEENCODE ENCODE+DECODEENCODE+DECODEENCODE+DECODEENCODE ENCODE+DECODEENCODE+DECODEENCODE+DECODEENCODE ENCODE+DECODEENCODE+DECODEENCODE+DECODEENCODE ENCODE+DECODEENCODE+DECODEENCODE+DECODEENCODE 


\section{Beyond the Computer}

GABRIEL PICKARD

A spectre is haunting virtual worlds, the spectre of the digital computer...

A radical reflection of its basic paradigms is long overdue... It is time we were left to our own devices, other devices....

The time has come for the Information Machine

$\mathrm{T}$

echnological development is a question of power, of power over the virtual and actual infrastructure of new media. The task is to reclaim and ensure accessibility. Equal and easy access is a prerequisite for an enduring right to the freedom of information which is the contribution that media can offer to social development. On the one hand accessibility is about recreating the user interface and adapting it to human needs, and on the other about simple and sustainable production of affordable mechanical infrastructure.

Computers are certainly useful, that is why they are used and produced. Nevertheless, we should look more closely at the figure of the user and user interaction...

Generally, the computer movement is seen as split into two broad camps: developers and users; developers are said to view the computer itself as the goal of their endeavors, while users follow independent agendas, towards some 'real' goal. But, as the sphere of information is autonomous and computers more ubiquitous, all activity utilising them also becomes increasingly self-referential.

In the course of time, the role of the developer has undergone strong changes, the main one being the introduction of the hardware/software paradigm, a differentiation which was irrelevant before. Certainly, free programmability has always been the most important 
feature of the digital computer, but users do not change programmes distributed as software, so for them free programmability is a 'lost feature'.

The hardware/ software dualism is essentially a distributional business model, and not a technical architecture, which arose from the need to share and distribute common algorithms. The power to freely programme was taken from the user and transferred to the developer, effectively turning both hardware and software developers themselves into users, as they were dependent on computers for their development process. The user became an inescapable paradigm via this neat self-referential fit. At the level of interaction, we are all users.

Chesher informs us about the invocational nature of the devices we know as digital computers. ${ }^{1}$ He points out that the main paradigm of interaction for the user interface of "invocational media" (computers) is "calling something up".

The user interface not only includes the $\mathrm{HCl}$ (Human Computer Interface) but also deeper invocational levels in both hardware and software, which present themselves as interfaces to the developer-user. Thus, for instance, we could say that programming languages are like ritual formulae to invoke certain algorithms.

Freely programmable machines supply an interface for algorithm transmission, to invocationally access the full spectrum of the machine's capabilities. Programming then is the task of most effectively representing an idea or model in interface dependant invocations.

All interaction with invocational media is similar, for example the point-and-click graphical user interface (GUI), where the correct button must be chosen to activate the desired function. Between desire and outcome there exists a tension, a gap, which must be procedurally bridged by the user's will. The quality of this gap is an indication of the individual user's computer literacy.

The dualism of developer/user is no longer sustainable, the whole computer movement has become a form of invocational user. We may discern three types of users: hackers, power-users and DAUs (German: Dümmst Anzunehmender User) - the dumbest possible user, the über dummy, who differ in terms of their 'computer literacy' and consequently the strength (effectiveness and precision) of will they are able to communicate in order to ease the tension between desire and outcome. Dealing with an invocational medium, the strength of will is dependant on the level of internalisation of computer specific invocational formalisms.

Hackers are a hybrid between what was originally visualised as the role of the user and the role of the developer, before the hardware/software paradigm. They are distinguished by their high level of internalisation of, and empathy with, the architecture of their invocational medium. The communication of will takes place internally, between the hacker's desire and the mental imitation of the invocational architecture, the actual invocation at the $\mathrm{HCl}$ becomes a peripheral act.

Power-users differ only in their level of internalisation and their concentration on an application's architecture, whereas DAUs (über dummies) have a very hard time interacting with their medium. Communication of will remains nearly impossible for them, until they internalise at least a narrow slice of invocational architecture and become gradually more 'computer literate'. 
The invocational interface is inhuman and defined by invocational formalisms that make it time consuming on all levels, for programming hackers as well as for DAUs (powerusers may still be best off, if their desire is limited to their application's capabilities) because of the amount of effort that must be invested in diagrammatically adjusting will communication to the invocational formalism. A more direct, non-invocational will communication is necessary to ensure accessibility. Further, the problem of cultural power, often addressed around the catchphrase 'digital divide', must be solved. It is evident and well known that material access is connected to discrimination in terms of class and race, and education for 'computer-literacy' is tied up with gender inequality.

We need other devices. And I do not mean some sort of Sony Home Entertainment or next generation Microsoft Tablet-PC. Rather, we need technology with a human face, for a free flow of information and without extensions such as 'Digital Rights Management' that are dictated by the techno-powerful establishment. Of course, simply and autonomously produced technology has a hard time competing with capitalist-industrial hardware, but often this hardware is by far over endowed with unnecessary capabilities.

In the social movement which established the 'computer-age', there has been a strong tendency to adopt pre-existing paradigms and architectures without much fundamental reflection, which may have been caused by the rush of a race for development and growth which threatened to overtake those who did not keep 'innovating', and promised to cover up misconceptions by sheer miniaturisation, speed, growth in capacity and complexity. This tendency prevails among both academic/ free-software and commercial/industrial developers.

The von Neumann Architecture (the basic paradigm for today's computer hardware) was a design for large institutional computers and describes a singularity: one central computer solving large mathematical problems. Certainly, this is not the task that computers tend to serve today, so why did developers adhere to this paradigm? The answer may be simplicity. Developing can be seen as the task of gradually simplifying aspects - effectively leaving complexity to the collective whole, which ends up as a mass of essentially simplified components.

Other devices should perform an equalisation of complexity and collectivisation of simplicity. One aspect that the von Neumann Architecture most gravely overlooks is multiplicity, revolving around a monolithic 'Central Processing Unit' which does not address interaction, the reason why contemporary computers added 'interrupts' for handling user interaction with the concept. Interaction (and not simply control) also between the device's components may be achieved via a strategy of modularity, a structure of multiple nodes instead of central processing.

The 'beige box' must be broken open and replaced by a network of interacting information processing components, the production of which should be simple enough to enable independence from centralised development powers. Simplicity of production and affordability might make these other devices interesting for issues related to development (in a socioeconomic sense), to bridge the 'digital divide'. Hopefully such an egalitarian design approach would boost the development of 'free hardware'. Nevertheless, until some new methodology of production is found, creating hardware to compete with the industrial complex seems all but doomed as a lost proposition. 
Standardisation and compatibility have been a huge economic, technical and social problem, a problem of power. Innovations have been thwarted, monopolies upheld and idiosyncrasies painstakingly maintained for the sake of compatibility. The reason for this lies in the industry's inability to cope with interaction. The first duty of any interactive node is to ensure its own interactivity via a multiplicity of interfaces, so that in a sufficiently rich network, singular incompatibility should not pose a problem. In such a network, the gradual introduction of new technological generations would be more easily possible.

Not only the ease of maintenance and production, but also of use, should characterise these other devices. Will communication would take place via minor invocational interfaces (such as buttons and switches on the devices), which should not feature a deep invocational interval, a complexity between invocation and result, but rather follow a straightforward form of interaction, leaving complex communication to the natural-language interface.

Natural communication via human speech has always seemed to be something of a 'holy grail' to computer scientists. The challenge here lies less in the recognition of words via phonetic patterns (voice-recognition), rather it is in truly understanding the meaning of these words. The spirit of this dream is captured in the famous 'Turing-Test' (in which a computer tries to imitate human communication, succeeding if a human is not able to discern it from other humans).

Understanding is the ability to represent a statement internally by connecting it to other representations (putting it into context); the level of understanding depends on the amount and diversity (depth) of the representation by connection.

A human interface, one that understands human thought, is essentially flexible. An invocational interface passes through invocations of approximate result, whereas a flexible interface passes through statements of approximate meaning, not defining the result. To understand correctly, a flexible interface must draw on a rich internal representation, which enables the statement to be represented in an environment meaning a correct result, from which the understanding medium can deduce an outcome. Conventional invocational interfaces are indiscrete and not processual; with understanding media, the process of understanding may be indiscrete and constant, involving multiple interactions, but must lead to a correct result, as meant by the communicative partner.

Meaning is always a process leading to an actuality, an approximate act (output), which is determined by the user's desire. So this process of 'leading to' should at best be flexibly (and simply) (re)definable to grasp the individual user's will.

Of course, such human interfaces may very well be built as programmes for conventional computers, for example in an OS (Operating System). Certainly not an OS in the common sense, offering a virtual-machine interface to overlying applications, rather without any independent applications at all, file system structure, GUI or API (Advanced Programmers Interface). Simplicity is not to be reached by hiding, but by making evident and shallowing deeper layers of the architecture, in a sort of non-architecture. A unification of data formats in vectorial data structures for flexible representation, without a differentiation between executable and data, application and document. What is commonly known in computer science as 'semantic networks' is the key to such new forms of information representation.

Semantic networks consist of entities connected by links, the most common form 
being such that the directional links are labelled and entities named. But if we reduce the concept of semantic networks, the most basic net would be one of abstract, unnamed entities and non-directional, unlabelled links (many different forms lie in between). Such a net would not rely on the implicit meanings that words evoke in human viewers, instead leaving the role of providing meaning to a given framework of meaning (Bedeutungsrahmen).

To speak in terms of an OS, supplying this Bedeutungsrahmen would mean outfitting certain basic entities (e.g. for hardware access) with meaning via the OS's functions. Or rather, what may be roughly considered to be the OS's functions, as executables and other raw data would be flexibly integrated into the net as linkable objects. Managing a space for memory-objects (such as entities, links or executable blocks), supplying these memoryobjects with a (sufficiently small) format which allows them to maintain reciprocal connections, and controlling hardware according to settings given by the network, whereby as much as possible should be abstracted into a representation via the net, are among the basic tasks of the OS. But the crucial task lies in offering different techniques for searching (datamining) and interfacing different network (and non-vectorial) data formats simultaneously.

Information is a realm of independent, abstract existence. One way of approaching the nature of information is by constructing a dualism between physical and non-physical, actual and virtual existence. This method tends either to overestimate the process of abstraction, hence ignoring the independence of information, or to settle for a purely negative definition, without further description. Refusing to clearly discriminate actual and virtual, or to accept abstraction as a hierarchical process, I choose to approach the nature of information by way of describing essential qualities as common characteristics of all information and propose that:

Information is systems and identities. Both systems and identities are special forms of discretion. All objects are discrete, they feature a distinction between in and out, inside the object exists the object's essence, outside are other essences. Identity is the point of radical discretion, at which discretion offers discretion to itself, independent of any content. Identities relate to another (so content is externalised), these relations take infinitely diverse forms (systematologies), for example the different forms of semantic net mentioned above. (Next to these flexible forms, structural systematologies are also possible, through which identities do not relate to another individually but rather collectively.)

Systems are not necessary for an independent existence of information, instead they are of importance to abstraction, distinguishing relations of one systematology from others and letting identities relate to one another via multiple systems. A system is an information parcel, a collective discretion and objectivisation for relation(s) of one systematology, which presents itself via the physical world in data. The relationship between data and information is hyperflexible, a system may present itself via infinitely multiple data while a datum may be abstracted to infinitely diverse systems. Any definite virtual existence, any entity (identity or discrete object) may be incorporated into a system.

If we see clearly that information is independent, we then make a mistake if we reduce the study of information solely to the process of communication. The cognitive and phenomenological implications of information are also of great importance. Nevertheless, communication has always been the most prominent occurrence of information, as it is evidently 
outside the root of discretion, the body. Communication is the transmission of virtuality in general, information is only involved if the message has a statement, possibly next to affective elements or noise. This statement may pass through multiple interfaces and be presented in diverse media, an understanding medium (e.g. the receiver) will then represent it by setting it into relation.

During the process of communication, as the statement passes interfaces, any non-identical entities (objects) are lost and must be re-approximated by the Bedeutungsrahmen of the understanding medium. If the systematology in which the understood statement is represented differs from the systematology which it abstracted to in another understanding medium (e.g. the sender), the systems may nevertheless be considered equivalent. Systematologies are not absolutely definable, only in an endless circle of relation to another via equivalence.

If we view systematology independently of concrete systems, we can formulate an explicit systematology in a system of another (implicit) systematology as a description of its forms of relation. An explicit equivalence is then given between explicit systematologies of the same (or explicitly equivalent) mother systems.

This theory of information is certainly not complete and still under development, more could be said on supra and subsystems, interfaces etc. and there is still more to be discovered. Compared to Cybernetics related Systems Theory, it departs in a different direction from some basic common ground of abstraction and independence, as it does not reduce systems to algorithmic systematologies. It definitely differs from what is generally called "Information Theory". ${ }^{2}$

\section{Towards the Information Machine}

The legendary "Universal Turing Machine" (TM) is the theoretical concept for describing computability and hence also the archetypal computer. It describes a basic machine, consisting of some form of storage tape and a mobile read/write head, which is able to execute any algorithm (which is why it is called universal). Any other implementation that may be simulated on the basic TM is considered to be 'Turing equivalent'. Nevertheless, most actual implementations of computers are not Turingequivalent, as they depart from the concept by introducing Input/ Output (I/O) mechanisms, asynchronous processes, which cannot be simulated by a TM. Broadening the concept to describe the dynamic actual world as one large computation not only makes false assumptions about the actual world, but also turns computation into an indistinguishable, useless concept. As it is, algorithms are hard enough to discern, because free equivalence lets virtually everything equivalate to a TM.

The concept of computation is in a crisis. ${ }^{3}$ The former 'digital computers' have already become invocational media in actual use, and computation does not offer us a model for describing or simulating intelligence. The crisis of computation is founded on the fact that computers are seen as systems. Models and concepts for these machines are systematic information, but not the material machines themselves.

Information Machine (IM) is a process. In thinking and during communication, information, in its static infinity, joins with the flowing realm of scarce materiality in processes. IM is not a system, it claims neither inside nor outside and accepts an already given endless realm, thus the process is one of discovery, one of representing always new facets of infor- 
mation. In a process to blur the demarcation between virtual and actual, constant development is necessary, which may only be approximately foretold, I can only give directions into which IM might flow.

IM is collective intelligence. Intelligence as dealing with information, communicating and manipulating data, understanding and reasoning, interacting and transacting. IM collectivises as an open process of collaborative interfacing machine elements and human individuals sharing information, accepting no outside and no individual computing unit. This intelligence, discovering the infinite realm of information, free of value or property schemes, proceeds across devices and individuals. As a process which is oriented at human accessibility, and which is more interested in a human-machine collaboration to form intelligence than in modelling natural intelligence (e.g. modelling the brain), IM certainly differs from the scientific efforts around 'Artificial Intelligence' (Al). Nevertheless, some disciplines of Al may be very useful to the process of IM, for example in creating flexible, evolutionary changing elements, and vice versa; IM would also be easy to integrate with autonomous units, offering them a rich field to interact with.

IM is other devices. Multiple elements interfacing to another take part in the process. Of course, the device-concept proposed above is very congruent with these techniques of IM, but virtual implementations, or implementations not based on mechanical devices are also possible. Effective techniques for setting into practice the information-theoretical model proposed above still need to be explored. Nevertheless I can assume some aspects.

Elements may be of a fixed or variable number of systems, systematologies or entities, feature explicit or implicit equivalence. Every element is in some way processual, be it in storing and retrieving, calculating, generating or emitting signals, performing these processes should always be as systematic as possible, involve identities rather than objects, and be directed at the interaction via interfaces to other elements. Elements may share given sets of a (theoretical) aspect of information which are then specified in the protocol of the interface, and/or exchange these aspects via the messages which pass through. For example, an interface could share a given set of basic entities and exchange systems of an array of mother systematologies and explicit equivalents, including the possibility to send messages to change the protocol. Generally, any configuration of aspects is possible for interfaces and the elements themselves; however non-identical, virtual objects may only be shared and are fixed, and at least one mother systematology is always implicit.

IM is a Transnet. At best, these interfacing devices would be equally distributed, connected by diverse long and short distance network-infrastructures. As interaction becomes the basic paradigm for all elements of $I M$, the network becomes much more ubiquitous and manifold. Free networks (such as 'WiFi', wireless networks) are an important field to develop towards IM. The use and architecture of the network would be radically different from the Internet we know today. It is not as if one great space of shared data is established, rather the realm of information is collectively explored and the participants cooperate as intelligence. IM would have a more gradual scope of different interactions ranging from ultra-local interaction, e.g. directly connected devices cooperating in presenting an understanding interface to one user, to local (short-distance connection) and distant (long-dis- 
tance and indirect connection) interactions. IM opens up new capabilities for networking and interfacing, a new seamlessnes, as freely definable as the interfaces themselves.

$I M$ is a process of will execution. The most important point of differentiation between Information Machine and Artificial Intelligence is the emphasis on human will. It arises in (and upholds) human individuality; it is procedural individuality. The virtual and actual objects which establish the Bedeutungsrahmen and the basic systems and systematologies of IM's elements which propel the process of IM should be designed with the user's will and desire in mind. Not by presupposing them, but rather by enabling their flexible communication and precise deduction. Algorithmical systems will still play an important role in this part of the process as they lend themselves to the representation of will. Desire lies at the root of meaning (starting with the monkey whose sense of meaning in relation to the bananas he perceives is based on the hunger to have one).

Desire leads to an internal representation and virtualisation, deriving from the archaic feelings attributed to perceptions. Because of this importance, the actual capabilities (for output) of IM's elements should be individually configurable and attempt to encompass a large spectrum of acts leading to actualities desired by humans, which may exceed the capabilities of contemporary computers, for example to address material desires via means of production. This may lead to the interesting situation in which the expansion and replenishment of the materiality of $I M$ is produced by capabilities of connected elements, forming a feedback circuit of sorts.

IM is other media. Are we entering post-human society? A society in which the predominant form is no longer artificial (i.e. produced by human skill), in which autonomous abstractions play an important role. Nevertheless, this society might be all too human and yet characterised by an ambivalent relation to humanity. Information technology is what our society is being built of, IM may be a vision (utopian or not) leading to a radically information and human orientated technology. Let me highlight some paths, of significance on their own accord, but which, if interconnected, may lead to Information Machine:

$>$ Free networks and free hardware design (especially for simplicity in production, distribution and infrastructure).

Political efforts to ensure a social framework which allows for an effective use of independent information.

New OS and interface design, with a special focus on natural language, for access independent of 'computer-literacy'.

$>$ Further development in new information theory and other (possibly new) alternative theories.

This is radical technology. Some may see it as more profitable to cooperate with the computer establishment, others may have playfully fallen in love with the architectures and paradigms (and computer games) of their well known computers, again others may not think it worth the effort to radically rebuild virtual worlds, and would rather continue the 
struggle in their own specific fields. I encourage all to responsibly keep a critical eye open, to reflect on, and to question well acquainted paradigms and everyday practices. Because we are entering society with the machines, the so-called 'content industry' is hegemonialising society's culture and governmental/military forces are taking over the cutting edge in technological development.

Where do you want to go today?

\section{NOTES}

1. In Chesher (2000) and Chesher (2002).

2. See Shannon (1948).

3. See Sloman (1996) for detailed discussion.

\section{REFERENCES}

1. Chesher, C. "Computers as Invocational Media" (PhD thesis, 2000, University of New South Wales).

2. Chesher, C. "Why the Digital Computer is Dead" (www.ctheory.net, 2002).

3. Shannon, C. E. "A Mathematical Theory of Communication" (in The Bell System Technical J ournal Vol. 27, 1948).

4. Sloman, A. "Beyond Turing Equivalence" (in Machines and Thought: The Legacy of Alan Turing 1996). 


\section{APP.lying Software A Reader-List Discussion}

(edit + design) A RE FLÅ G A N

APP.lying Software

[archive: www.sarai.net]

I = <snip $>$ from words to $\| s</$ snip $>$

What is Software?

[areflagan@artpanorama.com]

What is software? The mechanistic answer would be that it is assemblages of algorithms compiled to perform and automate specific tasks on a computer. If we resided on the circuit board, somewhere among its rigid corridors of conduction, such a reductive definition might surmise to understand software, but only within the dark limits of the black box. Let's look outside this box for a moment. / We are looking at a machine that synthesises and automates modalities of social, cultural and economic relations, removes most tinkering from its root, and installs a generalised operator to perpetuate a programme of utility valued and developed by its owners. Now that the initial question has partly been rephrased, it should be asked again. What is software? $\varnothing$

redistribution. pl

[harwood@scotoma.org]

\# Perl routines for the redistribution of the world's wealth

\# Takes the cash from the rich and turns it into clean drinking water wells

\# w.blake@scotoma.org

\# $\vee 0.0 .1 / \varnothing$

$$
\text { > [areflagan@artpanorama.com] }
$$

Profiling Software

[areflagan@artpanorama.com]

/ Profiling works in the background to facilitate decisions on entry and exit when packets travel port to port across borders of difference. And profiles very explicitly invite many more such analogies, laboured or not, precisely because they are instruments of conversion that always return to the currency they carry. This leads to the thought that persistently haunts me: that profiles explain why the world makes some sense at all, how evil divides itself from good, black from white, religions from each other, one culture from the next and so on. 
They are the troublesome and comforting ideological supplements that I carry around as inevitable baggage in return for knowledge and perception, those cerebral turns towards understanding and recognition. Profiles hence allow my views to converse across divides by putting the general before the specific, ideology before the individual. Through them the calibrated and manufactured impressions that encourage me to see a criminal in every black man and a terrorist in every Arab take root. Profiles are my hidden supplements to a point of view, and I honestly swear by them. Software profiles, that is. $\varnothing$

$>$ [amcgee@freeshell.org]

Who wrote this? Where is the original article located? $\mathbb{E}$

Software/Copyright Googlism

[tripta@sarai.net]

The answers are:

software is <http:// www.googlism.com/ ?subject=software>

copyright is <http:// www.googlism.com/ ?subject=copyright $>\varnothing$

> [areflagan@artpanorama.com]

I It does indicate how we may conduct our existential searches these days - through algorithmic processing with finite, programmed answers, i.e. through software. How do, for example, the omnipresent contact and calendar applications, coupled with their handy accessory, the PDA, fit into how life itself organises around data and specific software clusters? Ø

$>$ [sva2003@columbia.edu]

/ That's what most technology advertising would like us to believe. I Where software is decidedly different is that it can be changed. That, after all, is meant to be the point of differentiating between soft and hard wares - always an arbitrary division, of course. $\mathbb{E}$

A Case for PDA Student Computing

[human@electronetwork.org]

\section{A FEW BASIC ASSUMPTIONS}

(http:// www.electronetwork.org/articles/psc/) Before detailing what is needed, it would help to dispel aspects of present-day computing cultures, which are not needed in classroom computing for the most general utilities of computing, in its widest sense, as a learning device, as a support tool and not an education in itself. / Therefore, for some specific applications, open source software developed within local, national and international school systems may be co-developed and shared, instead.

\section{PDA STUDENT COMPUTING}

I All the issues inherent in traditional computers, from price to size to portability to troubleshooting and tech support, tend to a whole different approach to student computing. 
It is proposed that PDA Student Computers (PSC) are superior on almost every level, at which students are prepared to use them, in a costeffective way, in comparison with fullfledged computers whose resources may never get used before they are outdated. $\varnothing$

\begin{abstract}
$>$ [areflagan@artpanorama.com]
The PDA(ish) device you refer to has been developed in India, and is currently in its production phase. It is called the Simputer. I have also read about recent cases in South Africa, where some schools turned down the usual Microsoft gifts and instead installed old 486 machines running Linux. The stated goal was to teach networking and programming, and forsake the task of simply training software operators. I think this dilemma resonates throughout your proposal, and the question returns to what sort of economy education ultimately participates in. / $\varnothing$
\end{abstract}

\title{
3. PDA COMPUTER SOFTWARE
}

I As mentioned, with the hardware available today, off-the-shelf technologies could be used and designed to meet the specific needs and requirements of educational computing. They could be mass manufactured on such a scale as to bring the price-point down from those of commercial models.

\section{PDA COMPUTER SOFTWARE}

/ PDA Student Computers need an operating system that can use both proprietary and open source software programs. / Many of the best resources, such as dictionaries and other devices, exist in the open source community, and they would be superior in price and comparable in functionality to a commercial product, and therefore this open design is essential in the socioeconomics of PDA Student Computers.

\section{THE PSC DIGITAL CLASSROOM}

I In all, to summarise the PSC Digital Classroom as described, it is an available, malleable, robust, affordable, openended, upgradeable, efficient and perfectly sufficient computer system for use in primary and secondary schools. / It has most all the functionality that makes computers worthwhile to invest in, for student education, if the goal is to supplement the learning process, and open new horizons related to personal educational computing. $\varnothing$

> [areflagan@artpanorama.com]

I This is a really interesting area where I hope we can benefit from the insights and experiences garnered at Sarai. / What you propose seems to be taking shape on another continent - currently going through its own personal computer evolution. And all this is taking place while Microsoft is negotiating hefty discounts, up to $90 \%$, to become the OS and supplier of choice in these countries. We are perhaps talking some serious 'social aspects' of software here. / $\varnothing$ 


\begin{abstract}
>> [human@electronetwork.org]
I If such a platform exists, it would allow a computer that is not controlled but controllable, which starts off open - and not closed - to independent possibilities. / It is almost an issue of 'free computing', as in 'free speech'. By not restricting free development, it would resist enslavement to corporate models of hardware and software development, and the ideologies which place certain things at the top of the list, and others off the table or impossible, because of special interests and potential loss-of-current-profit models. / $\mathbb{E}$
\end{abstract}

Memo to the Government of Kerala

[ragu@asianetonline.net]

Members of FSUG-Kochi have submitted a memorandum to the Government of Kerala regarding the choice of software and syllabi prescribed for the IT@School project. / $\mathbb{E}$

:

Software is Religion

[menso@r4k.net]

Software is religion. The preachers seem to understand little about those they preach to, and the ones visiting the church understand only vaguely what the preachers are all about. Software is also religion because the unbelievers' questions are far too often answered by saying that software moves in mysterious ways. $\varnothing$

> [areflagan@artpanorama.com]

I The cathedral and the bazaar; the secular move to open source ad-

vocated by Eric Raymond in his seminal essay by that title. $\varnothing$

There are many churches scattered across the land. There is the Church of Windows, which looks nice but lots of the people visiting have trouble with the fact that bits and pieces of the ceiling tend to fall down and occasionally kill someone. There is the Church of Linux, which looks solid, yet once inside one discovers that 100 different priests all claim to be the best, and besides that the place could do with a good cleaning, too. $\varnothing$

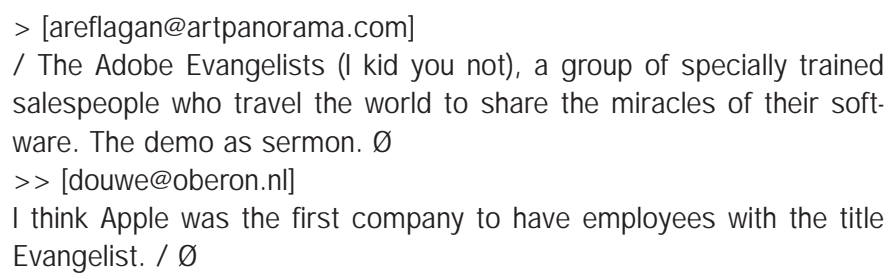

There's probably a church for every application or operating system ever made and it's 
believers are as fanatic in most cases as those of everyday religions. / Software is religion, because people expect miracles and the priests are unable to deliver (yet when it's time to collect money to support the church, the miracle is sold quickly with lots of extras). Software is religion, because there's the promise that if we use it, we will become better people. Software is religion, because it comes with Bibles that explain it all to us. Software is religion, because it will always remain a mystery to the masses, and there will always be questions it cannot answer. $\varnothing$

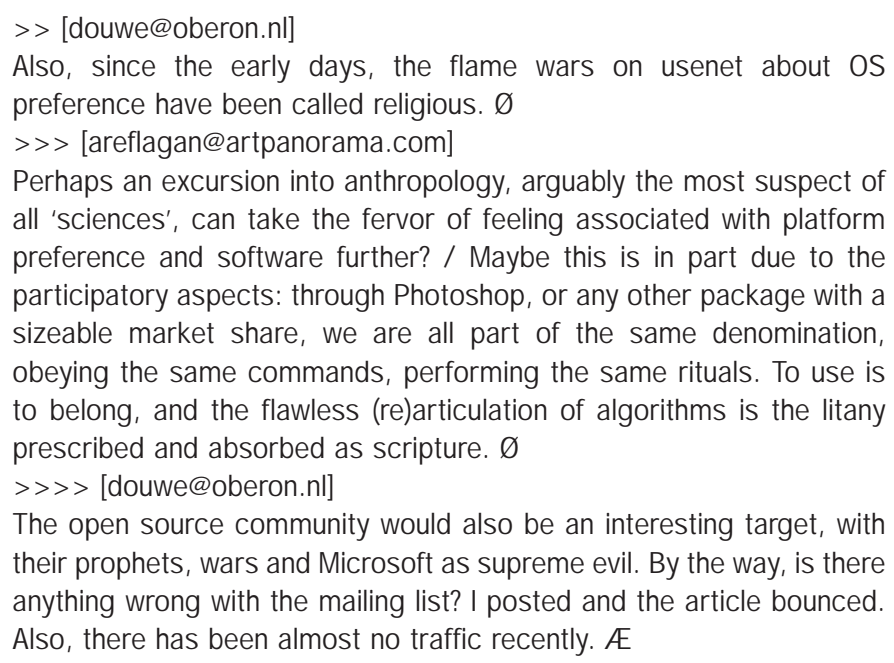

\section{$>$ I give up. The message was undeliverable. This is a fatal error.}

Human-Computer Oscillation and the Need for Calories

[harwood@scotoma.org]

(http:// www.scotoma.org/mouse) The foundation of this report is the human sensing system's contribution to the physical geography of the body: the orientation of the body in space, an awareness of spatial relationships and an appreciation of the specific qualities of different places and different things, both currently experienced and removed in time. The body's sensing systems offer important media through which space and time are experienced and made sense of in a computer interface. /

\section{TASKS}

Tasks are a specific chore or duty to be done. They exist on either side of our oscillation and are pre-programmed by the user's or computer's environment. / So it can be said: the user's objectification of content in the computer interface relies on the selective translation of user force through locator devices. Software (interface) requires the 
recognition of BITs on the part of the user in order to allow the user to objectify content within the interface. /

\section{THE MOUSE}

/ The mouse having no absolute origin is a relative device containing two states at the top level (working and not-working) and two parameters (movement and button-states). / This objectification [mapping of mouse input] in the interface allows the user to see software structures as part of a fixed environment that is external from themselves. / Objectification within this model is a kind of meta-system transition. / In objectification the new process controls not the old ones, but the objects representing these processes. I In interface design for instance, algorithms are defined as computational processes that we expect to be executed in a certain fixed manner by the user. Having established a reliable model of one specific aspect of objectification in interface design, the report reader may like to consider the following questions. Q: What are the consequences for the appropriation of value within capitalist systems if we interfere with this objectification process within interface design? $\varnothing$
> [areflagan@artpanorama.com]
The process has also been cast, in the Marxist critique, as one of alienation. I don't quite recognise the description that allows the user to 'see' this structure as fixed and external: it would effectively mean a transcendence to this reality and also, by some measure, a recovery of agency. Software is arguably a process that seeks to 'objectify' in favour of a certain remove. One recourse may be in the symbolic, interface design, which you do not enter into. / $\varnothing$
>> [harwood@scotoma.org]
The main focus of this question was to assert, or make apparent, the road to perfect art, in which the software will be no more then the concrete sum of its parts. The art will also be devoid of all social/ political/cultural/formal or economic value. The only use of computers allowed is that of a thoroughly aimless one. / $\varnothing$

Q: Having established that the selective reading of the user's input data through the mouse helps lead to objectification of content within interface, what happens if we create software that acts on all possible variables within mouse interaction? $\varnothing$

$>$ [areflagan@artpanorama.com]

/ In other words, what happens when we integrate the movements not anticipated and logged by software into software? / $\varnothing$

$>$ [harwood@scotoma.org]

I'm sorry, I can find no connection between this paragraph and the report. $\mathbb{E}$ 


\begin{abstract}
Alternative Software/The Forbidden Fruits of Computing [areflagan@artpanorama.com]

/ The relations Turing desired in computing were at their inception directed at one missed individual, rather than a generalised and disciplined body. They also spoke of a sexual difference - subtly restated in his choice of sex to determine human intelligence in the Turing Test - that cautiously countered the machine's universality. Once such pensive constructs enter the very definitions garnered here - those of our relations formed with the machine through hardware and our proof of its intelligent humanity in software - their universality as modes of knowledge about the life they perpetuate is called into question. When Turing took a bite of the cyanide-laced apple [his suicide], he chewed a chunk of that encounter in the Garden of Eden, which punished curiosity when it interfered with commands; he tarnished the purity of Snow White and the gravity of Newton's eureka that found enlightenment through reason. In computing, there should always be a lingering aftertaste, a protracted mortality, that recalls the tang of sweet and bitter juices Turing must have savoured as he pondered the fruits of his work, in that final system failure. $\varnothing$
\end{abstract}

$>$ [pankaj@sarai.net]

I Do you have any clue what you are writing, interpreting, misinterpreting? / $\varnothing$

5

>> [areflagan@artpanorama.com]

/ The prospects of understanding computing (or software/hardware) cannot belong to maths and logic alone, unless these are also recast within their own social, cultural and philosophical histories. / $\varnothing$ >> [supreet@sarai.net]

/ Maths and logic, if you notice, tend to be very dependable. / $\varnothing$ >> [pankaj@sarai.net]

/ I disagree. Social, cultural and philosophical histories are subjective matters and everyone has a different interpretation of them. / Maths and logic are different, because it's all imagined and delivered, mass hypnosis in a very orthodox form called education. $1+1=2$ can 1 question that? OK, that was a joke. / $\varnothing$

>>>> [areflagan@artpanorama.com]

on enterQuestion

global ganswer

if $1+1=2$ then ganswer $=$ FALSE

else if $1+1=11$ then ganswer $=$ TRUE

end if

updatestage

end enterQuestion $\varnothing$

>>>>> [supreet@sarai.net]

It just struck me that to implement this code, you would need to modify 
the mathematics; that is the basic operators to your choice of language: $1+1$ should not evaluate to 2 . Let's make an assumption that there is this clan or a tribe, which uses an alternate form of mathematics. This kind of alternate mathematics could be implemented like this:

\#include <iostream>

using namespace std;

class alternativeMathematics

\{

private:

int almv;

public:

alternativeMathematics (int val)

\{

almv=val;

\}

friend int operator+( alternativeMathematics \&t1, alternativeMathematics \&t2)

\{

return t1.val();

\}

friend int operator-( alternativeMathematics \&t1, alternativeMathematics \&t2)

\{

return t1.val()+t2.val();

\}

int val()

\{

return almv;

\}

\}

int main()

\{

alternativeMathematics $\mathrm{a}(1), \mathrm{b}(1), \mathrm{c}(0)$;

cout $<<a-b<<e n d l$;

cout $<<a+b<<e n d l$;

\}

Modify main() function to implement if-then-else/not operation. In this program $1+1=1$ and $1-1$ evaluates to $2 . \varnothing$

$>$ [supreet@sarai.net]

I It would be even better if you could point to a live problem/solution scenario where hardware/software constraints could be made glaringly visible. / $\varnothing$ 


\begin{abstract}
>> [areflagan@artpanorama.com]
/ This is the crux: the conjunctures of hardware/software/logic/maths and language/culture/society effectively seek to preclude such visibility. They seamlessly integrate their programmes into a machine operation, and thereby mechanize and, in the sense of a transcendental effect, naturalise their appearance. / $\varnothing$

$>$ [supreet@sarai.net]

I A neuron also performs almost the same function as a regular transistor would. It switches on / off. / Human beings are not special. $\varnothing$

:

> > > > > > > > > > > > > > > > > > > > > N Now, that's a bunch of bullshit!!, huh!!

> > > > > > > > > > > > > > > > > > > > What would be interesting to know is what's so bullshit about it, and on bullshit scale of one to ten, where it is rated? $\varnothing$

\section{0}

$>$ [Crosby_M@rocketmail.com]

I BUT, transcendentalists have been trying this [establishing a universalised norm] ever since the Tower of Babel and Plato's Republic, without ever being successful - because the world does not work this way or resists. / So we might be tempted to say that Kevin Kelly's "God is the Machine" is a bit hyped over "the mystical doctrine of universal computation", when increasingly research notes that instantiation DOES matter, especially if "there is no outside". / $\mathbb{E}$
\end{abstract}

The End

[tripta@sarai.net]

Halfbakery.com is a forum which allows users to initiate discussions around ideas and scripts for open source movies (until they are filmed).

APP.ended

On 11/2002 reader-list@sarai.net wrote... 


\section{"No Other Hand will Scratch My Back" Interview with Arash Zeini}

RAVIKAN T

Arash Zeini is a programmer and GNU/Linux enthusiast based in Tehran. Arash was an active participant at the Tactical Media Lab at Sarai, September 2003.1

>Ravikant: First of all, accept our congratulations on your excellent work on the FarsiKDE Desktop. Could you describe the basic features of the Persian version? How is it different from the English version, for example? What are the utilities you have translated?

$\gg$ Arash Zaini: Well, I have to thank you for your interest in our work and all the positive feedback that we have been receiving so far from Sarai. Thank you very much. FarsiKDE is basically a localised version of the K Desktop Environment that GNU/ Linux users know from various distributions. That means all user interaction with the computer will happen in Farsi. The GUI is in Farsi and all the messages - such as error messages - directed to the user are in Farsi as well. It is important to note that this applies to KDE. All non-KDE applications that are started within KDE need to be localised separately.

There is not much difference between the Farsi and English KDE versions, except that everything works right-to-left (RTL). All menu entries and widgets are located on the opposite site when compared to the English version. It is our plan to translate as many applications as possible. But this is not an easy task and we need a lot of time to complete the whole. As of now we have translated the base packages, which will give you a usable desktop. The next modules that are likely to be translated are KMail and KOffice in order to complete the list of basic applications. One thing sorely needed is a calendar. This, however, needs support at the KDE level. It is necessary to change the system's calendar based on local information, when the user changes the language or country. This is well on its way in KDE. We have written the J alali calendar and it will be incorporated into later KDE versions.

These settings are not necessary for all countries. But for Farsi and Iran it was necessary. We not only need BiDi support but our own calendar as well.

>Ravikant: Do give some details of how you went about the translation. It must have been a lot of teamwork. How many people participated in the actual exercise of translation? How many human hours were put in? How did you come together as a team and how did you divide the work? Did you run a list for the purpose? If so, how was the discussion organised?

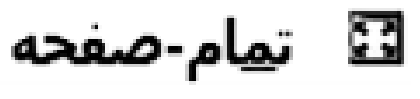


Did you go word/phrase by word/phrase, or did you lump some of these for discussion? What did you do for consistency?

$\gg$ Arash Zaini: I would like to use the chance to make a point: it was not only me who translated KDE, it was and is a team effort. Even if I had been able to do it myself, I would not have wanted to. I think it is important to live/continue the spirit and traditions of Free/ Libre and Open Source technologies. This is important for me. And here we are not talking of technology only. The alternative way of doing things is what is important, and teamwork is a major factor here.

(Some people say that Iranians don't know anything about teamwork and hence cannot succeed in team sports. Even if this was true, we would like to do it differently and show ourselves, and others, that this model works and that good software can be produced based on this alternative development model.)

Now to your question of How We Did It :-)

Around March 2001 I was informed that QT would soon be ready to 'host' languages with RTL scripts. That's when I began to be active again. I had contacted KDE in 1999 for the same purpose. But QT was not ready then.

The first step was to make a site and mailing list. In the beginning the mailing list was hosted at Yahoo! and now it is hosted at the KDE project. The combination of site and mailing list seemed to work. People began to subscribe and sometimes even discuss :-) At the same time I began to surf the web to see if I could find people that could help. This was rather unsuccessful. Even today, the situation is the same as in the beginning. There are a lot of interested people and the mailing list has around 90 members. But there are no real discussions, and not many volunteer for the task of translation.

There are apparently different approaches to translating huge projects like KDE. Some divide the work based on different modules. In that case one or two people are responsible for a whole module like kdebase or kdegraphics. But we translated all the files of kdelibs and kdebase together. After one of us had finished a file others would be informed, and work would begin on a new file.

The team consisted of 6 people in total, and 4 on average. As we mostly worked from one room, an e-mail discussion was not necessary; but yes, sometimes we did discuss each word and phrase. The main problem was and is to find adequate phrases for English terms in Farsi. In the spoken language people usually use English terminology, so it is not easy to say what should be used for words such as 'download'. If you look up a dictionary you will find entries that sound strange because they are not in wide usage, and you know that people won't recognise the item in the running application. That means that our culture is still too English oriented and we have to see that people can recognise the translation. This is a big problem and we have not been able to find a general solution for it. 'Download' is just a simple example, it gets complicated when it comes to words such as proxy, cache and other more technical terminology. Sometimes we saw ourselves forced to use a Farsi word alongside the English one in parenthesis. We think that we may be able to eliminate the English word in later versions of FarsikDE.

There is no formula of what to do. You really have to discuss and decide, sometimes

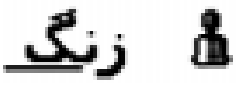


even non-democratically, because a lot of this is based on your own taste. For a while I used to make consistency checks before the initial commit. But due to time shortage I quit this and postponed the consistency check for the final revision. This turned out to be not such a good idea. The unification process is very difficult when you have to go through all the files. It is better to check each file as it becomes ready.

The final revision was done by one of the team members according to a list that he and I had compiled during the process of translation.

>Ravikant: What has been the response? How did people at different stages react to your work? Did some of them articulate purist anxieties? Alternatively, did some of them find particular equivalents either outlandish or bookish? To ask the question in a different way, what was the resource pool from which you picked up neologisms?

$>$ Arash Zaini: People have been reacting in different ways. In the beginning people did not really believe that we would do it and that we could do it. They especially did not believe that we would do it and then give it all away as Free/Libre desktop. But now that they see the result and see our modified KNOPPIX live CD, well, they don't have any choice but to believe us :-)

But the point about Free/ Libre technology is still not digested by many. I think even if they believe us, they just think that we are crazy. After I explain that the whole thing is just Free and open, they look at me sometimes as if I am a Martian :-) Well, they will learn to live with the idea!

But if we sum up, I think that most of them like the idea. However they have to see FarsiKDE in order to believe that we really did it and also to understand what has been done. They may know in general terms what a desktop is, but many Iranians don't know GNU/ Linux and KDE, and hence cannot imagine what it looks like and what it can do.

In order to present FarsiKDE to the public, we participated in an exhibition and the reactions were fabulous. We were really surprised. But I am still not sure if it was due to a sense for sensation or real interest.

With regard to neologisms, I have to say that we tried to stay as close as possible to dictionaries. We work with two dictionaries: an English-Persian and a special computational dictionary. The latter gives also a frequency count of each meaning, which was a great help in making decisions. The goal was to find the word that is most frequently used, but it had also to make sense to our own taste and understanding of the language. And it was important to use words that you can look up in a dictionary. Only in this way could we ensure that people would find meanings for less common and otherwise unknown Farsi words. We did not coin any new words. After all, one couldn't assume that our words would enter the dictionary some day.

>Ravikant: It seems the Farsi desktop for Windows wasn't there or was of poor quality when you started work on KDE. What is the situation now? Is there competition; if so, what kind and amount of effort is it going to take to convince people to change over to Linux and $\mathrm{KDE}$ ? What is the argument you offer to both old and new users? A related question - you 
are an entrepreneur. Have you been able to cash on the sale of localised KDE? I ask this because the work was of a collaborative and voluntary nature.

$>$ Arash Zaini: There has never been an official Micro \$oft desktop for Farsi or Iran. The only thing Micro \$oft offers is a keymap for typing Farsi, which differs from the standard Iranian keyboard, which we use for FarsiKDE. But there have been some Iranian versions of Windoze, which are based on the ones from Micro\$oft. What we have there are basically binary patches on top of Windoze. These desktops have never worked really that well. They are extremely unstable and not very usable in general. And we all know that their life is limited until Micro \$oft is officially represented in Iran. To make a long story short, there is no competition in that sense. But yes, people are used to using Windoze and it is not easy to convince them to change to any other OS. This goes along with some limitations found in Free/Libre open source applications and technologies. I am thinking mainly of some limitations in GIMP, missing variety of fonts for Farsi to be used in GNU/ Linux and all the stuff you can download from the Internet but only for Windoze platforms. How do I convince a hard-core Internet Casino player not to play Casino because the vendor doesn't support GNU/ Linux? Honestly I don't really try. We do this whole thing because we believe in it and think it is good to be Free and have alternatives. If people don't want to use it, then there is not much we/I can do. But we will continue to do what we think is right. The rest is up to people.

On the other hand, it is important for Free/ Libre open source technologies to come up with solutions that can convince the broader public rather than remaining a niche technology. I do not use anything non-Free on my Debian and run my 'Virtual RMS' every once and then to see that everything is OK, but I cannot expect this from everybody. People have other preferences and needs, and open source has to cover those.

As to the entrepreneurship: I do not like the word so I don't use it myself. But yes, we run a company. The company however is not separate from the open projects that we run. We all believe in FLOSS and that is what we concentrate on. Some things we do are community projects, some others are commercial projects, but even these are based on FLOSS.

We are not going to sell FarsiKDE as such. We now have a KNOPPIX CD customised to run with FarsiKDE and related issues as default, and will distribute this for free in Iran.

We certainly hope to be able to make some money by selling services based on FarsiKDE related projects. But Chapar Shabdiz (our company) did not calculate any income based on FarsiKDE. We don't depend on it. Also, we have all agreed that in case we make direct money from FarsiKDE, the money will be contributed back to the team and the company.

Some developers seem to think that FLOSS and business are unrelated. Well, I don't share this point of view. For me, it is perfectly fine if you use FLOSS to earn money or you earn money by doing FLOSS. I think that the theoretical writings of ESR (Eric S. Raymond) with regard to open source business models have validity and we would like to work with them. Still, there is absolutely no reason for me to think that FLOSS and business won't go together. The combination may not succeed, but I don't see much of an ethical problem if one stays close to the ideals of FLOSS.

> Ravikant: It is sometimes said that localisation or internationalisation is a futile project. We 
are, after all, global citizens and English is the lingua franca of the world, as it is predominantly the language of computing and the Internet. Obviously this is not true, as we have seen successful attempts at localisation in the case of Chinese, Japanese and other languages. The KDE i $18 \mathrm{n}$ project itself lists so many of them. But we are interested in your thoughts on the above trajectory of reasoning.

$>$ Arash Zaini: The simplest answer is: we all grow up in certain (given) cultural environments and circumstances. Most of the time we learn to think and express ourselves in a specific language; some of us learn the same for more than one language, but they still relate to a specific cultural environment. The same applies when we use computers as a way of selfexpression and communication. When we use computers we normally do not abstract from our environment, do not forget the language we know best. So what is wrong with enabling people to use it the way they feel most comfortable? I regard computers as tools to help us master certain things better. But they can do this in many different languages, and it is not necessary to limit them only to English. Many of us don't feel comfortable expressing ourselves in a language we are not that familiar with.

Interestingly the countries with the highest literacy rates for English - I am thinking here about the richer European countries - are the ones that localised computers to their own needs earlier than others. This feels weird!!! Is there something wrong with us :-) !!!

I think localisation is extremely important. I understand that the degree of importance might vary from country to country, but it doesn't change anything of the overall situation. The important factor here is the degree of literacy and fluency in English. It may be a different situation in India, but in Iran English is, and remains, a foreign language that is not mastered by the majority of people. Even among those who can handle English well, you find a high percentage of people who can read English but are not ready to write anything in English. This seems to be one reason why so many don't participate in public mailing lists. I get this answer frequently when I try to encourage people to post a question to the mailing list instead of sending it to me. Therefore, being able to read and write in your own language seems to be important.

And then there is the older generation that never learned English but would like to use computers for certain things. Again from my own experience, when I suggest to my grandfather that he should use a computer to communicate with his children who live abroad, the first thing he says is that he doesn't know English. It is interesting that it is not the fear to use computers that scares this 80 -year-old man away, but the fear of being forced to use English. I am sure this and related approaches/fears do not apply only to my grandfather but to many people, in Iran and elsewhere.

Now, English being the lingua franca of the Internet or computer world is a statement that needs a bit of differentiation. It certainly applies to the aspect of communication. A lot of people with different language backgrounds use English on the Internet as a means to communicate with each other. I don't see any problems here. But this argument does not suggest that localisation is not required. We do not want to challenge the role of English as a tool for international communication, but I would still like to pass along a Farsi joke to a friend in Farsi! I think this is important. 
English as the lingua franca may apply to the user interface. Yes, in fact it does, or maybe it did. But there is so much more to language usage than reading and writing user interfaces, even in the computer world. I am sure that English doesn't end at words like 'Menu', 'File', 'Edit', and its prose is not limited to some error messages. I also feel that without localisation so many cultures will eventually go under, or lose colour and taste. Let us come together with all diversity, which will make life so much more beautiful and interesting, not to say exciting.

If there are any political aspects connected to the lingua franca debate, I don't know.

> Ravikant: As you know, Indian languages too are struggling to localise and lots of fragmentary community efforts are on. But because of the peculiar historical and socio-political situation in India, we rarely get to hear about such efforts being made for Urdu. We do, however, see workaround packages and plug-ins (mostly for Windows) if we visit some Pakistani sites. Since Farsi is the script for Urdu as well, your work is bound to enable Urdu users in the sub-continent and elsewhere. There are some issues, though. Urdu, it seems, requires some extra characters from the ones used by the Persian language. What changes do we need to make to make your desktop usable for Urdu writing people as well? How difficult or easy is the task? What kind of assistance would you need if you were ever inclined to undertake this project?

>Arash Zaini: Let's differentiate between Urdu as a user interface language and Urdu as a script which we would like to write in using the GNU/Linux operating system or KDE.

Assume it is interesting for Urdu speaking people to try reading Farsi. When I visited Sarai we tried this, and I think the members of the Compughar, LNJ P [Cybermohalla project] loved it. But I don't think that FarsiKDE can replace a true Urdu desktop. However using FarsiKDE and its database/dictionary may help to speed up the localisation process. One has to investigate this. It would be great to have a person with knowledge of Urdu and Farsi in Iran to explore the possibilities.

As to typing Urdu: Here we need to have a standard keymap for Urdu first. I have looked into the matter a bit and it seems that there are some efforts on. Once Pakistan has its own Urdu keyboard layout, we need to make such a keyboard for XFree86 and try it out. I assume not much would be needed to make it run. But I am not an expert in the Urdu language and can only guess here.

So the necessary steps are: Make a keyboard layout, testing, debugging if necessary, submitting the layout to XFree86. Thereafter we have to see that we organise some nice Unicode fonts for Urdu.

It is very difficult to imagine working on a project for a language you don't really know. But I can imagine working on it as a cooperation between India/Pakistan and Iran. In that case, we would try to give technical assistance wherever we can. Localisation is best handled by people who speak and understand the language. In general we would love to cooperate with Sarai, or any one else, in this matter. The first step would be to make a To Do list of questions that remain unclear and try to find answers for them. 
>Ravikant: I gathered from an interview on the net that India happens to be one of your part-time locations, apart from Iran and Germany. What kind of an association do you have with India?

> Arash Zaini: I was always interested in classical Indian music. I think it was in 1992 that I first visited India. It was a short trip and India did not make any 'special' impression on me at that time. So I thought. But something must have changed at that time already, which showed its effects a few years later. In 1995 I began to study Indology in Cologne, which was immediately followed by frequent trips to India. The climax was that I got the chance to work and live for two years in Thiruvananthapuram with my wife. It was not an easy time, but one of the best experiences we ever had and are likely to have in our lives. We miss the monsoon rains and friends that we made in Kerala.

I think that, all in all, India is not just a part-time location for me; but why I like India or what it is that I like about India, I don't know, I cannot explain or maybe don't want to explain :-)

>Ravikant: Arash, you are a programmer with exceptional linguistic skills, which is a rare category. What interests me is why and how did you choose the world of computers? Does it have anything to do with your love for language, because it is obvious you did not like computers the way they existed.

$>$ Arash Zaini: Thanks for the flowers :-) I think I chose computers because I was not good enough at languages!

>Ravikant: This last question is a quote from http:// www.indlinux.org/hindi/kde/ - so far a non-existent project. Please have a look at the page and since I am a non-expert please give me your opinion on this quote:

"KDE is not yet ready for Indic scripts, as QT toolkit on which KDE is based doesn't support CTL (Complex Text Layout) for Indic scripts yet, though the basic unicode support for Indic ranges is there as of QT 3.0.3, and so from KDE 3.0 onwards to use this support, one needs to explicitly set the font of widget to a unicode font having the Indic glyphs according to Unicode. Recently one Indian language vendor Cyberscape Multimedia (Akruti) released a set of Truetype fonts for all languages. These fonts have been released under GNU GPL avialable at Akruti Indian Language Fonts.

Current plan for QT Indic support is to use the opentype fonts as base and make a Unicode font having glyphs for basic unicode range for all Indic scripts. Other glpyhs will be mapped into Private user area of Unicode. This font could be used for QT Indic rendering for time being (till QT has opentype support)."

$\gg$ Arash Zaini: I get to read a lot about the problems of other languages on the KDE lists and know a bit about the problems of Indic scripts. But I also know Lars Knoll from Trolltech and know that he always delivers what he promises. He is also the main person behind the BiDi support in QT. His last e-mail, on which I think this quote is partly based, sounded very

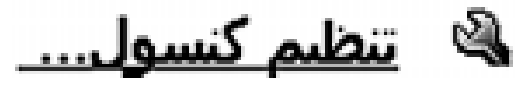


promising and support for Indic scripts cannot be too far away. If Indians keep on pushing and asking and testing, it will help in speeding things up.

It is at the end always us that should be aware and concerned about ourselves. Others can just help us, but not replace our own efforts. In Iran we have a saying: "No other hand will scratch my back".

I wish you all the best for your localisation projects.

This interview of Arash by Ravikant was conducted over e-mail.

\section{NOTES}

1. Arash Zeini is a programmer and free software enthusiast based in Tehran. He studied Indology and is the founder and managaing director of Chapar Shabdiz (http:// www.chaparshabdiz.com), a Tehran based company that offers Linux development and consulting services in areas such as application development, network infrastructure, Internet or web based solutions. Arash has worked on the creation of a Farsi version of the KDE desktop (http:// www.farsikde.org). Arash believes that KDE helps lower borders, and facilitates friendships and collaboration. He is an active member of Linuxlran.org (http://www.linuxiran.org). Arash Zeini can be contacted at: a.zeini@farsikde.org

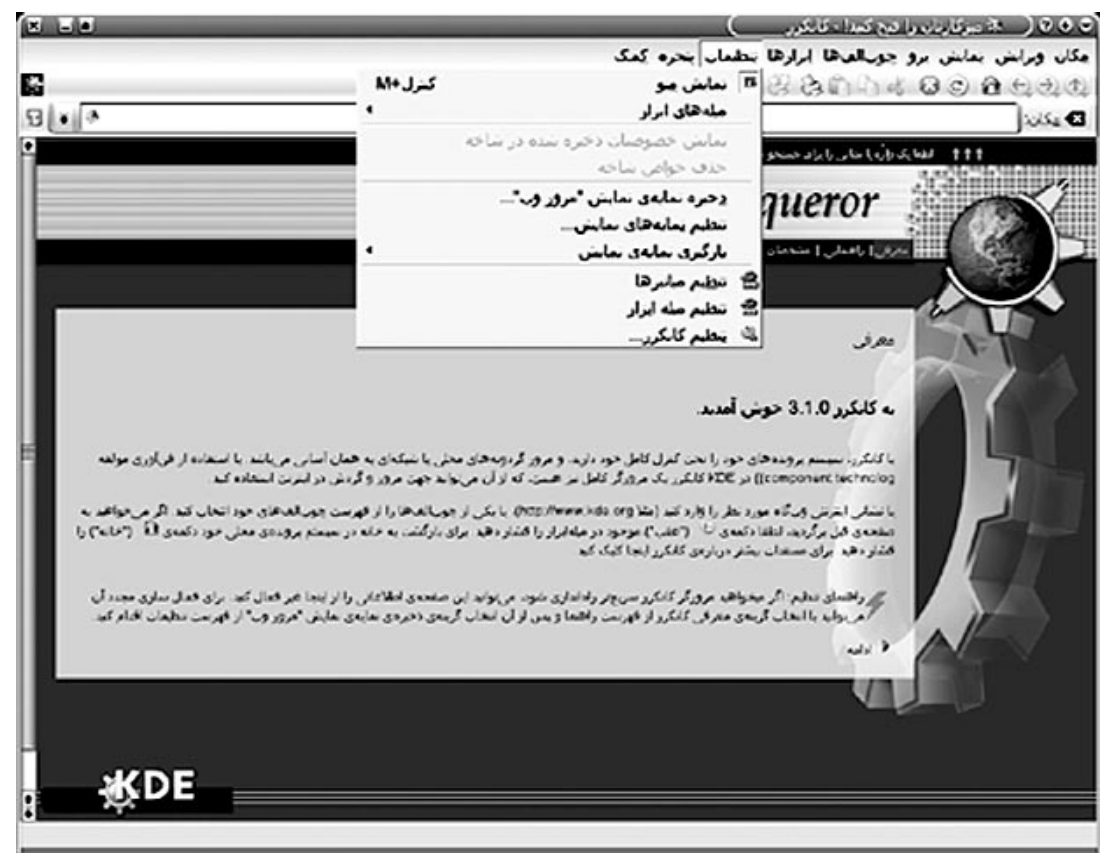


Indic, Especially Hindi, Computing An Index of Choices

$\mathrm{P}$ rogrammers and software from India may have been a glorified and lucrative export to the West but people here are still groping for a common language of communication. Obviously, I am not talking about the well known linguistic-scriptic diversity of the nation. What is at issue is communication - in the very basic sense of the term - because even though there have existed solutions galore, developed over a decade-and-a-half by diverse agencies and individuals, what is missing is their inter-operability. It is like living in a post-barter day and age with no bank to convert my currency into yours. To speak in computing terms, there is a plethora of software, mostly proprietary but also free: text editors, e-mail clients, chat software, transliterators, machine translators, OCRs, localised desktops and of course umpteen sites, but there is no commonality between them in terms of standards and the input/ output methods being deployed. Indic developers have taken their own sweet time to differentiate between a computer and a typewriter, which allows for writing in a single, predetermined way. The result is that most packages still do not enable switching across various keyboards. So, I may have to go shopping a whole month if I want my right configuration of fonts, operating system, browser and e-mail client and pray to God that most of my friends have the same stuff on their machine. Similarly, if I wish to read, for example, more than one Hindi newspaper online - mind you, they are all there - I will have to download fonts at every fresh site. Even if I am able to install them easily on my Windows machine, I will have to sweat it out if I am a Linux-lover.

This overkill of diversity kills the very purpose of something like the Internet, which theoretically at least, enables you to connect with multitudes at one keystroke. The diversity on the other hand is also a reminder of multiple levels of technological evolution, distribution and access; and an index of the whole history-in-the-making of Indic computing, where the future is as crucial as the present and the past.

Presently, if you wish to work with Indic scripts, the interface of your system will look something like the electrician in Hollywood films, with tools of different shapes, sizes and makes dangling from his waist. That is why people are waiting for a user-friendly standard to emerge. Hopefully, Bill Gates will fulfil his promise of releasing complete Operating System level support this October, and hopefully the lucky ones will immediately upgrade, probably by acquiring illegal copies. This may make their lives simpler but their connectivity will depend on others' acquisitions. Further, this may not be an ethically or professionally viable choice for everybody, especially for those who wish to contribute creatively in the ongoing voluntary efforts in Indic computing. So here is a select history and future of choices.

\section{Notes and Links:}

$<<$ Moment of Departure: When ttf Fonts Ruled $>>$

Most pioneering Hindi web sites, put up by Hindi-lovers abroad, either hosted material in the Roman script, 
ASCll-based transliterations, adopted Shusha fonts, devised their own fonts, or put up stuff as .pdf or .jpg images. The phonetic nature of Shusha came in handy for expatriate programmers working primarily with the qwerty keyboard. For samples see: www.manaskriti.com/kaavyaalaya.com; www.abhivyakti-hindi.org; www.anubhuti-hindi.org; www.hindinest.com - all of which run on Shusha.

For popular transliterators ITRANS and JTRANS go to: http://www.aczone.com/itrans/ and http://www. sibal.com/sandeep/jtrans/

The Devnag package of LaTex, for both Linux and Windows, has been usefully tested for publishing, printing and web hosting. For downloads visit: http:// www.tex.ac.uk/ tex-archive/languages/devanagari/

For a fairly comprehensive listing of Devanagari fonts and links to their sources see: http://www. cs.colostate. edu/ malaiya/ devafonts. htm

If you are looking for Mac phonetic fonts go to: http:// www.flash.net/ patelvk/ Hindi.html

Some other good links for fonts are: http://theory.theory.tifr.res.in/bombay/history/people/language/ hindi.html and http://rkk@acharya.iitm.ac.in/ind_fonts.html

Recently, www.akruti.com released a set of Indian language fonts under GPL, also accessible at http://fsf.org.in/ software/ software.html

\section{$<<$ Word Processors, E-mail, Web and Chat Tools $>>$}

Baraha 5.0 (www.baraha.com) for Windows is a fair use ware, for phonetic word processing in Kannada, Marathi and Hindi. The problem is you cannot selectively write or edit directly, you have to go through a transliterator. I-leap is another multilingual, versatile tool which, like Baraha, allows for Unicode conversion. http://tdil.mit.gov.in/humis/download/menu.htm offers a host of free downloads including fonts, keyboards and, if you like officious Hindi, a technical glossary as well. An advanced commercial version of this multilingual package is Indiapage from www. mithi.com

\section{$<<$ Unicode: Arrival of a Viable Standard? $>>$}

In the context of the unacceptability of the ISCII standard, the emergence of Unicode is a viable long-term option and both corporate companies and free software communities are working hard to develop solutions based on Unicode. It has the potential of making computing platform-independent and therefore exchange and circulation of information easy. For basic information and debates see: www.unicode.org; http:// www.alanwood.net/ unicode/devanagari.html and itm.ac.in/multi_sys/uni_iscii.html

Unicode support comes bundled with Windows/XP 2000. For phonetic typing one can use the free Takhti from http:// www.geocities.com/hanu_man_ji/ or the DevromU (developed by Bob Eaton) keymap along with keyman 6.0; or the wide ranging Aksharmala solutions (www.aksharmala.com). On the other hand Yudit (http:// www.yudit.org/) is an excellent multilingual, multi-keyboard text editor that works better for Linux machines. Unicode has facilitated the development of standardised desktops across Indian languages. One can see the status of translations and downloadable packages at: http:// indic-computing.sourceforge.net and http:// www.indlinux.org/ 


\section{Jal Chitra: Water Map Software for Rural Water Management}

VIKRAM VYAS

"The village will have its own waterworks, ensuring clean water supply. This can be done through controlled wells or tanks."

M.K. Gandhi, Harijan 26 J uly 1942

$\mathrm{T}$

he problem of meeting the water needs of a rural community is a complex problem. There is no doubt that in solving this problem IT can potentially play a useful role, but how to harness this potentiality is a question that has not received the attention it deserves. For example, a reasonable first step in a strategy for drought-proofing a village is to have an estimate of the amount of water that is reliably available to the village in a given month and to compare it with the water requirement of the village in that month. Quantifying the water deficiency in a given month and then estimating the cost of developing water sources to bridge this gap, perhaps through building rainwater-harvesting systems, or through recharging existing wells, and sharing this information with the larger village community could start the process of drought-proofing a village. Similarly, as is well known, often the question is not simply of the availability of water but of access to it. A very clear picture of the water situation in a village emerges if all the functioning water sources are shown on a community map of the village. These are just examples, there are many other detailed questions whose answer can be of much value to the community as it plans its water resources, but these are the questions that only the community itself can articulate and IT based tools should respond to them.

The first attempt at such a tool was the development of a mathematical model for determining the reliability of rainwater harvesting systems with covered tanks against recurrent droughts. In 1997 this model was converted into an easy to use free software, SimTanka. The original plan was to continue to develop various similar models, like a model for rainwater harvesting systems with open water reservoirs - Sim-Talab; a model for estimating the yield from wells and tube wells - Sim-Well; and then to integrate them in a unified model of various water sources available to a rural community. 
A serious risk in the use of IT for rural development is that it can become a case of solutions seeking problems. The development of Sim-Tanka suffered to an extent from this pitfall. Sim-Tanka was developed with the intention of helping a rural community design a reliable rainwater harvesting system using past rainfall data. In a technical sense the software is very useful, but a community does not approach its water resources in a piecemeal manner; it does not think in terms of optimised rainwater harvesting systems working in isolation. Thus while Sim-Tanka was received positively by many IT practitioners, and received a fair amount of positive publicity, its actual use in building rainwater harvesting systems has been insignificant.

The development of Jal-Chitra started with the recognition of this failure. More specifically it was the reluctance of the Barefoot College, Tilonia, to use Sim-Tanka in their programme of constructing rainwater harvesting systems that initiated the process of trying to understand what kind of information and analysis is truly useful to a rural community. The long development period of Jal-Chitra, which has now extended over more than three years, has been a continuous debate, discussion and dialogue to answer this question.

The result of this debate was recognition that there are three sets of information that can assist a Panchyat in managing its water sources:

An estimate of the monthly water budget of the village;

A way of keeping track of the maintenance work required for the various water sources; A community based water resource map of the village with information about access to water.

Further, to ensure transparency and accountability all this information has to be available to the entire village in Hindi.

The defining feature of J al-Chitra is its ability to allow a user to draw a community based water resource map of the village; further, by clicking on any of these sources the user can enter information about the amount of water available from that source, the details of any maintenance activity in that month and, if available, it also keeps record of the water quality test. The information so entered is then used to generate monthly water budgets, and various maintenance and water quality reports. These reports are in Hindi and can be printed and shared with the village at large.

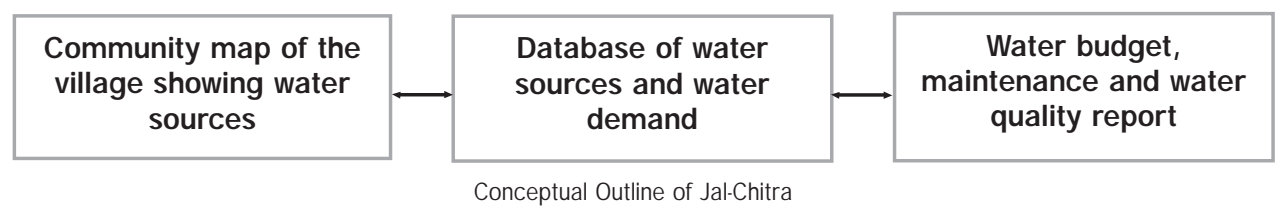

\section{J al-Chitra at a Glance}

1. Uses Hindi as the language for interacting with the user.

2. Allows users to draw interactive community based water resource maps of the village.

3. Allows the community to keep a monthly record of the amount of water available from each of the water sources.

4. Has a facility for keeping records of water quality testing. 
5. Has a facility for keeping records of maintenance work required and the maintenance work that has been done.

6. Estimates the water demand for domestic, livestock, and agriculture uses.

7. The farm records also suggest the optimal water irrigation required depending on the crop planted and the amount of rainfall.

8. Generates future monthly water budgets based on past records; as more monthly records are kept the corresponding estimates become more reliable.

9. Informs the community as to how much of its annual water need is being met from underground water and the approximate amount of recharging that is taking place.

10. Finds out the reliability of covered rainwater harvesting systems.

11. Estimates the amount of rainwater harvesting done by a village and compares it with the total potentiality of rainwater harvesting in the given village.

\section{Who Will Use J al-Chitra?}

Since the aim of Jal-Chitra is to provide a tool for the village community, it naturally raises the question how will the various rural communities access J al-Chitra? The tentative answer that has emerged from the testing of Jal-Chitra at Barefoot College, Tilonia, and with the Mazdoor Kisan Shakti Sangathan (MKSS), Devdungari, is that two kinds of institutions have to be involved. Firstly, voluntary organisations that are working directly with the village Panchayats and have access to a computer. Their role is that of an intermediary and one that will change once Panchayats themselves have access to computers.

Secondly, and perhaps most importantly, the village school has to be involved in the use of Jal-Chitra. The minimum information that Jal-Chitra needs to be useful is the monthly record of the amount of water available from various sources. This requires recording the discharge rate of handpumps, the area of water cover in the rainwater reservoir, the average depth of water in the reservoirs. For more advanced use, it also requires maintaining meteorological records like that of rainfall. The village children can do these activities, together with the exercise of making the village map. Apart from facilitating the use of J al-Chitra, this has the potential of making the education of a child living in village more engaging and rooted to her or his environment.

\section{Testing J al-Chitra}

Since January 2002 Jal-Chitra is being used in more than a dozen villages of Rajasthan. Its use in these villages roughly follows the following steps:

1. First a rough community map of the village is drawn on a paper.

2. A survey of all water sources is conducted.

3. A survey of the village is conducted to determine the approximate human and livestock population.

4. Water sources are then marked on the paper map.

5. The village community map showing all the water sources is then drawn on the computer using J al-Chitra.

6. Information about each of the water sources is then connected with the map of the village in Jal-Chitra. 
7. Every month all the water sources are surveyed to determine if they are functioning or not, the kind of repairs required and the approximate amount of water being withdrawn from each of the sources.

Using this information J al-Chitra generates the following monthly reports:

$>$ A monthly water budget of the village.

$>$ A maintenance report, indicating water sources that require some form of maintenance. $>$ A maintenance log of every water source in the village, showing all the repair works done on that source.

It is planned that these reports will be shared with the village community during the Gram-Sabha. To make full utilisation of all the tools incorporated in Jal-Chitra requires a basic hydro-geological survey of the village and an incorporation of the monthly meteorological records. Unfortunately, in the village where J al-Chitra is currently being tested, this information is missing. Incorporation of these records and an independent validation of the monthly water budget generated by Jal-Chitra are some of the pressing tasks.

For the testing of J al-Chitra in Silora Panchayat, the collection of the monthly information is the responsibility of a worker of Barefoot College, Tilonia, who has graduated from its night school. Ms. Lalita, who had formal education till lower high school and does not know any English, records the collected information in J al-Chitra. Some of the reports generated during the course of this testing are included below as computer screen shots. The testing of Jal-Chitra in Todgadh is of particular importance as it is being done in a manner

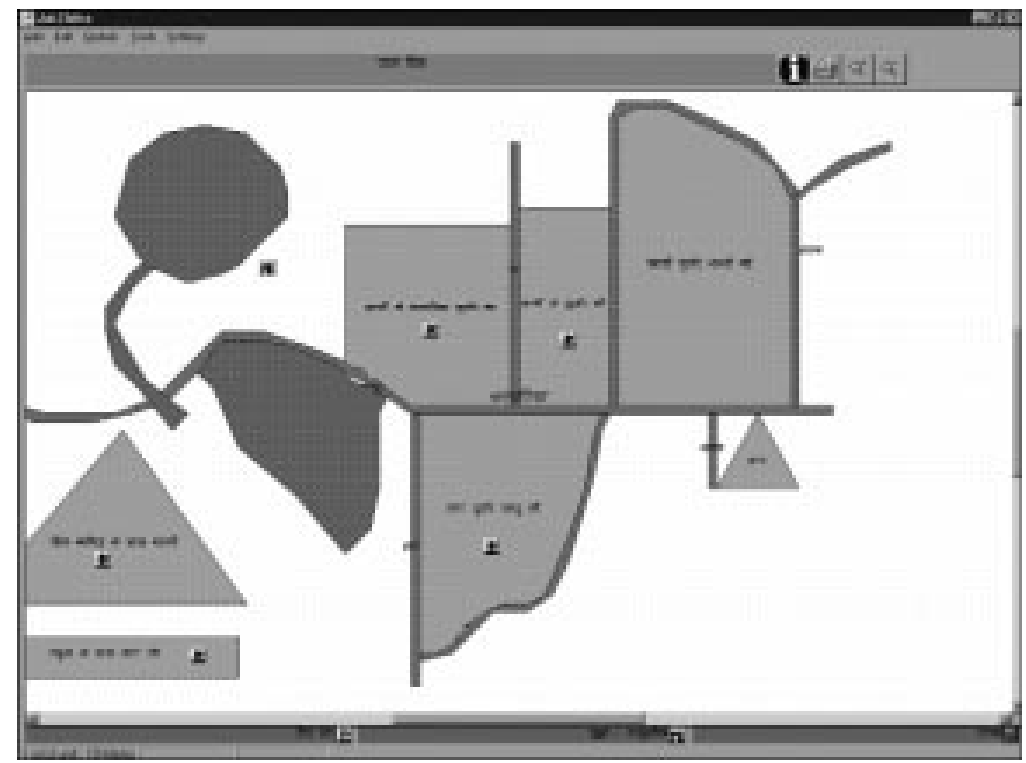

Figure 4 Schematic Community Water Resource Map of Kacharia Drawn by Ms. Lalita of the Barefoot College, Tilonia. 
close to its envisioned mode of usage. The high school students collect the monthly data of the amount of water available from various water sources and Vivek Ramkumar, a member of MKSS, then enters the information into J al-Chitra on his laptop computer. Further, another member of MKSS, Tejaram, is the head of the Todgadh Panchayat and can therefore potentially use the analys is coming from J al-Chitra in the Panchayat's development plan.

\section{Future of J al-Chitra}

Even the limited use of J al-Chitra has validated the basic premise behind its development. For example, the records of handpump maintenance and their maintenance log are vividly bringing out the water situation in various villages. Once these reports are shared with the whole of the village through Gram-Sabha then, hopefully, one will be able to see the use of Jal-Chitra as an advocacy tool.

There are still many questions whose answers will emerge only after a more extended use of J al-Chitra. One particularly important issue that has to be understood is how should Panchayats use the monthly water budget generated by J al-Chitra in its planning and water management exercise.

The development and the use of J al-Chitra has suggested two related projects. Firstly, there is a need to document the experience of developing, testing and using Jal-Chitra so that the lessons learned from this work can be analysed and shared with the wider community. Secondly, based on the testing of J al-Chitra and through a continuous dialogue with the members of various Panchayats where Jal-Chitra is being used, the development of a new version has to begin. It is hoped that the future development of J al-Chitra will take place within the paradigm of open and free software so that users, software developers and planners from all over the world can collaborate in its continuous development.

J al-Chitra is a result of collaboration between the Ajit Foundation, Jaipur, and Barefoot College, Tilonia. I am grateful to my colleagues at both these organisations. At the Barefoot College I am particularly grateful to Ms. Lalita for her insistence on the Hindi version of J al-Chitra and for her diligent testing of it. I am also grateful to Vivek Ramkumar of the MKSS and to the students of Todgadh High School who have been involved in the testing of J al-Chitra in Todgadh.

My views on the use of information technology for rural development have been greatly influenced by my conversations with Bunker Roy, Dr. Kamla Chowdhary, Laxman Singh, Prof. Narendra Singhi, Nikhil Dey and Prof. Vijay Vyas. I would like to thank them all for sharing their insights with me.

J al-Chitra is free software meant for Panchayats and voluntary organisations working with them. To obtain a copy of J al-Chitra please contact: The Ajit Foundation, 396 Vasundhara Colony, Jaipur - 302018 , India. 


\section{The (copylefted) Source Code for the Ethical Production of Information Freedom}

BIELLA COLEMAN

$F$ ree software hackers, and hackers in general, have an almost maniacal penchant and love, I mean true LOVE, for 'information freedom'. It is at once an ethical stance, an aesthetic sensibility, and increasingly an overt political issue. In this essay, I will address the emergence, constitution, and solidification of the hacker's ethical stance towards information freedom and sharing. In particular, how this is expressed by the free software developers of the Debian project: a non-commercial distribution of the Linux OS with over 800 developers worldwide. I will also address the macro and micro social spheres in which ethics are socially produced and expressed by free software hackers. The macro context is the larger socio-political milieu in which the practice of hacking generally unfolds, while the micro context relates to actual participation in the sphere of free software, especially those of development projects. Given the messiness that is social life, these two spheres are clearly not entirely distinct, but will nevertheless be analytically separated to clarify how ethics become a solid and social value, from what are initially more fuzzy, ambiguous and individual stances.

By looking at these two structural shapers of ethics, I will additionally argue that although hacking is often perceived as apolitical, hacking always tends to evoke political elements due to the nature of knowledge in our society. The quest for knowledge, which is an unmistakable core component of hacking, is a politics of transgression because the 'knowledge' that is sought is often inaccessible (or potentially so) at either a technological or legal level. It is this political condition that helps to explain the initial entry into the 'ethical realm' for hackers. But it is through more sustained participation in the world of free software, especially projects, that a deeper ethical practice is cultivated. Free software projects are spaces in which hackers can flesh out the skeleton of their ethics, especially through its 'exercise' or application.

Hacker politics don't look, smell or feel like your traditional forms of party politics, coalitions and protests. In fact, there is a seemingly paradoxical situation in which, on the one hand, many hackers state something to the effect of "I stay away from politics", or are accused by activists of being totally apolitical, while on the other hand the question of politics seems to loom at every corner of the practice and philosophy of hacking. There are, of course, a number of historical and current examples of explicitly political movements or organisations, like that of the EFF (Electronic Frontier Foundation) and FSF (Free Software Foundation). However, it does seem like the large majority of different types of hackers, whether it is your phone phreaker, cyberpunk, gamer, or open source developer, are NOT 
political. How then does one understand the political traces scattered all over the hacker cultural sphere? What does one make of dramatic hacker manifestos, DeCSS poetry, underground BBS and zines, and technical discussions about copyright and patent law that would leave any $3 \mathrm{~L}$ Berkeley Law Student breathless (or possibly ashamed, because hackers know just as much about computer law as law students without stepping in a classroom)?

Clearly, while it is difficult to put a finger on hacker politics, there is indeed something very political going on within and through hacking. I believe this has to do with the formal (as opposed to substantive) nature of hacker politics. The political is not something that hackers do - as an activist might when organising a protest or coalition - instead it is done by and through the very act of hacking. The politics, often of transgression, is embedded within the fibers of the practice of hacking. The political dimension remains obscure since it comes from the rationalised practice of programming and technological manipulation.

Before I explain what I mean more fully, I need to answer the basic, yet incredibly complex, question of what hacking is. Hacking is not easy to define; there are a range of ways one could explain the phenomena of hacking across time and space. However, I am going to be bold and present what I think is one of the fundamental traits of hacking. Here I will actually defer to a hacker and academic, Patrice Reimens, who offers one of the clearest definitions of hacking. Fittingly enough, in a piece that examines the difference between hacking and political activism. he writes: "To put it simply... the hacker ethic runs strikingly parallel to the formula - art pour l'art (art for art's sake). What matters here, is the realisation that unlike activists, hackers are focussed on the pursuit of knowledge and the exercise of curiosity for its own sake. Therefore, the obligations that derive from the hacker ethic are perceived by genuine hackers as sovereign and not instrumental, and always prevail above other aims or interests, whatever these may be, and if there are any at all..."

This sentiment has been expressed by countless others, including Levy's now cult classic Hackers (1984), and was revisited recently by Castells in the Internet Galaxy (2001). My experiences with free software hackers support this fundamental tenet. The spirit of exploration that forms the basis of hacking might start by taking apart a household blender, much to a mother's horror; then lead to learning how to programme at the age of 5 , much to the delight of the parental unit; then transform into locking oneself in the bedroom to read every computer manual, which parents duly confuse with pre-teen angst; then to learning every in and out of that simple operating system known as UNIX, discovering every last topographical and temporal feature of the Net much to the amazement of the anthropologist; and finally to volunteering their time to code on free software projects, often to the dismay, again, of their parents. Bruce Sterling expresses this deep proclivity for learning quite accurately when he writes that hackers are "possessed not merely by curiosity but by a positive lust to know". Though hacking as a practice and even a philosophy is much more complex than this, the pursuit of knowledge and learning through the material substratum of computers and the network is a basic undeniable element of computer hacking.

Most commentators parse out the political from this very core substance of hacking. For example, Castells notes that as opposed to your general hacking "there are, however, hacker subcultures built on political principles, as well as personal revolt", going on to note the überexample of Richard Stallman and the Free Software Foundation. Riemens who 
notes that political activists "do have objectives and aims that precede their action. Hackers on the other hand, are usually happy with the 'mere' but unrestricted pursuit of knowledge which reduces their political programme, if that can so be called, to the freedom of learning and enquiry".

But beyond this, I would like to suggest, that in order to better understand the social nature of hacking and the hacker proclivity toward ethical codes, we must see hacking as something fundamentally political. It is political because of the where and the how of hacking itself. This is the macro-context that I referred to in my introduction. Hackers' insatiable quest for knowledge has historically existed, and currently exists, in a larger socio-political and economic context where 'knowledge' - or at least the knowledge they want - is legally, technologically, or institutionally inaccessible for learning and especially for using. Art for art's sake does not occur in a vacuum, but in a context that gives the pursuit varying shades of a political, transgressive hue. This is a hue that lends itself towards adopting or thinking about ethical questions in the first place.

While transgression may not apply to taking apart the blender (yet) many activities of a hacker have been, are and have the potential to be illegal. One can even think about a good portion of the history of UNIX as a political battle over access to its source code. Inaccessible knowledge may come in the form of a patented algorithm, cryptography, the telephone system, or an API. Corporate policy, patents, trade secrets, copyrights, technological copy control measures, and currently more draconian legal schemes like the DMCA, are the main legal and institutional vehicles that over decades have created the categories of forbidden knowledge and illegal access, and thus have created the socio-political conditions that lay the ground for a politics of transgression. Even without explicitly political intentions, hacking still keeps alive the question of how the boundaries between public and private knowledge should be defined.

I would like to ask how it is that hackers on the ground experience this condition that I am marking as the necessary groundwork for the cultivation of ethics? And how does one express political subjectivity anyway? Hackers may not operate within a sphere where the threat of the political hammer is knocking on their heads, but there is a ghostly knock that can be heard in the halls of hacking. A ghost has taken more material form through the very visible hacker crackdowns of the early 1990s: the arrest and persecution of Kevin Mitnick, the visible arrest of Dmitry Skylarov at Defcon 9, the legal threat to J 0 Johansson over DeCss, the looming legal threat of the DMCA, the constant barrage of negative press and the media portrayal of hackers as criminal underground bandits and pirates.

Although the child programmers, barely out of the crib and hacking away with BASIC, may not be aware of the political nature of what they do (thankfully), it is not too long before many programmers become at some level aware that what they do is in some dimension illegal. There is a basic but ambiguous cognisance of what I have referred to as a politics of transgression. In fact, now younger hackers are becoming even more aware that hacking can have very legal and political repercussions. This is due to exposure early on to what I will call the hacker public sphere: a sphere composed of the online and off-line sites and domains in which hackers congregate to talk about all things technical, and increasingly, all things political (such as Slashdot, irc channels, local 2600 and LUG meetings, mailing 
lists). Many of my life experiences give testament to the minute, but powerful ways in which programmers came to realise that what they do is illegal, or at least potentially so. One of the funniest stories, which I have heard a number of times from Linux 'old timers', is of being accused of pirating software by computer lab staff while downloading (Free) Linux, when in fact they were JUST downloading the early versions of Linux which filled about forty floppies.

Given the inclination for knowledge and curiosity, the very act of circumventing access controls - whether human, legal or technological - has become an end in and of its elf. Along with a politics of transgression, a poetics of transgression has come to occupy a special place in certain hacker spheres, which admittedly tends not to be in the free software sphere. Forbidden fruit is sweet. Some of the most 'fun forms of hacking' are those in which you try to access forbidden knowledge, the harder to get, the more 'ripe for hacking'.

Thus, while hacking may not necessarily look like activist politics at a formal level, it is often fundamentally political. Indeed, the very act of hacking makes visible the constraints of knowledge in our society. It is in this amorphous, but still very real, contextualised space where the first seeds of ethical sentiments to information freedom are born.

Now I would like to switch to the micro-context of the free software project and look at how participation on a project like Debian contributes to the solidification of the ethical principles first developed out of the experience of transgression. It is interesting to note that within the space of free software development transgression does not occur because the copyleft, the main legal licence for free software projects, has materially and symbolically reterritorialised certain forms of knowledge. Copyleft has made source code permanently and legally accessible. Instead of engaging in the more subtle forms of transgressive politics that arise on the restrictive space of copyright and patents, Richard Stallman came up with a legal licence and political organisation that could confront the issue of knowledge head on.

Developers tend to come to the Debian project with some sort of ethical stance about information freedom, although it is usually not all that well thought out. Initially, some already hold the idea that 'information wants to be free' for moral and universalist reasons, while most Debian developers feel that 'information should be free' for practical reasons such as building better software. However, through continued participation in Debian many developers come to subscribe to a certain degree to both a moralistic and functional understanding of this hacker ethic of information freedom and sharing. As one developer noted, "We are hard-core about being free. Red Hat will bundle non-free. What Debian throws into the mix is that we are free and we are serious about being free. Certainly, you don't have to have such a devotion to it, but the fact is that there is a group of people that are so dedicated to freedom and openness".

Why the devotion? One might think that this sort of 'hard-core' position is simply an ethical belief that developers have and bring to projects. But it is more accurate to say that participation in projects is the site where the skeleton of ethics is given its flesh. Many developers talk about the fact that, although they were always committed to freedom, their knowledge about the legal issues surrounding software and content was bare until participating on Debian. The act of entry into the project itself nicely illustrates the ethical sociali- 
sation that developers first experience when entering the realm of the free software project. As part of the process to become a 'Debian Maintainer' the prospective developer has to pass a short test about the Debian Free Software Guidelines and their Social Contract. Although this is a very informal process, it marks a rite of passage into a project where ethics are made manifest through initiation exercises. Ethics are also realised in the detailed and complex discussions that occur on mailing lists, IRC and conferences about software licences, the practicalities of what licence to apply to your code, and even reflective discussion on the political nature of Debian itself. This was exemplified in a recent thread on the main Debian developer mailing list where there was a discussion on whether Debian is an example of political anarchy in action.

Over time a deep dedication to the organisation develops because of what developers learn and gain by participation. As much as Debian developers give their own time and know-how many feel they personally gain a tremendous amount from participation. They gain things like free technical tools to use at home or for work, the satisfaction of building a quality product that fellow peers use and admire, collaborative skills, new forms of knowledge and a sense of belonging to a community. One long-time participant has expressed it in the following way:

"I've learned about the intricacies and history and every detail of the Debian distribution, how its disparate components fit together, how its packaging system works. I've learned all sorts of little oddities of technical lore, and I've picked up a few programming languages and a lot of general programming knowledge. I've learned how to collaborate with folks spread out over the world and across time zones. I've learned how to argue effectively online, and I've learned that even though I tend to shy away from arguments, there are things that are worth arguing for. I've learned how to think about the large effects a work can have on a project, and how to take responsibility for and plan out those effects beforehand."

The experience of learning (non-technical and technical skills) and sharing helps to explain the strong allegiance that developers develop towards Debian, and the stronger ethical stance for information freedom and sharing that develops over time. The hacker drive for knowledge becomes more overtly ethical and socialised through participation on a free software project. Many free software projects provide a social space for the practice of sharing in which the classic geek tendency for elitism and bravado also gives way to a desire to help others, when developers come to recognise how much they have gained from others - whether it is in the form of software, help, or more intense learning. On Debian, the fundamental hacker pursuit for knowledge becomes an endeavour that is recognised as a social process that requires human interfacing and coders tend to honour the ethic of sharing. So while hackers might still love doing art for art's sake, they additionally come to do art for the sake of others.

I have explained how the experience of programming for a large project helps to substantially flesh out and solidify nascent ethical commitments that are part of the motivation for joining a project in the first place. Although we can conceptually separate the moral drive from the more practical or self-motivated reasons that form the underlying basis to join a project, the two eventually work to bolster each other. The technical success of free soft- 
302 / Sarai Reader 2003: Shaping Technologies

ware projects, and the personal gains from them, reflects the influence of the hacker belief in openness and sharing of information.

In conclusion, I hope that I was able to at least offer a rudimentary blue print of the conditions in which the hacker ethic gets constituted. Instead of presenting the hacker ethic for information freedom as a static and ideologically misguided commitment, I wanted to offer a processual account of the distinct social spaces where these ethics emerge, and the site of praxis where these ethics are solidified. In the process of doing this, I hope to have set the stage for inquiry into the peculiar and particular politics that emerge out of the techocultural practice of hacking, as well as the broader relationship between ethics and politics. Moreover, there will still have to be an inquiry that asks how the politics of freedom of information in the hacker sphere relates to a larger tradition in American politics of placing value in information freedom to overcome the tyranny of bureaucracy, to develop selfunderstanding of the law, and to empower the 'public' against false rhetoric. However, this can only be undertaken with a concrete understanding of the form and content of hacker ethics. 


\section{The Ghost in the Machine The Legal Capture of Technology}

the most significant peer-to-peer innovations that would completely change the structure of the music industry and the rules with which the music industry organised production and distribution. Needless to say, the community of music lovers underestimated the music industry's resolve to combat any technological change that threatened its control. As a result, in J uly 2000 Napster found itself dragged to court, to defend itself against a barrage of lawsuits claiming that Napster was liable for copyright infringement. This led to the second innovation - a legal one - where the courts held that Napster was liable to contributory infringement as it enabled thousands of people to share and copy MP3s for no cost. ${ }^{1}$

For a large number of people the decision of the Court came as a shock as it seemed to go against the general assumption that MP3 technology had emerged as a restoration of balance in favour of consumers who had lost out to the large recording companies. The Napster case also brought into the daily lives of people, for the first time, the harsh reality of the copyright system, as it featured in almost every newspaper and magazine. While this decision came as a surprise to the large number of music lovers, it did not surprise those who have been following the varied encounters that copyright law has had with tech-

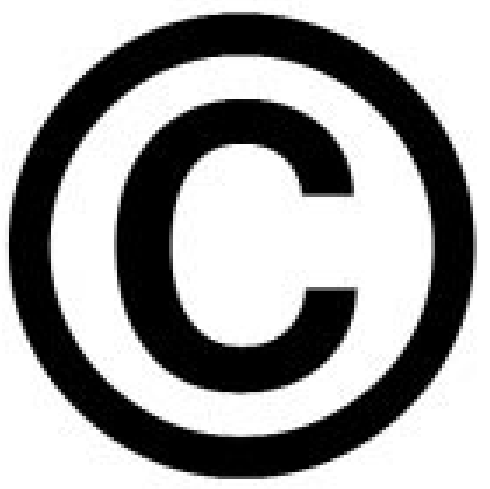


nology, from its inception in the $18^{\text {th }}$ century as a response to the print revolution to the current digital age.

The history of copyright law can, in a sense, be narrated by the changes it has gone through and the scope of protection that has been rearticulated particularly with respect to new markets enabled by new technologies. Every technological progress has altered the balance of control between copyright owners and users. Jane Ginsburg for instance says, "until the advent of the photocopier, copyright owners substantially controlled the production and dissemination of copies of works of authorship, as the public could not obtain one from a library or a friend. Before mass market audio and video recording equipment, copyright owners also controlled access to the works made publicly available through performances and transmissions; because the public could not see or hear the work without attending a licensed live performance, or viewing or listening to it through licensed media. With the arrival of these technologies, the de facto and often de jure balance substantially shifted to the users". 2

And yet with every technological change that enabled such a shift, copyright law has managed to emerge stronger by interpreting existing law in a manner so as to include technological change within its ambit. Two strategies that copyright law has classically adopted when it encounters a new technology:

Copyright owners seek to exploit the new technology to their advantage - an example of this is the manner in which copyright owners adapted to radio broadcasting where the courts expanded on the idea of 'public performance'.

Copyright owners seek to block the new technology - an example of this is the Betamax case where copyright owners claimed that Sony's invention of the video tape recorder enabled infringement by allowing viewers at home to record their favourite shows and watch them at a later date.

While courts have been reluctant to admit arguments of the second order, they have gone out of their way to innovate to ensure that the first objective is met. The issue to be examined, then, is the manner in which the law transforms technology to fit it within the existing relations of the means of production and dissemination of information in order to enable the exploitation of the new technology. Technology is therefore a legally mediated discourse that has to be interpreted or 'translated' by the law and deemed to be worthy of legal innovation that promotes the welfare of society at large. If it fails this legal test, it is an illegal and errant innovation that promotes the violation of existing laws.

Here I shall examine one of the ways in which copyright laws translate technology to make it fit within the existing relations of property and ownership. Beginning with the specific socioeconomic history of copyright's response to the printing press and the emergence of the figure of the author, I shall move to an analysis of the first instance when this romantic individual, the author, is challenged by the emergence of a soulless technology, photography, and the manner in which the courts infuse the new technology with the soul of an author. I shall finally claim that it is the setting up of the ideological figure of the romantic individual author that prohibits the law from understanding technological innovations in the present age - innovations that defy all of the normative premises upon which copyright law is based. 


\section{A Genealogical Account of the Author in Copyright ${ }^{3}$}

Before the invention of the printing press, the act of writing was a very localised activity and it was impossible to disseminate knowledge in any significant manner since the inaccuracies of copying prevented any widespread use of the written work. The invention of the printing press enabled a number of innovations. Duplication became easier and more accurate. Mass distribution became viable. The printing press revolutionised information storage, retrieval and usage. Printing, unlike writing, allowed a society to build on the past with a confidence that each step was being made on a firm foundation. Printing generated confidence that new information was an improvement over old. The revolution in the ability to accurately reproduce works fostered an understanding that progress can occur through a process of revision and improvement. The increased accuracy and rapidity of new editions made possible by the printing press made the most recent editions more valued than the older. Additionally, access was now available to the literate public. Printing provided a mechanism by which a larger reading public developed, thus constituting the emerging public sphere. ${ }^{4}$

This new reading public that emerged demanded books, original and reprints, and set in stage the crucial conflict over the ownership of such information. As Mark Rose observes, "a sufficient market for books to sustain a commercial system of cultural production" had to exist before the coming into being of a formal regime of intellectual property. What was earlier the monopoly of the Stationers Company, a guild recognised and regulated by the Crown, became a mass industrial activity with a number of publishers in the provinces (Scotland) publishing cheap reprints for the new reading public.

The reaction from the literary and artistic world was to move away from the 'ills of industrial revolution', and they began deploying the notion of the author as a unique and transcendent being, possessing originality of spirit. This romantic model was used as a means of rescuing the artists' works from the hostile market and the public for whom mass production made works available as never before, but at the risk of turning it into an industrial product. The romantic artist was therefore deemed to have property in an uncommodifiable imaginary self, so originality was elevated to being located in and belonging to the self of the author. And because the artist owns his original person or spirit, works created by such authors were also deemed to be original; and they could thus distinguish their personality from the expanding realm of mass produced goods.

There is then a dual move which is set in place where the concept of the 'modern proprietary author' is used as a weapon in the struggle between the London booksellers and the booksellers of the provinces, culminating in the landmark case of Donaldson v. Becket. The entire claim in Donaldson v. Becket is made in the name of protecting the rights of the author (it must be noted that no author was involved in the case) and the individuality of their ideas, even though the primary benefactors from this new system of knowledge ownership were publishers, since all authors assigned their copyright to the publishers before publication. The modern proprietary author simply created a useful euphemism for protecting company rights to copy.

This invocation of the author significantly ties up copyright to the concept of an author. The proprietary author emerges as the London publisher's mode of maintaining strict control over copyright. However, once unleashed, the idea of the author starts taking on a new 
meaning with unexpected consequences. It emerges as a new social relationship which will transform the way society perceives the ownership of knowledge. This establishment of the ideological figure of the author naturalises a particular process of knowledge production where the emphasis on individual contribution denigrates the concept of community knowledge and helps promulgate the notion of the individual as owner. ${ }^{5}$

\section{Portrait of the Camera as a Young Artist}

This romantic artist, once established, lives for a number of years without too many difficulties, until the invention of photography almost a century later. Edeleman states that "the eruption of the modern techniques of the reproduction of the real - photographic apparatuses, cameras - surprises the law in the quietude of its categories". ${ }^{6}$ Initially the law was not ready for the challenge that would be posed to it by this new technology. Faced with the question of whether a photograph could be considered on the same plane as a painting, the initial response of the courts was in the negative. For French law, the crucial question was whether or not the mechanical product could be said to have anything of 'man' in it at all. An authored work (it was argued) is imbued with something of the human soul, but a machine produced work is completely soulless. ${ }^{7}$

Yet, this soulless craft had at the same time also become an important economic activity with thousands in France making a living through photography and photographic technologies. France itself was exporting photographic images, and demands were soon made for the protection of these images and "the soulless photographer will be set up as an artist and the filmmaker as a creator since the relations of production will demand it". ${ }^{8}$

At this juncture it is worth reading closely one of the developments in the US with respect to photography. In Burrow-Giles lithographic co. v. Sarony ${ }_{1}{ }^{9}$ the Supreme Court was faced for the first time with the issue of whether an amendment to the Copyright Act to include photographs was constitutionally valid. The pictures in dispute were that of Oscar Wilde taken by Sarony and reprinted by Burrow-Giles without the permission of the photographer. The Supreme Court held that the amendment was valid and within the constitutional powers granted to Congress. However, to arrive at this conclusion the Court had to argue that photography could be protected in the same manner as any other work of creation as it emerged from an 'author'. How does the Court make this argument?

The Court observed that, "an author in that sense is 'he to whom anything owes its origin; originator; maker; one who completes a work of science or literature'. So, also, no one would now claim that the word 'writing' in this clause of the constitution, though the only word used as to subjects in regard to which authors are to be secured, is limited to the actual script of the author, and excludes books and all other printed matter. By writings in that clause are meant the literary productions of those authors; and Congress very properly has declared these to include all forms of writing, printing, engravings, etchings, etc. by which the ideas in the mind of the author are given visible expression. The only reason why photographs were not included in the extended list in the act of 1802 is, probably, that they did not exist; photography, as an art, was then unknown, and the scientific principle on which it rests, and the chemicals and machinery by which it is operated, have all been discovered long since that statute was enacted. We entertain no doubt that the constitution is 
broad enough to cover an act authorising the copyright of photographs, so far as they are representatives of original intellectual conceptions of the author".

The first move is therefore to equate the photographer, and what he does with photographic technology, to the status of an author - a concept which the law is very familiar with and can grasp without too much difficulty. But that does not automatically solve the Court's difficulty as it is still faced with the question of the role that technology plays in this production process.

In the words of the Court: "But it is said that an engraving, a painting, a print, does embody the intellectual conception of its author, in which there is novelty, invention, originality, and therefore comes within the purpose of the constitution in securing its exclusive use or sale to its author, while a photograph is the mere mechanical reproduction of the physical features or outlines of some object, animate or inanimate, and involves no originality of thought or any novelty in the intellectual operation connected with its visible reproduction in shape of a picture. That while the effect of light on the prepared plate may have been a discovery in the production of these pictures, and patents could properly be obtained for the combination of the chemicals, for their application to the paper or other surface, for all the machinery by which the light reflected from the object was thrown on the prepared plate, and for all the improvements in this machinery, and in the materials, the remainder of the process is merely mechanical, with no place for novelty, invention, or originality. It is simply the manual operation, by the use of these instruments and preparations, of transferring to the plate the visible representation of some existing object, the accuracy of this representation being its highest merit. This may be true in regard to the ordinary production of a photograph, and that in such case a copyright is no protection".

The answer is to distinguish between the mere mechanical technology that the camera seems to be and the transformation of that technology by the investment of the soul of the author. In this case the court poetically describes the photograph in dispute in the following way: "...It is a 'useful, new, harmonious, characteristic, and graceful picture, and that plaintiff made the same... entirely from his own original mental conception, to which he gave visible form by posing the said Oscar Wilde in front of the camera, selecting and arranging the costume, draperies, and other various accessories in said photograph, arranging the subject so as to present graceful outlines, arranging and disposing the light and shade, suggesting and evoking the desired expression, and from such disposition, arrangement, or representation, made entirely by plaintiff, he produced the picture in suit'. These findings, we think, show this photograph to be an original work of art, the product of plaintiff's intellectual invention, of which plaintiff is the author".

So, from being a soulless technology which could not be protected under copyright law, photographic technology gets elevated to the same status as a painting or any other great 'work of art' symbolising the creativity of the author. What then is the crucial legal innovation that was required for the law to understand this new technology and translate it within the terms of copyright law? In order for copyright law to be able to accept the claims of the photographer as a coequal author, it becomes important to resurrect the creative subject who had disappeared into the machine and a soul has to be found in the mechanical act, the soulless labour of operating a camera. ${ }^{10}$ But this soul or personality cannot flow 
through the apparatus, and the apparatus must be circumvented - otherwise the authorial credit would be void. It therefore needs to navigate its way through the apparatus and make its mark without actually touching the apparatus. It therefore needs to provide a mere "imprint of personality" - and this is never really found in the work but present everywhere else - in choice, technique, artistic practice etc.

The result of this creative subject's interaction with the mechanical object is a wholly new object, one which is now protected by copyright law. It is protectable because the new technology has been given an "imprint of personality" and is converted into an act marked by the sign of the author. Thus, the initial surprise felt by the law in its encounter with technology is rendered familiar and understandable. So "new technologies may surprise old categories, but only to be reformed according to existing conceptions of the world. Science and engineering may produce technologies that outstrip human capabilities, but these strange inventions are soon reconceived - domesticated and humanised - as they are put to use".11

\section{And Yet the Author Shall Rise Again}

Barthes may have been a bit premature in his announcement in the $60 \mathrm{~s}$ of the death of the author. For despite the various attempts to kill the author by conspiring technologists and poststructuralists, copyright's greatest invention has found himself resurrected in different ways.

For a number of years, computer software existed without any framework of protection and computer programmes were never considered works that were authored in the classical sense of the term. It is only in the $80 \mathrm{~s}$, with the emergence of a huge market for desktop computers, that any serious claim is made for the protection of software by intellectual property. The question that is posed sounds deceptively similar: under what theory of law can a computer programme be protected? We have already seen in the case of photography that when law encounters technology, it seeks to translate the phenomena into its own terms. Rather than explain the phenomena, it seeks to explain itself in renewed terms. If in the $18^{\text {th }}$ century there was a need for the author figure as a result of the market economy in literary texts, in the 80 s there was a need for a framework under which software could be protected. And when this problem of software arose all that was needed was to argue and show that components of software fell under the definition of literary works, and hence the authors of these works needed to be protected.

Intellectual property law has generally been divided into two categories - industrial property law and copyright law. Computer technology, while seemingly better fitted for the first, has in recent years been protected under copyright law. In Apple Computer Inc. v. Franklin Computer Corp. 714 F.2d 1240 (1983), the court was faced with the question of whether computer software was copyrightable.

Franklin, a small computer company that manufactured "Macintosh compatible" computers, was charged with infringing copyright on 14 different programmes written by Apple. These computers, Apple argued, used exact copies of their own software, with only minor changes like the elimination of the copyright warnings and authors' names. Apple claimed, and Franklin never denied, their software was copied. Apple claimed they could prove 
authorship because Franklin had not removed the author's names that had been embedded in the programmes. Franklin's argument was that the programmes were not protectable under copyright law and thus copies could be made.

The court held that "Apple does not seek to copyright the method which instructs the computer to perform its operating functions but only the instructions themselves. The method would be protected, if at all, by the patent law, an issue as yet unresolved". ${ }^{12}$ Franklin's attack on operating system programmes as "methods" or "processes" seems inconsistent with its concession that application programmes are an appropriate subject of copyright. Both types of programmes instruct the computer to do something. Therefore, it should make no difference for purposes of section 102 (b) whether these instructions tell the computer to help prepare an income tax return (the task of an application programme) or to translate a high level language programme from source code into its binary language object code form (the task of an operating system programme such as "Applesoft"). Since it is only the instructions that are protected, a 'process' is no more involved because the instructions in an operating system programme may be used to activate the operation of the computer than it would be if instructions were written in ordinary English, in a manual that described the necessary steps to activate an intricate, complicated machine. There is, therefore, no reason to afford any less copyright protection to the instructions in an operating system programme than to the instructions in an application programme.

Franklin's argument, receptively treated by the district court, that an operating system programme is part of a machine, mistakenly focusses on the physical characteristics of the instructions. But the medium is not the message. We have already considered and rejected aspects of this contention in the discussion of object code and ROM. The mere fact that the operating system programme may be etched on a ROM does not make the programme either a machine, part of a machine or its equivalent. Furthermore, as one of Franklin's witnesses testified, an operating system does not have to be permanently in the machine in ROM, but it may be on some other medium, such as a diskette or magnetic tape, where it could be readily transferred into the temporary memory space of the computer. In fact, some of the operating systems at issue were on diskette. As the CONTU majority stated, "Programmes should no more be considered machine parts than videotapes should be considered parts of projectors or phonorecords parts of sound reproduction equipment... That the words of a programme are used ultimately in the implementation of a process should in no way affect their copyrightability".

The Court held in Apple's favour and extended "copyright protection to all forms of software". In this decision the court reaffirmed the definition of 'literary' as indirectly including computer programmes as "works of authorship". As in the Donaldson v. Becket case, authorship granted to computer programmes works to maintain monopolistic control by the already advantaged. The underlying tension is between a large company with a virtual monopoly over a certain expression of an idea, and a smaller company wishing to produce a similar product. In both cases the author is suspiciously invisible in the dispute, but omnipresent in the justificatory arguments made by those who wish to establish the presence of the author. 


\section{Is Cyberspace the End of Copyright as we Know it?}

It is time to return to our original story: Napster and the turmoil caused to copyright law by a new technology. The story by now is almost painfully similar. A new technology emerges that changes the way in which people deal with the exchange of information, the technology is allowed to exist for a while - surprising the law - and then the law awakes to adapt the technology into a variant of an existing right. The question that I would however like to pose is this: Can the current digital moment be "domesticated and humanised" in the same manner that previous technological innovations have been?

Digital information on the Internet has effectively changed the rules in a manner which surprises the law like it has never been surprised before. For instance:

Information exchange has become easier through a process of duplication and multiplication in an unprecedented way. The transaction cost of exchanging information has become practically zero.

Authors lose control over their works much more easily as the work circulates and gathers new shapes and characteristics.

One major shift is that there is a change in emphasis from authorship to dialogue. (The text easily loses its bounded quality to become a part of the larger information network).

Everyone becomes a self-reliant desktop publisher.

Hypertext breaks the linearity of texts and thereby transgresses the boundaries of signification, including those set up by the author.

The figure of the author approaches and merges with the figure of the reader/critic.

Through the process of commentary and forwarding, etc., the reader becomes an overt collaborator in an unending process of reading and writing; also destroying notions of where the text begins and where it ends.

Increasingly the computer itself becomes the author or the artist.

Peter Jaszi, for one, argues that copyright is being displaced by three stronger systems of control which afford far greater protection. These are:

pseudocopyright - data protection efforts;

paracopyright - technological locks that makes it more difficult to copy information; metacopyright - the use of contracts to eclipse any limitations that copyright law may have.

One instance of paracopyright is found in the Digital Millennium Copyright Act of 1998, which is the enabling legislation for the WIPO copyright treaty. The Act provides the power to regulate technology. For instance, it prohibits the circumvention of any effective technological protection measure installed to restrict access to a copyrighted work. It prohibits the manufacture of any device or programme or offering of any service that is designed to defeat technological measures. ${ }^{13}$

While seemingly more encompassing than even the traditional strategy adopted by copyright law, namely the resurrection of the author, I would argue that it also seems to signal towards an inadequacy that the authorial discourse faces in the digital era. Whether this shift in the register of regulation - from exterior limits placed upon technology to internalised techno-limitation - will intensify or loosen the hold of law upon technology remains to be seen. 


\section{NOTES}

1. See, generally, Symposium: Beyond Napster: Debating the future of copyright on the Internet: Panel two: Which legal rules control? (50 Am. U.L. Rev. 389).

2. Ginsburg, Jane Copyright and control over new technologies of dissemination (Colum. L. Rev. 1613).

3. See, generally, Woodmansee, Martha The genius and the copyright: economic and legal conditions of the emergence of the 'author' (17 eighteenth-century stud. 425, 426, 1984); Rose, Mark The author as proprietor: Donaldson v. Becket and the genealogy of modern authorship (23 representations 51, 1988); Jaszi, Peter Towards a Theory of Copyright: The Metamorphoses of 'Authorship' (DUKE L.J. 455, 1991); Jaszi, Peter, "On the author effect: contemporary copyright and collective creativity" (in Cardozo Arts and Entertainment Law Journal 293, 1992).

4. Halbert, Debora "Computer technology and legal discourse: the potential for modern communication technology to challenge legal discourses of authorship and property" (opher://infolib.murdoch.edu.au:70/00/.ftp/ pub/ subj/law/jnl/ elaw/ comment/ halbert.txt).

5. Ibid.

6. Edelman, Bernard Ownership of the image: Elements for a Marxist theory of law quoted in Gaines, Jane Contested Culture: The Image, the Voice, the Law (University of North Carolina Press, Alan Trachtenberg, 1991) p. $45-46$.

7. Ibid.

8. Ibid.

9. 111 U.S. 53 (1884).

10. Gaines, Jane Contested Culture: The Image, the Voice, the Law (University of North Carolina Press, Alan Trachtenberg, 1991) p. 47.

11. Ibid.

12. See Diamond v. Diehr (450 U.S. 175, 67 L. Ed. 2d 155, 101 S. Ct. 1048, 1981).

13. See Vaidhyanathan, Siva Copyright and Copywrongs: The rise of intellectual property and how it threatens creativity (NYU Press, 2001, New York).

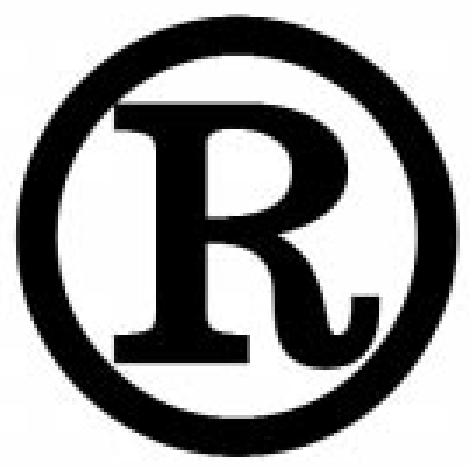


PRACTICES +POLITICSPRACTICES + POLITICSPRACTICES +POLITICS PRACTICES + POLITICSPRACTICES + POLITICSPRACTICES +

PRACTICES + POLITICSPRACTICES + POLITICS

PRACTICES + POLITICSPRACTICES

PRACTICES + POLITICS

PRACTICES

PRACTICES + POLITICSPRACTICES + POLITICSPRACTICES + POLITICS PRACTICES + POLITICSPRACTICES + POLITICSPRACTICES + POLITICS

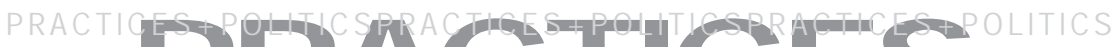

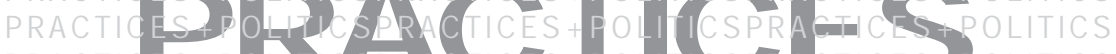

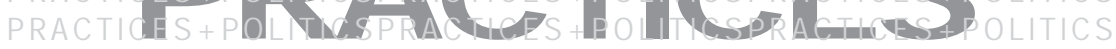
PRACTICES + POLITICSPRACTICES + POLITICSPRACTICES + POLITICS PRACTICES + POLITICSPRACTICES+POLITICSPRACTICES + POLITICS PRACTICES + POLITICSPRACTICES HPOLITICSPRACTICES + POLITICS PRACTICES + POLITICSPRACTICES-POLITICSPRACTICES + POLITICS PRACTICES + POLITICSPRACTICES + POLITICSPRACTICES + POLITICS

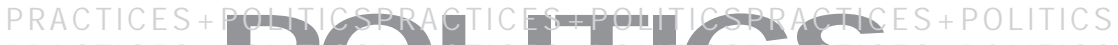
PRACTICES + P CLIT CSPRACTICES +P D LITIICSPRACTIGES + POLITICS PRACTICES + PLITICSPRACHAES +P DLITICSPR ACPICES + POLITICS PRACTICES + POLITICSPRACTICES + POLITICSPRACTICES + POLITICS PRACTICES + POLITICSPRACTICES + POLITICSPRACTICES + POLITICS PRACTICES + POLITICSPRACTICES + POLITICSPRACTICES + POLITICS PRACTICES + POLITICSPRACTICES + POLITICSPRACTICES + POLITICS PRACTICES + POLITICSPRACTICES + POLITICSPRACTICES + POLITICS PRACTICES + POLITICSPRACTICES + POLITICSPRACTICES + POLITICS PRACTICES + POLITICSPRACTICES + POLITICSPRACTICES + POLITICS PRACTICES + POLITICSPRACTICES + POLITICSPRACTICES + POLITICS PRACTICES + POLITICSPRACTICES + POLITICSPRACTICES + POLITICS PRACTICES + POLITICSPRACTICES + POLITICSPRACTICES + POLITICS PRACTICES + POLITICSPRACTICES +POLITICSPRACTICES + POLITICS PRACTICES + POLITICSPRACTICES + POLITICSPRACTICES + POLITICS PRACTICES + POLITICSPRACTICES + POLITICSPRACTICES + POLITICS PRACTICES + POLITICSPRACTICES + POLITICSPRACTICES + POLITICS PRACTICES + POLITICSPRACTICES + POLITICSPRACTICES + POLITICS PRACTICES + POLITICSPRACTICES + POLITICSPRACTICES + POLITICS 


\section{Technology, Trust and Terror}

LANGDON WIN NER

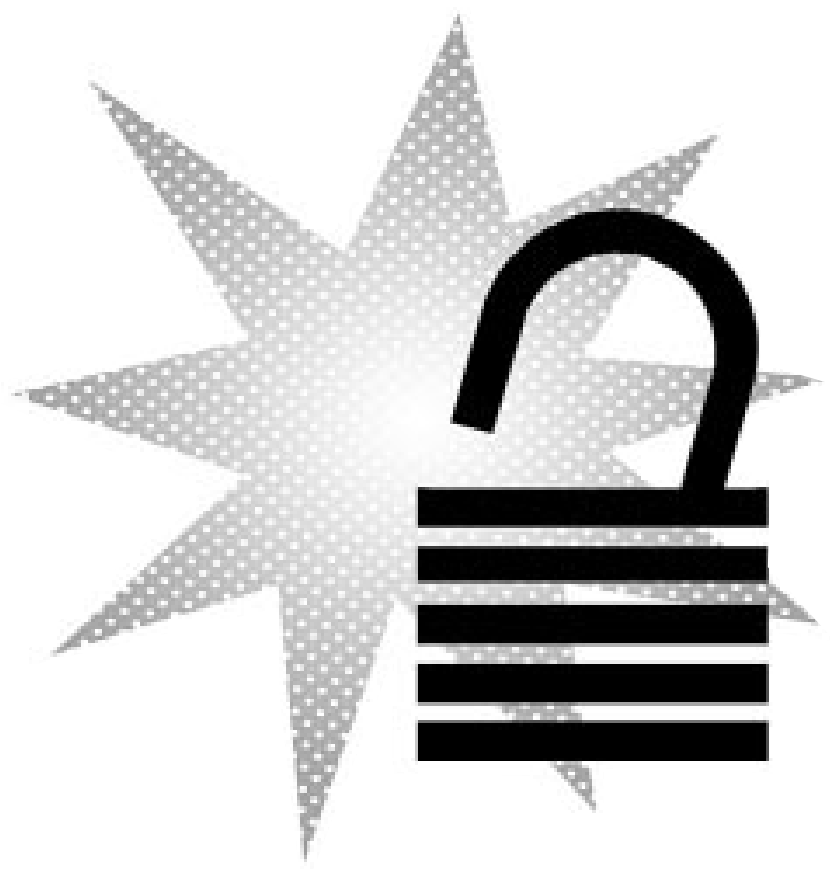

The beguiling but ultimately mistaken notion that technologies are 'merely tools' things we pick up, use and then put away - poses a major barrier for understanding how we live today. Missing in the tool/use perspective is an acknowledgment of a basic fact about people's relationship to the technological realm: our utter dependence upon the large, complex, artificial systems that surround us on every side, giving structure to everything we do.

For countries in the North, such dependence is welcomed with open arms because it seems crucial to prosperity and freedom. Large-scale, geographically extensive technologies enable us to move about as we wish, to communicate freely and to be released from the urgent demands of day-to-day survival that confronted previous generations and that still vex the less prosperous nations around the globe. 
But now another, more troubling dimension of technological complexity demands attention. Dependence on complex technological systems looms as a source of vulnerability. If any major component in the systems that support modern life ceases to function for a significant period of time, our prosperity, freedom and comfortable lives are threatened. This was a major concern in 1999, you will recall, as people agonised about the possibility of disastrous system collapse caused by $\mathrm{Y} 2 \mathrm{~K}$ programming. There were widespread fears that the energy grid, airline transportation, banking and other systems would be disrupted by computer malfunctions, plunging society into chaos. It turned out that, despite minor glitches here and there, the predicted $\mathrm{Y} 2 \mathrm{~K}$ chaos never arrived. But during the last months of 1999, the perception of vulnerability bordered on mass hysteria.

\section{Responses to Vulnerability}

There are several ways that our society routinely deals with the spectre of vulnerability. One strategy is to ensure that technical devices and systems are well engineered and protected from calamitous failure. Engineers and systems designers make sure that structural parts can hold an increment more than the normal loads they must support. Redundancies are also built into many systems so that if one part fails, another part takes over.

But good engineering is only part of the story. In free, democratic societies there is another way in which ordinary people have managed their relationship to vulnerability: they embrace an attitude of trust, holding on to the reasonable expectation that key technologies will always work reliably and not break down in ways that jeopardise our health, safety and comfort. This relationship is reciprocal; trust also informs the structure and operation of technological systems themselves. Many key components are built in ways that leave them open to the possibility of inadvertent or deliberate interference. Electrical power lines, phone lines, gas pipelines, dams, aqueducts, railroads, aeroplanes, elaborate works of architecture and the like, are often more or less naked to the world, open to view, minimally guarded from the kinds of interference that could render them inoperable. For many decades a common but largely unspoken expectation has been that people in prosperous industrial societies can be trusted not to dis rupt or destroy the workings of the key parts of the global technological order.

Most people accept the presence of major complex technologies because their wellbeing hinges on them, because there's no good reason to act destructively and, of course, because the law punishes overt acts of sabotage. Exceptions include occasional bombings by anarchists in the early $20^{\text {th }}$ century, acts of destruction by the Weathermen and political extremists in more recent times - Timothy McVeigh and the Unabomber among others. But for the most part, the relationship of openness and trust between individuals and complex systems has proven fairly resilient.

A very different understanding of how to manage large, complex systems characterises closed, guarded, totalitarian societies such as the Soviet Union under J oseph Stalin and Kim II Sung's North Korea. Regimes of this stripe hardened the design of their technologies and installed vast systems of policing and surveillance because they did not trust their own people. For any society that adopts strategies of this kind - pervasive suspicion and obsessive protection of core technologies - an inevitable consequence is the destruction of civil freedom. 
What would happen to our own society if the long-standing conventions of openness and trust were suddenly afflicted by a pervasive sense of vulnerability and dread? Would our rights, liberties and democratic institutions survive?

\section{Vehicles for Destruction}

In the aftermath of the attacks upon the World Trade Centre and the Pentagon, along with the subsequent anthrax scares, such questions have renewed urgency. Americans are now profoundly aware of their vulnerability. Dams, reservoirs, bridges, power plants, chemical plants, aqueducts, electrical transmission lines, liquid natural gas tankers - even the daily mail and systems of food supply - all seem wide open to attack.

As far as I can tell, both planes that left Boston on September 11 on their way to the Twin Towers flew right over my house in the Hudson River Valley. If the pilots had wanted to do maximum damage to the region, a far better target would have been the nuclear reactors at the Indian Point electrical power plant about sixty miles south. Since these facilities were not designed to withstand a direct hit by an airliner, targeting them might have caused catastrophic failure, and possibly a core meltdown as the fuel sank into the mud and water of the Hudson River. The resulting plume of radioactive steam and debris would have killed thousands of people very quickly and rendered much of the Northeast permanently uninhabitable. Perhaps we are lucky that the Al-Qaeda terrorists were so obsessed with the symbolic value of the World Trade Centre that they neglected what may have been more productive targets, America's 103 nuclear power plants.

Within the collection of infrastructures upon which we depend, there are many others that are essentially wide open, loosely protected. The nation's containerised cargo system provides a good example. Each year some six million sealed containers arrive from all around the world. At present, only two percent of these are ever inspected (although a new international programme aims to boost the level to 5-10 percent). If anyone had the ability to make or purchase a nuclear device or dirty bomb, a convenient way to deliver it would be to ship it by containerised freighter and, at the appointed moment, set it off. A recurring nightmare: one morning we turn on our televisions to find that San Francisco, San Pedro or New York has been levelled by a nuclear blast from a weapon hidden in one of those large steel crates.

There are many other horrifying scenarios, of course. If anyone had the desire to use it, a readily available, flexible delivery system for maximum destruction is the automobile, a fact all too clear in Ireland, England and the Middle East in recent decades. There are now some 230 million registered cars and trucks in the USA. The Oklahoma City bombing demonstrated how easy it is in an open society to fill a rental vehicle with explosives made of readily available chemical fertilisers and set it off in the middle of town. J ust as we previously had not thought about commercial airliners as flying bombs, Americans do not regard their beloved automobiles as flexible, ubiquitous instruments of destruction, although they sometimes serve that role in the Middle East and other troubled regions of the world.

Recognition of the vulnerability of open, complex, geographically extended technological systems is by no means new. In 537 A.D. the Gothic chieftain Vitiges and his forces laid siege to Rome. A crucial part of Vitiges' strategy was to cut the aqueducts leading to 
the city, forcing the Romans to rely on the inadequate stream of water from the Tiber River. As a result, the population fled Rome in droves, as much in response to water shortage as to the sack of the city. Scholars have long debated the various developments that caused the fall of the Roman Empire. But as geographer Gray Brechin observes in Imperial San Francisco, "the destruction of the aqueducts conclusively ended the rule of a city that had once boasted of itself as the caput mundi - the world's capital".

\section{The Withdrawal of Trust}

Following the atrocities of September 11, the world's current caput mundi, the United States, has struggled to find ways to confront revelations of its own vulnerability. To this point most of the emphasis has centred on a rapid shift from trust to mistrust, installing muscular socio-technical fixes that promise security against terrorism and place our whole population under suspicion.

Most prominent among proposed remedies is the USA-PATRIOT Act - "Uniting and Strengthening America by 'Providing Appropriate Tools Required to Intercept and Obstruct Terrorism'"'. This astonishing piece of legislation extends the government's power to listen in on private conversations, including cell phone conversations, nationwide; authorises surveillance of e-mail, web browsing and other Internet communication; and allows police to obtain a warrant to search a person's home without the person's knowledge.

Other steps in this vein include changes in America's immigration rules that allow the Attorney General to keep foreigners in detention even though an immigration judge orders them released. President Bush issued an executive order aimed at creating special military tribunals for foreign nationals suspected of terrorist acts, courts that lack many of the protections afforded by our laws and Constitution. Along this path hundreds of Muslim and Arab persons have been detained before being charged with a crime or breach of immigration status, in direct contradiction to the US Constitution. Even now, more than a year after the attack, it is difficult to obtain accurate accounting of who is being held and for what reason.

As the shadow of secrecy and suspicion has fallen across the land, useful government information about the nation's technological infrastructure - web sites on water systems, nuclear power plants, chemical plants and the like - have been removed or are severely restricted in content. For scholars, it is now much more difficult to study what used to be regarded as a perfectly mundane question: the structure and operation of technological systems. What used to be public information freely available to citizens is now regarded as crucial national 'intelligence' to be shielded from the grasp of spies and saboteurs.

The wave of new federal legislation and regulation is now mirrored in a host of antiterrorist laws passed by state legislatures, ones that feature strengthening the power of the police to monitor the activities of citizens who, for one reason or another, must be watched. In this new mood, the definition of terrorist activity is sometimes so broad and vague that it casts a shadow over a wide range of political activities - organising public protest marches, for example. Civil liberties groups are concerned that ordinary forms of political protest could be defined as terrorist and suppressed. This might include, for instance, the public gatherings to protest globalisation like those in Seattle and other cities in recent 
years. Unfortunately, episodes of political repression during times of civic distress - the Palmer raids after World War I, the incarceration of American citizens of J apanese decent during World War II, the malicious persecution of dissidents during the McCarthy era of the 1950s, and so on - are all too common in American history. When the nation feels threatened, freedom takes a beating.

\section{A Public Chill}

On radio and television talk shows and in newspaper editorials since the 9/11 attack there has been a strong tendency to define terrorism in broad, loose, inflammatory terms. The same penchant also afflicts lawmakers at all levels. Last spring the Maryland House of Delegates passed an anti-terrorism law extensive in its sweep. Dana Lee Dembrow of the Maryland House of Delegates remarked, "I realise that this bill basically says you can tap someone's phone for jaywalking, and normally I would say, 'No way'... But after what happened on September 11, I say screw 'em".

The nation's obsession with security now casts a chill upon public life and the only question is "How cold will it get?" For example, since the 1960s there has been a lively debate about privacy and personal liberty in the age of electronic data. A rough consensus formed that citizens ought to be free from the snooping of Government, corporations and private individuals. That consensus has now been demolished by the belief that widespread surveillance is necessary and that ingenious systems like the FBl's Carnivore (which can monitor everyone's e-mail and Internet activities) are exactly what is needed to defend the country.

Within post-9/11 security measures, protections of the US Constitution have been seriously weakened. Thus, the Fourth Amendment insists, "The right of the people to be secure in their persons, houses, papers, and effects, against unreasonable searches and seizures, shall not be violated, and no warrants shall issue, but upon probable cause, supported by oath or affirmation, and particularly describing the place to be searched, and the persons or things to be seized". But under the provisions of the USA-PATRIOT Act, authorities can now search everywhere, indefinitely, online and off, with one general warrant.

There is, alas, widespread spillover of these measures into civil society as a whole. Hoping to deflect suspicion, many Americans have become guarded and self-censoring. How often in recent weeks have I heard people say, "No, I don't worry about anti-terrorist legislation. I'd never do anything the authorities would be interested in anyway". Evidently, patriotism requires us to be compliant and predictable.

Typical of the mood of panic just after the 9/11 attacks was a news segment on NPR that asked security experts about everyday vigilance against terrorism. What should ordinary folks watch out for? Look for any signs of "unusual behaviour", one expert advised. This would include people wearing clothing that seems out of place, or saying things or making gestures that were not appropriate for a particular place or occasion. As I listened to the story, it struck me that what was identified as dangerous "unusual behaviour" were simply varieties of freedom - wearing what we like, saying what comes to mind, acting freely in public. 


\section{When Stable Structures Dissolve}

We cannot know the specific intentions of the September 11 terrorists. But if one of their aims was to render our way of life much less open and free, they have surely succeeded. At present Americans are restricting freedom of travel, limiting access to information, and narrowing the boundaries of political speech. In programmes like the J ustice Department's "Terrorist Information Protection System" (TIPS) we are modifying social life in ways that define people as suspects rather than citizens. In all deliberations about public policy (regardless of topic) terrorism and security have become the overriding concerns.

J ust as sixthcentury Romans abandoned their city when the aqueducts were cut, Americans seem to be abandoning essential parts of the democratic civic culture that developed during the past two centuries. This appalling turn of events is certainly evident in the material features of public buildings and grounds. A visit to Washington, D.C. shows the place transformed by ever-present ugly cement barriers, recurring security searches and ubiquitous surveillance cameras. The city has been redefined as capital of Homeland, a strange new country where once-cherished freedoms of thought, expression and movement are regarded as luxuries too dangerous to afford. (Citizens should ask: Is Homeland governed by the same constitution as the old USA?)

In the current mood, people view terror as something that has suddenly arrived from outside, inflicted upon an otherwise contented, harmonious society by 'evil-doers' from distant parts of the world. Obviously, there's much truth in that view. There are malevolent actors out there prepared to inflict death and destruction.

But seen from another vantage point, the terror we experience - the dread that now afflicts everyday life - resides in the very systems we have so ingeniously built during the past century. Modern, complex technologies succeed by wresting enormous stores of power from the natural realm, seeking to direct these powers in ways that are controllable and useful. An unhappy possibility can never be entirely eliminated, however: the prospect that these enormous forces will somehow be unleashed uncontrollably from systems and infrastructures originally built to contain them. In recent years, fears of this kind have focussed on rare technological accidents - the explosion of the Challenger space shuttle, for instance. Such misgivings also underscore contemporary evidence about environmental ills, including global warming. Our technology's controlled use of fossil fuels over many decades has generated uncontrollable, highly destructive shifts in climate.

Following the 9/11 attack, the horizons of catastrophe have shifted. The accomplishment of a jet airline is to contain and direct the highenergy fuel whose combustion enables rapid flight; the achievement in the engineering of skyscrapers is to defy gravity by ingeniously stacking tons upon tons of steel and other materials in high structures so that - despite their obviously precarious position - they will not fall down. But what if the physical potential in these achievements were suddenly released in ways not part of the original blueprint?

The horror of the World Trade Centre attack was that the power of two wonders of modern technology - the skyscraper and the jet airliner - came crashing together causing the carefully contained power of both systems to be released in catastrophic explosion, inferno and collapse. In this light, the ingenuity of the terrorists is to trigger processes that cause stable structures to dissolve. 
Deeply buried in our experience of modern technology is the elementary terror that powers we sought to control will escape our command and come back to injure or destroy us. Perceptions of this kind have surfaced in countless science fiction novels and films of the past century, turning our worst fears into mass entertainment. But beyond the paperbacks and movie screens an urgent question now sounds. How many systems of megatechnical might can one introduce before they begin to overwhelm the culture of democracy? As we construct complex, tightly coupled, geographically extended, powerful, but ultimately precarious systems, one result is a world filled with ticking time bombs waiting to go off.

\section{A Fortress Mentality}

America's knee-jerk response to this terror at present is the familiar strategy of hardening systems to prevent disruption. We are building new barriers around crucial systems and strengthening their internal components, surrounding them with elaborate methods of policing and surveillance. If it continues, this strategy of hardening technological systems will be a major drain on our economic resources and a hazard to both freedom and civility. But for the time being Americans and their leaders seem prepared to pay these costs, even though they will rapidly degrade our institutions - further starving schools of funds and commitment, for example - and weaken the fabric of democratic sociability.

Unfortunately, it is far from clear that the new measures will succeed. A study by the Department of Transportation released last spring found that in attempts to smuggle weapons through newly bolstered airport security gates, thirty percent of the guns and seventy percent of the knives got past the guards and scanning devices. Similar tests of security at nuclear power plants also produced disappointing results; breaching the barriers around these facilities seems to be fairly easy.

The human demands of policing complex systems are, over long periods of time, probably beyond people's ability to bear. You may recall an episode just after 9/11 when the Golden Gate Bridge was rumoured to be a terrorist target. Passage was closed for a while and then National Guard troops were brought in to screen the traffic. But television coverage showed exactly what you'd expect, guardsmen standing around, bored, shooting the breeze, not paying attention to the vehicles going by. And this was a nationwide terrorism alert at the highest level!

Faced with shortcomings of this kind there are calls to redouble our efforts by spending even more money, installing more sophisticated equipment, hiring more security personnel, subjecting the public to spiralling levels of hassle, search, surveillance and mistrust. An impartial observer looking at us from afar might be puzzled by how quickly and thoroughly these initiatives have begun to modify the American way of life. Why didn't the nation explore more fruitful ways of responding to the terror people feel? Why didn't Americans try harder to preserve their traditions of openness, trust and freedom?

In quest of security the nation is now preparing to go to war with a large nation said to belong to an "axis of evil". Again, this conveniently defines terror as something 'out there' rather than acknowledging some of its foundations 'in here', within the very frameworks that support high-tech ways of living. 


\section{Toward Safer Systems}

In my view, there are far better ways of responding to $9 / 11$ than the kinds of knee-jerk militarism, Orwellian surveillance and pre-emptive strikes on human rights that our leaders currently prefer. Urgently needed are measures that would address sources of insecurity and terror found at the very roots of modern civilisation. Hence, it seems wise to design technical systems that are loosely coupled and forgiving, structured in ways that make disruptions easily borne, quickly repaired. Certainly it makes sense to rely upon locally available, renewable energy and material resources, rather than foster dependency on global supplies always at risk. It seems sane to rely on technologies operated by people in local communities whom we get to know in a variety of roles and settings, not just as technical functionaries. It also seems high time to begin reducing our dependence upon overwhelming, risk-laden powers wrested from nature. Now we know: these powers may destroy not only fragile ecosystems, but the habitats of freedom as well.

Fortunately, the richness of human knowledge includes workable systems alternatives to today's complex, power-centred, globally extended, increasingly war-hungry dinosaurs. The construction of more peaceful, resilient systems can be accomplished through imaginative efforts (many of them well under way) aimed at living lightly on the earth with justice and compassion. Moving steadily along this path could also help eliminate grievances in the world's population that now serve as spawning grounds for terrorist attacks.

As the present atmosphere of hysteria, acquiescence and political opportunism subsides - and I believe it will - we must renew efforts to build institutions that merit our trust rather than fuel our fears.

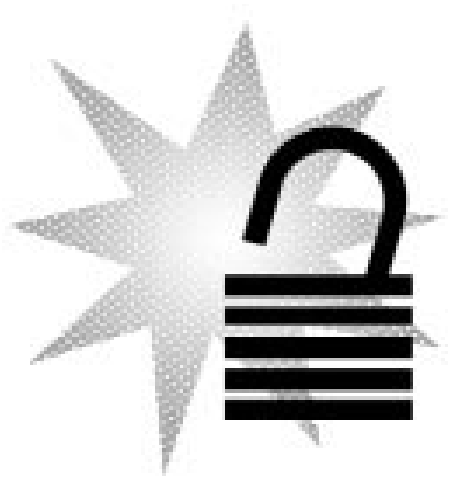




\section{Social Sorting in the Early $21^{\text {st }}$ Century Video Surveillance and Governance

t goes without saying that consolidating state power surveillance is on the agenda of the ruling classes. ${ }^{1}$ Elaborating techniques of social control has always been of high importance. While enhancing efficiency and productivity, surveillance also focusses on a functioning bureaucracy to maintain power and control. Furthermore, functioning surveillance systems are even more important in times of economic crisis and during times of war. ${ }^{2}$

It is the rise of new technologies that has enhanced the opportunities for the main aims of surveillance such as control and discipline. Technology does both: enabling globalisation processes and widening the opportunities for social control. With the ongoing fragmentation of advanced industrialised societies due to the "neoliberal project", ${ }^{3}$ a new trend emerges, from 'simple' control and discipline of people to identifying and classifying them: the social sorting of people.

Developments in technology such as innovations in transportation, information and (tele)communication have led to an increasing free flux of capital, goods and (enabled, forced, or prevented) the migration of people. Under neoliberal conditions, this globalisation process is to be described as both uneven and unjust on different scales - global, national, regional and local. While the 'global' meets the 'local' and vice versa, globalisation is a more precise term. Video surveillance started its career on the local level trying to improve traffic (and crowd) control. At the present time, video surveillance (CCTV: Closed Circuit Television) is on all scales one of the most prominent instruments to control, discipline, identify and sort people.

"She uses a scale of 100 to 2 to make it easier to transcribe the information. Each sector has its own command and its own surveillance system. Small cameras are fixed to the ceiling. Elena imagined the circuit and the surveillance room. Once she had seen the surveillance centre at New York's Penn Station. All the commuters were screened in corridors and platforms, and a grease-painted, blue-dressed policewoman with black glasses (a real policewoman) worked alone in a white basement ring rounded by TV screens; sitting in a swivel-chair she monitored the screens covering the walls. A microphone pinned at her blouse transmitted her voice and her breath. In the toilets perverts cooled down to their perversions; she supervised and informed the police squads in action one floor above. Three policemen were kicking a junkie who lay in a corridor leading to platform six." 


\section{Neoliberalisation: The Fordist Big Brother and his Post-Fordist Sisters ${ }^{4}$}

Faced with the decline of profitability of the Fordist mass-production industries and the crisis of the Keynesian welfare system, Western industrialised nation-states began to dismantle the basic institutional components of the postwar structures and pushed forward - first ideologically than practically - extended market discipline, competition, and commodification throughout all sectors of society. This process of neoliberalisation is neither monolithic in form nor universal in effect; instead it is highly uneven both socially and geographically. This is why the management of (in)security, (dis)order and (crowd) control is not the same in every nation-state (or even locality). Although it is obvious that for the last twenty years the neoliberal project has failed to establish a coherent basis for sustainable capitalist growth, it nonetheless transformed the institutional infrastructures upon which the Keynesian welfare state and its Fordist structure was grounded.

"In short, in this North Atlantic zone [North America and Western Europe] at least, there seems to have been a shift from the pattern of deregulation and dismantlement so dominant during the 1980s, which might be characterised as 'roll-back neoliberalism', to an emergent phase of active state-building and regulatory reform - an ascendant moment of 'roll-out neoliberalism'" (Peck and Tickell 2002, p. 384).

Or, as Lea (1997, p. 49) puts it, "'Post-Fordism' can be another name for the fact that in order to restore the conditions for profitable accumulation, capital must intensify its attack on the working class". This intensified attack comes with a new model of regulation; first focussing on the local level and second introducing governance instead of government. In order to effectively deal with the complexity of contemporary social problems on the local level, stakeholders from all spheres of local society are brought together to cooperate with the municipality as well as with each other. With the devolution of welfare production, the blurring of borders between traditional policy fields such as labour market policies, economic development, social and security policies is obvious. In all sectors that are involved in welfare and, increasingly, security production (public, private, voluntary and nonprofit), shifts in values, habits and organisational structures (e.g. an increasing market orientation) can be identified. All this is happening in an environment increasingly defined by devolution, leading to a workfare governance model (Eick 2002).

The ongoing commercialisation and competition that comes with "roll-out neoliberalism" in a glocalising world also leads to the blurring of borders between commercial, police and military activities that now appear as a "criminal justice military industrial complex". Video surveillance started within the Keynesian welfare state by defining the "citizen as a security risk" (Narr 1977). The second wave of CCTV takes into account the disruption of society that forces all individuals to take risks in areas such as labour, welfare, health, safety and tries to reconfigure and readjust its outcomes.

"MetaCops Unlimited is the official peacekeeping force... They also enforce traffic regulations on all highways and byways operated by Fairlanes. Inc.... MetaCops' main competitor, WorldBeat Security, handles all roads belonging to Cruiseways, plus has worldwide contracts... WorldBeat is smaller than MetaCops, handles more upscale contracts, 
supposedly has a bigger espionage arm - though if that's what people want, they just talk to an account rep at the Central Intelligence Corporation.

And than there's The Enforcers - but they cost a lot and don't take well to supervision. It is rumoured that, under their uniforms, they wear T-shirts bearing the unofficial Enforcer coat of arms: a fist holding a nightstick, emblazoned with the words SUE ME."

(Snowcrash Neal Stephenson 1992, p. 41-42)

\section{No Need to Smile: Digital Discrimination and the Biometric Back Office}

Closed circuit television has a history of almost fifty years now. In Germany, the first cameras in public space were installed in the late 1950s - firstly in Munich in 1958 followed a year later by Hanover, where the government eventually installed the first 25 pan-ilt-zoom cameras in a city-centre pedestrian zone in 1976. While most of the cameras that were installed in the period between the late 1950s and mid-1960s focussed on traffic management, they have been used to target 'marginalised' groups since then. Nowadays, they are conquering the whole range of everyday life. In 1976, special police squads started surveillance of demonstrations; the so-called "Action Paddy" run by the Federal Office of Criminal Investigation (BKA), the secret services Federal Intelligence Service (BND) and the Office for the Protection of the Constitution (BFV) tried to identify members of the so-called terrorist group Red Army Faction (RAF) in the surroundings of the NATO headquarters in Heidelberg. The attempt failed and the project was stopped after a period of six months. Meanwhile there are countless video surveillance projects all over Germany: playing grounds are monitored as well as welfare centres, public employment offices as well as schools, public transport systems as well as residential areas, and workplaces as well as shopping malls. Obviously, this list is incomplete (Hempel and Töpfer 2002; Eick 2003).

While this development was pushed forward by the federal government and commercial security companies during the 1960 s and 1970s, since the early 1990s video surveillance has been promoted, consumed or advertised by almost every part of current society, ${ }^{5}$ and thus has invaded all its fields, including private and public spaces as well as the Internet, which itself has to be seen as a surveillance tool.

The relations between CCTV and interventions in urban space are both economic and political. In the UK, for example, the introduction of video surveillance into the public spaces of (inner) cities and towns has been an attempt to support these areas in the face of growing competition with out-of-town retail parks that have been seen as relatively safer than the inner city areas (Fyfe and Bannister 1998). The now-privatised German railway company DeutscheBahn organises social sorting by means of video surveillance both to exclude marginalised groups and to compete with airlines that connect almost every major city in Germany and surrounding countries since the early 1990s. Nowadays, Germany's main railway stations are high security zones designed like the current panoptical airports (Eick 1998). In the US, the configuration of the tightly managed, security-conscious corporate plazas reflects concerns that the presence of social difference will have a negative financial impact. As Flusty notes, "A plaza's white-collar user mix adulterated by vagrants or a janitor's family on a picnic [means] a loss of prestige before the 'business community' and a resulting loss of clientele" (1997, p. 58). Evidently, city streets that have been sites and 
symbols of (democratic) protest and politics since the beginning of city building continue to be a source of anxiety to the leading class fearful of challenges to the very social order and power structures they want to sustain. According to managers and watchers of CCTV systems, we can easily describe video surveillance as a masculine or patriarchal technology. A gender structure is to be identified, not only because women use more time for shopping than men; a majority of them also use public transport, whereas men - whether police or private guards - are the watchers behind the camera. And even more, as Koskela states, "Women do not rely on those behind the camera because of the reproduction of patriarchal power. In urban space women are likely to be the ones who are looked at, the objects of the gaze. Furthermore, one of the very reasons for women's insecurity is their 'exaggerated visibility'. Paradoxically, women are marginalised by being at the centre (of the looks). Surveillance can be a way of reproducing and reinforcing male power. It is opening up new possibilities for harassment. Surveillance can be understood as the 're-embodiment' of women, as an 'extension of male gaze'"' (1999, p. 13).

Therefore, categorisation - social sorting - by video surveillance and related technologies is not only particularly prejudicial, relegating 'some' to second-class citizens because of their social status, color, ethnic background or religion, but reproduces patriarchal structures as well.

"After this he might have to get out of the city for a while and live somewhere else. Somewhere simple, where the only smart building was the local library... Busiest of all was the Marounuchi, the financial district and electronic Mecca, where crowds of screen gazers jostled their way along the communications thoroughfare like so many holiday makers heading for the beach. He liked this place most of all, for here the luminous world reached its apogee and here was most for him to steal - whole batches of files of patents, statistics, research, analyses, sales figures and marketing plans - a seemingly limitless store of weightless wealth."

(Gridiron Philipp Kerr, p. 407-408)

\section{From Suspicion to Seduction: The Conversion of Mixed Interests}

One has to highlight the very different spaces that are covered by CCTV in order to understand that its existence is not only to guarantee the ruling class' power, but also for profit: while it is true that political fears are an important driving force in introducing CCTV, it is also obvious that the current multi-stakeholder use of CCTV develops - following and transforming Jessop's $(2001,2002)$ arguments - what can be described as a shift from a Keynesian 'security state' to a Schumpeterian 'panic regime'. The multi-stakeholder use leads to what David Garland (2001) calls a "culture of control". ${ }^{6}$

In the UK, it is already estimated that with respect to camera surveillance in public and private spaces there is one camera for every eight persons. One can estimate that for 'developed' countries, at least for the UK as Steve Graham (1998) argues, video surveillance will become "the fifth utility" of the networked utilities - following gas, electricity, water, and telecommunication systems. Another aspect is noteworthy: although, after World War II the responsibility for computer development and CCTV was turned over to the 
commercial sector, it continues to be shaped by military interests, imperatives and funds. Thus, overseen militarily, a convergence between state and commercial surveillance is obvious. To the extent that technologies - such as communication, biometrics (the use of data extracted from the body), ${ }^{7}$ manual and automated CCTV and new 'low-intensity' weapons - have their origins in military research and development, they have moved into policing and customer tracking businesses largely on the 'trickle down' model of dispersion. As Haggerty and Ericson note, "There has been a change towards a more 'directed' approach to technology transfer", which they relate to "broader political transformations, the most important one being the disintegration of the Cold War threat" (2001, p. 54). This approach has been fuelled by $9 / 11$, says David Carey, a former high-ranking CIA officer and, since November 2001, the head of the Information Assurance Centre at Oracle Corporation, the world's largest database manufacturer: "In some ways, September 11 made business a bit easier. Previously, you pretty much had to hype the threat and the problem". His boss, Larry Ellison, proposes to reconstruct America's national security strategy along the lines of Oracle's business model:

"The Oracle database is used to keep track of basically everything. The information about your banks, your checking balance is stored in an Oracle database. Your airline reservation is stored in an Oracle database. What books you bought on Amazon is stored in an Oracle database. Your profile on Yahoo is stored in an Oracle database. We already keep track of where you work, how much you earn, where your kids go to school, were you late on your last mortgage payment, when's the last time you got a raise" (cited in Rosen 2002).

These separate commercial data are centralised in large databases maintained by credit card companies, whereas government data are mainly stored in disconnected databases: "The huge problem is the fragmented data. I really don't understand", states Ellison, who wants to consolidate the hundreds of state and federal databases into a single Oracle database (Ibid.). Part of this data registration and collection in the US as well as in other countries is workplace surveillance. Mainly used to assure further exploitation and minimise profit losses, more than one-third of the 40 million American workers with Internet access are under constant surveillance very easily, because every computer leaves behind a trail of breadcrumbs. As the American Management Association (AMA) summarises in its workplace testing survey in 2000 :

"Nearly three-quarters of major US firms (73.5\%) record and review employee communications and activities on the job. The figure has doubled since 1997, when AMA inaugurated its annual survey. Video surveillance for security purposes grew from $32.7 \%$ in 1998 to $35.3 \%$. The sample accurately mirrors AMA's corporate membership, who together employ one-fourth of the US workforce" (AMA 2000, p. 2, 4).

The combination of algorithm, biometrics and CCTV opens up fields like customer tracking, profiling and relationship management - monitoring and channelling the shopping habits of customers, and the ability to monitor, store, exchange, cross-index and retrieve digital information grows each year. Like the UK company Clickstream Technologies Plc. that invented the monitoring of mouse click streams on web sites to target online shopping behaviour, in J anuary 2002 the US company Brickstream Corp. introduced a system that pursues customers, collecting data about their 'real life' shopping habits. Advanced 
Interface Technologies introduced a pattern identification program, combining voice and face recognition with CCTV that allows gender identification in shopping centres to optimise customer conduction; plans are under way to connect customer tracking systems with data mining (Sietmann 2002, p. 150-153).

"The train whistle blew, softly this time, almost whispering for them to please leave quietly. There were no TV cameras, no Minicams to be seen. No footage of American citizens being herded onto cattle cars for future historical re-interpretationists to throw in their faces. The great lesson of Watergate: Never leave a paper trail. The lesson of Rodney King: Minimise video opportunities."

(21st Century Manzanar Perry Miyake 2002, p. 3)

\section{The Rise of a New Digital ABC: Algorithms, Biometry, Cameras}

The conventional way of verifying an alarm is to send a response either from the private security company or the police. Due to the high rate of false alarms and limitations on resources, the need for visual verification has increased, and the growth of CCTV, remote and on-site monitoring systems allowed the introduction of Automated Video Surveillance (AVS). Scholars argue that this is for operator concentration, saving of space, reduction of manpower, and enhancement of CCTV functions (Waring and Glendon 1998). It is obvious that AVS enables governments and commercial companies to reduce manpower and allows automatic responses, assisting human response and improving efficiency. In short, as Hesse $(2002$, p. 72) states, if "we consider the principles of protection as deter, detect, delay and respond, then the two objectives of CCTV and video motion detection are being continuously improved by the increases of technological advances". This is especially true when we think about the integration of biometrics into CCTV systems.

Advanced Video Motion Detection systems (VMD) like the Advanced Exterior Sensor project (AES) developed by Sandia National Laboratories in Albuquerque (New Mexico) and Livermore (California), combines the three sensor technologies of thermal infrared waveband, visible waveband and microwave radar with cameras and algorithms. Sandia is a research centre run by the Department of Energy (DoE) and the armaments company Lockheed Martin to "establish a permanent screen search system within global sensor networks. Conventional border control is to be supplemented by a system of monitoring security zones in the fore-field of the US' own borders" (Sietmann 2002, p. 95). As Sandia's project manager, Dave Nokes, states, "the long-term objective for the next years is to connect hundreds of sensor nodes that will be able to identify and pursue people in urban areas" (cited in Sietmann 2002).

The British QinetiQ PIc., a privatised subsidiary of the DERA (Defence Evaluation and Research Agency), developed a new personnel scanner out of a military all-weather camera; the system, displaying people naked on the monitors, will be able to screen 60 persons per minute from a distance of 30 meters to detect weapons and explosives (Ibid.).

Biometrics measure bodily life attributes (bios: life) and value them by characteristic (distinctive) features on the basis of a defined survey (metric: surveying). Biometry methods either work as verification systems (a user's identity has to match the implemented refe- 
rence measure, i.e. one-to-one comparison) or as identification systems (the system compares the implemented reference measure with acquired forms and discovers the most similar measure) focussing on minutiae of or in the human body. As the 'best match' in the latter system needs to have a defined minimum similarity, algorithms come into play. Whereas authentication systems with a PIN code are bit-precise 'right' or 'wrong', biometry systems have to work with a blunt reference-value. Therefore, the probability distribution of a system's decision-taking has to be categorised into 'true acceptance' and 'true rejections' (both the desired outcomes), and the 'false acceptance rate' (FAR) and 'false rejection rate' (FRR), both causing identification problems.

What needs to be highlighted here is that biometrics, including CCTV, both disembeds and de-couples information from its nexus - the whole human being. Secondly, while electronic legal and business transactions will increase, necessary authenticity mechanisms will lead to an unforeseeable exchange of biometry data, making re-identification and one-to-one marketing an easy task. Thus, the human being is being transformed into a data flow - for social sorting and profit generating purposes.

CCTV and biometrics are combined in several fields: the state-run prison in Mannheim (Germany) uses biometry terminals to monitor the movement of the 850 prisoners and their working hours, using their fingerprints. As the manager of the prison's financial department, Bernhard Ruland, states, the aim is to be sure at any time that "the correct prisoner is at the correct time at the correct place" (cited in Ziegler 2002, p. 38). ${ }^{8}$

Biometry is also used at several airports around the globe while using facial recognition systems and iris scanners. Schiphol Airport in Amsterdam uses the iris scan system Privium that checks the eyes to see if they match the ones recorded on a smart card before; Boston Logan Airport uses the Facelt system (Lyon, 2003); the Berlin Tegel Airport uses the ZN-Vision Technologies facial system to monitor their staff; the Sydney Airport uses the German system Cognitec to control its 6,000 personnel (Eick 2003); Keflavík Airport in Iceland too uses equipment from ZN-Vision Technologies, the world's leading German company in facial recognition situated in Bochum (Lucius 2002).

Expected to come are combinations of biometrics and CCTV with geographical profiling systems, like in the sniper case in Washington, D.C. in November 2002 (Grote 2002), and Global Information and Positioning Systems (GIS and GPS), expert systems and artificial neural networks (Hesse 2002). Boston began its Urban Neighbourhood Information System in the early 1990s, now using GIS. Data collected on block, group, tract and zip code level contributed by Boston public schools, Boston police, Department of Health, Business Directory, and others have led to a database including over 1,000 neighbourhood indicators (Pattavina et al 2002).

"J apanese television", he explained.

"That's nice", she said, not sure what response he was looking for.

"And not just J apanese. Chinese, Russian, every movie station in creation - I can get them all with this. My brother is in the Navy, works in electronics. He fixed me up with a special satellite dish that will pick up signals others can't. I can watch movies or TV shows from almost anywhere." 
"You speak Japanese?"

"Nope, but if I ever learn, I'll have something to watch."

(24/7, Jim Brown, 2001, p. 2-3)

\section{Breathing-space: Re-scaling the Surveillance of Injustice}

There are only a few evaluations, but current field research in Germany, Europe and the US shows that FA and FR rates are much higher in the field compared to those in controlled environments, such as companies' research areas or presented in computer fairs (Sietmann 2002; Hesse 2002). This is also true for CCTV systems, as Clive Norris and others have noted (Graham 1998; Lyon 2003).

Although there is evidence that biometric, genetic and video data may now be processed and cross-checked against each other, up to now this does not function on the level of everyday life. Even commercial research institutes and companies sometimes agree that it might take some more time to come forth with everything. An expert group of the US Federal Aviation Administration (FAA) concluded that the biometry industry "is not prepared to meet the demands of the FAA". Due to incomplete evaluations, it might take five to ten years "to have the maturity needed". TeleTrusT, an NGO funded by the German Department of Commerce, admitted error rates in fingerprint and facial recognition systems between 2 to 20 percent, ${ }^{9}$ and adds: "Biometric systems on a large scale will function within five, maybe even ten years" (cited in Sietmann 2002, p. 148).

Whether one wants to see these processes as 'Orwellian' or in the sense Foucault discussed Bentham's 'Panopticon', what needs to be highlighted is that most of the systems do not function properly and many are more or less easy to fool and overcome (Busch and Daum 2002; Costello 2002; Thalheim et al 2002; Ziegler 2002). But while algorithms, biometrics and neural networks are improving along with CCTV, GIS and GPS, the transformation of human beings into a set of parameters within given bandwidths is more than likely.

\section{NOTES}

1. Surveillance, as I use it here, refers to the increasingly routine use of personal data and systematic information in the administration of agencies, businesses and institutions. Surveillance, i.e. watching from above, at the same time implies a dominant position of the observer shaping the observed.

2. For example, since the sixteenth century technological innovations and the restructuring of the respective welfare systems have gone hand in hand, leading to administrative centralisation and transparency (Gilliom 2001, p. 22-37); ID-card systems have been introduced during times of war in several countries, in which they either remained in place or were dismantled (Torpey 2000).

3. Following Moody (1997, p. 119-120), I refer to the neoliberal project as a mixture "of neoclassical economic fundamentalism, market regulation in place of state guidance, economic redistribution in favour of capital (known as supply-side economics), moral authoritarianism with an idealised family at its centre, international free trade principles (sometimes inconsistently applied) and a thorough intolerance of trade unionism".

4. Playing together the 'minutiae game' with the human body (see below).

5. (Autonomous) media, artists and the (off-)culture industry are part of this promotion - somehow 'playing' with the panoptic and synoptic parts of the 'game' (see among others http://www.made.org and http:// www.panix.com). 
6. The notion of 'control' refers to an ongoing debate on whether or not current societies are shifting from 'disciplinary societies' to 'control societies'. Any detailed discussion of this complex picture would require a separate research paper (see Deleuze 1993). What can be said is that hidden CCTV systems focus more on 'control', whereas open systems clearly attempt to strengthen 'discipline'.

7. Biometrics: Individual attributes such as fingerprints, irises, retinas, hand geometry, vein patterns, voices, faces and of course DNA; for an overview see Lyon 2003.

8. It is clear, of course, that like welfare centres and refugee camps, homeless shelters and prisons are most likely to be covered by CCTV; indeed, as an internal report from the Berlin Senate notes: "The surveillance by CCTV and sensor systems within and outside of the establishment [state prison Tegel, V.E.] is, due to worn out material and malfunctions, no longer guaranteed. The sensors have been switched off because of nonrepairable malfunctions" (Expertenkommission 1995, p. 53); in some cases of surveillance, 'dummies' and illegal systems are in operation (Reichert et al 2002, p. 6-7; Ziegler 2002, p. 38; Eick 2003).

9. To compare: an error rate of only $0,1 \approx$ (per mille!) out of ten million flight passengers will lead to about 1,000 false alarms; given current worldwide travel, an unacceptable number.

\section{REFERENCES}

1. Busch, Christoph and Henning Daum "Frei von Zweifel? Biometrische Erkennung: Grundlagen, Verfahren, Sicherheit" (c't No. 5, 25 February 2002) p. 156-161.

2. Costello, Sam "J apanese researcher gums up biometrics scanners" (Infoworld http:// www.infoworld.com/ articles/hn/ xml/ 02/05/16/020516hngums.xml, 16 May 2002).

3. Deleuze, Gilles "Postskriptum über die Kontrollgesellschaften" (Unterhandlungen 1972-1990 1993, Frankfurt/M.) p. 254-262.

4. Eick, Volker "Der deutsche Bahnhof - Zentrale oder Filiale der panoptischen Stadt des 21. Jahrhunderts? Aktuelle Sicherheitsdiskussionen - strategien und praxen bei und im 'Umfeld' der Deutschen Bahn AG" (http:// www. bigbrotherawards.de/2000/.gov/add.html, 1998, Frankfurt/M.).

5. Eick, Volker "New strategies of 'policing' the poor: Berlin's neo-liberal security system" (Paper presented at the conference Urbanising War/Militarising Cities: Cities as Strategic Sites November 6-9 2002, Manchester, http:// www.surf.salford.ac.uk/ documents/strategicsites.htm).

6. Eick, Volker "We call it hard technology for a hard world" (Surveillance in Germany and its Industry unpublished, 2003, Berlin).

7. Expertenkommission (ed.) "Bericht der unabhängigen Expertenkommission für eine Sicherheitsanalyse der Berliner J ustizvollzugsanstalten des geschlossenen Männervollzugs" (Internal paper, May 1995, Berlin).

8. Flusty, Steven "Building Paranoia" (in Ellin, Nan (ed.) Architecture of Fear 1997, New York) p. 47-59.

9. Fyfe, Nick R. and J on Bannister "The eyes upon the street: Close-circuit television surveillance and the city" (in N. R. Fyfe (ed.) Images of the Street: Planning, Identity and Control in Public Space 1998, London) p. 254-267.

10. Garland, David The Culture of Control (2001, Oxford).

11. Gilliom, John Overseers of the Poor: Surveillance, Resistance, and the Limits of Privacy (2001, Chicago/London).

12. Graham, Steven "Towards the Fifth Utility? On the Extension and Normalisation of Public CCTV" (in Norris, Clive, Jade Moran and Gary Armstrong (eds) Surveillance, Closed Circuit Television and Social Control 1998, Aldershot) p. 89-112.

13. Grote, Andreas Algorithmus zur geografischen Lokalisierung von Straftätern (http:// www.telepolis.de, 12 October 2002). 
14. Haggerty, Kevin D. and Richard V. Ericson "The Military Technostructures of Policing" (in Kaska, Peter B. (ed.) Militarising the American Criminal J ustice System 2001, Boston) p. 43-64.

15. Hempel, Leon and Eric Töpfer Inception Report (Working Paper No. 1, http://www. urbaneye.net, 2002, Berlin).

16. Hesse, Layne "The Transition from Video Motion Detection to Intelligent Scene Discrimination and Target Tracking in Automated Video Surveillance Systems" (Security J ournal Vol. 15, No. 2, 2002) p. 69-78.

17. Jessop, Bob "Globalisation, Entrepreneurial Cities and the Social Economy" (in Hamel, Pierre, Henri Lustiger-Thaler and Margit Mayer (eds) Urban Movements in a Globalising World 2000, London/New York) p. $81-100$.

18. Jessop, Bob The Future of the Capitalist State (2002, Cambridge).

19. Kerr, Philip Gridiron (1995, London).

20. Koskela, Hille "The Gaze without Eyes: Video Surveillance and the Changing Nature of Urban Space" (in Koskela, H. (ed.) Fear, Control \& Space: Geographies of Gender, Fear of Violence, and Video Surveillance 1999, Helsinki) p. 1-23.

21. Lea, John "Post-Fordism and Criminality" (in Jewson, Nick and Susanne MacGregor (eds) Transforming Cities, Contested Governance and New Spatial Divisions 1997, London/New York) p. 42-55.

22. Lucius, Robert V. "Das Profil der Masse" (Frankfurter Allgemeine Zeitung 1 August 2002) p. 13.

23. Lyon, David (ed.) Surveillance as Social Sorting: Privacy, Risk and Automated Discrimination (2003, London/ New York).

24. Miyake, Perry $21^{\text {st }}$ Century Manzanar (2002, Los Angeles).

25. Moody, Kim Workers in a Lean World (1997, New York).

26. Narr, Wolf-Dieter (ed.) Wir Bürger als Sicherheitsrisiko (1977, Reinbek).

27. Pattavina, April, Glenn Pierce and Alan Saiz "Urban Neighbourhood Information Systems: Crime Prevention and Control Applications" (J ournal of Urban Technology Vol. 9, No. 1, 2002) p. 37-55.

28. Peck, Jamie and Adam Tickell "Neoliberalising Space” (Antipode Vol. 34, No. 3, 2002) p. 380-404.

29. Piglia, Ricardo Die abwesende Stadt (1994, Köln/Le Bois).

30. Reichert, Andreas, Andreas Zirngibl and Robert Kotok "Videoempirie" (Videoüberwachung in Berlin TU Berlin, WS 2001/2002).

31. Ronneberger, Klaus, Stephen Lanz and Walter Jahn Die Stadt als Beute (1999, Bonn).

32. Rosen, Jeffrey "Silicon Valley's Spy Game" (The New York Times Magazine http://www.nytimes.com/ 2002/04/14/magazine/14techno.html, 14 April 2002).

33. Sietmann, Richard "Die ultimative Überwachung. Personen-, Objekt- und Raumkontrolle mit neuartigen Techniken" (c't No. 17, 12 August 2002) p. 94-95.

34. Stephenson, Neal Snowcrash (1992, London).

35. Thalheim, Lisa, Jan Krissler and Peter-Michael Ziegler "Körperkontrolle Biometrische Zugangssicherungen auf die Probe gestellt" (c't No. 11, 21 May 2002) p. 114-123.

36. Torpey, John The Invention of the Passport. Surveillance, Citizenship and the State (2000, Cambridge).

37. Waring, Alan and lan Glendon Managing Risk (1998, London).

38. Ziegler, Peter-Michael Katzenjammer "Biometrie: eine Branche in Erklärungsnot” (c't No. 12, 3 J une 2002). 
Practices + Politics / 331

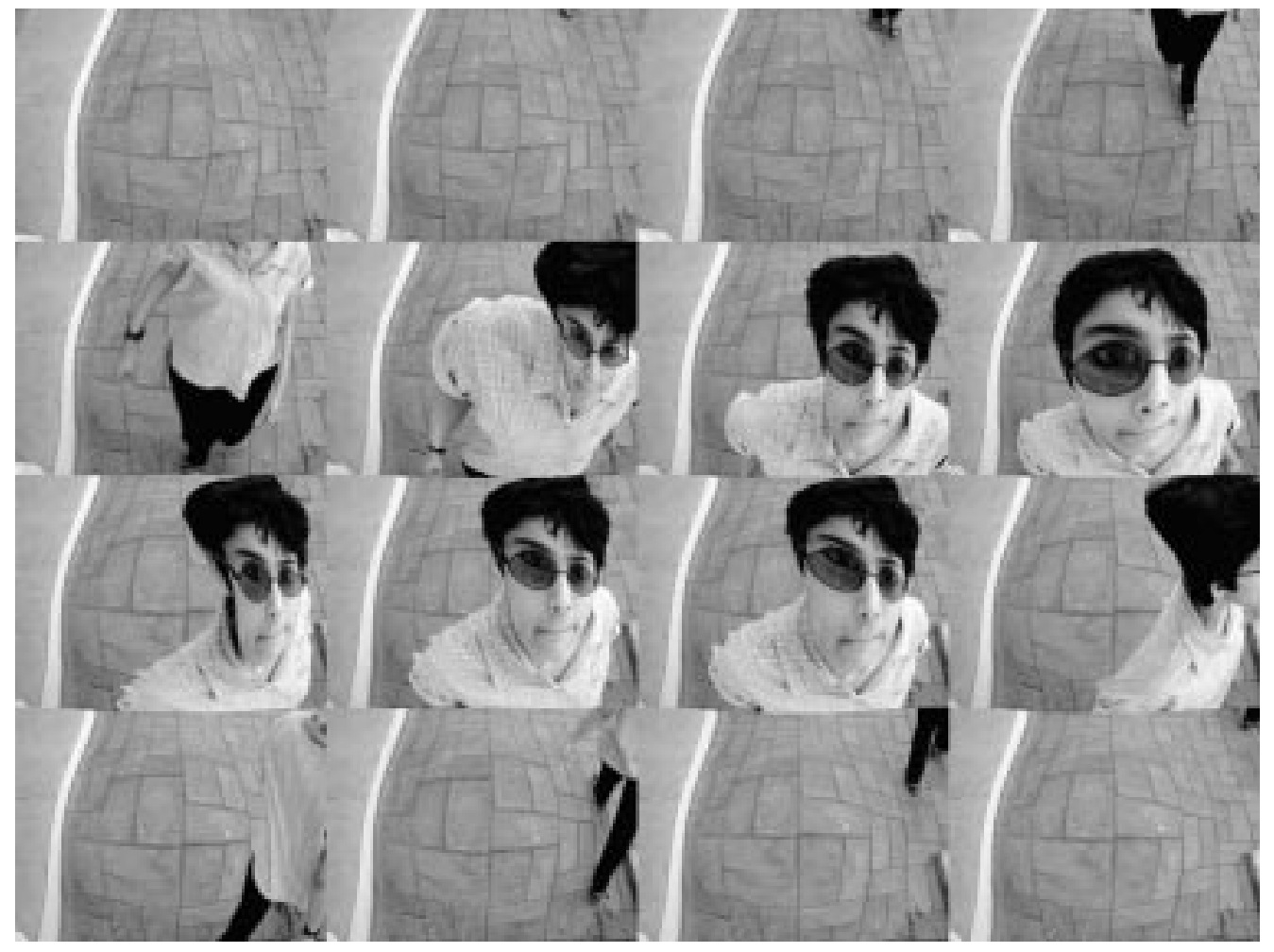




\section{Resistance is Futile Peer-to-Peer File Sharing and Big Media}

ROBERT X CRINGELY

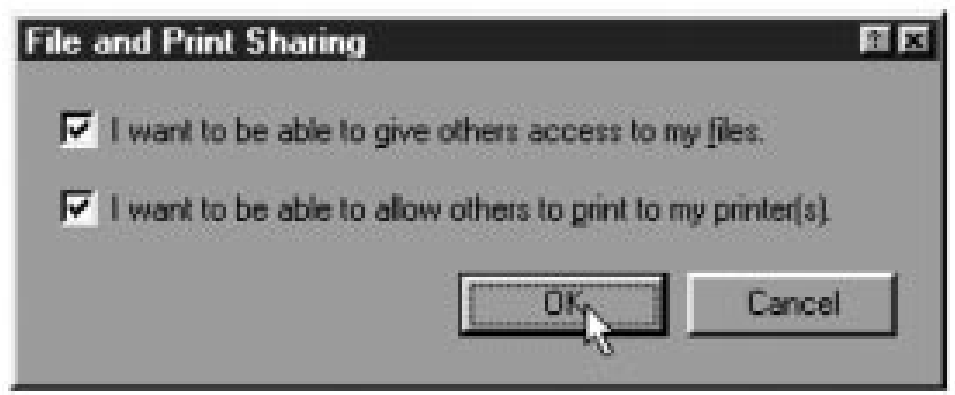

M aybe you saw the story about a paper from Microsoft Research analysing peer-topeer file sharing networks with the conclusion that they can't be stopped - not by the law, not by the movie studios and record companies, not even by mighty Microsoft and its Palladium initiative for trusted computing. Swapping songs, and maybe movies, is about to reach a critical mass beyond which it simply can't be stopped, or so the kids in Redmond think. The story is interesting and that it came from Microsoft is even more interesting, although the authors carefully disassociated themselves from their employer in the paper.

But this all pales in comparison to the implications of their conclusions. These are smart folks who are taking a stand that is surely not popular with their company, so I think there is a pretty strong reason to believe they are correct. If so, then what does it mean? Are record companies and movie studios doomed? As a guy whose work is regularly rippedoff, am I doomed too? And will the print publishers go away, leaving us with only weblogs to keep us warm? I don't think so, but the world is likely to change some as a result.

Maybe it would help to take a look at what publishers, broadcasters and Movie Moguls do that makes them significant contributors to our culture: they take financial risks by backing talented people in the hope of making money. Publishers, broadcasters, filmmakers and record executives have taken the time and spent the money to build both a commercial infrastructure and a brand identity. The most extreme version of such financial risk-taking is spending tens of millions - sometimes hundreds of millions - to make a movie. Forgetting for the moment that some of these media people are greedy pond dwellers, let's ask the 
important question - how are peer-to-peer file sharing systems going to replace 100 -milliondollar movies? Peer-to-peer systems can share such movies, but since there is no real peerto-peer business model that can generate enough zeroes, such systems are unlikely to finance any epic films. Well, right there is a problem: people LIKE epic films, but even with the best editing and animation software, there is no way some kid with a hopped-up Mac or PC is going to make Terminator 4. One can only guess that people will continue to go to movies and eat popcorn and watch on the big screen, despite however many copies of Divx there are in the world.

Peer-to-peer movie piracy is practical only in the manner that any organised crime is practical: it works only as long as the host remains strong enough to support the parasite. Tony Soprano can't run New Jersey because then everyone would be a crook and there would be nobody to steal from except other crooks. There would be no more innocent victims. The same goes with movie piracy, which needs a strong movie industry from which to steal. If the industry is weakened too much by piracy, the pirates begin to hurt themselves by drying up their source of material. It is very doubtful that this will happen, because in all likelihood the pirates want to go to movies too.

But the same is not true for records. This is because technology has reached the point where amateurs can make as good a recording as the professionals. The next Christina Aguilera CD could be recorded at her house, or mine, just as easily as in some big recording complex on Abbey Road.

And text: well, text is even worse because it is the easiest of all to steal. My columns are published in newspapers and web sites and handed in as college essays all over the world and there is almost nothing I can do about it because tracking down the perps costs me more than their crime. From the perspective of the established publishers, there is also the horrible possibility that people might actually come to prefer material they find for free on the Internet - not just pirated material but even original material. This column, after all, is free, and my Mother claims to find some value in it from time to time.

So movies, while they may be hurt by peer-to-peer, won't be killed by it. But print publishing and music recording could be seriously hurt. Maybe this is good, maybe it is bad, but most probably it is inevitable.

Of course, the recording and publishing executives, who often work for the same parent company, aren't going to go without a fight. We are approaching the end of the first stage of that fight, the stage where they try to have their enemy made illegal. But the folks at Microsoft Research now say quite definitively that legal action probably won't be enough. That's when we enter stage two, which begins with guerrilla tactics in which copyright owners use the very hacking techniques they rail against to hurt the peer-to-peer systems. This too shall pass when bad PR gets to the guerrillas. The trick to guerrilla or terrorist campaigns is to not care what people think, but in the end, Sony (just one example) cares what people think. This is when the record companies and publishers will appear to actually embrace peer-to-peer and try to make it their own. This will be a ruse, of course, the next step in the death of a corrupt and abusive cultural monopoly. They'll say they will do it for us. They'll say they are building the best peer-to-peer system of all, only this one will cost money and it won't even work that well. There is plenty of precedent for this behaviour in other industries. 
My favourite historical example of this phenomenon comes from the oil business. In the 1920s, the Anglo-Persian Oil Company had a monopoly on oil production in the Middle East, which they generally protected through the use of diplomatic - and occasionally military - force against the local monarchies. Then the Gulf Oil Company of Pittsburgh, Pennsylvania, literally sneaked into Kuwait and obtained from the Al-Sabah family (who still run the place) a licence to search for oil. The Anglo-Persian Oil Company did not like Gulf's actions, but they were even more dismayed to learn that Gulf couldn't be told to just go to hell. Andrew Mellon, of the Pittsburgh Mellons, was the US Secretary of the Treasury, and he wasn't about to let his oil company be pushed around by the British Foreign Office. So Anglo-Persian and the Foreign Office did their best to delay Gulf, which worked for several years. They lied a little, lost a few maps, failed to read a telegram or two, and when Gulf still didn't go away, they turned to acting stupid. As the absolute regional experts on oil exploration, they offered to do Gulf's job, to save the Americans the bother of searching for oil in Kuwait by searching for them.

The Anglo-Persian Oil Company searched for oil in Kuwait for 22 years without finding a single drop. Remember that Kuwait is smaller than Rhode Island, and not only is it sitting on top of more than 60 billion barrels of oil, it has places where oil has been known for more than 3,000 years to seep all the way to the surface. Yet Anglo-Persian was able to fulfill its contract with Gulf and keep two oil rigs continually drilling in Kuwait for 22 years without finding oil. To drill this many dry wells required intense concentration on the part of the British drillers. They had to not only be NOT looking for oil, they had to very actively be NOT LOOKING for oil.

Back to music and text publishing. I think we should expect industries to offer peer-topeer systems that won't work very well and will cost us something instead of nothing. In the long run, however, these systems will probably die too, at which point the music and the print folks will have to find another way to make their livings. This will not be because of piracy, but because of the origination of material within the peer-to-peer culture itself. We're not that far from a time when artists and writers can distribute their own work and make a living doing so, which makes the current literary and music establishments a lot less necessary.

But these establishments won't die altogether because of the record companies' backlists of music, because peer-to-peer doesn't do a very good job of self-organising and indicating what is important, and because people won't take tablet computers with them to the bathroom. So we will have little movies and little records and little magazines on the Internet since the Internet is made up of so many different interest groups. For the larger population, there will still be Brittany Spears and Stephen King singing and writing for big labels. And that will only start to change when the first really big artists jumps from old media to the new, trading 15 percent of $\$ 30$ times 100,000 copies for 100 percent of $\$ 0.50$ times 1 million copies. The Grateful Dead showed that it is possible to make a great living even in competition with some of their audience. This is a lesson all old media must learn in time. Either that, or die. 


\section{The 'Darknet' \& Trusted Computing}

RANA DASGUPTA

7 he problem with that time - and we're talking cusp of the $21^{\text {st }}$ century - is that no one was prepared to do much intellectual labour. Everyone knew that relations were jamming - I know, I wrote stuff down - but there was no imagination in the air and no one tried to think of new forms - new economic forms, legal forms, social forms; and those that were making money up till then just tried to protect their old revenue streams as strenuously and for as long as they could. It was ridiculous. I guess that big corporations had had a long stint of ordinary people identifying with their interests, so they thought they could sell anything to them. Maybe that was it. But that was never going to last in the face of this.

You have to realise that in those days sending digital objects around the Internet didn't have the feel of a crime. Everyone was doing it. In some cases they'd made complex infrastructures for doing so. They had built deep social webs over that space that gave them a sense of owning it. A lot of people lived their whole lives in electronic space - everything: personal stuff, social, cultural and intellectual... Even the corporations themselves had told them they could do anything they wanted with wired computers!- remember that time? - it was all about freedom and breaking out of the past into a future of unlimited communications possibilities.

And the crackdown was ferocious. So when you think about it, what happened next wasn't very surprising.

The corporations knew they were playing a time game. It was going down but they thought make money from it while it's still here. The first system was pretty basic - allocation of unique serial numbers to documents to allow tracing, automatic authentication of software, hardware, digital objects - it would disable anything unrecognised, fake, copied, old, free or blacklisted. They knew they weren't using their imaginations. I have it right here: on November $18^{\text {th }} 2002$, some guys from Microsoft stood up at a conference in Washington, DC and put it bluntly, "In addition to severe commercial and social problems, these schemes suffer from several technical deficiencies, which, in the presence of an effective darknet, lead to their complete collapse. We conclude that such schemes are doomed to failure". ${ }^{1}$ (Yes: that was when "darknet" was a term of corporate abuse...)

But you get together a coalition of that size and they are not going to let their expen- 
sive systems go down so easily. People didn't have a clue what this was going to mean. Even the people who were trying to wake everyone up sound naïve in retrospect; even campaigners like Richard Stallman sounded incredulous: he wrote, in terms that sound endearing today, that these systems "will continually download new authorisation rules through the Internet, and impose those rules automatically on your work. If Microsoft, or the US government, does not like what you said in a document you wrote, they could post new instructions telling all computers to refuse to let anyone read that document. Each computer would obey when it downloads the new instructions. Your writing would be subject to 1984-style retroactive erasure. You might be unable to read it yourself".2

Like I say, though, all these crazy locks on doors, all these paranoid systems rejecting even software that was perfectly good, all those covert middle class people who had never been criminals before, all the show trials and raids - it didn't really solve what it was meant to solve. Corporations never managed to take possession again of fluid digital commodities. But they lost the friendly faces they'd tried so hard to don. Sad, when you think about it. I put it down to the distinct lack of imagination of that time.

\section{NOTES}

1. Biddle, Peter, Paul England, Marcus Peinado and Bryan Willman "The Darknet and the Future of Content Distribution" (paper presented at 2002 ACM Workshop on Digital Rights Management, Washington, D.C., http:// crypto.stanford.edu/DRM2002/ darknet5.doc, 18 November 2002).

2. Stallman, Richard "Can you trust your computer?". For a more detailed examination of the implications of these technologies for users: www.gnu.org/philosophy/can-you-trust.html.
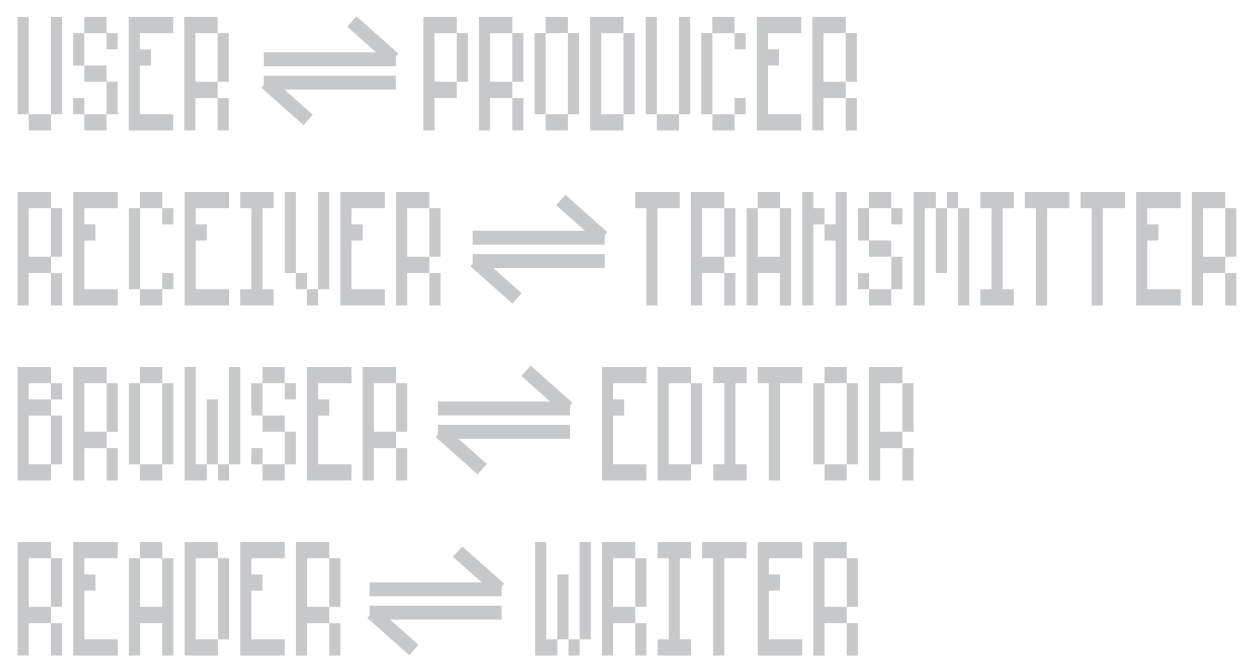


\section{Free as in Air An Interview with Vortex}

$\mathrm{T}$ he Georgian terraces on the corner of Hackney Road and Cambridge Heath Road house the usual run-down collection of cheap supermarkets, betting shops and kebab houses that you can find anywhere on the frayed edge of East London gentrification. The tall antenna protruding from the end flat could easily be mistaken for another taxi radio mast. In fact, the only clue that the air is humming with data, transmitted over a mesh of homebrewed Free Network nodes, is an innocuous sticker on the window of the upstairs flat that reads "free2air".

This is the headquarters of the free2air project, and home of its founder Vortex (a.k.a. Adam Burns). free2air is one of a global movement of Free Networks; networks that are built, maintained and grown by the labour of participants. From the kitchen window overlooking the gas works, Vortex points out five or six antennae as far as a kilometre away: neighbouring nodes that are connected to free2air by radio link. The network is fast and unmetered, so locals within line of sight use it to distribute audio/video streams, test software and share files amongst themselves.

This is not to say that the network is entirely non-commercial. In his sitting room Vortex shows me some exotic equipment. A small grey box connected to a router spreads out a network signal over the mains power lines reaching several houses along the street. The cheap Internet/call shop downstairs uses a twin grey box to share (as a commercial arrangement) the Internet connectivity of free2air, which helps subsidise the maintenance and growth of the free network.

Vortex picks up his bicycle and spins the wheels. Multicoloured LED lights spring to life drawing fantastic patterns like an electronic catherine wheel. "The ultimate geek toy", he says, grinning. "I've got to get more batteries for the next Warpeddling session".

WarPeddling is the cyclist's version of WarDriving: taking a wireless networked computer out in a car, and observing the presence and activities of any wireless nodes in the area. Although he uses the term, Vortex is quick to distance himself from the hype surrounding it. The word 'War' prepended to almost any motile activity has become a source of endless mass-media hysteria, in which Free Networking with the gadget appeal of wifi are paraded as 'edgy' or even avant-garde. Although this has been useful for the propagation of the Free Network idea, it has also been a flashback to the early 90 s net hype, and how the 'hacker' myth was used to scare people into letting government and big business administrate the Internet.

'Warchalking', for example, entails drawing symbols in chalk (based on a depression-

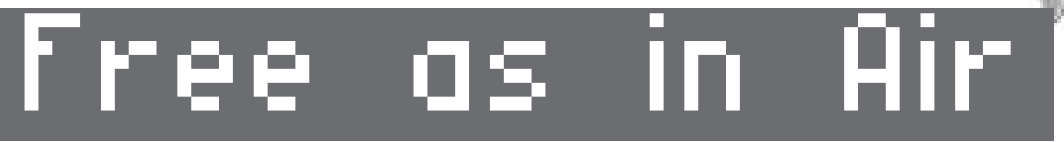


era 'hobo language') to represent the presence and state of a wireless network in an area. Not only was this 2002 's greatest tech-hype media story, but the spectacle of laptop wielding technocrats territorialising the city was also a frank demonstration of the digital divide between the high-tech office and the street. This is not to say that the street is any less privileged a place than the network. In the wake of 'zero tolerance' inner city schemes and the suspension of Habeas Corpus in proposed 'anti-terror' legislation, the inner cities are beginning to look as regulated, exclusive and surveilled as the Internet.

However, the Free Network is not simply an extension of the Internet, but aspires to supersede it on some levels. This local information network to which access is geographically and socially determined is a formal inversion of McLuhan's much-abused idea of the 'Global Village': the utopian promise of 'online identity' and 'virtual community' that was used to sell the corporate Internet, and then hijacked for profit.

Although the technical infrastructure of the Free Network is built from the same routers, switches and software as the Internet, its origin has more in common with traditional independent media networks such as the Italian 'Free Radio' movement, New York's 'Paper Tiger' community TV station and the rich history of activist publishing and local distribution.

The terminology of 'community' that many Free Networks use is difficult. This is clearly a community of sorts, but not in the sense understood by 'community media'. The multiple modes of computer network usage preclude a unified experience of the network felt by listeners to the same radio station. One person might be sending e-mail, another listening to an audio stream. They are both using the Free Network, but are experiencing it very differently, so what does 'community' mean in this context? 'Community' also suggests some level of communal ownership of resources. However, if each participant owns their own node, and regulates use of resources such as electricity supply and roof access, what is communally owned?

Last year when Vortex was in hospital recovering from an operation, a gang of locals from the free2air network mobilised to clamber on to nearby roofs, finding friendly network connections to try to get wireless net access for him while he recovered. So while the experience of the network may well be alienated from any traditional sense of 'community', there is clearly a sense of belonging and a mutual generosity.

Vortex has also been helping to create a 'Pico Peering Agreement'. Drafted during an international meeting of Free Networkers in Berlin in October 2002, the agreement outlines the shared responsibilities and resources of the Free Network while trying not to limit its potential uses. The concept is taken from the way that huge 'backbone' Internet providers such as Linx in London or MAE West in the US use 'peering agreements' to barter rights to trans it data across each other's networks. This process applied on the lowest level of peers, that of individual, privately owned computers, becomes a pico or 'tiny' peering agreement.

This marks a potential turning point for Free Networks. As the corporate model of Internet infrastructure crumbles along with the Nasdaq index and media giants enforce draconian copyright laws internationally, these alternative models of network provision seem increasingly viable. The careful, legal formalisation of relationships between these 'pico peers' might pave the way for a more widespread peer network that operates independently of large providers or telcos. 
While there is still a lot of work to be done, both technical and social, free2air operates between the private and the public; articulating a communal space without falling into the adjacent traps of technocratic exclusivity, and top-down patronage.

>S Saul Albert: What does the word 'community' mean in the context of free2air and the Pico Peering Agreement?

$\gg$ Vortex: We're not constructing a community, communities self-form through our actions. I think it's very hard to say that a community is there because someone puts up a wireless gateway. That's one of the problems I had with the title of Rob Flickinger's book, Building Community Wireless Networks. ${ }^{1}$ I thought, 'Well, why is the ' $\mathrm{C}$ ' word in that book title at all?' J ust because a wireless gateway may be 'non-commercial' in some traditional sense, we're all bagged and boxed into the word 'community' that can be easily dismissed. Well, no thanks.

$>S A$ : There's nothing in that book that really deals with what is actually meant by the word 'community'.

$\gg \mathrm{V}$ : That's right, and I think this [Pico Peering] document starts to define the boundaries of communal participation, participation with each other, forming at least some structure; and the real community would form itself around that and everything else that we're doing.

$>S A$ : So rather than communal ownership, its communal participation, communal sweat.

$\gg \mathrm{V}$ : Absolutely. The participation forms the community.

$>S A$ : Where do the roots of ownership in wireless networks come from? We're talking about spectrum rather than land for example, but if you work on the land, you own it after a while. What is owned and what is communal? The activity?

$\gg \mathrm{V}$ : At the level of this planned document, what is common is the peering, the Pico Peering, the carriage of traffic for the greater good. In a sense it is a common wealth of information transfer and that can be nothing less and, at least to begin with, maybe nothing more. It might be as clinical and as technical as that.

$>$ SA: It is probably useful that it's so basic.

$\gg \mathrm{V}$ : Yes, but even so, there are many surrounding issues, as we tried to flesh out in Berlin, what the implications are for your local legal environment etc. I still get frustrated when [communal ownership of] services are mentioned, ${ }^{2}$ because I just don't see a useful way around that yet. At the moment Pico Peering should be about shunting data traffic. That's what a network, or a network of networks is all about. Personally, although I don't know what political nuance this would have in various parts of the world, I'm still thinking of words like 
'Federation'. That's the word I like to use, and l'd like to keep [this network] a non-entity: fluid, but defined by documents like this Pico Peering Agreement.

$>S A$ : For me 'Federation' is quite a libertine term.

$\gg V$ : Yes, it is soaked with other contexts. Umbrella groups like freenetworks.org could be an entity or banner that we all rally around, ${ }^{3}$ but I don't really want one banner. For a network of networks, or a community of communities if you like, decentralisation is the way to maintain a 'peer-to-peer' structure with no central organisation.

$>S A$ : Do you think the word 'free' is a good one to use?

$\gg \mathrm{V}$ : As we said in Berlin, I prefer the word 'Open', but even that is laden with problems. On the whole I do like 'free'. There are worse abusers of the word than us.

$>$ SA: I liked it because it does have this double meaning, there is always a discourse about it, maybe it is useful in that sense, and it does not have one fixed meaning... l've heard you raise objections to the idea of authentication, of identifying someone in the network before you allow them access. Why is that?

$\gg$ : Well, Why? What does authentication mitigate against? And how do you know the form of identity you have is accurate? There are whole procedures for people who are really paranoid about this. They don't swap PGP keys without a face-to-face meeting and accepted ID. ${ }^{4}$ You present your passport, then you hand-deliver a written PGP public key, and only then can you communicate with these people. Without that, some people won't accept PGP as a strong form of identification, because it can't be verified as being accurate - so how far do you take authentication? In the end there are technical measures to identify a machine that is abusing your network in some way, and there are the tools to manage that abuse. You might be able to, for instance, block the machine, or you may even go to the strange extent of monitoring the traffic to determine an e-mail address to communicate with them. You may do lots of things, or you may decide to use regulatory software, such as Nocat, ${ }^{5}$ on that abuser's IP address and say "Hi, you're taking up way too much of this bandwidth, this is an automated message asking you to be a responsible member of this community, please tone it down a bit". It all depends what policy of management you want to impose on your network, but the actual true identity of someone is immaterial.

Even if you ask people to register under a pseudonym - Why? Maybe, as James Stevens advocates ${ }^{6}$ it would help with building trust and social communication if you had some sort of 'handle', but that's like every J oe Schmuck web site which asks you to register a username and password... another one? I'm not convinced of how 'community building' that would be.

Maybe it can have some good... For instance, one of the issues with the East End Net lists at the moment is that people that we don't personally know are joining the lists, ${ }^{7}$ thinking these are a purely operational forum for the organisation of the network. That is a good 
indication of success, but at the same time we'd like to communicate the idea of East End Net as an informal cultural and community noticeboard. But I'm still wary of the collection of identities that could be used later for marketing purposes.

$>S A$ : Do you have people popping up on the network that you don't know?

$\gg$ V: Yes, all the time.

$>S A:$ And it doesn't bother you?

$\gg$ V: Not at all.

$>S A:$ Do you use any security products?

$\gg \mathrm{V}$ : I don't use the wireless component of this network unless I need to. All traffic out there is caveat emptor. That's up to the people who use it. If they're transiting super secret information, they have to take the necessary steps. We're just offering a service. We're not responsible for the way they treat their own data. Maybe it needs a 10-page disclaimer... "use of this product is not guaranteed to fry your dinner for you". That's my attitude.

With regards to Nocat, I'm still not $100 \%$ convinced either way. I can see where James Stevens is coming from, that collecting information is useful, but how far do you take it? I don't know yet. I did plan to put a trial Nocat up, and I will consider using it as an incident management tool. If I wanted to use it to get in touch with someone using the wireless net who passes traffic through our network, I can do it. I can ask Nocat to intercept this person's web traffic and talk to them. However, most abuse so far has come from peer-to-peer which just slams through the network, people leave their machines on, sucking up bandwidth.

>SA: Do you have bandwidth trouble yet?

$\gg \mathrm{V}$ : No. There have been moments, but as a rule, no.

$>S A$ : I also wanted to ask you about privacy. It seems like another word that crops up in conversation and writing about wireless networks a lot, but what does it mean in this context?

$\gg$ V: From an IT security standpoint, l'd define privacy as a control measure or a way of limiting access to information. Privacy, therefore, means that if information is only destined for a known group of people, you can use technologies such as encryption to control information access in that manner. If you want to control access to data, encryption can be used. That's data in transit, but the same applies to data in storage.

$>S A$ : So it falls to each person in the network to secure their own data? 
$\gg$ : Again, with ownership comes responsibility. Once you've got a piece of data, it is up to you how you treat it, how you disseminate it etc. I'm not one of these hardcore crypto junkies, because it is not worth my time to set up the network to do that, and it is severely limiting on the extension of the network because then you have to show people how to set up IPsec, and then there's the problem of NATing through it and a whole minefield. ${ }^{8}$ If you want to run secure systems that pass through our network, fine, but I'm not going to do the work. It is implemented in corporate environments because they have legal and best practice requirements to do so, but this is a different environment. ISPs like authentication for example, so they can have some level of surety that their services are used by the person who pays for them. Commercial operations have far more interest in having these controls imposed because there is money at stake.

$>S A$ : That was the idea I got from looking at ownership in the network, that privacy is a mechanism for controlling property, either transit as property, or intellectual property as property in a traditional sense.

$\gg V$ : I can see why, within this structure, encryption and/or some form of strong authentication may be required. And when the network grows in an ad hoc way and we start having dynamic routing, it might just be too easy for people to inject false routes and bring the network down. That is not a risk we want to deal with all the time. To stop that we may have to swap cryptographic keys between major sections of network, so as to minimise that damage. I can see that in the future, but not yet. It's like any kind of abuse, you have to identify it and then talk to people in the network around you to resolve the issue.

>SA: So privacy isn't a big issue in the general design of the network?

$\gg V$ : No. Because it's far more dangerous for you to collect your e-mail via POP server on the Internet than it is to have an unencrypted wireless network around. ${ }^{9}$ In POP you're sending your password in cleartext through networks over which you have no control. I've never lost any e-mail. But then again, none of my e-mail is really that important. If it were, I'd secure it or hire someone to set it up for me. It's a practical philosophy of being lazy, and wanting to keep things as open and as easy as possible. The KISS principle. ${ }^{10}$

$>S A$ : I think it is going to be much easier to motivate people to be lazy.

$\gg \mathrm{V}$ : Yes. You can't anticipate all the problems until they occur. When you do, iron them out. That's part of standard IT security incident procedures. Once something happens, you fix it, and then you go through a review cycle and incident forensics, and work out how to prevent it happening again. There's no point wasting your time trying to predict everything that's going to happen beyond the obvious.

$>S A$ : The nice thing about reactive security is that the Pico Peering Agreement (PPA) may be able to pare the basic responsibilities of node owners down to a few sentences, but with 
an ever-expanding set of footnotes that might become quite technical, and can be constantly updated.

$\gg \mathrm{V}$ : That's probably why I started [the PPA] with definitions of things I thought were needed, just to make sure that the terminology is understood. Do you know about the triple-A?

$>S A:$ No.

$\gg \mathrm{V}$ : Ok. Authentication, Authorisation, and Access Control are the three As that define different dimensions of IT security controls. Authentication is a satisfactory level of identification of who or what you're dealing with. Iris scanning, fingerprinting, PIN numbers are all ways of identifying an entity. Authorisation is what you allow that entity to do. Access Control is regulating access to resources, firewall rulesets and such.

$>S A$ : So in community networks, or open networks or free networks, or whatever you want to call them...

$\gg \mathrm{V}$ : I call it THE NETWORK in capital letters, like in legal documents. THE NETWORK defines the one in question. Other networks have a small ' $n$ '. That was my solution in the end, I couldn't think of another way of describing it.

>SA: Well, in THE NETWORK, authentication, authorisation and access control seem to be unnecessary.

$\gg \mathrm{V}$ : No, access control will be necessary. If you're passing data through, you want to make sensible decisions on what data you allow into your network. For example, the firewall ruleset on gateways here are as follows: ${ }^{11}$ transit traffic is totally open, outgoing traffic is totally open, but inbound traffic, and traffic into the dungeon downstairs (a proto-computer room with about 5 or 6 servers) is controlled. I don't mind passing of data or surfing the net or whatever, but access to the resources on my network, I want to keep separate, and have strong control over how that's used and who uses it.

$>$ SA: What resources are you talking about?

$\gg$ V: Data, services, all sorts. I've got trial software running down there, and development stuff.

>SA: So when we're talking about data, services, anything that's your property, suddenly access control becomes an issue. This is what I'm trying to find, where is the edge of what is communally owned, and why is authorisation, privacy and security not relevant to it?

$\gg$ V: It's all relevant, but l'd say that for the people who want to get involved in Pico Peering, one fundamental is that we should have Free Transit of data across our network. That is the 
cornerstone of what is communal. Anything else such as data and services you should be free to, and must, manage; but they are not, strictly speaking, within the common wealth. That's part of education in this project, educating people to be aware of the side effect responsibilities of ownership of their network resources, both the parts they wish to share, as well as the parts they wish to keep to themselves. If transit traffic is taking up most of your available bandwidth, you've got to start thinking about how you can take responsibility for your ownership of transit across your network.

$>$ SA: So the starting point is open, and controls are put in place by degrees as they become necessary.

$\gg \mathrm{V}$ : Yes, the same sort of thing as when we were talking about Nocat. You may find that due to a renegade host (maybe just a screwed up machine that's spitting out huge ICMP packets and is affecting your network) you need to put an access control on that host to prevent it disturbing other activities on your network. So it's this reactive approach again. How you deal with that, short of blocking the packets, is an interesting question. Sometimes it will be hard to communicate with the owner of that machine to tell them to turn it off. You may find it difficult to track that person down. That is where the benefits of authentication come into play. If you authenticate and relate a machine to a person, then presumably you've got human contact somehow, probably via e-mail. However, I still rail against authorisation because I think it is open to further appropriation. Users, databases, unless we're very careful can be harvested and so on. I'm very suspicious. There's no highly distributed tool that would enable us to do it that I'm comfortable with.

>SA: I still think it's a political standpoint. As much as is possible is put into a common, open or non-owned context. Ownership seems to be a key question in how we articulate the network, because once you've identified what is common and how to try and maintain the commonality of it, you can. Transit seems to be that commonality, obviously, a bit like the right to transit through physical space.

$\gg$ V: Yes, you want to avoid the "Halt, who goes there" moment. It is that point, philosophically, that we want to keep open. A packet passing through THE NETWORK is like a passenger passing through the transit lounge in an airport; it doesn't have to show a passport to get to the next destination. It is there at the hospitality of the owner of that part of THE NETWORK. However packets don't really wait very long, so maybe it's not the best metaphor, but it shows the difference between transit traffic (that just sits in the transit lounge and then passes on) and incoming traffic; a packet wanting to come into your little country which you then regulate with access control, authentication and authorisation to your own set of standards whatever they may be.

The problem is that if you're not going to have an open transit lounge, and you're not going to let everyone of every colour and flavour sit in your transit lounge chairs, then put a sign up. If you don't want smoking, put up a sign saying "No Smoking"; if you don't want 'peer-to-peer' across your network, put up a sign saying no peer-to-peer through this com- 
mon ground. Then take a control mechanism to enforce that - one you're happy with. The problem will be that unless there are standard ways of declaring this, troubleshooting networks later might become a nightmare. You need to be able to say that you would like to be open, but due to external circumstances or the way things are in your physical or legal environment, you can't allow certain types of traffic across THE NETWORK. Then what needs to happen is that this declaration has to sync up with the reality of how your access control is implemented. Otherwise it might be very difficult to diagnose routing issues or access issues that hop over various networks. This is the dual meaning with the word open; you are being open and communicative about the things that you don't allow. It is a communal responsibility to communicate, to participate, to declare. You don't even have to be logical or give reasons, it doesn't have to make sense, it is openness - as in transparency.

\section{NOTES}

1. Flickinger, Rob Building Wireless Community Networks (O'Reilly \& Associates, 2001, New York/ London). This is a 'mainstream' tech publisher's attempt to cash in on the Free Networks idea. As Vortex points out, the book is mostly technical and never addresses the social implications and applications of the technology.

2. Such as web servers, mail servers, SMS gateways, mapping programmes etc.

3. Freenetworks.org is a general service that maps locations of network nodes globally, rather than just locally. It has been seen as a 'central' database of FreeNetwork nodes.

4. Pretty Good Privacy, a strong cryptographic system for identifying and verifying digital 'signatures'.

5. One of a number of software products developed for Free Networks to regulate and authenticate access to the network (see http:// www.nocat.net).

6. James Stevens, co-founder of http:// www.consume.net, a large Free Network group in London.

7. The e-mail lists associated with free2air for organisation, discussion and social communications.

8. Network Address Translation; a way to use one computer as a 'gateway' for other machines to connect to the network. The gateway has a public IP address, and it routes data between machines it can see on this public address and other computers behind it that are on a private network. Vortex is referring to the fact that securing the communications of the gateway interferes with its ability to perform NAT.

9. Post Office Protocol: the protocol that many people use to collect and send their e-mail. POP is insecure because passwords are sent unencrypted, and can be read by anyone who is monitoring the IP traffic of a machine.

10. Keep It Simple Stupid: http:// www.tuxedo.org/ esr/jargon/html/ entry/ KISS-Principle.html

11. A firewall ruleset is a document that defines how a gateway deals with network requests. 


\section{The Language of Tactical Media \\ JOANNE RICHARDSON}

\section{"World War III will be a guerrilla information war, with no division between military and civilian participation."}

Motto of Tactical Media Crew, borrowed from Marshall McLuhan

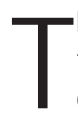
he future is a series of small steps leading away from the wreckage of the past; sometimes its actors walk face forward, blind to the history played out behind their backs, other times, they walk backwards, seeing only the unfulfilled destiny of a vanished time. The promise of the tactical media of the future - the end of the spectacular media circus as everyone begins to lay their hands on cheap 'do it yourself' media technologies made possible by new forms of production and distribution - was inspired by a distinction between tactics and strategies made by Michel de Certeau in 1974. Strategies, which belong to states, economic power and scientific rationality, are formed around a clear sense of boundary, a separation between the proper place of the self and an outside defined as an enemy. Tactics insinuate themselves into the other's place without the privilege of separation; they are not a frontal assault on an external power, but makeshift, temporary infiltrations from the inside through actions of thefts, hijacks, tricks and pranks. But for de Certeau, the distinction was almost entirely focussed on the power of reading (the consumption of signs) to transform submission into subversion. The most memorable example of tactics in The Practice of Everyday Life is the indigenous Indians who under Spanish colonisation appear to be submissive but really "often made of the rituals, representations and laws imposed on them something quite different from what their conquerors had in mind; they subverted them not by rejecting or altering them, but by using them with respect to ends and references foreign to the system they had no choice but to accept". Apparently submissive, they kneel, bow down, put their hands together in prayer, but they don't believe the words; when they mouth them they secretly mean something that was not intended by the original producers. The strength of their 'resistance' is in their silent interpretations of these rituals, not in their transformation.

Maybe the most interesting thing about the theory of tactical media is the extent to which it abandons rather than pays homage to de Certeau: making tactics not a silent pro- 
duction by reading signs without changing them, but outlining the way in which active production can become tactical in contrast to strategic, mainstream media. The examples of tactical media have become almost canonical by now: billboard pirating by Adbusters, plagiarised web sites by the Italian hackers, 0100101110101101 .org, RTMark's mock web sites for G.W. Bush and the World Trade Organisation, and (as theYes Men) their impersonations of WTO representatives to deliver messages that don't challenge the WTO's position but over-identify with it to the point of absurdity. In contrast to mainstream media, tactical interventions don't occupy a stable ideological place from which they put forward counterarguments; they speak in tongues, offering temporary revelations. But while shifting the emphasis from the consumption of signs to an active form of media production, the theory of tactical media seems to have lost some of the original contours of de Certeau's distinction. The tactical media universe as mapped by David Garcia and Geert Lovink in The ABC of Tactical Media also included 'alternative' media, although its logic seems quite different. Grassroots initiatives which are focussed on building a community around other values than the mainstream do occupy an ideological place that is marked as different; they don't infiltrate the mainstream in order to pirate or detourn it, as RTMark might infiltrate the media image of the WTO.

And especially in the recent transformation of alternative media into the global Indymedia network, the separation between Indymedias' alternative voice and the mainstream enemy is quite evident. Indymedia critiques the pretensions of mass media to be a true, genuine, democratic form of representation; it opposes the false media shell with counter-statements made from a counter-perspective - a perspective that is not questioned because it is assumed as natural. My Italian friends who work with Indymedia showed me a video they co-produced about the anti-globalisation demonstrations in Prague and asked what I thought. I replied that it was a good piece of propaganda, but as propaganda it never examined its own position. In this video you see a lot of activists who came to Prague from America, UK, Netherlands, France, Spain, Italy, etc; occasionally you even get ossified Leninist bullshit from members of communist parties. What you really don't get is any reflection of the local Czech context - many locals denounced what they saw as an attempt to playact a revolution by foreigners who invoked slogans from an ideology the Czechs themselves considered long obsolete. The confrontation of these different perspectives is absent from the video, since it is meant to promote Indymedia's own anarcho-communist position, raised to the level of a universal truth. And in this sense it was as strategic and dogmatic as mainstream media; it was only the content of its message that differed.

De Certeau was a child of his time; maybe as a former J esuit he was more timid and better behaved than his siblings, but he played with the same conceptual toys. In its historical moment tactics was an important idea that sought to define a way of subverting the information spectacle that would avoid using the same tools (strategies) against its opponent. Tactics recycled the Situationist idea of detournement: taking over the images and words from mass culture, but putting them through an unexpected detour, using them in a way they were not originally intended by combining them in surprising combinations, heretical juxtapositions. The Lettrists kidnapped a priest and, dressed in his gown, gave a sermon at the Notre Dame on the death of god; the SI altered the soundtracks of karate and 
porn films to reflect the struggle against bureaucracy; even striking workers during May 68 stole the media image of James Bond with a gun for a poster announcing themselves as the new spectre haunting the world. These were neither art, nor political speech; their disruptive power was that they did not use the familiar, straightforward language of politics. Their wit and lack of directness was a measure of their success; the danger always lurking in the background was that this new mode of production through theft and infiltration of public spaces, including the media, could ultimately be used to deliver the same kind of blunt, inflexible propaganda as the media spectacle. As a practice, detournement reflected a contradiction between the recognition that fighting on the same terrain as the enemy is a seductive but inevitable trap, and the desire to occupy the buildings of power under a new name. This contradiction crystallised in the hijacking metaphor: detourne was a verb commonly used to describe the hijacking of a plane.

The SI played upon this connotation, announcing their own productions as hijackings - of films, of politics, of quotidian desires. The terrorist as a symbolic equivalent of the subversion of power was never far in the background of associations. And in an almost straight line stretching across the precipice of history, aesthetic terrorism continues to be invoked as an honorific title. Etoy advertise themselves as "digital terrorism"; in an interview, Mark Dery called CAE a "philosophical terrorist cell" and made comparisons to the Red Brigades; RTMark is often congratulated for its brand of "media terrorism". Now it could be lamented that an unfortunate metaphor is being applied to practices that are very different - but in what sense is the affinity only a matter of metaphor? Terrorism is a way that the weak, lacking the strength in numbers and political influence, can try to make use of the strong by infiltrating their places of power, in the hope that the temporary seizure of a key building, an airplane, or a politician might shift the balance of things and bring power to the bargaining table. Ever since terrorism abandoned the tradition of tyrannicide and became a form of propaganda of the deed, it operated through a hijack of the media. Letters to the press, communiqués: five minutes under the opaque illumination of the media spotlight. The terrorist use of media hijacks is the point where tactical media and strategy meet - it may be a surprise infiltration rather than a direct attack, but an infiltration with a clear sense of separation between its own position and that of the enemy, an infiltration that ultimately mirrors the political organisation, juridical system and mode of expression of the power it opposes. The Red Brigades' hierarchy of brigades, columns, national branches, and an executive committee was a double of the centralist organisation of the state; the Weather Underground's counter-institution of 'proletarian' justice mimicked the obscenity of the law in reverse: "We now find the government guilty and sentence it to death on the streets". And today's fundamentalist terrorism is a mirror of the network society of a stateless, global capitalism. Western educated bin Laden militants don't belong to any specific country; they travel the globe from Bosnia to Paris and New York, use the Internet and cellular phones, and have access to communication networks even in a desert cave.

Asking how media can be used tactically today implies a recognition of the contradictory history in which the idea was born - the moment of crisis when new social forces rendered old categories obsolete, and Marxism began to reveal itself as a bankrupt system in which capitalism found not its abolition but its supreme fulfilment. But alongside new ideas 
and the search for a new language, lingered old modes of organisation dating back to the Jacobin terror of the French Revolution, and the mythic image of the armed, militant hero. Tactics sought to express a new way that the weak could fight against power by using different tools - but in the old language of military engagement.

Before de Certeau, the distinction between tactics and strategy was invoked by Clausewitz in 1812. Tactics is the manner of conducting each separate combat; strategy is the means of combining individual combats to attain the general objective of the war. Tactics is the deployment of individual parts; strategy, the overview of the whole. This is a very different distinction from de Certeau's opposition between modes of combat; de Certeau's tactics is closer to what Clausewitz called strategem - a concealed, indirect movement which doesn't actually deceive but provokes the enemy to commit errors of understanding. This is analogous to what Sun Tzu termed a "war of manoeuvre" - an artifice of diversion undertaken by weak forces against a large, well organised opponent, an unexpected move that entices the enemy, leading him to make mistakes and eventually selfdestruct. Whether direct or concealed, offensive or defensive, using the strength of numbers or the artifice of diversion, both strategy and tactics belong to the art of warfare and have the same objectives: conquering the armed power of the enemy, taking possession of his goods and other sources of strength, and gaining public opinion by destroying the enemy's credibility. And perhaps this is the limitation of a media theory based on a distinction between tactics and strategies - ultimately both are a form of war against an enemy power. The tactics of media hacks may differ from the strategy of independent, alternative media in their formal aspects, but what seems common to both is their self-definition through an act of opposition. A fake G.W. Bush page cannot exist without the authentic one, which it parodies. Indymedia cannot exist without global capital, whose abuses it chronicles, or without mainstream media, whose falsifications it denounces. The mainstream also needs an embodiment of opposition to the universal values of democracy, enlightened humanitarianism, and the right to consume without restraint. And after the collapse of the other of 'Eastern Europe,' the image of the terrorist is now the perfect media fantasy, the face against which it can define its own values in reverse.

This reflection was occasioned by my editorial participation in the $4^{\text {th }}$ Next 5 Minutes Festival; it's an attempt to think about its content, which proposes an investigation of the meaning of tactical media in the wake of September 11, and its decentralised organisational structure, which will transform it into a series of dispersed but linked events, each focussed on different local issues. If, as David Garcia admits, the idea of tactical media grew out of a specifically Amsterdam context (or perhaps in a wider sense, the liberal democratic context of the countries of advanced capitalism), it is commendable that N5M4 is attempting to transcend its origins and include initiatives that were previously left out of what seemed to be a primarily 'Western' idea of tactical media. The editorial team for N5M4 includes media tacticians like CAE, members of the Indymedia network, media centres in post-socialist countries which provide infrastructural support and access and education to local producers, and European organisations which provide ICT assistance to groups in Mali, Ghana, Tanzania, Uganda, Zambia, Jamaica, and Bolivia. Under the expanded cover concept of tactical media are included what appear to be both tactical and strategic media, 
as well phenomena that differ from both insofar as they are not forms of warfare - initiatives to provide infrastructure, improved access, means of communication and exchange to people who for economic and political reasons are lacking these means. These modes of production and exchange are not primarily constituted by being directed against an enemy; the content is not determined in advance through a preconceived opposition, but left to be shaped by its producers. Now to my mind, labelling all these diverse practices forms of 'tactical media' risks missing precisely their differences and making the term meaningless. This loss of signification seems to correspond, in inverse proportion, to the recent inflation of 'tactical media' as a cool label on the market of ideas. Instead of analysing concretely what is inherent in different forms of media production and the ideologies they shelter and preserve, the term papers over their contradictions. Tactical media is good, progressive, alternative, etc. There is no need to ask questions, its truth already appears selfevident.

After making some extremely arrogant, offensive films of Maoist propaganda during the early 1970s, Godard became embarrassed. And started making films that had nothing to say. Here \& Elsewhere - we went to Palestine a few years ago, Godard says. To make a film about the coming revolution. But who is this we, here? Why did we go there, elsewhere? And why don't here and elsewhere ever really meet? What do we mean when we use this strange word 'revolution'? It is only when he was old that Godard learned how to ask questions, stumbling around like a foreigner in a language and a history he did not possess. Here \& Elsewhere, which came out in the same year as de Certeau's book, occupies no fixed position, moves towards no preconceived destination, and takes nothing for granted, not even its own voice. In an era dominated by a politics of the message (statements, declarations of war, communiqués, demands in the form of new five-year plans), it searches for a politics of the question.

The idea of tactical media is the harbinger of a question both necessary and timely: how is it possible to make media otherwise, media that expresses its solidarity with the humiliated thoughts and incomprehensible desires of those who seem doomed to silence, media that does not mirror the strategic power of the mainstream by lapsing into a self-certain propaganda identical to itself and blind to its own history. But the language of tactical media simultaneously imprisons the idea of a different type of media production inside a theory of warfare, as a media of opposition, determined to conquer the enemy. While it is necessary to continue asking the question and experimenting with media that work in situations of crisis and adversity, it is also important to know when to change terrain. As wars rage around us - wars that rationalise the trafficking in merchandise under the shadow of sublime principles, wars against terrorism, wars against drugs, wars of information against information - maybe what we need least is to advertise our practice as an extension of one or another principle of warfare. When asked to take sides, for or against, siding with one army or the other, sometimes the only real answer is not to play the game. This refusal should not be confused with an exodus, a silent passivity, or a patient resignation. It is the vigilance of continuing to think, beyond the obvious - of a third, a fourth, or fifth alternative to the apocalyptic or utopian sense of the media. 
Practices + Politics / 351
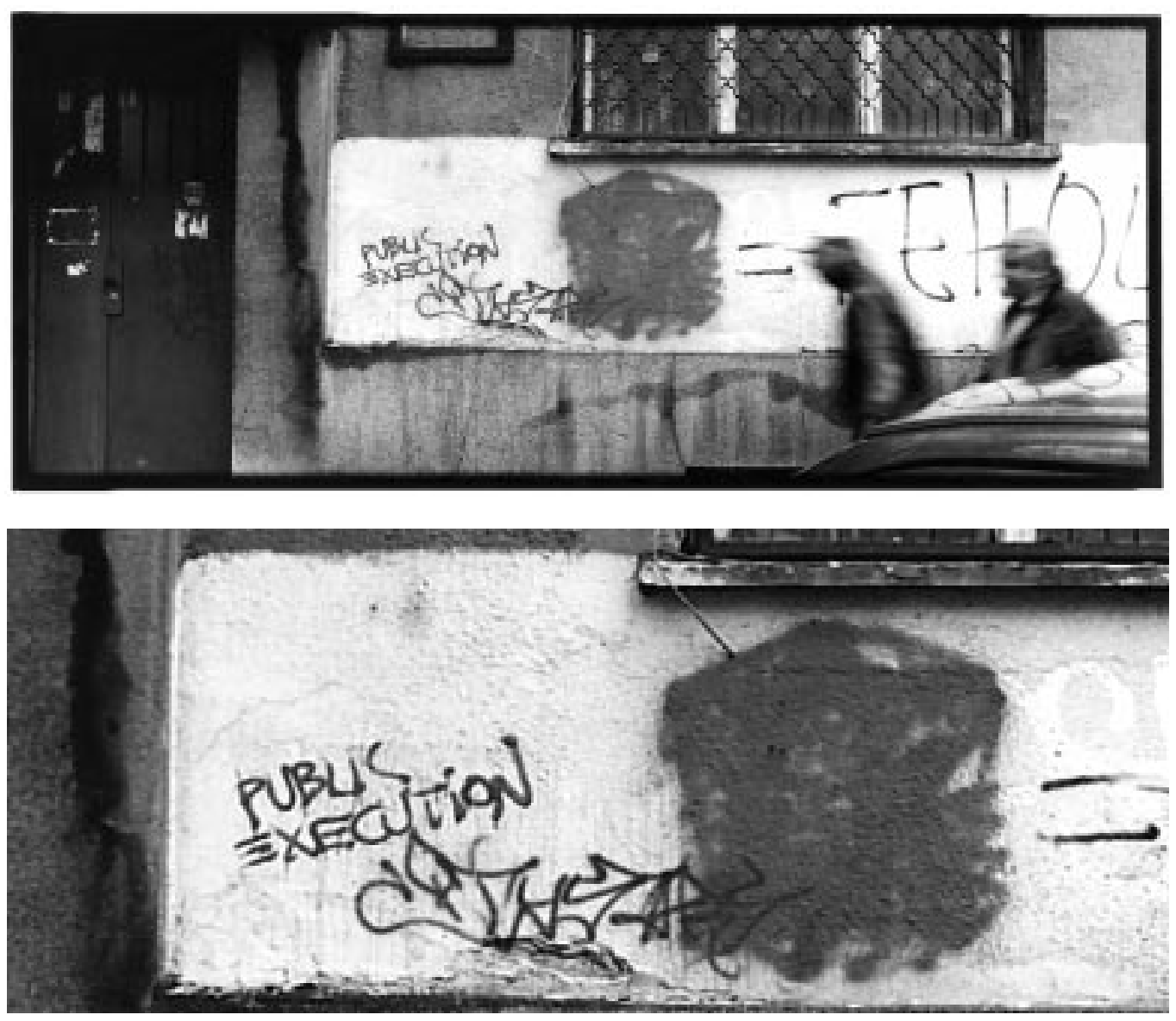


\section{Alternative Radio A Personal Testimony}

have been a radio interventionist, doing combat on the airwaves, since 1978. Alternative Radio, my 'organisation', is part of a burgeoning movement of community based, noncommercial stations in alliance with independent producers.

I produce and distribute a weekly one-hour public affairs programme that is broadcast on more than one hundred stations in the United States and Canada, as well as to over seventy countries via shortwave. The technical aspect is not very complicated and the cost is quite modest. The US, with all its media problems, has by far the most developed and evolved network of community radio stations in the world. There are about 100 such stations in the country. For example, Pacifica, established in 1949, has five stations: New York, Houston, Berkeley, Los Angeles and Washington, D.C.

A little background first. I moved to Boulder, Colorado in July 1978. A friend who picked me up at the airport told me that KGNU had recently gone on the air and was looking for people to do radio. I quickly submitted a proposal and before I knew it I was doing a weekly one-hour programme which later expanded to two-and-a-half hours. Mind you I had no background in the medium. KGNU was open and supportive, but actual training in radio art and craft was limited due to the usual formula: too few staff, doing too much work. Much of what I learned about 'doing' radio came on and off the air in an auto-didactic fashion. I gradually developed my editing, production, interviewing and other skills. Some grants and awards followed, which were all very gratifying. But I was still very much a local voice.

A significant turn in my audio evolution came in 1986. I was appointed programme director of KRZA, a new bilingual station in Alamosa, in the San Luis Valley in southern Colorado. During my tenure there I learned the intricacies and mysteries of the satellite system. I began Alternative Radio in late 1986 in a bizarre way. I did something unheard of: I put up, on the satellite in one block, three-and-a-half hours of Noam Chomsky, a ninetyminute lecture followed by four thirty-minute interviews. It was my first national broadcast. No one told me that most stations usually only have half-hour or one-hour slots. It was the proverbial learning experience. However, the Pacifica network did pick up the programmes and listener response was tremendous. AR was on its way.

How do I do a programme? First of all I use professional equipment: a SONY TC-D5M portable tape recorder that costs about $\$ 600$, an Electrovoice RE-50 microphone which runs to about \$150, SONY MDR-V600 headphones, \$70, and an AKG mic stand, \$ 30. 
There are of course other configurations. Some producers prefer a SONY Walkman-PRO or a Marantz tape recorder. Others are advocating DAT machines. Whatever you get, don't chintz. Get good reliable equipment. Forget K-Mart bargains and completely forget using cheap tape. Always record on chrome cassettes from name manufacturers. I use Maxell, but the others, TDK, Fuji, etc. are comparable. And it is best for recording purposes to have 90 or 100 -minute cassettes.

Know your equipment well and have full confidence in it and yourself before you venture out into the field. If the financial as pect is daunting, then most stations, with conditions, will permit you to borrow equipment. Secondly, I tape and edit a lecture or interview. Let's say Winona LaDuke is giving a talk in Boulder at the University of Colorado. Her topic is "Social J ustice, Racism and the Environmental Movement". I get her permission to record before she speaks. I record her presentation. It is brilliant. I decide to turn it into an AR national programme. My associate Sandy Adler transcribes the tape. The transcript helps me enormously for I can see the tape. I time all the paragraphs and then start the actual editing process. I boil the programme down to some fifty-odd minutes, tack on my music theme on both ends, add an introduction and closing and it is ready to go up on 'the bird', the satellite.

Another example. I want to do an interview with Marilyn Young, the historian who teaches at New York University. Her book The Vietnam Wars is impressive. I contact her to see if she would like to be interviewed. She agrees. I go to New York and interview her. I then go through the same procedure as with LaDuke although this time I have expended much more time and money in the collection process. Some of my programmes are locally generated but frequently I have to travel to find what I am looking for. I often feel that I am a hunter and gatherer. I go out and get tape and then bring it back to be cooked! A heartening development in the last couple of years is that I have established a coterie of field producers in various parts of the US and Canada who send me tapes which I then turn into programmes. Thirdly, most of the cooking is done at KGNU studios where I continue to do local political and world music programmes. I was Station Office Manager in 1981 and then from 1987 to 1991 I was the News and Public Affairs Director.

There is a healthy give and take between me and the station. I give them tapes to offer to listeners who become members during their fundraisers, and I help with on-air pledge rapping, i.e. asking listeners to send in money, as well as in a variety of other ways.

Finally, I reserve in advance a regular time, day and channel on the satellite. I express the completed programme to the uplink. I use the one in Ames, lowa. The satellite system is the electronic umbilical cord linking hundreds of stations. It is run by National Public Radio. But fear not. All they want is your money. I have never heard a peep from them about the content of any of my programmes. Some 400 -plus stations have dishes or downlinks, i.e. they are capable of receiving programmes. There are some 20 uplinks through which programmes are distributed. Working with satellite deadlines is a constant stimulation. It is like having a Damocles sword of tape over your head at all times. The programme has to be at the uplink before the scheduled uplink time. Stations record the programme off the satellite and air it during a designated time. It is possible to broadcast live off the satellite and that is the case for news and breaking events, hearings, marches, etc. 
Of all the electronic media there is no question that radio is the least expensive. And as far as I am concerned it is the most satisfying. There is something very intimate about radio. It doesn't rob or preempt the listener's imagination. And for spoken words, which is what I do, it is the best. An hour is a decent amount of time to cover a subject.

Alternative Radio programmes focus on the media, US foreign policy, racism, the environment, indigenous rights, NAFTA/GATT, economic issues and other topics. Recent programmes have included Elaine Bernard on "Creating a New Party", Juliet Schor on "The Overworked American", Ali Mazrui on "Afrocentricity and Multiculturalism", Edward Said on the "Israel/PLO Accord", Helena Norberg-Hodge on "Rethinking Development", a two-part debate on NAFTA, and Michael Parenti on "The Struggle for Democracy".

I distribute via satellite. Fees run about $\$ 100$ per programme. The fee also gets me into the DACS (Direct Access Communications System). It is a device somewhat akin to a news wire. Every station that has a satellite dish has one. The DACS is the eyes and ears of the satellite. Programme and news directors check it to find out what's up! The DACS tells them for example that on Tuesday, November 9 at 1400 eastern time on channel 6 , Alternative Radio is offering a programme on GATT featuring Herbert Chao Gunther. The DACS is a direct way to reach all the stations that are interconnected to the satellite system. I mail, fax and phone stations to nudge them further. Unfortunately, the satellite system is limited to the US. That means I have to send tapes via mail to Canada, Australia and elsewhere - clearly an expensive and inefficient method.

I look forward to the day when we'll be globally connected. How do I support my 'operation'? Directly through the sale of printed transcripts and audio cassettes to listeners. I don't charge the stations. It is important that the programmes be broadcast so I make it as simple and as painless as possible for stations. My goal is to disseminate diverse perspectives and views. It does me little good to produce a programme and then have it sit on a shelf. There are stations and there are stations. Some of them won't go anywhere near my work. Most of these stations are NPR (National Public Radio) types. Their licences are mostly controlled by colleges and universities and their schedules consist of lots of NPR news and other network produced programmes with a good dollop of classical music and/or jazz. Sometimes stations like WGBH in Boston, KCFR in Denver or WHYY in Philadelphia are not institution based but nevertheless have very narrow politics. NPR type programme directors and managers worship at the chimerical icons of balance and objectivity, the kind exemplified by "Morning Edition" and "All Things Considered". AR represents to them a bias. It is advocacy radio and hence anathema to their ears. Listeners must be protected from ideas outside the framework of received wisdom.

However, scattered around the country there are a handful of NPR type stations that are willing to take risks and explore. They need to be encouraged and their numbers need to increase. A two-pronged strategy seems appropriate. We need to create our own media as well as penetrate existing structures. One of my goals is getting beyond the choir. Certainly our friends need information, news and analyses but simply preaching to the converted is neither intellectually, nor emotionally satisfying. It is not easy, but I can attest from my own experience that breakthroughs do happen. A sustainable media movement cannot abandon these possibilities. The other category is community run stations where there is a 
pluralism in programming and certainly more diversity in terms of gender and race among staff and volunteers. Community-run stations have been growing steadily in numbers since the mid-1970s.

Noam Chomsky has observed that when he visits a town or city that has a station, people tend to be more informed and aware of what is going on. Radio provides a means of intellectual self-defense and a vehicle for connecting with others. One of the things I love to do is visit stations like KMUD in Garberville, California or KMUN in Astoria, Oregon or WERU in E. Orland, Maine or Co-op Radio in Vancouver, British Columbia. Though lacking in resources, the vitality, energy and sense of commitment at these stations is inspiring. And yes, there is political infighting and there are struggles, but the positives far outweigh the negatives. The overwhelming number of on-air programmers are volunteers. It is the exact opposite of the NPR group where virtually only paid staff are on-air and volunteers are used for answering the phone during fundraisers.

A new development with potential is low-watt micro radio, sometimes referred to as pirate radio. It is a mechanism that does an end-run around the stations which are the gatekeepers of the airwaves. Micro radio has the virtue of being cheap. However, its narrow signal range limits its audience. William Barlow of Howard University writes that community radio "has more democratic potential than any other form of mass media operating in the United States". Activists should seriously consider radio as a medium for action and engagement. There are more and more signs that that is happening.

All these efforts are to be encouraged, but they must locate themselves in a larger context. Edward Herman wrote in the very first $Z$ Papers that "a full-fledged democratisation of the media can only occur in connection with a thoroughgoing political revolution". The trend towards greater media concentration will continue. The amount of literature documenting corporate control and domination of media is staggering. We have done our homework and while that critique is ongoing, I believe it is essential for psychological, as well as political reasons, to project and produce positive alternatives. It is vital that it happen. And radio offers just such an opportunity.

Alternative Radio (http:// www.alternativeradio.org) is a weekly one-hour public affairs programme offered free to all public radio stations in the US, Canada, Europe, South Africa, Australia, and on short-wave on Radio for Peace International. 
ALT+OPTIONALT+OPTIONALT+OPTIONALT+OPTIONALT+OPTION ALT + OPTIONALT+OPTIONALT+OPTIONALT +OPTIONALT +OPTION ALT + OPTIONALT+OPTIONALT+OPTIONALT+OPTIONALT+OPTION ALT+OPTIONALT+OPTIONALT+OPTIONALT+OPTIONALT+OPTION ALT +OPTIONALT+OPTIONALT+OPTIONALT +OPTIONALT+OPTION ALT+OPTIONALT+OPTIONALT+OPTIONALT+OPTIONALT+OPTION ALT + OPTIONALT+OPTIONALT+OPTIONALT+OPTIONALT + OPTION ALT +OPTIONALT+OPTIONALT+OPTIONALT +OPTIONALT+OPTION ALT + OPTIONALT + OPTIONALT + OP WIOINEALT + OPTION ALT + OPTION ALT + OPTIONALT + OPTIONALT OOPTIDNALT + OPTION ALT +OPTION ALT+ OPTION ALT + OPTIONALTAOPTION ALT + OPTION ALT + OPTION ALT + OPTIONALT + OPTIONALT + OPTIONALT + OPTIONALT+OPTION ALT + OPTIONALT + OPTIONALT + OPTIONALT + OPTIONALT +OPTION $A L T+O P T I O N A L T+O P T I O N A L T+O P T I O N A L T+O P T I O N A L T+O P T I O N$ ALT + OPTIONALT + OPTIONALT + OPTIONALT + OPTIONALT + OPTION ALT + OPTIONALT + OPTIONALT + OPTIONALT + OPTIONALT + OPTION

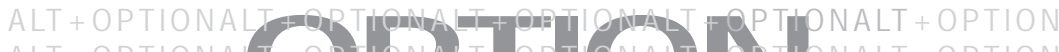
$A L T+O P T I O N A$ T T OP TIONALT + OPT ONATT + OPTIONALT +OPTION ALT + OPTIONALT+OPTION ALT + OPT QNEAL + OPTION ALT + OPTION ALT+OPTIONALT+OPTIONALT + OPTIONALT+OPTIONALT +OPTION ALT + OPTIONALT + OPTION ALT + OPTIONALT + OPTIONALT + OPTION ALT + OPTIONALT+OPTION ALT + OPTIONALT + OPTIONALT + OPTION ALT+OPTIONALT+OPTIONALT + OPTIONALT + OPTIONALT + OPTION ALT+OPTIONALT+OPTIONALT+OPTIONALT+OPTIONALT+OPTION ALT+OPTIONALT+OPTIONALT+OPTIONALT+OPTIONALT+OPTION ALT+OPTIONALT+OPTIONALT+OPTIONALT+OPTIONALT+OPTION ALT+OPTIONALT+OPTIONALT+OPTIONALT +OPTIONALT+OPTION ALT +OPTIONALT+OPTION ALT+OPTIONALT+OPTIONALT+OPTION ALT + OPTIONALT +OPTIONALT + OPTIONALT + OPTIONALT +OPTION ALT + OPTIONALT + OPTIONALT + OPTIONALT + OPTIONALT + OPTION ALT + OPTIONALT +OPTIONALT + OPTIONALT + OPTIONALT +OPTION ALT +OPTIONALT + OPTION ALT + OPTIONALT +OPTIONALT + OPTION ALT + OPTIONALT + OPTION ALT + OPTIONALT +OPTIONALT + OPTION ALT + OPTIONALT + OPTION ALT + OPTIONALT + OPTIONALT + OPTION ALT +OPTIONALT+OPTIONALT + OPTIONALT+OPTIONALT+OPTION 


\section{A Concise Lexicon Of / For the Digital Commons}

RAQS MEDIA COLLECTIVE

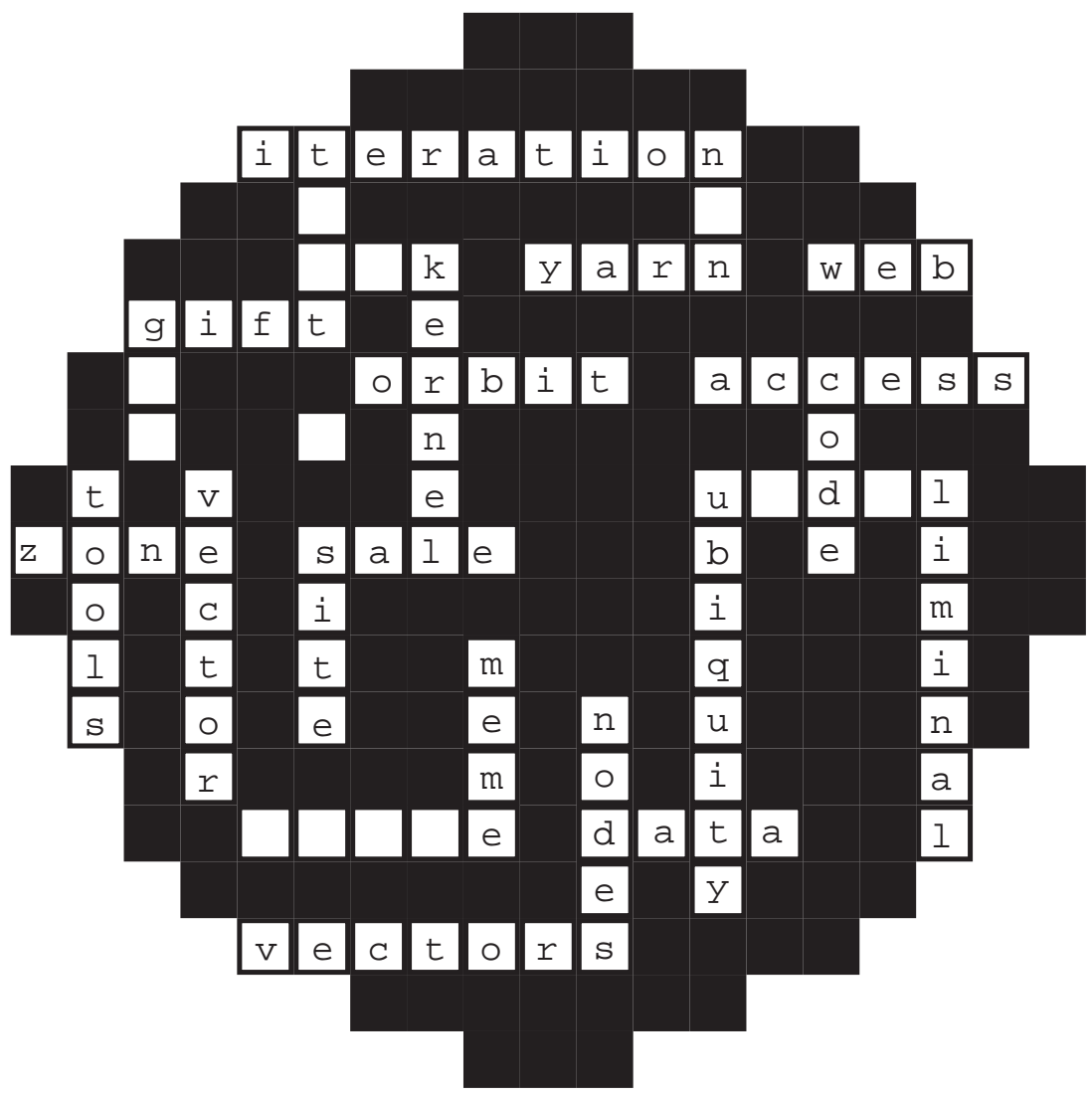

\section{ACCESS}

The facility to log on and log in to a space or a network where people and meanings gather. To be present, to have the ability, the key, to decode a signal, to open doors, to be able to download/upload on to any system of signs and signals - be it the Internet, a book, an art work, or a dinner party. There can be no excess of access. 


\section{BANDWIDTH}

Describes the dimensions that are necessary for messages, signals and communications to get through. The greater the bandwidth of a system, the higher the number of messages and the higher the quantum of information that it can accommodate at any given time. It follows from this that access is a function of bandwidth. More people can make themselves heard when there is room for them to speak and be spoken to. Bandwidth translates into content-rich information, streams of video, audio and text flowing into each other. It also translates at the moment into cash. The hard cash and control that comes from selling pictures and sounds and numbers to more and more people.

\section{CODE}

That which carries embedded within it a sign. A code is always a way of saying something to mean something other than that which is merely said. A code can be 'opened', in the sense that it can be accessed and entered, as opposed to 'broken'. An open-access culture of communication 'reveals the source' of its codes. A closed culture of communication blocks access to its codes. 'Free code' is code which welcomes entry, and is open to change. 'Free code' needs to be shared for it to grow. Code connotes community, a community of 'encoders, decoders and code sharers'. Like eggs, code is sometimes best had scrambled.

\section{DATA}

Information: Can mean anything from numbers to images, from white noise to noise to sound. A weather report, a portrait, a shadow in surveillance footage, a salary statement, birth and death statistics, a headcount in a gathering of friends, private e-mail, ultra high frequency signals, sale and purchase transactions and the patterns made by pedestrians as they walk in a city - all of this can be and is data. Data, like coal, uranium and other minerals vital to the running of the world economy is mined, processed, refined and sold at a high price. Battlefields, early twenty-first-century inter-personal relationships and stock exchanges have been known to be hypersensitive to data traffic. Data mining is a major emerging industry in Delhi. The miners lead very quiet days, and spend long nights coding in low temperature zones called "Data Outsourcing Centres".

Contrarily, the word Data (dãtã) in Hindi/Sanskrit is taken to mean 'giver', which suggests that one must always be generous with information, and make gifts of our code, images and ideas. To be stingy with data is to violate an instance of the secret and sacred compacts of homophonic words from different cultural/spatial orbits (dãtã in Hindi and 'data' in English) as they meet in the liminal zone between languages, in the thicket of the sound of quotidian slips of the tongue. Errors in transmission and understanding too carry gifts and data.

\section{ENSEMBLE}

The conceit or delight in togetherness in an increasingly anomic, fragmented world. Playing or working together to create finished or unfinished works. Chamber musicians, criminals, code-hackers and documentarists form ensembles. Artists try to. Effective ensembles are high bandwidth assemblies that build into their own architecture portals for random access 
into themselves. They are, when they are at their best, open systems that place a premium on shared information within them. They can at times maintain high levels of secrecy while appearing to be transparent. Here, confidentiality is an index of practices in gestation. Mined data is, sometimes, restored to natural states of information entropy in data dissembling ensembles, which have been found to work best at night in media labs. The Raqs Media Collective is an ensemble and everything it does is an ensemble of existing or anticipated practices.

\section{FRACTAL}

The self-organising design of repeating, replicating structures, often found in snowflakes, tree branch growth patterns, molecular structures and free code. Every part of a fractal pattern carries within it the signature or the emboss of the whole. A single fractal iteration carries within it the kernels of all others of its kind. Every fractal is a rescension of every other fractal that has grown from within it. In the same way a fragment of free code, or free cultural code, carries within it a myriad possibilities of its own reproduction and dispersal within a shared symbolic or information space. Fractals best describe the geometry of the matrices that are formed when data is shared instead of being just mined and shipped by a community of coders. Fractals are the fruit trees of the unconscious designing mind.

\section{GIFT}

Something freely given, and taken, as in free code. Gift givers and gift takers are bound in networks of random or pre-meditated acts of symbolic exchange. The code begets the gift as the form of its own survival over time. In this way a gift is a quiet meme. Reciprocity begets reciprocity. The principle of the gift demands that the things being given be priceless, in other words so valuable as to be impossible to quantify in terms of the possibilities of abstract generalised exchange. The gift must at the same time, be easy to bear and keep, easy to use and there must be no guilt involved in its destruction or dispersal when its use value either changes or demands redistribution in order to be effective. Gifts open doors to our own possibilities of generosity. In this way they facilitate access to the things we did not even know we had. And, there is such a thing as a free lunch, although it requires the pursuit of a special recipe.

\section{HETEROGENOUS}

That which begins in many places, like the story of a person's life. Diverse, dispersed, distributed, as in the authorship of culture, and in the trajectories of people who come to a site. Interpretations and ideas embrace greater freedom only when they encompass heterogeneity. In this, they are like most intimacies and some kinds of fruitcake. The richer they are, the more layers they have.

\section{ITERATION}

An articulation, when seen as an event, is an iteration. Utterances, whispers, manifestoes, graffiti, stories, rumours and fragments of poetry found in the streets - each of these are 
iterations. The organised rendition of a stretch of code is also an iteration. Iteration implies a willingness to say something, and access to the means of saying it, and a time in which it can be said. Every iteration resonates through orbiting memes that are set off on their vectors by the fact of an utterance. An iteration is the kernel of a rescension. It needs to be said, and then said again.

\section{J OURNAL}

A record of the everyday. Annals of matters varied and quotidian. Data from day to day to day. On reams or scraps of any material that can carry the emboss of time. The material may vary from newsprint to video to sound to binary code, or a combination of the same, and the journal may transmogrify from being a witness, to a participant in that which is being recorded. The extent and scale of 'participation' depends on the frequency of entries into the journal, and the number of correspondents it can muster. The higher the frequency of entries or number of correspondents, the greater is the intensity of the inscription of a time on a journal. A densely, thickly inscribed journal is one that is usually open access in terms of writing, reading and publishing. Why else would strangers want to write in? An open journal expects to be published anywhere at all. An open journal actively practices xenophilly. When a journal becomes more than a gazetteer of a moment it turns into a history. It then begins to make sense of itself as much as it does about a time that it spans. Conversely, every history begins life as a journal.

\section{KERNEL}

The core of a work or an idea. The central rescension, of a narrative, a code, a set of signs or any other structure that invites modification, extrapolation and interpretation, by its very presence. Here, the term core must not be confused with 'origin' or with any other attributions of originality, which mean little within an open access system. It is almost impossible to determine the origins of a code, because the deeper we go into the constitutive elements of a code, the more it branches out to a series of nodes within and outside a given system of signs. It is more meaning ful to talk of the 'custody', rather than the 'origin' of any system of signs.

A kernel is often the custodian of a line of ideas that represents within itself a momentarily unique configuration. Kernels embody materials in states of intense concentration. This is because they have to encapsulate a lot of information, or nourishment, or structure building materials, within very limited dimensions. The density of information within a kernel is a key to its own extensibility. The more the thread that is rolled into a tight ball, the more it can be unwound. Kernels, by their limitedness and compactness, are portable, not cumbersome. As in the kernels of certain fruits, they may be hard to crack, but once they have been opened, they yield delicious and nourishing stuff. Kernels lend themselves to easy reproduction, but are fragile and often in need of protection. This protection may also come in the form of an outer layer of interpretation, which states the purposes and nature of the kernel, so that it is not prised open to answer every basic query about itself. 


\section{LIMINAL}

Interstitial, vestibular and peripheral. Far from the centre, close to the border. A zone both between and without larger structures. Liminal spaces and moments are those into which large stable structures leak animated data about themselves and the world. Things happen in liminal zones. A city carries within it the contradiction of liminal zones located in its centre, because inner cities are the city's farthest borderlands. Liminal fringes are often the most conducive environments for the culture of memes. This is because exiled images, ideas and meanings from several stable structures mingle in the corridors between them. Here, bereft of identities and other certainties, they are free to be promiscuous and reproduce. They infect each other with recombinant strands of thought and image. At the same time, the perspective of liminality brings intimacy to bear on an exclusion. Being liminal is to be close to, and yet stand outside the site of the border of any stable system of signs, where meaning is frayed from being nibbled at on the edges. Nothing can know the centre better than the sideways glance of peripheral vision. Liminality may be acquired from prolonged exposure to the still air of airport departure lounges, thick and over-boiled tea at the Inter State Bus Terminus on the ring road in Delhi, or the subliminal flicker of a cursor in an e-mail message.

\section{MEME}

The life form of ideas. A bad idea is a dead meme. The transience as well as the spread of ideas can be attributed to the fact that they replicate, reproduce and proliferate at high speed. Ideas, in their infectious state, are memes. Memes may be likened to those images, thoughts and ways of doing or understanding things that attach themselves, like viruses, to events, memories and experiences, often without their host or vehicle being fully aware of the fact that they are providing a location and transport to a meme. The ideas that can survive and be fertile on the harshest terrain tend to do so, because they are ready to allow for replicas of themselves, or permit frequent and far-reaching borrowals of their elements in combination with material taken from other memes. If sufficient new memes enter a system of signs, they can radically alter what is being signified. Cities are both breeding grounds and terminal wards for memes. To be a meme is a condition that every work with images and sounds could aspire towards, if it wanted to be infectious, and travel. Dispersal and infection are the key to the survival of any idea. A work with images, sounds and texts needs to be portable and vulnerable, not static and immune, in order to be alive. It must be easy to take apart and assemble, it must be easy to translate, but difficult to paraphrase, and easy to gift. A dead meme is a bad idea.

\section{NODES}

Any structure that is composed of concentrated masses of materials which act as junction points for the branching out of extensible parts of the overall system may be described as nodal. The concentrations or junctions being the nodes. A nodal structure is a rhizomic structure, it sets down roots (that branch out laterally) as it travels. Here, nodes may also be likened to the intersection points of fractal systems, the precise locations where new fractal iterations arise out of an existing pattern. A work that is internally composed of memes is inherently nodal. Each meme is a junction point or a node for the lateral branch- 
ing out of the vector of an idea. In a work that is made up of interconnected nodes, the final structure that emerges is that of a web in which every vector eventually passes through each node at least once on its orbit through the structure of the work. In such a structure, it becomes impossible to suppress or kill an idea once it is set in motion, because its vectors will make it travel quickly through the nodes to other locations within the system, setting off chains of echoes and resonances at each node that trace a path back to the kernel of the idea

These echoes and resonances are rescensions, and each node is ultimately a direct rescension of at least one other node in the system and an indirect rescension of each junction within a whole cluster of other nodes. Nodes, when written, perhaps erroneously, as 'no-des' gives rise to an intriguing hybrid English/Eastern-Hindi neologism, a companion to the old words - des and par-des. Des (in some eastern dialects of Hindi, spoken by many migrants to Delhi) is simply homeland or native place; par-des suggests exile and an alien land. 'No-des' is that site or way of being, in des or in par-des, where territory and anxieties about belonging, don't go hand in hand. Nodes in a digital domain are 'No-des'.

\section{ORBIT}

A path that describes the continuous movement of anything within a structure. Because the movement within it is continuous, it (an Orbit) is also impossible to define in terms of origin or destination. What is possible to determine at any given moment is the vector of an orbit. A meme, when orbiting within a structure of signs, is neither travelling away from its origin, nor is it travelling towards a destination.

This is why, in an open access system, which is composed of memes, it is meaningless to talk in terms of authors and audiences, rather one can only speak of the node where one got on to an idea, and the junction where one got off, perhaps to enter the vector of another orbiting meme. Sometimes a work of interpretation, like certain comets and other stellar objects, can have an eccentric orbit. This means that there is always a likelihood of a cluster of signs and images from afar, brushing past objects on its path, entering the orbits of other constellations, when it is least expected to. The sky of meaning is full of shooting stars.

\section{PORTABILITY}

The feature of a system or work that best describes its ability to move quickly through different spaces and mediums. A sign or a meme that can travel well between image, sound and text media is portable. A work, which while it speaks of one site, is understood in another location, is portable. A work that describes many locations in the course of its interpretative orbit is also portable. A portable work is rich in memes, which act as engines for its movements, and is endowed with compact kernels that can travel well without danger of being cracked open. Briefcases, languages, postcards, Swiss knives, computers, jests, stories and shoes are portable. Gifts, because they change hands, must always be portable. Monuments can never be. The life histories of some (itinerant) individuals and (nomadic) communities make them approximate the condition of portability. 


\section{QUOTIDIAN}

Common but not commonplace. The memorable nature of the everyday. Memory walking down a street and turning a corner. Memory buzzing in a hard disk. Ubiquitous, the dirt in a site, the fog in a liminal zone, that which is thickened through repetition.

Milk, computers, onions, computers, pyjamas, computers, carpal tunnel syndrome, computers, accidents, computers, sex, computers, bread, computers, night, computers, class, computers, skin, computers, love, computers, money, computers, headaches, computers, police, computers, buses, computers, bicycle, computers, radio, computers, horoscopes, computers, matrimonials, computers, funerals, computers, biscuits, computers, conversations, computers, silences, computers.

The quotidian is that which makes a journal turn, over time, into a history, because it induces the search for patterns and meanings in an otherwise tangled mass of time, in memes iterated beyond reasonable limits. Routine, yet random, the quotidian nature of anything demands fleeting moments of lucid engagement with the real world, which now includes within it the world that is forged every time any fingers do a qwerty dance on a keyboard. The quotidian is a measure of all things, rare and commonplace.

\section{RESCENSION}

A re-telling, a word taken to signify the simultaneous existence of different versions of a narrative within oral, and from now onwards, digital cultures. Thus one can speak of a 'southern' or a 'northern' rescension of a myth, or of a 'female' or 'male' rescension of a story, or the possibility (to begin with) of Delhi/Berlin/Tehran rescensions of a digital work. The concept of rescension is contraindicative of the notion of hierarchy. A rescension cannot be an improvement, nor can it connote a diminishing of value. A rescension is that version which does not act as a replacement for any other configuration of its constitutive materials.

The existence of multiple rescensions is a guarantor of an idea or a work's ubiquity. This ensures that the constellation of narrative, signs and images that a work embodies is present, and waiting for iteration at more than one site at any given time. Rescensions are portable and are carried within orbiting kernels within a space. Rescensions taken together constitute ensembles that may form an interconnected web of ideas, images and signs.

\section{SITE}

Location, both as in the fact of being somewhere, and also as in the answer to the question of 'where', that 'somewhere' is. Hence, situation. In a system of signs, site - understood in the sense of the kernel of a situation - is not necessarily a place, although a place is always a site. A site can be a situation between and through places. A web site is an address on the Internet that always implies a relation of desire between hosts and visitors. In other words, it doesn't really mean anything for a place to exist (virtually) if it is left unvisited. In this way, a site can be both located as well as liminal. Real as well as potential. A system of signs (a work) that carries the markings of a location on a map may be situated in the relation that a map has to the world. It may be situated between the map and the 
world. This situation may be a special characteristic of the work's portability, in that, although mobile the work always refers to the relation between sites that fall on its orbit. In this way, marking a site as an address calls for the drawing up of relations between a location and the world.

A site is a place where the address is. A site is a place where the work belongs. A situation between these two locations (where the work is and where it belongs) is a site where the work orbits. A site is also a place where people need to wear hard hats to protect themselves from random falling bodies, travelling in eccentric orbits.

\section{TOOLS}

Things that help make things. Ideas, instruments, concepts, ways of doing things, and ways of being or acting together that are conducive to creative work. In the context of an online environment, a community or an ensemble of people is as much an instrument as a software application. Conversely, a tool emerges when a group of people discover a method that helps them act together to create something. Again, a work that acts as a navigation aid, a browser or interface in a web of memes, is also a tool with which to open and search for other tools.

\section{UBIQUITY}

Everywhere-ness. The capacity to be in more than one site. The simple fact of heterogeneous situation, a feature of the way in which clusters of memes, packets of data, orbit and remain extant in several nodal points within a system. The propensity of a meme towards ubiquity increases with every iteration, for once spoken, it always already exists again and elsewhere.

It begins to exist and be active (even if dormantly) in the person spoken to as well as in the speaker. Stories and the kernels of ideas travel in this way. A rescension, when in orbit, crosses the paths of its variants. The zone where two orbits intersect is usually the site of an active transaction and transfer of meanings. Each rescension carries into its own trajectory memes from its companion. In this way, through the encounters between rescensions, ideas spread, travel and tend towards ubiquity. That which is everywhere is difficult to censor, that which is everywhere has no lack of allies. To be ubiquitous is to be present and dispersed in 'no-des'. Sometimes, ubiquity is the only effective answer to censorship and isolation.

\section{VECTOR}

The direction in which an object moves, factored by the velocity of its movement. An idea spins and speeds at the same time. The intensity of its movement is an attribute of the propensity it has to connect and touch other ideas. This gives rise to its vector functions. The vector of a meme is always towards other memes, in other words the tendency of vectors of data is to be as ubiquitous as possible. This means that an image, code or idea must attract others to enter into relationships that ensure its portability and rapid transfer through different sites and zones. The vectors of different memes, when taken together, form a spinning web of code. 


\section{WEB}

An open fabric woven of strands and knotted at usually regular, but equally possibly irregular, intervals. Intricately structured, accessible and yet endowed with complex networks of coded messages. The world wide web is a zone in which a digital constellation of memes can find an orbit. A web of code is used to harvest meanings, just as a web of threads is used to harvest fish.

\section{XENOPHILLY}

Friendliness and hospitality towards others, a human quality that best describes the moral economy of an ideal digital domain. The search for connectedness, and the desire to travel along the vectors from elsewhere. The meaning of the hyphen that transforms 'no-des' into a positive value.

\section{YARN}

Fabrics, and stories, are made from yarn. A yarn is a snatch of reality that travels by word of mouth. Or it is shipped along with lots of html cargo. It is said that each fragment of code contains rumours and gossip, or yarns about the makers of the code. Yarns collect in basement cyber cafés, in stairwells of cinemas, in call centres and behind the opaque surface of the walls of an apartment whose address is Error 404, which can be anywhere and everywhere at once. In these places, yarn collectors stitch different stretches of code-fabric to make long bolts of data, which are then taken apart by hackers, and distributed into many orbits. Yarns can adjust the amount of information they bear in relation to the width of bandwidth. That is why yarns are good kernels.

\section{ZONE}

A site, within a location, or a work, that demands an attenuated awareness because of the porosity of the lines that demarcate its existence. A zone is differentiated from a grid that frames a site because its borders are fluid and accessible, or because they witness a lot of traffic. It is difficult to distinguish the centre from the liminal periphery of a zone. Alertness about where one stands is a prerequisite for entering any zone. A zone may also be described as the overlap between orbits in a work, where memes transfer material from one orbit to another, where logic likes to fuzz. The zone of a work extends to the outer circumference of the orbit of its ideas.

Zones are places where serendipity might be commonplace, and the commonplace serendipitous. They are best entered and exited at twilight on shunting cars along abandoned railroads that connect different data stations. The timing of twilight may vary, depending on one's longitude, but twilight lingers longer in the zone of the web. 


\section{The Wireless Commons Manifesto}

(HTTP:// DEV.WIRELESSCOM MONS.ORG)

W have formed the Wireless Commons because a global wireless network is within our grasp. We will work to define and achieve a wireless commons built using shared spectrum, and able to connect people everywhere. We believe there is value to an independent and global network which is open to the public. We will break down commercial, technical, social and political barriers to the commons. The wireless commons bridges one of the few remaining gaps in universal communication without interference from middlemen and meddlers.

Humanity is on the verge of a turning point because the Internet has transformed the way humans relate with one another. All communication can be traced to a human relationship, whether it's lovers exchanging instant messages or teenagers sharing music. The Internet has given us the ability to communicate faster and more cheaply than ever before in history.

The Internet's value increases exponentially with the number of people who are able to participate. In today's world, communication can take place without the use of antiquated telecommunications networks. The organisations that control these networks are limping anachronisms that are constrained by the expense and physical necessity of using wires to build their networks. Because of this, they cannot serve the great mass of people who stand to benefit from a wireless commons. Their interests diverge from ours, and their control over the network strangles our ability to communicate.

Low-cost wireless networking equipment which can operate in unlicensed bands of the spectrum has started another revolution. Suddenly, ordinary people have the means to create a network independent of any physical constraint except distance. Wireless can travel through walls, across property boundaries and through a community. Many communities have formed worldwide to help organise these networks. They are forming the basis for the removal of the traditional telecommunication networks as an intermediary in human communication. 
The challenge facing community networks is the one limiting factor of wireless communication: distance. The relationships that can be formed across a community wireless network are limited by their physical reach. Typically these networks are growing to the size of a city, and growth beyond that point requires coordination and a strategic vision for community wireless networks as a whole. Without this coordination, it is hard to see how the worldwide community of wireless networking groups will ever merge their systems and create a true alternative to existing telecommunication networks.

There are many barriers to the creation of a global network. So far, the focus has been on identifying the technical barriers and developing methods to overcome them. But technical problems are the least of our worries, the business, political and social issues are the real challenges facing community networks. Hardware and software vendors need to understand the business rationale for implementing our technical solutions. Politicians need to understand our requirements for universal access to unlicensed spectrum. The public needs to understand that the network exists and how to get access. Unless these problems are identified and addressed, the community wireless movement will never have influence beyond a local level.

Most importantly, the network needs to be accessible to all and provisioned by everyone who can provide. By adding enough providers to the network, we can bridge the physical gaps imposed by the range of our equipment. The network is a finite resource which is owned and used by the public, and as such it needs to be nurtured by the public. This, by its very nature, is a commons.

Becoming a part of the commons means being more than a consumer. By signing your name below, you become an active participant in a network that is far more than the sum of its users. You will strive to solve the social, political and technical challenges we face. You will provide the resources your community consumes by cooperating with total strangers to build the network that we all dream of. 


\section{A Hacker Manifesto Version 5.7}

MCKENZIE WARK

01. There is a double spooking of the world, the double of abstraction. The fortunes of states and armies, companies and communities depend on it. All contending classes - the landlords and farmers, the workers and capitalists - revere, yet fear the relentless abstraction of the world on which their fortunes yet depend. All the classes but one: the hacker class.

2. Whatever code we hack, be it programming language, poetic language, maths or music, curves or colourings, we create the possibility of new things entering the world. Not always great things, or even good things, but new things. In art, in science, in philosophy and culture, in any production of knowledge where data can be gathered, where information can be extracted and where in that information new possibilities for the world are produced, there are hackers hacking the new out of the old. While hackers create these new worlds, we do not possess them. That which we create is mortgaged to others, and to the interests of others, to states and corporations who control the means for making worlds we alone discover. We do not own what we produce - it owns us.

03. And yet we don't quite know who we are. While we recognise our distinctive existence as a group - as programmers, artists, writers, scientists or musicians - we rarely see these ways of representing ourselves as mere fragments of a class experience that is still struggling to express itself as itself, as expressions of the process of producing abstraction in the world. Geeks and freaks become what they are negatively through the exclusion by others. Hackers are a class, but a virtual class - a class as yet to hack its elf into manifest existence as itself, as the utopian class.

4. Abstraction may be discovered or produced, may be material or immaterial, but abstraction is what every hack produces and affirms. To abstract is to construct a plane upon which otherwise different and unrelated matters may be brought into many possible relations. It is through the abstract that the virtual is identified, produced and released.

5. As the abstraction of private property was extended to information, it produced the hacker class as a class. Hackers must sell their capacity for abstraction to a class that owns the means of production, the vectoralist class - the emergent ruling class of our time. The vectoralist class is waging an intensive struggle to dispossess hackers of their intellectual property. Patents and copyrights all end up in the hands, not of their creators, but 


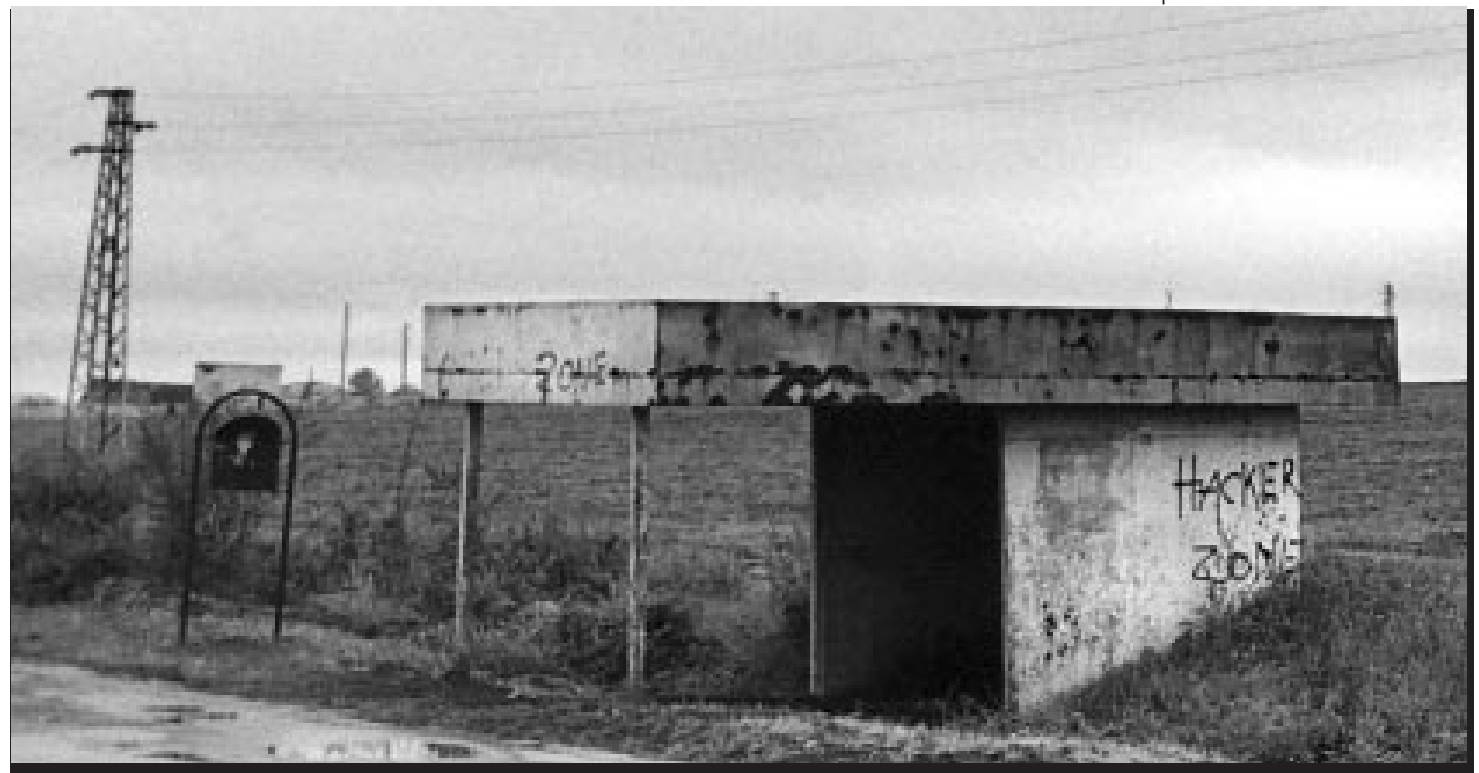

in those of the vectoralist class that owns the means of realising the value of these abstractions. The vectoralist class struggles to monopolies abstraction. Hackers find themselves dispossessed both individually and as a class.

6. Production produces all things, and all producers of things. Production produces not only the object of the production process, but also the producer as subject. Hacking is the production of production. The hack produces a production of a new kind, which has as its result a singular and unique product and a singular, unique producer. Every hacker is at one and the same time producer and product of the hack and emerges in its singularity as the memory of the hack as process.

07. The hack produces both a useful and a useless surplus, although the usefulness of any surplus is socially and historically determined. The useful surplus goes into expanding the realm of freedom wrested from necessity. The useless surplus is the surplus of freedom itself, the margin of free production unconstrained by production for necessity.

8. The production of a surplus creates the possibility of the expansion of freedom from necessity. But in class society, the production of a surplus also creates new necessities. Class domination takes the form of the capture of the productive potential of society and its harnessing to the production, not of liberty, but of class domination itself. The ruling class subordinates the hack to the maintenance of forms of production that maintain class power, and the suppression or marginalisation of other forms of hacking.

O9. The class struggle, in its endless setbacks, reversals and compromises returns again and again to the unanswered question - property - and the contending classes return again 
and again with new answers. The working class questioned the necessity of private property and the communist party arose, claiming to answer the desires of the working class. The answer, expressed in the Communist Manifesto was to "centralise all instruments of production in the hands of the state". But making the state the monopolist of property has only produced a new ruling class, and a new and more brutal class struggle. But perhaps this was not the final answer, and the course of the class struggle is not yet over. Perhaps there is another class that can pose the property question in a new way - and offer new answers to breaking the monopoly of the ruling classes on property.

10. Information, like land or capital, becomes a form of property monopolised by a ruling class, in this case a class of vectoralists, so named because they control the vectors along which information is abstracted, just as capitalists control the material means with which goods are produced and pastoralists the land with which food is produced. Information circulated within working class culture as social property belonging to all. But when information in turn becomes a form of private property, workers are dispossessed of it and must buy their own culture back from its owners, the vectoralist class. The whole of time, time itself, becomes a commodified experience.

11. Vectoralists try to break capital's monopoly on the production process, and subordinate the production of goods to the circulation of information. The leading corporations divest themselves of their productive capacity, as this is no longer a source of power. Their power lies in monopolising intellectual property - patents and brands - and the means of reproducing their value - the vectors of communication. The privatisation of information becomes the dominant, rather than a subsidiary, aspect of commodified life. As private property advances from land to capital to information, property itself becomes more abstract. J ust as capital as property frees land from its spatial fixity, information as property frees capital from its fixity in a particular object.

12. The hacker class, producer of new abstractions, becomes more important to each successive ruling class, as each depends more and more on information as a resource. The hacker class is the class with the capacity to create not only new kinds of object and subject in the world and new forms of property in which they may be represented, but new kinds of relations beyond the property form.

13. Property constitutes an abstract plane upon which all things may be things with one quality in common, the quality of property. Land is the primary form of property. Pastoralists acquire land as private property through the forced dispossession of peasants who once shared a portion of it in a form of public ownership. Capital is the secondary form of property, the privatisation of productive assets in the form of tools, machines and working materials. Capital, unlike land, is not in fixed supply or disposition. It can be made and remade, moved, aggregated and dispersed. An infinitely greater degree of potential can be released from the world as a productive resource once the abstract plane of property includes both land and capital. But the abstraction of commodity production does not end 
with capitalism. The transformation of information into an even more abstract form of property, abstracted even from its material expression, takes commodification into a third, as yet uncharted phase of development.

14. Hackers must calculate their interests not as owners, but as producers, for this is what distinguishes them from the vectoralist class. Hackers do not merely own, and profit by owning, information. They produce new information, and as producers need access to it free from the absolute domination of the commodity form. Hacking as a pure, free experimental activity must be free from any constraint that is not self-imposed. Only out of its liberty will it produce the means of producing a surplus of liberty and liberty as a surplus.

15. Private property arose in opposition not only to feudal property, but also to traditional forms of the gift economy, which were a fetter to the increased productivity of the commodity economy. The gift becomes a marginal form of property, everywhere invaded by the commodity, and turned towards mere consumption. As vectoral production develops, the means appear for the renewal of the gift economy. Everywhere that the vector reaches, it brings into the orbit of the commodity. But everywhere the vector reaches, it also brings with it the possibility of the gift relation.

16. The hacker class has a close affinity with the gift economy. The hacker struggles to produce a subjectivity that is qualitative and singular, in part through the act of the hack itself. The gift, as a qualitative exchange between singular parties, allows each party to be recognised as a singular producer, as a subject of production, rather than as a commodified and quantified object. The gift expresses in a social and collective way the subjectivity of the production of production, whereas commodified property represents the producer as an object, a quantifiable commodity like any other, of relative value only. The gift of information need not give rise to conflict over information as property, for information need not suffer the artifice of scarcity once freed from commodification.

17. The vectoralist class contributed, unwittingly, to the development of the vectoral space within which the gift as property could return, but quickly recognised its error. As the vectoral economy develops, less and less of it takes the form of a social space of open and free gift exchange, and more and more of it takes the form of commodified production for private sale. The vectoralist class can grudgingly accommodate some marg in of socialised information, as the price it pays in a democracy for the furtherance of its main interests. But the vectoralist class quite rightly sees in the gift a challenge not just to its profits but to its very existence. The gift economy is the virtual proof for the parasitic and superfluous nature of vectoralists as a class.

18. The vectoral class struggles at every turn to maintain its subjective power over the vector, but as it continues to profit by the proliferation of the vector, some capacity over it always escapes control. In order to market and profit by the information it peddles over the vector, it must in some degree address the vast majority of the producing classes as sub- 
372 / Sarai Reader 2003: Shaping Technologies

jects, rather than as objects of commodification. The hacker class seeks the liberation of the vector from the reign of the commodity, but not to set it indiscriminately free. Rather to subject it to collective and democratic development. The hacker class can release the virtuality of the vector only in principle. It is up to an alliance of all the productive classes to turn that potential to actuality, to organise themselves subjectively, and use the available vectors for a collective and subjective becoming.

19. Progress is possible, plagiarism implies it. 


\section{CONTRIBUTORS (in alphabetical order)}

Amanda McDonald Crowley (Adelaide/ Helsinki) is a cultural worker, researcher, facilitator and curator working primarily in the fields of new media/ electronic arts. She is currently an arts worker in residency at Sarai (December 2002-March 2003), supported by the Arts Residency Program of Asialink. amc@autonomous.org

Ana Viseu (Toronto) is a researcher currently working at the University of Toronto on her PhD dissertation entitled "Sociotechnical Worlds: The visions and realities of bodynets". Her thesis work combines an exploration of the visions and desires that drive the development of the technology, with a case study of the implementation of wearables in the workplace. Ana is a Marshall McLuhan fellow and a Knowledge Media Design Institute graduate fellow. ana.viseu@utoronto.ca; http://fcis.oise.utoronto.ca/ aviseu; http:// privacy.openflows.org/

Andreas Broeckmann (Berlin) lives and works in Berlin. Since the autumn of 2000 he has been the artistic director of transmediale: International Media Art Festival Berlin. Broeckmann holds a PhD from the University of East Anglia/UK and studied art history, sociology and media studies. He worked as a project manager at V2_Organisation Rotterdam, Institute for the Unstable Media, from 1995-2000. ab@transmediale.de

Andrew Feenberg (San Diego) is professor of Philosophy at San Diego State University. He is the author of Lukacs, Marx and the Sources of Critical Theory (Rowman and Littlefield, 1981; Oxford University Press, 1986), Critical Theory of Technology (Oxford University Press, 1991), Alternative Modernity (University of California Press, 1995) and Questioning Technology (Routledge, 1999). Dr. Feenberg has also published on the Japanese philosopher Nishida Kitaro. He is recognised as an early innovator in the field of online education, a field he helped create in 1982. afeenber@mail.sdsu.edu

Are Flågan (Norway) is currently based in the United States. He works with photography and the various computer media that have taken over image production and fascinatingly infused it with coding, interactivity and networking. An enthusiastic writer, he has contributed to many publications and served as the editor and designer of one. In 2000, he received his Master of Fine Arts degree from the University of New Mexico. areflagan@artpanorama.com; http://www.transcodex.net

Arun Mehta (Delhi) is a telecommunications engineer, Internet and radio enthusiast and a human rights activist based in Delhi. He is a President of the Society for Telecommunications Empowerment and moderates several discussion lists on law, technology and society: India-gii@cpsr.org; netradio@egroups.com; free-india@egroups.com; cyberlaw-india@egroups.com. indata@satyam.net.in

Awadhendra Sharan (Delhi) is a historian and a visiting fellow at the Centre for the Study of Developing Societies. He is also a fellow of the Sarai programme. He is currently working on a research project that connects environment and urban space, with reference to the city of Delhi. He also coordinates the Archivebuilding activities at Sarai. sharan@sarai.net

Bharti Kher (Delhi) is a visual artist who lives and works in New Delhi. khergupta@hotmail.com

Biella Coleman (Chicago) is currently an anthropology graduate student at the University of Chicago studying the free software movement in San Francisco. She has worked on a research sailing vessel, studied religion and spent a long time playing "Ultimate". biella@healthhacker.com

\section{Cybermohalla:}

Babli Rai was at the Compughar at LNJP basti, Central Delhi, till her marriage that took her to Bihar in January this year. Her peers at the lab hope she will continue interactions, setting newer terms of longdistance engagement. 
374 / Sarai Reader 2002: The Cities of Everyday Life

Dhirender $\mathbf{P}$ Singh is one of the twelve young men and women researchers and media practitioners at the newly set up Compughar at Dakshinpuri resettlement colony, South Delhi. He is currently tapping his informal networks in the cable operations to open up possibilities for a monthly cable magazine from the labs.

Mehrunnissa Ansari has been with the LNJP Compughar since it was set up in June 2001. She is adept with the image editing free software, GIMP.

Naseem Bano returned to LNJP and the Compughar after a brief period during which her house, burnt in a fire that gutted many in May 2002, was being rebuilt.

Yashoda Singh works at the LNJP Compughar and is passionate about writing and playing with images using a scanner and GIMP. She shares her diaries and technical skills with her peers at the DP lab.

David Barsamian (Boulder) is a media activist, chronicler of dissidence and founder of Alternative Radio, which is a weekly one-hour public affairs programme, offered free to all public radio stations in the US, Canada, Europe, South Africa, Australia, and on short-wave on Radio for Peace International. http:// www.alternativeradio.org; dbarsamian@hotmail.com

Debjani Sengupta (Delhi) teaches literatures in English at Indraprastha College, Delhi University. She has recently edited Mapmaking, an anthology of short fiction in Bengali on the Partition of 1947 (Srishti Books, 2002, Delhi). debjanisgupta@yahoo.com

Eugene Thacker (Atlanta) is an assistant professor of New Media at the Georgia Institute of Technology. He has published widely on the social, cultural, and political aspects of biotechnologies, and his book Biomedia is forthcoming (University of Minnesota Press). He participates in the BmTP research project and is a collaborator with Biotech Hobbyist. http://www.lcc.gatech.edu/ ethacker; http:// www. biotechhobbyist.org. eugene.thacker@lcc.gatech.edu

Gabriel Pickard (Berlin) is a German high school student. After school, he studies phenomenology and OSdesign, practices some creative activism and writes for his "werglog". http://werg.demokratica.de; werg@demokratica.de

Ian Haig (Melbourne) explores the more perverse side of the human body's relationship with technology. His work follows the trajectory of human devolution and the monstrous, and is concerned with the dysfunctional excesses of everyday technologies and the psychopathology of digital culture. Some recent projects have included Brain Tumor Helmet with Microwaves (2002) Excelsior 3000: Bowel Technology Project (2001) The Anti Ergonomic Hump Machine (2001). http://www.ianhaig.net; http://www.media-arts.rmit. edu.au/lan_Haig/thing.html; ian.haig@rmit.edu.au

J oanne Richardson (Cluj) is an ex-philosopher and freelance organiser of media festivals and conferences, including Art Servers Unlimited 2 and Reality Check for CyberUtopias with [mama] in Zagreb, and a N5M4 Cluj tactical media lab. At present she coordinates several projects in Romania, including Frequency Free Radio, Reality SF Video Collective, and a brand new Indymedia Romania. She is an editor of subsol webzine, author of essays on media culture and politics, and of Twilight of the Idols, a book on the net.avant.garde. http://subsol.c3.hu. subsol@mi2.hr

Kajri J ain (Delhi/ Melbourne) holds a PhD in Art History and Theory from the University of Sydney. She has been a Fellow at the Getty Research Institute, Los Angeles, and is currently Australian Research Council Postdoctoral Fellow at the School of Communication and Creative Arts, Deakin University, Melbourne, collaborating on a project on television, globalisation and social change in India. She has also worked as a graphic designer in New Delhi and Sydney. Forthcoming Gods in the Bazaar: the Economies of Indian Calendar Art (Duke University Press). kajrij@yahoo.com

Lawrence Liang (Bangalore) is a legal researcher with the Alternative Law Forum, Bangalore. He is currently 
working on the project "Intellectual Property and the Knowledge/Culture Commons" in collaboration with Sarai. www.altlawforum.org; lawrenceliang@vsnl.net

Lex Bhagat (New York) bought his first Aiwa stereo recording Walkman on Canal Street in New York City in 1990, and has found his relation to the written word increasingly precarious since then. He is coeditor, with Greg Gangemi and Jason Quarles, of Sound Generation: Recording - Tradition - Politics (Chronoplastics, 2003.) Currently travelling in Asia, he is working on an extended essay on the political dimensions of sound and sound recording. He speaks and writes regularly in the US on the prison crisis. bandshell@onebox.com

Linda Carroli (Brisbane) is a writer whose reviews, essays and articles have been published globally. She is editor of fineArt forum, an art, science and technology electronic magazine based in Brisbane. She has also written several hypertexts collaboratively and independently including the award-winning "Water always writes in Plural" with J osephine Wilson. http:// www.fineartforum.org; Icarroli@pacific.net.au

McKenzie Wark (New York) is the author of Virtual Geography (Indiana UP) and most recently, Dispositions (Salt Publishing). He was a coeditor of the Nettime anthology Readme! mw35@nyu; mckenziewark@hotmail.com

Mike Hunter (Sydney, Nova Scotia) is a part-time lecturer at the University College of Cape Breton, Sydney, Nova Scotia, Canada, where he is also editor-in-chief of UCCB Press Inc. He is a PhD candidate in the joint Graduate Programme in Communication and Culture at York and Ryerson Universities, Toronto. His research interests include media, the nature of discourse, and children's discourse. He is assistant editor of TOPIA: Canadian J ournal of Cultural Studies. mike_hunter@uccb.ca

Nimmi Rangaswamy (Chennai) is a research scholar, currently working on the social impact of new technologies in South India. She has worked earlier on Dravidian identity politics and the media. She has been an assistant editor with the Economic and Political Weekly (Mumbai). nimmi89@hotmail.com

Parvati Sharma (Delhi) studied literature and history and worked as an editor in online publications. She is currently working as an editor and researcher at the Sarai Media Lab. Her interests include experimental video, writing, and popular culture. parvati@sarai.net

Pauline van Mourik Broekman (London) is co-publisher and editor of the London based technoculture magazine Mute, which she co-founded with Simon Worthington as the Art and Technology Newspaper in 1994. Apart from editing Mute, she writes regularly on art, media and technology for journals and books. http:// www.metamute.com; pauline@metamute.com

Phanishwarnath Renu (1921-77) was a celebrated Hindi novelist, story and scriptwriter and socialist activist (in India and Nepal) who pioneered the trend of the so-called aanchalik upanyas (regional novel) in Hindi. In content and form he remained playfully authentic. His best known works are Maila Aanchal and Teesri Kasam, which also became the subject of the eponymous Basu Bhattacharya film (1966).

Pradip Saha (Delhi) is a designer, filmmaker and photographer and managing editor of Down to Earth magazine. He has worked on book and print design, environmental communication and exhibition design. His interests include bottled water, industrial waste and urban ecology. prosaha@hotmail.com

Rabindranath Tagore (1869-1941) was a Bengali poet, novelist, essayist, composer, painter and educational pioneer. He won the Nobel Prize for literature in 1916 and founded Vishwa Bharati University and Shantiniketan, a cultural community dedicated to the ideals of universal humanism. The works of Rabindranath Tagore were liberated from copyright on 31 December 2001.

Raqs Media Collective (Delhi) is a group of media practitioners, filmmakers and writers. They are co-initiators of Sarai, with Ravi Vasudevan and Ravi Sundaram. Their work includes the installations Architecture for Temporary Autonomous Sarai (with Atelier Bow Wow, 2003), 28.28N/77.15E::2001/2002, Locationn, and A/S/L (all 2002); OPUS, an online application for collaborative creation (2002); the CD-Rom Global Village 
376 / Sarai Reader 2002: The Cities of Everyday Life

Health Manual v1.0 (with Joy Chatterjee, 2000); and the films, In the Eye of the Fish (1997) Present Imperfect, Future Tense (1996). http://www.opuscommons.net; raqs@sarai.net

Rana Dasgupta (Delhi) is a writer based in Delhi. His first novel will be published by Heinemann in 2004. rana_dasgupta@yahoo.com

Ravi Agarwal (Delhi) is a photographer and an environmentalist. He heads Toxics Link and Srishti, environmental groups based in India. As a photographer his interest lies in documenting 'work' and labour. He has shown widely, including at Documenta11 (Kassel, Germany, 2002) and co-authored a book Down and Out: Labouring Under Global Capitalism (OUP, 2000). ravig@del6.vsnl.net.in

Ravikant (Delhi) is a historian, writer and translator. He coordinates the language project at Sarai. He has coedited (with Sanjay Sharma) Deewane-Sarai and (with Tarun Saint) Translating Partition. ravikant@sarai.net

Renu lyer (Delhi) studied fine arts at the Faculty of Fine Arts, MS University, Baroda. She is an artist and works at the Sarai Media Lab as a designer and interface animator. renu@sarai.net

Robert X Cringely is the author of the best-selling book Accidental Empires: How the Boys of Silicon Valley Make Their Millions, Battle Foreign Competition, and Still Can't Get a Date. He writes a weekly column at http:// www.pbs.org/cringely, and a monthly column for Inc Magazine. bob@cringely.com

Rupsa Mallik (Maryland/ Delhi) is currently programme associate with the Centre for Health and Gender Equity where she works on the programme "Expanding Choices" in the population, family planning and reproductive health programmes. http://www.genderhealth.org; rmallik@genderhealth.org

Sabeena Gadihoke (Delhi) teaches Video and Television Production at the AJK Mass Communication Research Centre, Jamia University, New Delhi. She is a documentary filmmaker and works as an independent cameraperson. sgadihok@vsnl.com

Saul Albert (London) writes, codes, speaks and teaches. He is currently engaged as the under-secretary of the University of Openness, and is on a grant supported by the AHRB. His interests include critical cartography, feral institutions, and personal neologisms. http:// uua.twenteenthcentury.com; saul@twenteenthcentury.com

Shahid Datawala (Delhi) is a photographer, designer and fanatical collector of technological paraphernalia. He is passionately interested in matchboxes, typewriters, projectors and old cars. He is currently pursuing a photographic documentation project on Delhi Cinemas on an Independent Research Fellowship from Sarai. shahiddatawala@yahoo.com

Shveta (Delhi) studied journalism and social work. She is currently associated with the Cybermohalla Project at Sarai, and has translated and coedited Galiyon Se / by Lanes - the Cybermohalla Book (2002). Her interests include alternative pedagogy, sexuality and communication practices.shveta@sarai.net

'Siddhartha' Ghosh (Kolkata) was the pen name of Amitabha Ghosh (1948-2002). Ghosh studied Mechanical Engineering at J adavpur University, and was a writer (of essays, science fiction, short stories and writing for children) translator and designer. He contributed to the visual materials archive of the Centre for the Study of Culture and Society, Kolkata. Cchobi Tola: Bangalir Photography Charcha ("Taking Pictures: The Cultivation of Photography by Bengalis", Ananda Publishers, 1988, Calcutta) is a landmark book.

Simon Griffiths (Birmingham) lives, plays and works in Birmingham, UK. He is currently writing a dissertation on Kathy Acker, and Gilles Deleuze and Felix Guattari. He is also involved with the Lowtech arts group Access to Recycled Technology. http://www.a2rt.org; info@a2rt.org

Srinivas Kuruganti (New York) is a photographer based in New York. He is interested in the marginal realities that gather around the issues of labour and sexuality. http:// srinivaskuruganti.com; srinikuruganti@hotmail.com

Steve Dietz (Minneapolis) is curator of New Media at the Walker Art Centre in Minneapolis, Minnesota, USA, 
where he founded the New Media Initiatives department in 1996. He is responsible for programming the online Gallery 9, including more than 20 net art commissions and one of the earliest archive-collections of net art, the Walker's Digital Arts Study Collection. He has organised and curated several landmark new media exhibitions, including Beyond Interface: net art and Art on the Net (1988); Shock of the View: Artists, Audiences, and Museums in the Digital Age (1999); Digital Documentary: The Need to Know and the Urge to Show (1999). Translocations, an online exhibition, is featured as part of How Latitudes Become Forms, an international exhibition of contemporary art at the Walker Art Centre, which opened in February 2003. http:// www.walkerart.org/gallery9/ dietz/; steve.dietz@walkerart.org

subRosa is a reproducible cyberfeminist cell of cultural researchers committed to combining art, activism, and politics to explore and critique the effects of the intersections of the new information and biotechnologies on women's bodies, lives and work. subRosa produces artworks, activist campaigns and projects, sneak attacks, publications, media interventions and public forums that make visible the effects of the interconnections of technology, gender, and difference; feminism and global capital; new bio and medical technologies and women's health; and the changed conditions of labour and reproduction for women in the integrated circuit. subRosa's name honours feminist pioneers in art, activism, labour, and politics: Rosa Bonheur, Rosa Luxemburg, Rosie the Riveter, Rosa Parks. http:// www.cyberfeminism.net/subrosa/index.html; subrosa@cyberfeminism.net

Sumit Ray (Delhi) works as Consultant/Faculty in Critical Care Medicine at Sir Gangaram Hospital, New Delhi and has more than a passing interest in sociology, history, politics and public health. Sumit Ray is an occasional traveller and wildlife enthusiast. sray67@hotmail.com

Suzy Small (London) studied Media and Communications at the University of New South Wales in Sydney. She completed her Honours year in 2001, having focussed her studies on mobile telephony and the way that it affects communication and the experience of space, with particular emphasis on the use of text messaging. She is now based in London, working in web design, studying digital art and travelling as much as possible. suzannelsmall@yahoo.co.uk

Uma Maheshwari Kalpagam (Allahabad) is professor at the G.B. Pant Social Science Institute. With her multiple and shifting identities, she is these days most of the time an anthropologist and occasionally lapses to being an economist, which she has been for long anyway. She is however steadfast in her interest in Gender Studies. kalpagam25@rediffmail.com

Uma Shankar (Delhi) is a sound recordist and poet. He is presently working as a consultant archivist with the Archive and Research Centre on Ethnomusicology at the American Institute of Indian Studies, Gurgaon. umashanks@hotmail.com

Veena Das (Delhi/ Baltimore) is professor of Anthropology at J ohn Hopkins University, Baltimore. She has widely published on issues of violence, subjecthood and identity. She has recently coedited the two volume Oxford India Companion to Sociology and Social Anthropology (Oxford University Press, 2003, Delhi), Remaking a World (University of California Press, 2001) and Violence and Subjectivity (University of California Press, 2000). veenadas@jhu.edu

Vikram Vyas ( aipur) is a physicist, and an associate of the International Centre for Theoretical Physics, Trieste, Italy. He is also associated with the Ajit Foundation, a voluntary organisation. His research interests are in theoretical particle physics and in the use of computers as a tool for sustainable development. http:// homepage.mac.com/vsvyas/af.html; visquare@satyam.net.in

Volker Eick (Berlin) is a researcher with the "From Welfare to Work. Berlin - Los Angeles" project at the J ohn F. Kennedy Institute, Department of Political Science, Free University of Berlin. http:// www.workfare.ipn.de; eickv@zedat.fu-berlin.de 
Wireless Commons is a web site and an online community committed to the idea that the emerging wireless networks must be seen and used as a global commons. Signatories to the wireless commons manifesto so far include: Adam Shand, Bruce Potter, Paul Holman, Cory Doctorow, Ben Laurie, David P. Reed, Schuyler Erle, Matthew Asham, Lawrence Lessig, J on Lebkowsky, James Stevens, Steven Byrnes, Richard MacKinnon and Duane Groth. http:// www.wirelesscommons.org/

Yoshiharu Tsukamoto (Tokyo) is an architect, and founder member (with Mamoyo Kaijima) of the Atelier Bow Wow. He is an Associate Professor at the Tokyo Institute of Technology. Atelier Bow Wow has exhibited art/architectural projects at various international art exhibitions, including the Shanghai and Kwanju Biennales (2002) and (in collaboration with Raqs Media Collective) at the How Latitudes Become Forms exhibition at the Walker Art Centre, Minneapolis (2003). Atelier Bow Wow books include Pet Architecture Guidebook (World Photo Press, 2001) and Made in Tokyo (Kajima Institute Publishing Co. Ltd.) http:// www.dnp.co.jp/museum/nmp/madeintokyo_e/mit.html; tsukamot@arch.titech.ac.jp

EDITORS (in alphabetical order)

\section{@ Sarai}

Jeebesh Bagchi (Delhi) is a media practitioner, researcher, artist and filmmaker with the Raqs Media Collective, and one of the initiators of Sarai. He has been coordinating the Cybermohalla (cyber neighbourhood) project and is currently working on a series of inter-media and digital projects at the Sarai Media Lab. jeebesh@sarai.net

Monica Narula (Delhi) is a media practitioner, artist, filmmaker, cinematographer and photographer with the Raqs Media Collective, and one of the initiators of Sarai. She is currently working on a series of new media and digital culture projects at the Sarai Media Lab. monica@sarai.net

Ravi Sundaram (Delhi) is a fellow of the Centre for the Study of Developing Societies, Delhi and one of the initiators of Sarai. He coordinates the Public and Practices in the History of the Present project at Sarai. ravis@sarai.net

Ravi S Vasudevan (Delhi) is a fellow of the Centre of the Study of Developing Societies, Delhi and a coinitiator of the Sarai programme, and has edited Making Meaning in Indian Cinema. He also coordinates the Public and Practices in the History of the Present project at Sarai. raviv@sarai.net

Shuddhabrata Sengupta (Delhi) is a media practitioner, artist, filmmaker and writer with the Raqs Media Collective and one of the initiators of Sarai. He is currently working on a series of new media and digital culture projects at the Sarai Media Lab. shuddha@sarai.net

\section{@ Waag Society}

Geert Lovink (Brisbane) is a media theorist and Internet critic, currently based in Brisbane. He is co-founder of the community provider Digital City, the Nettime mailing lists, and an Australian network for Internet research and culture. Recently published books are Dark Fiber, a collection of his essays on critical Internet culture, and Uncanny Networks, a collection of interviews with media theorists and artists (MIT press). geert@xs4all.nl

Marleen Stikker (Amsterdam) is the director of the Waag Society for Old and New Media. She was an initiator of the Digital City, Europe's first Internet community. marleen@waag.org 


\section{ACKNOWLEDGEMENTS}

"The Possible Futures of Technology in China" by Andrew Feenberg is to be published as the preface to the Chinese edition of Alternative Modernities: The Technical Turn in Philosophy and Social Theory (China Social Sciences Press, forthcoming 2003).

"New Visual Technologies in the Bazaar" by Kajri J ain is a shorter version of a chapter in her ongoing book project Gods in the Bazaar: The Economies of Indian Calendar Art (Duke University Press, forthcoming).

"Taking Pictures: The Early Days of Photography in Bengal" by Siddharth Ghosh, is an extract from Chhobi Tola: Bangalir Fotografi Chorcha (Ananda Publishers, 1988, Kolkata).

"The Home and Beyond: Domestic and Amateur Photography by Women in India (1930-1960)" by Sabina Gadihoke is based on a research project, with the support of the India Foundation for the Arts, Bangalore.

"Panchlight" by Phanishwarnath Renu was first published in Suprabhat (Calcutta, January-February 1958) and later compiled in Thumri, Bharat Yayavar and in Renu Rachanavali Vol. 1 (Rajkamal Prakashan, 1995 New Delhi). "Airborne" by Rabindranath Tagore is an extract from Paroshyey, Rabindra Rachnavali (Centenary Edition).

"Stolen Rhetoric: The Appropriation of Choice by ART Industries" by subRosa is available at http:// www.obn.org/reading_room/writings/html/stolen.html

"Becoming Mobile: SMS and Portable Text" by Suzy Small was published in Mobile Minded (Mieke Gerritzen (ed), Ginko Press, 2002).

"Dreams of an (Un)Certain Future" by Steve Dietz is modified by the author from "Ten Dreams of Technology" published in Leonardo (Vol. 35, No. 5, MIT Press, 2002).

"Technology, Trust and Terror" by Langdon Winner was first published in the Tech Knowledge Revue 3.1 (22 October 2002) and is available online at http:// www.netfuture.org/2002/0ct2202_137.html\#1

"Resistance is Futile: Peer-to-Peer File Sharing and Big Media" by Robert X. Cringely was first published in the "I, Cringley: The Pulpit" column on www.pbs.org at www.pbs.org/cringely/pulpit/pulpit20021128.html

"Alternative Radio: A Personal Testimony" by David Barsamian is an excerpt from his text in War, Lies \& Videotape (International Action Center, 2000).

"The Concise Lexicon of/for the Digital Commons" by Raqs Media Collective was published in Documenta11 _Platform 5: Exhibition Catalogue, published by Hatje Cantz, J une 2002. An online version of this text is available at http:// www.sarai.net/compositions/ texts/ works/lexicon.htm

"The Wireless Commons Manifesto" is downloaded from http:// www. wirelesscommons.org

"A Hacker Manifesto (Version 5.7)" by McKenzie Wark is a condensed version of the manifesto. A longer version can be found at http://subsol.c3.hu/subsol_2/contributors0/warktext.html

\section{Photo Credits}

Monica Narula: pgs vi, 3, 22, 28, 74, 103, 106, 331, 382, inside back cover

Rana Dasgupta: pgs 14, 15, 351, 369

Pradip Saha: pgs 95, 99

Ravi Agarwal: 29, 32

\section{The Reader Online}

A PDF version of this publication is available at: www.sarai.net/ journal/ reader3.html 


\section{Sarai Reader 01}

\section{The Public Domain}

The Sarai Reader 01 provides an overview of some of the concepts and new kinds of labour models that are having a crucial impact on the way that many individuals are re-conceiving their relationship to society.

Biblio, November-December 2001

An online edition of this book is available at: www.sarai.net/ journal/ reader1.html

\section{Sarai Reader 02 The Cities of Everyday Life}

The Sarai Reader 02 is an ambitious and successful attempt at negotiating the bewildering contemporary and makes many powerful arguments. In the Indian context, where there has been little focus on such a modern city, the Reader makes a valuable contribution in its collection of essays that delineate the particularities of our own urban space

Biblio, J uly-August, 2002

An online edition of this book is available at: www.sarai.net/ journal/ reader2.html 


\section{Deewan-e-Sarai 01}

\section{Media Vimarsh:// Hindi J anpad}

...Sarai needs to be congratulated for the idea of this beautiful and intelligent series. I feel that Deewan-e-Sarai deserves to be collected and preserved

Hans, February 2002

The contents of the Deewan-e-Sarai signal a keen awareness of the latent truths and the manifest workings of contemporary media. It lends depth to consciousness about the media and, far from being cynical, it attempts to find a sensitive balance between the challenges and infinite possibilities that confront media practice today.

Rashtriya Sahara, November 2002

An online edition of this book is available at:

http:// hindi.sarai.net/ deewan/ deewan01.html

ISBN 81-901429-2-5 October 2002; pg 235, 6.5" x 9.5"; INR $175(\mathrm{pb})$ : US\$ 15 : Euro 15

\section{Galiyon Se / by lanes}

Galiyon Se / by lanes emerges from a year's work with the Sarai/Ankur "Cybermohalla" (Cyber Neighbourhood) Project at the Compughar - a Media Lab at LNJP Basti, a working-class neighbourhood, in Delhi. It includes diary notes, reflections, memory games and imaginative writing by the young people associated with the project.

About Galiyon Se / by lanes

What is unique about this book... are the voices from the alleys, the myriad senses of wonder, the inscriptions of imagination, the circuits of anxiety... [All this] makes this book a document that contributes a great deal to the understanding of the public domain within the city of Delhi.

Pustak-Vaarta, September-October 2002

An online edition of this book is available at:

http:// www.sarai.net/ community/ cybermohalla/ book01/ bylanes.htm

ISBN 81-901429-1-7 J uly 2002; Hindi \& English; pg 236, 7" x 9"; INR 250 : US\$ 15 : Euro 15

For order write to:

publications@sarai.net or Programmes, Sarai/CSDS, 29 Rajpur Road, Delhi 110054, India. 
382 / Sarai Reader 2002: The Cities of Everyday Life
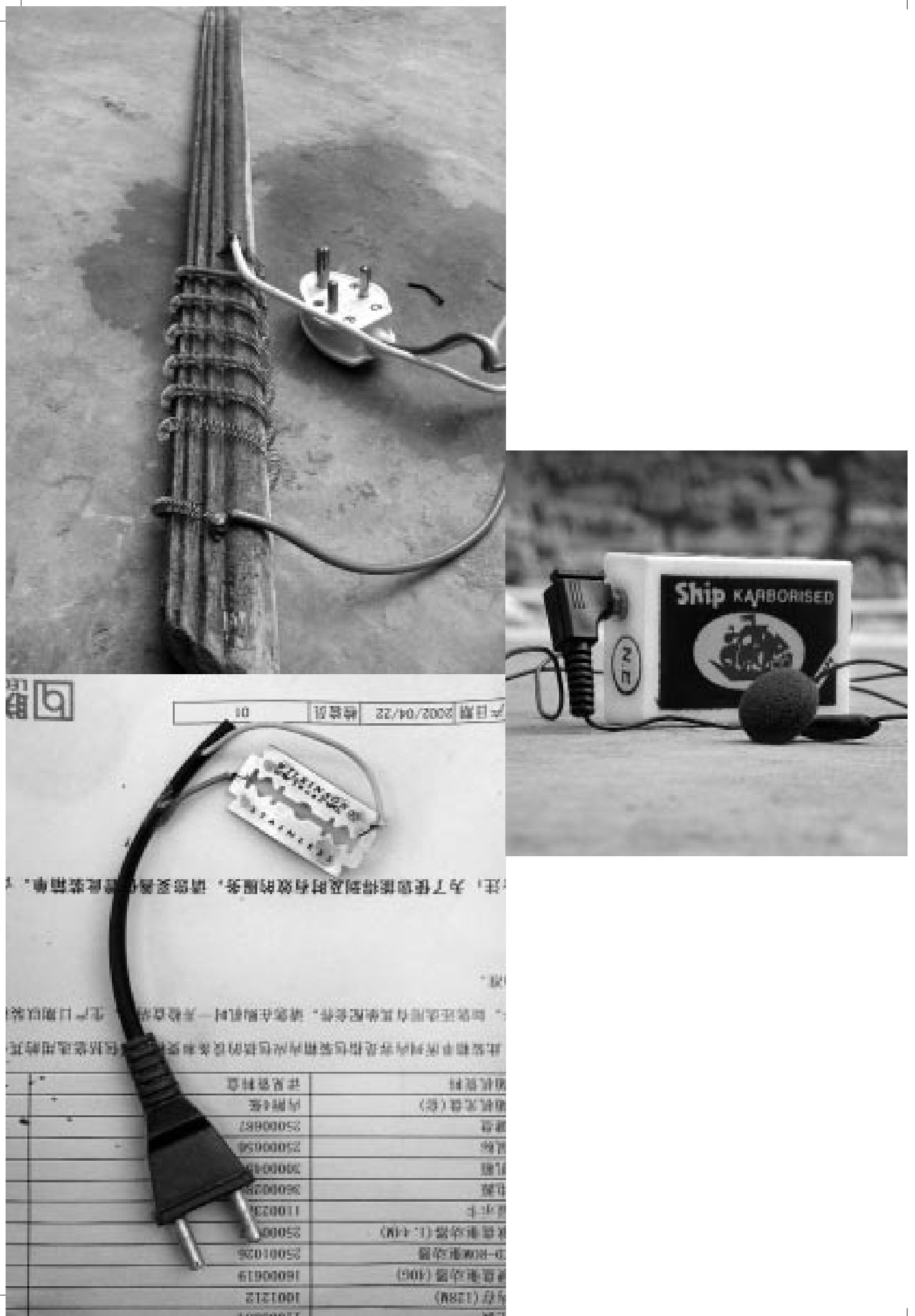

Ki 


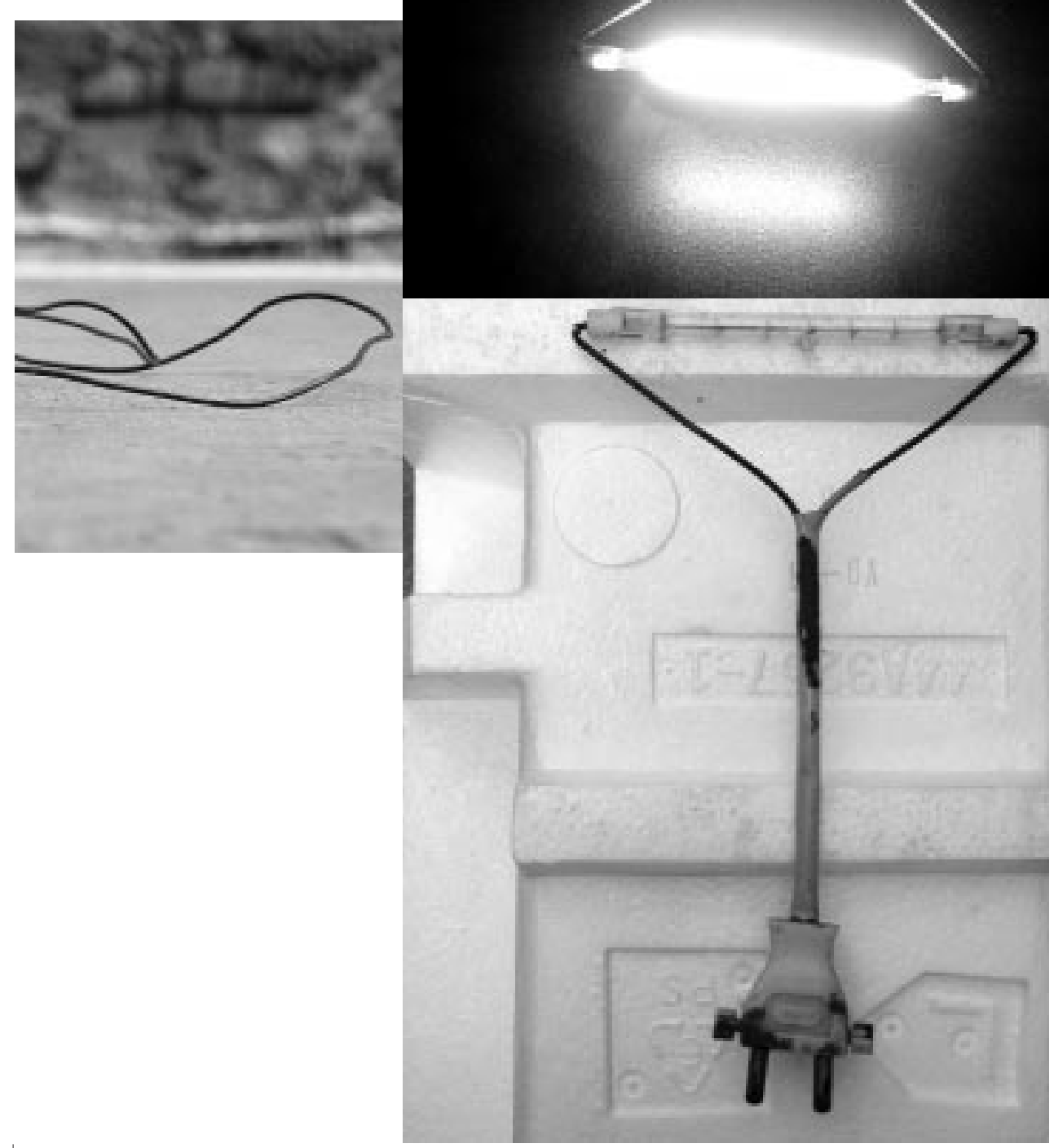




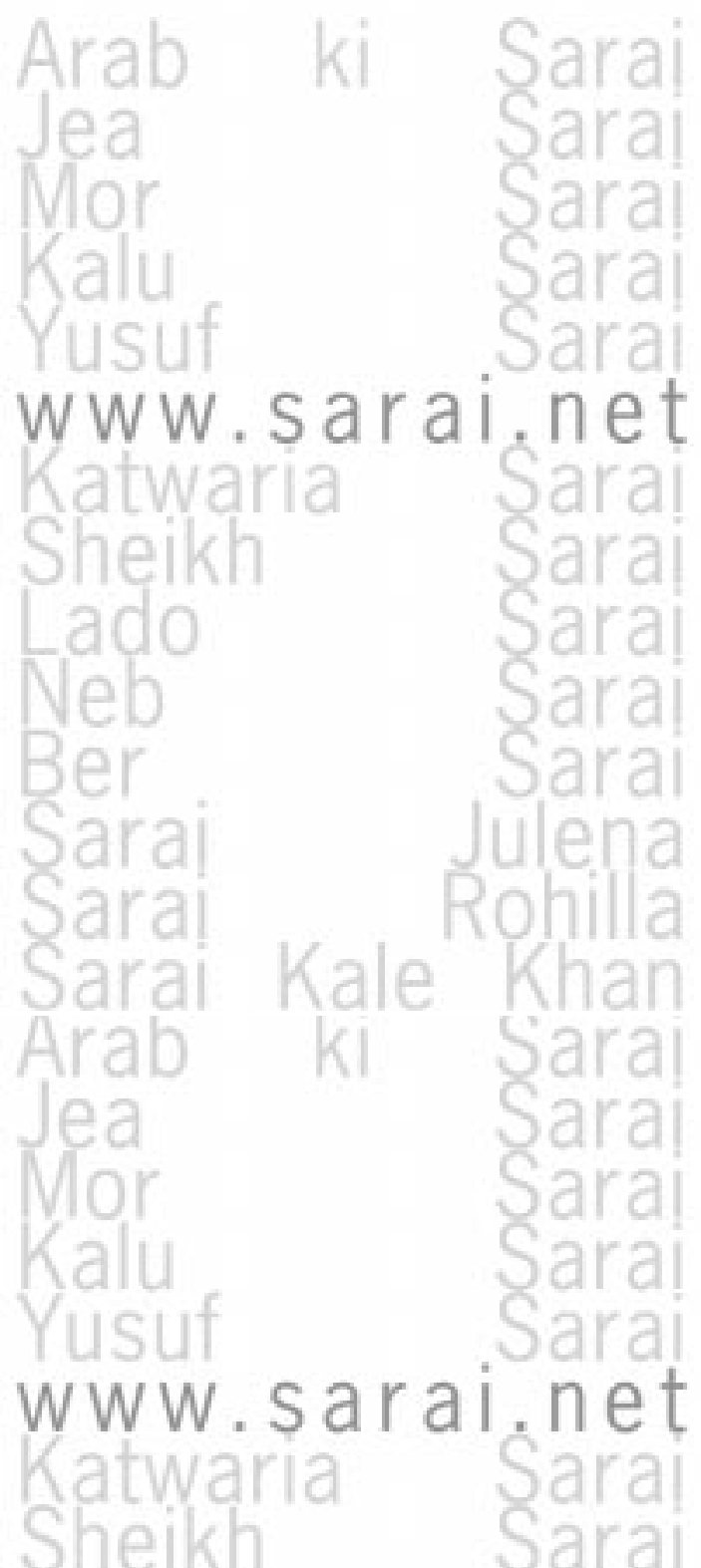

Sarai: (se-rai, saray, sho-rai) n (Hindi, Urdu, Punjabi, Bengali, Persian, Turkish)

A Sarai is an enclosed space in a city or beside a highway, where travellers and caravans can find shelter, sustenance and companionship; a tavern, a public house, a meeting place; a destination and a point of departure; a place to rest in the middle of a journey.

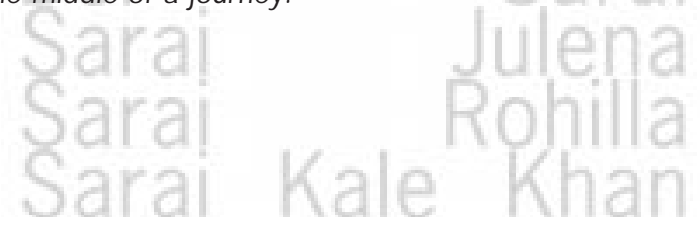

